Bernd Blessin

\title{
Innovations- und Umweltmanagement in kleinen und mittleren Unternehmen
}




\section{Innovations- und Umweltmanagement in kleinen und mittleren Unternehmen}

Die sehr stark durch Unternehmerpersönlichkeiten geprägten kleinen und mittleren Unternehmen (KMU) sind maßgebliche Träger des Strukturwandels in Deutschland. KMU werden insgesamt als "innovativ“ und "kreativ“ charakterisiert. Dennoch zeigen sich deutliche Unterschiede zwischen den KMU. Die Untersuchung verdeutlicht die Relevanz einer systematischen, strategischen Unternehmensführung in KMU und identifiziert in einer theoretischen und empirischen Analyse die Erfolgsfaktoren von KMU. Als zentraler Erfolgsfaktor erweist sich die Innovativität des Unternehmens. Das Innovationsmanagement bildet daher einen Schwerpunkt der Arbeit. Kernaspekte sind dabei die Schaffung einer Innovationskultur sowie die Entwicklung von Innovationszielen und -strategien. Ein weiterer Schwerpunkt ist das Umweltmanagement in KMU, dessen Bedeutung als Erfolgsfaktor derzeit noch unterschätzt wird.

Bernd Blessin wurde 1966 in Stuttgart geboren. Nach seiner Ausbildung zum Bankkaufmann studierte er von 1988 bis 1993 Wirtschaftswissenschaften an der Universität Hohenheim. Von 1994 bis 1998 war er als wissenschaftlicher Mitarbeiter von Prof. Dr. Klaus Herdzina am Institut für Volkswirtschaftslehre sowie als Dozent für die Bankakademie e.V. in Stuttgart tätig. Seit 1998 ist er Vorstandsreferent im Personalressort des Gerling-Konzern in Köln. 
Innovations- und Umweltmanagement

in kleinen und mittleren Unternehmen 


\title{
Hohenheimer Volkswirtschaftliche Schriften
}

\author{
Herausgegeben von \\ Prof. Dr. Rolf Caesar, Prof. Dr. Harald Hagemann, \\ Prof. Dr. Klaus Herdzina, Prof. Dr. Jörn Kruse, \\ Prof. Dr. Renate Ohr, Prof. Dr. Walter Piesch, Prof. Dr. Ingo schmidt, \\ Prof. Dr. Peter Spahn, Prof. Dr. Gerhard Wagenhals, \\ Prof. Dr. Helmut Walter
}

Band 29

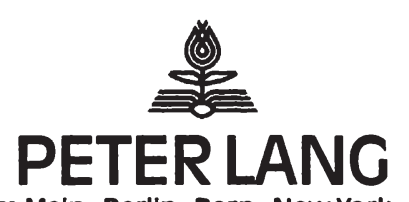

Frankfurt am Main - Berlin - Bern - New York · Parls · Wien 


\title{
Bernd Blessin
}

\section{Innovations- und Umweltmanagement in Kleinen und mittleren Unternehmen}

\author{
Eine theoretische \\ und empirische Analyse
}

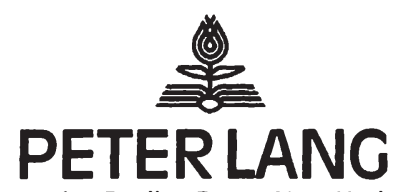

Frankfurt am Main - Berlin - Bern - New York - Paris - Wien 
Die Deutsche Bibliothek - CIP-Einheitsaufnahme

Blessin, Bernd:

Innovations- und Umweltmanagement in kleinen und mittleren Unternehmen : eine theoretische und empirische Analyse /

Bernd Blessin. - Frankfurt am Main ; Berlin ; Bern ; New York ; Paris ; Wien : Lang, 1998

(Hohenheimer volkswirtschaftliche Schriften ; Bd. 29)

Zugl.: Hohenheim, Univ., Diss., 1998

ISBN 3-631-33632-2

Open Access: The online version of this publication is published on www.peterlang.com and www.econstor.eu under the international Creative Commons License CC-BY 4.0. Learn more on how you can use and share this work: http:// creativecommons.org/licenses/by/4.0.

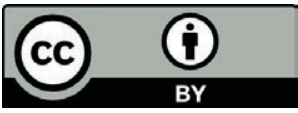

This book is available Open Access thanks to the kind support of ZBW - Leibniz-Informationszentrum Wirtschaft.

Gedruckt auf alterungsbeständigem, säurefreiem Papier.

\author{
D 100 \\ ISSN 0721-3085 \\ ISBN 3-631-33632-2 \\ ISBN 978-3-631-75468-9 (eBook) \\ (C) Peter Lang GmbH \\ Europäischer Verlag der Wissenschaften \\ Frankfurt am Main 1998 \\ Alle Rechte vorbehalten.
}

Das Werk einschließlich aller seiner Teile ist urheberrechtlich geschützt. Jede Verwertung außerhalb der engen Grenzen des

Urheberrechtsgesetzes ist ohne Zustimmung des Verlages unzulässig und strafbar. Das gilt insbesondere für

Vervielfältigungen, Übersetzungen, Mikroverfilmungen und die Einspeicherung und Verarbeitung in elektronischen Systemen.

Printed in Germany 134567 


\section{Geleitwort}

Die Diskussion über die Beziehungen zwischen ökonomischen und ökologischen Zielen wird auf gesamtwirtschaftlicher wie auch auf einzelwirtschaftlicher Ebene weiterhin intensiv geführt. Nicht zuletzt vor dem Hintergrund der Standortdiskussion wird die Frage gestellt, ob ein Zurückstellen ökologischer Belange nicht notwendig sei, um arbeitsplatzschaffendes Wachstum zu ermöglichen bzw. zumindest nicht zu gefährden. Dabei fällt auf, daß die Argumentationen nicht nur auf der politischen Ebene, sondern z.T. auch unter Ökonomen vorurteilsgeprägt und oft wenig differenziert sind. An dieser Stelle setzt der Autor an und schafft Abhilfe, indem er

- die enge Verknüpfung von Innovationsaktivitäten (und damit Wirtschaftswachstum) und Umweltschutzstrategien deutlich macht,

- die Thematik ausdrücklich auf die bislang eher vernachlässigten, aber in quantitativer und qualitativer Hinsicht überaus bedeutsamen kleinen und mittleren Unternehmen (KMU) fokussiert,

- das Thema sowohl gesamt- als auch einzelwirtschaftlich ausleuchtet,

- seine Schlußfolgerungen durch eine empirische Untersuchung belegt und abstützt.

Bezüglich aller vier angesprochenen Punkte kann die Arbeit als innovativ bezeichnet werden. Bedenkt man weiter, daß über $99 \%$ der Unternehmen in Deutschland in die Kategorie der KMU gehören, so ist die vom Verfasser behandelte Frage nach den Defiziten und Erfolgsfaktoren von $\mathrm{KMU}$ in den Bereichen Innovations- und Umweltmanagement und ihren möglichen Verknüpfungen hochgradig relevant und aktuell. Dabei gelingt es dem Autor, das Innovationsund Umweltmanagement als zentrale Erfolgsfaktoren kleiner und mittlerer Unternehmen herauszuarbeiten, ihre Interdependenzen deutlich werden zu lassen und sie in den Kontext strategischer Unternehmensfuihrung dieser Unternehmen einzubauen. Darüber hinaus trägt er durch eine Differenzierung der KMU zum Abbau gängiger Pauschalurteile über vermeintliche Stärken und Schwächen dieser Unternehmen bei. Andererseits kann er zeigen, daß eine beachtliche Zahl von KMU die aus Innovativität und speziell aus dem Umweltschutz erwachsenden Chancen allenfalls ahnen, aber noch nicht entschlossen aufgreifen. Damit sind diese Unternehmen aufgefordert, die Notwendigkeit eines systematischen Innovationsmanagements im Rahmen der Unternehmensführung zu erkennen und ihre gelegentlich noch zu kritische und zurückhaltende Einstellung zur Umweltthematik zu überdenken. 



\section{Vorwort}

Innovation ist ein Prozeß, der Veränderung bewirkt. Sie entsteht aus einer Idee, einem Gedanken, entwickelt sich, reift und sucht sich ihren Weg. Voraussetzung für Innovation und deren Realisierung ist u.a. Freiheit und Kreativität, sowie ein Rahmen, der dieses bietet - z.B. ein kleines oder mittleres Unternehmen.

Eine Dissertation entsteht ebenfalls aus einer Idee, die uber einen gewissen Zeitraum heranreift. Voraussetzung ist auch hierbei Freiheit, ein kreatives Klima, Zielorientierung sowie ein Rahmen, der dieses bietet - das kleine Unternehmen "Lehrstuhl". Ein besonderer Dank gilt daher dem Entrepreneur - meinem Doktorvater Herm Prof. Dr. Klaus Herdzina, der mir die Möglichkeit gab, als Intrapreneur meine Ideen umzusetzen und mir dabei alle erdenklichen Freiheiten ließ. Großartige Unterstützung erhielt ich auch durch Anke Höfel und Gerlinde Spang sowie Martin Würthner, die mir in diesem und weiteren Projekten unermüdlich zur Seite standen. Darüber hinaus danke ich meinen Kollegen an der Universität Hohenheim, vor allem aber Stephanie Hegner, Inge Huttenlocher, Dr. Bernd Nolte, Dr. Reinhard Scharff, Jürgen Schechler und Dr. Stephan Seiter. Genannt seien an dieser Stelle auch Prof. Dr. Helmut Kuhnle und Prof. Dr. Harald Hagemann, denen ich für ihre freundliche und konstruktive Mitwirkung an meinem Promotionsverfahren herzlich danke.

Finanzielle Unterstützung fand das Projekt durch den Europäischen Forschungsschwerpunkt für den Ländlichen Raum (EFLR), den Regionalverband Neckar-Alb sowie die Arbeitsämter Reutlingen/Tübingen und Zollernalb. Hervorzuheben sind hier Herr Dieter Gust, Frau Waltraud Wilsch-Rademacher und Frau Karin Oppermann, deren persönlicher Einsatz mir den Zugang zu den Unternehmen in der Region Neckar-Alb wesentlich erleichtert hat. Ein Dank geht auch an die Stiftung Ausbildung, Fort- und Weiterbildung der Landesgirokasse Stuttgart 19 , die mit einem großzügigen Druckkostenzuschuß, die Veröffentlichung dieser Arbeit unterstützt hat. Vielfältige logistische Unterstützung erhielt ich durch die Professoren Dr. Sabine Bergler, Concordia University, Montreal und Dr. Marc Feeley, Université de Montréal.

Ein ganz besonderer Dank geht an meine Familie. Sie war mir in vielfältiger Weise eine große Hilfe - auch Meere und Kontinente waren hierbei kein Hindernis - und hat damit entscheidend zum Gelingen dieser Arbeit beigetragen.

Ob diese Dissertation eine Innovation darstellt ist dem Urteil des Lesers und damit dem Markt überlassen. Daß sie eine Veränderung bewirkt, bleibt zu hoffen. 



\section{Inhaltsverzeichnis}

1. Problemstellung und Aufbau der Untersuchung 1

1.1 Problemstellung der Untersuchung 1

1.2 Aufbau der Untersuchung 4

2. Kleine und mittlere Unternehmen 7

2.1 Begriff und Charakterisierung $\quad 7$

2.1.1 Quantitative Merkmale 7

2.1.2 Qualitative Merkmale 9

2.2 Die gesamtwirtschaftliche Bedeutung kleiner und mittlerer Unternehmen 10

2.2.1 Die quantitative Bedeutung kleiner und mittlerer Unternehmen 11

2.2.2 Die qualitative Bedeutung kleiner und mittlerer Unternehmen 14

2.3 Die Unternehmen des Verarbeitenden Gewerbes in der Region Neckar-Alb 16

2.3.1 Situationsanalyse der Region Neckar-Alb 16

$\begin{array}{ll}\text { 2.3.2 Design und Methodik der Untersuchung } & 19\end{array}$

2.3.2.1 Die Erhebung der Daten 19

2.3.2.2 Die Auswertung der Daten 21

2.3.3 Charakterisierung und Typisierung der untersuchten Unternehmen 22

3. Unternehmensführung und Management

in kleinen und mittleren Unternehmen $\quad 27$

$\begin{array}{lll}3.1 & \text { Begriff und Charakterisierung } & 27\end{array}$

3.2 Die Rolle des Unternehmers 28

3.2.1 Der Unternehmer in der ökonomischen Theorie 28

3.2.2 Die zentralen Eigenschaften des Unternehmers in kleinen und mittleren Unternehmen $\quad 33$

3.3 Die strategische Ausrichtung der Unternehmensführung in kleinen und mittleren Unternehmen

3.3.1 Begründung einer Strategischen Unternehmensfuhrung als Bezugsrahmen 
3.3.2 Analyse des Unternehmensumfeldes 41

3.3.2.1 Das Makro-Umfeld des Unternehmens 42

3.3.2.2 Die Branchen-, Wettbewerbs- und Marktanalyse 45

3.3.2.3 Der Stakeholder-Ansatz $\quad 50$

3.3.3 Analyse der internen Unternehmenssituation 52

3.3.3.1 Die Wertkettenanalyse $\quad 52$

3.3.3.2 Die Funktionsbereichsanalyse $\quad 54$

3.3.3.3 Die Produktlebenszyklusanalyse $\quad 59$

3.3.3.4 Die Portfolioanalyse 64

$\begin{array}{lll}\text { 3.3.4 Erfolgsfaktorenanalyse } & \mathbf{7 2}\end{array}$

3.3.4.1 Ergebnisse der empirischen Erfolgsfaktorenforschung 73

3.3.4.2 Erfolgsfaktoren kleiner und mittlerer Unternehmen $\quad 80$

3.4 Unternehmenskultur, Unternehmensphilosophie und Unternehmenspolitik 85

3.4.1 Die Unternehmenskultur als Orientierungsbasis

- eine Begriffsbestimmung $\quad 85$

3.4.2 Die Konkretisierung der Unternehmenskultur durch die

Unternehmensphilosophie und die Unternehmenspolitik 87

3.5 Unternehmensziele 90

$\begin{array}{lll}\text { 3.5.1 Begriffsbestimmung } & 90\end{array}$

3.5.2 Die Struktur des Zielsystems 91

3.5.2.1 Die Dimensionen des Zielsystems 91

3.5.2.2 Ordnungskriterien des Zielsystems 93

3.5.3 Ergebnisse der empirischen Zielforschung 94

3.6 Unternehmensstrategien 100

$\begin{array}{lll}\text { 3.6.1 Begriffsbestimmung } & 100\end{array}$

$\begin{array}{lll}\text { 3.6.2 Die Struktur des Strategiesystems } & 102\end{array}$

3.6.2.1 Die Dimensionen der Strategie 103

3.6.2.2 Ordnungskriterien des Strategiesystems 103

3.6.3 Strategieformulierung und ausgewăhlte Strategiearten 107

3.6.3.1 Wachstumsstrategien 108

3.6.3.2 Wettbewerbsstrategien 111

3.6.4 Die Implementierung der Strategien im Unternehmen 115

$\begin{array}{lll}3.7 & \text { Zwischenergebnis } & 117\end{array}$ 
4.1 Begriff und Charakterisierung 121

4.1.1 Der Innovationsprozeß im Rahmen des technischen Fortschritts 121

4.1.1.1 Begriff und Arten der Technologie 121

4.1.1.2 Begriff und Arten der Innovation $\quad 122$

4.1.1.3 Phasen des technischen Fortschritts 125

$\begin{array}{ll}\text { 4.1.2 Innovationsmanagement - eine Begriffsabgrenzung } & 128\end{array}$

4.2 Innovationen im gesamt- und einzelwirtschaftlichen Kontext 130

4.2.1 Die gesamtwirtschaftliche Bedeutung von Innovationen 130

4.2.2 Die einzelwirtschaftliche Bedeutung von Innovationen 137

4.3 Innovationsmanagement in kleinen und mittleren Unternehmen 139

4.3.1 Gestaltungsbereiche des Innovationsmanagements 139

4.3.1.1 Notwendigkeit des Innovationsmanagements 139

4.3.1.2 Das Qualitătsmanagement als Komponente des Innovationsmanagements 141

4.3.2 Innovationsorientierte Analyse des Unternehmensumfeldes 144

4.3.3 Innovationsorientierte Analyse der internen Unternehmenssituation 149

4.3.3.1 Die Funktionsbereichsanalyse $\quad 150$

4.3.3.2 Die Produktlebenszyklusanalyse $\quad 160$

$\begin{array}{lll}\text { 4.3.3.3 Die Portfolioanalyse } & 163\end{array}$

4.4 Innovationskultur $\quad 166$

4.4.1 Die Rolle des Unternehmers 166

4.4.2 Die Schaffung eines innovativen Umfeldes 171

4.4.3 Die Schaffung einer Lernenden Organisation 175

$\begin{array}{lll}4.5 & \text { Innovationsziele } & 181\end{array}$

4.5.1 Die Bildung von Innovationszielen 181

4.5.2 Innovation im Zielsystem der Unternehmen 182

4.6 Innovationsstrategien 183

4.6.1 Ansätze zur Ableitung von Innovationsstrategien 183

4.6.2 Wachstumsstrategien als Maßstab der Innovativität 188

$\begin{array}{lll}4.7 & \text { Zwischenergebnis } & 192\end{array}$ 
5.2 Umweltschutz im gesamt- und einzelwirtschaftlichen Kontext

5.2.2 Die einzelwirtschaftliche Bedeutung des Umweltschutzes

5.3 Umweltmanagement in kleinen und mittleren Unternehmen 201

5.3.1 Gestaltungsbereiche des Umweltmanagements 201

5.3.2 Umweltorientierte Analyse des Unternehmensumfeldes 203

5.3.3 Umweltorientierte Analyse der internen Unternehmenssituation 204 5.3.3.1 Operative Instrumente des Umweltmanagements 205

5.3.3.2 Strategische Instrumente des Umweltmanagements 218

5.3.4 Technische und organisatorische Einbindung des

Umweltschutzes $\quad 222$

5.3.4.1 Technische Einbindung des Umweltschutzes 222

5.3.4.2 Organisatorische Einbindung des Umweltschutzes 226

5.4 Der Umweltschutz in der Unternehmenskultur 230

5.5 Umweltschutzziele 234

5.5.1 Die Integration von Umweltschutzzielen in das Zielsystem des Unternehmens 234

5.5.2 Die Formulierung von Umweltschutzzielen 235

5.5.3 Die Zielbeziehungen zwischen ökonomischen und ökologischen Unternehmenszielen $\quad 236$

5.6 Umweltschutzstrategien 241

5.6.1 Ansătze zur Ableitung von Umweltschutzstrategien 241

5.6.2 Umweltorientierte Basisstrategien 243

$\begin{array}{lll}\text { 5.6.3 Umweltorientierte Wettbewerbsstrategien } & 249\end{array}$

$\begin{array}{lll}\text { 5.7 Zwischenergebnis } & 253\end{array}$

$\begin{array}{ll}\text { 6. Schlußbemerkungen } & 257\end{array}$

$\begin{array}{ll}\text { Anhang } & 263\end{array}$

$\begin{array}{ll}\text { Literatur } & 321\end{array}$ 


\section{Abbildungsverzeichnis}

Abb. 3-1: Typen strategischer Grundhaltungen nach KIRSCH UND TRUX

Abb. 3-2: Elemente der Branchenstruktur nach PORTER

Abb. 3-3: Das Modell der Wertkette nach PORTER

Abb. 3-4: Die Funktionsbereiche des Unternehmens

Abb. 3-5: Exemplarisches Gliederungsschema der Funktionsbereiche Unternehmensfuihrung, Forschung und Entwicklung sowie Personalwesen

Abb. 3-6: Profil der internen Stärken und Schwächen

Abb. 3-7: Idealtypische Darstellung der Phasen des Produktlebenszyklus

Abb. 3-8: Das Marktwachstum-Marktanteil-Portfolio der Boston Consulting Group

Abb. 3-9: Das Marktattraktivität-Wettbewerbsvorteil-Portfolio von McKinsey

Abb. 3-10: Die Unternehmenskultur als Orientierungsbasis des Unternehmens

Abb. 3-11: Gliederung der Strategiearten nach den Ebenen des Planungssystems

Abb. 3-12: Wettbewerbsstrategien

Abb. 4-1: Die Phasen des technischen Fortschritts

Abb. 4-2: Abgrenzung von Technologie-, F\&E- und Innovationsmanagement

Abb. 4-3: F\&E-Ausgaben (in \% des BIP) in verschiedenen Ländern der OECD (1995)

Abb. 4-4: Nutzung innovationsrelevanter Informationsquellen durch die Unternehmen in der Region Neckar-Alb

Abb. 4-5: Qualifizierungsbedarf der beiden Erfolgstypen

Abb. 4-6: Nutzung der betrieblichen Weiterbildung durch die beiden Erfolgstypen

Abb. 4-7: Die Marktzyklen der beiden Erfolgstypen

Abb. 4-8: Das Technologie-Portfolio nach PFEIFFER u.a.

Abb. 4-9: Die fünf Disziplinen nach SENGE

Abb. 4-10: Verfolgung der Produkt-Markt-Strategien durch die beiden Erfolgstypen

Abb. 5-1: Schema einer Stoff- und Energiebilanz

Abb. 5-2: Das Konzept der Stoff- und Energiebilanzierung 
Abb. 5-4: Exemplarische Inhalte betrieblicher Umweltpolitik

Abb. 5-5: Förderung bzw. Beeinträchtigung von Unternehmenszielen durch die Verfolgung von Umweltschutzzielen

Abb. 5-6: Strategische Verhaltensweisen um Anforderungen des Umweltschutzes zu genügen 


\section{Tabellenverzeichnis}

Tab. 2-1: Klassifikation der Unternehmensgröße nach der Zahl der Beschäftigten

Tab. 2-2: Prozentuale Verteilung der Beschäftigtengrößenklassen innerhalb der Wirtschaftsbereiche am 25.5.1987 in Deutschland (West)

Tab. 2-3: Prozentuale Anteile der Beschäftigtengrößenklassen der Wirtschaftsbereiche an der Gesamtzahl der Unternehmen und Beschäftigten am 25.5.1987 in Deutschland (West)

Tab. 2-4: Prozentuale Anteile der Wirtschaftsbereiche in Baden-Württemberg 1990 bis 1996 an der Bruttowertschöpfung der Unternehmen (in Preisen von 1991, unbereinigt)

Tab. 2-5: Anteile der Unternehmen und Beschäftigten an den Wirtschaftszweigen des Verarbeitenden Gewerbes in Baden-Württemberg und der Region Neckar-Alb 1995 (in \%)

Tab. 3-1: Interessen interner und externer Anspruchsgruppen des Unternehmens

Tab. 3-2: Analyseraster zur Bestimmung unternehmerischer Erfolgs- und Mißerfolgsprofile nach KRÜGER

Tab. 3-3: Ergebnisse der Meta-Erfolgsfaktoren-Analyse nach FRrTZ

Tab. 3-4: Selbsteinschätzung der Wettbewerbsvorteile der beiden Erfolgstypen

Tab. 3-5: Ergebnisse der empirischen Zielforschung zu Inhalt und Rangordnung von Unternehmenszielen

Tab. 3-6: Strategien im Überblick

Tab. 3-7: Matrix der Produkt-Markt-Strategien und Intensität ihrer Anwendung durch die Unternehmen in der Region Neckar-Alb

Tab. 4-1: Die Merkmale von KAIZEN und Innovation

Tab. 4-2: Entwicklung der Aufwendungen für Forschung und Entwicklung der beiden Erfolgstypen von 1990 bis 1995

Tab. 5-1: Nutzung von Instrumenten des Umweltcontrolling durch die beiden Erfolgstypen

Tab. 5-2: Nutzung von Emissionsvermeidungstechnologien durch die beiden Erfolgstypen

Tab. 5-3: Einschätzung der Umweltprobleme entlang des Produktlebenszyklus durch die beiden Erfolgstypen

Tab. 5-4: Inhalt und Rangordnung von Unternehmenszielen bei den beiden Erfolgstypen 


\section{Abkürzungsverzeichnis}

\begin{tabular}{|c|c|}
\hline Abb. & Abbildung \\
\hline Aufl. & Auflage \\
\hline bez. & bezüglich \\
\hline $\mathrm{BMBF}$ & $\begin{array}{l}\text { Bundesministerium für Bildung, Wissenschaft, Forschung } \\
\text { und Technologie }\end{array}$ \\
\hline BMI & Bundesministerium des Innern \\
\hline BMWi & Bundesministerium für Wirtschaft \\
\hline bzw. & beziehungsweise \\
\hline ca. & circa \\
\hline CWQC & Company Wide Quality Control \\
\hline d.h. & das heißt \\
\hline DIN & Deutsches Institut für Normung e.V., Deutsche Industrie-Norm \\
\hline DM & Deutsche Mark \\
\hline EFLR & Europäischer Forschungsschwerpunkt für den Ländlichen Raum \\
\hline EG & Europäische Gemeinschaft \\
\hline EMAS & Environmental Management and Audit Scheme \\
\hline $\mathrm{EN}$ & Europäische Norm \\
\hline EU & Europäische Union \\
\hline etc. & et cetera \\
\hline e.V. & eingetragener Verein \\
\hline f. & folgende \\
\hline FCKW & Fluorchlorkohlenwasserstoffe \\
\hline ff. & fortfolgende (z.B. die beiden unmittelbar folgenden Seiten) \\
\hline FN & Fußnote \\
\hline $\mathrm{F} \& \mathrm{E}$ & Forschung und Entwicklung \\
\hline gdi & $\begin{array}{l}\text { Gottlieb-Duttweiler-Institut für wirtschaftliche und soziale Fragen, } \\
\text { Zürich }\end{array}$ \\
\hline HBM & Harvard Business Manager \\
\hline HBR & Harvard Business Review \\
\hline Hrsg. & Herausgeber, herausgegeben \\
\hline HWProd & Handwörterbuch der Produktionswirtschaft \\
\hline i.d.R. & in der Regel \\
\hline i.e.S. & im engeren Sinn \\
\hline Ifo-Institut & Institut für Wirtschaftsforschung \\
\hline insb. & insbesondere \\
\hline IÖW & Institut für ökologische Wirtschaftsforschung \\
\hline ISO & International Organization for Standardization \\
\hline
\end{tabular}


i.V.m.

IWÖ

i.w.S.

Jg.

ЛT

$\mathrm{KMU}$

KVP

Mio.

Mrd.

NAGUS

Nr.

OECD

o.g.

o.V.

R\&D

RKW

ROI

S.

SGE

SGF

Sig.

SRU

s.u.

RuR

Sig.

SME

Sp.

Tab.

TPM

TQC

TQM

Tsd.

u.a.

UAG

USA

usw.

u.U.

v.a. in Verbindung mit

Institut für Wirtschaft und Ökologie an der Hochschule St. Gallen im weiteren Sinn

Jahrgang

Just in Time

kleine und mittlere Unternehmen

Kontinuierlicher Verbesserungsprozeß

Million(en)

Milliarde(n)

Normenausschuß Grundlagen des Umweltschutzes

Nummer

Organisation for Economic Co-operation and Development

oben genannt $(e, e r)$

ohne Verfasser(in)

Research and Development

Rationalisierungskuratorium der Deutschen Wirtschaft, RKW e.V. return on investment

Seite

Strategische Geschäftseinheiten

Strategische Geschäftsfelder

Signifikanz

Der Rat von Sachverständigen für Umweltfragen

siehe unten

Raumforschung und Raumordnung

Signifikanz

Small and Medium-sized Enterprises

Spalte

Tabelle

Total Productive Maintenance

Total Quality Control

Total Quality Management

Tausend

und andere, unter anderem

Umwelt-Audit-Gesetz

United States of America

und so weiter

unter Umständen

vor allem 


$\begin{array}{ll}\text { Verf. } & \text { Verfasser } \\ \text { vgl. } & \text { vergleiche } \\ \text { vs. } & \text { versus } \\ \text { WiSt } & \text { Wirtschaftswissenschaftliches Studium } \\ \text { WISU } & \text { Das Wirtschaftsstudium } \\ \text { WZB } & \text { Wissenschaftszentrum Berlin } \\ \text { z.B. } & \text { zum Beispiel } \\ \text { ZfB } & \text { Zeitschrift für Betriebswirtschaft } \\ \text { zfbf } & \text { Zeitschrift für betriebswirtschaftliche Forschung } \\ \text { zfo } & \text { Zeitschrift Führung + Organisation } \\ \text { ZFP } & \text { Zeitschrift für Forschung und Praxis } \\ \text { ZfU } & \text { Zeitschrift für Umweltpolitik und Umweltrecht } \\ \text { z.T. } & \text { zum Teil } \\ \text { ZUR } & \text { Zeitschrift für Umweltrecht }\end{array}$




\section{Problemstellung und Aufbau der Untersuchung}

\subsection{Problemstellung der Untersuchung}

Die deutsche Wirtschaft befindet sich in einer Phase des tiefgreifenden strukturellen Umbruchs. Allerdings scheint der Strukturwandel ${ }^{1}$ nur zögernd voranzuschreiten, so daß auf lange Sicht die internationale Wettbewerbsfähigkeit der Bundesrepublik Deutschland und damit auch der "Standort Deutschland" zunehmend in Frage gestellt ist. Begleitet wird dieser Prozeß von einem gesellschaftlichen Wertewandel, einer steigenden Arbeitslosigkeit, einer zunehmenden Zahl von Insolvenzen, Produktionsverlagerungen ins Ausland sowie einem Verdrängungswettbewerb durch das Hinzutreten neuer Anbieter und die Freizügigkeit von unternehmerischen Aktivitäten und Kapital auf globalisierten und stark differenzierten Märkten. Hinzu kommt ferner das Schwinden traditioneller Wettbewerbsvorteile deutscher Anbieter durch die weltweite Verbreitung technischen Wissens und Könnens und die Verfügbarkeit qualifizierter Arbeitskräfte in vielen Ländern. ${ }^{2}$

In diesem Zusammenhang scheint der Emeuerungsfähigkeit (Innovativität) eine zentrale Stellung zuzukommen. ${ }^{3}$ Doch auch bezüglich der Innovativität der deutschen Wirtschaft müssen Zweifel angebracht werden, wobei AUDRETSCH anmerkt, daß "the Innovations-Krise is not so much a deficiency of innovative activity but rather an inability to shift the technological paradigm away from the more traditional industries and towards new emerging industries" ${ }^{4}$, und damit ebenfalls auf das grundsätzliche Problem des Strukturwandels hindeutet.

Vor dem Hintergrund einer weitgehend mittelständischen Prägung der deutschen Wirtschaft und ausgehend von der allgemeinen Annahme, daß es gerade kleinen und mittleren Unternehmen aufgrund ihrer Flexibilität und Innovativität besser gelingt, sich an wandelnde Rahmenbedingungen anzupassen, müßten es eigentlich die kleinen und mittleren Unternehmen sein, die den Strukturwandel vorantreiben. Sie würden damit neben ihrer eigenen gleichzeitig auch die gesamtwirtschaftliche internationale Wettbewerbsfähigkeit aufrechterhalten. Daher gilt es zu klären, welche Defizite und Erfolgsfaktoren kleine und mittlere Unternehmen (KMU) haben, die eine aktive Einflußnahme auf den Prozeß des Strukturwandels behindern bzw. begünstigen.

Zur Problematik des Strukturbegriffes vgl. ausführlich Herdzina, K. (1981), S. 118-134 und S. 211.

2 Vgl. dazu u.a. Sachverståndigenrat (1995), S. 172f.; Reichhardt, I. (1995), S. 198-202. Vgl. ferner Löbbe, der unter Berücksichtigung weiterer Komponenten ein tendenziell positives Bild vom "Standort Deutschland" zeichnet, Lőbbe, K. (1991), S. 65-69 und Löbbe, K. (1994).

3 Vgl. z.B. Solow, RM. (1957); Johnson, S.C./Jones, C. (1957); Hübner, H./Jahnes, S. (1992), S. 1628; Harhoff, D. u.a. (1996), S. 5; Matraves, C. (1997), S. 6.

4 Audretsch, D.B. (1995b), S. 14. Vgl. dazu auch Albach, H. (1983), S. 22. 
Kleine und mittlere Unternehmen wurden in der wissenschaftlichen Literatur lange Zeit vernachlässigt. Begründen läßt sich dies erstens mit der großen Heterogenität kleiner und mittlerer Unternehmen. In ihnen lassen sich seltener die in der Theorie vorhandenen Organisationsund Strukturmodelle wiederfinden. Sie scheinen auf der Analyse-, Ziel-, Strategien- und Maßnahmenebene eher "hemdsärmelig" vorzugehen, sofern zwischen diesen vier Schritten überhaupt unterschieden wird. Entsprechend lassen sich nur schwer allgemeingültige oder wissenschaftlich fundierte Aussagen treffen. Zum zweiten sind die Abgrenzungskriterien, die eine klare Trennung zwischen Kleinstunternehmen, kleinen und mittleren Unternehmen und Großunternehmen erkennen lassen, wobei auch diese Begriffswahl fragwürdig ist, umstritten. Einerseits mußte Konsens darüber erzielt werden, ob die Klassifizierung auf quantitative oder qualitative Kriterien oder eine Kriterienkombination zurückgreift. Andererseits müßte die Einteilung an die entsprechende Branchensituation bzw. die spezifischen Rahmenbedingungen angepaßt werden, da beispielsweise ein Dienstleistungsunternehmen mit 100 Mitarbeitern anders zu beurteilen wäre als ein Industriebetrieb mit der gleichen Beschäftigtenzahl bzw. ein eigentümergeleitetes Unternehmen anders als ein managergeleitetes Unternehmen. Außerdem spielt u.U. auch eine Rolle, daß die Untersuchung oder Beratung von großen bekannten Unternehmen spektakulärer und lohnender ist, da sowohl die Wertigkeit der Aufgabe scheinbar mit der Unternehmensgröße korreliert als auch potentiell alle betriebswirtschaftlichen Problembereiche abgedeckt werden. Im Falle großer Unternehmen scheint auch der Zugang leichter, da der Umgang mit externen Beratern oder Beobachtern alltäglich ist. Diese Hemmschwelle muß in vielen kleinen und mittleren Unternehmen erst überwunden werden.

Thre gesamtwirtschaftliche Bedeutung hinsichtlich ihres Anteils an der Gesamtzahl der Unternehmen, an den Beschäftigten sowie am Umsatz führte letztlich zu einer steigenden Beachtung in der wissenschaftlichen Literatur. Wahrscheinlich sind es aber auch gerade die Heterogenität und die Vielzahl der unterschiedlichen Gegebenheiten, die eine Herausforderung zur Beschäftigung mit diesem Thema darstellen.

Beide Aspekte lassen sich als Begründung für die vorliegende Untersuchung anführen. Die Unternehmensstruktur der deutschen Wirtschaft zeigt, daß 99,7\% aller Unternehmen weniger als 500 Beschäftigte haben, dabei ca. 70\% der Arbeitsplätze zur Verfügung stellen und etwa $50 \%$ des Bruttoinlandsproduktes erwirtschaften. ${ }^{5}$ Kleine und mittlere Unternehmen sind damit ein bedeutender Faktor bei der Bewältigung des Strukturwandels in der Bundesrepublik Deutschland. Bei diesem Prozeß müßte sie ihre eingangs erwähnte mutmaßliche Innovativität und Flexibilität unterstützen. Im Mittelpunkt der Arbeit steht somit die Frage nach der tatsächlichen Innovativität bzw. Innovationsorientierung kleiner und mittlerer Unternehmen und ferner, ob eine unterschiedliche Innovationsneigung ein bedeutender Erfolgsfaktor im Wett-

5 Vgl. Pfohl, H.-C./Kellerwessel, P. (1990), S. 28. Je nach Quelle und Abgrenzung ergeben sich kleine Differenzen, die die Aussage in der Tendenz jedoch nicht einschrănken. Vgl. dazu auch Abschnitt 2.2.1. 
bewerb ist. Dabei erschwert zwar einerseits die Heterogenität die Analyse der Unternehmenssituation sowie die Formulierung von Handlungsempfehlungen, sie dient aber andererseits als Ausgangspunkt für die Erarbeitung von Gemeinsamkeiten unabhängig von der Betriebsgröße oder der Branchenzugehörigkeit.

Gerade kleine und mittlere Unternehmen sehen sich ständig wirtschaftlichen und gesellschaftlichen Veränderungen ihres Umfeldes ausgesetzt. Der unternehmerische Erfolg und die Überlebensfähigkeit hängen in hohem Maße von der Fähigkeit ab, sich auf die neuen Rahmenbedingungen einzustellen. Die theoretische und empirische Analyse der vorliegenden Untersuchung soll daher zeigen, wie es kleinen und mittleren Unternehmen gelingt, sich auf die zunehmende Komplexität des Umfeldes einzustellen, d.h., ob sie in der Lage sind, eine zukunftsorientierte Unternehmensführung aufzubauen, die die nachhaltige Überlebensfähigkeit des Unternehmens sichert, gleichzeitig ihre Wettbewerbsfähigkeit steigert und langfristige Erfolgsfaktoren generiert. ${ }^{6}$

Der Erfolg von Unternehmen läßt sich ökonomisch zunächst anhand von zu- oder abnehmenden Marktanteilen, Deckungsbeiträgen oder Umsätzen beurteilen. Diese Beurteilung greift aber zu kurz. Die Reduktion der Ziele und der Tätigkeit des Unternehmens auf rein wirtschaftliche Aspekte wäre eine zu starke Vereinfachung. Sie wird dem Unternehmen als Bestandteil und Gestaltungsfaktor der Gesellschaft nicht gerecht. Von herausragender Bedeutung für die zukünftigen Erfolgsfaktoren des Unternehmens scheinen daher Innovationen und vor dem Hintergrund zunehmender weltweiter Umweltprobleme der betriebliche Umweltschutz zu sein.

Die Aufgabenstellung dieser Arbeit, Innovations- und Umweltmanagement im Rahmen der Unternehmensfuhrung kleiner und mittlerer Unternehmen als Erfolgsfaktoren im Wettbewerb darzustellen, setzt eine Analyse der gesamt- und einzelwirtschaftlichen Rahmenbedingungen voraus, in denen sich kleine und mittlere Unternehmen in der Bundesrepublik Deutschland befinden. Dabei wird beabsichtigt, ein Problembewußtsein für die sich ändernden Anforderungen an die Unternehmensfuihrung aufgrund des komplexer und dynamischer werdenden Umfeldes zu schaffen und den Blick auf jene erfolgskritischen Faktoren zu lenken, die zu einem nachhaltigen Erfolg des Unternehmens beitragen können.

$\mathrm{Zu}$ diesem Zweck wurden im Rahmen einer empirischen Untersuchung von Unternehmen in der Region Neckar-Alb (Baden-Württemberg, vgl. Anlage 1) die einbezogenen Unternehmen auf ihr Innovations- bzw. Umweltmanagement hin überprüft.

In einem ersten Schritt wird die Bedeutung von Innovationen auf der gesamtwirtschaftlichen und insbesondere der einzelwirtschaftlichen Ebene herausgearbeitet. Die Betrachtung auf der

6 Vgl. Steger, U. (1988), S. 251; Servatius, H.-G. (1985), S. $6 f$. 
gesamtwirtschaftlichen Ebene wird zeigen, in welchen Bereichen deutsche Unternehmen besonders innovativ sind und welche internationale Stellung sie damit einnehmen. Auf der Unternehmensebene wird der Innovationsorientierung kleiner und mittlerer Unternehmen nachgegangen, die letztlich Rückschlüsse auf das Innovationsmanagement erlaubt. Hierdurch soll geprüft werden, ob die Innovativität bewußt als Bestandteil der Unternehmensführung und damit als Wettbewerbsfaktor angesehen wird.

In einem zweiten Schritt wird in einer erweiterten Betrachtung der Überlegung nachgegangen, ob für die nachhaltige Sicherung der Unternehmensexistenz auch ökologische Aspekte ins unternehmerische Kalkül einbezogen werden müssen, zumal ihnen auf gesamtwirtschaftlicher wie auch auf einzelwirtschaftlicher Ebene hohe Relevanz beigemessen wird. Der Anspruch einer umweltorientierten Produktion und mit ihr die Annäherung von Ökonomie und Ökologie scheint sich aber kaum in der betrieblichen Realität niederzuschlagen. ${ }^{7}$ Entsprechend werden Anhaltspunkte dafür gesucht, ob sich eine festgestellte Innovationshaltung auch im Bereich des betrieblichen Umweltmanagements wiederfinden läßt. Hierzu werden ebenfalls Ziele und Strategien der Unternehmen im Rahmen des betrieblichen Umweltschutzes erforscht.

Bei der Diskussion der genannten Komponenten "Innovations- und Umweltmanagement" im Rahmen der Unternehmensfuhrung in kleinen und mittleren Unternehmen kann es aber nicht nur darum gehen, ihre Bedeutung lediglich abzubilden. Da ihnen von den Unternehmen unterschiedliches Gewicht beigemessen wird, gilt es ferner, sie zu erläutern und sie in die UrsacheWirkung-Zusammenhänge unternehmerischer Entscheidungsprozesse einzubetten. Damit ist letztlich auch das Ziel verbunden, Hinweise auf den Abbau von Schwächen, aber auch zum Ausbau von Stärken zu geben, um den Herausforderungen des Strukturwandels bzw. des Wettbewerbs durch flexible Anpassung und durch aktive Gestaltung zu begegnen.

\subsection{Aufbau der Untersuchung}

Die aufgeworfenen Fragen werden in der vorliegenden Untersuchung sowohl theoretisch als auch empirisch analysiert. Ausgangspunkt der Arbeit - und ein erster Teil des Fundaments - ist die Betrachtung der gesamtwirtschaftlichen Bedeutung kleiner und mittlerer Unternehmen (Kapitel 2). Hierfür werden in Kapitel 2.1 zunächst die begrifflichen Grundlagen geschaffen sowie verschiedene Klassifizierungsmöglichkeiten von Unternehmen aufgezeigt, die eine differenzierte Betrachtung erst möglich machen. Im Anschluß daran wird der Beitrag kleiner und mittlerer Unternehmen an der wirtschaftlichen Leistungserstellung in Deutschland anhand ausgewählter Indikatoren aufgezeigt (2.2). Da das Verarbeitende Gewerbe traditionell und in weiten Teilen Deutschlands, insbesondere aber in Baden-Württemberg, noch immer eine her-

7 Vgl. Kreikebaum, H. (1994), S. 104. 
ausragende Stellung im wirtschaftlichen Leistungsprozeß einnimmt, wird die Betrachtung auf diesen Wirtschaftszweig fokussiert (2.3). Vor allem im Verarbeitenden Gewerbe finden sich Problembranchen wie beispielsweise der Maschinenbau, die chemische Industrie, die elektrotechnische Industrie sowie das Leder-, Textil- und Bekleidungsgewerbe, die vom Strukturwandel in erheblichem Ausmaß betroffen sind. Gleichzeitig lassen sich aber auch hier Unternehmen ausmachen, die in herausragender Weise ihre Anpassungsfähigkeit unter Beweis stellen und aktiv Gestaltungsoptionen wahrnehmen. Da die Region Neckar-Alb mit einer Vielzahl der vorgenannten Probleme belastet ist, wurde sie als Untersuchungsraum ausgewählt. Eine Analyse der Situation in der Region Neckar-Alb wird daher in diesem Kapitel vorgenommen. Hier findet sich auch die Beschreibung des Designs und der Methodik der Untersuchung sowie eine Charakterisierung und Typisierung der Unternehmen des Verarbeitenden Gewerbes in der Region.

In einem weiteren Untersuchungsschritt wird die gesamtwirtschaftliche Betrachtungsebene verlassen, um in Kapitel 3 den zweiten Teil des Fundaments zu legen. Ausschlaggebend für den einzelwirtschaftlichen Erfolg ist eine systematische und zukunftsorientierte Unternehmensführung. Nach der begrifflichen Einordnung und Charakterisierung in Kapitel 3.1 wird auf die herausragende Stellung des Unternehmers im Rahmen der Unternehmensführung kleiner und mittlerer Unternehmen eingegangen (3.2). Anschließend werden in vier Schritten, die sich in entsprechender Form auch in den Kapiteln 4 und 5 wiederfinden, Instrumente zur Analyse der Unternehmenssituation (3.3), Unternehmenskultur, -philosophie und -politik (3.4), Unternehmensziele (3.5) sowie Unternehmensstrategien (3.6) dargestellt sowie deren Relevanz aufgezeigt.

Für die Aufrechterhaltung der Wettbewerbsfähigkeit eines Unternehmens scheint die Erneuerung seines Produktprogrammes bzw. der genutzten Produktionsverfahren von elementarer Bedeutung zu sein. Das 4. Kapitel der Arbeit widmet sich daher dem Innovationsmanagement als wesentlichem Teilbereich der Unternehmensführung. Zunächst soll auch hier eine grundlegende Begriffserklärung und Charakterisierung stattfinden, die die Neuerungsaktivitäten einordnen und die verschiedenen Innovationsarten beschreiben (4.1). Auf dieser Basis können dann Innovationen auf der gesamt- und einzelwirtschaftlichen Ebene betrachtet werden (4.2). Die Kapitel 4.3 bis 4.6 zeigen analog zur Vorgehensweise in Kapitel 3 Analyseinstrumente, Innovationskultur, Innovationsziele und Innovationsstrategien auf. Die im Rahmen der empirischen Untersuchung gewonnenen Erkenntnisse werden jeweils innerhalb der einzelnen Kapitel im Anschluß an die theoretischen Überlegungen dargestellt.

Mit einem in der Bundesrepublik Deutschland stetig steigenden Umweltbewußtsein in weiten Teilen der Bevölkerung scheinen sich auf den ersten Blick auch die Marktchancen umweltfreundlicher Produkte und damit letztlich auch die Chancen einer umweltorientierten Produk- 
tion zu verbessern. Das artikulierte Umweltbewußtsein spiegelt sich aber meist nicht in den Kaufentscheidungen wider. Wie nun der ökologischen Herausforderung auf der einzelwirtschaftlichen Ebene begegnet wird, ist Inhalt des 5. Kapitels, der Analyse des betrieblichen Umweltmanagements. Die Vorgehensweise bewegt sich im gleichen Schema wie das vorangegangene Kapitel 4.

In Kapitel 6 werden die wichtigsten Analyseergebnisse der theoretischen und empirischen Untersuchung zusammengefaßt und Handlungsempfehlungen zu einer innovations- und umweltorientierten Unternehmensführung abgeleitet. 


\section{Kleine und mittlere Unternehmen}

\subsection{Begriff und Charakterisierung}

Mit der Klassifizierung von Wirtschaftseinheiten in Klein-, Mittel- und Großbetriebe bzw. -unternehmen ${ }^{8}$ wird eine quantitative Aussage getroffen, die das Ausmaß der potentiellen oder effektiven wirtschaftlichen Tätigkeit zum Ausdruck bringen soll. ${ }^{9}$ Die große Heterogenität der in der Praxis vorhandenen Unternehmen sowie deren Vielschichtigkeit und Dynamik erschweren die Entwicklung eines einheitlichen Größenmaßes, das eine angemessene Berücksichtigung der betrieblichen Besonderheiten erlaubt. ${ }^{10}$ Zur Berücksichtigung dieser Besonderheiten werden daher zusätzlich zu den quantitativen Merkmalen oftmals qualitative Merkmale herangezogen, die den Blick für das Wesen der Unternehmen öffnen sollen. ${ }^{11}$

\subsubsection{Quantitative Merkmale}

Eine Möglichkeit, die Betriebsgröße nach quantitativen Merkmalen zu messen, zeigt BusSE VON COLBE auf. Er gliedert hierzu die Merkmale in Anlehnung an den betrieblichen Leistungsprozeß in drei Gruppen, die einzeln oder als Vektorelement genutzt werden können:

1. Merkmale zur Messung der Einsatzmengen elementarer Produktionsfaktoren, wie z.B. Zahl der Anlagen, Werkstoffmengen, Zahl der Arbeitskräfte bzw. Arbeitsstunden.

2. Merkmale zur Messung des Kapitaleinsatzes, wie z.B. Bilanzsumme, Höhe des bilanziellen Eigenkapitals.

8 In der Literatur findet häufig eine Unterscheidung zwischen Betrieb, Unternehmen und Unternehmung statt. Der Betrieb wird in diesem Zusammenhang als wirtschaftlich und rechtlich unselbständig angesehen. Als technisch-wirtschaftliche Einheit im Sinne einer Produktionsstätte ist der Betrieb dem Unternehmen bzw. der Unternehmung als finanzielle-rechtliche Einheit untergeordnet. Vgl. z.B. Busse von Colbe, W. (1974), Sp. 566f.; Pfohl, H.-C./Kellerwessel, P. (1990), S. 2; Macharzina, K. (1995), S. 13f. Vgl. ferner Busse von Colbe, W. (1964), S. 17-28; Günzel, D. (1975), S. 2f.; Nydegger, A. u.a. (1983), S. 11; Mugler, A. (1995), S. 3; Keßler, U. (1992), S. 82ff.; U.S. Small Business Administration (1990), S. 11, FN 12.

Für die im Rahmen dieser Untersuchung betrachteten Unternehmen sind in der Regel die technischwirtschaftliche und die finanzielle-rechtliche Einheit identisch. Infolgedessen werden die Begriffe synonym verwendet. Allgemein soll unter einem Unternehmen ein offenes, autonomes, dynamisches, ökonomisches und sozio-technisches System verstanden werden. Vgl. Bleicher, K. (1971), S. 12; Bleicher, K. (1979), S. 8 bzw. grundsătzlich Ulrich, H. (1970) und von Bertalanffy, L. (1950).

Zum Systembegriff vgl. die Ausfuhrungen von Ulrich, der ein System als "eine geordnete Gesamtheit von Elementen, zwischen denen irgendwelche Beziehungen bestehen oder hergestellt werden können" versteht, Ulrich, H. (1970), S. 105.

9 Vgl. Busse von Colbe, W. (1974), Sp. 567.

10 Vgl. Pfohl, H.-C./Kellerwessel, P. (1990), S. 3.

11 Vgl. McGuire, J.W. (1976), S. 117. Zur Beschreibung quantitativer und qualitativer Kriterien zur Unterscheidung von Betriebsgrößen vgl. u.a. Pfohl, H.-C./Kellerwessel, P. (1990), S. 4f.; Mugler, A. (1995), S. 17-30; Günzel, D. (1975), S. 7-28; BMBF/BMWi (Hrsg.) (1997), S. 8ff. 
3. Merkmale zur Messung der Leistungsmengen und -werte, wie z.B. Produktionsmengen, Absatzmengen und Umsatz, Wertschöpfung. ${ }^{12}$

Abgesehen von den Kriterien "Mitarbeiterzahl" und "Umsatz" sind die vorgenannten Merkmale jedoch nur unter erheblichem Aufwand ermittelbar. Aufgrund ihrer schnellen und weitgehend problemlosen Ermittlung in den Unternehmen sowie ihrer leichten Vergleichbarkeit eignen sich die beiden vorgenannten Merkmale insbesondere als Basis für statistische Erhebungen, auch wenn hierdurch die Unterschiede zwischen den einzelnen Unternehmen bzw. das Wesen eines Unternehmens nicht vollständig erfaßt werden können. Richtungweisend sind in diesem Zusammenhang die Klassifizierungen der Europäischen Kommission bzw. der Small Business Administration ${ }^{13}$ in den USA. Die Europäische Kommission definiert folgende Klassen:

\section{Tab. 2-1: Klassifikation der Unternehmensgröße nach der Zahl der Beschäftigten}

\begin{tabular}{|c|c|}
\hline Klassifikation & Beschäftigte \\
\hline Mikrounternehmen & $1-9$ \\
\hline $\begin{array}{c}\text { Kleine und } \\
\text { Mittlere Unternehmen }\end{array}$ & $10-499$ \\
\hline Großunternehmen & $\geq 500$ \\
\hline
\end{tabular}

Quelle: Commission of the European Communities (Hrsg.) (1990), S. 2.3. ${ }^{14}$

Bei der Festsetzung der Förderungswürdigkeit von Unternehmen z.B. im Rahmen europäischer Programme zur Technologieförderung wird als vorläufige Definition eine Kombination aus den Merkmalen Beschäftigtenzahl, Jahresumsatz und Besitzverhältnisse gewählt. Ein kleines bzw. mittleres Unternehmen im Sinne dieser Definition

12 Vgl. Busse von Colbe, W. (1974), Sp. 568ff. sowie ferner Busse von Colbe, W. (1964), S. 29-59.

13 Vgl. U.S. Small Business Administration (1989), S. 18, FN 13.

14 Eine weitere Differenzierung findet dahingehend statt, daß als "KMU im engeren Sinn" Unternehmen mit 10 bis 199 bzw. als "KMU im weiteren Sinn" Unternehmen mit 1 bis 499 Beschăftigten betrachtet werden. Dieselbe Einteilung der Unternehmensgrößenklassen wird auch vom Statistischen Bundesamt gewählt, vgl. z.B. Statistisches Bundesamt (Hrsg.) (1996).

Vgl. zur Abgrenzungsschwelle zwischen KMU und Großunternehmen ferner z.B. Mugler, A./Schmidt, K.-H. (Hrsg.) (1995), S. 119; Hunger, J.D./Wheelen, T.L. (1996), S. 362.

Eine Aufstellung internationaler Mittelstandsabgrenzungen auf Basis der Beschäftigtenzahl liefert Hamer, E. (1990a), S. 49.

Nach Pfohl und Kellerwessel müßte eine Differenzierung der Grenzen der Betriebsgrößen entsprechend der jeweiligen Branche vorgenommen werden. Vgl. Pfohl, H.-C./Kellerwessel, P. (1990), S. 10. Eine solche Differenzierung wäre der Übersichtlichkeit der Untersuchung allerdings abträglich. 
- hat höchstens 500 Beschäftigte;

- weist einen Jahresumsatz von weniger als 38 Millionen ECU auf;

- befindet sich zu höchstens einem Drittel im Besitz eines anderen Unternehmens, das größer als ein kleines bzw. mittleres Unternehmen ist (institutionelle Anleger sind hiervon ausgenommen). ${ }^{15}$

\subsubsection{Qualitative Merkmale}

Exakter als durch quantitative Merkmale läßt sich das Wesen und die Vielschichtigkeit eines Unternehmens durch qualitative Merkmale erfassen. Kleine und mittlere Unternehmen zeichnen sich dabei durch die zentrale Stellung der Unternehmerpersönlichkeit sowie die große Bedeutung zwischenmenschlicher Beziehungen im Unternehmen aus. ${ }^{16}$ Als weitere Differenzierungskriterien sind u.a. der Führungsstil, die Organisationsstruktur oder die Besitzverhältnisse denkbar. ${ }^{17}$

Die vorgenannte Stellung des Unternehmers dient beispielsweise HAMER als Abgrenzungskriterium zwischen kleinen, mittleren und großen Unternehmen. ${ }^{18}$ Entsprechend liegen für ihn die Übergänge zur nächsten Betriebsgrößenklasse dort, wo sich Einbindung und Aufgaben des Unternehmers deutlich ändern. Im Kleinunternehmen ist der Unternehmer direkt und unter persönlicher Mitarbeit oder im Team in das Tagesgeschäft eingebunden. Ab etwa zehn Beschäftigten reduziert sich die direkte Mitarbeit, während die indirekte Führung und die Delegation von Aufgaben zunehmen, ohne daß dabei jedoch die Führungskompetenz abgegeben wird. Mit Überschreiten der Schwelle von 300 Beschäftigten kann das Unternehmen in der Regel nicht mehr durch einen Alleinunternehmer geführt werden und verläßt damit den Bereich mittelständischer Unternehmen ${ }^{19}$. "Die Grenze zwischen mittelständischen Unternehmen und Großunternehmen liegt also dort, wo ein Unternehmen so groß wird, daß es vom Eigentümer-Unternehmer nicht mehr persönlich geführt werden kann oder soll, sondern aus seiner Persönlichkeitssphäre ausgegliedert und zur Führung an Manager abgegeben wird." ${ }^{20}$

Problematisch an dieser Betriebsgrößenabgrenzung ist zunächst die Vermengung quantitativer und qualitativer Kriterien sowie die enge und zugleich quantitative Verwendung des Mittel-

\footnotetext{
15 Vgl. Europäische Kommission (1995), S. 64.

16 Vgl. Gantzel, K.-J. (1962), S. 279.

17 Vgl. Pfohl, H.-C./Kellerwessel, P. (1990), S. 5. Für eine vergleichende Gegenüberstellung der typischen Charakteristika kleiner und mittlerer Unternehmen und Großunternehmen siehe Anlage 5.

18 Vgl. Hamer, E. (1990a), S. 13f.

19 Der Begriff des "mittelstăndischen Unternehmens" bezieht sich unter soziologischer Betrachtung auf die gesellschaftliche Stellung des Unternehmers. Vgl. dazu ausfulhrlich Gantzel, K.-J. (1962). Da in dieser Arbeit eine betriebgroßßenbezogene Betrachtung gewăhlt wird, erscheint der Begriff "kleine und mittlere Unterneh-

20 men" (KMU) als angemessen.

Hamer, E. (1990a), S. 39.
} 
standsbegriffes, die den mit diesem Begriff verbundenen Werthaltungen und Einstellungen nicht gerecht wird. ${ }^{21}$ Daneben finden branchenspezifische Besonderheiten ebenfalls keine Beachtung.

Die umfassende Betrachtung der aufgezeigten Vielfalt der Merkmale zur Beschreibung der Unternehmensgröße, die ihrerseits wiederum durch eine Vielzahl von Untermerkmalen operationalisiert werden müßten, scheint weder sinnvoll noch praktikabel zu sein. Und obwohl bislang kein einheitliches Größenmaß verfügbar ist ${ }^{22}$, soll hier auch nicht der Versuch unternommen werden, der Vielzahl von Klassifizierungsmöglichkeiten eine weitere hinzuzufügen. Im Rahmen dieser Untersuchung werden daher Unternehmen mit 20 bis unter 500 Beschäftigten als kleine und mittlere Unternehmen bezeichnet.

\subsection{Die gesamtwirtschaftliche Bedeutung kleiner und mittlerer Unternehmen}

Kleinen und mittleren Unternehmen ist in wirtschaftlicher Hinsicht eine hohe Bedeutung beizumessen. Sie haben einen großen Anteil an der Produktion und Bereitstellung von Sachgïtern und Dienstleistungen, sind wichtige Zulieferer der Großindustrie und sorgen für Wettbewerb. Sie stehen darüber hinaus in dem Ruf, innovativ, flexibel und effizient zu sein. ${ }^{23} \mathrm{Zu}$ rückgefuhrt werden kann dies auf kurze Informations- und Kommunikationswege und die Konzentration der Entscheidungsbefugnisse in einer Hand, die eine Voraussetzung für die rasche Anpassung an sich ändernde Marktverhältnisse und Bedürfnisse sind. Eine herausragende Bedeutung wird ihnen aber auch bei der Schaffung von Arbeits- und Ausbildungsplätzen zugesprochen. Zum einen gibt es Hinweise darauf, daß kleine und mittlere Unternehmen vor allem in Jahren des allgemeinen Beschäftigungsrückgangs ein bedeutender Faktor zur Erhaltung von Arbeits- und Ausbildungsplätzen waren. Ihrer räumlichen Verteilung entsprechend tragen sie hierdurch zum anderen zur Abfederung sozialer Spannungen in vom wirtschaftlichen Strukturwandel besonders hart betroffenen Regionen bei und sorgen damit zugleich für gesellschaftliche Stabilität. ${ }^{24}$

${ }^{21}$ Vgl. zur Charakterisierung mittelstăndischer Unternehmen insbesondere Gantzel, K.-J. (1962), S. 280f. sowie Mugler, A. (1995), S. 23 und die dort angegebene Literatur.

22 Vgl. Zeitel, G. (1990), S. 25.

23 Vgl. Longenecker, J.G./Moore C.W. (1991), S. 41-48; Mugler, A./Schmidt, K.-H. (Hrsg.) (1995), S. 298. Für eine Relativierung der volkswirtschaftlichen Bedeutung kleiner und mittlerer Unternehmen vgl. Bade, F.-J. (1987), S. 72-77. Deeks sieht zwar in KMU einen bedeutenden Vermögenswert einer entwickelten Volkswirtschaft. Seiner Ansicht nach leisten sie allerdings nicht den Beitrag, zu dem sie potentiell in der Lage wăren. Dies laß sich einerseits auf beschränkte unternehmerische bzw. Managementfähigkeit oder -motivation zurückführen. Andererseits mangelt es auch am Verstăndnis für die gesellschaftliche Einbindung des Unternehmens bzw. dessen strategische Ausrichtung. Vgl. Deeks, J. (1973), S. 47.

$24 \mathrm{Vgl}$. Commission of the European Communities (Hrsg.) (1990), S. 1.2f.; BMBF/BMWi (Hrsg.) (1997), S. 1114. 
Für einen auch weiterhin hohen Stellenwert sprechen nach MUGLER UND SCHMIDT drei Thesen. $^{25}$ Mit dem Strukturwandel erfolgt eine Verschiebung vom sekundären zum tertiären Sektor (Verschiebungsthese). Das damit verbundene überproportionale Wachstum des Dienstleistungssektors sowie die traditionelle Dominanz in diesem Wirtschaftsbereich führt zu einer Stärkung kleiner und mittlerer Unternehmen. Gemäß der Leistungsthese lassen sich zahlreiche Branchen anführen, in denen Größeneffekte ("economies of scale") eine untergeordnete Rolle spielen, d.h. hier nimmt die Rentabilität mit steigender Unternehmensgröße ab. Daran knüpft auch die Menschlichkeitsthese an, die auf die Überschaubarkeit der Verhältnisse abhebt. In kleinen und mittleren Unternehmen lassen sich soziale und humane Bedürfnisse (z.B. persönliche Kontakte und Kommunikation, familiäre Arbeitssituation) eher befriedigen als in Großunternehmen.

Damit ist die quantitative und qualitative Relevanz kleiner und mittlerer Unternehmen angesprochen. Beide Aspekte werden nachfolgend eingehender beleuchtet.

\subsubsection{Die quantitative Bedeutung kleiner und mittlerer Unternehmen}

Die quantitative Rolle kleiner und mittlerer Unternehmen verdeutlicht Tab. 2-2. Dabei zeigt sich in allen Wirtschaftsbereichen eine überragende Dominanz, was die Anzahl dieser Unternehmen anbelangt. Hinsichtlich der Beschäftigten und, wie später noch gezeigt wird, der Umsätze und der Wertschöpfung sind jedoch starke Differenzen erkennbar.

Die Übersicht in Tab. 2-2 belegt die quantitative Bedeutung des Mittelstandes, der unter Einschluß der Kleinst-, Klein- und Mittelunternehmen in der Summe 99,8\% der Unternehmen und $65,7 \%$ der Beschäftigten stellt. Die deutsche Wirtschaft kann somit als mittelständisch bzw. kleinbetrieblich strukturiert charakterisiert werden. ${ }^{26}$ In einem weiteren Schritt soll nun nachvollzogen werden, welche Anteile die einzelnen Beschäftigtengrößenklassen in den jeweiligen Wirtschaftsbereichen an der Gesamtzahl der Unternehmen bzw. der Gesamtzahl der Beschäftigten in Deutschland haben.

25 Vgl. Mugler, A./Schmidt, K.-H. (Hrsg.) (1995), S. 43.

26 Dies entspricht auch der Definition der Europäischen Kommission. Bezüglich der Abgrenzungskriterien vgl. Commission of the European Communities (Hrsg.) (1990), S. 2.4. Vgl. zur mittelständischen Strukturierung der Bundesrepublik Deutschland auch Hamer, E. (1990a), S. 54f.; Zeitel, G. (1990), S. 26-29; Fritsch, M. (1993), S. 39-48; Mugler, A./Schmidt, K.-H. (Hrsg.) (1995), S.43; Matraves, C. (1997), S. 4. Ähnliches laßßt sich z.B. auch furr die USA aufzeigen, vgl. Acs, Z.J./Audretsch, D.B. (1993b), S. 61-64; U.S. Small Business Administration (1995), S. 111; Hunger, J.D./Wheelen, T.L. (1996), S. 361 f.

Im Verarbeitenden Gewerbe zeigen sich leichte Differenzen. Hier haben die Unternehmen unter $500 \mathrm{Be}-$ schăftigten einen Anteil von $99,45 \%$, wăhrend sie $50,05 \%$ der Beschäftigten stellen. Die Unternehmen zwischen 20 und 499 Beschäftigten haben einen Anteil von 12,61\% an den Unternehmen und $36.07 \%$ an den Beschäftigten. Vgl. Statistisches Bundesamt (Hrsg.) (1996), S. 132; eigene Berechnungen. 
Tab. 2-2: Prozentuale Verteilung der Beschäftigtengrößenklassen innerhalb der Wirtschaftsbereiche am 25.5.1987 in Deutschland (West)

\begin{tabular}{|c|c|c|c|c|c|c|c|c|}
\hline \multirow{3}{*}{$\begin{array}{l}\text { Wirtschafts- } \\
\text { bereich }\end{array}$} & \multicolumn{8}{|c|}{ Unternehmen mit ... bis ... Beschäftigten (in \%) } \\
\hline & \multicolumn{2}{|c|}{$1-9$} & \multicolumn{2}{|c|}{$10-19$} & \multicolumn{2}{|c|}{$20-499$} & \multicolumn{2}{|c|}{500 und mehr } \\
\hline & Unt. & Besch. & Unt. & Besch. & Unt. & Besch. & Unt. & Besch. \\
\hline Land-/Forstwirt., & & & & & & & & \\
\hline Fischerei & 89,5 & 53,3 & 7,2 & 19,1 & 3,4 & 27,1 & 0,0 & 0,5 \\
\hline Produzierendes & & & & & & & & \\
\hline Gewerbe & & & & & & & & \\
\hline - insgesamt & 74,5 & 12,8 & 13,7 & 8,7 & 11,5 & 36,4 & 0,4 & 42,1 \\
\hline - Verarb. Gew. & 73,9 & 10,2 & 13,0 & 6,8 & 12,6 & 36,1 & 0,5 & 47,0 \\
\hline Handel und Ver- & & & & & & & & \\
\hline kehr & 90,0 & 30,6 & 6,1 & 9,8 & 3,9 & 27,1 & 0,1 & 32,5 \\
\hline Dienstleistungs- & & & & & & & & \\
\hline unternehmen & 92,6 & 42,5 & 4,9 & 10,1 & 2,4 & 25,9 & 0,1 & 21,5 \\
\hline
\end{tabular}

Quelle: Statistisches Bundesamt (Hrsg.) (1996), S. 132; eigene Berechnungen. ${ }^{27}$

Mit einer Rate von 42,1\% weisen die Dienstleistungsunternehmen in ihrer Gesamtheit den höchsten Anteil an den Unternehmen in Deutschland auf und setzen sich damit deutlich vor den Bereich Handel und Verkehr (31,8\%) sowie das Produzierende Gewerbe $(18,5 \%)$. Werden als Kriterien die Beschäftigten in den Unternehmen herangezogen, so zeigt sich eine deutliche Verschiebung der Bedeutung hin zum Produzierenden Gewerbe, das mit insgesamt 50,2\% den höchsten Anteil an den Beschäftigten aufweist. Der Anteil der Beschäftigten im Dienstleistungsgewerbe bzw. im Handel und Verkehr beläuft sich dort auf 24,9\% bzw. 24,6\% (vgl. im einzelnen Tab. 2-3).

Damit läßt sich zum einen ein noch immer hoher Beitrag des Produzierenden Gewerbes und zum anderen ein ebenfalls bedeutsamer Anteil des Dienstleistungsgewerbes feststellen, der wohl in Zukunft noch weiter expandieren wird. Hiervon werden beide Wirtschaftsbereiche profitieren, da sie u.a. im Bereich der produktionsorientierten Dienstleistungen zahlreiche Berührungspunkte besitzen.

27 Die Aggregation von Handel, Verkehr und Nachrichtenübermittlung zu "Handel und Verkehr" bzw. von Kreditinstituten und Versicherungsgewerbe sowie Dienstleistungen i.e.S. zu "Dienstleistungen" wurde notwendig, um eine einfachere Vergleichbarkeit der Daten auf nationaler Ebene mit jenen auf Länder- bzw. regionaler Ebene herzustellen.

Vgl. in Ergånzung hierzu Commission of the European Communities (Hrsg.) (1990), S. 4.7. Zum Vergleich finden sich ferner in Anlage 6 die Werte auf europæischer Ebene. Es zeigt sich, daß hier den Unternehmen mit unter 500 Mitarbeitern vor allem in Bezug auf den Anteil an den Beschăftigten (71,9\%) eine noch höhere Bedeutung zukommt. 
Tab. 2-3: Prozentuale Anteile der Beschäftigtengrößenklassen der Wirtschaftsbereiche an der Gesamtzahl der Unternehmen und Beschäftigten am 25.5.1987 in Deutschland (West)

\begin{tabular}{|c|c|c|c|c|c|c|c|c|}
\hline \multirow{3}{*}{$\begin{array}{c}\text { Wirtschafts- } \\
\text { bereich }\end{array}$} & \multicolumn{8}{|c|}{ Unternehmen mit ... bis ... Beschäftigten (in \%) } \\
\hline & \multicolumn{2}{|c|}{$1-9$} & \multicolumn{2}{|c|}{$10-19$} & \multicolumn{2}{|c|}{$20-499$} & \multicolumn{2}{|c|}{500 und mehr } \\
\hline & Unt. & Besch. & Unt. & Besch. & Unt. & Besch. & Unt. & Besch. \\
\hline Land-/Forstwirt., & & & & & & & & \\
\hline Fischerei & 1,20 & 0,34 & 0,10 & 0,12 & 0,05 & 0,17 & 0,00 & 0,00 \\
\hline Produxierendes & & & & & & & & \\
\hline Gewerbe & & & & & & & & \\
\hline - insgesamt & 18,51 & 6,40 & 3,39 & 4,34 & 2,84 & 18,15 & 0,10 & 20,98 \\
\hline - Verarb. Gew. & 11,85 & 3,98 & 2,08 & 2,67 & 2,02 & 14,12 & 0,09 & 18,39 \\
\hline Handel und Ver- & & & & & & & & \\
\hline kehr & 28,58 & 7,54 & 1,91 & 2,41 & 1,24 & 6,67 & 0,02 & 7,99 \\
\hline Dienstleistungs- & & & & & & & & \\
\hline unternehmen & 38,94 & 10,57 & 2,05 & 2,51 & 1,03 & 6,45 & 0,04 & 5,35 \\
\hline
\end{tabular}

Quelle: Statistisches Bundesamt (Hrsg.) (1996), S. 132; eigene Berechnungen.

Die Dominanz und die Verflechtung des Produzierenden und des Dienstleistungsgewerbes wird in Baden-Württemberg besonders deutlich. Baden-Württemberg ist traditionell durch das Verarbeitende Gewerbe geprägt, das allerdings in den letzten Jahren einen Bedeutungsrückgang erfuhr. ${ }^{28} 1996$ haben die Dienstleistungsunternehmen erstmals die Wirtschaftsleistung des Verarbeitenden Gewerbes übertroffen (vgl. Tab. 2-4). Sie werden mit einer anhaltenden Expansion auch künftig ein Wachstum der Wirtschaft begünstigen. Zurückzuführen ist diese Entwicklung insbesondere auf die Zunahme unternehmensbezogener Dienstleistungen, wie sie beispielsweise von Unternehmensberatern, Wirtschaftsprüfern oder Architekten erbracht werden. In der Tatsache, daß das Verarbeitende Gewerbe mittelfristig dennoch der bedeutendste Arbeitgeber in Baden-Württemberg bleibt und in dieser Funktion durch den Dienstleistungsbereich nicht zu ersetzen ist, liegt die Begründung für die Fokussierung der Untersuchung auf diesen Wirtschaftsbereich. ${ }^{29}$

28 In baden-württembergischen Unternehmen des Verarbeitenden Gewerbes mit mehr als 20 Beschäftigten nahm von 1990 bis 1996 die Zahl der Beschäftigten um 19,6\% ab, die Zahl der Betriebe sank um 15,0\%, lediglich der Gesamtumsatz konnte leicht um ca. 6,8\% zulegen. Vgl. Statistisches Landesamt Baden-Württemberg (1997a); eigene Berechnungen. Für die Entwicklung der Beschäftigtengrößenklassen hinsichtlich Beschättigten-, Umsatz-, Investitions- und Wertschöpfungsanteil vgl. auch Bade, F.-J. (1987), S. 72-77.

29 Vgl. dazu auch Löbbe, der die Zukunft der deutschen Wirtschaft vor allem in technologie- und humankapitalintensiven, weltmarktorientierten Industriebereichen sowie in unternehmensbezogenen Servicedienstleistungen sieht, Löbbe, K. (1994), S. 51. 
Tab. 2-4: Prozentuale Anteile der Wirtschaftsbereiche in Baden-Württemberg 1990 bis 1996 an der Bruttowertschöpfung der Unternehmen (in Preisen von 1991, unbereinigt)

\begin{tabular}{|c|c|cc|c|c|}
\hline Jahr & $\begin{array}{c}\text { Land- und } \\
\text { Forstwirtschaft, } \\
\text { Fischerei }\end{array}$ & $\begin{array}{c}\text { Produzierendes Gewerbe } \\
\text { insgesamt }\end{array}$ & $\begin{array}{c}\text { Handel } \\
\text { Verarbeitendes } \\
\text { Gewerbe }\end{array}$ & $\begin{array}{c}\text { Dienstleistungs- } \\
\text { unternehmen }\end{array}$ \\
\hline 1990 & 1,7 & 53,3 & 44,3 & 13,3 & 31,7 \\
1991 & 1,3 & 52,6 & 43,9 & 14,1 & 32,9 \\
1992 & 1,8 & 51,2 & 42,3 & 14,0 & 33,0 \\
1993 & 1,6 & 48,2 & 39,4 & 14,3 & 35,9 \\
1994 & 1,6 & 47,7 & 39,1 & 13,9 & 36,7 \\
1995 & 1,6 & 46,9 & 38,5 & 13,8 & 37,7 \\
1996 & 1,8 & 45,9 & 37,8 & 13,6 & 38,7 \\
\hline
\end{tabular}

Quelle: Statistisches Landesamt Baden-Württemberg (1997b), S. 4f.; eigene Berechnungen.

\subsubsection{Die qualitative Bedeutung kleiner und mittlerer Unternehmen}

Mit der quantitativen Bedeutung eng verwoben ist die qualitative Relevanz kleiner und mittlerer Unternehmen für die wirtschaftliche und gesellschaftliche Entwicklung der Bundesrepublik Deutschland. ZEITEL zeigt hierzu ein Reihe von Funktionen auf, die die zentrale Stellung der kleinen und mittleren Unternehmen in der deutschen Volkswirtschaft weiter untermauern. $^{30}$ Sie lassen sich zu zwei ubergeordneten Funktionen zusammenfassen,

- den wirtschaftlichen Ordnungsfunktionen und

- den gesellschaftlichen Ordnungsfunktionen.

In Bezug auf die wirtschaftliche Ordnungsfunktion kleiner und mittlerer Unternehmen ist zunächst ihr großer "Beitrag zu einem funktionsfähigen Leistungswettbewerb und damit zur Erhaltung der Marktwirtschaft" ${ }^{31}$ hervorzuheben. Daneben sind sie durch ihr flexibles Reagieren in der Lage, bei einer Verschlechterung der wirtschaftlichen Rahmenbedingungen ihre Produktion anzupassen, ohne zugleich einen Abbau der Beschäftigten vorzunehmen. Sie verhalten sich somit weniger prozyklisch als größere Unternehmen und tragen dadurch zu einer Beschäftigungskontinuität bei (konjunktur- und beschäftigungspolitische Funktion). ${ }^{32}$ Ihre Anpassungsfähigkeit an Nachfrage- und Marktveränderungen kommt in der Bereitstellung

30 Vgl. auch im folgenden Zeitel, G. (1990), S. 29-40. Vgl. dazu ferner Hamer, E. (1990a), S. 15f.; Mugler, A. (1995), S. 31-35; Mugler, A./Schmidt, K.-H. (Hrsg.) (1995), S. 43ff. und S. $119 f$.

31 Zeitel, G. (1990), S. 31.

32 Vgl. Bade, F.-J. (1987), S. 72f. Vgl. ferner Birch, D.L. (1981) und (1987), der KMU einen besonders hohen Anteil an der Schaffung von Arbeitsplätzen zuweist. 
eines vielfältigen und differenzierten Angebotes an Waren und Dienstleistungen zum Ausdruck, wodurch sie zum einen eine Bedarfsdeckungsfunktion im Konsum- und Investitionsgüterbereich übernehmen und zum anderen im Rahmen einer Markterschließungsfunktion Versorgungslücken schließen und neu entstehenden Bedarf decken. Thre dezentrale Verteilung ermöglicht damit zugleich das Schließen räumlicher Versorgungsengpässe bzw. verbreitert das Angebot von Arbeitsplätzen in räumlichen Randgebieten. Ein hohes Maß an Anpassungsfähigkeit führt, sofern sie mit Innovationsbereitschaft verbunden ist, zu einer Verbesserung der Wettbewerbsposition und damit gleichzeitig zur Bewältigung des Strukturwandels sowie zu einer regional ausgewogenen Wirtschaftsstruktur (wettbewerbs- bzw. strukturpolitische Funktion). Zur Sicherung des langfristigen Erfolgs bzw. der Wettbewerbsposition zählt auch die internationale bzw. globale Ausrichtung des Angebotes, wobei zunächst Nachteile in Form von fehlenden economies of scale, eingeschränktem Zugang zu Informationen und Kapital, eingeschränkten Verkaufsunterstlitzungs- und Markierungsmöglichkeiten sowie höheren Transaktionskosten überwunden werden müssen. Ausgeglichen werden können diese Nachteile durch die bereits angesprochene Flexibilität und Anpassungsfähigkeit sowie die Bedienung von Nischen, die für größere Unternehmen unattraktiv scheinen. ${ }^{33}$ Das Gewicht kleiner und mittlerer Unternehmen bei der Sicherung der internationalen Wettbewerbsfähigkeit ist daher nicht zu unterschätzen. Insgesamt übernehmen kleine und mittlere Unternehmen entscheidende wirtschaftliche Funktionen, die sich letztlich auch positiv auf das Wirtschaftswachstum auswirken können (Wachstumsfunktion). Vor allem ihr Beitrag zum technischen Fortschritt durch marktgerichtete Forschungs- und Entwicklungsaktivitäten kann als Beitrag zu einem dynamischen Leistungswettbewerb gewertet werden, wodurch sich der Kreis wieder schließt.

Neben den aufgezeigten wirtschaftlichen Funktionen übernehmen kleine und mittlere Unternehmen auch wichtige gesellschaftliche und soziale Funktionen. Eng verknüpft mit dem zuletzt genannten technischen Fortschritt und dem damit verbundenen Beitrag zu Forschung und Entwicklung ist ihre bildungspolitische Funktion, die sie als eine tragende Säule des dualen Berufsausbildungssystems übernehmen. Sie sind damit direkt in die Aus-, Fort- und Weiterbildung eingebunden und für die Qualität und Quantität der ausgebildeten Fachkräfte verantwortlich. Die Qualität und die Quantität der Fachkräfte bestimmen zugleich die gesamt- wie auch die einzelwirtschaftliche Leistungsfähigkeit kleiner und mittlerer Unternehmen. Daneben tragen die Arbeitsbedingungen in kleinen und mittleren Unternehmen zu einer Humanisierung des Arbeitsplatzes bei. Insbesondere die oftmals familiäre Atmosphäre, kurze Kommunikations- und Informationswege sowie unbürokratische Handlungsweisen verstärken die Bindung an das Unternehmen und vermindern dadurch die Fluktuation, wodurch wiederum die Beschäftigungskontinuität gefördert wird.

33 Vgl. Schmidt, K.-D. (1996), S. $12 f$. 
Letztlich ist es das gesellschaftspolitische Ziel der Bundesrepublik Deutschland, eine demokratische und zugleich freiheitlich pluralistische Gesellschaft zu gewährleisten. Untermauert wird dies durch die im Grundgesetz verankerten Grundrechte, wie beispielsweise das Recht auf freie Entfaltung der Persönlichkeit (Art. 2), das Recht auf freie Arbeitsplatz- und Berufswahl (Art. 12) oder das Recht auf Gewährleistung von Eigentum (Art. 14). Eine Gesellschaft und mit ihr die Unternehmen bedürfen dieser stabilisierenden Rechte als Grundlage und Chance zur individuellen Selbstentfaltung und Übernahme von Eigenverantwortung. Leistungs- und Verantwortungsbereitschaft sowie Kreativität werden insbesondere mit kleinen und mittleren Unternehmen in Verbindung gebracht. Insofern sind sie eine Voraussetzung für demokratische und marktwirtschaftliche Strukturen und übernehmen damit "eine gesellschaftspolitisch hoch einzuschätzende Leitfunktion" ${ }^{34}$.

\subsection{Die Unternehmen des Verarbeitenden Gewerbes in der Region Neckar-Alb}

\subsubsection{Situationsanalyse der Region Neckar-Alb}

Die Region Neckar-Alb liegt im Bundesland Baden-Württemberg und konstituiert sich durch die Landkreise Reutlingen und Tübingen sowie den Zollernalbkreis (vgl. Anlage 1). Auf sie entfallen 6,5\% der Bevölkerung und ca. 5,3\% der Bruttowertschöpfung Baden-Württembergs. 35

Die Region Neckar-Alb ist durch einen ausgeprägten Anteil des Verarbeitenden Gewerbes gekennzeichnet. ${ }^{36}$ Auffallend innerhalb des Verarbeitenden Gewerbes sind insbesondere die hohen Anteile in den Wirtschaftszweigen Leder-, Textil- und Bekleidungsgewerbe sowie Stahl-, Maschinen- und Fahrzeugbau (vgl. Tab. 2-5).

Diese von der Strukturkrise besonders betroffenen Wirtschaftszweige erschwerten zusätzlich die Bewältigung der Rezession im Jahr 1993. Die wirtschaftliche Abwärtsbewegung setzte hier, verglichen mit den Landes- bzw. Bundeswerten, früher und zugleich stärker ein, gleichzeitig fallen die Erholungstendenzen zum Teil geringer als in den genannten Vergleichsräu-

34 Zeitel, G. (1990), S. 29. Vgl. dazu auch Hamer, E. (1990a), S. 13.

35 Vgl. Statistisches Landesamt Baden-Württemberg (1995), S. 1f.; Statistisches Landesamt BadenWürttemberg (1997c), S. 11. Für eine Charakterisierung der Region Neckar-Alb vgl. auch Regionalverband Neckar-Alb (1995); Herdzina, K./Nolte, B. (1995); Herdzina, K./Blessin, B. (1996); Herdzina, K. u.a. (1996); WIFO (1996); Koschatzky, K. (1997).

36 Vgl. Statistisches Landesamt Baden-Württemberg (1997b), S. 22. Ohne Berücksichtigung des Staates sowie der privaten Haushalte hatten die Wirtschaftbereiche in der Region Neckar-Alb folgende Anteile: Land- und Forstwirtschaft (1,0\%); Produzierendes Gewerbe $(53,8 \%)$, davon Verarbeitendes Gewerbe $(43,0 \%)$; Handel und Verkehr (13,1\%); Dienstleistungsunternehmen (32,2\%). 
men aus. ${ }^{37}$ Festmachen läßt sich dies an der Anzahl der Betriebe, der Beschäftigten sowie an der Entwicklung des Gesamtumsatzes. Die Anzahl der Betriebe ging in der Region NeckarAlb zwischen 1990 und 1995 um 19,4\%, in Baden-Württemberg lediglich um 13,3\% zurück. Bei der Entwicklung der Beschäftigten sind die Differenzen weniger deutlich. Hier kommt es zu einer fast gleichförmigen anhaltenden Verminderung der Beschäftigten, wobei der Abbau in der Region Neckar-Alb 19,9\% und in Baden-Württemberg 19,6\% betrug. Im Falle der Gesamtumsätze sind die Unterschiede wieder deutlicher zu sehen. Zwar erholten sich die Gesamtumsätze auf baden-württembergischer und regionaler Ebene bis 1995 auf ein Niveau, das über dem des Jahres 1990 liegt. Jedoch war der Rückgang in der Region Neckar-Alb stärker als auf baden-württembergischer Ebene und die Erholung erfolgte auch nicht in gleichem MaBe. Die aufgezeigten Tendenzen setzten sich im Jahr 1996 fort.

Neben den zum Teil ungünstigen strukturbedingten wirtschaftlichen Voraussetzungen weist die Region eine Reihe von positiven Entwicklungspotentialen auf, von denen hier insbesondere auf die Infrastrukturpotentiale hingewiesen werden soll. ${ }^{38}$ Hervorzuheben sind eine Reihe von Hochschul- und Forschungseinrichtungen wie beispielsweise die Universität Tübingen, verschiedene Fachhochschulen, Steinbeis-Transferzentren und Max-Planck-Institute, die die Grundlage für die Bildung eines regionalen Humankapitalstocks bilden. Ferner verfügt die Region über gute verkehrstechnische Anbindung an die nördlich gelegene Region Stuttgart bzw. den Flughafen Stuttgart sowie im Süden an die Schweiz (mit dem Flughafen Basel), wodurch sowohl nahe regionale Märkte als auch internationale Märkte schnell erreichbar sind.

37 Vgl. Statistisches Landesamt Baden-Württemberg (1997a), S. 4 und S. 53; Herdzina, K./Blessin, B. (1996), S. 5-9.

38 Eine vertiefende Betrachtung regionaler Entwicklungspotentiale findet sich bei Scharff, R. (1993). Zur Innovationsinfrastruktur in lăndlich geprăgten Răumen vgl. Nolte, B. (1996). 
Tab. 2-5: Anteile der Unternehmen und Beschäftigten an den Wirtschaftszweigen des Verarbeitenden Gewerbes in Baden-Württemberg und der Region NeckarAlb 1995 (in \%)

\begin{tabular}{|c|c|c|c|c|}
\hline \multirow{2}{*}{ Wirtschaftszweig } & \multicolumn{2}{|c|}{ Baden-Württemberg } & \multicolumn{2}{|c|}{ Region Neckar-Alb } \\
\hline & Unt. & Besch. & Unt. & Besch. \\
\hline $\begin{array}{l}\text { Ernåhrungsgewerbe und Tabakverar- } \\
\text { beitung }\end{array}$ & 7,5 & 4,9 & 6,0 & 5,4 \\
\hline Leder, Textil- u. Bekleidungsgewerbe & 7,2 & $4,4^{*}$ & 28,6 & $21,1^{*}$ \\
\hline Holz-, Papier- und Druckgewerbe & 14,6 & 8,4 & 11,0 & $2,9^{*}$ \\
\hline Chemische Industrie & 3,2 & $4,8^{*}$ & 2,7 & $\ldots *$ \\
\hline $\begin{array}{l}\text { Herstellung von Gummi- und Kunst- } \\
\text { stoffwaren }\end{array}$ & 6,2 & 5,3 & 4,8 & 4,1 \\
\hline $\begin{array}{l}\text { Glas, Keramik, Steine, Erden } \\
\text { Stahl-, Maschinen-, Fahrzeugbau: }\end{array}$ & 5,1 & 2,4 & 3,3 & 2,2 \\
\hline $\begin{array}{l}\text { Metallerzeugung und -bearbeitung, } \\
\text { Herstellung von Metallerzeugnissen }\end{array}$ & 15,3 & 10,8 & 11,1 & 11,8 \\
\hline Maschinenbau & 18,3 & 21,8 & 15,4 & 22,6 \\
\hline Fahrzeugbau & 3,2 & 15,4 & 1,8 & 7,5 \\
\hline Elektrotechnische Industrie: & & & & \\
\hline $\begin{array}{l}\text { Herstellung von Büromaschinen, Da- } \\
\text { tenverarbeitungsgeräten und -ein- } \\
\text { richtungen; Elektrotechnik, Feinme- } \\
\text { chanik und Optik }\end{array}$ & 13,4 & 17,1 & 10,8 & 13,0 \\
\hline $\begin{array}{l}\text { Herstellung von M8beln, Schmuck, } \\
\text { Musikinstrumenten, Sportgerăten, } \\
\text { Spielwaren usw. }\end{array}$ & 6,1 & 4,3 & 4,5 & 2,4 \\
\hline insgesamt in \% & 100,1 & 99,6 & 100,0 & 93,0 \\
\hline
\end{tabular}

* unvollstăndige Daten

Quelle: Statistisches Landesamt Baden-Württemberg (1996b), S. 4 und S. 53; eigene Berechnungen. ${ }^{39}$

39 Ein direkter Vergleich deutscher, baden-württembergischer und regionaler Daten ist aufgrund des unterschiedlichen Aggregationsniveaus bzw. der unterschiedlichen Aggregationskriterien auf Bundes- bzw. Länderebene nicht möglich. Für einen Vergleich der Beschăftigten im Verarbeitenden Gewerbe zwischen Deutschland und Baden-Württemberg vgl. z.B. Statistisches Bundesamt (Hrsg.) (1996), S. 116. BadenWürttemberg stellt mit ca. 1,52 Mio. Mitarbeitern den zweithöchsten Anteil (17,8\%) an den sozialversicherungspflichtig Beschäftigten im Verarbeitenden Gewerbe Deutschlands. Ferner zeigt sich dort auf deutscher Ebene ein höherer Anteil der Wirtschaftszweige Chemische Industrie; Glas, Keramik, Steine, Erden; Metallerzeugung und -bearbeitung sowie Nahrungs- und Genußmittel, wohingegen Baden-Württemberg ein Übergewicht in den Wirtschaftszweigen Stahl-, Maschinen- und Fahrzeugbau sowie Elektrotechnik aufweist. 


\subsubsection{Design und Methodik der Untersuchung}

\subsubsection{Die Erhebung der Daten}

Die vorliegende empirische Untersuchung basiert auf einer Vollerhebung kleiner und mittlerer Unternehmen des Verarbeitenden Gewerbes in der Region Neckar-Alb. Es wurden mit Unterstützung des Regionalverbandes Neckar-Alb, der Arbeitsämter Reutlingen/Tübingen und Zollernalb sowie des Landratsamts Zollernalb an insgesamt 812 Unternehmen Fragebögen versandt (vgl. Anschreiben und Fragebogen in Anlage 2 und 3 des Anhangs). ${ }^{40}$

Die für gewöhnlich auftretenden Nachteile einer Untersuchung mittels standardisiertem Fragebogen, wie beispielsweise eine geringe Rücklaufquote, die Unkontrollierbarkeit der Erhebungssituation oder die Unmöglichkeit, genauere Erklärungen zu einzelnen Fragen zu erhalten, konnten mit Hilfe der logistischen Unterstützung durch die vorgenannten Institutionen in der Region Neckar-Alb sowie durch die persönliche Ansprache der Unternehmen weitgehend umgangen werden. ${ }^{41}$

Zur Sicherstellung der Gültigkeit (Validität) wurde versucht, die Untersuchungsergebnisse durch umfangreiche theoretische Vorarbeiten abzusichern. Soweit durch die Formulierung der Fragen und Antwortkategorien, durch Kontrollfragen und den Aufbau des Fragebogens gestaltbar, wurde dieser Problematik in besonderer Weise Rechnung getragen. Ferner wurden als primäre Ansprechpartner die jeweiligen Geschäftsführer gewählt, da diese Personengruppe über ein hohes $\mathrm{Maß}$ an persönlicher Urteilsfähigkeit und aktuellen Unternehmensinformationen verfügt, um die gewünschten Einschätzungen vornehmen zu können. Zudem ist der Geschäftsfuihrer, der oftmals gleichzeitig Eigentümer ist, maßgeblich als Entscheidungsträger für die Einfuihrung von Produkt- und Prozeßinnovationen verantwortlich.

Hinsichtlich der Verläßlichkeit (Reliabilität) der Ergebnisse konnte auf die Erfahrungen aus Forschungsprojekten der Europäischen Forschungsstelle für den Ländlichen Raum (EFLR) zurückgegriffen werden. Dort wurden bereits vergleichbare Studien mit ähnlichen Fragestel-

40 Der Adressensatz (Stand 31.12.1993) wurde im Zuge der Untersuchung auf den aktuellen Stand gebracht, so daß sich zum 31.12.1995 eine Grundgesamtheit von 709 Unternehmen in der Region Neckar-Alb ergab, die mehr als 20 Beschäftigte aufwiesen. Hierin liegt auch die Abweichung von der amtlichen Statistik begründet, die für 1995 noch 720 Unternehmen auswies, vgl. Statistisches Landesamt Baden-Württemberg (1996b), S. 53.

Von einer Befragung der Kleinstunternehmen (hier: 1 - 19 Mitarbeiter) mußte aus pragmatischen Gründen abgesehen werden. Eine Vollerhebung unter Einbeziehung dieses Unternehmenskreises hätte einerseits die finanziellen und personellen Möglichkeiten überstiegen und andererseits die Auswertung und Interpretation der Daten erschwert, da diese Betriebsgrößenklasse in der amtlichen Statistik wie auch in vergleichbaren Untersuchungen größtenteils ebenfalls unberücksichtigt bleibt.

41

Dennoch kann auch durch diese Vorgehensweise nicht ausgeschlossen werden, daß die Befragten durch die standardisierten Antwortmöglichkeiten u.U. in eine ihnen nicht immer geläufige Begriffswelt gezwängt wurden bzw. a priori nicht absehbare Unternehmensspezifika entsprechend erfaßt werden konnten. Ferner ist ebenfalls nicht auszuschließen, daß sich eher die betriebswirtschaftlich aktiveren und erfolgreichen Unternehmen beteiligt haben, was die erzielten Ergebnisse u.U. in ein zu positives Licht rückt. 
lungen durchgeführt. ${ }^{42}$ Die dem hier zugrundeliegenden Untersuchungsgegenstand entsprechenden Adaptionen der Fragestellungen und der Antwortkategorien wurden in Expertengesprächen erörtert, so daß auf einen gesonderten Pre-Test verzichtet werden konnte. Zur Absicherung wurden die Ergebnisse in den Unternehmergesprächen (s.u.) noch einmal (ex post) überprüft. Die Reliabilität der Daten kann somit als hinreichend gegeben betrachtet werden.

Insgesamt gingen 195 Fragebögen ein. Bezogen auf die Grundgesamtheit von 709 Unternehmen ergab sich damit eine Bruttorlicklaufquote von 27,36\%. Für die Auswertung konnten letztlich 178 Fragebögen genutzt werden, was einer Nettorücklaufquote von $25,11 \%$ entspricht.

Die schriftliche Befragung wurde durch eine persönliche Befragung ergänzt. Diese umfaßte 33 Unternehmen der Region Neckar-Alb, die sich an der schriftlichen Befragung beteiligt haben. ${ }^{43}$ In den Gesprächen auf Geschäftsfuhrer- bzw. Betriebsleiterebene wurde ein teilstandardisierter Leitfaden verwendet, der zehn Themenschwerpunkte der o.g. Untersuchung noch einmal vertieft beleuchtete. Die Schwerpunkte erstreckten sich auf die Themengebiete Unternehmensführung, Forschung und Entwicklung (F\&E), Innovativität bzw. Produktalter, Innovationshemmnisse, Import- und Exportbesonderheiten, Kundenorientierung, Umwelt- und Qualitätsmanagement, interne Organisation und Durchführung von Qualifizierungsmaßnahmen bzw. Nachfrage nach externen Qualifizierungsmaßnahmen sowie (öffentliche) Förderung von Projekten.

Für die Auswahl der an diesen Gesprächen beteiligten Unternehmen waren Branchen- oder Betriebsgrößengesichtspunkte von eher nachrangiger Bedeutung. Im Vordergrund standen positive bzw. negative Abweichungen bei den vorgenannten Themenschwerpunkten. So wurden auf der einen Seite u.a. Unternehmen mit hohen Aufwendungen im Forschungs- und Entwicklungsbereich, hohen Exportquoten (insb. in den Wachstumsregionen Südostasien, Südamerika oder Osteuropa) oder Besonderheiten im Umwelt- oder Personalmanagement ausgewählt. Auf der anderen Seite waren es Unternehmen mit beispielsweise hohen Beschäftigungs- oder Umsatzrückgängen.

Der qualitativen Vorgehensweise entsprechend wurde für die Datenerhebung das narrative bzw. offene Interview gewählt. Diese Form der Befragung bietet dem Befragten die Möglichkeit, das Gesprächsthema innerhalb eines vorgegebenen Rahmens unternehmensspezifisch selbst zu wählen sowie die Antworten frei zu formulieren und somit eigene Schwerpunkte zu setzen. Wo dies möglich war, wurde im Anschluß an das Interview eine Betriebsbegehung vorgenommen, um einen zusătzlichen Gesamteindruck des Unternehmens zu bekommen.

${ }^{42}$ Vgl. Herdzina, K./Nolte, B. (1995); Herdzina, K. u.a. (1996). Vgl. ferner Nolte, B. (1996).

43 Anlage 4 zeigt die Unternehmen auf, die an der personlichen Befragung teilgenommen haben. 
Die Rücklaufquote von über 25\%, die geringen Abweichungen der Branchenstruktur bzw. der Unternehmensgrößenklassen ${ }^{44}$ der untersuchten Unternehmen von der Grundgesamtheit sowie die Konzentration auf Geschäftsleitungsmitglieder als Auskunftspersonen stellen einen hohen Validitäts- und Reliabilitätsgehalt hinreichend sicher und erlauben in Verbindung mit den Ergebnissen der persönlichen Befragung ein Ableiten repräsentativer und qualitativer Aussagen und Schlußfolgerungen aus den empirischen Erhebungen.

\subsubsection{Die Auswertung der Daten}

Die Analyse der Daten erfolgte mit Hilfe von bi- und multivariaten Dependenzanalysen. Durch die Dependenzanalysen lassen sich Art und Intensität von a priori angenommenen Kausalzusammenhängen zwischen zwei oder mehr Merkmalen (Variablen) untersuchen. Die Variablen werden dazu in eine oder mehrere abhängige (determinierte) und eine oder mehrere unabhängige (determinierende) Variable eingeteilt. Für den Fall, daß die Skalenniveaus der Variablen nominal skaliert sind, kommen als Verfahren die Kreuztabellierung und die Kontingenzanalyse in Betracht. ${ }^{45}$

Die Voraussetzung zur Darstellung möglicher Kombinationen nominaler Variablenausprägungen in Form einer Matrix (Kreuztabelle) ist, daß die Variablen in sich gegenseitig ausschließende Gruppen unterteilt werden. Die Kreuztabellierung zeigt zwar Zusammenhänge zwischen zwei oder mehreren Variablen auf, sie ist jedoch nicht in der Lage, Aussagen hinsichtlich der Signifikanz bzw. Stärke des Zusammenhangs zu machen.

Hier setzt die Kontingenzanalyse an, die die Signifikanz der Unterschiede zwischen nominal skalierten Variablen sowie die Stärke des Zusammenhangs zwischen abhängiger und unabhängiger Variable untersucht. Die Signifikanz der Unterschiede läßt sich mit dem ChiQuadrat-Unabhängigkeitstest ermitteln. Hierfür muß das Signifikanzniveau bzw. die Höhe der Irrtumswahrscheinlichkeit $(\alpha)$ der Dependenzanalyse festgelegt werden. Ansatzpunkt für die statistische Überprüfung ist die Formulierung einer Nullhypothese, die die Übereinstimmung zweier Gruppen hinsichtlich einer Variablen zum Ausdruck bringt. Das Ziel ist jedoch die Ermittlung von Unterschieden, d.h. ein Verwerfen der Nullhypothese, wodurch die Annahme der Alternativhypothese ${ }^{46}$ ermöglicht wird. Das Problem bei der Überprüfung der Nullhypothese ist das Auftreten von zwei Fehlentscheidungen, nämlich die unberechtigte Ablehnung der Nullhypothese (Fehler 1. Art) bzw. das unberechtigte Beibehalten der Nullhy-

44 Zur prozentualen Verteilung der Unternehmensgrößenklassen in der Grundgesamtheit und im Rücklauf vgl. Anlage 7.

45 Vgl. Henze, A. (1994), S. 81-85. Zur Verdichtung der in der Untersuchung erhobenen Informationen zu einem übersichtlichen und aussagefăhigen Datenbündel wurde als Hilfsmittel die SAS-Software für Windows, Version 6.11 herangezogen.

46 Als alternativer Begriff findet sich auch "Arbeitshypothese" z.B. bei Ronz, B./Strohe, H.G. (Hrsg.) (1994), S. 265; Berekoven, L. u.a. (1993), S. 248f. oder "Gegenthese" z.B. bei Henze, A. (1994), S. $73 f$. 
pothese (Fehler 2. Art). Da sich die genauen Fehlerwahrscheinlichkeiten nicht ermitteln lassen, wird in der Literatur für die Irrtumswahrscheinlichkeit bzw. das Signifikanzniveau üblicherweise ein Wert von 5\% vereinbart. Die Alternativhypothese wird also angenommen und die Nullhypothese abgelehnt, wenn $\alpha \leq 0,05$ ist. Dieses Ergebnis wird als signifikant oder statistisch gesichert bezeichnet. Im Falle eines Signifikanzniveaus von $\alpha \leq 0,01$ wird dieses Ergebnis als hochsignifikant bezeichnet. ${ }^{47}$

Der Unzulänglichkeit des Chi-Quadrat-Tests, bei zu kleinen Stichproben $(\mathrm{n}<40)$ bzw. bei zu geringer Zellenbelegung (mehr als $20 \%$ der Zellen haben eine Belegung von $<5$ ) nicht aussagekräftig zu sein, kann mit dem exakten Test von FISHER begegnet werden. ${ }^{48}$

Sowohl der Chi-Quadrat-Test als auch der exakte Test von FISHER informieren jedoch nicht über die Stärke des Zusammenhangs zwischen den Variablen. Die Stärke des Zusammenhangs bringt der Kontingenzkoeffizient (C) zum Ausdruck. Für den Fall vollständiger Unabhängigkeit der beiden Variablen voneinander nimmt $\mathrm{C}$ den Wert 0 an. Mit steigendem Chi-Quadrat năhert sich C dem Wert $1 .^{49}$

\subsubsection{Charakterisierung und Typisierung der untersuchten Unternehmen}

Hinsichtlich des Zieles der Untersuchung, ein breites Spektrum von Ansätzen und Gestaltungsmöglichkeiten aufzuzeigen, die das Innovations- und Umweltmanagement im Rahmen der Unternehmensführung kleiner und mittlerer Unternehmen zu Erfolgsfaktoren im Wettbewerb werden lassen, ist mit der Operationalisierung der abhängigen Variablen der Untersuchung ein besonderes methodisches Problem verbunden. Die Komplexität und Vielschichtigkeit der beiden Themenbereiche schließt eine Beschränkung der Betrachtung auf finanzwirtschaftliche Erfolgsgrößen (wie z.B. ROI, Gewinn, Kosten, Deckungsbeiträge) aus. Ferner stehen weitere methodische Aspekte einer Berücksichtigung finanzwirtschaftlicher ErfolgsgröBen entgegen. Zum einen erschwert die branchenübergreifende Anlage der Untersuchung die zutreffende Interpretation der erhaltenen Erfolgsindikatoren erheblich, da beispielsweise ein erwirtschafteter Gewinn nur unter Berücksichtigung der speziellen Branchen- bzw. Unternehmenssituation als erfolgreich oder als weniger erfolgreich interpretiert werden kann. Zum anderen ist die Bereitschaft insbesondere kleiner und mittlerer Unternehmen, die vielfach kei-

47 Vgl. Sachs, L. (1992), S. 178-189; Henze, A. (1994), S. 74f. und S. 83ff.; Berekoven, L. u.a. (1993), S. 248251; Bortz, J. (1993), S. 145; Dufner, J. u.a. (1992), S. 129ff. und S. 179-188. Zum Chi-Quadrat-Test vgl.

48 Vgl. Dufner, J. u.a. (1992), S. 181 und S. 184-188. ferner Eschenbach, R.Müler, C. (Hrsg.) (1992), S. 79; Müller, W. (1997), S. $220 f$.

49 Vgl. Henze, A. (1994), S. 85 und Ronz, B./Strohe, H.G. (Hrsg.) (1994), S. 192f., die auch die Berechnung des korrigierten Kontingenzkoeffizienten aufzeigen, der von der Tabellengroße unabhăngig ist und zu einer größeren Straffung des Zusammenhangs zwischen den Variablen führt, als dies beim unkorrigierten Kontingenzkoeffizienten der Fall wäre. Zur Wahrung der Übersichtlichkeit wird in dieser Untersuchung lediglich das Signifikanzniveau (Sig.) angegeben. 
ner Publizitätspflicht nachkommen müssen, zur Preisgabe solcher Informationen sehr gering, weshalb auch erhebungstechnische Erwägungen einer Verwendung derartiger Indikatoren entgegenstehen.

Entsprechend wurde ein Weg zur Erhebung der Erfolgswirkungen innovativer bzw. umweltorientierter unternehmerischer Handlungen gewählt, der objektiv meßbare Größen (Umsatz) und subjektive Einschätzungen (Innovationen, Innovationsorientierung) miteinander verbindet und somit eine Kompromißlösung auf hohem Niveau bietet. Der besondere Vorteil dieser Vorgehensweise besteht darin, auf qualitative (meßbare) Daten nicht vollständig verzichten zu müssen, zumal sich der Umsatz auch in kleinen und mittleren Unternehmen relativ leicht erheben läßt. Daneben kann die Interpretation des Erfolgsbeitrags bestimmter Indikatoren auf die Ebene der Entscheidungsträger in die Unternehmen verlagert werden. Mit dieser Form der Operationalisierung läßt sich somit die Gefahr der Antwortverweigerung aus Gründen der Vertraulichkeit reduzieren, und gleichzeitig kann der Langfristigkeit der Wirkungen im Hinblick auf eine zukunftsorientierte Unternehmensführung hinreichend Rechnung getragen werden.

Zur Operationalisierung der abhängigen Variablen wurde nach hierfür geeigneten typischen Merkmalen gesucht. Diese Merkmale sollen Gruppen von Unternehmen (Erfolgstypen) ergeben, die sich hinreichend genau gegeneinander abgrenzen lassen und für die sich signifikant - mindestens aber qualitativ - voneinander unterscheidbare Aussagen treffen lassen. Sie müssen also innovative erfolgreiche Unternehmen und die Ursachen ihres Erfolges identifizieren, die dann mit den übrigen Unternehmen verglichen werden können. Die für die Differenzierung der beiden Erfolgstypen gewählten Merkmale lassen sich in der folgenden Weise beschreiben:

Angesichts der Arbeitshypothese, daß die Einfuihrung neuer Produkte (Produktinnovationen) bzw. die Einfuihrung oder wesentliche Veränderung von Produktionstechniken (Prozeßinnovationen) in den Unternehmen relevant sein könnte, wurde als erstes Merkmal das Vorhandensein von Innovationsaktivitäten gewählt. ${ }^{50}$ Die Selbsteinschätzung der Unternehmen in

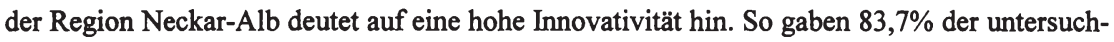
ten Unternehmen an, innerhalb der zurückliegenden fünf Jahre ${ }^{51}$ Innovationen eingeführt zu haben. Differenziert nach Produkt- und Verfahrensinnovationen, waren 71,9\% produktinnovativ, $59,6 \%$ prozeßinnovativ und $47,8 \%$ sowohl produkt- als auch prozeßinnovativ. Produkt-

50 Vgl. Frage 3/1 und 3/2 des Fragebogens im Anhang.

51 In der Literatur finden sich unterschiedliche Klassifizierungsmöglichkeiten bezüglich des für die Messung der Innovativităt zugrundezulegenden Zeitraums. Eine Zeitspanne von fünf Jahren liegt beispielsweise den Untersuchungen von Vaessen, P./Keeble, D. (1995); Hunger, J.D./Wheelen, T.L. (1996); Nolte, B. (1996) zugrunde. Ein Zeitraum von drei Jahren wird beispielsweise von Hamer, E. (1990a) präferiert. 
oder prozeßinnovativ und damit innovativ im Sinne der Untersuchung sind demnach 83,7\% der Unternehmen.

Da ein wesentliches Ziel der Untersuchung das Aufzeigen von erfolgreichen Innovationsstrategien ist, wurde der Kreis, der sich als innovativ bezeichnenden Unternehmen, in einem zweiten Schritt auf diejenigen reduziert, die Innovativität als Wettbewerbsvorteil betrachten. Bei diesen Unternehmen liegt die Vermutung nahe, daß die aktive Suche nach Produktund/oder Prozeßinnovationen ein zentraler Bestandteil der Unternehmensführung ist, d.h. diese Unternehmen haben ein Innovationsbewußtsein entwickelt und erkennen die Innovativität als strategischen Wettbewerbsfaktor. ${ }^{52}$ Das zweite Merkmal zur Unterscheidung der Gruppen ist also das Vorhandensein eines Innovationsbewußtseins. Reduziert man die Zahl der innovativen Unternehmen auf diejenigen mit Innovationsbewußtsein, so verbleiben $69,1 \%$ der Unternehmen. 53

Fortschrittliche Technologien bzw. Produkte müssen zwar als strategischer Wettbewerbsvorteil erkannt werden, daneben müssen sie sich aber auch in einer positiven Entwicklung des Unternehmens bemerkbar machen. Damit wurde als drittes Merkmal die Entwicklung des Umsatzes herangezogen. ${ }^{54}$ Aus dem Kreis der Unternehmen, die die ersten beiden Kriterien erfullen, wurden jene 30\% herausgefiltert, die im Untersuchungszeitraum 1990 bis 1995 das höchste Umsatzwachstum innerhalb ihrer Branche zu verzeichnen hatten. ${ }^{55}$

Die Wahl des 30\%-Kriteriums (genau: $29,2 \%$ ) erwies sich deshalb als sinnvoll und zweckmäßig, weil sich gerade bei dieser Schwelle eine vergleichsweise homogene Gruppe von Unternehmen herauskristallisierte, die sich in zahlreichen Fragen des Innovations- und Technologiemanagements, des Personalmanagements ${ }^{56}$ und - mit gewissen Einschränkungen - des Umweltmanagements signifikant von der Gegengruppe unterscheidet.

Die innovativen bzw. innovationsbewußten und umsatzmäßig besonders erfolgreichen Unternehmen stehen also im Mittelpunkt dieser Untersuchung. Diese ca. 30\% der untersuchten Unternehmen umfassende weitgehend homogene Unternehmensgruppe wird im folgenden als

52 Ein teilweise abweichender Begriffsinhalt wird dem Innovationsbewußtsein z.B. bei Hauschildt beigemessen. Er versteht darunter zunächst das Erkennen einer Neuerung und erst dann systematisches und zielorientiertes (bewußtes) Innovationsmanagement, Vgl. Hauschildt, J. (1986).

53 Vgl. Frage $2 / 6$, bei der $69,7 \%$ der Unternehmen ihre fortschrittliche Technologie bzw. ihre fortschrittlichen Produkte sowie $52,8 \%$ viele Produktinnovationen als speziellen Wettbewerbsvorteil ihres Unternehmens betrachten.

54

Die Umsatzentwicklung kann als Indikator für die generellen Wachstumsaussichten und damit des Erfolgs von Unternehmen dienen.

55 Die Umsatzentwicklung der Unternehmen in dieser Unternehmensgruppe war zugleich deutlich besser als die Entwicklung der jeweiligen Branchenumsătze auf baden-württembergischer Ebene, vgl. Anlage 8.

56 Auf das Personalmanagement in KMU wird in dieser Untersuchung nicht vertiefend eingegangen. Personalorientierte Problem- und Gestaltungsbereiche finden nur dann Berücksichtigung, wenn sie in unmittelbarem Zusammenhang mit den Anforderungen an ein betriebliches Innovations- und Umweltmanagement stehen. Für weitere Forschungsergebnisse vgl. Herdzina, K./Blessin, B. (1996), S. 47-62. 
die "besonders erfolgreichen Unternehmen" bezeichnet. Die Vergleichsgruppe bilden die "weniger erfolgreichen Unternehmen" ("übrige"). Bei dieser ca. 70\% der Unternehmen umfassenden Gruppe ist mindestens eines der oben definierten Erfolgskriterien nicht erfüllt. Damit soll keinesfalls zum Ausdruck kommen, daß die Unternehmen der Vergleichsgruppe durchweg nicht wettbewerbsfähig oder erfolglos sind. Auch in dieser Gruppe sind durchaus innovative oder umsatzstarke Unternehmen enthalten, die im einzelnen sogar deutlich über dem Branchenwachstum liegen. Aufgrund der angelegten Kriterien gehören sie lediglich nicht in die Gruppe der besonders erfolgreichen Unternehmen. ${ }^{57}$

Alternativ zur vorgenannten Einteilung der untersuchten Unternehmen wurden selbstverständlich auch Gruppen nach ausschließlich objektiven Kriterien gebildet, die sich vornehmlich an der Unternehmensgröße orientieren. Hierzu wurden die Unternehmen in vier Beschäftigtengrößenklassen bzw. in drei Umsatzgrößenklassen eingeteilt. Die Begründung hierfür liegt in erster Linie darin, daß mit der Betrachtung dieser "gängigen" Kriterien zumindest ansatzweise eine Vergleichbarkeit mit den Ergebnissen anderer Studien hergestellt werden kann. Ferner zeigten sich bei einzelnen Fragestellungen signifikantere Ergebnisse als bei dem oben beschriebenen Einteilungsmodus. Es wäre an dieser Stelle jedoch verfrüht, den gewählten Einteilungsmodus daraufhin als unbrauchbar abzulehnen. ${ }^{58}$

Mit den vorgenannten Managementkategorien sind die zentralen Ursachen für den Erfolg der besonders erfolgreichen Unternehmen identifiziert. Auf diese Faktoren wird in den Kapiteln 4 und 5 näher eingegangen. Die Basis hierfür bildet das nun folgende Kapitel 3, in dem die besonderen Problembereiche der Unternehmensführung in kleinen und mittleren Unternehmen aufgezeigt werden.

57 Weder produkt- noch prozeßinnovativ sind nach eigenen Angaben 16,3\% der Unternehmen. Sie wurden in einer ergänzenden Betrachtung untersucht und als "nicht-innovative Unternehmen" bezeichnet. Die Lesbarkeit und der Überblick über die einzelnen Ergebnisse würde jedoch verlorengehen, wenn zusătzlich zur Differenzierung nach den Erfolgstypen und nach der Unternehmensgroße jeweils auch die Resultate der nichtinnovativen Unternehmen sowie der entsprechenden Gegengruppe dargestellt werden. Die Präsentation dieser Ergebnisse wird daher auf die Fälle beschränkt, die für die Verdeutlichung der Situation besonders geeignet sind.

58

Zur Verteilung der besonders erfolgreichen und der weniger erfolgreichen Unternehmen auf die Unternehmensgroßßenklassen vgl. Anlage 9. 



\section{Unternehmensführung und Management in kleinen und mittleren Unternehmen}

\subsection{Begriff und Charakterisierung}

Im Verbund der betrieblichen Funktionen ${ }^{59}$ nimmt die Unternehmensführung ${ }^{60}$ durch ihren Bezug zum Gesamtunternehmen sowie ihre zwischenmenschliche Komponente eine exponierte Stellung ein und ist somit wesentlich für den Erfolg und Mißerfolg des Unternehmens am Markt verantwortlich. Zur Sicherung der langfristigen Unternehmensexistenz muß sie die unternehmensinternen und -externen Veränderungsprozesse antizipieren und sowohl die Struktur des Unternehmens als auch die Führung und mit ihr die Einstellung sowie das Selbstverständnis des Unternehmens bzw. jedes einzelnen Organisationsmitgliedes entsprechend anpassen.

Damit deutet sich bereits die Vielschichtigkeit an, die mit dem Begriff der Unternehmensführung verbunden ist. Üblicherweise werden zwei Bedeutungsvarianten unterschieden: ${ }^{61}$

- Unternehmensführung im institutionellen Sinn beinhaltet die Beschreibung derjenigen Personen (-gruppen) und ihrer Tätigkeiten, die im Unternehmen leitende Aufgaben erfüllen.

- Unternehmensführung im funktionellen Sinn beinhaltet die Beschreibung der Prozesse und Funktionen, die die Leitung eines Unternehmens mit sich bringt.

Unternehmensführung umfaßt somit den institutionellen Rahmen, dessen Gestaltung die Überlebens- und Entwicklungsfähgikeit des Ganzen ermöglichen soll. Daneben beinhaltet sie

59 Ulrich unterscheidet zunächst fünf Funktionsbereiche im Unternehmen: Beschaffung, Verwaltung, Produktentwicklung, Produktion und Absatz. In einer weiteren Differenzierung werden dann marktleistungsbezogene Funktionsbereiche (Produktentwicklung, Produktion, Absatz), betriebsmittelbezogene Funktionsbereiche (Personalwesen, Anlagenwirtschaft, Materialwirtschaft, Informationswesen, Finanzwesen) sowie der unternehmensbezogene Funktionsbereich (Gesamtführung des Unternehmens) unterschieden. Vgl. Ulrich, H. (1970), S. 46-49 sowie die Weiterentwicklung im St. Galler Management-Modell, Ulrich, H./Krieg, W. (1974) und Bleicher, K. (1996).

60 Die deutschen Begriffe Unternehmensführung bzw. Leitung oder Führung eines Unternehmens werden in der Literatur vielfach als Synonyme oder Übersetzungen des anglo-amerikanischen Begriffes "Management" angeboten. Vgl. z.B. Ulrich, H. (1970), S. 36f.; Hopfenbeck, W. (1997), S. 327; Bea, F.X. u.a. (1993), S. 8; Gabler Wirtschaftslexikon (1993), S. 2179. Eine Sammlung verschiedener Begriffsverwendungen findet sich bei Macharzina, K. (1995), S. 34. Für eine kritische Betrachtung der synonymen Verwendung vgl. Staehle, W.H. (1994), S. 65ff. Da eine Unterscheidung im Rahmen dieser Arbeit nicht von Bedeutung ist, sollen die Begriffe in dieser Arbeit synonym verwendet werden, auch wenn der Bereich der Unternehmensführung letztlich nur eine Teilmenge des Managements darstellt.

$\mathrm{Zu}$ Theorien und Ansätzen der Unternehmensführung sei an dieser Stelle zunächst auf Macharzina, K. (1995), S. 43-78 verwiesen.

61 Vgl. z.B. Ulrich, H. (1970), S. 317ff.; Hopfenbeck, W. (1997), S. 328-338; Staehle, W.H. (1994), S. 65; Ulrich, P./Fluri, E. (1995), S. 13ff.; Bea, F.X. u.a. (1993), S. 2. 
die Lenkung durch Bestimmung von Zielen sowie das Festlegen, Auslösen und Kontrollieren zielgerichteter Aktivitäten und letztlich die Entwicklung als Ergebnis von Gestaltungs- und Lenkungsprozessen bzw. als eigenständige Entwicklung durch die Adaption von Wissen, Können und Einstellungen. ${ }^{62}$ Dementsprechend läßt sich Unternehmensführung als die zielorientierte Gestaltung, Lenkung und Entwicklung des Unternehmens in sach- und personenbezogener Hinsicht charakterisieren. ${ }^{63}$

In kleinen und mittleren Unternehmen wird die Unternehmensfïhrung in der Regel durch (Eigentümer-) Unternehmer oder geschäftsführende Gesellschafter ausgeübt. Sie übernehmen dabei zum Teil auch allgemeine administrative Aufgaben und wirken selbst produktiv mit, wodurch die Zeit fur zentrale, koordinierende, typisch unternehmerische Aufgaben eingeschränkt wird. Die daraus resultierende Vernachlässigung der Führungsaufgaben läßt an die Stelle einer zielorientierten Planung häufig mehr oder weniger geschickte Improvisation oder intuitives Handeln treten. Unternehmensführung, die lediglich "im Kopf" des Unternehmers stattfindet, entzieht sich aber der Überprüfbarkeit und läßt den Grad der Zielerreichung bzw. der Strategieumsetzung im unklaren. Gleichzeitig eignet sie sich in dieser Form kaum für den Aufbau von langfristigen Erfolgsfaktoren zur Sicherung der Wettbewerbsfähigkeit des Unternehmens.

Im Mittelpunkt dieses Kapitels steht folglich die Charakterisierung der Unternehmerpersönlichkeit als zentralem Bestimmungsfaktor der Unternehmensführung in kleinen und mittleren Unternehmen sowie die Darstellung der Elemente und Instrumente der Unternehmensführung, mit deren Hilfe sich dann die Unternehmensleitbilder als Komponenten der Unternehmenskultur, die Unternehmensziele sowie die Unternehmensstrategie entwickeln lassen.

\subsection{Die Rolle des Unternehmers}

\subsubsection{Der Unternehmer in der ökonomischen Theorie}

In kleinen und mittleren Unternehmen nimmt der Unternehmer in der Regel eine zentrale Stellung ein. Insbesondere die unternehmerischen Wertvorstellungen, Ansichten, Motive und Ziele sind für den Erfolg bzw. Mißerfolg eines Unternehmens entscheidend verantwortlich. Die Beschreibung des Unternehmers soll daher ein deutliches Bild von der Unternehmerpersönlichkeit vermitteln und den Zugang zu einem ganzheitlichen Verständnis des Unternehmens erleichtern.

62 Vgl. Jahnes, S. (1997), S. 28.

63 Vgl. Hopfenbeck, W. (1997), S. 327. Zur Bestimmung des Unternehmensfuhrungsbegriffes vgl. beispielsweise auch Ulrich, H. (1990), S. 13-18; Bea, F.X. u.a. (1993), S. 1ff.; Mugler, A./Schmidt, K.-H. (Hrsg.) (1995), S. $133 f$. 
Die Beschäftigung mit der Thematik des Unternehmers bzw. des Entrepreneurs hat eine lange Tradition, ${ }^{64}$ ohne daß dies zu einer allgemein akzeptierten Unternehmertheorie geführt hätte. Vielen dieser Ansätze gemeinsam ist der innovierende Unternehmer, an den im Zusammenhang mit ökonomischem Wachstum und Produktivitätsfortschritt gedacht wird. ${ }^{65}$

Bereits CANTLlon, SAY und MILL setzten sich mit den Eigenschaften des Unternehmers (Entrepreneur) auseinander. ${ }^{66}$ CANTILLON war 1755 der erste, der die entscheidende Rolle des Unternehmers bei der wirtschaftlichen Entwicklung auf der Basis individueller Eigentumsrechte erkannte. Er sieht im Unternehmer jemanden, der Entscheidungen unter Unsicherheit triff, indem er Waren zu einem fixen Preis kauf, zu diesem Zeitpunkt jedoch den genauen Absatzpreis bzw. die genaue Absatzmenge noch nicht kennt. ${ }^{67}$

Weitere Ansätze für die Entwicklung einer ökonomischen Theorie des Unternehmertums, die eine Analyse der Gründe ökonomischen Erfolgs bzw. Mißerfolgs ermöglichen sollen, finden sich bei SCHUMPETER bzw. den Vertretern der Österreichischen Schule. In jüngerer Zeit ist vor allem der Ansatz von CAsson hervorzuheben.

SCHUMPETER sieht im Unternehmer einen Innovator, der ein wirtschaftliches Potential erkennt und eine "neue Kombination durchsetzt" ${ }^{68}$, wodurch eine deutliche Abgrenzung zum Erfinder oder Entwickler neuer Technologien stattfindet. Das Wesen des Unternehmertums liegt somit darin, daß unternehmerisches Denken und Handeln stattfindet, bevor neue Konsumentenbedürfnisse oder neue Produkte entdeckt wurden. SCHUMPETER beschreibt dies als "Prozeß der schöpferischen Zerstörung"69, der ein Ausbrechen aus dem Marktgleichgewicht bedeutet und somit die Haupttriebkraft der ökonomischen Entwicklung ist. ${ }^{70}$ Als Motive hierfür nennt SCHUMPETER neben dem Gewinnmotiv das Streben nach sozialer Machtstellung, die Freude

${ }^{64}$ Für einen Überblick siehe z.B. Long, W. (1983); Bull, I./Willard, G. (1995); Timmons, J.A. (1994); Casson, M.C. (1982).

65 Vgl. Baumol, W.J. (1995), S. 19. Dieser Zusammenhang mag auch der Grund für das Phänomen sein, daß für ein schwindendes Produktivitäts- bzw. Wirtschaftswachstum zum Teil das sinkende Angebot an Unternehmern bzw. deren schwächer werdender Unternehmergeist verantwortlich gemacht wird. Nachzuvollziehen ist dies an stärker werdenden Appellen an die Unternehmerschaft durch die Politik sowie eine Ausdehnung von Existenzgrundungsprogrammen.

66 Vgl. Cantillon, R. (1755); Say, J.B. (1880); Mill, J.S. (1848).

67 Vgl. Cantillon, R. (1755), S. 62-75. Mill wies bei seinen Überlegungen dem Unternehmer ebenfalls die Funktion der Risikoübernahme ("risk-bearing") zu. Vgl. Mill, J.S. (1848). Vgl. dazu ferner Baumol, W.J. (1993), S. 12; Deakins, D. (1996), S. 8f.

68 Schumpeter, J.A. (1934b), S. 116. Schumpeter unterscheidet fünf Arten der Innovation: Einführung neuer Güter, Einführung neuer Produktionsmethoden, Öffnung neuer Märkte, Erschließung neuer Bezugsquellen, Entwicklung neuer Organisationsstrukturen. Vgl. dazu die Ausführungen in Abschnitt 4.1.1.

69 Vgl. Schumpeter, J.A. (1950), S. 137f.

70 Vgl. Schumpeter, J.A. (1912), S. 172-180; Schumpeter, J.A. (1950), S. 214. Damit unterscheidet sich der Schumpetersche Unternehmer von dem bei Cantillon und Say beschriebenen. Sie stellen eher auf den Firmengründer ab, unabhängig davon, ob er innovativ ist oder nicht. Vgl. dazu Baumol, W.J. (1995), S. 18f. 
am schöpferischen Gestalten sowie das Erfolgsstreben um des Erfolges willen. ${ }^{71}$ Obwohl der Unternehmer hierbei Risiken eingeht, beziehen sich diese nach Schumpeters Ansicht ausschließlich auf seine Funktion als Geldgeber bzw. Güterbesitzer und nicht auf die Unternehmerfunktion selbst. ${ }^{72}$

Für die Vertreter der Österreichischen Schule $^{73}$ ist der Unternehmer die Schlüsselfigur im Marktprozeß. Hervorzuheben sind hier insbesondere die Arbeiten von KIRZNER, dessen Ansichten über den Unternehmer sich von denen Schumpeters in einigen Punkten unterscheiden. ${ }^{74}$ Während bei SCHUMPETER lediglich außergewöhnliche Menschen die Fähigkeit zu einem Unternehmer besitzen, hat bei KIRZNER jeder das Potential zu einem Unternehmer. ${ }^{75}$ Der Unternehmer bei KIRZNER nutzt profitable Tauschmöglichkeiten, die andere übersehen ha-

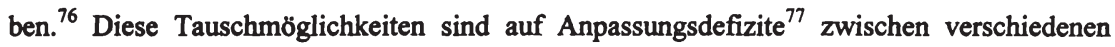
Märkten zurlickzuführen. Indem er die daraus entstehenden Bedürfnisse und Ineffizienzen erkennt sowie die sich ergebenden Gewinnmöglichkeiten nutzt, werden die auf den Märkten entstehenden Ungleichgewichte durch die Reaktion des Unternehmers immer wieder abgebaut. ${ }^{78}$ Voraussetzung dafür, daß der Unternehmer diese Rolle übernehmen kann ,is absence of privilege and freedom of entrepreneurial entrys679, d.h. die Gewißheit, daß er eine erkannte Gelegenheit verfolgen darf. ${ }^{80}$ Die bedeutendste Rolle des Unternehmers besteht daher in der Preisregulierung bzw. -festlegung.

Nach den beiden vorgenannten Ansätzen erwachsen Gewinnmöglichkeiten aus Innovationen ${ }^{81}$ bzw. Arbitragegeschäften ${ }^{82}$. Im Falle von Innovationen übernimmt für gewöhnlich der Unter-

71 Vgl. Schumpeter, J.A. (1912), S. 138; Schumpeter, J.A. (1934a), S. 93f. Vgl. auch Albach, H. (1979), S. 538f. bzw. zur Kritik am Schumpeter-Unternehmer S. 539ff.

72 Vgl. Schumpeter, J.A. (1912), S. 290.

73 Carl Menger, Eugen von Boehm-Bawerk, Ludwig von Mises, Friedrich von Hayek sowie Israel M. Kirzner.

74 Für eine kritische Betrachtung der Schumpeterschen Theorie vgl. Kirzner, I.M. (1979), S. 115-119.

75 Vgl. Schumpeter, J.A. (1912), S. 162ff. und S. 177 i.V.m. Deakins, D. (1996), S. 10.

76 Vgl. Kirzner, I.M. (1984), S. 3, der an dieser Stelle weiter ausfuhrt: „It is the alertness of the entrepreneur that leads him to recognise what others and even the entrepreneur himself may earlier have failed to notice". Der Unternehmer bei Kirzner bedient sich damit der Möglichkeiten, die aus neuen Technologien entstehen. Eine ähnliche Sichtweise vertreten auch Meredith, G.G. u.a. (1987), S. 1.

77 Vollstăndige Information schließt das unternehmerische Element in Entscheidungsprozessen aus. Die Möglichkeiten gewinnbringenden Handels entstehen aufgrund unvollständiger Information. Die Nutzung zusătzlicher Informationen ermöglicht dem Unternehmer, Vorteile aus profitablen Gelegenheiten zu ziehen. Im Marktgleichgewicht besteht aufgrund vollständiger Information keine Funktion für den Unternehmer. Vgl. Kirzner, I.M. (1979), S. 109ff.; Deakins, D. (1996), S. 9. Kirzner bemerkt hierzu, daß sein Unternehmer in einem sich stăndig ändernden Umfeld durch Spekulation bzw. Nutzung von Arbitragen die Wirtschaft zu einem Gleichgewicht führt, wohingegen Schumpeters Unternehmer "acts to disturb an existing equilibrium situation" (Hervorhebung im Original), Kirzner, I.M. (1974), S. 72 sowie S. 73f. und S. 81; Kirzner, I.M. (1979), S. 111f. und S. 115-119.

79 Kirzner, I.M. (1984), S. 8.

${ }^{80}$ Das Erzielen eines unternehmerischen Gewinns setzt nach Kirzner dabei nicht das Eigentum voraus, d.h. bei der Nutzung von Arbitragen sind keine eigenen Ressourcen (Investitionsmittel) notwendig. Vgl. Kirzner, I.M. (1979), S. 94ff.

81 Vgl. Schumpeter, J.A. (1934a), S. 133-136; Baumol, W.J. (1993), S. 1-4; Casson, M.C. (1995), S. 85. 
nehmer das aktive Management der Ressourcen in seinem Einflußbereich, wohingegen bei der Arbitrage lediglich das Erkennen einer Gewinnmöglichkeit bei der Überbrückung von Märkten notwendig ist. Die Überbrückung kann dabei zeitlich, räumlich oder sachlich (Transformation z.B. in neue Produkte) erfolgen. Ein Großteil unternehmerischen Handelns in einer Marktwirtschaft geht in der Tat auf die Verbesserung von Handelsbedingungen zurück, d.h. auf die Senkung von Transaktionskosten. ${ }^{83}$

Einen weiteren Ansatz für die Beschreibung des Unternehmers bzw. des Unternehmertums versucht CASsON in seiner "theory of the entrepreneur" zu entwickeln. ${ }^{84}$ Für CASSON ist Unternehmertum (Entrepreneurship) eine individuelle Fähigkeit, die bestimmte Individuen in die Lage versetzt, langfristige Entscheidungen zur Reallokation oder Organisation knapper Ressourcen zu treffen. Entsprechend definiert er den Unternehmer als "someone who specializes in taking judgmental decisions about the coordination of scarce resources" 85 . Aus dieser Definition gehen verschiedene Charakteristika des Unternehmers hervor. Er strebt unabhängig von anderen als Individuum Entscheidungen und Werturteile für komplexe Probleme an, für die keine offensichtlich korrekten Lösungsschemata vorliegen. Dabei hebt er sich dadurch ab, daß er sich auf das Auffinden von Lösungen für komplexe Situationen spezialisiert hat sowie aktiv plant. Hierzu bedarf es nicht nur einer optimistischen Einstellung, sondern auch der $\mathrm{Zu}$ versicht, daß dieser Optimismus gerechtfertigt ist. Dies bedingt ebenfalls eine begrenzte Risikoaversion. Die Koordination knapper Ressourcen hebt ferner den dynamischen Aspekt des Unternehmertums hervor: Koordination verändert die Allokation, um zu einer Situationsverbesserung zu gelangen. Unternehmertum wird somit durch selbstmotiviertes und am eigenen Nutzen orientiertes Streben zu einem kontinuierlichen Prozeß ${ }^{86}$ Als weitere Voraussetzungen sind Personalfuhrungsqualitäten und Teamfähigkeit in Verbindung mit einem gut ausgebauten Netzwerk unterschiedlichster Informationsquellen und Ratgeber notwendig. ${ }^{87}$

82

Kirzner, 1.M. (1974), S. 48, Kirzier, 1.M. (1979), S. 94ff

3 Vgl. Casson, M.C. (1995), S. 84ff. Transaktionskosten sind Kosten, die bei Marktaustauschprozessen entstehen. Sie umfassen Such-, Informations-, Verhandlungs-, Vertragsdurchfuhrungs-, Überwachungskosten etc., vgl. Coase, R.H. (1960), S. 15; Picot, A. (1991), S. 344f.

84

85

86

Vgl. Casson, M.C. (1982), S. 23ff. und Casson, M.C. (1995), S. 80-86. Die Allokation bzw. Organisation knapper Ressourcen bedingt zugleich die Verfügungsgewalt über sie. Folglich benötigt erfolgreiches Unternehmertum auch eine ausreichende Ausstattung mit finanziellen Mitteln.

87 Vgl. Casson, M.C. (1995), S. 99f. Casson geht davon aus, daß alle unternehmerischen Fähigkeiten zu einem gewissen Grad angeboren sind und nur bedingt durch Training oder Erfahrung erlernt werden können. Die von ihm herausgearbeiteten Făhigkeiten sind: self-knowledge, imagination, practical knowledge, analytical ability, search skill, foresight, computational skill, communication skill, delegation skill, organizational skill. So ist z.B. die Phantasie/Vorstellungskraft oder der Weitblick nicht erlembar, wohingegen analytische, mathematische oder praktische sowie Delegations- oder Organisationsfähigkeiten gefördert werden können. Vgl. Casson, M.C. (1982), S. 35f. Casson gelangt nach der Darstellung seiner Unternehmertheorie zu dem Schluß, daß diese letztlich ein Spezialfall einer umfassenden Theorie okonomischer und sozialer Prozesse ist. Ferner stellt der Ansatz von Casson die Verbindung zur Transaktionskostentheorie her, indem er ausdrulcklich die Kosten der unternehmerischen Funktionsausübung berücksichtigt. Dies wurde in den früheren Ansätzen von Schumpeter und Kirzner vernachlässigt. 
Zusammenfassend können die Ansätze von KIRZNER und CASSON als Weiterentwicklung der neoklassischen Theorie eingeordnet werden, da sie den Markt als Prozeß verstehen. Die treibende Kraft ist die Bewegung hin zum Gleichgewicht, wobei dieses letztlich das Resultat unternehmerischer Initiative ist. $^{88}$

Neben den vorgenannten Theorien finden sich in der Literatur noch zahlreiche weitere Versuche der Entwicklung von Unternehmertheorien, ${ }^{89}$ deren erschöpfende Beschreibung den Rahmen dieser Arbeit sprengen würde. Dennoch soll auf die Ansätze von LEIBENSTEN bzw. KNIGHT hingewiesen werden, die neben den oben genannten in der Literatur häufig diskutiert werden. LEIBENSTEIN betrachtet Unternehmertum als kreative Antwort auf X-Ineffizienzen. ${ }^{90}$ Der nach Gewinn strebende Unternehmer versucht diese Wirtschaftlichkeitsdefizite abzubauen, indem neue Beschaffungsmärkte gesucht, neue Einsatzfaktoren, die die Effizienz der vorhandenen Produktionsmethoden verbessern, beschafft bzw. neue Methoden eingefuihrt werden oder indem der Unternehmer, ähnlich zu KIRZNER, eine Überbrückungsfunktion ausübt. Letztlich liefert LEIBENSTEIN aber keine Hypothesen über unternehmerisches Verhalten. ${ }^{91}$ Bei KNIGHT ist der Unternehmer der Empfänger des Reingewinns, der die Belohnung für das Tragen der Unsicherheitskosten darstellt. ${ }^{92}$ Dabei stellt für KNIGHT das Vertrauen in die eigene Urteilsfähigkeit, in Verbindung mit einer geringen Risikoaversion sowie Selbstvertrauen, die bedeutendste Eigenschaft des Unternehmers dar. KNIGHT stellt daneben die Übernahme von Leitung und Verantwortung als charakterisierende Merkmale des Unternehmers heraus. ${ }^{93}$

88 Zur Kritik an den beiden Theorien vgl. Harper, D.A. (1996), S. 16-19, der insbesondere das Erklărungsdefizit bez. des unternehmerischen Wissens und Wissenserwerbs hervorhebt.

89 Vgl. Casson, M.C. (1982), S. 364-383.

90 Vgl. Leibenstein, H. (1966); Leibenstein, H. (1968). X-Ineffizienzen sind der Grad an Ineffizienz bei der Ressourcenverwendung innerhalb des Unternehmens, d.h. sie messen, in welchem Ausma $\beta$ das Unternehmen sein Produktivitătspotential verfehlt. Sie entstehen aufgrund von Motivationsdefiziten oder weil Ressourcen aufgrund von unzureichenden Informationen bzw. durch Fehlinterpretationen falsch genutzt oder verschwendet werden.

91 Vgl. Leibenstein, H. (1968). Vgl. dazu ferner Kirzner, I.M. (1979), S. 126f.; Casson, M.C. (1982), S. 364 367.

92 Dabei unterscheidet Knight zwischen Unsicherheit und Risiko. Das Risiko läßt sich durch Wahrscheinlichkeiten charakterisieren und kann versichert werden. Unsicherheit hingegen kann nicht berechnet und demnach auch nicht versichert werden. Die Übernahme dieses Restrisikos zeichnet den Knightschen Unternehmer aus. Hier setzt auch die Kritik an diesem Unternehmerbild an. Ein Unternehmer wăre nach dieser Sichtweise jeder, der bereit ist, Risiken einzugehen, indem er Entscheidungen über eine ungewisse Zukunft fällt. Die findige und suchende Rolle, die etwa Kirzner dem Unternehmer zuweist, wird hier vernachlässigt.

93 Vgl. Kirzner, I.M. (1974), S. 81-84; Casson, M.C. (1982), S. 370-373; Deakins, D. (1996), S. 11f. Vgl. zur Übernahme einer Führungsfunktion durch den Unternehmer auch Baumol, W.J. (1993), S. 4. 


\subsubsection{Die zentralen Eigenschaften des Unternehmers in kleinen und mittleren Unternehmen}

Aufbauend auf den oben dargestellten Theorien, wobei die Ansätze von SCHUMPETER und KIRZNER im Vordergund stehen, wurde insbesondere in der amerikanischen Literatur versucht, die Eigenschaften des Unternehmers zu erfassen und seine zentrale Stellung im Unternehmen bzw. im ökonomischen Prozeß zu charakterisieren. Die Risiko tragende und Unsicherheit reduzierende Rolle (KNIGHT) sowie die Rolle des Vermittlers (KIRZNER bzw. CASSON) in Verbindung mit der Funktion des Innovators (SCHUMPETER) zeigen insgesamt, daß der Unternehmer vor allem in Phasen der Unsicherheit bzw. des Wandels eine wichtige Schlüsselstellung im wirtschaftlichen Prozeß einnimmt. Ferner entstehen die Charakteristika kleiner und mittlerer Unternehmen gerade durch die Person des Unternehmers. Die Unternehmerperson bildet das Fundament kleiner und mittlerer Unternehmen. Also hängt auch Erfolg und Mißerfolg des Unternehmens eng mit der Persönlichkeit des Unternehmers zusammen. 94

An dieser Stelle müssen zwei Erklärungsrichtungen zur Beschreibung von Unternehmern voneinander abgegrenzt werden. Die Untersuchungsansätze zur Erfassung des Wesens von Unternehmern teilen sich in jene, die den Unternehmer ausschließlich als Unternehmensgründer in das Zentrum ihrer Überlegungen stellen und jene, die neben dem Unternehmensgründer insbesondere den Unternehmensführer betrachten.

Wird der Unternehmer ausschließlich mit dem Gründer eines Unternehmens gleichgesetzt, ${ }^{95}$ steht dahinter in erster Linie der Gedanke, daß mit der Gründung eines neuen Unternehmens ein Prozeß des Wandels initiiert wird, der zugleich zu wirtschaftlichem Wachstum führen soll. ${ }^{96}$ Sicherlich darf diese Funktion nicht unberücksichtigt bleiben, zumal in ihr auch die Begründung für eine Zunahme von Existenzgründungsinitiativen (z.B. durch Beratungsangebote, die Einrichtung von Gründerparks, die Vergabe günstiger Darlehen) insbesondere in

94 Witte verweist zwar darauf, daß es unrealistisch sei, eine Einengung der Entscheidungsprozesse auf die Person des Unternehmers vorzunehmen, da das Vordringen von Kapitalgesellschaften sowie die Trennung von Eigentum und Management in Verbindung mit zunehmender Entscheidungsdelegation die Loslösung vom Ein-Personen-Entscheidungsmodell erfordern. Vgl. Witte, E. (1973b), S. 5. Gegen diese Auffassung spricht jedoch zunächst die in Abschnitt 2.2.1 aufgezeigte quantitative Bedeutung der Kleinst-, Klein- und Mittelunternehmen, die in der Regel von Einzelpersonen geführt werden. Dennoch zeigt Witte gerade hierdurch bereits die konsequente Weiterentwicklung einer Verbundwirkung zwischen dem Unternehmer als Entrepreneur und den Mitarbeitern als Intrapreneure auf, die an der (innovativen) Entscheidungsfindung beteiligt sind. Auf diese Beziehung wird an verschiedenen Stellen vertiefend eingegangen.

95 Vgl. u.a. Burch, J.G. (1986), S. 13; U.S. Small Business Administration (1985), S. 119; Bygrave, W.D. (1995), S. 130.

96 Vgl. Burch, J.G. (1986), S. 5, der auf S. 24 weiter ausfuhrt: "The entrepreneur is, indeed, the change agent, the source of innovation and creativity, the schemer, the heart and soul of economic growth." Vgl. dazu auch U.S. Small Business Administration (1985), S. 125. 
wirtschaftlichen Problemphasen liegt. ${ }^{97}$ Sie greift aber dennoch zu kurz. So gehen von Unternehmensgründungen oftmals nicht die erhofften Strukturwandel- und Wachstumseffekte aus, da die Zahl der überlebensfähigen Gründungen letztlich hinter den Erwartungen zurückbleibt. ${ }^{98}$ Daneben ist der ideale Unternehmensgründer eben nicht als der "risk-taking, profitmaximizing economic man, independent, competitive, materialistic and single-minded in his pursiut of wealth"99 $\mathrm{zu}$ charakterisieren. Ferner bleiben die von SCHUMPETER und KIRZNER beschriebenen wirtschaftlichen Veränderungsprozesse durch unternehmerisches Handeln ohne Beachtung. Schließlich läßt sich diese Funktion nur schwer operationalisieren und damit empirisch untersuchen, da keine eindeutige Aussage daruber besteht, zu walchem Zeitpunkt der Gründungsprozeß abgeschlossen ist und der Unternehmensführungsprozeß beginnt. ${ }^{100}$

Für die Charakterisierung des Unternehmers in seiner Funktion als Unternehmensführer wurden zahlreiche Versuche unternommen, ${ }^{101}$ denen es aber nicht gelungen ist, aus den umfangreichen Charaktereigenschaften diejenigen herauszufiltern, die die Komplexität unternehmerischen Handelns erfassen und dabei gleichzeitig Ansatzpunkte für die Erklärung unternehmerischen Handelns liefern. Ohne den Anspruch auf Vollständigkeit erheben zu wollen, finden sich bei einer Reihe von Charakteristika Überschneidungen:

97 So erwachsen nach Burch durch die Gründung neuer Unternehmen weitere unternehmerische Gelegenheiten, wie beispielsweise die Computer-, die Biotechnologie- sowie die Kommunikationsindustrie zeigen oder wie es in den USA an bestimmten regionalen Beispielen (Silicon Valley, Route 28 oder Raleigh) nachvollzogen werden kann. Vgl. Burch, J.G. (1986), S. 5 i.V.m. Rothwell, R. (1989), S. 52.

98 Deakins fuhrt dazu aus, daß eine hohe Anzahl von Firmengründungen zwar imposant aussehen mag, dahinter verbirgt sich jedoch die Tatsache, daß viele Neugrtindungen das erste Jahr bzw. die ersten drei Jahre nicht uberleben. Deakins zeigt anhand verschiedener Untersuchungen in Großbritannien auf, daß die große Mehrheit kleiner Firmen nicht in der Lage ist, umfangreich Arbeitsplătze zu schaffen bzw. sicherlich kaum jemals mehr als 20 Mitarbeiter beschăftigen wird. Vgl. Deakins, D. (1996), S. 40-45. Darüber hinaus sinkt die Überlebenswahrscheinlichkeit mit abnehmender Gründungsgroßße deutlich. Vgl. U.S. Small Business Administration (1983), S. 70f.; Timmons, J.A. (1994), S. 9-13. Daher sind Strukturwandel- oder Beschăftigungseffekte durch Unternehmensgrilndungen mit großer Zurulckhaltung zu beurteilen.

99 Deeks, J. (1973), S. 40f. Hőchstens 10\% der Unternehmensgrilnder in den bei Deeks dokumentierten Studien konnten in dieser Weise charakterisiert werden.

${ }^{100}$ An diesem Defizit setzt Audretsch an, indem er den Versuch unternimmt, ein neues operationales Maß furr Unternehmertum zu finden. Hierzu reduziert er Unternehmertum auf die Grilndung eines neuen Unternehmens und versucht damit zwei okonomische Phănomene miteinander zu verbinden, den Beginn eines neuen Unternehmens sowie sein Überleben. Vgl. Audretsch, D.B. (1995a), S. 103-122. Die von Audretsch aufgezeigten Ergebnisse geben jedoch nur Anhaltspunkte aber die Dynamik, d.h. die Grundung bzw. Löschung von Unternehmen, innerhalb der untersuchten Industriezweige. Er räumt selbst ein, daß Unternehmensgründungen von der Kapital-, der Forschungs- und Entwicklungs- bzw. Werbeintensităt oder dem Konzentrationsgrad der jeweiligen Branche abhängen. Somit gelingt es ihm mit seinem Ansatz ebenfalls nicht, die Theorie entscheidend voranzubringen bzw. das Wesen des Unternehmers năher zu charakterisieren.

${ }^{101}$ Eine Übersicht verschiedener Unternehmercharakteristika in der Literatur findet sich bei Carland, J.W. u.a. (1984), S. 356 ergănzt durch Timmons, J.A. (1994), S. 198. Vgl. auch Kets de Vries, M.F.R (1977), S. 3843. Teilweise wird im Rahmen der Unternehmensführung eine Differenzierung zwischen Unternehmer und Manager vorgenommen. So sehen beispielsweise Mugler und Schmidt den Unternehmer als Kapitalgeber und Unternehmensleiter mit hoher Motivation, während der Manager die Unternehmensleitung aufgrund höherer Qualifikation inne hat. Vgl. Mugler, A./Schmidt, K.-H. (Hrsg.) (1995), S. 78f. Bei Baumol besteht die unternehmerische Aufgabe darin, "to locate new ideas and to put them into effect", die Managementaufgabe besteht hingegen in der effizienten und effektiven Ausfuhrung innerhalb bestehender Strukturen. Ein Zusammenfallen der Aufgaben in einer Person wird dabei nicht ausgeschlossen. Vgl. Baumol, W.J. (1968), S. 64f.; Baumol, W.J. (1993), S. $2 \mathrm{ff}$. 
- die Suche und Nutzung von Gelegenheiten; ${ }^{102}$

- die Übernahme von (kalkulierbaren, überschaubaren) Risiken; ${ }^{103}$

- das innovative bzw. kreative Handeln; ${ }^{104}$

- die Orientierung am Leistungsprinzip; ${ }^{105}$

- das Eingehen von Kooperationen bzw. Bilden von Netzwerken; ${ }^{106}$

- das Streben nach Unabhängigkeit. ${ }^{107}$

Das Eingehen von Kooperationen bzw. das Bilden von Netzwerken sowie das Streben nach Unabhängigkeit schließen sich nur vordergründig gegenseitig aus. In der Suche nach Kooperationspartnern bzw. der Einbindung in Netzwerke kann das Streben nach Verbesserung der eigenen Fähigkeiten und Fertigkeiten sowie die Steigerung des eigenen Wissens gesehen werden, wodurch letztlich die Wahrung der Unabhängigkeit ermöglicht wird.

Neben der Darstellung des Unternehmers anhand einzelner Charakteristika wurde auch mehrfach der Versuch unternommen, Unternehmertypologien durch die Vereinigung mehrerer Charakteristika zu einem übergreifenden Konstrukt herauszuarbeiten. ${ }^{108}$

Einen zentralen Beitrag zur Typisierung von Unternehmern liefern MILES UND SNOw, die sich an den Einstellungsmustern gegenüber dem Markt orientieren. ${ }^{109}$ Die Anpassungsfähigkeit des Unternehmens an die externen und internen Rahmenbedingungen hängt von der Fähigkeit ab, die Komplexität und Dynamik des Marktes zu reduzieren. Der Anpassungsprozeß läßt sich

${ }^{102}$ Vgl. Meredith, G.G. u.a. (1987), S. 1; Timmons, J.A. (1994), S. 7; Harper, D.A. (1996), S. 82; Hunger, J.D./Wheelen, T.L. (1996), S. 37.

${ }^{103}$ Vgl. Longenecker, J.G./Schoen, J.E. (1975), S. 27f.; Kets de Vries, M.F.R. (1985), S. 160f.; Ibrahim, A.B./Goodwin, J.R (1986), S. 45; Meredith, G.G. u.a. (1987), S. 3; Hamer, E. (1990a), S. 28-31; Longenekker, J.G./Moore C.W. (1991), S. 13f.; Steinhoff, D./Burgess, J.F. (1993), S. 34f.; Timmons, J.A. (1994), S. 7; Mugler, A./Schmidt, K.-H. (Hrsg.) (1995), S. 82; Hunger, J.D./Wheelen, T.L. (1996), S. 35.

${ }^{104}$ Vgl. Longenecker, J.G./Schoen, J.E. (1975), S. 27; Carland, J.W. u.a. (1984), S. 358; Ibrahim, A.B./Goodwin, J.R. (1986), S. 45; Baumol, W.J. (1993), S. 1; Timmons, J.A. (1994), S. 7; Mugler, A./Schmidt, K.-H. (Hrsg.) (1995), S. 82; Hunger, J.D./Wheelen, T.L. (1996), S. 37.

${ }^{105}$ Vgl. Kets de Vries, M.F.R. (1985), S. 160f.; Meredith, G.G. u.a. (1987), S. 4; Longenecker, J.G./Moore C.W. (1991), S. 13; Mugler, A. (1995), S. 14. Der Begriff "need for achievement", der hier mit Orientierung am Leistungsprinzip übersetzt wurde, geht zurilck auf McClelland, D.C. (1961). Vgl. auch McClelland, D.C. (1987), S. 221-227.

${ }^{106}$ Vgl. Bull, I./Willard, G. (1995), S. 10ff.; Hunger, J.D./Wheelen, T.L. (1996), S. 371 f.

${ }^{107}$ Vgl. Longenecker, J.G./Schoen, J.E. (1975), S. 28f.; Meredith, G.G. u.a. (1987), S. 4; Ibrahim, A.B./Goodwin, J.R. (1986), S. 45; Harper, D.A. (1996), S. 138.

${ }^{108} \mathrm{Vgl}$. als einen der ersten Ansätze hierzu die Unternehmertypologie von Schumpeter, die durch die Phasenbetrachtung von Heuss eine Erweiterung fand. Vgl. Schumpeter, J.A. (1928), S. 483ff. und Heuss, E. (1965), S. 8-13.

Neben den hier dargestellten Unternehmertypologien von Miles und Snow bzw. Kirsch und Trux finden sich weitere Typologien beispielsweise bei Preston, L.E. (1977), S. 13-19; Carland, J.W. u.a. (1984), S. 357f.; Pleitner, H.J. (1984), S. 514ff.; Bamberger, J./Pleitner, H.J (Hrsg.) (1988), S. 39-59; Fröhlich, E./Pichler, J.H. (1988), S. 59-62; Mugler, A./Schmidt, K.-H. (Hrsg.) (1995), S. 147-150. Vgl. ferner auch die bei Mintzberg, H. (1989), S. 116-130 dargestellte "Entrepreneurial Organization".

${ }^{109}$ Vgl. Miles, R.E./Snow, C.C. (1978). Vgl. zu diesem Ansatz ferner Specht, G./Zörgiebel, W.W. (1985), S. 496-511; Hunger, J.D./Wheelen, T.L. (1996), S. 102f.; Bamberger, J./Bonacker, R. (1994), S. 66f. 
dabei in drei Teilprobleme gliedern, zu deren Lösung die Unternehmensführung (der Unternehmer) ständig in der Lage sein muß. ${ }^{110}$ Das unternehmerische Problem beinhaltet die Festlegung geeigneter Produkt-Markt-Kombinationen, d.h. die Auswahl geeigneter Produkte oder Dienstleistungen sowie die Definition geeigneter Zielmärkte oder Marktsegmente. Die Lösung des technischen Problems erfordert die Wahl geeigneter Produktionstechnologien und Distributionswege, während sich das Organisationsproblem auf die Wahl zukünftiger Innovationsfelder sowie Möglichkeiten der Struktur- und Prozeßrationalisierung bezieht.

Aus der unterschiedlichen Anpassung an die drei Teilprobleme entwickeln MnES UND SNOw vier Unternehmertypologien, den Verteidiger, den Prospektor, den Analysierer und den Reagierer. ${ }^{111}$ Verteidiger ändern ihre Produkte und die Märkte, auf denen sie tätig sind, nur selten. Aufgrund ihres engen Produkt-Markt-Programmes und einfacher Schlüsseltechnologien sind sie in erster Linie auf die Verteidigung ihres Einflußbereiches, in dem sie ein hohes Expertenwissen aufweisen, fixiert. Thre Konkurrenzfähigkeit versuchen sie hauptsächlich über den Preis oder die Qualität bzw. durch Verbesserung der Produktionseffizienz zu erhalten. Im Gegensatz dazu zeichnet Prospektoren die Fähigkeit aus, in Trendbrüchen Möglichkeiten für neue Produkte und Märkte zu erkennen und diese zu nutzen. Entsprechend kann ihr Einflußbereich als breit und sich ständig entwickelnd charakterisiert werden. Hierzu benötigen sie ein breit gefächertes Technologiepotential sowie eine hohe Flexibilität, die sie durch Investitionen in Informations- und Kommunikationsnetzwerke, die einen Zugang zu neuen Potentialen ermöglichen sollen, aufrechterhalten. Eine Mischung aus den beiden vorgenannten Typen stellen die Analysierer dar. Sie streben einen Ausgleich zwischen dem Auffinden und Nutzen neuer Produkt-Markt-Kombinationen und dem Beibehalten traditioneller Produkt- und Konsumentengruppen an. Die Transformation des innovativen Einflußbereichs erfolgt durch Imitation, sobald der Markterfolg durch Prospektoren nachgewiesen werden konnte. Im eher stabilitätsorientierten Bereich agiert das Unternehmen auf der Basis formalisierter Strukturen und Prozesse routiniert und effizient. Das gleichzeitige Wahren von Flexibilität und Stabilität stellt hohe Anforderungen an die organisatorischen Ausgleichsmechanismen. Reagierer zeichnen sich durch inkonsistentes und instabiles Anpassungsverhalten aus. Die Unternehmensfuihrung hat weder ein klar formuliertes Konzept der Organisationsstrategie noch passen die Organisationsstruktur und die Prozesse zu den gewählten Strategien; bzw. es werden Strategie-Struktur-Beziehungen beibehalten, obwohl sich bedeutende Veränderungen der Rahmenbedingungen ergeben haben. Eine Anpassungsreaktion auf sich ändernde Rahmenbedingungen kommt folglich nur unter hohem Druck zustande.

${ }_{110}^{110}$ Vgl. Miles, R.E./Snow, C.C. (1978); S. 21-28.

${ }^{111}$ Vgl. dazu ausfuhrlich Miles, R.E./Snow, C.C. (1978), S. 31-93. 
Der aufgezeigte Ansatz findet durch die Überlegungen von KIRSCH UND TRUX eine Erweiterung. ${ }^{112}$ Sie differenzieren sechs Typen strategischer Grundhaltungen, von denen sich fünf in einer Matrix positionieren lassen (Verteidiger, Risikostreuer, Architekt, Innovator, Prospektor), während sich der Reagierer nicht einordnen läßt. Die Dimensionen der Matrix orientieren sich an den Produkt-Markt-Strategien (konservativ - progressiv) bzw. an der Einstellung hinsichtlich der Such- und Auswahlaktivitäten (Spezialist - Generalist):

\section{Abb. 3-1: Typen strategischer Grundhaltungen nach KIRSCH UND TRUX}

\begin{tabular}{l|c|c|c|}
\multicolumn{1}{c}{ Spezialist } & \multicolumn{1}{c}{ Synergist } & Generalist \\
\cline { 2 - 4 } konservativ & Verteidiger & & Risikostreuer \\
\cline { 2 - 4 } $\begin{array}{l}\text { analysierend (liberal) } \\
\text { reformerisch } \\
\text { (progressiv) }\end{array}$ & & Architekt & \\
\cline { 2 - 4 } & Innovator & & Prospektor \\
\cline { 2 - 4 }
\end{tabular}

Quelle: in Anlehnung an Kirsch/Trux (Perspektiven, 1981), S. 300.

Dem Analysierer bei MILES UND SNOw entspricht hier am ehesten der Architekt, der an seinem Kerngeschäft festhält bzw. dieses als Ausgangsbasis für die Suche nach und die ErschlieBung von neuen Produkt- oder Marktpotentialen nutzt. Der Innovator ist einem spezialisierten Prospektor vergleichbar, dessen Suche nach neuen Aktivitäten auf wenige Produkte und Segmente beschränkt ist. Der Risikostreuer kann als diversifizierter Verteidiger eingeordnet werden, d.h. er ist ein Verteidiger, der sich verschiedene Standbeine geschaffen hat.

Die Gemeinsamkeiten der in beiden Ansätzen als Reagierer bezeichneten Unternehmertypen beziehen sich lediglich auf deren Strategielosigkeit. Diese ist aber bei dem von KIRSCH UND TRUX beschriebenen Reagierer durchaus beabsichtigt, da er sich hiermit die notwendige Freiheit und Flexibilität bewahren will, um auf Veränderungen der Rahmenbedingungen spontan reagieren zu können. Hierin liegen sowohl die Stärken als auch die Schwächen dieser Grundhaltung. Zwar lassen sich Ressourcen für den Planungsprozeß einsparen und können als "Manövriermasse" bei der Umsetzung von Problemlösungen eingesetzt werden, mit dem Verzicht auf Planung muß bei steigender Komplexität und Dynamik der Rahmenbedingungen aber auch die "Manövriermasse" vergrößert werden und es wächst zugleich die Gefahr von Fehlgriffen. ${ }^{113}$

$\overline{112}$ Vgl. Kirsch, K./Trux, W. (1981), S. 299-307; Kirsch, W. (1983), S. 157-162.

${ }^{113}$ Vgl. Kirsch, K./Trux, W. (1981), S. 299ff. 


\subsection{Die strategische Ausrichtung der Unternehmensführung in kleinen und mittleren Unternehmen}

\subsubsection{Begründung einer Strategischen Unternehmensführung als Bezugsrahmen}

Unternehmen sind dadurch gekennzeichnet, daß die Unternehmensführung bewußt oder unbewußt durch Unternehmensführungssysteme unterstützt bzw. geprägt wird, die die Organisation des laufenden Geschäftsbetriebs überlagern. ${ }^{114}$ Vor allem in kleinen und mittleren Unternehmen scheint die Unternehmensfuhrung eher intuitiv und situativ als systematisch und zukunftsorientiert zu sein. ${ }^{115}$ Eine systematische und zukunftsorientierte Unternehmensführung gewinnt aber immer mehr an Bedeutung, da die Markt- und Wettbewerbsprozesse zunehmend komplexer und dynamischer sowie die wirtschaftlichen Rahmenbedingungen zunehmend unsicherer werden. Gleichzeitig wachsen auch innerhalb des Unternehmens die Anforderungen an die dispositiven und strategischen ${ }^{116}$ Fähigkeiten des Unternehmers.

In dieser Situation besteht die besondere Herausforderung an die Unternehmensfuihrung darin, die Unternehmensleistungen, die Unternehmensorganisation und vor allem die Unternehmensführung selbst auf diese Veränderungen einzustellen. Zur Annahme dieser Herausforderung bedarf es eines konsistenten und vorausschauenden unternehmerischen Denkens, Entscheidens und Handelns. Ansatzpunkte für das frühzeitige und vor allem hinreichend rechtzeitige Erkennen von Entscheidungs- und Handlungsmöglichkeiten und -notwendig-keiten bietet das Konzept der "Strategischen Unternehmensführung". ${ }^{117}$ Diese spezifische Führungskonzeption hat die Steuerung und Koordination der Entwicklung des Unternehmens zum Ziel und erweitert die rational-ökonomische Führung durch die bewußte Einbeziehung des Umfeldes ${ }^{118}$ ins unternehmerische Kalkül. Indem das Unternehmen als Ganzes systematisch in sein Umfeld

${ }^{114}$ Vgl. Kirsch, W. (1991), S. 46.

${ }^{115}$ Vgl. Mugler, A./Schmidt, K.-H. (Hrsg.) (1995), S. 125-129; Hamer, E. (1990b).

${ }^{116}$ Der Strategiebegriff stammt ursprünglich aus dem Bereich der Staats- und Kriegführung und wurde in den $60 \mathrm{er}$ Jahren durch Alfred D. Chandler und H. Igor Ansoff in die Betriebswirtschaftslehre eingefuhrt. Vgl. dazu ausfuhrlich Abschnitt 3.6.1.

${ }^{117}$ Zur "Strategischen Unternehmensfuhrung" bzw. zum "Strategischen Management" vgl. z.B. Ansoff, H.I. (1965), (1980) und (1988); Schendel, D.E./Hofer, C.W. (Hrsg.) (1979); Hofer, C.W./Schendel, D. (1978); Puimpin, C. (1981); Kirsch, K./Trux, W. (1981); Kirsch, W. (1991); Kreilkamp, E. (1987), Bea, F.X./Haas, J. - (1997); Hinterhuber, H.H. (1996) und (1997); Aaker, D.A. (1995); David, F.R. (1995); Thompson, A.A./Strickland, A.J. (1996); Hahn, D. (1990). Eine Darstellung verschiedener strategischer Ansătze findet sich bei Eschenbach, R./Kunesch, H. (1996). Für eine Differenzierung zwischen klassischer und strategischer Unternehmensfuhrung siehe Wöhe, G. (1996), S. 99ff.

Für eine ausführliche Darstellung der Entwicklungslinien des Strategischen Managements vom traditionellen strategischen Management (z.B. Ansoff) über Market-based View of Strategy (z.B. Porter) und Resourcebased View of Strategy (z.B. Pümpin, Prahalad/Hamel) zum wertorientierten strategischen Management (z.B. Rappaport, Gomez/Weber) vgl. Eberhardt, S. (1997), S. 68-83.

${ }^{118}$ Zur Vermeidung von Abgrenzungsproblemen zwischen der natürlichen oder ökologischen, der räumlichen sowie der soziologischen Umwelt des Unternehmens, wird die soziologische Umwelt als Umfeld bezeichnet. 
eingefügt wird, soll es leichter und schneller auf die komplexen und dynamischen internen und externen Herausforderungen reagieren können.

Strategisches Management bedeutet dabei jedoch nicht, "durch die Formulierung einer konzeptionellen Gesamtsicht und die Bestimmung der generellen strategischen Stoßrichtung die langfristige Entwicklung des Unternehmens bereits heute in allen Einzelheiten festzulegen"119. Strategisches Management bildet das Fundament einer evolutionären Führung ("Management of Evolution") und ist somit auf eine schrittweise Schaffung und Sicherung von Erfolgsfaktoren im Rahmen von Lemprozessen ${ }^{120}$ gerichtet. Die ständig erneut angestoßenen Lernprozesse sollen verhindern, "daß Konzepte und Leitideen 'erstarren' und sie ein 'Eigenleben' entwikkeln, das unter veränderten Bedingungen nicht mehr adäquat ist. Ein Strategisches Management macht die Unternehmung somit zu einem 'ideal seeking system', zu einem System, das den Fortschritt und die Annäherung an ein sich stets wandelndes Ideal sucht und laufend bestrebt sein muß, alte Ideale und Leitbilder zu überprüfen, gegebenenfalls zu verwerfen und neue zu finden"121. Strategisches Management konzentriert sich auf das Aufzeigen und Schließen langfristiger Ergebnislücken und schafft die Voraussetzung für eine systematische Nutzung eines sich wandelnden, aber gestaltbaren Umfeldes.

Hierin scheinen aber die Umsetzungsprobleme des Konzeptes in kleinen und mittleren Unternehmen zu liegen. Zwar wird ihnen eine hohe (technologische) Anpassungsfähigkeit nachgesagt, diese ist jedoch aufgrund der Einstellung des Unternehmers kaum auf eine bewußte Planung der Zukunft zurückzuführen (methodisches Defizit). ${ }^{122}$ MUGLER sieht die Hindernisse für die Implementation einer Strategischen Unternehmensführung in kleinen und mittleren Unternehmen insbesondere im Zeitproblem, in der Orientierung auf Stabilität und Routine, in Barrieren beim Zugang zu adäquaten Informationen, in der Wahrnehmung unvereinbarer Rollen sowie in einem instrumentalen Defizit. ${ }^{123}$

$\overline{119}$ Kirsch, K./Trux, W. (1981), S. 340.

${ }^{120}$ Zum organisationalen Lernen bzw. zur Lernenden Organisation vgl. Abschnitt 4.4.3.

${ }^{121}$ Kirsch, K./Trux, W. (1981), S. 386. Ein System ist nach Ulrich, H. (1970), S. 105 "eine geordnete Gesamtheit von Elementen, zwischen denen irgendwelche Beziehungen bestehen oder hergestellt werden können". Er wandelt damit die ursprüngliche Definition von Flechtner, H.-J. (1966), S. 353 leicht ab. Ähnliche Definitionen finden sich bei Bleicher, K. (1971), S. 11 und Heinen, E. (1976), S. 24.

${ }^{122}$ Vgl. Mugler, A. (1995), S. 121.

${ }^{123}$ Die Hindernisse resultieren aus der Rolle des Unternehmers als Planer, Ausführender und Kontrolleur. Er befindet sich damit in einer Situation, die kognitive Dissonanzen begünstigt und das Aufdecken von Widersprüchen erschwert. Daneben sind die in der Betriebswirtschaftslehre bereitgestellten Planungsinstrumente weitgehend auf Großunternehmen zugeschnitten. Die Adaptierung auf $\mathrm{KMU}$ wird erst in jüngerer Zeit vorgenommen. Vgl. Mugler, A. (1995), S. 121f. Vgl. ferner d'Amboise, G./Muldowney, M. (1986), S. 18; Laukamm, T. (1985), S. 281; Brodbeck, H. (1995), S. 31. Zu den konzeptionellen und theoretischen Schwăchen am Konzept des Strategischen Managements vgl. Kirsch, K./Trux, W. (1981), S. 293ff. Hinzu kommt eine uberwiegend technisch orientierte Ausbildung der Unternehmer in den KMU des Verarbeitenden Gewerbes, die einen Zugang zu betriebswirtschaftlichen Führungs- und Planungsinstrumenten erschwert. Die in diesem Zusammenhang ebenfalls genannten Hindernisse Zeitproblem, Orientierung auf Stabilităt und Routine sowie Informations- und Kommunikationsbarrieren erweisen sich auch als Hindernisse im Rahmen des Innovations- 
Den Hindernissen bzw. Hinderungsgründen bei der Einführung des Strategischen Managements in kleinen und mittleren Unternehmen stehen eine Reihe positiver Aspekte gegenüber. ${ }^{124}$ Das verbindende Element zwischen unternehmerischem Denken und Handeln sowie Strategischem Management ist die ganzheitliche Betrachtung des Unternehmens. Die ganzheitliche Betrachtung soll die Übersicht über das Unternehmen bewahren und die Positionsbestimmung des Unternehmens ermöglichen. Daneben erleichtert die Transparenz der unternehmerischen Strategien den Mitarbeitern ein zielorientiertes Handeln. Werden sie darüber hinaus in den Strategieentwicklungsprozeß eingebunden, erhöht dies zugleich ihre Motivation bei der Umsetzung. Die Transparenz schafft ferner die Möglichkeit, Planungslücken und -inkonsistenzen aufzudecken und regt zur Ursachenforschung an. Letztlich bedeutet die Antizipation verschiedener zukünftiger Situationen durch die Entwicklung von Handlungsalternativen im Rahmen einer Strategie eine erhebliche Zeitersparnis.

Für die Evolution des Strategischen Managements, d.h. die Implementierung in kleinen und mittleren Unternehmen eignet sich die von $\mathrm{KIRSCH}$ UND TRUX vorgeschlagene dreistufige Vorgehensweise. In einer ersten Stufe sollen zunächst, eventuell unterstützt durch externe Berater, besonders wichtige Einzelprojekte des Strategischen Managements initiiert werden. Durch die daraus resultierenden Lerneffekte wird es in der zweiten Stufe möglich, in einem regelmäßigen Zyklus strategische Programme zu institutionalisieren. Die dritte Entwicklungsstufe bedeutet eine institutionalisierte Ausdifferenzierung und Verselbständigung der unternehmenspolitischen Rahmenplanung. ${ }^{125}$ Dabei versteht es sich von selbst, daß es kein Patentrezept für ein Strategisches Management geben kann. Die Heterogenität und Eigenheiten der Unternehmen und ihrer Umfeldbedingungen müssen sich auch in den unternehmensspezifischen strategischen Konzepten wiederfinden.

Zusammenfassend läßt sich die Strategische Unternehmensfuihrung bzw. das Strategische Management als Versuch charakterisieren, den wachsenden Anforderungen aus dem Unternehmensumfeld sowie dem Unternehmen selbst besser gerecht zu werden, indem eine langfristige Steuerung der Unternehmensentwicklung angestrebt wird, die der Entwicklung und Erhaltung von Erfolgsfaktoren dient. Die Sicherung der Anpassungs- und Transformationsfähigkeit des Unternehmens mittels einer strategischen Ausrichtung der Unternehmensführung beinhaltet ferner den Einsatz entsprechender Instrumente zur Analyse der externen und internen Bedingungen, ${ }^{126}$ d.h. des Unternehmensumfeldes und der internen Unternehmenssituati-

bzw. Umweltmanagements und werden daher dort vertieft behandelt. Die bei Mugler aufgezeigten Hindernisse wurden auch in den Unternehmergesprächen im Rahmen dieser Arbeit deutlich.

${ }^{124}$ Vgl. Mugler, A. (1995), S. 121.

${ }^{125}$ Vgl. Kirsch, K./Trux, W. (1981), S. 342ff.

${ }^{126}$ Vgl. Mugler, A./Schmidt, K.-H. (Hrsg.) (1995), S. 146; Servatius, H.-G. (1985), S. 51. Nach Servatius besteht die Transformationsfähigkeit eines Unternehmens darin, "durch eine Veränderung des Unternehmenspotentials nachhaltige Vorteile gegenüber Wettbewerbern im Hinblick auf vorhandene oder neue Umfeldpotentiale zu erreichen", Servatius, H.-G. (1985), S. 45. 
on. Die Informationen aus dieser Analyse bilden die Basis für die Identifikation der unternehmensspezifischen Erfolgsfaktoren sowie für die Formulierung der unternehmensspezifischen Leitbilder, der Unternehmensziele und -strategien. ${ }^{127}$

\subsubsection{Analyse des Unternehmensumfeldes}

Werden Unternehmen als offene, autonome, dynamische, ökonomische und sozio-technische Systeme charakterisiert ${ }^{128}$, so lenkt dies die Aufmerksamkeit auf die vielfältigen Austauschbeziehungen zwischen dem Unternehmen und seinem Umfeld. Die Ermittlung der markt- und wettbewerbsbezogenen Chancen und Risiken des Unternehmens erfordert eine gründliche Analyse der Umfeldbedingungen, da Informationen über die relevanten Umfeldbedingungen und über deren zu erwartende Veränderungen die Grundlage für strategische Entscheidungen der Unternehmensfuhrung bilden. ${ }^{129}$ Der Unternehmensführung kommt dann die Aufgabe $\mathrm{zu}$, auf der Basis der gewonnenen Informationen durch eigene Initiative gestaltend und lenkend in die komplexen Systemzusammenhänge einzugreifen. ${ }^{130}$ Die Ausrichtung des Unternehmens auf seine spezifischen Umfeldbedingungen ist ein konstitutives Merkmal jeder strategischen Planung. Für die Beschaffung, Aufbereitung und Bewertung der Informationen aus dem Unternehmensumfeld stehen Hilfsmittel zur Verfügung, die jedoch vor allem in kleinen und mittleren Unternehmen vielfach noch $\mathrm{zu}$ wenig genutzt werden. ${ }^{131}$

Eine Möglichkeit zur Systematisierung der Analyse der externen Rahmenbedingungen ist ihre Aufgliederung in ein Makro- bzw. ein Mikro-Umfeld. ${ }^{132}$ Von kleinen und mittleren Unter-

${ }^{127}$ Zur Bedeutung der Information vgl. den Überblick bei Hübner, H. (1996), S. 1-4 sowie speziell für den Wettbewerb vgl. Porter, M.E./Millar, V.E. (1986).

128 Siehe FN 8.

${ }^{129}$ Als Umfeldbedingungen werden diejenigen Daten bezeichnet, denen das Unternehmen nach außen hin gegenübersteht, und die es bei seiner strategischen Planung berücksichtigen muß. Vgl. hierzu grundsätzlich Ulrich, H. (1970), S. 161; Ulrich, H./Krieg, W. (1974), S. 18ff.; Ulrich, H. (1978), S. 275. Für eine Übersicht der wesentlichen Umfeldentwicklungen mit Relevanz furr KMU vgl. Mugler, A./Schmidt, K.-H. (Hrsg.) (1995), S. 50. Zur Umfeldanalyse vgl. z.B. Utterback, J.M. (1979); Hunger, J.D./Wheelen, T.L. (1996), S. 82-113; Ulrich, H. (1990), S. 64-88.

${ }^{130}$ Vgl. Zahn, E. (1996), S. 43; Ulrich, H./Probst, G.J.B. (1995), S. 250. Porter fuhrt dazu aus, "that environmental change is relentless and firms, through innovation, have considerable latitude in both influencing their environment and responding to it", Porter, M.E. (1991), S. 111. Sowie ferner: "The local environment creates potential for competitive success, but firms must sense and respond to it. Firms also have a considerable ability to influence their environment in ways that reinforce or detract from their capacity to accumulate skills and resources and to innovate ...", Porter, M.E. (1991), S. 115. Vgl. dazu auch Thompson, J.L. (1993), S. 439.

${ }^{131}$ Die Informationen stellen eine wesentliche Grundlage der Unternehmensführung dar. Als externe Quellen kommen z.B. die statistischen Landes- und Bundesămter, die Deutsche Bundesbank, Ministerien, Industrieund Handelskammern bzw. Handwerkskammern, Wirtschaftsforschungsinstitute, Verbände, Unternehmensberater oder Internationale Organisationen in Frage. Als interne Quellen bieten sich u.a. das Rechnungswesen und Controlling bzw. die (Außendienst-) Mitarbeiter an.

${ }^{132}$ Vgl. Bleicher, K. (1979), S. 9-31; Kreikebaum, H. (1997), S. 40-46; Nieschlag, R. u.a. (1991), S. 612-626; Müller, C. (1995), S. 114-142; Ulrich, H./Krieg, W. (1974), S. 20; Ulrich, H. (1990), S. 66-84; Pümpin, C. (1980), S. 24-27. Vgl. in Erweiterung dazu die Analyse der Megatrends im Unternehmensumfeld bei Steinbach, R.F. (1997), S. 14-22. 
nehmen kaum zu beeinflussen sind die externen Rahmenbedingungen des Makro-Umfeldes. Sie setzen sich zusammen aus den politisch-rechtlichen, ökonomischen, technologischen, ökologischen und sozio-kulturellen Umfeldbedingungen des Unternehmens. Unter dem Mikro-Umfeld werden die Beziehungen zu Abnehmern, Lieferanten, Absatzhelfern bzw. -mittlern und Wettbewerbern betrachtet. Teilweise werden auch die Mitarbeiter, die Kapitalgeber bzw. relevante Institutionen mit einbezogen. ${ }^{133}$ Eine Systematik zur Analyse des MikroUmfeldes nennt als Instrumente und Entscheidungshilfen der strategischen Unternehmensführung die Branchen-, Wettbewerbs- und Marktanalyse. Eine alternative Form der Betrachtungsweise stellt der Stakeholder-Ansatz dar, dessen Hauptvertreter R.E. FrEEMAN ist. ${ }^{134}$ Als Stakeholder können Bezugs-, Interessen- oder Anspruchsgruppen bezeichnet werden, die in Beziehung zum Unternehmen stehen. ${ }^{135}$

\subsubsection{Das Makro-Umfeld des Unternehmens}

Die politisch-rechtlichen Umfeldbedingungen auf den für das Unternehmen relevanten Märkten werden durch die Aktivitäten des Staates und der Körperschaften mit Gesetzgebungshoheit vorgegeben und sind damit für das Unternehmen bindend. Auf den internen Bereich des Unternehmens wirken z.B. die gesetzlichen Regelungen des Gesellschaftsrechts, der Unternehmensverfassung, des Arbeits- und Tarifvertragsrechts und der Betriebsverfassung sowie technische Sicherheits- und Prüfvorschriften. Demgegenüber wirken Gesetze und Verordnungen zur Finanz- und Währungspolitik, zur Wirtschafts-, Wettbewerbs- und Konjunkturpolitik, zum Außenhandel sowie zur Steuer- und Umweltschutzgesetzgebung oder auch zum Patentschutz auf die Beziehungen des Unternehmens nach außen.

Eine unmittelbare Beeinflussung der politisch-rechtlichen Bedingungen durch kleine und mittlere Unternehmen ist aufgrund der großen Heterogenität ihrer Ziele kaum möglich. Den von der Gesetzgebung gesteckten Rahmen muß die Unternehmensfuihrung als einen die Entscheidungs- und Handlungsfreiheit beschränkenden Datenkranz berücksichtigen. Sie ist dabei aber gleichzeitig gefordert, das durch die marktwirtschaftliche Grundordnung dennoch verbleibende hohe Maß an Selbstbestimmung aktiv und offensiv zu nutzen. Eine Möglichkeit hierzu besteht u.a. auf Verbandsebene, von wo aus beispielsweise auf den Gesetzgebungsprozeß Einfluß genommen werden kann.

${ }^{133}$ An dieser Stelle offenbaren sich die immensen Abgrenzungsschwierigkeiten zwischen dem externen und dem internen Bereich des Unternehmens. Folglich kommt es auch bei der Darstellung der Umfeldbedingungen zu teilweise unlogischen Ausführungen. Um Überschneidungen zu vermeiden, sei für die Erläuterung der $\mathrm{Be}-$ stimmungsfaktoren des Mikro-Umfeldes auf die Darstellungen im Rahmen des Stakeholder-Ansatzes bzw. der Branchenstrukturanalyse nach Porter verwiesen.

${ }^{134}$ Vgl. Freeman, R.E. (1984).

${ }^{135}$ Der Stakeholder-Ansatz umfaßt dabei sowohl externe als auch interne Anspruchsgruppen. Vgl. ausfuhrlich Abschnitt 3.3.2.3. 
Das ökonomische Umfeld, in welches das Unternehmen unmittelbar eingegliedert ist, wird geprägt durch die gesamtwirtschaftlichen Rahmenbedingungen und deren Entwicklung bzw. deren Einwirkung auf die Bedingungen und die Entwicklung auf den für das Unternehmen relevanten Märkten. Dabei sollte sich die Analyse nicht auf die Entwicklung der eigenen Branche oder auf die Abschätzung der Entwicklung auf den bislang bearbeiteten Beschaffungs- und Absatzmärkten beschränken. ${ }^{136}$ Mit zunehmenden Internationalisierungs- und Diversifizierungsbestrebungen der Unternehmen erscheint eine solche Betrachtung als zu eng und kurzsichtig. Die Abschätzung der zukünftigen Entwicklung bzw. das Erkennen von langfristigen Entwicklungslinien muß somit branchen- bzw. marktübergreifend erfolgen, da die Änderungen der Marktkonstellationen die Chancen und Gefahren des zukünftigen Handelns des Unternehmens beeinflussen. Indikatoren der gesamtwirtschaftlichen Entwicklung sind z.B. die Entwicklung des Bruttoinlandsprodukts, der Wachstumsrate der Produktion, des internationalen Handels, der öffentlichen und privaten Investitionen, des Einkommens und seiner Verwendung, der Inflationsrate, der Zahl und der Struktur der Erwerbspersonen, des Umfangs und der Struktur der Bevölkerung etc. ${ }^{137}$

Das technologische Umfeld des Unternehmens umfaßt zunächst alle technischen Entwicklungen der Produktionsprozesse und Produkte, die für das Unternehmen in Zukunft relevant sein könnten. In einer erweiterten Betrachtung sind aber auch Informationen über Veränderungen sozialer und organisatorischer Technologien (z.B. Führungs-, Organisations-, Management-Technolgien etc.) einzuholen. Erfolgreiche technische Innovationen ${ }^{138}$ sind an die geeignete Kombination von Produkt- und/oder Prozeßtechnologie und Unternehmensführungstechnologie gebunden. Je eher Entwicklungen im Bereich von Wissenschaft und Forschung von den Unternehmen erkannt werden, desto größer ist der Aktionsspielraum, über den sie zur innovativen Anpassung an derartige Wandlungen verfügen. In Analogie zum ökonomischen Umfeld darf die Informationssuche über technische Entwicklungen nicht auf die eigene Branche fokussiert werden, da z.B. neue Technologien z.T. in Bereichen eingesetzt werden, für die sie zunächst nicht konzipiert wurden. ${ }^{139} \mathrm{Da}$ aber Innovationen eine zentrale Determinante für die Wettbewerbsfähigkeit und den Erfolg kleiner und mittlerer Unternehmen darstellen, muß das Problem der richtigen Einschätzung der Entwicklung gelöst werden ${ }^{140}$, damit Innovationen im Unternehmen selbst forciert oder schnellstmöglich adaptiert werden.

\footnotetext{
${ }^{136}$ Vgl. die Ausführungen zur Branchen-, Wettbewerbs- und Marktanalyse in 3.3.2.2.

${ }^{137} \mathrm{Vgl}$. zu den volkswirtschaftlichen Gesamtgrößen und Einflußgrøßen des okonomischen Umfeldes Kreikebaum, H. (1997), S. 43; Ulrich, H. (1990), S. 78ff.; Macharzina, K. (1995), S. $15 f$.

${ }^{138} \mathrm{Vgl}$. vertiefend hierzu die Kapitel 4 bzw. 5.

${ }^{139}$ Vgl. Ulrich, H. (1990), S. 76.

${ }^{140}$ Hilfestellung können hier insbesondere Innovationsberater bzw. Innovationstransferstellen bieten. Vgl. dazu auch Nolte, B. (1996), S. 126-129.
} 
Das ökologische Umfeld bzw. die ökologische Sphäre umfaßt die unbelebte Natur mit den Umweltmedien Boden, Wasser und Luft sowie die belebte Natur mit den Bereichen Ökosysteme $^{141}$, Mensch, Flora und Fauna. Die natürliche Umwelt ist als ein dynamisches System zu verstehen, als die Gesamtheit verschiedener Systeme, die in Wechselwirkung miteinander stehen. ${ }^{142}$ Der Mensch ist als natürliches Lebewesen Bestandteil dieses Systems, in das er allerdings durch die Nutzung und Belastung systemverändernd eingreift. Folglich sind die umweltrelevanten wirtschaftlichen Handlungen des Unternehmens für die strategische Planung in doppelter Hinsicht von Bedeutung. Einerseits beschränken die Umweltbedingungen, z.B. die Verfügbarkeit von Ressourcen und Energie, sowie die Trends im Umweltschutz, z.B. die Umweltschutzregelungen und das Umweltbewußtsein, die wirtschaftlichen Optionen des Unternehmens, die die Unternehmensleitung bei ihren operativen und strategischen Entscheidungen zur Verfügung hat (Reaktion), andererseits bietet der Umweltschutz aber auch Chancen, Wettbewerbspositionen durch umweltfreundliche Produktionsverfahren oder Produkte zu besetzen bzw. auszubauen (Aktion).

Das sozio-kulturelle Umfeld stellt eine Residualgröße dar. Die sich in dieser Sphäre widerspiegelnden gesellschaftlichen Strukturen manifestieren sich zwar teilweise im Wirtschaftsgeschehen, sie lassen sich jedoch allein durch wirtschaftliche Größen nicht zum Ausdruck bringen. Dies geht vor allem darauf zurück, daß an Unternehmen "Ansprüche gestellt werden, die sich vom klassischen Unternehmungszweck, der Güterproduktion und -bereitstellung, her nicht erfassen und rechtfertigen lassen; dies ließ die Vorstellung der Unternehmung als gesellschaftliche oder 'öffentliche Institution' und das Konzept der 'sozialen Verantwortung' der Unternehmung entstehen"143.

Die gesellschaftliche Umgebung des Unternehmens wird geprägt durch die Struktur der Bevölkerung (Alter, Beruf, Einkommen, Bildung etc.), d.h. durch die demographische Dimension. Daneben sind Sozial- und Gesellschaftsstrukturen sowie die Beziehungen gesellschaftlicher Institutionen untereinander $\mathrm{zu}$ analysieren (sozio-organisationale Dimension). Ferner muß sich das Unternehmen an verändernde Einstellungen und Verhaltensweisen von Kunden bzw. der Öffentlichkeit anpassen. Diese äußern sich z.B. in einem zunehmenden Umweltbewußtsein ${ }^{144}$, in einem geänderten Arbeits- und Freizeitverhalten, in Veränderungen des Kon-

${ }^{141}$ Ein Ökosystem ist nach Jahnes, S./Tammler, U. (1997), S. 7 "die funktionelle Einheit aus Organismen (Biozonose) und ihrer Umwelt (Biotop), welche durch vielfaltige Wechselwirkungen miteinander verknüpft sind".

${ }^{142}$ Vgl. dazu ausfuhrlich Jahnes, S./Tammler, U. (1997), S. 7-10.

${ }^{143}$ Ulrich, H. (1990), S. 69f. (Hervorhebung im Original). Der Begriff der "sozialen Verantwortung" wird verstärkt durch den Begriff "Unternehmensethik" substituiert. Vgl. auch Abschnitt 3.4.2.

${ }^{144}$ Umweltbewußtsein gilt als notwendige Voraussetzung fir eine effektive Umweltpolitik. In den vergangenen Jahren haben verschiedene Studien ein steigendes Umweltbewußtsein aufgezeigt. Vgl. bez. des konsumorientierten Umweltbewußtseins Tiebler, P. (1992), S. 184f;; Wicke, L. u.a. (1992), S. 422-432; Meffert, H./Bruhn, M. (1996). Die an den Tag gelegten Kauf- und Verhaltensweisen spiegeln das gestiegene Bewußtsein allerdings nur bedingt wider. Es bestehen Divergenzen zwischen Wissen und Handeln (kognitive Disso- 
sumverhaltens, der kulturellen Normen, des Anspruchsniveaus der Mitarbeiter, der Arbeitseinstellung und des politischen Verhaltens (normative Dimension).

\subsubsection{Die Branchen-, Wettbewerbs- und Marktanalyse}

Die aus der Analyse des Makro-Umfeldes gewonnenen, noch sehr unspezifischen Informationen werden im Zuge der Branchen-, Wettbewerbs- und Marktanalyse ergänzt und verdichtet. $^{145}$

Die Branchen- bzw. Branchenstruktur- und Wettbewerbsanalyse ${ }^{146}$ betrachtet die ökonomischen Merkmale der Branche, in der das Unternehmen derzeit tätig ist, bzw. in der Zukunft tätig sein will. Porters Konzept der Umfeldanalyse betrachtet dabei neben der Branche an sich auch deren Binnengefüge. Sie dient dem Unternehmen zum Vergleich der eigenen Entwicklung mit der des Branchendurchschnitts z.B. hinsichtlich Umsatz, Beschäftigtenentwicklung oder Arbeitsproduktivität. Sie dient aber auch dazu, Konzentrations- und Kooperationsbestrebungen oder Veränderungen der Größenstruktur der direkten Wettbewerber festzustellen. Sinnvoll ist es ferner, die Entwicklung verwandter Wirtschaftszweige zu beobachten, um Anregungen für die eigene strategische Ausrichtung oder für Diversifikationsmöglichkeiten zu erhalten.

Die Branchenstruktur und Wettbewerbsanalyse sieht in den Branchenmerkmalen wesentliche Determinanten für den langfristigen Unternehmenserfolg. PORTER ist der Auffassung, daß zur Formulierung einer Produkt-Markt-Strategie zunächst der Wettbewerb innerhalb der Branche, in der ein Unternehmen konkurriert, untersucht werden müsse. Der Wettbewerb innerhalb einer Branche kann an fünf Wettbewerbskräften ${ }^{147}$ festgemacht werden: den Lieferanten, den Abnehmern, den Ersatzprodukten und den potentiellen neuen Konkurrenten sowie den Wett-

nanzen), d.h. eine Unterteilung in ökologisches "Wissen" und "Handeln". Vgl. dazu ausfuhrlich Freimann, J. (1996), S. 81-99 sowie ferner Töpfer, A. (1985), S. 241; Schathausen, F. (1988), S. 276; Meffert, H. (1990), S. 77; Meffert, H. u.a. (1990), S. 42 und S. 45; Meffert, H. (1991b), S. 94; Meffert, H./Bruhn, M. (1996), S. 640; Kroeber-Riel, W./Weinberg, P. (1996), S. 671ff. Zu den Entstehungsbedingungen des Umweltbewußtseins vgl. Langheine, R./Lehmann, J. (1986).

${ }^{145}$ Die Branchen-, Wettbewerbs- sowie Marktanalyse ubberlappen sich in hohem Maße. So findet sich beispielsweise kein Konsens bei der Abgrenzung des relevanten Marktes. Da das Aufgreifen dieser Diskussion zu weit ginge, sei auf Herdzina, K. (1993), S. 79-85 und Blank, P.-U. u.a. (1995) verwiesen. Ferner greift eine ausschließliche Betrachtung der eigenen Branche bzw. der derzeitigen Konkurrenten zu kurz, da z.B. durch Diversifizierungsbestrebungen Konkurrenten entstehen können, die ursprünglich einer anderen Branche angehörten. Daher sind die in der Literatur vorgenommenen Darstellungen äußerst kritisch zu betrachten. Beispielsweise findet sich bei Kreikebaum, H. (1997) eine Trennung der drei Analysen, Porter, M.E. (1996) und (1995) behandelt die Branchen- und die Wettbewerbsanalyse gemeinsam, während Ulrich, H. (1990) die Konkurrenzanalyse im Rahmen der Absatzmarktanalyse beschreibt. Eine eindeutige Abgrenzung ist somit nicht gegeben.

${ }^{146}$ Vgl. Porter, M.E. (1996); Porter, M.E. (1995). Vgl. dazu ferner Kreikebaum, H. (1997), S. 118ff.; Hunger, J.D./Wheelen, T.L. (1996), S. 91-97; Bea, F.X./Haas, J. (1997), S. 86-90; Macharzina, K. (1995), S. 251255; Hax, A.C.Majluf, N.S. (1991), S. 52.

${ }^{147}$ Vgl. zu den fünf Wettbewerbskrăften Porter, M.E. (1995), S. 25-56, Porter, M.E. (1996), S. 22-27. 
bewerbern in der Branche selbst. Die Branche kann dabei als Industriebereich verstanden werden, der Produkte herstellt, die sich nahezu ersetzen können.

\section{Abb. 3-2: Elemente der Branchenstruktur nach PORTER}

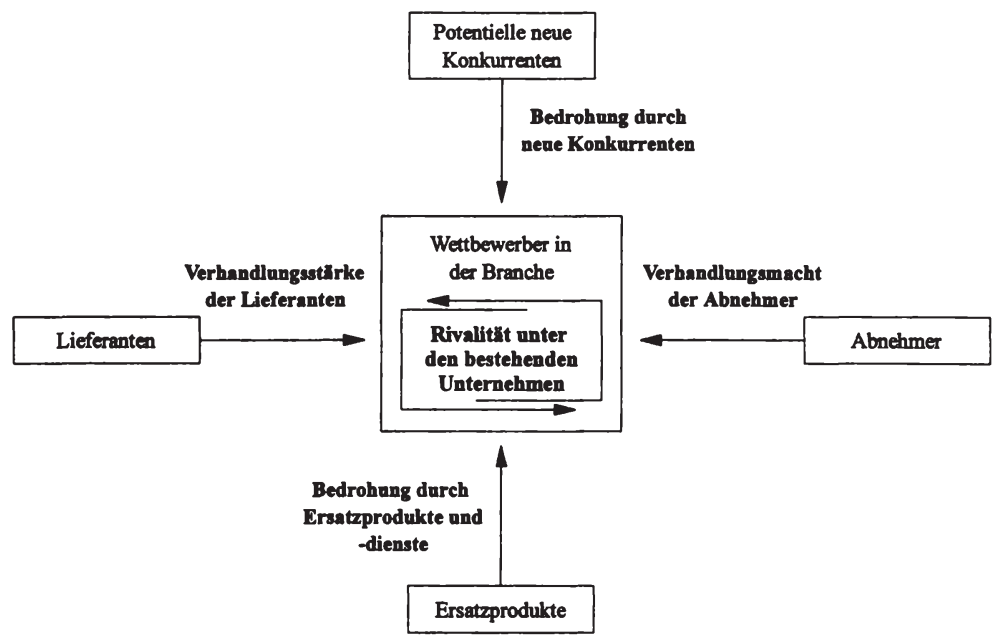

Quelle: Porter, M.E. (1995), S. 26.

Die Verhandlungsstärke der Lieferanten resultiert aus ihrer direkten Einflußmöglichkeit auf Preis und Qualität der Leistung. Ihre Macht nimmt zu, wenn oligopolistische Lieferstrukturen bestehen, die Substitutionsmöglichkeiten eingeschränkt sind bzw. die analysierte Branche von untergeordneter Bedeutung ist. Die Verhandlungsstärke vor allem mittelständischer Lieferanten hat jedoch in weiten Teilen abgenommen. Zwar werden durch die Reduzierung der Lieferanten im Rahmen der Verschlankung von Großunternehmen ("lean management" ${ }^{148}$ ) einzelne Zulieferbetriebe zu sog. Systemlieferanten und erhalten dadurch z.T. eine monopolartige Stellung. Dies bedeutet aber eher eine gestiegene Abhängigkeits- denn eine gestiegene Machtposition. Daraus folgt eine Nachfragemacht der Abnehmer in verschiedenen Teilbereichen des Marktes, die vor dem Hintergrund sich dynamischer entwickelnder Märkte höhere Ansprüche an Qualität und Innovativität ihrer Zulieferbetriebe stellen. Gleichzeitig besteht die Gefahr der Bedrohung etablierter Unternehmen durch neue Konkurrenten. Diese setzen sich zusammen

${ }^{148}$ Beim Lean-Management-Konzept steht die betriebliche Prozeßoptimierung im Vordergrund. Dabei sollen durch effiziente Organisations- und Führungsstrukturen u.a. die Kosten gesenkt, die betrieblichen Ablăufe beschleunigt und die Qualităt der Erzeugnisse gesteigert werden. Vgl. Butterbrodt, D. (1997), S. 124f.; Weiß, R. u.a. (1997), S. 75. 
aus Newcomern, vor allem sind es Gründer kleiner und mittlerer Unternehmen, die Nischen oder Teilmärkte besetzen, oder aus bestehenden Unternehmen, die ihr Angebot erweitern oder diversifizieren. Damit eng verbunden ist die Bedrohung durch Ersatzprodukte oder -dienste. ${ }^{149}$

Die Analyse der Wettbewerber ${ }^{150}$ innerhalb der eigenen Branche soll Auskunft über das Leistungsangebot und die unternehmerischen Aktivitäten der Wettbewerber geben und so einer Fehlallokation der eigenen Ressourcen entgegenwirken. Im Mittelpunkt steht die Antizipation, mindestens aber das frühzeitige Erkennen von Produkt- und Prozeßinnovationen bzw. von Marktstrategien der Konkurrenten, um ihnen in adäquater Weise zu begegnen. Gelingt dies nicht, können Marktanteilsverluste und langfristig die Gefährdung der Unternehmensexistenz die Folge sein.

Die Analyse der Wettbewerber bildet einen notwendigen Bestandteil für die StärkenSchwächen-Analyse im Rahmen der Unternehmensanalyse, da dort die eigenen Potentiale u.a. an den Daten der Wettbewerber gemessen werden. ${ }^{151}$ Voraussetzung für die Durchfuihrbarkeit der Analyse ist die Beschaffung geeigneter Informationen über die Wettbewerber. Im Vordergrund stehen dabei die Unternehmer- und Managementeigenschaften, die Finanzkraft, die technischen Potentiale, die Innovationskraft, das Anwendungs- und Problemlösungs-Knowhow, die Produkteigenschaften und Produktionsmerkmale, das Preis-Leistungs-Verhältnis, der Bekanntheitsgrad, die Anziehungskraft für neue Mitarbeiter, die Berücksichtigung ökologischer Aspekte etc. Liegen diese Daten vor, können die gegenwärtigen Ziele und Strategien der Wettbewerber ermittelt, ihre Annahmen über sich selbst und über die Branche identifiziert sowie ihre Stärken und Schwächen analysiert werden. Als problematisch dürfte sich vor allem im Hinblick auf kleine und mittlere Unternehmen erweisen, daß diese zum großen Teil nicht publikationspflichtig sind, wodurch die Informationsgewinnung erschwert wird. Ein weiteres Problem stellt die Auswahl der zu betrachtenden Konkurrenten dar. Eine Verengung auf die "größten" Wettbewerber wäre zu kurzsichtig. Wichtig ist, auch kleinere Unternehmen mit in die Betrachtung einzubeziehen, was vor allem in dynamischen und wachstumsstarken Märkten von besonderer Bedeutung ist. Somit darf sich die Auswahl der Wettbewerber nicht auf deren absolute Größe beschränken, sondern muß auch die Höhe der Marktanteile bzw. die Entwicklungspotentiale berücksichtigen.

${ }^{149}$ Die bei Porter vorgenommene Trennung zwischen neuen Anbietern und neuen Produkten bzw. Dienstleistungen ist nur begrenzt einsichtig. Letztlich spielt es keine Rolle, von wem neue Produkte oder Dienstleistungen angeboten werden, ob von bestehenden oder von neuen Konkurrenten. In beiden Fällen verschärft sich der Wettbewerb. Sinnvoll ist sie insoweit, als der Blickwinkel über die Branchengrenze hinaus erweitert wird und 150 so eine Sensibilisierung für die Entwicklungen jenseits der eigenen Branche stattfindet.

Vgl. Porter, M.E. (1995), S. 78-109.

${ }^{151} \mathrm{Vgl}$. Abschnitt 3.3.3.2. Dort wird auch das Benchmarking-Konzept behandelt, das den Vergleich der eigenen Produkte, Dienstleistungen und Prozesse mit denen der besten Wettbewerber oder mit denen anerkannter Spitzenunternehmen beinhaltet. 
Die Analyse der Branchenstruktur und der Wettbewerber bildet gleichzeitig eine wesentliche Voraussetzung für die Bestimmung einer Wettbewerbsstrategie, mit der in erster Linie die eigene Position innerhalb der Branche verbessert werden kann. Mit einer geeigneten Wettbewerbsstrategie ist es den Unternehmen teilweise aber auch möglich, Einfluß auf die Branchenstruktur selbst zu nehmen. ${ }^{152}$ Zur Ausnutzung dieses strategischen Potentials lassen sich die generischen Strategien von PORTER ${ }^{153}$ heranziehen. Für die Sicherung der langfristigen Wettbewerbsfähigkeit schlägt PORTER drei Strategietypen vor: die Strategie der umfassenden Kostenfuhrerschaft, die branchenweite Differenzierungsstrategie und die auf ein Marktsegment abzielende Konzentrationsstrategie. ${ }^{154}$ Damit wird erneut deutlich, daß die Analyse nicht auf die eigene Branche beschränkt bleiben darf. Diversifikationsanstrengungen in anderen Branchen müssen ebenso ins Kalkull mit einbezogen werden. Für das einzelne Unternehmen bedeutet der Wettbewerb einerseits eine Bedrohung, da eigene Marktanteile verteidigt bzw. gegen die Konkurrenz gewonnen werden müssen. Andererseits ist dem Wettbewerb gesamtwirtschaftlich das positive Element der ständigen Herausforderung immanent, wodurch letztlich Innovativität gefördert wird.

Der Ansatz von PORTER trägt zu einem Fortschritt in der Wettbewerbsanalyse bei. Hinzuweisen ist jedoch auf die mangelnde Trennschärfe zwischen den einzelnen Analysedimensionen. Auch ist der Anwendungsnutzen begrenzt, da "für das Zusammenspiel der fuinf Einflußfaktoren der Branchenstruktur ... lediglich kasuistische, nicht jedoch nomologische Aussagen bereitgestellt" ${ }^{\prime 155}$ werden. Auch entspricht die isolierte Betrachtung einzelner Beziehungszusammenhänge und das Konstanthalten der Schlüsselvariablen des Gesamtzusammenhanges nicht der Realität. Ferner äußert sich PORTER nur spärlich über das methodische Vorgehen bei der Beurteilung interner und externer Faktoren. ${ }^{156}$ Über die von PORTER behandelten Wettbewerbskräfte hinaus bestehen weitere Kräfte, die Einfluß auf den Wettbewerb nehmen. So beeinflussen beispielsweise gesellschaftliche Entwicklungen, wie etwa ein stärkeres Umwelt-, Qualitäts- oder etwa Kostenbewußtsein sowie staatliche Handlungen und Eingriffe, z.B. umweltorientierte Beschaffung, Abschreibungsmöglichkeiten etc., ebenfalls die Branchen- und Wettbewerbsverhältnisse. ${ }^{157}$

${ }^{152}$ Die Kenntnis des Marktes und der Anteile der Wettbewerber, insbesondere deren Kosten- und Gewinnsituation, sind wichtige Informationen, die mittels einer geeigneten Wettbewerbsstrategie wiederum die Realisierung von Erfahrungskurveneffekten erlauben. Vgl. Henderson, B.D. (1974), S. 90f.

${ }^{153}$ Vgl. Porter, M.E. (1995), S. 62-77, der hier die Verbindung zwischen der Vielfalt wettbewerblicher Prozesse und einem strategischen Management herstellt und einen konzeptionellen Rahmen zur Wettbewerbsanalyse und Ableitung von Grundstrategien in unterschiedlichen wettbewerblichen Umfeldern entwickelt.

${ }_{155}^{154} \mathrm{Vgl}$. dazu die Ausfuhrungen in Abschnitt 3.6.3.2.

155 Macharzina, K. (1995), S. 253.

${ }^{156} \mathrm{Vgl}$. Macharzina, K. (1995), S. $253 \mathrm{ff}$.

${ }^{157}$ Vgl. dazu die Erweiterung des Porterschen Konzeptes bei Freeman, R.E. (1984), S. 139-144, der mit "other stakeholders" eine zusătzliche Wettbewerbskraft anfuhrt, die weitere Anspruchsgruppen, wie z.B. Gewerkschaften, den Staat oder Umweltschutzgruppen in die Betrachtung mit einbezieht. Eine modifizierte Darstellung bietet auch Hinterhuber, H.H. (1996), S. 121 an. Vgl. ferner Meffert, H. (1991a), S. 11 ff.; Meffert, H./Kirchgeorg, M. (1994), S. 30 ff., die insbesondere auf okologische Aspekte abzielen. 
Neben der Branchenstruktur- und Wettbewerbsanalyse steht mit der Marktanalyse ein weiteres Instrument zur Verfügung, das zur Erhebung externer Umfeldbedingungen herangezogen werden kann. ${ }^{158}$ Die Marktanalyse umfaßt die Untersuchung der Eigenschaften abgegrenzter Märkte und Teilmärkte bzw. Marktsegmente und stellt damit eine direkte Verbindung zwischen der Angebots- und Nachfrageseite, dem eigenen Leistungsangebot sowie dem der Wettbewerber her.

Ziel der Marktanalyse ist es, Informationen über Gegebenheiten und Veränderungen der Märkte, Teilmärkte bzw. Marktsegmente zu gewinnen und daraus Strategien im Beschaffungs- und Absatzbereich abzuleiten. Von besonderem Interesse sind

- das Marktvolumen (Marktpotential),

- das Marktwachstum (vergangene und zukünftige Entwicklung),

- der eigene Marktanteil (vergangene und zukünttige Entwicklung),

- die Marktanteile der wichtigsten Anbieter und Nachfrager und

- die Preisentwicklung (vergangene und zukünftige Entwicklung). ${ }^{159}$

Bei der Gewinnung der Daten kann auf die bereits genannten Quellen sowie die Informationen aus der Analyse des Makro-Umfeldes bzw. der Branchen- und Wettbewerbsanalyse zurückgegriffen werden. Insbesondere der eigene Außendienst hat die Möglichkeit, die für die Geschäftspolitik interessanten Daten kostengünstig und aktuell zu erheben, da sich im Kundengespräch auf einfachem Wege wertvolle Informationen über Bedürfnisse, Anregungen oder Konkurrenzangebote sammeln lassen.

Damit marktbezogene Erfolgsfaktoren wirksam werden können, müssen die zu untersuchenden Märkte definiert und abgegrenzt werden. ${ }^{160}$ Eine Möglichkeit der Abgrenzung zur Analyse der Marktbedingungen ist die grobe Differenzierung zwischen den Beschaffungs- und den Absatzmärkten. ${ }^{161}$ Für die Analyse der Beschaffungsmärkte sind insbesondere die Rohstoffbzw. Vorproduktmärkte, der Investitionsgütermarkt, der Kapital- und der Energiemarkt sowie auch der Arbeitsmarkt von Bedeutung. Gegenstand einer Analyse der Beschaffungsmärkte und ihrer Entwicklung sind Menge und Qualität ${ }^{162}$ der Bezugsgüter, ihre Verfügbarkeit unter dem Gesichtspunkt der technologischen Entwicklung, die Preis- und Bezugsbedingungen, vorhandene oder künftige Lieferrisiken sowie die bisherigen und die potentiellen Lieferanten.

${ }^{158}$ Vgl. Kreikebaum, H. (1997), S. 123-128.

${ }^{159}$ Vgl. Kreikebaum, H. (1997), S. 123.

${ }^{160}$ Zur Marktabgrenzung vgl. z.B. Ulrich, H. (1990), S. 82ff.; Bussiek, J. (1997), S. 16; Kreikebaum, H. (1997), S. $123 \mathrm{ff}$. Auf die bei der Identifikation des relevanten Marktes entstehenden Probleme wurde bereits an früherer Stelle hingewiesen. Vgl. FN 145.

${ }^{161}$ Vgl. Ulrich, H. (1990), S. 82ff.

162 Der Aspekt der Qualităt der Bezugsgüter bzw. eine qualităts- und umweltorientierte Produktion gewinnt zunehmend an Bedeutung. Teilweise werden bereits jetzt Zertifizienungen nach ISO $9000 \mathrm{ff}$. oder die Beteiligung am EG-Öko-Audit zur Aufrechterhaltung von Abnehmer- bzw. Lieferantenbeziehungen vorausgesetzt. 
Die Analyse der Absatzmärkte beleuchtet die Nachfrage- und die Konkurrenzsituation. Die Untersuchung der Nachfrage setzt die Segmentierung des Gesamtmarktes nach Abnehmergruppen, regionalen Gesichtspunkten, Absatzwegen, Kundengrößenklassen usw. voraus. Dabei sind Informationen über Marktvolumen und Marktpotential, Marktwachstum, Marktanteile sowie Preis- und Ertragsbedingungen einzuholen. Die Segmentierung ist so weit voranzutreiben, daß konkrete Produkt- und Marktentscheidungen getroffen werden können.

Der besondere Vorteil dieses Instruments liegt in der Erweiterung des Blickwinkels über die eigene Branche bzw. uber die aktuellen Wettbewerber hinaus.

\subsubsection{Der Stakeholder-Ansatz}

Eine alternative Aufgliederung bzw. Verfeinerung der vorgenannten Umfeldanalysen kann im Stakeholder-Ansatz gesehen werden. ${ }^{163}$ Er bildet dabei durch die Betrachtung sowohl unternehmensexterner als auch unternehmensinterner Zusammenhänge zugleich ein Verbindungsglied zur anschließend dargestellten Unternehmensanalyse. Als Stakeholder werden Personen, Personengruppen oder Institutionen bezeichnet, die im Erreichen ihrer Ziele vom Unternehmen abhängen oder von denen das Unternehmen abhängt (vgl. Tab. 3-1). ${ }^{164}$

Durch den Stakeholder-Ansatz soll die Perspektive der Unternehmensfuihrung eine Erweiterung finden, indem neben den Anteilseigner- und Managerinteressen auch die Interessen gesellschaftlicher Bezugsgruppen berücksichtigt werden. ${ }^{165}$ Wird jedoch von der rechtstatsächlichen Situation ausgegangen, nach der in der Mehrzahl der Unternehmen neben den Unternehmensvertretern und Anteilseignern allenfalls Arbeitnehmervertreter an der Gestaltung von Unternehmensfuhrungsentscheidungen mitwirken, besitzt der Stakeholder-Ansatz "eine eher geringe Relevanz und genießt daher vornehmlich theoretische Bedeutung"166.

${ }^{163}$ Vgl. vor allem Freeman, R.E. (1984) sowie ferner Ulrich, P./Fluri, E. (1995), S. 78f.; Macharzina, K. (1995), S. 9; Hinterhuber, H.H. (1996), S. 2ff. Der Stakeholder-Value-Ansatz und der Shareholder-Value-Ansatz bilden die Grundlage eines wertorientierten strategischen Managements. Vgl. zu letzterem v.a. Rappaport, A. (1981), (1986) und (1994) sowie Gomez, P/Weber, B. (1989). Eine ausfuhrliche Darstellung des StakeholderValue-Ansatzes zur Sicherung der langfristigen wirtschaftlichen Leistungsfähigkeit von Unternehmen findet sich bei Eberhardt, S. (1997). Er zeigt zugleich mit der Verbindung des Shareholder- und des StakeholderAnsatzes einen modifizierten Ansatz zum Value-Management auf, der die Vorteile beider Ansătze kombiniert. Durch die Konzentration auf die Kerngruppen der Kunden, der Lieferanten, der Mitarbeiter sowie der Kaptialgeber ist der modifizierte Ansatz furr die vorliegende Arbeit jedoch zu eng.

${ }^{164}$ Vgl. Freeman, R.E. (1984), S. 46; Schaltegger, S./Sturm, A. (1992), S. $8 f$.

${ }^{165}$ Vgl. Bleicher, K. (1991), S. 17; Macharzina, K. (1995), S. 8.

${ }^{166}$ Macharzina, K. (1995), S. 8. 
Tab. 3-1: Interessen interner und externer Anspruchsgruppen des Unternehmens ${ }^{167}$

\begin{tabular}{|c|c|}
\hline $\begin{array}{l}\text { Anspruchsgruppe } \\
\text { (Stakeholder) }\end{array}$ & Interessen (Ziele) \\
\hline L. Interne Anspruchsgruppen & \\
\hline 1. Unternehmensführung & $\begin{array}{l}\text { Erhaltung von Macht, Einfluß und Prestige, Selbständigkeit, Entscheidungs- } \\
\text { autonomie, Verwirklichung eigener Ideen, Einkommen }\end{array}$ \\
\hline 2. Eigenkapitalgeber & $\begin{array}{l}\text { Sicherheit und Verzinsung des bereitgestellten Kapitals, Teilnahme an der } \\
\text { Wertsteigerung, Einfluß auf die Unternehmensführung }\end{array}$ \\
\hline 3. Mitarbeiter & $\begin{array}{l}\text { Sicherheit von Arbeitsplatz und Einkommen, soziale Sicherheit, zufrieden- } \\
\text { stellende Arbeitsbedingungen, Selbstentfaltung, Aus-, Fort- und Weiterbil- } \\
\text { dungsmöglichkeiten, Aufstiegsmöglichkeiten, Mitbestimmung, zwischen- } \\
\text { menschliche Kontakte, Anerkennung }\end{array}$ \\
\hline II. Externe Anspruchsgruppen & \\
\hline 1. Fremdkapitalgeber & $\begin{array}{l}\text { Sicherheit und vertragsgerechte Rückzahlung des bereitgestellten Kapitals, } \\
\text { Einfluß auf die Unternehmensfuhrung }\end{array}$ \\
\hline 2. Lieferanten & $\begin{array}{l}\text { Kontinuierliche, langfristige Abnahmevereinbarungen, günstige Konditio- } \\
\text { nen, erfullbare Qualitătsstandards, Zahlungsfăhigkeit }\end{array}$ \\
\hline 3. Abnehmer/Kunden & $\begin{array}{l}\text { Qualitative und quantitative Leistungsfahigkeit, günstige Preise, zusătzliche } \\
\text { Dienstleistungen wie Beratung, Kredit, Service, Lagerhaltung, Just-in-time- } \\
\text { Lieferung etc. }\end{array}$ \\
\hline 4. Kooperationspartner & Beteiligung, Informationsaustausch, gemeinsame Projekte, Einflußnahme \\
\hline 5. Wettbewerber & Einhaltung fairer Grundsătze \\
\hline $\begin{array}{l}\text { 6. Staat und Gesellschaft } \\
\text { (lokale und nationale Behör- } \\
\text { den, nationale und internatio- } \\
\text { nale Verbănde und Organisa- } \\
\text { tionen, politische Parteien, } \\
\text { Bürgerinitiativen, allgemeine } \\
\text { Öffentlichkeit/Medien) }\end{array}$ & $\begin{array}{l}\text { Bereitstellung und Sicherung von Arbeitsplătzen, Zahlung von Steuern, } \\
\text { Sozialleistungen, Einhaltung von Normen und Gesetzen, Beiträge zur Infra- } \\
\text { struktur, Beteiligung an Kultur- und Bildungseinrichtungen, Beiträge an } \\
\text { Verbände, Organisationen und Parteien, Anerkennung und Verfolgung der } \\
\text { Ansprüche von Arbeitnehmer- und Arbeitgeberverbănden, Beitrăge zur Lö- } \\
\text { sung gesellschaftlicher Probleme, Umweltschutz }\end{array}$ \\
\hline
\end{tabular}

Der Ansatz zielt in seiner Anlage in erster Linie auf Großunternehmen ab. Wird jedoch weniger auf die direkte Einbindung der unterschiedlichen Interessengruppen in die Unternehmensfuihrungsentscheidungen abgehoben und der Ansatz vielmehr zur Systematisierung und Berücksichtigung der heterogenen Ziele im Rahmen der Entscheidungsfindung herangezogen, erhält er auch für kleine und mittlere Unternehmen hohe faktische Relevanz.

${ }^{167}$ Vgl. Freeman, R.E. (1984), S. 8ff; Macharzina, K. (1995), S. 9; Ulrich, P./Fluri, E. (1995), S. 79; Hinterhuber, H.H. (1996), S. 3. 
Problematisch bleibt dabei die Identifikation aller relevanten Anspruchsgruppen. ${ }^{168}$ Dies ist Gegenstand eines entsprechenden Anspruchsgruppen-Managements ${ }^{169}$, mit dessen Hilfe die Anspruchsgruppen und deren konkrete Interessen identifiziert werden und ein für beide Seiten akzeptabler Interessenausgleich herbeigeführt wird, ohne daß der Handlungsspielraum des Unternehmens zu stark beschnitten wird. Gleichzeitig kann die intensive und konstruktive Auseinandersetzung mit den unterschiedlichen Anspruchsgruppen bereits frühzeitig auf schwache Signale ${ }^{170}$ sich ändernder Entwicklungstrends hinweisen. Die für das Unternehmen daraus entstehenden Chancen und Risiken können dann ensprechend berücksichtigt werden.

\subsubsection{Analyse der internen Unternehmenssituation}

Aufbauend auf der Analyse des Unternehmensumfeldes erfolgt eine kritische Betrachtung der internen Bedingungen, die einen weiteren Baustein der strategischen Unternehmensfuihrung darstellen. Das Ziel ist die Entwicklung eines Systems unternehmensspezifischer Erfolgsfaktoren. Für die Unternehmensanalyse stehen eine Reihe von Instrumenten und Konzepten zur Verfügung. Von diesen sollen hier der Wertkettenanalyse, der Funktionsbereichsanalyse auf der Basis des St.-Galler-Management-Modells in Verbindung mit dem Stärken-Schwächenund dem Benchmarking-Konzept, der Produktlebenszyklusanalyse sowie der Portfolioanalyse besondere Beachtung geschenkt werden. Die Begründung für die Wahl dieser Instrumente und Konzepte liegt in ihrem Bekanntheits- und Verbreitungsgrad. Dies erleichtert die Überprüfung ihres Einsatzes im Rahmen der dieser Arbeit zugrundeliegenden empirischen Untersuchtung.

\subsubsection{Die Wertkettenanalyse}

Eine Mőglichkeit zur Systematisierung der Unternehmensanalyse zeigt PORTER mit seinem Denkansatz der Wertkette (Wertschöpfungskette) auf. ${ }^{171}$ PORTER zerlegt hierzu das Unternehmen in einzelne Aktivitäten, um so die Ursachen von Wettbewerbsvorteilen zu untersuchen. Er geht dabei davon aus, daß jedes Unternehmen eine individuelle Wertkette besitzt und durch die Beziehungen zu Lieferanten und Abnehmern in ein System vor- und nachgelagerter

${ }_{168}$ Vgl. Staehle, W.H./Grabatin, G. (1979), S. $97 f$.

${ }^{169}$ Vgl. Achleitner, P. (1985), S. 121-133.

${ }^{170}$ Die Ergebnisse der strategischen Unternehmensführung korrelieren mit der Qualităt der für die Entscheidungen herangezogenen Informationen. Von besonderer Bedeutung in diesem Zusammenhang ist die Erfassung sogenannter "schwacher Signale" ("weak signals") für Trendbrüche und Diskontinuităten, deren Übersehen fur das Unternehmen gravierende Konsequenzen haben kann. Die Identifikation schwacher Signale ermöglicht das frühzeitige Erkennen von Diskontinuităten und damit von Innovationspotentialen. Dadurch können produkt- und produktionsbezogene Problemstellungen erkannt und gelöst werden, noch bevor man sie breit diskutiert. Vgl. Ansoff, H.I. (1975), S. 21-33; Ansoff, H.I. (1980), S. 187; Ansoff, H.I./McDonnell, E.J. (1996), S. 383-399. Zur Beschreibung vgl. ferner Kirsch, W. (1991), S. 253ff.; Liessmann, K. (1987), S. $118 \mathrm{ff}$.

${ }^{171}$ Vgl. Porter, M.E. (1996), Kapitel 2. Vgl. dazu auch Thompson, J.L. (1993), S. 429-439; Macharzina, K. (1995), S. 245-250; Bea, F.X./Haas, J. (1997), S. $97 \mathrm{ff}$. 
Wertketten eingebunden ist. Die Unterschiede in den Wertketten der Unternehmen bilden zugleich eine potentielle Quelle von Wettbewerbsvorteilen. ${ }^{172}$ Für ein Unternehmen entstehen Wettbewerbsvorteile dort, wo die Abnehmer für sie relevante Leistungsmerkmale besser einschätzen als bei den Wettbewerbern des Unternehmens. Daher schlägt PORTER eine marktbzw. branchenbezogene Vorgehensweise bei der Analyse von Wettbewerbsvorteilen vor.

Die Wertkette selbst setzt sich aus den Wertaktivitäten und der Gewinnspanne zusammen. "Wertaktivitäten sind die physisch und technologisch unterscheidbaren, von einem Unternehmen ausgeführten Aktivitäten. Sie sind die Bausteine, aus denen das Unternehmen ein für seine Abnehmer wertvolles Produkt schafft. Die Gewinnspanne ist der Unterschied zwischen dem Gesamtwert und der Summe der Kosten, die durch die Ausführung der Wertaktivitäten entstanden sind." ${ }^{173}$ Die Wertkette stellt ein System interdependenter Aktivitäten innerhalb eines Unternehmens dar, die sich in primäre Aktivitäten (Eingangslogistik, Operationen, Marketing und Vertrieb, Ausgangslogistik, Kundendienst) und unterstützende Aktivitäten (Beschaffung, Technologieentwicklung, Personalwirtschaft, Unternehmensinfrastruktur) gliedern lassen.

\section{Abb. 3-3: Das Modell der Wertkette nach PORTER}

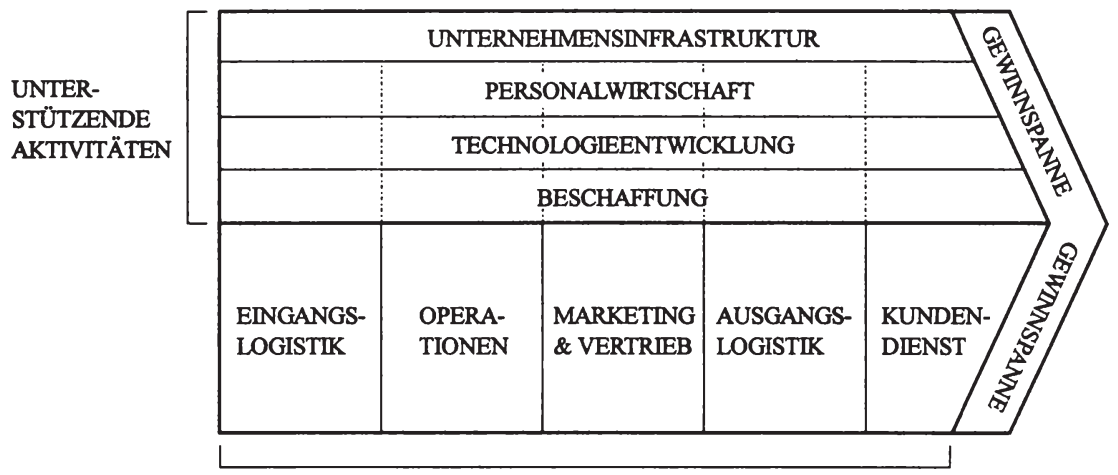

PRIMÄRE AKTIVITÄTEN

Quelle: Porter, M.E. (1996), S. 62.

Die fünf Kategorien primärer Aktivitäten der Wertkette umfassen die physische Herstellung des Produktes, dessen Verkauf und Vertrieb, den Kundendienst sowie die Eingangs- und Ausgangslogistik und differieren in ihrer Ausgestaltung bzw. ihren Schwerpunkten je nach Bran-

172 Vgl. Porter, M.E. (1996), S. 59ff.

${ }^{173}$ Porter, M.E. (1996), S. 64. 
che und Unternehmensstrategie. Die vier Kategorien der unterstützenden Aktivitäten übernehmen eine Versorgungsfunktion für die primären Aktivitäten. Sie lassen sich ebenfalls in eine Reihe einzelner Wertaktivitäten zerlegen. ${ }^{174}$ Dabei spielt vor allem die Technologieentwicklung, d.h. genauer die Produkt- und Prozeßentwicklung, im Verarbeitenden Gewerbe eine Schlüsselrolle und bestimmt als wichtigster Einzelfaktor die Wettbewerbsvorteile.

Neben der Systematisierung der Unternehmensaktivitäten in strategisch relevante Tätigkeiten lassen sich mit dem analytischen Instrument der Wertkette auch deren Kostenbeiträge ermitteln sowie vorhandene und potentielle Differenzierungsmöglichkeiten herausarbeiten. Die daraus entstehenden Kosten- und Differenzierungsvorteile bilden letztlich die Basis der Wettbewerbsvorteile des Unternehmens. Mit der Analyse der Verflechtungen zwischen den einzelnen Geschäftsfeldern eines Unternehmens dient das Instrument ferner zum Aufspüren von Synergieeffekten. Gleichzeitig erweitert die Wertkettenanalyse den Betrachtungshorizont einer ausschließlich unternehmenszentrierten Sichtweise um die Einbeziehung des Unternehmensumfeldes (insbesondere des Branchenumfeldes). ${ }^{175}$

Das Konzept beruht auf überwiegend qualitativen und aus Einzelbeispielen abgeleiteten Aussagen und bedarf daher noch einer empirischen Überprüfung. Außerdem wird nicht beantwortet, wie die strategischen Vorteile wahrzunehmen sind. Die hierfür notwendigen, empirisch abgesicherten Ursache-Wirkung-Zusammenhänge liefern z.B. das Erfahrungskurvenkonzept oder das PIMS-Programm (vgl. Abschnitt 3.3.3.4 und 3.3.4.1). BEA UND HAAS kritisieren insbesondere die wenig einleuchtende Zusammenstellung der einzelnen Aktivitäten sowie die zu starke Ausrichtung an den klassischen betrieblichen Funktionen. Daneben weisen sie darauf hin, daß die Unternehmensinfrastruktur nach neuesten Erkenntnissen eine gleichberechtigte und eigenständige strategische Position einnimmt und nicht lediglich dienende Funktionen erfüllt. $^{176}$

\subsubsection{Die Funktionsbereichsanalyse}

Die im Unternehmen erbrachten Leistungen in Form mehrstufiger, arbeitsteiliger Prozesse bilden typische Tätigkeitskomplexe bzw. Funktionsbereiche. ${ }^{177}$ Nach ULRICH UND KRIEG lassen sich drei Funktionsbereiche unterscheiden:

- der Führungsbereich,

- der Versorgungsbereich und

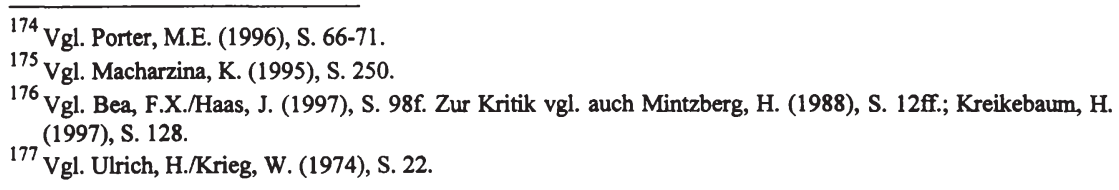


- der Vollzugsbereich. ${ }^{178}$

Der Führungsbereich (unternehmensbezogener Funktionsbereich) stellt das Bindeglied zwischen dem Unternehmensumfeld und dem Unternehmen selbst dar. Indem hier die Gestaltung, Steuerung und Kontrolle des Unternehmens als Ganzheit stattfindet, überlagert und durchdringt dieser Funktionsbereich die beiden operationalen Bereiche Versorgung und Vollzug. Der Versorgungsbereich stellt durch die Beschaffung und Verwaltung der Betriebsmittel die Verbindung zu den Beschaffungsmärkten des Unternehmens her. In diesen Funktionsbereich fallen das Personal-, Anlagen-, Material-, Finanz- und Informationswesen. Die Verbindung zu den Absatzmärkten bildet der Vollzugsbereich. Die mit der Marktleistung des Unternehmens in Zusammenhang stehenden Funktionsbereiche umfassen die Forschung und Entwicklung, die Produktion sowie den Absatz. ${ }^{179}$

\section{Abb. 3-4: Die Funktionsbereiche des Unternehmens}

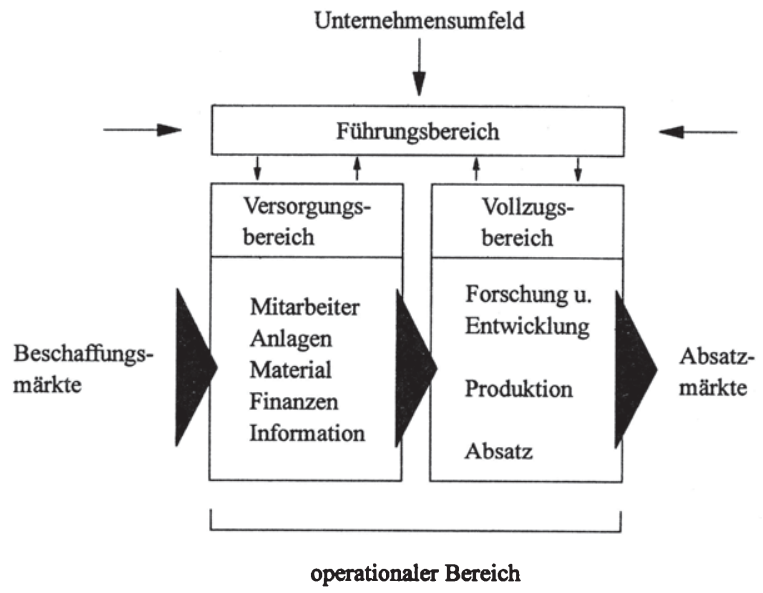

Quelle: in Anlehnung an Ulrich, H./Krieg, W. (1974), S. 23.

Diese sehr grobe Einteilung muß für die Analyse des Unternehmensgeschehens in Subsysteme oder -bereiche bzw. in Merkmale untergliedert werden, die durch den unternehmensinternen und den Vergleich mit den relevanten Wettbewerbern die Stärken und Schwächen ${ }^{180}$ des Un-

${ }^{178}$ Vgl. Ulrich, H./Krieg, W. (1974), S. $22 \mathrm{f}$.

${ }^{179}$ Vgl. Ulrich, H. (1970), S. 47ff.; Ulrich, H./Krieg, W. (1974), S. $22 f$.

${ }^{180}$ Die Stärken (Schwächen) eines Unternehmens sind Charakteristika in Form von Outputs, strukturellen Merkmalen bzw. Leistungspotentialen, die eine Aufgabenerfullung (nicht) gewăhrleisten bzw. die über (unter) den vergleichbaren Ergebnissen der Wettbewerber liegen. Vgl. z.B. Brauchlin, E./Wehrli, H.-P. (1994), S. 62; Hinterhuber, H.H. (1992), S. 83. Zum Begriff des Leistungspotentials vgl. Gälweiler, A. (1979a), S. 20. 
ternehmens offenbaren. Zur Verdeutlichung sollen die Bereiche Unternehmensführung, Forschung und Entwicklung sowie Personalwesen herausgegriffen und Möglichkeiten der Feingliederung aufgezeigt werden ${ }^{181}$ :

\section{Abb. 3-5: Exemplarisches Gliederungsschema der Funktionsbereiche Unternehmens-} führung, Forschung und Entwicklung sowie Personalwesen

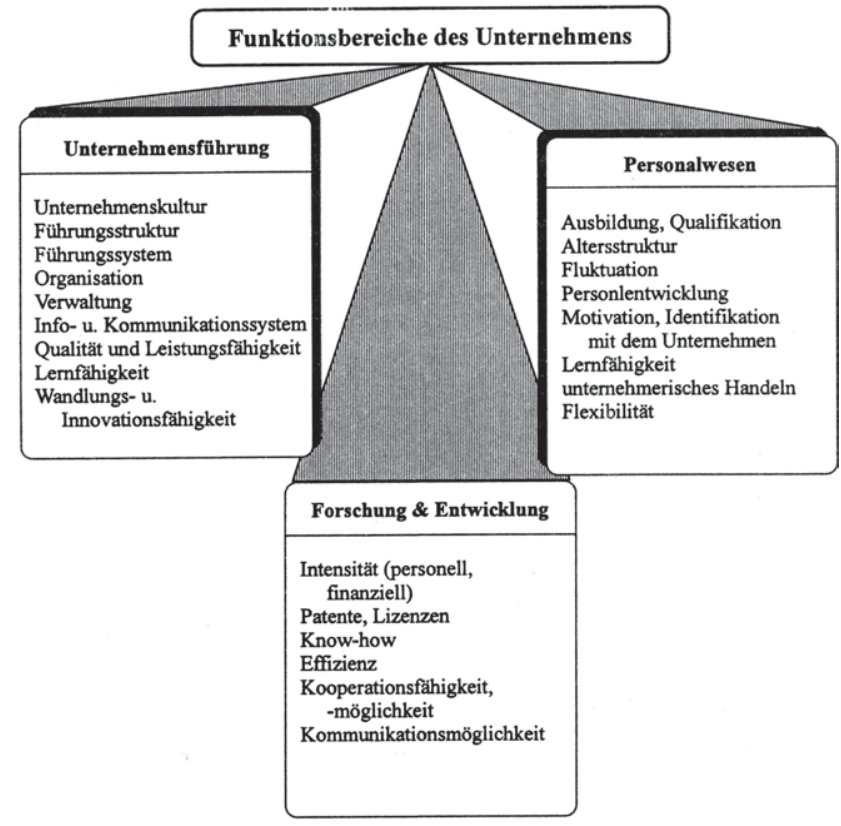

Der sich an die Feingliederung der einzelnen Bereiche anschließende Schritt besteht in deren Bewertung. Die sich daraus ergebenden Potentiale und Defizite können dann den Ergebnissen aus der Wettbewerbsanalyse (vgl. Abschnitt 3.3.2.2) gegenübergestellt und in Form eines Profils der internen Stärken und Schwächen anhand einer kardinalen Punkteskala visualisiert werden.

${ }^{181}$ Ausführliche Gliederungsvorschläge finden sich in Hinterhuber, H.H. (1992), S. $85-93$ und Pümpin, C. (1980), S. 22f. Vgl. ferner Bircher, B. (1976), S. 320; Brauchlin, E./Wehrli, H.-P. (1994), S. 62f.; Bea, F.X./Haas, J. (1997), S. 100ff.; Thompson, J.L. (1993), S. $287 \mathrm{ff}$. 
Abb. 3-6: Profil der internen Stärken und Schwächen

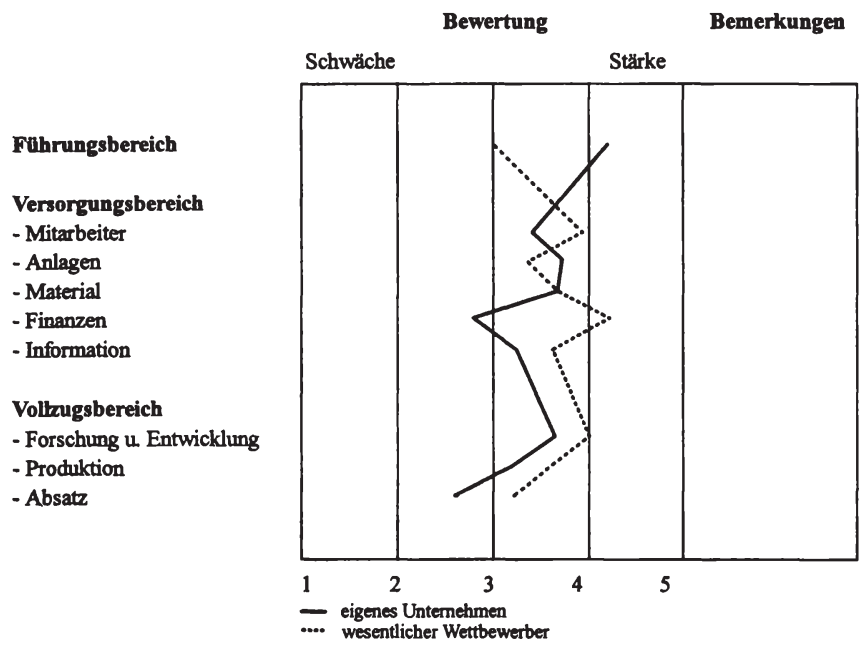

Untersuchungen in kleinen und mittleren Unternehmen zeigen, daß die Stärken-/Schwächenanalyse nur selten institutionalisiert verfolgt wird. ${ }^{182}$ Allerdings "spricht vieles dafür, daß die strategische Denkweise des mittelständischen Unternehmers gerade in diese Richtung gehen sollte" ${ }^{183}$.

Möglicherweise kann dies mit Hilfe des Benchmarking-Konzepts gelingen, das derzeit breit diskutiert wird. ${ }^{184}$ Das Konzept beruht auf dem Verständnis, daß Spitzenleistungen nur dann erbracht werden können, wenn das Unternehmen auf der Basis der "industry best practices" handelt. ${ }^{185}$ Benchmarking kann als ein kontinuierlicher und systematischer Vorgang verstanden werden, bei dem die eigenen Produkte, Prozesse und Leistungen gemessen und die daraus resultierenden Ergebnisse mit dem besten Unternehmensbereich (internal Benchmarking), dem besten Wettbewerber (competitive Benchmarking) oder einem anerkannten Marktfuihrer (functional Benchmarking), unabhängig von dessen Branche, verglichen werden. ${ }^{186}$ Entsprechend liegt das Ziel des Konzepts darin, "aus dem Vergleich mit den Besten zu lernen, die

${ }_{182}$ Vgl. Pohl, H.-J./Rehkugler, H. (1986), S. 92; Fröhlich, E./Pichler, J.H. (1988), S. 116.

${ }^{183}$ Fröhlich, E./Pichler, J.H. (1988), S. 116.

${ }^{184}$ Für eine Darstellung des Konzepts vgl. Camp, R.C. (1994); Karlöf, B./Östblom, S. (1994); Horváth, P./Herter, R.N. (1992) sowie ferner Kreitmeier, R. (1996), S. 70f.; Zink, K.J. (1995), S. 259-277. Zu Ansatzpunkten, Arten und Phasen vgl. insbesondere Töpfer, A. (Hrsg.) (1997).

185 Vgl. Camp, R.C. (1994), S. 3.

${ }^{186}$ Vgl. Camp, R.C. (1994), S. 13-16; Karlöf, B./Őstblom, S. (1994), S. V; Kamiske, G.F./Brauer, J.-P. (1995), S. 10 . 
wirkungsvollsten Methoden (Best Practice) herauszufinden, zu adaptieren und die Leistungsfähigkeit des eigenen Unternehmens zu steigern, um selbst die Spitzenposition als Bester unter den Besten (Best of the Best) zu erreichen" ${ }^{187}$.

Die wesentlichen Schritte sind damit vorgezeichnet. Erforderlich ist eine Bewertung der eigenen Stärken und Schwächen, eine Bewertung der Stärken und Schwächen der herangezogenen Referenzunternehmen, das Lernen von ihnen sowie die Beseitigung der eigenen Schwächen bzw. der Ausbau der eigenen Stärken. ${ }^{188}$ Dazu wird der Benchmarking-Prozeß in mehrere Prozeßschritte gegliedert. ${ }^{189}$ CAMP unterscheidet dabei die Prozeßschritte der Planung, Analyse, Integration und Aktion. Ein weiterer Schritt, die Reife, ist dann erreicht, wenn dem Unternehmen die Implementation der neuen Praktiken gelungen ist und eine Führungsposition eingenommen wird. In der Planungsphase werden die Untersuchungsinhalte ("Was"), die Vergleichspartner und -inhalte ("Wer"/"Woran") und die Art der Datenerhebung ("Wie") festgelegt. Anschließend müssen die notwendigen Daten beschafft und analysiert werden, damit die Leistungslücken aufgezeigt und die zukünftige Leistungsfähigkeit abgeschätzt werden kann. Für die Integration der Resultate aus der Benchmarking-Studie müssen die Ergebnisse kommuniziert und bei den Mitarbeitern Akzeptanz für die daraus abgeleiteten Ziele erreicht werden. Die Aktionsphase beinhaltet die Entwicklung von Aktionsplänen zur Umsetzung, Durchführung und Beobachtung sowie die fortlaufende Anpassung. ${ }^{190}$

Die erfolgreiche Durchführung des Benchmarkings bedingt die Festlegung geeigneter Beurteilungskriterien sowie die Auswahl vorbildlicher Referenzunternehmen und selbstverständlich die Bereitschaft der teilnehmenden Unternehmen, die entsprechenden Prozesse etc. lückenlos offenzulegen. ${ }^{191}$ Bereits bei der Wettbewerbsanalyse wurde die Identifikation geeigneter Referenzunternehmen problematisiert. Sollen, wie es das Konzept vorschlägt, die Produkte, Prozesse und Leistungen nicht ausschließlich mit den besten Unternehmen der eigenen Branche verglichen werden, sondern generell mit Unternehmen, die eine Spitzenposition einnehmen,

${ }^{187}$ Kamiske, G.F./Brauer, J.-P. (1995), S. 11. Kamiske und Brauer zeigen auch die unterschiedlichen Arten des Benchmarking auf. Sie unterscheiden internes, wettbewerbsorientiertes, funktionales und allgemeines/generisches Benchmarking. Vgl. Kamiske, G.F./Brauer, J.-P. (1995), S. $12 \mathrm{ff}$.

Als Beispiel für ein funktionales Benchmarking kann die Zusammenarbeit zwischen der Mettler Toledo (Albstadt) GmbH und Asean Brown Boveri (ABB) herangezogen werden. Mettler Toledo versuchte mit diesem Benchmarkingprozeß, dessen Schwerpunkt auf den Bereichen Produktionstechnik und Logistik lag, die eigene Position als Marktfuhrer durch Verbesserungen in den genannten Bereichen zu sichern bzw. weiter auszubauen.

${ }^{188}$ Vgl. Camp, R.C. (1994), S. 4 f.

${ }^{189}$ In der Literatur lassen sich drei-, vier-, funf-, sechs- bzw. achtphasige Benchmarking-Prozesse finden. Vgl. Camp, R.C. (1994); Horváth, P./Herter, R.N. (1992), S. 8; Karlöf, B./Östblom, S. (1994), S. 86ff.; Langner, H. (1994), S. 38ff.; Pieske, R. (1992), S. 150; Töpfer, A. (1997), S. $202 \mathrm{f}$.

190 Vgl. Camp, R.C. (1994), S. 20-25.

${ }^{191}$ Rau zeigt in diesem Zusammenhang vier hauptsächliche Fehlerquellen auf, die eine erfolgreiche Durchfuhrung des Benchmarking gefahrden: Erhebung unubersichtlicher Datenmengen, Wahl der falschen Benchmarks, keine Berilcksichtigung des Zeitfaktors sowie Fehlbesetzung des Benchmarkingteams. Vgl. Rau, H. (1996). 
könnte eine Verschärfung des Problems eintreten, da der Zugang zu Informationen erschwert wird. Gleichzeitig liegt möglicherweise gerade im Vergleich mit einem branchenfremden Unternehmen, das in keinem direkten Wettbewerbsverhältnis mit dem eigenen Unternehmen steht, ein Vorteil, da vor allem kleine und mittlere Unternehmen den Informationsaustausch scheuen. Der Informationsaustausch auf einer partnerschaftlichen Basis stellt aber lediglich eine grundsätzliche Bedingung dar. Zwingend notwendig ist, daß beide Parteien einen Vorteil aus dem Vergleich ziehen können. Ein anderes Unternehmen kann somit nur dann für einen direkten Vergleich gewonnen werden, wenn das eigene Unternehmen selbst über Spitzenleistungen verfügt.

Es versteht sich von selbst, daß mit einer zunehmenden Zahl von Unternehmen, die Benchmarking betreiben, die Ähnlichkeiten der verfolgten Konzepte immer größer werden. "Der Wettbewerb gerät zu Serien von Wettläufen auf identischen Pfaden, die keiner gewinnen kann." ${ }^{192}$ Folglich müssen die Erkenntnisse aus dem Benchmarking in eine eindeutige Strategie münden, die eine klare Positionierung ermöglicht.

Die Stärken-/Schwächeanalyse bzw. das Benchmarking stellen vergangenheitsbezogene Konzeptionen dar. Zur Abrundung muß unter strategischen Gesichtspunkten ein Bezug zur Zukunft hergestellt werden, indem die Wechselwirkungen der Umfeldveränderungen mit den Stärken und Schwächen des Unternehmens antizipiert werden. Treffen negative Entwicklungen im Umfeld des Unternehmens auf Schwächen, entstehen Risiken für das Unternehmen. Analog ergeben sich aus dem Zusammenspiel von Stärken des Unternehmens und positiven Entwicklungen im Umfeld tatsächliche oder potentielle Chancen. ${ }^{193}$

\subsubsection{Die Produktlebenszyklusanalyse}

Annahmen über Gesetzmäßigkeiten bei der Umsatz- bzw. Absatzentwicklung von Gütern haben in der ökonomischen Diskussion eine lange Tradition. Erste Überlegungen finden sich bei MARSHALl bzw. bei KuZNETS, BURNS, FABRICANT und HofFManN, die empirische Verläufe der Entwicklungslinien der Produktion von Gütern aufzeigen. ${ }^{194}$ Die Umsatz- bzw. Absatzentwicklung läßt sich in verschiedene Phasen einteilen, die Marktentwicklungsphasen. ${ }^{195}$

192 Porter, M.E. (1997), S. 45. Vgl. dazu auch Bea, F.X./Haas, J. (1997), S. 314.

${ }^{193}$ Zur Analyse der Stärken und Schwächen, Chancen und Risiken (SWOT- bzw. TOWS-Analyse, von: Strengths, Weaknesses, Opportunities, Threats) vgl. Hunger, J.D./Wheelen, T.L. (1996), S. 142-148; Macharzina, K. (1995), S. 276f. Vgl. ferner Anlage 10 als Beispiel für die Zusammenfuhrung der Umfeldanalyse und der Stärken-/Schwächenanalyse zur Chancen-/Risikenanalyse.

${ }^{194}$ Vgl. Marshall, A. (1890) bzw. Kuznets, S. (1930); Burns, A.F. (1934); Fabricant, S. (1940); Hoffmann, W. (1940).

${ }^{195}$ Für einen Überblick über die Theorie der Marktentwicklungsphasen vgl. Herdzina, K. (1981), S. 154-157. Eine theoretische Fundierung des Marktphasenkonzepts findet sich bei Heuss, E. (1965), S. 25-104. Das Marktphasenkonzept findet in unterschiedlichen Bereichen Anwendung. So hat Vernon z.B. das Produktzyklusmodell auf den internationalen Handel übertragen. Vgl. Vernon, R. (1966). Femer kann das Phasenkon- 
Auf der Grundlage des Marktphasenkonzepts wurde in den fünfziger und sechziger Jahren das klassische Modell des Produktlebenszyklus entwickelt und als Führungs- und Planungsinstrument eingesetzt. ${ }^{196}$

Das Konzept des Produktlebenszyklus ${ }^{197}$ geht davon aus, daß Produkte einem Lebenszyklus (Alterungsprozeß) unterliegen, der sich ähnlich dem biologischen Zyklus in verschiedene Entwicklungs- bzw. Marktphasen einteilen läßt.

In einer weiten Begriffsverwendung umspannt der Produktlebenszyklus den Zeitraum von der Entstehung der Produktidee über die Einfuhrung und Verbreitung des Produktes bis zu dessen Ausscheiden bzw. einer denkbaren Neu-, Wieder- oder Andersverwendung (Verwertung). Damit lassen sich drei Teilzyklen unterscheiden, der Entstehungs-, der Markt- und der Recyclingzyklus. Wird eine enge Betrachtungsweise gewählt, umfaßt diese ausschließlich den Marktzyklus (vgl. Abb. 3-7).

Der Entstehungszyklus umfaßt die Teilschritte Ideenfindung, Konkretisierung, Forschung und Entwicklung sowie Produktions- und Absatzvorbereitung bzw. Erprobung. Im Entstehungszyklus werden die Entscheidungen über konkrete strategische Zukunftsgeschäftsfelder getroffen. ${ }^{198}$ In dieser Phase fallen ausschließlich Kosten und keine Erlöse an. Besonders kleine und mittlere Unternehmen sind in dieser Phase vor allem dann im Nachteil, wenn fixkostenintensive Forschung und Entwicklung betrieben werden muß. Für sie lassen sich Wettbewerbsvorteile durch Innovationen somit eher durch Anpassungs- bzw. inkrementale Innovationen als durch Basisinnovationen realisieren.

Der Marktzyklus kann in mehrere Phasen eingeteilt werden, und zwar in die Einführungs-, die Wachstums-, die Reife-, die Sättigungs- bzw. die Degenerationsphase. Die Markteinführungsphase beginnt mit dem Eintreten des Produktes in den Markt. Sie ist durch niedrige Wachstumsraten der Umsätze bzw. einen negativen Deckungsbeitrag gekennzeichnet. Ferner müssen

zept auch auf die Unternehmensentwicklung, auf Produkt- und Prozeßtechnologien, auf Nutzenpotentiale an196 gewandt oder als Analyseinstrument der Innovativität eingesetzt werden.

${ }^{96} \mathrm{Zu}$ den ersten Vertretern des klassischen Modells des Produktlebenszyklus zählen Dean, J. (1950); Tinbergen, J. (1952); Schaffer, E. (1953); Forrester, J.W. (1959); Patton, A. (1959); Booz, Allen \& Hamilton (1968), S. 4f. Für eine zusammenfassende Beschreibung des klassischen Modells vgl. Siegwart, H./Senti, R. (1995), S. 4-12.

${ }^{197}$ Zum Konzept des Produktlebenszyklus vgl. Levitt, T. (1965), S. 81-94; Cox, W.E. jr. (1967), S. 375-384; Williamson, O.E. (1975), S. 200f.; Abell, D.F. (1980), S. 16f.; Day, G.S. (1981), S. 60-67; Brockhoff, K. (1974), Sp. 1763-1770; Pfeiffer, W. u.a. (1982), S. 22-34; Kotler, P./Bliemel, F. (1992), S. 539-566; Kreikebaum, H. (1997), S. 109-112.

Utterback und Abernathy entwickelten aus der Synthese von Produkt- und Prozeßlebenszyklusmodellen ein dynamisches Technologielebenszyklusmodell, das die Innovativität des Unternehmens auf dessen Entwicklungsstand zurückführt. Vgl. Utterback, J.M./Abernathy, W.J. (1975) sowie die Erweiterung dieses Modells durch Hayes, R.H./Wheelwright, S.C. (1979a) und (1979b).

${ }^{198}$ Bereits in dieser Phase kommen auch Aspekte des Innovations- und Umweltmanagements zum Tragen, da hier die Grundlagen fulr Produkt- und Prozeßinnovationen gelegt sowie die Umweltwirkungen von Produkten und Prozessen maßgeblich beeinflußt werden können. 
in ihr noch beträchtliche Investitionen in den Auf- und Ausbau der Produktions- und Vertriebsorganisation sowie zur Überwindung von Marktwiderständen bzw. zur Erhöhung der Kaufbereitschaft getätigt werden. Hier, wie auch in der sich anschließenden Wachstumsphase, besteht ein großer Spielraum für Produkt- und Verfahrensverbesserungen zur Anpassung an die Kundenwünsche. In der Wachstumsphase steigt das Marktvolumen durch zunehmende Diffusion, wodurch die Zone positiver und stark steigender Deckungsbeiträge erreicht wird. Das Absatzvolumen und die Deckungsbeiträge erreichen in der Reifephase ihren Höchststand, die Zuwachsraten verringern sich jedoch bereits. Produkt- oder Verfahrensverbesserungen werden hier ausschließlich unter Kostengesichtspunkten vorgenommen. Soll ein Übergang in die Sättigungs- oder sogar die Degenerationsphase verhindert werden, muß durch Innovation oder Variation einer Präferenzverschiebung seitens der Kunden entgegengewirkt werden. Mittels eines "relaunch"199, d.h. einer Neueinführung bzw. einer Neuplazierung im Anschluß an eine Produktvariation soll das hohe Umsatzniveau gehalten werden. In der Săttigungsphase hat die Produktlebenszykluskurve u.U. schon ihr Maximum überschritten. Der Absatz beginnt in dieser Phase zu stagnieren, die Deckungsbeiträge gehen zurück. Da die Marktkapazitäten ausgeschöpft sind, müssen verstärkt präferenzerhaltende bzw. -schaffende Maßnahmen ergriffen werden oder bereits gezielte Desinvestitionen vorgenommen werden. Möglicherweise ist ein Eintritt in eine letzte Phase, die durch starke Absatz- und Deckungsbeitragsrilckgänge gekennzeichnet ist, nicht zu vermeiden. Dann sind Rückgänge in der Schrumpfungs- oder Degenerationsphase auch mit konzentriertem Einsatz des Marketing kaum aufzuhalten. Der Kampf um Marktanteile bzw. der starke Substitutionswettbewerb zwingt zu schwache Anbieter aus dem Markt. ${ }^{200}$

In einem sich an den Marktzyklus anschließenden Abschnitt, dem Recyclingzyklus, werden gebrauchte und ausgediente Produkte gesammelt (Redistribution) und je nach Zustand einer Neu-, Wieder- oder Andersverwendung (Verwertung) zugeführt. Diese Phase muß bereits bei der Entstehung des Produktes eingeplant werden, da die Hersteller im Rahmen einer ökonomisch-ökologischen Optimierung des Gesamtprozesses zunehmend über den Vorgang des Geund Verbrauchs ihrer Produkte hinaus Fragen der Redistribution bzw. der Verwertung oder Beseitigung antizipieren müssen. Da die umweltgerechte Produktgestaltung sowie die Rückfuihrung ${ }^{201}$ und Verwertung in ihrer Gesamtheit zu einem zunehmend wichtigen Erfolgsfaktor werden, erfordern umweltorientierte Produkte ein ganzheitliches Konzept nach dem Grundsatz "from cradle to grave". Die aus diesem Grundsatz ableitbaren Kriterien müssen bereits im

${ }^{199}$ Hierfur finden sich auch andere Bezeichungen wie beispielsweise "life extension" oder "market stretching". Vgl. Levitt, T. (1965), S. 87.

${ }^{200}$ För eine erweiterte Betrachtung vgl. Bea, F.X./Haas, J. (1997), S. 111 sowie bez. einer ganzheitlichen Betrachtung des Produktlebenszyklus z.B. Pfeiffer, W. u.a. (1982), S. 26-33; Dyllick, T. (1989), S. 16f.; Hübner, H./Jahnes, S. (1992), S. 1635; Herdzina, K./Blessin, B. (1996), S. 29 .

${ }^{201} \mathrm{Zu}$ den Entscheidungskriterien für die Auswahl eines geeigneten Rückführungskanals vgl. Meffert, H./Kirchgeorg, M. (1994), S. 52. 
Lastenheft im Rahmen des Forschungs- und Entwicklungsprozesses als Nebenbedingungen Eingang finden, damit in dieser letzten Phase keine zusätzliche bzw. eine möglichst geringe finanzielle Belastung auf das Unternehmen zukommt.

\section{Abb. 3-7: Idealtypische Darstellung der Phasen des Produktlebenszyklus}

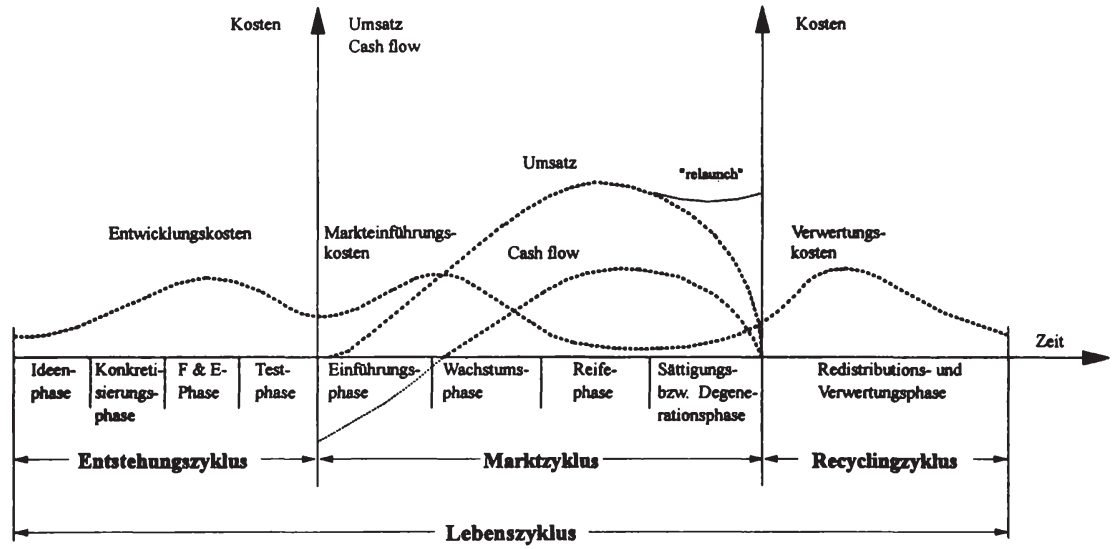

Quelle: erweiterte Abbildung nach Herdzina, K./Blessin, B. (1996), S. 30.

Die Anwendungsmöglichkeiten des Lebenszykluskonzepts sind breit gestreut. In den einzelnen Phasen lassen sich absatzpolitische und marktspezifische Charakteristika erkennen, die die Ableitung von Forschungs- und Entwicklungsaktivitäten, die Prognose zukünttiger Absatzentwicklungen, die Beurteilung der Erfolgsträchtigkeit eines Produkts sowie die langfristige Produkt- oder Produktionsprogrammplanung ermöglichen und somit als Grundlage zur Entscheidungsfindung, zur Formulierung von Strategien bzw. zur strategischen Erfolgskontrolle herangezogen werden können. ${ }^{202}$ Das Konzept bietet somit ein deskriptives und explikatives Planungs- und Kontrollinstrument. Entsprechend formuliert DAY: "The product life cycle is a versatile framework for organizing contingent hypotheses about appropriate strategy alternatives and directing management attention toward anticipation of the consequences of the underlying dynamics of the served market." ${ }^{203}$ Der Ansatz sowie die fur die einzelnen Phasen formulierten Strategien sind dabei jedoch nicht als vorgegebene Muster zu betrachten,

${ }^{202}$ Vgl. Levitt, T. (1965), S. 91 ff.; Moore, W.L./Tushman, M.L. (1982), S. 131-150; Engelhardt, W.H. (1989), Sp. 1595 ff.; Kotler, P./Bliemel, F. (1992), S. 564f.; Arthur D. Little (Hrsg.) (1994), S. 80. Brockhoff betont vor allem die Notwendigkeit, durch geplante Forschung und Entwicklung zur Erhaltung des Unternehmens beizutragen, indem ein kontinuierlicher Ersatz ausscheidender Produkte durch neue erfolgt, vgl. Brockhoff, K. (1993), S. 179-182.

${ }^{203}$ Day, G.S. (1981), S. 65 
an denen sich die Entscheidungen der Unternehmensfuhrung normativ auszurichten haben. ${ }^{204}$ Sie sollen vielmehr als Anhaltspunkte für einen aktiv und unternehmensspezifisch zu gestaltenden Prozeß betrachtet werden.

Das Konzept wurde vielfach kritisiert. ${ }^{205}$ Die grundsätzliche Kritik an Phasenmodellen bezieht sich auf die ihnen zugrundeliegende Vorstellung, daß sich die einzelnen Abschnitte aus einer Reihe zeitlich aufeinanderfolgender Ereignisse zusammensetzen. Mit einer abgeschlossenen Einführungsphase beginnt die Wachstumsphase, danach die Reifephase usw. Da die Übergänge zwischen den Phasen nicht trennscharf bestimmt werden können, besteht die Schwierigkeit nun darin, die einzelnen Phasen gegeneinander abzugrenzen. Die Phasenlänge schwankt in Abhängigkeit vom Produkt bzw. von der Branche und läßt sich ebenfalls nicht eindeutig bestimmen. ${ }^{206}$ Zugleich sind die deterministischen Vorstellungen über das Verlaufsmuster, die aus den im Konzept enthaltenen Ablauf- und Verhaltensannahmen resultieren, fragwürdig. Der Kurvenverlauf kann durch verschiedene Einflüsse verändert werden. Neben der Möglichkeit des Unternehmens, durch Produktinnovation und -repositionierung die Gestalt der Kurve zu beeinflussen, wirken beispielsweise auch konjunkturelle Einflüsse auf den Kurvenverlauf, was den Einsatz als strategisches Planungsinstrument erschwert. Ein weiteres Problem der Produktlebenszyklusanalyse liegt in "der Schwierigkeit einer genauen Bezugsgrößendefinition, d.h. der eindeutigen Abgrenzung des relevanten Marktobjektes, auf das sich die Aussagen des Modellkonzeptes beziehen"207.

Das Modell kann daher keine Allgemeingültigkeit aufweisen, wie verschiedene empirische Untersuchungen auch gezeigt haben. ${ }^{208}$ Wird aber von generalisierenden oder normativen Aussagen abgesehen und vielmehr auf die deskriptiven und explikativen Eigenschaften abgestellt, so veranschaulicht das Lebenszykluskonzept dem Entscheidungsträger dennoch die Altersstruktur seiner Produkte sowie die sich im Zeitablauf ändernden Absatzbedingungen. ${ }^{209}$

${ }^{204}$ Vgl. Siegwart, H./Senti, R. (1995), S. 11.

${ }^{205}$ Vgl. Engelhardt, W.H. (1989), Sp. 1598f.; Hax, A.C./Majluf, N.S. (1991), S. 224f.; Kotler, P./Bliemel, F. (1992), S. 564ff.; Day, G.S. (1981), S. 60 und S. 65.

${ }^{206}$ Dieses Problem wurde auch in der zugrundeliegenden Untersuchung offenbar. Insbesondere die Unternehmen aus dem Textil- und Bekleidungsgewerbe hatten mit der Einordnung ihrer Produkte in den Produktlebenszyklus erhebliche Probleme. Der sehr kurze Lebenszyklus der durch Modeeinflusse bestimmten Produkte (zwei bis vier Kollektionen pro Jahr) erfordert einen kontinuierlichen Entwurf neuer Modelle. In solchen Fällen muß das Produktlebenszyklus-Konzept durch andere Instrumente ergänzt werden (z.B. die Portfolioanalyse).

${ }^{207}$ Engelhardt, W.H. (1989), Sp. 1598.

${ }^{208} \mathrm{Vgl}$. Siegwart, H./Senti, R. (1995), S. 7-12.

${ }^{209}$ Vgl. Milling, P./Maier, F. (1996), S. 34. Vgl. dazu auch die Erweiterung zu einer LebenszyklusPortfoliomatrix, bei der der Lebenszyklusphase die Wettbewerbsposition gegenübergestellt wird, in Roventa, P. (1981), S. 167-173 und in Hax, A.C./Majluf, N.S. (1991), S. 207-210. 


\subsubsection{Die Portfolioanalyse}

Das Portfolio-Management integriert neben dem vorstehenden Lebenszykluskonzept zwei weitere Planungskonzepte, und zwar das Erfahrungskurvenkonzept und das Konzept der Strategischen Geschäftsfelder bzw. -einheiten. ${ }^{210}$ Die Erfahrungskurve ist als Weiterentwicklung der Lernkurve anzusehen. Die Erfahrungskurve basiert auf dem empirisch belegten Zusammenhang zwischen über die Zeit kumulierten Produktionsmengen, Absatzmengen oder Marktanteilen und zunehmenden Kostendegressionseffekten, d.h. sinkenden Stückkosten. Die Beziehung zwischen Stückkosten und kumulierter Produktionsmenge ergibt eine fallende Kurve bzw. bei logarithmischer Darstellung eine fallende Gerade. Sie stellt damit eine integrierte Kurve aller Kosten eines Unternehmens dar, an der sich nicht nur die eigenen Kosten abschätzen lassen, sondern auch die Kostenabstände zu den Wettbewerbern, sofern die entsprechenden Informationen vorliegen. Dem Konzept liegt die Beobachtung zugrunde, daß mit jeder Verdopplung der kumulierten Menge eines Produktes die inflationsbereinigten Wertschöpfungskosten eines Stückes tendenziell um ca. 20 bis $30 \%$ zurückgehen. ${ }^{211}$ "Aus dem Verlauf der Kostenkurve und der Preiskurve werden im Rahmen der Portfolio-Analyse Erkenntnisse für die Positionierung der strategischen Geschäftsfelder gewonnen." ${ }^{12}$ Strategische Geschäftsfelder (SGF, Strategic Business Area) stellen die gedankliche Segmentierung der gesamten unternehmerischen Tätigkeitsfelder in einzelne Tätigkeitsbereiche dar (Außensegmentierung). Sie dienen im Rahmen einer strategischen Unternehmensführung der Komplexitätsreduktion des Unternehmensumfeldes bzw. ermöglichen gezielte Marktbearbeitungsstrategien. Strategische Geschäftseinheiten (SGE, Strategic Business Unit) stellen organisatorische Einheiten im Unternehmen dar (Innensegmentierung). Sie grenzen Produktoder Leistungsgruppen voneinander $a b$ und ermöglichen so die Formulierung und Umsetzung spezifischer Strategien. ${ }^{213}$

${ }^{210}$ Vgl. Brauchlin, E./Wehrli, H.-P. (1994), S. 64; Pfeiffer, W. u.a. (1982), S. 35-43; Kreikebaum, H. (1997), S. 98-109.

${ }^{211}$ Vgl. Henderson, B.D. (1974), S. 19-27; Hax, A.C./Majluf, N.S. (1991), S. 133-151; Karlöf, B./Östblom, S. (1994), S. 9f. Für eine kritische Betrachtung des Konzepts vgl. Timmermann, A. (1985), S. 200f.; Bea, F.X./Haas, J. (1997), S. 120f. Als Kritik kann ferner Porters Konzept der Wettbewerbsstrategien aufgefaßt werden (vgl. Abschnitt 3.6.3.2), da er die Sichtweise, daß der Unternehmenserfolg ausschließlich von Erfahrungseffekten und den daraus resultierenden Kostendegressionseffekten abhängt relativiert, indem er darauf hinweist, daß Unternehmenserfolg auch aus einer Differenzierungstrategie resultieren kann.

212 Bea, F.X./Haas, J. (1997), S. 121.

${ }^{213}$ Zur Differenzierung zwischen SGF und SGE vgl. Bea, F.X./Haas, J. (1997), S. 126-134. Diese ist jedoch für das weitere Vorgehen nicht relevant, weshalb vereinfachend der Begriff "Strategische Geschäftseinheiten" (SGE, Strategic Business Unit) verwendet wird. Im Falle von KMU lassen sich in der Regel die wichtigsten Mărkte (Produkt-Markt-Kombinationen) als Strategische Geschăftseinheiten verstehen, auf denen die Unternehmen operieren. Für eine Abgrenzung von SGE vgl. Abell, D.F. (1980), S. 17f. und S. 169-173. Vgl. ferner Brenken, D. (1988), S. 117. Zur Kritik vgl. Timmermann, A. (1985), S. $201 \mathrm{f}$. 
Die Grundidee der Portfolioanalyse stammt aus dem finanzwirtschaftlichen Bereich. Dort bezeichnet ein Portfolio die optimale Mischung aus mehreren Investitionsmöglichkeiten. ${ }^{214}$ In Analogie dazu stellt das Portfolio eines Unternehmens die (optimale) "Gesamtheit der Produkte und/oder Dienstleistungen, mit denen sich die Unternehmung zu einem gegebenen Zeitpunkt auf dem Markt präsentiert" ${ }^{\prime 215}$ dar. Als Instrument zur Unterstützung der Unternehmensund der Umfeldanalyse zielt die Portfolioanalyse auf eine aus der Sicht eines diversifizierten Unternehmens möglichst vorteilhafte Mischung verschiedener einzelner Investitionen ab, indem sie "eine konzeptionelle Gesamtsicht der strategischen Stoßrichtungen im Produkt/Marktbereich"216 erleichtert. Ihr Zweck ist es, die strategische Position der einzelnen Geschäfte zu bewerten und Erfolgsfaktoren sichtbar zu machen, um der Unternehmensleitung damit eine Basis für den Ressourceneinsatz zu geben. Hierzu werden in Form einer zweidimensionalen Matrix die jeweils zugrundeliegenden Bewertungsdimensionen abgebildet. Dabei reflektiert eine Dimension (Achse) Umfeldeinflüsse auf das Unternehmen, die tendenziell unkontrollierbare Einflußgrößen darstellen (z.B. Markt, Marktattraktivität), wohingegen die zweite Dimension (Achse) eine Unternehmensvariable repräsentiert, die beeinflußt werden kann (z.B. Wettbewerbsvorteile, Fähigkeiten). Die zugrundeliegenden Produkte oder SGE werden dann in die Felder eingezeichnet (Ist-Portfolio) und ihre fördernde oder gefährdende Wirkung auf den Unternehmenserfolg analysiert, um daraus Strategien abzuleiten. ${ }^{217}$ Die abgeleiteten Strategien "besitzen den Charakter heuristischer Prinzipien, die die Suche nach dem gewünschten Ziel-Portfolio und der strategischen Stoßrichtung leiten sollen"218. So können beispielsweise Investitionsentscheidungen unterstützt werden, um mittels "Investition", "selektiver Investition" oder "Desinvestition" eine Ausgewogenheit zwischen den SGE sowie zwischen alten und neuen Produkten zu schaffen. Zur besseren Visualisierung der Bedeutung der SGE können die Punkte ihrem Umsatz oder Deckungsbeitrag entsprechend verschieden groß gezeichnet werden.

Die kommunikationsfreundliche und leicht verständliche Darstellung der strategischen Situation eines diversifizierten Unternehmens begründet die weite Verbreitung dieses Instrumentes

${ }^{214}$ Die von Markowitz entwickelte Methode der Portfolioanalyse diente ursprünglich der Bestimmung der optimalen Zusammensetzung finanzieller Vermögensteile bei risikobehafteten Erwartungen. Vgl. Markowitz, H.M. (1959). Zu den Grundgedanken der Portfolio-Analyse und des darauf aufbauenden Strategischen Managements vgl. Roventa, P. (1981) und Kreilkamp, E. (1987) sowie ferner Kirsch, K./Trux, W. (1981), S. 296307; Kirsch, W. (1991), S. 280-285.

${ }^{215}$ Hinterhuber, H.H. (1996), S. 148.

${ }^{216}$ Kirsch, W. (1991), S. 280.

${ }^{217}$ Die theoretischen und teilweise empirisch validierten Grundlagen für die Formulierung von Strategien liefern das Erfahrungskurvenkonzept, die Ergebnisse der PIMS-Studie (vgl. Abschnitt 3.3.4.1) sowie die Beobachtung uber die sich im Lebenszyklus wandelnde Kapitalbindung und -freisetzung. Vgl. Brenken, D. (1988), S. 74; Neubauer, F.F. (1990), S. 283-310.

${ }^{218}$ Kirsch, K./Trux, W. (1981), S. 297. 
in der Praxis. Gleichzeitig liefert die Portfolio-Analyse einen Bezugsrahmen für eine intensive Auseinandersetzung der Unternehmensführung mit der Zukunft. ${ }^{219}$

Die gebräuchlichsten Portfolio-Konzepte sind das Marktwachstum-Marktanteil-Portfolio der Boston Consulting Group (BCG) und das Marktattraktivität-Wettbewerbsvorteil-Portfolio des Beratungsunternehmens McKinsey \& Company, Inc.

Beim Portfolio-Konzept der Boston Consulting Group ${ }^{220}$ wird das Umfeld durch das Marktwachstum und die interne Situation des Unternehmens durch den Marktanteil charakterisiert. Die Klassifizierung der beiden Dimensionen in "hoch" und "niedrig" läßt eine 4Felder-Matrix entstehen:

\section{Abb. 3-8: Das Marktwachstum-Marktanteil-Portfolio der Boston Consulting Group}

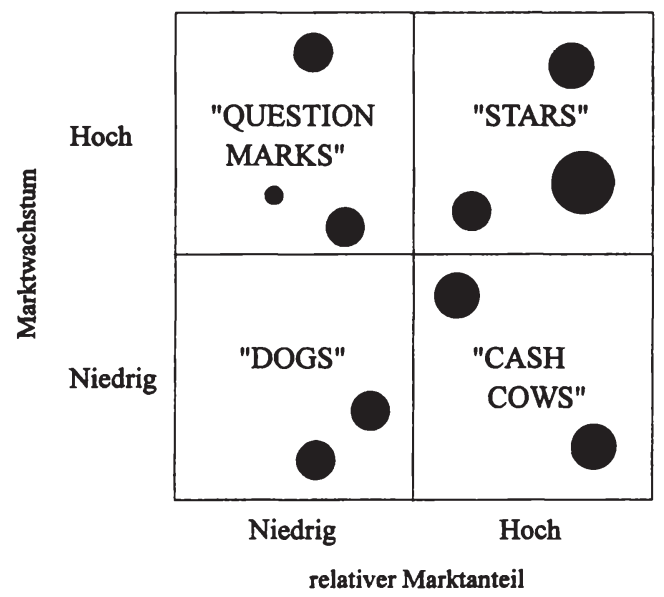

Entsprechend ihrem relativen Marktanteil und der Wachstumsrate auf dem jeweiligen Markt $^{221}$ werden die SGE in die jeweiligen Felder eingetragen. Anhand ihrer Position in der Matrix lassen sich vier Grundtypen von SGE unterscheiden, die einheitliche Charakteristika aufweisen und daher strategisch gleich (normiert) behandelt werden können. Die Normstra-

\footnotetext{
${ }^{219}$ Dabei ist jedoch darauf hinzuweisen, daß Portfoliokonzepte in der Regel retrospektiv angelegt sind. Daneben ist ihr Aussagegehalt stark von der Güte der herangezogenen Daten abhängig. Der Portfolioanalyse als Instrument im Prozeß der Strategieentwicklung kann damit lediglich eine unterstutzende Funktion zugewiesen werden.

${ }^{220}$ Vgl. Hedley, B. (1977). Vgl. ferner Roventa, P. (1981), S. 132-151; Hax, A.C./Majluf, N.S. (1991), S. 152179; Kotler, P./Bliemel, F. (1992), S. 57-60; Macharzina, K. (1995), S. 291-302.

${ }^{221}$ Zur Berechnung vgl. Hax, A.C./Majluf, N.S. (1991), S. 153ff.
} 
tegien geben dabei die Richtung an, in die die Geschäftseinheiten in den Quadranten entwikkelt werden sollen. ${ }^{222}$

Nachwuchsprodukte mit geringem Marktanteil auf stark wachsenden Märkten werden als "Question Marks" bezeichnet und erfordern die besondere Aufmerksamkeit der Unternehmensführung. Sie befinden sich in der Einfuihrungs- bzw. frühen Wachstumsphase des Lebenszyklus und stehen in einer relativ schlechten Wettbewerbsposition, erwirtschaften dadurch lediglich einen geringen oder sogar negativen Cash flow und benötigen zu ihrer $\mathrm{Zu}$ kunftssicherung Zuschüsse anderer SGE. Für die Geschäftseinheiten in diesem Quadranten kommen zwei gegensätzliche Normstrategien in Frage: eine Offensiv- bzw. Wachstumsstrategie, um weitere Marktanteile hinzuzugewinnen und dadurch die Wettbewerbsposition zu verbessern, oder eine Desinvestitionsstrategie, sofern die anvisierten Marktanteile bzw. ein Einholen der Wettbewerber nicht erreichbar sind.

Die als "Stars" gekennzeichneten strategischen Geschäftseinheiten weisen einen hohen Marktanteil in einem schnell wachsenden Markt auf und lassen sich daher in die Wachstumsphase des Lebenszyklusses einordnen. Die durch diese Produkte erwirtschafteten Gewinne sollten zur Sicherung der eigenen Marktposition verwendet sowie durch weitere Mittel möglichst ergänzt werden, um den Marktanteil weiter zu erhöhen. Als Normstrategien für den Ausbau bzw. die langfristige Sicherung der Wettbewerbsposition ergeben sich folglich Investitionsund Wachstumsstrategien.

Ebenfalls günstig positioniert sind die "Cash Cows". Sie bewegen sich zwar in einem stagnierenden oder nur geringfügig wachsenden Markt, weisen jedoch aufgrund ihres hohen Marktanteils Kostenvorteile auf. Das primäre Ziel ist, die Produkte durch geringfügige Investitionen in der Reifephase zu halten, da sie letztlich Mittel freisetzen, die zur Unterstützung anderer SGE herangezogen werden können. Zur Nutzung der vorhandenen Kostenvorteile ist als ein weiteres Ziel auch die Verlängerung dieser Phase (relaunch) vorstellbar. Insgesamt sollten aber keine weiteren Mittel in die Marktentwicklung investiert werden. Als Normstrategien kommen Abschöpfungs- bzw. Defensivstrategien in Frage, die jedoch kein verfrühtes Austreten aus dem Markt induzieren sollten.

Die als "Dogs" charakterisierten Geschäftseinheiten beinhalten Auslaufprodukte mit geringem Marktanteil auf wenig wachsenden Märkten. Die in der Sättigungs- bzw. Degenerationsphase befindlichen Produkte erwirtschaften oft einen negativen Deckungsbeitrag. Da sie Ressourcen binden und für eine bessere Positionierung unverhältnismäßig hohe Mittel aufgewendet werden müßten, sollten sie über Abschöpfungs- oder Desinvestitionsstrategien aus dem Portfolio eliminiert werden.

${ }^{222}$ Zur Beschreibung der Quadranten vgl. z.B. Hedley, B. (1977), S. 10f.; Roventa, P. (1981), S. 147-150; Hax, A.C./Majluf, N.S. (1991), S. 157-161. 
Ein Portfolio ist dann im Gleichgewicht, wenn Produkte, die am Cash flow zehren (Star- und Nachwuchsprodukte), in ausreichendem Maße von jenen Produkten alimentiert werden können, die den Cash flow erwirtschaften (Cash Cows).

Faßt man die Kritik an diesem Portfolio-Konzept zusammen, so fußt sie zunächst auf den zugrundeliegenden Konzepten, dem Erfahrungskurvenkonzept und dem Lebenszykluskonzept. ${ }^{223}$ Darüber hinaus wird vor allem die starke Vereinfachung auf die beiden Dimensionen "relativer Marktanteil" und "Marktwachstum" kritisiert. Ihre Einteilung in "hoch" und "niedrig" sowie die den beiden Dimensionen zugrundeliegenden Zusammenhänge bieten zwar eine klare Grundstruktur und eine hohe Plausibilität, stellen aber letztlich eine zu starke Simplifizierung dar. So ist der Zusammenhang zwischen Marktanteil und Rentabilität nicht unbedingt stark, da auch niedrige Marktanteile durchaus rentabel sein können. Ferner bilden Marktanteile nur einen Aspekt der Wettbewerbsposition. Daruber hinaus kann die zu starke Fokussierung auf den Marktfuhrer dazu verleiten, Wettbewerbern in schnell wachsenden Märkten zu wenig Beachtung zu schenken. Außerdem bilden Wachstumsraten nur einen Aspekt der Branchenattraktivität. ${ }^{224}$

Aufgrund der Kritik an der vereinfachenden und relativ groben Darstellung des BCGPortfolios entwickelte die General Electric Corporation in Zusammenarbeit mit McKinsey eine 9-Felder-Matrix, bestehend aus der Dimension Markt- oder Branchenattraktivität als Charakterisierung der externen Gegebenheiten und dem relativen Wettbewerbsvorteil zur Veranschaulichung der betrieblichen Dimension. ${ }^{225}$ Die Erweiterung der strategierelevanten Einflußfaktoren ist an den Ergebnissen der PIMS-Studie ${ }^{226}$ ausgerichtet.

Die Markt- oder Branchenattraktivität, die die Gewinn- und Wachstumsperspektiven der betrachteten Märkte bzw. Branchen zum Ausdruck bringt, fügt sich zusammen aus den Kriterien

- Marktwachstum und Marktgröße,

- Marktqualität,

- Energie- und Rohstoffversorgung sowie

- Umfeldsituation. ${ }^{227}$

${ }^{223}$ Vgl. Macharzina, K. (1995), S. 300ff.; Hax, A.C./Majluf, N.S. (1991), S. 171-179; Roventa, P. (1981), S. $150 \mathrm{ff}$.

${ }^{224}$ Vgl. Hunger, J.D./Wheelen, T.L. (1996), S. 170. Macharzina charakterisiert das BCG-Portfolio "als theoretisch brüchig, empirisch offen, konzeptionell reduktionistisch und die realen Einflußfaktoren unzulăssig vereinfachend", Macharzina, K. (1995), S. 302 (im Original kursiv).

${ }^{225}$ Vgl. Clifford, D.K. u.a. (1975), S. 11-17; Hax, A.C./Majluf, N.S. (1991), S. 180-204; Hinterhuber, H.H. (1996), S. 146-147; Roventa, P. (1981), S. 151-166.

${ }^{226} \mathrm{Vgl}$. Abschnitt 3.3.4.1.

${ }^{227}$ Für eine weitere Differenzierung der Kriterien vgl. Hinterhuber, H.H. (1996), S. 150f.; Macharzina, K. (1995), S. 305. 
Der relative Wettbewerbsvorteil setzt sich ebenfalls aus mehreren Haupt- und diese wiederum aus einer ganzen Reihe von Nebenkriterien zusammen. Die Hauptkriterien sind

- die relative Marktposition,

- das relative Produktionspotential,

- das relative Forschungs- und Entwicklungspotential sowie

- die relative Qualifikation der Führungskräfte und Mitarbeiter. ${ }^{228}$

Damit liegt den hier verwendeten Dimensionen ein wesentlich umfangreicherer Datenpool zugrunde als es bei der BCG-Matrix der Fall ist, wodurch die Erstellung des Portfolios allerdings aufgrund der höheren Komplexität aufwendiger wird. ${ }^{229}$

\section{Abb. 3-9: Das Marktattraktivität-Wettbewerbsvorteil-Portfolio von McKinsey}

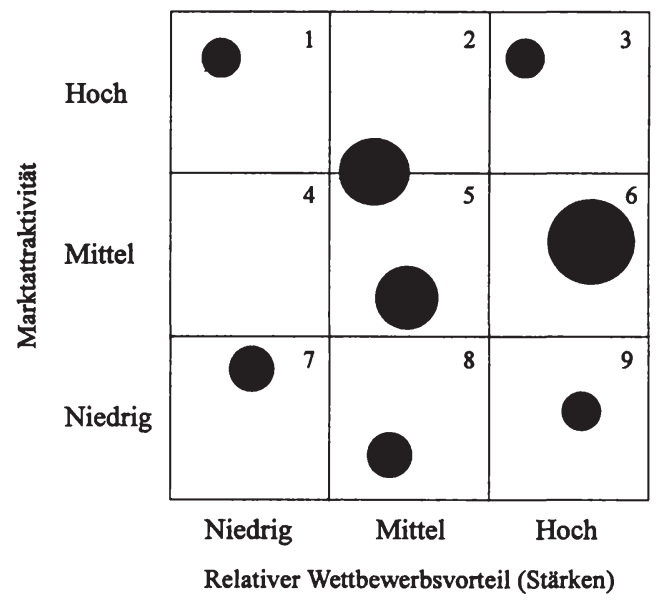

Nach der Positionierung der SGE in der Matrix können erneut Normstrategien für die einzelnen Quadranten abgeleitet werden:

- Investitions- und Wachstumsstrategie (Quadranten 2, 3, 6);

- selektive Strategie (Quadranten 1, 5, 9),

- Abschöpfungs- bzw. Desinvestitionsstrategie (Quadranten 4, 7, 8). ${ }^{230}$

\footnotetext{
${ }^{228}$ Für die diesen Hauptkriterien zugrundeliegenden Nebenkriterien vgl. Hinterhuber, H.H. (1996), S. 151ff.; Macharzina, K. (1995), S. 304. Hinterhuber erweitert die Hauptkriterien ferner um die Kernkompetenzen des Unternehmens (vgl. dazu auch Abschnitt 3.3.4).

${ }^{229}$ Zur Erstellung der Portfolio-Matrix vgl. Hinterhuber, H.H. (1996), S. 154-159.

${ }^{230} \mathrm{Vgl}$. auch im folgenden Hinterhuber, H.H. (1996), S. 163-169.
} 
Strategische Geschäftseinheiten, die in Quadranten liegen, deren Marktattraktivität bzw. deren relativer Wettbewerbsvorteil als mittel bis hoch einzuschätzen ist $(2,3,6)$, tragen langfristig zur Wertsteigerung des Unternehmens bei. Kurzfristig kann die Cash-flow-Bilanz aufgrund der Kapazitätserweiterungen negativ sein. Zum Ausbau bzw. zur Sicherung zukünftiger Erfolgsfaktoren benötigen sie daher, ähnlich den "Stars" in der BCG-Matrix, finanzielle Zuweisungen von anderen SGE. Die Normstrategien sind entsprechend als Investitions- und Wachstumsstrategien oder aber auch als Innovationsstrategien zu klassifizieren.

Sind die SGE in den diagonalen Quadranten plaziert, wird ein selektives Vorgehen notwendig. HINTERHUBER differenziert drei Arten selektiver Strategien. Für den Quadranten 1 schlägt er Offensivstrategien vor, die je nach Perspektive der SGE die Extreme Investition bzw. Aufgabe annehmen können. Der zentrale Quadrant (5) macht Übergangsstrategien notwendig. Hier sollte der Versuch unternommen werden, ohne großen Ressourceneinsatz eine Rechtsverschiebung der SGE zu erreichen bzw. abzuwarten, wie sich die Marktattraktivität verschiebt. Im neunten Quadranten sind Defensivstrategien zweckmäßig. Da sie der Finanzierung der Wachstumssektoren dienen (vgl. "Cash Cows"), sollte das Unternehmen bestrebt sein "(1) die relativen Wettbewerbsvorteile zu halten, (2) Konkurrenzunternehmungen abzuhalten, in dieses Marktsegment einzudringen, und (3) den Cash flow zu maximieren"231.

Abschöpfungs- und Desinvestitionsstrategien werden letztlich für die Quadranten 4, 7 und 8 empfohlen. Bei diesen SGE handelt es sich um obsolete Produkte und Leistungen (vgl. "Dogs"), bei denen keine hohen Gewinnchancen zu erwarten sind. Sie sollten daher durch attraktivere Produkte und Leistungen ersetzt werden, um die hier gebundenen Ressourcen gewinnbringender einzusetzen.

Die Kritik $^{232}$ an der Marktattraktivität-Wettbewerbsvorteil-Matrix bezieht sich paradoxerweise auf eine ihrer grundlegenden Leistungen. Entwickelt wurde die Matrix, um der zu starken Simplifizierung des BCG-Ansatzes entgegenzuwirken. Doch gerade darin liegt ein Kritikpunkt, da durch die mehrdimensionalen Indikatoren das Element der Komplexität eingefuihrt wird. Dieses Problem wird durch die Subjektivität der Einschätzung der Indikatoren noch verstärkt und setzt sich auch im zweiten Kritikpunkt, der Beurteilung der Branchenattraktivität, fort.

Zusammenfassend kann die Portfolioanalyse als Instrument betrachtet werden, das das Aufzeigen von Potentialen einzelner Geschäftseinheiten ermöglicht und mit Hilfe der Normstrategien auf grundsätzliche strategische Stoßrichtungen hinweist, die zur Schließung von Lük-

\footnotetext{
${ }^{231}$ Hinterhuber, H.H. (1996), S. 167f.

${ }^{232}$ Vgl. Hax, A.C./Majluf, N.S. (1991), S. 203f. Sie empfehlen die BCG-Matrix als nützlichen Mechanismus für die Wettbewerbsanalyse und die McKinsey-Matrix für die Diagnose und strategische Ausrichtung des eigenen Unternehmens. Zur Kritik vgl. ferner Macharzina, K. (1995), S. 306-310.
} 
ken genutzt werden können. ${ }^{233}$ Nicht zu verkennen ist allerdings, daß Portfolioverfahren klare Begrenzungen haben. Besonders bei sich verändernden Strukturen innerhalb von Branchen weisen sie durch ihren in der Tendenz rückblickenden Ansatz Defizite auf, d.h. sie können lediglich strategische Stoßrichtungen für existierende strategische Geschäftseinheiten liefern. Innovationen oder der Aufbau neuer strategischer Geschäftseinheiten sind nicht ohne weitergehende Überlegungen ableitbar. Damit besteht die Gefahr, daß eingefahrene Vorstellungen über Marktattraktivität und Wettbewerbsposition innovative Ansätze dominieren. ${ }^{234}$

Die Portfolio-Methode kann in jenen Unternehmen sinnvoll eingesetzt werden, die über mehrere voneinander abgrenzbare SGE verfügen. ${ }^{235}$ Damit scheint das Instrument für kleine und mittlere Unternehmen nur begrenzt einsatzfähig zu sein. Bestätigung findet dieser Eindruck in den Ergebnissen von POHL UND REHKUGLER, die lediglich in 3\% der von ihnen untersuchten Unternehmen die Verwendung von Portfolio-Konzepten vorfanden. ${ }^{236}$ Die dieser Arbeit zugrundeliegende Studie kann zwar nicht den empirischen Nachweis über die Verwendungsrate des Portfolio-Konzeptes in den untersuchten Unternehmen erbringen, es zeigt sich aber doch, daß einer Anwendung des Konzeptes in den Unternehmen aufgrund ihres Sortimentsumfanges bzw. Diversifikationsgrades grundsätzlich nichts entgegensteht.

Die Ausführungen unter Abschnitt 3.3.2 und 3.3.3 haben Möglichkeiten und Instrumente der Umfeld- und Unternehmensanalyse, die Grundlage einer systematisch und strategisch orientierten Unternehmensführung sind, aufgezeigt. Im Mittelpunkt der Analyse steht dabei die Erfassung der eigenen Mittel und Ressourcen sowie deren Beurteilung. Daraus kann dann auf die erweiterten Stärken und Schwächen des Unternehmens geschlossen werden. In Abhängigkeit von der Umfeldentwicklung, d.h. der Entwicklung auf den Kapital- oder Abnehmermärkten, bei Wettbewerbern und Kooperationspartnern bzw. auf gesamtgesellschaftlicher Ebene, gilt es anschließend abzuschätzen, ob sich aus den Stärken Chancen bzw. ob sich aus den Schwächen Risiken für das Unternehmen ergeben. Entsprechend muß sich das Unternehmen - ausgehend von seinem Selbstverständnis - Ziele setzen und Strategien entwickeln, mit denen langfristige Erfolgsfaktoren aufgebaut und gesichert werden können. Die Erfolgsfaktorenanalyse steht daher im Mittelpunkt des nächsten Abschnitts.

\footnotetext{
${ }^{233}$ Vgl. Kirsch, W. (1991), S. 360 i.V.m. Brenken, D. (1988), S. 96.

${ }^{234}$ Vgl. Cooper, R.G. (1984a), S. 6 und Cooper, R.G. (1984b), S. 152. Bezüglich der allgemeinen Kritik am Portfolio-Konzept vgl. ferner Timmermann, A. (1985), S. 202-206; Ansoff, H.I. (1988), S. 115f.; Brauchlin, E./Wehrli, H.-P. (1994), S. 67; Siegwart, H./Senti, R. (1995), S. 27; Hunger, J.D./Wheelen, T.L. (1996), S. 171f.; Kreikebaum, H. (1997), S. 80-83.

Für eine Verbindung des Portfolio-Konzeptes mit den verschiedenen Unternehmertypologien vgl. Kirsch, K./Trux, W. (1981), S. 306f. und Kirsch, W. (1991), S. 284f. Fur weitere Versionen der Portfolioanalyse vgl. Mauthe, K.-D./Roventa, P. (1983), S. 116-124.

${ }^{235}$ Vgl. Mugler, A. (1995), S. 173.

${ }^{236}$ Vgl. Pohl, H.-J./Rehkugler, H. (1986), S. 92.
} 


\subsubsection{Erfolgsfaktorenanalyse}

Die Analyse der unternehmensexternen und -internen Bedingungen sowie der Vergleich der dadurch sichtbar gewordenen Stärken und Schwächen mit anderen Unternehmen läßt noch keine Aussage darüber zu, welche Faktoren die Ursache für den Erfolg oder den Mißerfolg des Unternehmens bilden. ${ }^{237}$ Das Auffinden und der Aufbau von Erfolgsfaktoren ${ }^{238}$ stellt somit eine Basisaufgabe im strategischen Planungsprozeß dar, da sie die zentralen Gestaltungsparameter für den langfristigen Unternehmenserfolg repräsentieren. ${ }^{239}$ Erfolgsfaktoren beziehen sich auf Produkte und Märkte und können in Kostenvorteilen, Qualitätsvorteilen, überdurchschnittlichen Marktanteilen, Imagevorteilen, Distributionsvorteilen usw. zum Ausdruck kommen. ${ }^{240}$

Können durch Lernprozesse einzelne Erfolgsfaktoren sinnvoll integriert werden, entwickelt sich daraus eine unternehmensspezifische Ressourcenbasis aus materiellen, finanziellen und personellen Kompetenzen, die unter dem Begriff der Kernkompetenzen ("core competencies") von PRAHALAD UND HAMEL in die Diskussion eingebracht wurden. ${ }^{241}$ In Anlehnung an PRAHALAD UND HAMEL bzw. STALK u.a. charakterisiert HINTERHUBER Kernkompetenzen als integrierte Gesamtheit organisatorischer Lemprozesse aus Know-how, Einstellungen, Abläufen und Technologien,

- die für den Kunden erkennbar und wertvoll sind,

- die gegenüber der Konkurrenz einmalig sind,

- die schwer imitierbar sind und

- die potentiell den Zugang zu einer Vielzahl von Märkten eröffnen. ${ }^{242}$

${ }^{237}$ Zur Messung des Erfolgs schlägt Albach sechs Kriterien vor: Umsatzrentabilităt, Wachstumsrate des Anlagevermögens, Wachstumsrate des Eigenkapitals, Verhältnis Marktwert zu Buchwert, Gesamtkapitalrentabilităt, Eigenkapitalrentabilitat. Vgl. Albach, H. (1987), S. 637f. Bamberger und Pleitner fugen den quantitativen Maßgroßßen Wachstum, Rentabilităt, Marktanteil, Unabhăngigkeit auch qualitative Kriterien ("die Zufriedenheit des Managers bezüglich der Zielerreichung und die Erreichung der Interessen anderer Organisationsteilnehmer") hinzu. Vgl. Bamberger, J./Pleitner, H.J (Hrsg.) (1988), S. 11.

${ }^{238}$ Von einer Unterscheidung der Begriffe "Erfolgsfaktor" und "Erfolgspotential" wird abgesehen.

${ }^{239}$ Vgl. Grochla, E. (1982), S. 112; Pümpin, C. (1981), S. 7f.; Gălweiler, A. (1979a), S. 18; Liessmann, K. (1987), S. 95. Vgl. grundlegend Heinrich, W. (1967), S. 157-224.

${ }^{240}$ Vgl. Pümpin, C. (1981), S. 7 f.

${ }^{241}$ Vgl. Prahalad, C.K./Hamel, G. (1990). Vgl. ferner Stalk, G. u.a. (1992); Rasche, C. (1994); Rastogi, P.N. (1995); Hinterhuber, H.H. (1996). Durch die Konzentration auf das Wesentliche und die Berücksichtigung der Synergien zwischen den Geschäftseinheiten und Produkten, stehen nicht mehr die Strategischen Geschäftseinheiten im Zentrum des Interesses, sondern die Kernkompetenzen. Die Kernkompetenzen stellen die verbindende Basis des Erfolgs mehrerer Strategischer Geschăftseinheiten dar. Damit ist zugleich eine Abkehr von dezentral geprägtem Management hin zu einer eher zentralen Koordinierung verbunden, ein Umstand, der vor allem der Situation in KMU entgegenkommt. Zur Kritik vgl. Porter, M.E. (1997), S. $51 \mathrm{ff}$. der v.a. die verkürzende, von einer ganzheitlichen Betrachtung des Unternehmens ablenkende, Sichtweise hervorhebt.

${ }^{242}$ Siehe Hinterhuber, H.H. (1996), S. 11. Vgl. auch Aaker, D.A. (1995), S. 181 bzw. ausfurlich Rasche, C. (1994), S. 69-90. 
Ist das Unternehmen in der Lage, seine Kernkompetenzen zu identifizieren und sie systematisch auszubauen, besteht die Möglichkeit, auf der Basis der Kernkompetenzen schneller innovative Problemlösungen anbieten zu können, aus denen dann Wettbewerbsvorteile des Unternehmens am Markt resultieren. Wettbewerbsvorteile ${ }^{243}$ können nach GAITANIDES UND SJURTS entstehen, wenn die relevanten Wettbewerber über heterogene Ressourcen (-bündel) verfügen, Faktormarktunvollkommenheiten existieren, die eine kurzfristige Überwindung der asymmetrischen Ressourcenausstattung verhindern, und die knappen Ressourcen sich zu einmaligen Kernfähigkeiten bündeln und weiterentwickeln lassen, die aus Kundensicht ihren Niederschlag in einem Zusatznutzen bei den angebotenen Marktleistungen finden. ${ }^{24}$ Da die unternehmensspezifischen Erfolgsfaktoren bzw. Kernkompetenzen die Bestimmungsfaktoren der Wettbewerbsvorteile des Unternehmens sind, müssen diese zunächst identifiziert werden. Erst dann ist das Unternehmen auch in der Lage, auf diese Bestimmungsfaktoren zielgerichtet einzuwirken, sie zu schützen bzw. sie auf veränderte Bedingungen einzustellen. ${ }^{245}$

\subsubsection{Ergebnisse der empirischen Erfolgsfaktorenforschung}

Die Identifikation von Faktoren, die dem Unternehmen die Möglichkeit bieten, Wettbewerbsvorteile aufzubauen, ist das zentrale Anliegen der Erfolgsfaktorenforschung. $\mathrm{Zu}$ diesem Zweck wird die ganzheitliche Betrachtungsebene des Unternehmens verlassen, da davon ausgegangen werden kann, "daß trotz der Mehrdimensionalität und Multikausalität des Unternehmenserfolgs einige wenige Einflußfaktoren über Erfolg und Mißerfolg entscheiden"246. Gerade in der Mehrdimensionalität und Multikausalität liegt jedoch die Problematik der Erfolgsfaktorenforschung. Aus der Vielzahl möglicher erfolgskritischer Faktoren müssen diejenigen extrahiert werden, die für den langfristigen Unternehmenserfolg verantwortlich sind. Die nachfolgend dargestellten empirischen Ansätze versuchen folglich, den Umfang möglicher Einflußgrößen auf eine übersichtliche und handhabbare Zahl zu reduzieren, auf die bei der strategischen Ausrichtung des Unternehmens zurückgegriffen werden kann.

Die PIMS-Studie (Profit Impact of Market Strategies) ist eines der umfangreichsten empirischen Forschungsprojekte auf strategischem Gebiet. Zweck des 1972 von SCHOEFFLER und General Electric entwickelten Programmes war es, herauszufinden, wie sich strategische

${ }^{243}$ Grundlage einer Diskussion ubber Wettbewerbsvorteile wäre an sich eine allgemein akzeptierte Definition des Wettbewerbs. Eine solche existiert nicht. Vgl. Herdzina, K. (1993), S. 11 f. Als stark verkürzte und daher nicht unproblematische Arbeitsdefinition soll Wettbewerb als das Streben nach eigenen Vorteilen zu Lasten anderer betrachtet werden. Der Wettbewerbsvorteil grundet sich somit auf Faktoren bzw. Kompetenzen, uber die die Wettbewerber nicht in gleichem Maße verfugen. Vgl. dazu auch Perillieux, R. (1987), S. 17; Zörgiebel, W.W. (1983), S. $14 f$.

${ }^{244}$ Vgl. Gaitanides, M./Sjurts, I. (1995), S. 63.

${ }^{245}$ Vgl. Rasche, C. (1994), S. 78. Zur Verdeutlichung der Begriffe "Erfolgsfaktor", "Kemkompetenz" und "Wettbewerbsvorteil" siehe auch das Praxisbeispiel der August Beck GmbH \& Co. in Anlage 11.

${ }^{246}$ Steinbach, R.F. (1997), S. 56. 
Schlüsseldimensionen auf die Rentabilität und das Unternehmenswachstum auswirken. ${ }^{247}$ "The Profit Impact of Market Strategy (PIMS) program ... is a multicompany activity designed to provide each participating company with reliable data on the consequences of strategic actions. ... PIMS operates by pooling information on the business-strategy experiences of the member companies." 248 Betrachtet werden dazu einzelne SGE der Partnerunternehmen. An der PIMS-Datenbank haben sich mittlerweile 450 Unternehmen mit über 3.000 SGE beteiligt. ${ }^{249}$ Die PIMS-Studie führte zu einem Regressionsmodell, das 37 Einflußfaktoren in Beziehung zum Ertrag setzt, die die Varianz des Return on Investment (ROI) zu $80 \%$ erklären. ${ }^{250}$ Darüber hinaus werden 19 Variable erfaßt, die ca. $70 \%$ der Varianz des Cash flow zwischen den SGE erklären. ${ }^{251}$ Diese 37 bzw. 19 Variablen wurden auf neun strategische Haupteinflußgrößen verdichtet: die Investitionsintensität, die Produktivität, die Marktposition, das Marktwachstum, die Qualität der Produkte und Leistungen, Innovation sowie Differenzierung von den Wettbewerbern, vertikale Integration, die Kostenentwicklung und die strategischen Absichten. ${ }^{252}$ Auch wenn mit der PIMS-Studie grundlegende strategische Erfolgsfaktoren identifiziert werden konnten, darf dennoch nicht außer acht gelassen werden, daß trotz der hohen Anzahl an teilnehmenden Unternehmen eine Repräsentativität der Daten nicht gewährleistet werden kann. Die Kritik richtet sich ferner auf den unvollständigen Modellansatz, eine lediglich geringe theoretische Fundierung sowie eine nicht eindeutige Richtung der aufgezeigten Kausalzusammenhänge. Entsprechend muß die Gültigkeit der Ergebnisse aus der PIMSStudie stark relativiert werden. ${ }^{253}$ "Grundsätzlich bietet das PIMS-Projekt den daran beteiligten Unternehmen [dennoch, der Verf.] eine erheblich weitergehende strategische Unterstützung, sei es zum Auffinden der wichtigsten Erfolgsfaktoren und deren Gewichtung oder sei es zur Formulierung von Strategien und deren Bewertung." 254

Die Untersuchung von Peters uND WATERMaN ("In Search of Excellence") ${ }^{255}$ über erfolgreiche Unternehmen zeigt, daß diese gegenüber dem Rest der Unternehmen gravierende Unterschiede aufweisen. In ihren Vorarbeiten konnten sie zunächst sieben voneinander abhängige Variable ausmachen, die Struktur, die Strategie, das Stammpersonal, den Stil, die Systeme, das Selbstverständnis und die Spezialkenntnisse des Unternehmens. Die vorgenannten Variablen wurden im Laufe des Projekts präzisiert und zu einem Unternehmensfuihrungsmodell mit

\footnotetext{
${ }^{247}$ Vgl. Schoeffler, S. u.a. (1974); Schoeffler, S. (1983); Buzzell, R.D./Gale, B.T. (1989).

248 Schoeffler, S. (1983), S. 23-1.

${ }^{249}$ Vgl. Buzzell, R.D./Gale, B.T. (1989), S. XI.

${ }^{250} \mathrm{Vgl}$. Schoeffler, S. u.a. (1974), S. 140.

251 Vgl. Kreilkamp, E. (1987), S. 377.

${ }^{252}$ Vgl. Schoeffler, S. (1983), S. 23-5f. Vgl. ferner Pümpin, C. (1981), S. 15 und Kreilkamp, E. (1987), S. 377ff., der die Erfolgsdeterminanten auf die sieben erstgenannten reduziert.

${ }^{253}$ Vgl. Kreilkamp, E. (1987) S. 398-407; Meffert, H. (1994), S. 66f.

254 Kreilkamp, E. (1987), S. 407.

${ }^{255}$ Vgl. Peters, T./Waterman, R. (1982).
} 
sieben Grunddimensionen, dem sog. 7-S Framework oder 7-S-Modell weiterentwickelt. ${ }^{256}$ Das 7-S-Modell beinhaltet als "harte Faktoren" die Struktur, die Strategie sowie die Systeme. Diese stehen zu den als zunehmend wichtiger erachteten "weichen Faktoren" in einem interdependenten Verhältnis. Letztere setzen sich aus dem Selbstverständnis des Unternehmens (Werte, Kultur), den Spezialkenntnissen, dem (Führungs-) Stil und dem Stammpersonal zusammen. $^{257}$ Besonderheiten erfolgreicher, innovativer Unternehmen fassen PETERS UND WATERMAN in acht Merkmalen zusammen: $:^{258}$

1. Primat des Handelns: Im Vordergrund steht eine aufgaben- und handlungsorientierte Haltung, die eine teamorientiert-experimentelle Entscheidungsfindung in den Vordergrund und eine eher analytisch orientierte Entscheidungsfindung in den Hintergrund rückt.

2. Nähe zum Kunden: Kundenorientierung bedeutet, über das Anbieten herausragender Qualität, Serviceleistungen und Zuverlässigkeit hinaus das Lernen von den Kunden, da hieraus neue Produktideen und Innovationen entstehen können.

3. Freiraum für Unternehmertum: Innovative Unternehmen schaffen eine Atmosphäre, in der Kreativität, Entscheidungsfreiheit und unternehmerischer Einsatz gepflegt werden.

4. Produktivität durch Menschen: Herausragende Unternehmen betrachten ihre Mitarbeiter als die eigentliche Quelle von Qualităts- und Produktivitätssteigerung.

5. Sichtbar gelebtes Wertesystem: Werden Unternehmenswerte von allen Organisationsmitgliedern akzeptiert und verinnerlicht, haben sie entscheidenden Einfluß auf die Leistungsfähigkeit.

6. Bindung an das angestammte Geschäft: Die geschäftlichen Aktivitäten bzw. Diversifizierungsanstrengungen sollten nur so weit gehen, wie das eigene Know-how und die eigenen Fähigkeiten sinnvoll eingesetzt werden können.

7. Einfacher, flexibler Aufbau: Einfachheit der Organisationsstrukturen und unbürokratische Arbeitsabläufe werden angestrebt und eine breite, informelle Kommunikation gepflegt.

8. Straff-lockere Führung: Erfolgreiche Unternehmen schaffen eine ausgewogene Mischung zwischen zentralen und dezentralen Strukturen sowie Freiräume für Initiative und eigene Lösungswege.

PETERS UND WATERMAN charakterisieren diese Merkmale selbst als wenig bahnbrechend. Doch auch wenn einige von ihnen, vielleicht sogar die meisten, Binsenweisheiten sind, stellen

${ }^{256}$ Vgl. Peters, T./Waterman, R. (1982), S. 8-16 bzw. Pascale, R.T./Athos, A.G. (1981).

257 Vgl. dazu das Praxisbeispiel in Macharzina, K. (1995), S. 780-783.

${ }^{258}$ Vgl. Peters, T./Waterman, R. (1982), S. 13-16 sowie auch Kreilkamp, E. (1987), S. 18f.; Liessmann, K. (1987), S. 94f.; Servatius, H.-G. (1988), S. 117f. Vgl. ferner Albach, H. (1987), S. 640-659. 
sie die Unterscheidungsmerkmale zwischen den bestgeführten und den übrigen Unternehmen dar. Das innovative Element an diesem Ansatz ist, daß erstmals der Einfluß des Faktors Selbstverständnis des Unternehmens (Wert und Kultur) hervorgehoben wird, und daß die Voraussetzung für den langfristigen Unternehmenserfolg eine ausgewogene Kombination verschiedener Faktoren ist. ${ }^{259}$

Schwachpunkte des Konzepts liegen im unzureichend präzisierten Erfolgsbegriff sowie in der Vernachlässigung unternehmenshistorisch bedingter bzw. kulturbedingter Entwicklungen und Einflüsse. Zudem ist eine Verallgemeinerung der Aussagen wegen der mangelnden Repräsentativität und wegen des Fallstudiencharakters nicht möglich. Ferner blieb die postulierte Kausalität zwischen den weichen Faktoren und dem Unternehmenserfolg unbelegt. ${ }^{260}$ Neben der methodischen Kritik wurde die Richtigkeit der Ergebnisse einerseits durch die Realität in Frage gestellt, da bereits wenige Jahre nach der Untersuchung einige der betrachteten Unternehmen erhebliche Erfolgseinbrüche zu verzeichnen hatten. Andererseits stellten die Autoren die Ergebnisse später selbst in Frage. PETERS UND AUSTIN reduzieren die Erfolgsfaktoren auf die Kundenbetreuung, die fortwährende Innovation, die Organisationsmitglieder sowie die Führung, ${ }^{261}$ während WATERMAN nur noch in der Innovativität des Unternehmens einen strategischen Einflußfaktor auf den Erfolg sieht. ${ }^{262}$ Letztlich hält PETERS sogar das dauerhafte Halten einer Spitzenposition am Markt für fraglich. ${ }^{263}$

Einen weiteren Ansatz zur Erfassung der für den Unternehmenserfolg verantwortlichen Faktoren stellen die auf einer ganzheitlichen Sichtweise des Unternehmens beruhenden Erfolgsund Mißerfolgsprofile nach KRŨGER dar. ${ }^{264}$ KRÜGER identifizierte sechs Erfolgssegmente als dem Gewinn vorgelagerte Maßgrößen für den Unternehmenserfolg. Die analytisch gewonnenen Erfolgssegmente setzen sich zusammen aus den Trägern, der Philosophie und Kultur, der Strategie, der Struktur, den Systemen und dem Realisationspotential. ${ }^{265}$ Sie werden durch 21 Erfolgskomponenten näher operationalisiert (vgl. Tab. 3-2).

Das von KRÜGER erstellte Mißerfolgsprofil ergibt, daß Mißerfolge auf ein Bündel unterschiedlicher Ursachen zurückzuführen sind. Allen voran sind dies Schwächen im ProduktMarkt-Konzept und eine unzureichende Gewinn- und Ertragsorientierung. Weitere Defizite finden sich in der Qualifikation des Managements, der Organisation der Unternehmensspitze, dem finanziellen Potential sowie im Bereich Marketing/Vertrieb/Marktforschung. Der Mißer-

\footnotetext{
${ }^{259}$ Vgl. Peters, T./Waterman, R. (1982), S. 16f.; Kreilkamp, E. (1987), S. 19.

${ }^{260}$ Vgl. Macharzina, K. (1995), S. 784. Vgl. ferner Kriger, W. (1989), S. 13-18.

261 Vgl. Peters, T.J./Austin, N. (1985).

${ }^{262}$ Vgl. Waterman, R.H. (1988).

${ }^{263}$ Vgl. Peters, T.J. (1987), S. 3 f.

${ }^{264}$ Vgl. Krüger, W. (1988).

${ }^{265}$ Vgl. Krüger, W. (1988), S. $29 f$.
} 
folg entsteht somit aus einer defizitären Kombination der Segmente "Strategie", "Träger" und "Struktur". ${ }^{266}$ Das Erfolgsprofil dagegen hängt von relativ wenigen Komponenten ab. Hier stehen das Produkt-Markt-Konzept, die Gewinn- und Ertragsorientierung, der Bereich Marketing/Vertrieb/Marktforschung sowie die Innovationsorientierung als erfolgsentscheidende Komponenten im Vordergrund. Das für den Unternehmenserfolg bedeutendste Segment ist damit die "Strategie". Insgesamt zeigt Krügers Untersuchung, daß den strategierelevanten Erfolgskomponenten "sowohl für die Erklärung von Erfolg wie von Mißerfolg die höchste Bedeutung" ${ }^{267}$ zukommt.

Tab. 3-2: Analyseraster zur Bestimmung unternehmerischer Erfolgs- und Mißerfolgsprofile nach KRÜGER

\begin{tabular}{|c|c|c|c|c|c|c|}
\hline $\begin{array}{l}\text { Erfolgs- } \\
\text { segmente }\end{array}$ & Träger & $\begin{array}{c}\text { Philosophie/ } \\
\text { Kultur }\end{array}$ & Strategie & Struktur & Systeme & $\begin{array}{c}\text { Realisations } \\
\text { potential }\end{array}$ \\
\hline 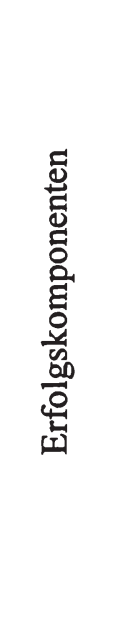 & $\begin{array}{l}\text { Qualifikation } \\
\text { des Manage- } \\
\text { ments } \\
\text { Motivation } \\
\text { des Manage- } \\
\text { ments } \\
\text { Fuhrungs- } \\
\text { verhalten }\end{array}$ & $\begin{array}{l}\text { Vorhanden- } \\
\text { sein/ Konsis- } \\
\operatorname{tenz} / \text { Akzep- } \\
\operatorname{tanz} \text { von Leit- } \\
\text { bildern }\end{array}$ & $\begin{array}{l}\text { Gewinn/ } \\
\text { Ertrags- } \\
\text { orientierung } \\
\text { Kosten- } \\
\text { orientierung } \\
\text { Anpassungs- } \\
\text { fahigkeit/ } \\
\text { Flexibilităt } \\
\text { Innovations- } \\
\text { orientierung } \\
\text { Produkt/ } \\
\text { Markt- } \\
\text { Konzept }\end{array}$ & 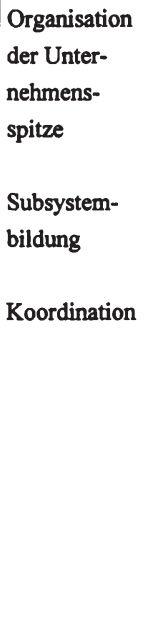 & $\begin{array}{l}\text { Führungs- } \\
\text { systeme } \\
\text { Planungs/ } \\
\text { Steuerungs/ } \\
\text { Kontroll- } \\
\text { systeme } \\
\text { Controlling } \\
\text { Rechnungs- } \\
\text { und Info- } \\
\text { Systeme }\end{array}$ & $\begin{array}{l}\begin{array}{l}\text { Finanz- } \\
\text { potential }\end{array} \\
\text { Human Capi- } \\
\text { tal } \\
\text { F \& E } \\
\text { Einsatzgüter } \\
\text { Fertigung } \\
\text { Marketing/ } \\
\text { Vertrieb/ } \\
\text { Marktfor- } \\
\text { schung }\end{array}$ \\
\hline
\end{tabular}

Quelle: in Anlehnung an Krüger, W. (1988), S. 32.

Das STRATOS-Projekt ${ }^{268}$ ist ein Forschungsprojekt, bei dem das strategische Verhalten kleiner und mittlerer Unternehmen sowie dessen Bestimmungsfaktoren und seine Auswirkungen auf den Unternehmenserfolg im Mittelpunkt steht. An der Untersuchung beteiligten sich 1.135

\footnotetext{
${ }^{266}$ Vgl. Krüger, W. (1988), S. 35ff. und S. 41.

${ }^{267}$ Krüger, W. (1988), S. 41.

${ }^{268}$ Vgl. Fröhlich, E./Pichler, J.H. (1988); Bamberger, J./Pleitner, H.J (Hrsg.) (1988); Gabele, E. (1989). STRATOS steht für "Strategic orientations of small and medium-sized enterprises".
} 
Unternehmen aus acht europäischen Staaten. ${ }^{269}$ Neben der Charakterisierung unterschiedlicher Unternehmertypen ${ }^{270}$ wurden insgesamt 26 Faktoren untersucht, die den Aufbau von Wettbewerbsvorteilen ermöglichen. ${ }^{271}$ Aus diesem Faktorenpool wurde von den untersuchten Unternehmen dem Faktor Produktqualität der höchste Einfluß auf die Erzielung von Wettbewerbsvorteilen eingeräumt. ${ }^{272}$ Nachrangig folgten die Lieferzuverlässigkeit, der gute Ruf der Firma, die Qualifikation der Mitarbeiter, die Flexibilität der Firma, die Qualität des Managements sowie das lokale Image und die persönlichen Kontakte. Werden die 26 Einzelfaktoren zu gröBeren Einheiten zusammengefaßt, ergibt sich ein Modell mit sechs Gruppen von Faktoren zur Erreichung von Wettbewerbsvorteilen kleiner und mittlerer Unternehmen:

- Humankapital und Image,

- Technologische Fähigkeiten,

- Leistungsprogramm,

- Produktentwicklung und Verkaufsförderung,

- Kostenfuihrerschaft und Preispolitik sowie

- Marktpräsenz und Finanzkraft. ${ }^{273}$

Zwar müssen trotz der breiten empirischen Basis, die das STRATOS-Projekt aufweist, Abstriche bei der Repräsentativität der Ergebnisse gemacht werden, ${ }^{274}$ aber davon abgesehen bietet STRATOS länderübergreifend hervorragende Einblicke in die Verhaltensweisen kleiner und mittlerer Unternehmen.

Mit den vorstehenden Konzepten kann selbstverständlich nur ein geringer Teil des äußerst umfangreichen Spektrums an Konzepten und Untersuchungen der Erfolgsfaktorenforschung aufgezeigt werden. Doch bereits dieser kleine Ausschnitt verdeutlicht die auf die unterschiedlichen Untersuchungsdesigns zurückzuführende Heterogenität der Ergebnisse. Gleichzeitig fallen aber auch Überschneidungen bzw. die teilweise Deckungsgleichheit der Ergebnisse auf. Zur Objektivierung der Erkenntnisse der Erfolgsfaktorenforschung faßt FRITZ die Ergebnisse

${ }^{269}$ Belgien, Deutschland, Finnland, Frankreich, Großbritannien, Niederlande, Österreich und Schweiz. Vgl. Fröhlich, E./Pichler, J.H. (1988), S. 5.

${ }^{270}$ Vgl. Fröhlich, E./Pichler, J.H. (1988), S. 59-72 und Bamberger, J./Pleitner, H.J (Hrsg.) (1988), S. 47-54. Vgl. ferner Abschnitt 3.2.2.

${ }^{271}$ Vgl. Fröhlich, E./Pichler, J.H. (1988), S. 118ff.; Bamberger, J./Pleitner, H.J (Hrsg.) (1988), S. 83ff.

${ }^{272}$ Von den befragten Unternehmen halten $61 \%$ diesen Faktor für sehr wichtig und $32 \%$ für wichtig. Vgl. Bamberger, J./Pleitner, H.J (Hrsg.) (1988), S. 84.

${ }^{273}$ Vgl. dazu ausfuhrlich Gabele, E. (1989), S. 624ff.

${ }^{274}$ Vgl. insbesondere die Ergebnisse für Deutschland bei Fröhlich, E./Pichler, J.H. (1988), S. 6 mit den Ergebnissen aus Abschnitt 2.2.1, Tab. 2-2. Daneben wurden lediglich die drei Sektoren Bekleidung, Nahrung und Elektronik betrachtet, was eine weitere Beschrănkung der Aussagekraft bedeutet. Die Ergebnisse und Aussagen können, was die Autoren auch selbst betonen, somit nur für die Stichprobe gelten. Vgl. Fröhlich, E./Pichler, J.H. (1988), S. 7. 
von 40 Untersuchungen in einer Meta-Erfolgsfaktoren-Analyse zusammen und identifiziert dadurch die in den zugrundegelegten Ansätzen am häufigsten genannten Erfolgsfaktoren. ${ }^{275}$

Tab. 3-3: Ergebnisse der Meta-Erfolgsfaktoren-Analyse nach FRITZ

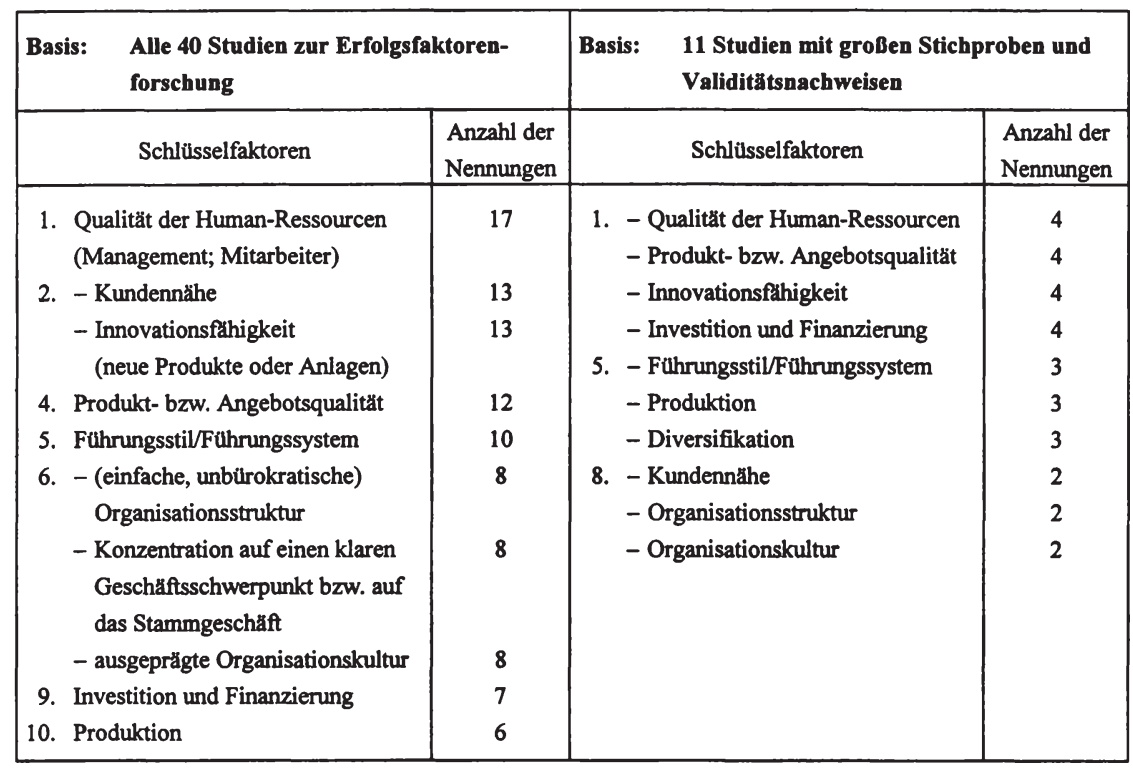

Quelle: in Anlehnung an Fritz, W. (1990), S. 104.

Das Ergebnis der Meta-Analyse aller 40 Untersuchungen weist die Qualität der HumanRessourcen als den am häufigsten ermittelten Erfolgsfaktor aus. Mit Abstand folgen die Erfolgsfaktoren Kundennähe, Innovationsfähigkeit und Produkt- bzw. Angebotsqualität. Ein leicht verändertes Ranking ergibt sich, wenn ausschließlich die bezüglich des Stichprobenumfangs und der nachgewiesenen Validität vergleichsweise solideren Untersuchungen betrachtet werden. Dann liegen die Erfolgsfaktoren Qualität der Human-Ressourcen, Produkt- und Angebotsqualität, Innovationsfähigkeit, Investition und Finanzierung gleichauf an der Spitze. FRITZ betont allerdings, daß aus den vorstehenden Ergebnissen "ein Rückschluß auf die Bedeutung der einzelnen Erfolgsfaktoren für das Zustandekommen des Unternehmenserfolges nicht exakt möglich ist; denn die dort verarbeiteten Studien berücksichtigen nur teilweise dieselben Erfolgsfaktoren, und die wenigsten dieser Studien geben Aufschluß über die Einfluß-

${ }^{275}$ Vgl. Fritz, W. (1990). 
stärke einzelner Erfolgsfaktoren auf den Unternehmenserfolg im Vergleich zu anderen Erfolgsfaktoren"276.

\subsubsection{Erfolgsfaktoren kleiner und mittlerer Unternehmen}

Zunächst bleibt die Frage unbeantwortet, ob unternehmensgrößenspezifische Erfolgsfaktoren existieren, da keine der vorgenannten Untersuchungen einen solchen Vergleich vornimmt. Lediglich vier der bei FRITZ aufgezeigten Studien legten den Untersuchungsschwerpunkt auf kleine und mittlere Unternehmen. ${ }^{277}$ Diesen lassen sich drei weitere Studien hinzufügen, die ebenfalls den Fokus ausschließlich auf kleine und mittlere Unternehmen richten.

POHK UND REHKUGLER ${ }^{278}$ untersuchten 217 Unternehmen aus den Bereichen Verarbeitendes Gewerbe sowie Handel, Verkehr und sonstige Dienstleistungen in den Kammerbezirken Bremen und Stade. Die von den Unternehmen in einer Selbsteinschätzung genannten Erfolgsfaktoren waren der Service, die Produktqualităt, die Sortimentsbreite, die Personalqualifikation sowie die Finanzkraft. ${ }^{279}$ Allerdings schränken die Autoren die Reichweite dieser Aussagen selbst ein, da erstens eine Übertragung auf andere Regionen nur nach Prüfung der dort vorliegenden Einflußfaktoren zulässig wäre, da zweitens bei einer Rücklaufquote von $13,9 \%$ Verzerrungen entstehen können und da drittens aufgrund zu kleiner Felderbesetzungen die Signifikanzen teilweise nicht nachgewiesen werden konnten. ${ }^{280}$

Ziel der Untersuchung von NYDEGGER, OBERHÄNSLI UND HARRINGER ${ }^{281}$ war, Erkenntnisse über die Wettbewerbsfähigkeit der schweizerischen Wirtschaft zu gewinnen, die sich hauptsächlich aus kleinen und mittleren Unternehmen zusammensetzt. In die Untersuchung wurden 70 Unternehmen aus der Textil-, der chemischen und der Maschinenbauindustrie einbezogen, die als wichtigste Wettbewerbsvorteile im Vergleich zur Konkurrenz ihre Flexibilität, die Qualität sowie ihr vielgestaltiges Sortiment angaben. ${ }^{282}$ Auch wenn die Autoren mit ihrer Stichprobe versuchten, möglichst nah an die Zusammensetzung der Grundgesamtheit heranzukommen, bleiben dennoch Vorbehalte aufgrund des kleinen Stichprobenumfangs bestehen.

Die Ergebnisse der eigenen Untersuchung aus der schriftlichen Befragung sowie der persönlichen Unternehmerbefragung in der Region Neckar-Alb bestătigen die vorgenannten Resulta-

\footnotetext{
${ }^{276}$ Vgl. Fritz, W. (1990), S. 104 (Hervorhebung im Original).

${ }^{277}$ Vgl. die bei Fritz zitierten Studien von Albach, von Gottschlich, der Industriekreditbank AG sowie STRATOS.

${ }^{278}$ Vgl. Pohl, H.-J./Rehkugler, H. (1986).

279 Vgl. Pohl, H.-J./Rehkugler, H. (1986), S. 77.

${ }^{280}$ Vgl. Pohl, H.-J./Rehkugler, H. (1986), S. 63.

281 Vgl. Nydegger, A. u.a. (1983).

${ }^{282} \mathrm{Vgl}$. Nydegger, A. u.a. (1983), S. 2 und S. 144.
} 
te in weiten Teilen. ${ }^{283}$ Die Gesamtheit der befragten Unternehmen sieht die speziellen Wettbewerbsvorteile ihres Unternehmens ${ }^{284}$ in der flexiblen Anpassung an Kundenwünsche, der hohen Verarbeitungsqualität sowie einem besonderen Kundenservice:

Tab. 3-4: Selbsteinschätzung der Wettbewerbsvorteile der beiden Erfolgstypen

\begin{tabular}{|l|c|cc|cc|}
\hline \multicolumn{1}{|c|}{ Wettbewerbsvorteile } & Gesamt & $\begin{array}{c}\text { besonders erfolgreiche } \\
\text { Unternehmen }\end{array}$ & $\begin{array}{c}\text { weniger erfolgreiche } \\
\text { Unternehmen }\end{array}$ \\
\hline $\begin{array}{l}\text { flexible Anpassung an Kun- } \\
\text { denwïnsche }\end{array}$ & 4,56 & 4,63 & $(1)$ & 4,54 & $(1)$ \\
hohe Verarbeitungsqualităt & 4,46 & 4,49 & $(2)$ & 4,45 & $(2)$ \\
besonderer Kundenservice & 4,23 & 4,30 & $(4)$ & 4,20 & $(3)$ \\
fortschrittliche Technologie/ & 3,93 & 4,40 & $(3)$ & 3,73 & $(4)$ \\
$\begin{array}{l}\text { Produkte } \\
\text { viele Produktinnovationen }\end{array}$ & 3,54 & 4,06 & $(5)$ & 3,29 & $(7)$ \\
besonderes Design/ Gestaltung & 3,48 & 3,29 & $(7)$ & 3,55 & $(5)$ \\
hohe Umweltfreundlichkeit & 3,48 & 3,82 & $(6)$ & 3,34 & $(6)$ \\
günstige Preise & 3,20 & 3,06 & (8) & 3,26 & $(8)$ \\
\hline
\end{tabular}

Quelle: eigene Berechnungen. ${ }^{285}$

Die Ergebnisse zeigen ferner, daß bezüglich der Wettbewerbsvorteile bei der Mehrzahl der Kriterien keine gravierenden Unterschiede zwischen den als besonders erfolgreich und den als weniger erfolgreich charakterisierten Unternehmen bestehen. Lediglich bei den Kriterien "fortschrittliche Technologie/Produkte" und "viele Produktinnovationen" bzw. bei dem Kriterium "hohe Umweltfreundlichkeit" waren die Differenzen hoch signifikant bzw. signifikant. ${ }^{286}$

Die grundsätzliche Problematik in fragebogengestützten Untersuchungen liegt in einem begrenzten und vorgegebenen Antwortraster. Dies wird in allen der oben aufgezeigten Untersuchungen deutlich. Da sich nicht beliebig viele Faktoren abfragen lassen, müssen diese auf eine noch überschaubare Zahl begrenzt werden. Die Begrenzung der Faktoren bedeutet ferner, daß bei deren Auswahl Schwerpunkte im Hinblick auf das Untersuchungsziel gesetzt werden bzw. bestimmte Faktoren ausgeblendet werden. Als Beispiel hierfür kann die Umweltorientierung der Unternehmen genannt werden. Findet sie keinen Eingang in den Fragenkatalog, kann sie auch nicht von den Unternehmen als Erfolgsfaktor gekennzeichnet werden. Sie wird in den von FRITZ angefuihrten Arbeiten lediglich bei TÖPFER explizit als Erfolgsfaktor erwähnt. ${ }^{287}$

\footnotetext{
${ }^{283} \mathrm{Vgl}$. Abschnitt 2.3.2.1.

284 Siehe Frage 2/6 des Fragebogens im Anhang.

${ }^{285}$ Skala von 1= "trifft gar nicht zu" bis 5 = "trifft sehr zu"; in Klammern: Rang. Die Typisierung der Unternehmen in der Region Neckar-Alb ergab zwei Erfolgstypen, und zwar die besonders erfolgreichen bzw. die weniger erfolgreichen Unternehmen (vgl. Abschnitt 2.3.3).

${ }^{286}$ Sig.: 0,002 und Sig.: 0,005 bzw. Sig.: 0,038.

${ }^{287}$ Vgl. Fritz, W. (1990), S. 94-103.
} 
Entsprechend dem Ziel der hier vorliegenden Arbeit wurden schwerpunktmäßig jene marktorientierten Wettbewerbsvorteile abgefragt, die in Bezug zum Innovations- und Umweltverhalten der Unternehmen stehen. Der aus den vorgegebenen Antwortkategorien entstandene Nachteil der Schwerpunktsetzung konnte auch durch das Zusatzfeld "sonstige" Wettbewerbsvorteile nur begrenzt aufgelöst werden. Aus diesem Grund wurde dieser Aspekt im Rahmen der 33 Unternehmergespräche erneut aufgegriffen. Die Frage nach den die Wettbewerbsvorteile des Unternehmens begründenden Faktoren erfolgte ungestützt, d.h. ohne Vorgabe von Antwortmöglichkeiten. Nach der prozentualen Häufigkeit der Nennungen geordnet ergaben sich folgende Antworten:288

1. Flexibilităt, Aktualität, Schnelligkeit $54 \%$

2. Qualităt $33 \%$

3. - Kundenorientierung, -kontakt $25 \%$

- Innovativität

5. Qualifikation der Mitarbeiter $21 \%$

6. - Management $17 \%$

- (inter-) nationale Verbindungen

- Technologie

- Motivation der Mitarbeiter

- Betriebsgröße.

Die Ergebnisse der Unternehmerbefragung können keinen Anspruch auf Repräsentativität erheben. Da sie aber das Resultat aus der schriftlichen Befragung bestätigen, sind sie für Tendenzaussagen durchaus geeignet. Sie erweitern daruber hinaus den Antworthorizont der schriftlichen Befragung insbesondere um die Qualifikation der Mitarbeiter bzw. des Managements (Qualität der Human-Ressourcen).

Die in dieser Untersuchung vorgenommene Unterscheidung der Unternehmen nach Unternehmensgrößenklassen kann nur bedingt Aufschluß über eine Verschiebung der Bedeutung der für die Wettbewerbsvorteile verantwortlichen Erfolgsfaktoren liefern, da lediglich kleine und mittlere Unternehmen einbezogen wurden. Somit sind zwar Tendenzaussagen möglich, diese bedürfen aber einer genaueren empirischen Überprufung. Werden zunächst die Unterschiede in den Betriebsgrößenklassen betrachtet, zeigen sich zum Teil deutliche Verschiebungen der Rangplätze. ${ }^{289}$ Unternehmen mit weniger als 50 Mitarbeitern sehen ihre Vorteile eher in der flexiblen Anpassung an Kundenwuinsche, der Verarbeitungsqualität, dem Kundenservice und in fortschrittlicher Technologie bzw. in fortschrittlichen Produkten. Bei den Unternehmen mit mehr als 200 Mitarbeitern stehen Verarbeitungsqualität, fortschrittliche Techno-

${ }^{288}$ Vgl. Blessin, B. (1997), S. 6 und S. 22.

${ }^{289} \mathrm{Vgl}$. Anlage 12. 
logie bzw. Produkte und dann erst die Anpassung an Kundenwünsche und der Kundenservice im Vordergrund. Ein nahezu identisches Bild läßt sich bei der Differenzierung nach Umsatzgrößenklassen zeichnen. Bei Unternehmen mit weniger als 30 Mio. DM Umsatz ergibt sich die gleiche Rangfolge wie bei Unternehmen mit weniger als 50 Mitarbeitern. Die Unternehmen mit mehr als 100 Mio. DM Umsatz schätzen die Verarbeitungsqualität, die Fortschrittlichkeit der Technologie bzw. der Produkte sowie (Produkt-) Innovativität gefolgt vom Kundenservice am höchsten ein. ${ }^{290}$

Dadurch wird die Vermutung bestärkt, daß Unterschiede in den Erfolgsfaktoren zwischen Unternehmen unterschiedlicher Größe existieren, die jedoch im Rahmen dieser Arbeit nicht aufgedeckt werden können. Werden die Ergebnisse der vorgenannten, auf kleine und mittlere Unternehmen zugeschnittenen Untersuchungen zusammengefaßt, so zeigt sich eine deutliche Übereinstimmung beim Faktor Produktqualität. Als weitere Faktoren werden Service und Kundendienst, Flexibilität, Innovativität sowie die Qualifikation der Mitarbeiter und der Unternehmensführung genannt. Die für die Erzielung von Wettbewerbsvorteilen relevanten Erfolgsfaktoren kleiner und mittlerer Unternehmen sind zusammenfassend gekennzeichnet durch Qualität, Kundenorientierung, Innovativität und Qualifikation. Diese sehr global formulierten Erfolgsfaktoren müssen selbstverständlich auf unternehmensspezifische Faktoren fokussiert werden, die in ihrer Gesamtheit die speziellen Kernkompetenzen des Unternehmens bilden und damit langfristige Wettbewerbsvorteile darstellen.

Die Innovativität ist damit als ein zentraler Erfolgsfaktor identifiziert. Darüber hinaus steht sie in einem engen Beziehungsgeflecht zu den übrigen Erfolgsfaktoren. Die Interdependenz zeigt sich beispielsweise darin,

- daß Qualitätsverbesserungen Innovationen darstellen bzw. Innovationen neue Qualitäten ermöglichen,

- daß aus dem intensiven Kontakt mit den Kunden Innovationen entstehen bzw. durch Innovationen Kundenverbindungen intensiviert oder neu aufgebaut werden können, oder

- daß Qualifikationen Innovationen fördern bzw. Innovationen neue Qualifikationen bedingen. ${ }^{291}$

Der Umweltschutz bzw. die Umweltorientierung der Unternehmen wird an dieser Stelle noch nicht als zentraler Erfolgsfaktor erkennbar. Im Hinblick darauf, daß in der vorliegenden Untersuchung eine hohe Umweltfreundlichkeit als Wettbewerbsvorteil einerseits nur unwe-

${ }^{290}$ Dabei sind die Ergebnisse bei der flexiblen Anpassung an Kundenwilnsche (Sig.: 0,008) und der fortschrittlichen Technologie/Produkte (Sig.: 0,028) hoch signifikant bzw. signifikant.

${ }^{291}$ Siehe dazu ausführlich Kapitel 4. In einer erweiterten Sichtweise konnen auch im innerbetrieblichen Interaktionsproze $\beta$ Kundenbeziehungen dargestellt werden. 
sentlich niedriger eingeschätzt wird als Produktinnovationen (vgl. Tab. 3-4) und andererseits signifikant die erfolgreichen von den weniger erfolgreichen Unternehmen trennt, erscheint eine intensivere Betrachtung gerechtfertigt. Gestützt wird dies ferner dadurch, daß der Umweltschutz in einem engen Beziehungszusammenhang zur Innovativität der Unternehmen steht und parallel zum gewachsenen Umweltbewußtsein in der Gesellschaft auch immer stärker ins Blickfeld der (empirischen) Forschung rückt sowie in der Literatur zunehmend als eigenständiger Erfolgsfaktor erkannt wird. Zwischen dem Umweltschutz und den vier aufgezeigten Erfolgsfaktoren in kleinen und mittleren Unternehmen sind ebenfalls starke Interdependenzen erkennbar. Umweltorientierte Produkte oder Produktionsverfahren beinhalten durch den geschaffenen Zusatznutzen auch eine höhere - wenn auch zum Teil nur subjektive Qualität, sie werden zunehmend eine Voraussetzung für die Aufrechterhaltung der Kundenbeziehungen, sie forcieren weitere Innovationsschritte und sie sind Ausgangspunkt sich ändernder Qualifikationen. In dieser Arbeit wird daher versucht, auf empirischem Weg die Stellung des Erfolgsfaktors "betrieblicher Umweltschutz" in kleinen und mittleren Unternehmen zu erfassen (siehe Kapitel 5).

Als Zwischenfazit dieses Kapitels kann somit festgehalten werden: Hat ein Unternehmen durch eine systematische Umfeld- und Unternehmensanalyse seine speziellen Erfolgsfaktoren erkannt, müssen diese mit Hilfe geeigneter Strategien zielgerichtet ausgebaut und gesichert werden, damit langfristig haltbare Wettbewerbsvorteile entstehen. Dieser Prozeß darf jedoch nicht auf die Initiative der Unternehmensfuhrung beschränkt bleiben, sondern muß das ganze Unternehmen erfassen. Folglich müssen auch durch unternehmensinterne Veränderungen im Rahmen der Unternehmenskultur und -politik (vgl. Kapitel 3.4) Möglichkeiten geschaffen werden, Einfluß auf die erfolgswirksamen Faktoren zu nehmen, die in ihrer Gesamtheit die Kernkompetenzen darstellen, mit denen wiederum Wettbewerbsvorteile erzielt werden können. Eine besondere Bedeutung kommt dabei den Unternehmenszielen und den Unternehmensstrategien zu, die Inhalt der sich daran anschließenden Kapitel 3.5 und 3.6 sind. 


\subsection{Unternehmenskultur, Unternehmensphilosophie und Unternehmenspolitik}

\subsubsection{Die Unternehmenskultur als Orientierungsbasis \\ - eine Begriffsbestimmung}

Kleine und mittlere Unternehmen sind Systeme, die in ihrer Unternehmensgeschichte und -tradition oftmals in starkem Maße durch die Persönlichkeit eines Unternehmers oder einer Unternehmerfamilie geprägt wurden bzw. werden. Aus der Unternehmensgeschichte und -tradition entwickelt sich in den meisten Fällen eine unternehmensspezifische Kultur - ein Kern grundlegender Eigenschaften, durch den das Unternehmen eine unverwechselbare Identität erhält, die alle Bereiche des Unternehmens durchdringt und den Organisationsmitgliedern als Orientierungs- und Verhaltensmuster dient. Neben der Wirkung nach innen strahlt sie auch auf das Unternehmensumfeld aus und produziert in der Öffentlichkeit ein spezifisches "Image", ein Abbild ihrer Identität. ${ }^{292}$ Die Unternehmenskultur kann somit als die Gesamtheit der durch Evolution und Tradierung entstandenen Normen, Wertvorstellungen, Denkund Handlungsweisen, die das Verhalten aller Organisationsmitglieder prägt und die von den Organisationsmitgliedern geprägt wird, charakterisiert werden. ${ }^{293}$ Sie beeinflußt als Orientierungsbasis die Unternehmensphilosophie, die Unternehmensvision und die Unternehmenspolitik (vgl. Abb. 3-10). ${ }^{294}$

${ }^{292}$ Vgl. Kirsch, K./Trux, W. (1981), S. 316f. Zum Unternehmensimage vgl. Buß, E. (1988), S. 8 f.

${ }^{293}$ Zur Definition des Begriffes vgl. ferner Kobi, J.-M./Wütherich, H.A. (1986), S. 3-7; Becker, F.G. (1991), S. 585; Hall, R. (1992), S. 139; Rastogi, P.N. (1995), S. 209; Hunger, J.D./Wheelen, T.L. (1996), S. 123; Hinterhuber, H.H. (1997), S. 236; Kremmel, D. (1996), S. 51 ff.; Mugler, A./Schmidt, K.-H. (Hrsg.) (1995), S. 366; Meffert, H. (1988), S. 337. Zur Bedeutung der Unternehmenskultur als relevante Größe der strategischen Unternehmensfuhrung, ihrer verhaltensprägenden Wirkung sowie Formen und Gestaltung einer Kulturveränderung vgl. Bleicher, K. (1990); (1991), Teil C; (1996), S. 183-210 sowie Kobi, J.-M./Wütherich, H.A. (1986), S. 11-28. Für die Erläuterung der Unternehmenkultur kann auch auf das Lebenszyklusmodell zurückgegriffen werden, da sich bei der Entwicklung der Unternehmenskultur ebenfalls unterschiedliche Phasen kennzeichnen lassen. Sie entsteht mit der Gründung des Unternehmens, wächst und reift mit dessen Entwicklung und kann in eine Krise geraten, sofern sie den Erfolg des Unternehmens nicht mehr gewăhrleisten kann. Vgl. Kremmel, D. (1996), S. 64-68.

294

An dieser Stelle ist darauf hinzuweisen, daß sich in der Literatur kein einheitliches Begriffs- und Ordnungsschema für die genannten Begriffe findet. Das hier entwickelte Begriffs- und Ordnungsschema kann seinerseits lediglich eine grobe Systematik bieten, da eine tiefergehende Analyse vom Ziel und Zweck der Arbeit zu weit ablenken würde. Die Wechselwirkung zwischen den Normen, Wertvorstellungen, Denk- und Handlungsweisen des Unternehmens (Unternehmenskultur) und denen des Organisationsmitgliedes wird u.a. in Senges Modell der Lernenden Organisation hervorgehoben (vgl. dazu ausfuhrlich Abschnitt 4.4.3). 


\section{Abb. 3-10: Die Unternehmenskultur als Orientierungsbasis des Unternehmens}

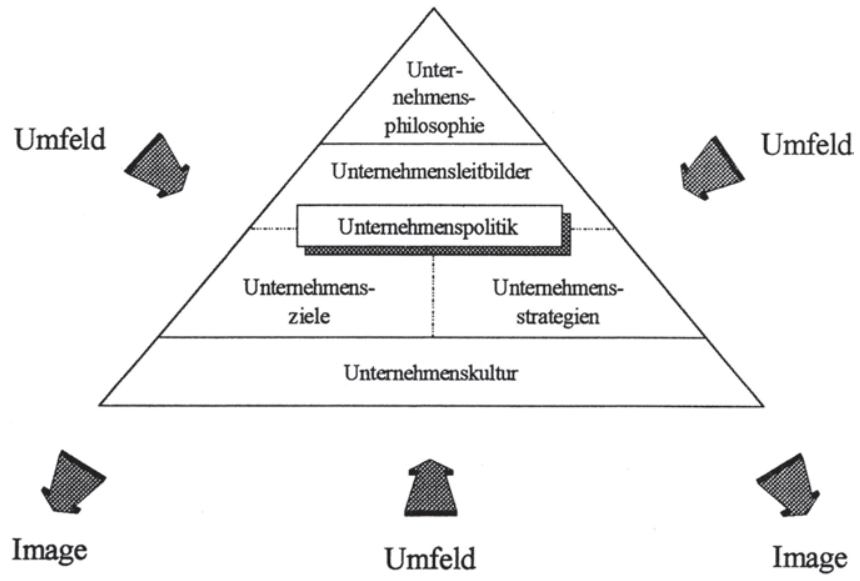

Als einzigartige, immaterielle, intangible Ressource ("invisible assets") erfährt die Unternehmenskultur im Rahmen der Diskussion um eine primär an internen Erfolgspotentialen ausgerichtete ressourcenorientierte Unternehmensfuhrung besondere Beachtung, da sie aufgrund ihres unternehmensspezifischen Charakters eine rasche Nachahmung durch Wettbewerber erschwert. ${ }^{295}$ Sie wird daher von einigen Autoren als eigenständiger Erfolgsfaktor hervorgehoben. ${ }^{296}$ Diese Betrachtungsweise findet aber vielfach keinen Eingang in die Unternehmensfulhrung kleiner und mittlerer Unternehmen, ${ }^{297}$ obwohl gerade hier auch ohne schriftliche Fixierung die unternehmensspezifische Kultur besonders stark und eine nie in Frage gestellte Selbstverständlichkeit ist. Verfügt das Unternehmen über eine starke Unternehmenskultur, dann sollte diese auch zu einem Erfolgsfaktor entwickelt werden. Dem Unternehmer bzw. der Unternehmensfuhrung kommt dabei die schwierige Aufgabe $\mathrm{zu}$, "die in einem langfristigen Prozeß erreichte Kulturstärke nachhaltig - als arteigene, unternehmensspezifische Kulturprofilierung - gegenüber dem Wettbewerb abzuschirmen und als Nutzungspotential allein dem sie generierenden Unternehmen zugänglich zu machen"298 und sie gleichzeitig so flexibel zu gestalten, daß sie einer Transformation des Unternehmens als Reaktion auf externe oder interne

${ }^{295}$ Vgl. Wolfrum, B. (1994b), S. 32. Als intangible Ressourcen konnen nach Hall Vermoggenswerte (z.B. Markennamen, Patente, Copyrights, registrierte Designs, Vertrăge, Ruf, Netzwerke) und Fæhigkeiten bzw. Kompetenzen (z.B. Know-how, Kultur) bezeichnet werden. Vgl. Hall, R. (1992) und (1993). Vgl. ferner Johnson, H.T./Kaplan, R.S. (1987), S. 202; Aaker, D.A. (1989), S. 91f.; Polanyi, M. (1989), S. 49-65; Porter, M.E. (1991), S. 102; Gaitanides, M./Sjurts, I. (1995), S. 65 und S. 76.

${ }^{296}$ Vgl. Peters, T./Waterman, R. (1982), S. 9f.; Krüger, W. (1988), S. 29f.; Meffert, H. (1988), S. 336; Bromann,

P./Piwinger, M. (1992), S. 24f.; Wolfrum, B. (1994b), S. 32.

${ }^{297}$ Vgl. Bussiek, J. (1997), S. 15.

${ }^{298}$ Bleicher, K. (1993b), S. 3406. 
Veränderungen nicht im Weg steht. $\mathrm{Ob}$ also ein Unternehmen innovativ, dynamisch, pragmatisch oder reaktiv auf Umfeldveränderungen reagiert, wird weitgehend durch kulturelle Normen bestimmt. So sind beispielsweise Offenheit und Toleranz eine notwendige Voraussetzung für die Schaffung eines innovativen Umfeldes, das die Basis einer Innovationskultur im Unternehmen darstellt. $^{299}$

\subsubsection{Die Konkretisierung der Unternehmenskultur durch die Unternehmens- philosophie und die Unternehmenspolitik}

Eine Konkretisierung erfährt die Unternehmenskultur in der Unternehmensphilosophie bzw. -vision ${ }^{300}$ und in der Unternehmenspolitik (vgl. Abb. 3-10). Die Unternehmensphilosophie beinhaltet allgemeine Zielvorstellungen und Werte, die eine Interpretation der wirtschaftlichen und gesellschaftlichen Funktion und Position des Unternehmens darstellen. ${ }^{301}$ Mit dem Entwurf eines Zukunftsbildes, dessen Realisierbarkeit einerseits erkennbar, andererseits aber so weit entfernt liegt, um die Begeisterung der Mitarbeiter für eine neue Wirklichkeit zu wekken, ${ }^{302}$ gibt sie Auskunft über den Sinn und Zweck des Unternehmens sowie die angestrebte Entwicklung. Während die Unternehmenskultur in jedem sozialen System unwillkürlich als gewachsenes Phänomen auftritt, "wird die Unternehmensphilosophie von der Unternehmensleitung durch bewußte Willens- und Konsensbildungsprozesse entworfen" ${ }^{303}$ und ist somit ein geplantes Phänomen. Die normativen Aussagen der Unternehmensphilosophie werden auf der strategischen Ebene durch die Unternehmenspolitik operationalisiert. ${ }^{304}$

Die wesentlichen Merkmale der Unternehmenspolitik sind nach ULRICH gekennzeichnet durch originäre, allgemeine und langfristig wirksame Entscheidungen, die das Verhalten des Unternehmens bestimmen: durch die Festlegung des obersten Zielsystems, des erforderlichen Leistungspotentials und der anzuwendenden Strategien sowie durch das Ziel, das Überleben des Unternehmens in einer sich verändernden Umwelt durch Anpassung zu sichern. ${ }^{305}$ Die Unternehmenspolitik kann somit zusammenfassend als Inbegriff grundlegender Maximen

\footnotetext{
${ }^{299}$ Vgl. dazu ausführlich Abschnitt 4.4.2.

${ }^{300}$ Für beide Begriffe findet sich in der Literatur keine einheitliche Definition. Von einer Differenzierung wird abgesehen, da sie für den Fortgang der Arbeit unerheblich ist. Für eine Darstellung der Unternehmensvision sei insbesondere auf Hinterhuber, H.H. (1996), S. 83-96 und Bleicher, K. (1996), S. 97-102 verwiesen. Daneben wird auch auf eine Einordnung bzw. Abgrenzung der Unternehmensethik verzichtet. Zur Unternehmensethik vgl. beispielsweise Kreikebaum, H. (1996); Leisinger, K.M. (1997); Neugebauer, U. (1994); Ulrich, P./Fluri, E. (1995), S. 62-76.

${ }^{301}$ Zum Begriff der Unternehmensphilosophie vgl. z.B. Ulrich, H. (1970), S. 290; Meffert, H. (1983), S. 30; Ulrich, P./Fluri, E. (1995), S. 53; Butterbrodt, D. (1997), S. 103.

${ }^{302} \mathrm{Vgl}$. The Boston Consulting Group (Hrsg.) (1988), S. 7.

${ }^{303}$ Kremmel, D. (1996), S. 59.

${ }^{304}$ Für eine năhere Beschreibung der normativen, strategischen und operativen Unternehmensführungsebene vgl. Gälweiler, A. (1979b), S. 254; Ulrich, H./Probst, G.J.B. (1995), S. 276-283; Ulrich, P./Fluri, E. (1995), S. 18-22; Bleicher, K. (1990), S. 879 und (1996), S. 73-77; Zink, K.J./Hauer R. (1995), S. 106-109.

${ }^{305}$ Vgl. Ulrich, H. (1990), S. 21.
} 
bezeichnet werden, zu denen Leitbilder (Grundsätze) ${ }^{306}$, Ziele und Strategien zu rechnen sind. ${ }^{307}$

Akzeptanz für die Inhalte der Unternehmenspolitik kann am ehesten geschaffen werden, wenn die Organisationsmitglieder in den Entscheidungsproze $ß$ einbezogen werden. ${ }^{308}$ Ein solches Vorgehen ist in kleinen Unternehmenseinheiten durchaus denkbar, setzt allerdings einen partizipativen bzw. kooperativen Führungsstil voraus. Wie jedoch bereits an anderer Stelle aufgezeigt wurde, sind kleine und mittlere Unternehmen durch eine patriarchalische Führung geprägt, die in der Regel keine Gruppenentscheidungen zuläßt. ${ }^{309}$ In diesem Fall bzw. wenn sich aufgrund der Unternehmensgröße eine Einbindung aller Mitarbeiter in den Entscheidungsprozeß nicht gewährleisten läßt, sollte zumindest in ausreichendem Umfang über den Entscheidungsprozeß informiert werden, um die notwendige Motivation für die Umsetzung zu schaffen.

Die Unternehmenspolitik wird im Unternehmensleitbild, in den Unternehmenszielen und den Unternehmensstrategien verbalisiert. Der Prozeß der Entwicklung, Implementierung und Umsetzung der Unternehmensziele und Unternehmensstrategien nimmt im Rahmen des Strategischen Managements eine exponierte Stellung ein. Wie sich zeigen wird, kommt diesem Prozeß auch innerhalb des Innovations- und des Umweltmanagements eine besondere Bedeutung zu. Aus diesem Grund rechtfertigt sich die Darstellung der Unternehmensziele sowie der Unternehmensstrategien in gesonderten Kapiteln (vgl. Kapitel 3.5 sowie 3.6).

Das Unternehmensleitbild bzw. die Unternehmensgrundsätze stellen die grundlegende Willenskundgebung der Unternehmensführung dar. Im Unternehmensleitbild kommt somit eine orientierungsgebende und richtungweisende Idealvorstellung zum Ausdruck, wie das Unternehmen in Zukunft sein und wo es stehen soll. ${ }^{310}$ Ein schlüssiges Unternehmensleitbild ist eine wichtige Grundlage für das Unternehmen, um im Wettbewerb erfolgreich bestehen zu können. Der "Markterfolg [einer Unternehmung, der Verf.] wird dabei um so sicherer und um so nachhaltiger, je klarer ihre Unternehmensgrundsătze formuliert sind und je breiter die Akzeptanz ihrer Mitarbeiter dafür ist" ${ }^{311}$. Gerade für kleine und mittlere Unternehmen ist dies von besonderer Bedeutung, da sie ihre eingeschränkten personellen und finanziellen Mittel

\footnotetext{
${ }^{306}$ Die Begriffe "Unternehmensleitbild" und "Unternehmensgrundsătze" werden synonym verwandt.

${ }^{307}$ Vgl. Kirsch, W. (1991), S. 356. Vgl. zum Begriff der Unternehmenspolitik ferner Ulrich, H. (1990), S. 18f.; Hinterhuber, H.H. (1996), S. 43; Kirsch, W. (1997a), S. 457.

${ }^{308}$ Vgl. Ulrich, H. (1990), S. 47.

${ }^{309}$ Vgl. Abschnitt 2.1.2 bzw. die Charakteristika kleiner und mittlerer Unternehmen von Pfohl und Kellerwessel in Anlage 5. Vgl. dazu ferner Hamer, E. (1990a), S. 87-95.

${ }^{310}$ Vgl. Ulrich, H./Krieg, W. (1974), S. 32. Vgl. ferner Brauchlin, E. (1984), S. 313; Ulrich, H. (1990), S. 31 und S. 91-97; Bleicher, K. (1996), S. 218; Hinterhuber, H.H. (1996), S. 101-105; Sonntag, K. (1996), S. 43; Hopfenbeck, W. (1997), S. 586-590.

${ }^{311}$ Ehrnsperger, F. (1994), S. 24.
} 
zielorientiert und konzentriert einsetzen müssen. ${ }^{312}$ Nach EHRNSPERGER sind die wichtigsten Inhalte von Unternehmensgrundsätzen:

- der Sinn des Unternehmens sowie der Sinn der Arbeit im Unternehmen,

- der Kompetenzanspruch des Unternehmens,

- die Willenserklärung in bezug auf wichtige Ziele und Verhaltensänderungen,

- die Darstellung der Gründe für den unternehmerischen Optimismus,

- der Ausdruck des Selbstbewußtseins,

- die Beschreibung der traditionellen Werte des Unternehmens,

- die Reaktion des Unternehmens auf den Wertewandel,

- der Informationsstil bei fundamentalen Veränderungen im Unternehmen,

- die Grundhaltung in bezug auf Kundenwiunsche,

- das Selbstverstăndnis des Unternehmens in bezug auf Unternehmenskommunikation (Werbung, Public Relations) und Schulung

- die Grundhaltung des Unternehmens in bezug auf den Standort

- die soziale Verpflichtung. ${ }^{313}$

Auf der Grundlage dieser Inhalte erhält das Unternehmensleitbild eine ordnende, integrierende, kreativitäts- und flexibilitätsfördernde Funktion, indem es:

- den Mitarbeitern transparente Handlungsanleitungen für die Erreichung eines gemeinsamen Zieles bietet (Ordnungsfunktion),

- die Aktivitäten der Mitarbeiter ausrichtet und koordiniert (Integrationsfunktion),

- durch impulsgebende Prozesse innovative Vorstellungen generiert (Kreativitätsfunktion) und

- durch permanenten Abgleich mit dem Unternehmensumfeld Änderungsmechanismen in Gang setzt (Flexibilitätsfunktion). ${ }^{314}$

Das Unternehmensleitbild dient somit der Sinngebung, Sinnvermittlung und Sinnfindung im Tätigwerden für ein Unternehmen. ${ }^{315}$ Die Idealvorstellung von der Zukunft des Unternehmens, die durch das Leitbild vorgezeichnet wird, soll mit Hilfe der Unternehmensziele und

$\overline{312}$ Vgl. Brauchlin, E. (1984), S. 313.

${ }^{313}$ Siehe Ehmsperger, F. (1994), S. 24 und Neumarkter Lammsbräu (Hrsg.) (1995), S. 9. Vgl. daneben auch die in Bromann, P./Piwinger, M. (1992), S. 54; Meffert, H. (1994), S. 82ff. bzw. in Kirsch, W. (1997b), S.106110 aufgezeigten Inhalte von Unternehmensleitbildern.

${ }^{314}$ Vgl. altemativ die von Liessmann, K. (1987), S. 128 aufgezeigten Funktionen. Teilweise werden auch den Unternehmenszielen Funktionen eingerăumt. Bea, F.X./Haas, J. (1997), S. 67f. unterscheiden Entscheidungsfunktion, Koordinationsfunktion, Motivationsfunktion, Informationsfunktion, Kontrollfunktion und Legitimationsfunktion. Vgl. daneben auch Meffert, H./Kirchgeorg, M. (1989b), S. 183 und (1992), S. 140f.; Macharzina, K. (1995), S. 179.

${ }^{315}$ Vgl. Bleicher, K. (1996), S. 95. 
Unternehmensstrategien erreicht werden. Durch sie findet eine Konkretisierung dieses $\mathrm{Zu}$ standes statt (Ziele) bzw. wird der Weg dorthin vorgezeichnet (Strategien).

\subsection{Unternehmensziele}

\subsubsection{Begriffsbestimmung}

Unternehmerische Entscheidungen beziehen sich auf zahlreiche Sachverhalte und erfordern ständig die Wahl zwischen verschiedenen Alternativen. Orientiert sich dieser Prozeß an einem bestimmten Zustand in der Zukunft, liegt ein Ziel vor. Zielentscheidungen legen somit einen als erstrebenswert angesehenen Zustand des Unternehmens in der Zukunft fest. ${ }^{316}$ Eine systematische und zukunftsorientierte Unternehmensfuhrung setzt folglich die Formulierung klarer und eindeutiger Ziele voraus, die diesen Zustand verbalisieren. Damit werden alle Unternehmensangehorigen gezwungen bzw. in die Lage versetzt, sich mit den Unternehmens- und Umfeldaktivitäten auseinanderzusetzen, wodurch Stärken und Schwächen sowie Chancen und Risiken offengelegt werden. Die damit einhergehende Vorauskoordination ist verbunden "mit der optimalen Ausnutzung von Unternehmungspotentialen, der ausgleichenden Anpassung an Umweltveränderungen, der Ungewißheitsabsorption, der Motivation und Lenkung von Mitarbeitern sowie der Erhőhung der Flexibilităt und Lernfähigkeit der Planenden" ${ }^{317}$. Verändern sich die unternehmensrelevanten Bedingungen, müssen die Ziele jedoch auch kurzfristig veränderbar sein. Sie sind daher ständig zu überprüfen und, falls notwendig, den veränderten Realităten anzupassen. ${ }^{318}$ Damit Unternehmensziele den Organisationsmitgliedern als Orientierungsrahmen dienen können, müssen sie in den Dimensionen Inhalt, Ausmaß und Zeitbezug realistisch formuliert sein. ${ }^{319}$

Nach HEINEN kann die Gesamtheit von Zielsetzungen als eine Menge von Elementen aufgefaßt werden, die in einem bestimmten Beziehungszusammenhang stehen. Das durch die Rela-

${ }^{316}$ Vgl. Heinen, E. (1976), S. 18; Hauschildt, J. (1977), S. 9. Die Qualităt dieser Entscheidungen hăngt unmittelbar von den verfugbaren Informationen ab, die damit auch Einfluß auf die Zielformulierung, -verfolgung und -erreichung nehmen.

${ }^{317}$ Siegwart, H./Senti, R. (1995), S. 23.

${ }^{318}$ Vgl. Frohlich, E./Pichler, J.H. (1988), S. 93. Siehe dort auch die Abgrenzung von Ziel, Wert und Ideal.

${ }^{319}$ Bei der Formulierung von Zielen müssen nach Haberfellner, R. u.a. (1994), S. 142-152 folgende Prinzipien beachtet werden: Wertorientierung, Lossungsneutralităt, Operationalităt, Vollstăndigkeit hinsichtlich der Zielinhalte, Berücksichtigung aller wichtigen Informationsquellen und Interessenlagen, Feststellbarkeit der Zielerfüllung, Prioritătensetzung, Widerspruchsfreiheit von Teilzielen sowie Überblickbarkeit und Bewältigbarkeit des Zielkatalogs. Allerdings meint Jahnes, S. (1997), S. 65, daß Unternehmensziele, so sie überhaupt vorhanden sind, "zumeist nur teilweise strukturiert, unscharf voneinander abgegrenzt und vage definiert" sind. Darüber hinaus werden Unternehmensziele nicht in ausreichendem Maß kommuniziert, so daß sie nicht allen Mitarbeitern bekannt sind. 
tionen zwischen den einzelnen Elementen gebildete Netz stellt ein System dar, das Zielsystem. $^{320}$

\subsubsection{Die Struktur des Zielsystems}

Unternehmen werden durch die Initiative und die Zielvorstellungen des Unternehmers bzw. der Unternehmensführung geprägt. Die Analyse der Struktur des Zielsystems hat deshalb von den Zielvorstellungen der verantwortlichen Personen auszugehen. Wie sich in der empirischen Zielforschung zeigt, bestehen die Zielsysteme des einzelnen Unternehmens aus einer Vielzahl heterogener Einzelziele, die sich durch unterschiedliche Dimensionen und Ordnungskriterien charakterisieren lassen.

\subsubsection{Die Dimensionen des Zielsystems}

Die Präzisierung von Unternehmenszielen kann mit Hilfe der Dimensionen Zielinhalt, Ausmaß der Zielerreichung sowie zeitlicher Bezug erfolgen.

Der Zielinhalt kennzeichnet die Sachdimension, d.h. die sachliche Festlegung des angestrebten Zustandes in der Zukunft. Beispiele unternehmerischer Zielinhalte sind Gewinn, ${ }^{321} \mathrm{Um}$ satz, Marktanteil, Wirtschaftlichkeit, Unternehmenssicherung, Liquiditätssicherung, Unabhängigkeit, Prestige, Macht sowie auch soziale und ethische Inhalte. ${ }^{322}$ Keine grundsătzlich anderen Zielinhalte, aber eine veränderte Perspektive ergibt sich bei der Festlegung des angestrebten Zustandes unter Berücksichtigung der verschiedenen Anspruchsgruppen (Stakeholder). So werden beispielsweise im Hinblick auf die Kapitalgeber entsprechende Liquidităts- und Rentabilitätsziele oder im Hinblick auf die Kunden (bzw. den Markt) Innovationsziele formuliert, durch die sich der Kundennutzen erhöht, der wiederum die Erreichbarkeit von Marktanteilen determiniert. ${ }^{323}$

Demgegenüber findet der Umweltschutz in den von HEINEN aufgezeigten Zielen keine explizite Erwähnung. In den von ihm angeflihrten ethischen und sozialen Bestrebungen, weist er jedoch darauf hin: "Wirtschaftliches Handeln nach ethischen Prinzipien bedingt, daß die sittli-

\footnotetext{
${ }^{320}$ Vgl. Heinen, E. (1976), S. 24; Bleicher, K. (1971), S. 12f.; Staehle, W.H./Grabatin, G. (1979), S. 90.

${ }^{321}$ Bei der Diskussion der Unternehmensziele steht hăufig die Gewinn- oder Rentabilitătsmaximierung im Mittelpunkt. Vgl. Günzel, D. (1975), S. 18; Heinen, E. (1993), S. 3444. Beispielsweise formulierte Wơhe noch 1960: "Der Betrieb im marktwirtschaftlichen Wirtschaftssystem ... kennt nur ein Ziel: den maximalen Gewinn, also die größtmögliche Rentabilität zu erreichen", Wöhe, G. (1960), S. 23 (Hervorhebung im Original). Dies wurde von ihm spăter modifiziert: "Für die Unternehmung als marktwirtschaftlich orientiertem Betrieb ist die langfristige Gewinnmaximierung das oberste Ziel" (Hervorhebung im Original), Wohe, G. (1996), S. 124. Hierin kommt bereits eine Relativierung des Gewinnstrebens zum Ausdruck. Vgl. dazu ferner die Ergebnisse der empirischen Zielforschung in Abschnitt 3.5.3.

322 Vgl. dazu ausfuhrlich Heinen, E. (1976), S. 59-81; Hörschgen, H. (1992), S. 471.

${ }^{323}$ Vgl. Wieselhuber, N. (1996), S. 333-337.
} 
chen Werte des Kulturkreises, dem der Unternehmer angehört, beachtet und gefördert werden. Es beruht auf der Überzeugung, daß durch eigene Handlungen die berechtigten Interessen anderer Personen nicht geschädigt werden dürfen"324. Daraus lassen sich implizit auch Umweltschutzziele ableiten. Dabei ist es unerheblich, worauf die unternehmerischen Antriebskräfte zurückzuführen sind, auf individualethisch motivierte Verhaltensweisen von seiten des Unternehmers oder auf gesellschaftlich institutionalisierte Normen.

Eine weitere Dimension zur eindeutigen Festlegung unternehmerischer Ziele ist das AusmaB, in dem die Zielerreichung anzustreben ist. Die Bestimmung des Zielausmaßes legt in absoluter oder relativer Form das verfolgte Anspruchsniveau fest. ${ }^{325}$ Beispielsweise bezeichnet ein "Gewinn von mindestens 1 Mio. DM" ein absolutes Anspruchsniveau, während ein "Marktanteil von 10\%" ein relatives Anspruchsniveau bezeichnet. Ferner sind zwei Möglichkeiten zu unterscheiden, die das Zielausmaß bestimmen: Einerseits steht das Streben des Entscheidungsträgers im Mittelpunkt, diejenigen Alternativen auszuwählen, für die die Zielvariablen optimale Werte annehmen (Optimierer). Andererseits kann der Entscheidungsträger die Lossungssuche bereits dann abbrechen, "wenn die Zielvariable einen bestimmten - als befriedigend angesehenen - Wert ubersteigt" ${ }^{326}$ (Satisfizierer). Die Bestimmung sowie die Erreichung eines theoretischen Optimums setzt vollständige Information voraus. Dies ist, sofern überhaupt möglich, mit hohen Informationskosten verbunden, wobei nicht bekannt ist, ob die im Vergleich zur Ausgangssituation ermittelten Alternativen besser sind und die entstandenen Kosten rechtfertigen. Kann das Optimalziel nicht erreicht werden, bricht der Entscheidungsträger die Suche nach Alternativen dann $a b$, wenn ein befriedigendes Niveau erreicht ist. "Eine Alternative ist als befriedigend anzusehen, wenn Kriterien bekannt sind, welche die Mindestanforderungen an eine Lösung des Wahlproblems beschreiben und die in Frage stehende Alternative diese Anforderungen erfüllt oder übertrifft." 327

Das Ziel ist vollständig bestimmt, wenn die dritte Dimension, der zeitliche Bezug, festgelegt ist. Die Zeitdimension beinhaltet den Zeitpunkt - und damit implizit auch den Zeitraum - bis zu welchem ein Ziel erfullt sein soll. ${ }^{328} \mathrm{KIRSCH}$ unterscheidet auch hier nach absoluten ("bis zum 31.12.2000") und relativen bzw. komparativen ("schneller als beim Konkurrenten") Zeitdimensionen. $^{329}$

\footnotetext{
324 Heinen, E. (1976), S. 81.

${ }^{325} \mathrm{Vgl}$. Kirsch, W. (1991), S. 199f.

${ }^{326}$ Heinen, E. (1976), S. 82.

${ }^{327}$ Heinen, E. (1976), S. 83 (im Original teilweise kursiv).

${ }^{328}$ Vgl. Heinen, E. (1976), S. 85-89.

${ }^{329}$ Vgl. Kirsch, W. (1991), S. 200. Vgl. dazu auch die Ausfulhrungen zur statischen bzw. komparativ-statischen Zielformulierung bei Heinen, E. (1976), S. 86ff.
} 


\subsubsection{Ordnungskriterien des Zielsystems}

Die Differenzierung der Ziele nach Inhalt, erstrebtem Ausmaß und zeitlichem Bezug verdeutlicht bereits, daß die Ziele in einem bestimmten Beziehungszusammenhang stehen. Innerhalb des Zielsystems kann einerseits eine Ordnung nach den Beziehungstypen hergestellt werden, d.h. nach Rang, Präferenz und Zielbeziehungen. ${ }^{330}$

Durch die Mittel-Zweck-Beziehung zwischen den Zielen ergeben sich Rangunterschiede, die den Stellenwert eines Zieles in einem hierarchisch aufgebauten Zielsystem verdeutlichen. Die Rangunterschiede können durch die Hierarchieklassen Ober-, Zwischen- und Unterziele ausgedrückt werden. Die Mittel-Zweck-Beziehung der im Zielsystem enthaltenen Elemente kann mit Hilfe eines Beispiels verdeutlicht werden. Das Unterziel "Verbesserung der Qualifikation der Mitarbeiter" stellt ein Mittel zur Erreichung eines ersten Zwischenzieles, der "Verbesserung der Qualität" dar. Durch die Qualitätsverbesserung vermindern sich Ausschuß sowie Kontrollkosten, wodurch somit das Erreichen eines weiteren Zwischenzieles, der "Senkung der Stückkosten" ermöglicht wird. Zwischen dieser Zielsetzung und dem Oberziel "Gewinnsteigerung" besteht wiederum eine Mittel-Zweck-Beziehung.

Ergeben sich bei der Bewertung von Zielinhalten Präferenzen bzw. Prioritäten, wird die Einteilung in Haupt- (Primär-) und Neben- (Sekundär-) ziel möglich. Die Differenzierung ist jedoch nur dann von Bedeutung, wenn es gilt, zwischen zwei gleichrangigen Zielen abzuwågen. Ziele mit höheren Beiträgen zur Erreichung des Oberzieles besitzen eine höhere Präferenz als Ziele mit niedrigeren Zielerreichungsbeiträgen. ${ }^{331}$

Mit den Zielbeziehungen wird das gegenseitige Verhältnis von Zielen beschrieben. Grundsätzlich lassen sich komplementäre, konkurrierende und indifferente Zielbeziehungen feststellen. ${ }^{332}$ Ziele stehen in einem komplementären Verhältnis, wenn mit der Erfüllung des einen Zieles auch der Zielerreichungsgrad des anderen Zieles gesteigert wird, wie dies z.B. bei der Rentabilitäts- und der Gewinnerhöhung der Fall ist. Eine konkurrierende Beziehung liegt vor, wenn die Erfullung eines Zieles zu einer Minderung des Zielerreichungsgrades des zweiten führt. Als Beispiel kann die Intensivierung des Services bei gleichzeitiger Kostenminimierung angefuihrt werden. Zielindifferenz oder -neutralität bedeutet, daß die Erfüllung eines Zieles keine Wirkung auf die Erfullung eines anderen hat. Ein indifferentes Verhältnis zwischen zwei Unternehmenszielen ist lediglich bei einer isolierten Betrachtung ableitbar. Innerhalb eines umfassenden Zielsystems wird sich daher immer eine komplementäre bzw. eine konkurrierende Zielbeziehung ableiten lassen. ${ }^{333}$

\footnotetext{
${ }^{330}$ Vgl. Heinen, E. (1976), S. 94-113; Kirsch, W. (1991), S. 200-204.

331 Vgl. Macharzina, K. (1995), S. 180 f.

${ }^{332}$ Vgl. Heinen, E. (1976), S. 94-102; Hörschgen, H. (1992), S. 466f.

${ }^{333}$ Vgl. Heinen, E. (1976), S. 95.
} 
Neben der Ordnung nach Beziehungstypen kann nach HEINEN andererseits auch die Bildung von diversen Teilmengen als Ordnungskriterium innerhalb des Zielsystems herangezogen werden. Dabei unterscheidet er folgende Klassifikationen:

- quantifizierbare und nicht-quantifizierbare Ziele,

- operationale und nicht-operationale Ziele,

- Absatz-, Produktions- und Finanzierungsziele,

- kurz-, mittel- und langfristige Ziele sowie

- Wachstums-, Erhaltungs- und Schrumpfungsziele. ${ }^{334}$

Diese Klassifikationen fuihren zurilck zu den oben angefuihrten Dimensionen des Zielsystems, da emeut Zielinhalte, Zielausmaße und die Zeitdimension sowie auch Rang, Präferenz und Zielbeziehungen angesprochen werden.

\subsubsection{Ergebnisse der empirischen Zielforschung}

"Die empirische Zielforschung untersucht die Art, das Ausmaß und die relative Bedeutung der in der Unternehmenspraxis angestrebten Ziele. Sie sucht ferner festzustellen, welcher Personenkreis zu welchen Zeitpunkten und Gelegenheiten in der Unternehmung an der Zielbildung beteiligt ist. Schließlich gehen die Bemühungen dahin, Aufschluß zu gewinnen, ob und in welcher Weise Inhalt, Ausmaß und relative Bedeutung der Unternehmerziele im Zeitablauf

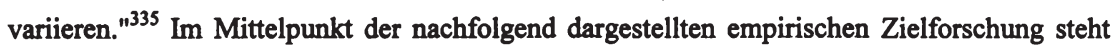
die Frage, welche Ziele in Untermehmen dominieren. ${ }^{336}$ Bezliglich der Situation in der Bundesrepublik Deutschland sind zwei "altere" Untersuchungen von HEINEN und HAUSCHIIDT ${ }^{337}$ sowie verschiedene "jüngere" Untersuchungen hervorzuheben. Zu letzteren zählen die Studie von TÖPFER sowie die Untersuchungen der beiden Forschergruppen um RAFFÉE und um MEFFERT.

334 Vgl. dazu ausfuhrlich Heinen, E. (1976), S. 113-125.

${ }^{335}$ Heinen, E. (1976), S. 30.

${ }^{336}$ Daneben beschäftigt sich die empirische Zielforschung auch mit dem faktischen Zustandekommen von Unternehmenszielen sowie dem Zusammenhang zwischen Zielbildung und Realisierung. Vgl. Macharzina, K. (1995), S. 188.

Grundsătzlich gelten auch hier die im Rahmen der empirischen Erfolgsfaktorenforschung bereits diskutierten Probleme (vgl. Abschnitt 3.3.4.2), die v.a. durch ein begrenztes und vorgegebenes Antwortraster entstehen. Vgl. zu den Problemen der empirischen Zielforschung ferner Macharzina, K. (1995), S. 193ff.

${ }^{337}$ Wird der Betrachtungswinkel erweitert, konnen zu den "allteren" Untersuchungen beispielsweise auch die Studien von Kaplan, Dirlam und Lanzillotti sowie von Raia gerechnet werden. Kaplan, Dirlam und Lanzillotti untersuchten insbesondere die preispolitischen Ziele amerikanischer Großunternehmen. Daraus ergaben sich als wichtigste Ziele der Preispolitik, die Sicherung einer angemessenen Rentabilität, die Stabilisierung der Preise und Gewinnmargen, der Erhalt oder die Verbesserung der Wettbewerbsposition. Vgl. Kaplan, A.D.H. u.a. (1958), S. 128. Raias Untersuchung beschränkte sich auf ein Unternehmen von dem er 16 Basisziele aufzeigt. Hervorstechend ist dabei v.a. die starke Innovationsorientierung, die in verschiedenen Zielen zum Ausdruck kommt. Vgl. Raia, A.D. (1965), S. 51 ff. Weitere empirische Untersuchungen aus dem angelsăchsischen Sprachraum sind bei Blattner und Schuke dokumentiert. Vgl. Blattner, N. (1977), S. 106-116; Schuke, A. (1977), S. 145-166. 


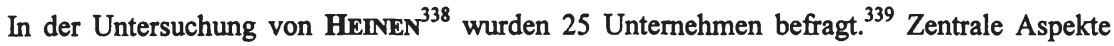
waren die Ermittlung des die Ziele festlegenden Personenkreises bzw. die Art und Rangordnung dieser Ziele. HEINEN stellt als wichtige Unternehmensziele den Gewinn, die Sicherheit, die soziale Verantwortung gegenüber der Belegschaft, den Marktanteil, die Unabhängigkeit, die Kundenpflege, das Wachstum sowie das Prestige fest. ${ }^{340}$ Er weist jedoch auch darauf hin, daß nicht von einem fest umrissenen Zielsystem innerhalb des Unternehmens ausgegangen werden kann, da die Unternehmensziele und ihre Gewichtung nicht immer explizit und für alle Mitarbeiter festgelegt werden. ${ }^{341}$

Die Untersuchung von HaUSCHسDT ${ }^{342}$ stellt eine Meta-Analyse empirischer Arbeiten zur Zielforschung dar. Die in diesen Untersuchungen aufgefundenen Unternehmensziele verdichtet er zu vier Hauptgruppen: dem Streben nach Gewinn, dem Streben nach Größe oder Wachstum, dem Streben nach einer technologischen Profilierung der Leistungen und der Leistungsprogramme sowie dem Streben nach Konsonanz mit Bezugsgruppen außerhalb und Interaktionspartnern innerhalb des Systems. ${ }^{343}$

In den vorstehenden Untersuchungen dominierten ökonomische und insbesondere ertragswirtschaftliche Ziele. In den "neueren" Untersuchungen zeigt sich einerseits eine Veränderung in der Rangfolge der Unternehmensziele - dies trifft v.a. auf das Gewinnziel zu - sowie andererseits eine Erweiterung des unternehmerischen Zielsystems um nicht-ökonomische Ziele.

Deutlich wird dies bereits bei TÓPFER, ${ }^{344}$ der auf der Basis einer Befragung von 196 Industrieunternehmen mit mehr als 500 Mitarbeitern die Sicherung der Wettbewerbsfähigkeit als dominantes Unternehmensziel ermittelte. ${ }^{345}$ Nachrangig folgten die Ziele angemessener Gewinn, Erhaltung der Arbeitsplätze, Verbesserung der Marktposition, Erhaltung der Marktposition, Umweltfreundlichkeit der Produkte und Benutzerfreundlichkeit der Produkte (vgl. Tab. 3-5).

Die Forschungsgruppe um RAFFÉE ${ }^{346}$ stellte mehrere Untersuchungen an, in denen sich eine Verschiebung der Zielgewichtungen ergeben hat. FRITZ, FÖRSTER, RAFFÉE UND SILBE-

\footnotetext{
${ }^{338}$ Vgl. Heinen, E. (1976), S. 37-44.

${ }^{339}$ Eine nahere Charakterisierung der Unternehmen nimmt Heinen nicht vor.

${ }^{340}$ Siehe dazu auch die von Heinen ermittelten Ranghăufigkeiten der Unternehmensziele. Vgl. Heinen, E. (1976), S. 39-43. Er weist bereits in seiner Kritik an der Gewinnmaximierung als Ausgangspunkt der Zielforschung darauf hin, "daß Gewinnstreben nur e i n e s der Ziele unternehmerischen Handelns sein kann". Heinen, E. (1976), S. 29.

${ }^{341}$ Vgl. Heinen, E. (1976), S. 38.

${ }^{342} \mathrm{Vgl}$. Hauschildt, J. (1977).

${ }^{343}$ Vgl. Hauschildt, J. (1977), S. 25f. Eine năhere Charakterisierung der in den jeweiligen Untersuchungen betrachteten Unternehmen erfolgt nicht.

${ }^{344} \mathrm{Vgl}$. Töpfer, A. (1985).

${ }^{345}$ Vgl. Topfer, A. (1985), S. 245ff.

${ }^{346}$ Für einen Überblick siehe Raffée, H. u.a. (1992).
} 
$\mathbf{R E R}^{347}$ konnten 1985 in einer Untersuchung in 202 Industrie- und Handelsunternehmen ähnliche Tendenzen wie bereits TÖPFER erkennen. Ihre Industriebefragungen bei 43 Unternehmen $^{348}$ sowie die Handelsbefragungen bei 13 großen Kaufhauskonzernen bzw. Versandhandelsunternehmen und 146 Unternehmen des Elektro-Einzelhandels zeigten den Gewinn als nachrangiges Ziel. Werden die Ergebnisse der drei Unternehmensgruppen zusammengefaßt, kann die Sicherung des Unternehmensbestandes als dominantes Unternehmensziel identifiziert werden. In einer 1987 durchgeführten Studie von RAFFÉE, FÖRSTER UND KRUPP ${ }^{349}$ wird die Relativierung des Gewinnzieles noch deutlicher. Fand sich bei TÖPFER sowie bei FRTT, FÖRSTER, RAFFÉE UND SILBERER das Gewinnziel noch auf dem zweiten bzw. dritten Rang, war es in dieser Untersuchung mit dem achten Rangplatz nur von mittlerer Bedeutung (vgl. Tab. 3-5). Die Autoren heben ferner die Einstufung sozialer und ökologischer Unternehmensziele hervor. So nehmen insbesondere die okologischen Unternehmensziele im Vergleich mit den Studien von TÖPFER sowie FRTTZ, FÖRSTER, RAFFÉE und SILBERER einen höheren Rangplatz ein. Eine weitere Studie von RAFFÉE UND FRrTz ${ }^{350}$ im Jahr 1990 kam im Grunde zu gleichgerichteten Befunden. Als die wichtigsten Ziele klassifizierten die 144 befragten Industrieunternehmen die Kundenzufriedenheit, die Sicherung des Unternehmensbestandes, die Wettbewerbsfähigkeit sowie die Qualität des Angebotes. Den gewinn-, rentabilitäts- und kostenorientierten Unternehmenszielen maßen sie eine nachrangige Bedeutung bei (vgl. Tab. 35). ${ }^{351}$

Durch die Ergebnisse der Forschungsgruppe um MEFFERT wurde wiederum eine Höherbewertung der gewinn-, rentabilitäts- und kostenorientierten Unternehmensziele offenbar. MEFFERT UND KIRCHGEORG untersuchten 197 Unternehmen des Verarbeitenden Gewerbes mit mehr als 100 Mitarbeitern, die das langfristige Gewinnziel im Zusammenhang mit den

\footnotetext{
${ }^{347}$ Vgl. Fritz, W. u.a. (1985).

${ }^{348}$ Vgl. Tab. 3-5. Die untersuchten Unternehmen gehören der Konsumgüterindustrie an. Eine Aussage uber deren Große wird nicht getroffen.

${ }^{349}$ Vgl. Raffée, H. u.a. (1988) sowie ferner die Veroffentlichung von Fritz, Förster, Wiedmann und Raffée in: Fritz, W. u.a. (1988). Die mündlich durchgefuhrte Befragung bezieht sich auf 53 Industriebetriebe (Kraftfahrzeug, Freizeit, Elektro). Uber die UnternehmensgröBen werden keine Aussagen getroffen.

${ }^{350}$ Vgl. Raffée, H./Fritz, W. (1990); Raffée, H./Fritz, W. (1992).

${ }^{351}$ In der Studie werden 144 Unternehmen des Verarbeitenden Gewerbes mit mehr als 50 Mitarbeitern untersucht. 127 Unternehmen $(88,2 \%)$ haben weniger als 500 Mitarbeiter. Die Studie bezieht sich somit uberwiegend auf KMU.

Aufgrund der Kritik von Meffert und Kirchgeorg an den zuvor veröffentlichten Forschungsresultaten, die sich v.a. auf die zeitlich undifferenzierte Erhebung des Gewinnzieles bezog, wurde in dieser Studie analog zu der Unterscheidung von Meffert und Kirchgeorg zwischen "kurzfristiger" und "langfristiger" Gewinnerzielung differenziert. Anders aber als bei Meffert und Kirchgeorg, wo die langfristige Gewinnerzielung auf Platz 2 und die kurzfristige Gewinnerzielung auf Platz 13 rangierte, und damit eine nach wie vor dominierende Bedeutung des Gewinnzieles in der Gestalt der langfristigen Gewinnerzielung gesehen wurde, bestătigte sich hier durch die Rănge 5 bzw. 22 die eher rückläufige Bedeutung des Gewinnzieles. Vgl. Raffée, H./Fritz, W. (1992), S. 31 Of. i.V.m. Meffert, H./Kirchgeorg, M. (1989a), S. 13ff.; Meffert, H./Kirchgeorg, M. (1989b), S. 188ff.; Kirchgeorg, M. (1990), S. 233-238. Zu einer Relativierung siehe auch Kirsch oder Albach. Letzterer sieht das primäre Ziel mittelständischer Unternehmen darin, "ihre Kunden zufriedenzustellen und - als Nebenprodukt gewissermaßen - Gewinne zu erzielen", Albach, H. (1984), S. 36; Kirsch, W. (1991), S. 239f.
} 
wettbewerbsstrategischen Zielen auch weiterhin als dominierenden Bestandteil des unternehmerischen Zielsystems ansehen (vgl. Tab. 3-5). ${ }^{352}$

Diese Einschätzung wird in den Ergebnissen der eigenen Untersuchung ebenfalls deutlich. Auch die 178 in der Region Neckar-Alb untersuchten kleinen und mittleren Unternehmen des Verarbeitenden Gewerbes weisen der Sicherung der Wettbewerbsfähigkeit und der langfristigen Gewinnerzielung den höchsten Stellenwert zu, gefolgt von den Zielen Kosteneinsparung und Produktivitätssteigerung. Erst im Anschluß daran werden mit dem Unternehmens- und Produktimage und der Mitarbeitermotivation außerökonomische Ziele genannt (vgl. Tab. 3-5). Der Umweltschutz als Unternehmensziel ist von eher untergeordneter Bedeutung. In der Einschätzung des Umweltschutzes als Unternehmensziel zeigt sich ein zunächst deutlicher Unterschied zwischen der Untersuchung von MEFFERT UND KIRCHGEORG und der eigenen Untersuchung. Bei MEFFERT UND KIRCHGEORG rangierte dieser 1989 noch auf Platz acht, während die 1996 untersuchten kleinen und mittleren Unternehmen des Verarbeitenden Gewerbes diesen lediglich auf Rang zwölf plazieren. ${ }^{353}$ Die Differenzierung der Unternehmen nach erfolgreichen bzw. weniger erfolgreichen Unternehmen sowie die Differenzierung nach Betriebs- bzw. Umsatzgrößenklassen zeigt nur vereinzelt Abweichungen vom Gesamtergebnis (vgl. Anlage 13). So messen beispielsweise die Unternehmen der Betriebsgrößenklasse mit weniger als 50 Mitarbeitern der Kooperation mit Abnehmern und dem Handel sowie der Erhaltung von Arbeitsplätzen eine höhere Bedeutung bei als die Unternehmen höherer Betriebsgrößenklassen. In der Betriebsgrößenklasse mit mehr als 200 Mitarbeitern fällt auf, daß die langfristige Gewinnerzielung lediglich den dritten Rang einnimmt und die Marktanteilsziele und die Unternehmenswachstumsziele vergleichsweise höher eingeschätzt werden. Tendenziell lassen sich diese Resultate auch bei einer Unterscheidung nach Umsatzgrößenklassen erkennen. Dort ist besonders bemerkenswert, daß die Unternehmen mit mehr als 100 Mio. Umsatz den Umweltschutz als Unternehmensziel deutlich höher einstufen als dies in den beiden übrigen Umsatzgrößenklassen der Fall ist.

\footnotetext{
${ }^{352}$ Vgl. Meffert, H./Kirchgeorg, M. (1989a), S. 13ff.; Meffert, H./Kirchgeorg, M. (1989b), S. 188ff.; Kirchgeorg, M. (1990), S. 233-238; Ostmeier, H. (1990), S. 113f. Vgl. dazu auch Hofer, C.W./Schendel, D. (1978), S. 1f. und S. $20 \mathrm{f}$.

${ }^{353}$ Für eine ausfuhrlichere Diskussion des Umweltschutzes als Unternehmensziel vgl. Kapitel 5.5.
} 


\begin{tabular}{|c|c|c|c|c|c|}
\hline $\begin{array}{c}\text { Töpfer } \\
196 \text { Unternehmen } \\
1985\end{array}$ & $\begin{array}{c}\text { Fritz/ Förster/ Rafrée/ } \\
\text { Silberer } \\
43 \text { Unternehmen } \\
1985\end{array}$ & $\begin{array}{c}\text { Rafiéd Förster/ Krupp } \\
53 \text { Unternehmen } \\
1987\end{array}$ & $\begin{array}{c}\text { Raffed Fritz } \\
144 \text { Unternehmen } \\
1990\end{array}$ & $\begin{array}{c}\text { Mefiert/ Kirchgeorg } \\
197 \text { Unternehmen } \\
1989\end{array}$ & $\begin{array}{l}\text { eigene Untersuchung } \\
178 \text { Unternehmen } \\
1996\end{array}$ \\
\hline $\begin{array}{l}\text { 1. Sicherung der } \\
\text { Wettbewerbsfahigkeit } \\
\text { 2. angemessener } \\
\text { Gewinn } \\
\text { 3. Verbesserung der } \\
\text { Marktposition } \\
\text { 3. Benutzerfreundlich- } \\
\text { keit der Produkte } \\
\text { 5. Erhaltung der Markt- } \\
\text { position } \\
\text { 6. Erhaltung der Arbeits- } \\
\text { plätze } \\
\text { 7. Umweltfreundlichkeit } \\
\text { der Produkte }\end{array}$ & $\begin{array}{l}\text { 1. Sicherung des Unter- } \\
\text { nehmensbestandes } \\
\text { 2. Qualităt des Angebots } \\
\text { 3. Gewinn } \\
\text { 4. Deckungsbeitrag } \\
\text { 5. Soziale Verant- } \\
\text { wortung } \\
\text { 6. Ansehen in der } \\
\text { Öffentlichkeit } \\
\text { 7. Umsatz } \\
\text { 8. Wachstum des } \\
\text { Unternehmens } \\
\text { 9. Verbraucherversor- } \\
\text { gung } \\
\text { 10. Marktanteil } \\
\text { 11. Macht und Einfluß } \\
\text { auf den Markt } \\
\text { 12. Umweltfreundlich- } \\
\text { keit/Schonung natür- } \\
\text { licher Ressourcen } \\
\text {.. }\end{array}$ & $\begin{array}{l}\text { 1. Wettbewerbsfahigkeit } \\
\text { 2. Qualităt des Angebots } \\
\text { 3. Sicherung des Unter- } \\
\text { nehmensbestandes } \\
\text { 4. Qualitatives Wachs- } \\
\text { tum } \\
\text { 5. Ansehen in der } \\
\text { Öffentlichkeit } \\
\text { 6. Verbraucherver- } \\
\text { sorgung } \\
\text { 7. Deckungsbeitrag } \\
\text { 8. Gewinn } \\
\text { 9. Soziale Verant- } \\
\text { wortung } \\
\text { 10. Schonung natürlicher } \\
\text { Ressourcen und um- } \\
\text { weltfreundliche Pro- } \\
\text { duktion } \\
\text { 11. Verbraucherversor- } \\
\text { gung mit besonders } \\
\text { umweltfreundlichen } \\
\text { Produkten } \\
\text { 11. Unabhängigkeit } \\
\text { 13. Umsatz } \\
\text { 14. Marktanteil } \\
\text { 15. Quantitatives Wachs- } \\
\text { tum } \\
\text { 16. Macht und Einfluß } \\
\text { auf den Markt }\end{array}$ & $\begin{array}{l}\text { 1. Kundenzufriedenheit } \\
\text { 2. Sicherung des Unter- } \\
\text { nehmensbestandes } \\
\text { 3. Wettbewerbsfahigkeit } \\
\text { 4. Qualităt des Angebots } \\
\text { 5. Langfristige Gewinn- } \\
\text { erzielung } \\
\text { 6. Gewinnerzielung ins- } \\
\text { gesamt } \\
\text { 7. Kosteneinsparungen } \\
\text { 8. Gesundes Liquidităts- } \\
\text { polster } \\
\text { 9. Kundenloyalităt } \\
\text { 10. Kapazitătsauslastung } \\
\text { 11. Rentabilităt des Ge- } \\
\text { samtkapitals } \\
\text { 12. Produktivitătssteiger- } \\
\text { ungen } \\
\text { 13. Finanzielle Unab- } \\
\text { hăngigkeit } \\
\text { 14. Mitarbeiterzufrieden- } \\
\text { heit } \\
\text { 15. Umsatz } \\
\text { 16. Erhaltung und Schaf- } \\
\text { fung von Arbeitsplăt- } \\
\text { zen } \\
\text { 17. Wachstum des Unter- } \\
\text { nehmens } \\
\text { 18. Marktanteil } \\
\text { 19. Umweltschutz } \\
\text {.. }\end{array}$ & $\begin{array}{l}\text { 1. Sicherung der Wett- } \\
\text { bewerbsfahigkeit } \\
\text { 2. Langfristige Gewinn- } \\
\text { erzielung } \\
\text { 3. Produktivitats- } \\
\text { steigerungen } \\
\text { 4. Kosteneinsparungen } \\
\text { 5. Mitarbeitermotivation } \\
\text { 6. Image } \\
\text { 7. Erschließung neuer } \\
\text { Mărkte } \\
\text { 8. Umweltschutz } \\
\text { 9. Erhaltung von } \\
\text { 10. Arbeitsplătzen } \\
\text { 10. Karktanteil } \\
\text { 11. Kooperation mit dem } \\
\text { Handel } \\
\text { 12. Umsatz } \\
\text { 13. Kurzfristige Gewinn- } \\
\text { erzielung }\end{array}$ & $\begin{array}{l}\text { 1. Sicherung der Wett- } \\
\text { bewerbsfăhigkeit } \\
\text { 1. Langfristige Gewinn- } \\
\text { erzielung } \\
\text { 3. Kosteneinsparungen } \\
\text { 3. Produktivitătssteiger- } \\
\text { ungen } \\
\text { 5. Unternehmens-/ } \\
\text { Produktimage } \\
\text { 5. Mitarbeitermotivation } \\
\text { 7. Erschließung neuer } \\
\text { Mărkte } \\
\text { 7. Umsatz } \\
\text { 9. Kooperation mit } \\
\text { Abnehmern/ Handel } \\
\text { 9. Erhaltung von } \\
\text { Arbeitsplătzen } \\
\text { 11. Marktanteil } \\
\text { 12. Umweltschutz } \\
\text { 12. Unternehmenswachs- } \\
\text { tum } \\
\text { 12. Kooperation mit } \\
\text { Lieferanten } \\
\text { 15. Kurzfristige Gewinn- } \\
\text { erzielung }\end{array}$ \\
\hline
\end{tabular}


Eine zusammenfassende Bewertung der vorliegenden Untersuchungsergebnisse ergibt folgende Entwicklungstendenzen:

- Die Dominanz des Gewinnzieles kann nur ansatzweise revidiert werden. Bei einer Differenzierung zwischen langfristigem und kurzfristigem Gewinnziel kann eine hohe Bedeutung des langfristigen Gewinnzieles nachgewiesen werden.

- Mit der Sicherung der Wettbewerbsfähigkeit bzw. des Unternehmensbestandes sowie der langfristigen Gewinnerzielung treten zukunftsorientierte, strategische Ziele in den Vordergrund.

- An den Anspruchsgruppen (Stakeholder) orientierte sowie soziale und umweltbezogene Unternehmensziele finden zunehmend Eingang in das Zielsystem der Unternehmen.

- Innovations- und Umweltziele nehmen als Zwischenziele (Instrumente) zur Realisierung der Oberziele in ihrer Bedeutung zu.

- Die Zielbeziehungen zwischen ökonomischen und ökologischen Zielen scheinen zunehmend indifferenter bzw. teilweise sogar komplementärer Natur zu sein.

In den vorgestellten Untersuchungen der "jüngeren" empirischen Zielforschung wird zum Teil ein deutlicher Fokus auf ökologische Belange offenbar. ${ }^{354}$ Die Beschäftigung mit diesem Thema im Rahmen der empirischen Zielforschung resultierte u.a. aus einem seit den achtziger Jahren stetig gestiegenen Umweltbewußtsein ${ }^{355}$. Ein auslösendes Moment für diesen Anstieg ist sicherlich im Reaktorunfall in Tschernobyl zu finden, infolge dessen z.B. auch das Bundesumweltministerium gegründet wurde. Begünstigt wurde die Hinwendung zu ökologischen Zielen darüber hinaus durch eine positive wirtschaftliche Entwicklung sowie der auch zunehmend von unternehmerischer Seite unterstützten These einer indifferenten bzw. sogar komplementären Beziehung zwischen ökonomischen und ökologischen Zielen. Fraglich ist demnach, ob bei einer Verschlechterung der wirtschaftlichen Situation erneut eher ein Konflikt zwischen ökonomischen und ökologischen Zielen gesehen wird. Das Absinken des Umweltschutzziels in der eigenen Untersuchung scheint zumindest auf eine solche Tendenz hinzudeuten.

Innovationsziele fließen zwar implizit z.B. in Form von Qualitäts-, Kosteneinsparungs-, Produktivitätssteigerungs- oder Markterschließungszielen in die genannten Untersuchungen ein, sie werden aber in keiner der vorgestellten Studien explizit hervorgehoben. Da sich die deutsche Wirtschaft international vor allem im Bereich der Hoch- oder Spitzentechnologie ihre

354 Vgl. die Studien von Töpfer, von Raffée, Förster und Krupp sowie von Meffert und Kirchgeorg.

${ }^{355}$ Vgl. auch FN 144. 
Wettbewerbsfähigkeit bewahren muß, ist es gerade die Innovativität eines Unternehmens, die als Zwischenziel die langfristige Wettbewerbsfähigkeit sichern bzw. zu einer langfristigen Gewinnerzielung beitragen kann. Aus diesem Grund legt diese Arbeit einen besonderen Schwerpunkt auf den Aspekt der Innovativität der Unternehmen.

Kleine und mittlere Unternehmen - und hier insbesondere die Unternehmen des Verarbeitenden Gewerbes - stellen einen bedeutenden Wirtschaftsfaktor in der Bundesrepublik Deutschland dar. Diese Tatsache bleibt in den vorgestellten Untersuchungen ebenfalls weitgehend unberücksichtigt. Dies kann zum einen auf die bereits angedeutete große Heterogenität kleiner und mittlerer Unternehmen zurlickgeführt werden. Zum anderen erschwert die für kleine und mittlere Unternehmen typische Zurückhaltung bei der Preisgabe von Informationen eine Untersuchung innerhalb dieser Unternehmensgrößenklasse. Die vorliegende Arbeit stellt daher den Versuch dar, kleine und mittlere Unternehmen entsprechend ihrer wirtschaftlichen Bedeutung in den Vordergrund zu rücken und zu einer Verminderung der Untersuchungsdefizite auf dem Gebiet der Erforschung kleiner und mittlerer Unternehmen beizutragen.

\subsection{Unternehmensstrategien}

\subsubsection{Begriffsbestimmung}

Der Strategiebegriff ist zu einem modischen Schlagwort geworden. Daraus ergibt sich zwangsläufig eine Vielfalt an Verwendungsweisen und Definitionen des Begriffes, die vom Kern der Bedeutung teilweise erheblich abweichen.

Nach GÄLWEILER läßt sich der Strategiebegriff vom altgriechischen "strataegeo" ableiten. "Der erste Teil 'stratos' heißt dabei: Etwas weit Ausgebreitetes und alles andere Überlagerndes, im materiellen wie im geistigen Sinn; etwas, was alles andere umfaßt, übergreift und in sich enthält und damit in der Hierarchie der Zwecke und Ziele eine übergeordnete Bedeutung hat. Der zweite Teil 'ágo' heißt: Tun und handeln und sich dabei vor allem an dem zuvor Genannten, d.h. dem Übergeordneten orientieren. ${ }^{1356}$ Im Vordergrund steht demnach die Ausrichtung der Entscheidungen und Handlungen an übergeordneten Zielen, ohne sich dabei von vordergruindigen Dringlichkeiten ablenken zu lassen.

Ursprünglich war Strategie die Kunst der Staats- und Kriegführung. Erst später fand eine Einengung auf eine militärische Begriffsverwendung statt. ${ }^{357} \mathrm{Im}$ militärischen Bereich waren es vor allem vON CLAUSEWITZ und vON MOLTKE, die sich intensiv mit der Strategie in der

${ }^{356}$ Gälweiler, A. (1981), S. 44.

${ }^{357}$ Vgl. Gälweiler, A. (1981), S. 44f.; Staehle, W.H. (1994), S. 561. 
Kriegfuihrung auseinandersetzten. ${ }^{358}$ Nach vON CLAUSEWITZ entwirft die Strategie "den Kriegsplan, und an dieses Ziel knüpft sie die Reihe von Handlungen an, die zu ihm führen sollen, das heißt sie macht die Entwürfe zu den einzelnen Feldzügen und ordnet in diesen die einzelnen Gefechte an" ${ }^{359}$. VON MOLTKE bringt dies prägnanter zum Ausdruck, indem er in der Strategie die "Fortbildung des ursprünglich leitenden Gedankens entsprechend den stets sich ändernden Verhältnissen" ${ }^{360}$ sieht.

Über die Entwicklung der Spieltheorie fand der Strategiebegriff Eingang in die Wirtschaftswissenschaften. ${ }^{361}$ Eine intensive Diskussion der Thematik im Bereich der Betriebswirtschaftslehre stießen CHANDLER ${ }^{362}$ und ANSOFF $^{363}$ an. CHANDLER definiert in seiner Untersuchung der Strategien und Strukturen großer US-amerikanischer Unternehmen Strategie als "... the determination of the basic long-term goals and objectives of an enterprise, and the adoption of courses of action and the allocation of resources necessary for carrying out these goals" ${ }^{364}$. Seither erfolgte eine umfangreiche Auseinandersetzung mit der Thematik vor allem aufgrund der Erkenntnis, "that a firm needs a well-defined scope and growth direction, that objectives alone do not meet this need, and that additional decision rules are required if the firm is to have orderly and profitable growth" ${ }^{365}$. Die Diskussion fuhrte, wie bereits eingangs erwähnt, zu einem umfangreichen Angebot an Begriffsdefinitionen, die trotz abweichender Intentionen als gemeinsame Basis die Langfristigkeit der Betrachtungsweise herausheben. ${ }^{366}$ Dies bringen auch HOFER UND SCHENDEL zum Ausdruck, indem sie die Strategie eines Unternehmens als "the major link between the goals and objectives the organization wants to achie-

${ }^{358}$ Vgl. von Clausewitz, K. (1832); von Moltke, H. (1925).

${ }^{359}$ Von Clausewitz, K. (1832), S. 159 bzw. ausführlich S. 98-117. Zum militărischen Ursprung vgl. ferner u.a. Gălweiler, A. (1981), S. 36-45; Zorrgiebel, W.W. (1983), S. 16; Hinterhuber, H.H. (1990), S. 3-46 und S. 50.

${ }^{360}$ Von Moltke, H. (1925), Bd. I, S. 241.

${ }^{361}$ Vgl. von Neumann, J./Morgenstern, O. (1944). Sie bezeichnen Strategien als "sets of rules" (S. 44) und fuhren weiter aus: "Imagine now that each player $k=1, \ldots, n$, instead of making each decision as the necessity for it arises, makes up his mind in advance for all possible contingencies; i.e. that the player $\mathrm{k}$ begins to play with a complete plan ... We call such a plan a strategy." (S. 79, Hervorhebung im Original).

362 Vgl. Chandler, A.D. (1962).

${ }^{363}$ Vgl. Ansoff, H.I. (1965).

${ }^{364}$ Chandler, A.D. (1962), S. 13. Vgl. dort insb. die vier Fallstudien der Unternehmen Du Pont, General Motors, Standard Oil Company (New Jersey) und Sears, Roebuck and Company.

${ }^{365}$ Ansoff, H.I. (1965), S. 103. Siehe dazu auch Gälweiler, der im frühzeitigen Erkennen der grundlegenden Entscheidungs- und Handlungsmöglichkeiten und -notwendigkeiten den Kern strategischen Denkens, Entscheidens und Handelns sieht. Das frühzeitige Erkennen wird um so wichtiger, je länger die Zeit ist, die zur Schaffung der notwendigen Erfolgsvoraussetzungen benötigt wird. Gälweiler, A. (1979b), S. 252. Buzzell und Gale stellen ferner fest, daß sich mit Hilfe des PIMS-Programmes ein Zusammenhang zwischen Unternehmensstrategie und Unternehmenserfolg nachweisen läßt. Vgl. Buzzell, R.D./Gale, B.T. (1989), S. XI.

${ }^{366}$ Vgl. z.B. Chandler, A.D. (1962), S. 13; Galweiler, A. (1979b), S. 252; Grochla, E. (1982), S. 112; Perillieux, R. (1987), S. 17; Meffert, H./Kirchgeorg, M. (1993), S. 145; Bea, F.X./Haas, J. (1997), S. 45; Porter, M.E. (1997), S. 48. Vgl. in diesem Zusammenhang auch Chandlers Differenzierung zwischen Strategie und Taktik: "Strategic decisions are concerned with the long-term health of the enterprise. Tactical decisions deal more with the day-to-day activities necessary for efficient and smooth operations. But decisions, either tactical or strategic, usually require implementation by an allocation or reallocation of resources - funds, equipment, or personnel." Chandler, A.D. (1962), S. 11 (Hervorhebung im Original). Vgl. dazu auch von Moltke, H. (1925), Bd. I, S. 242. 
ve and the various functional area policies and operating plans it uses to guide its day-to-day activities" ${ }^{1367}$ betrachten. Sie sehen ferner die Strategie als "the match between an organization's resources and skills and the environmental opportunities and risks it faces and the purposes it wishes to accomplish." ${ }^{368}$ Unternehmensstrategien stellen demnach eines der bedeutendsten Werkzeuge der Unternehmensführung dar, um dem externen und internen Wandel zu begegnen. Folglich lassen sich Strategien als langfristig orientierte Allokations- und Handlungspläne zur Entwicklung und Sicherung unternehmerischer Erfolgspotentiale definieren. ${ }^{369}$

\subsubsection{Die Struktur des Strategiesystems}

Unternehmerisches Handeln erfordert eine Vielzahl von Strategien. Beispielsweise müssen entsprechend der getroffenen Produkt- und Produktionsentscheidungen Ressourcen materieller, finanzieller und personeller Art beschafft und in den Produktionsprozeß sinnvoll integriert werden. Die daraus entstehenden Produkte müssen abgesetzt werden, wobei z.B. zu entscheiden ist, ob dies auf lokalen, nationalen oder internationalen Märkten erfolgt.

Strategien zur nachhaltigen Sicherung des Unternehmens können nur auf der Basis eines operativen, konsistenten Unternehmenszielsystems aufbauen. Hierfür ist es notwendig, die Ziele zu spezifizieren, mögliche Alternativen zu untersuchen, zu bewerten und die geeigneten Alternativen auszuwählen. ${ }^{370}$ Aus den Zielen lassen sich dann Strategien ableiten. Sie spezifizieren die Leitwerte (Ziele) und stellen damit Vorgaben für konkretes Handeln dar. Die durch das Unternehmen festgelegten Strategien lassen erkennen, wie bestehende und potentielle Stärken dazu benutzt werden, Umfeldbedingungen und deren Veränderungen gemäß den unternehmerischen Absichten zu begegnen. Entsprechend kann im Zusammenhang mit den Unternehmensstrategien ebenfalls von einem System gesprochen werden. Analog zu den Unternehmenszielen lassen auch sie sich anhand ihrer Dimensionen bzw. diverser Ordnungskriterien unterscheiden.

\footnotetext{
${ }^{367}$ Hofer, C.W./Schendel, D. (1978), S. 13. Vgl. dazu auch Galweiler, A. (1981), S. 50.

${ }^{368}$ Hofer, C.W./Schendel, D. (1978), S. 11.

${ }^{369}$ Vgl. z.B. Pümpin, C. (1981), S. 7f.; Bea, F.X./Haas, J. (1997), S. 45; Meffert, H./Kirchgeorg, M. (1993), S. 145; Antes, R. (1988), S. 11; Gaitanides, M./Sjurts, I. (1995), S. 62.

${ }^{370}$ Vgl. z.B. Hofer, C.W./Schendel, D. (1978), S. 6; Schendel, D.E./Hofer, C.W. (Hrsg.) (1979), S. 14; Brenken, D. (1988), S. 85-100; Ansoff, H.I. (1988), S. 21 ff.; Hinterhuber, H.H. (1996), S. 22. Bezuglich der zeitlichen Abfolge der Formulierung von Unternehmenszielen und -strategien herrschen in der Literatur unterschiedliche Auffassungen. Während beispielsweise die vorgenannten Autoren ein Zielsystem für die Formulierung von Strategien voraussetzen, weisen z.B. Kirsch, Steger und Kreikebaum darauf hin, daß das Zielsystem erst wăhrend bzw. am Ende des Planungsprozesses spezifiziert werden kann. Zunăchst gilt es, im Anschluß an eine Markt- und Konkurrenzanalyse Strategien - auch im Hinblick auf die verfugbaren Ressourcen - festzulegen. Vgl. Kirsch, W. (1991), S. 222; Steger, U. (1993), S. 189-193 und Kreikebaum, H. (1997), S. 62f. und $67 f$.
} 


\subsubsection{Die Dimensionen der Strategie}

Unternehmerischen Entscheidungen liegen in der Regel mehrdimensionale Probleme zugrunde, zu deren Lösung im Rahmen einer strategischen Unternehmensführung mehrdimensionale Strategien notwendig sind. HINTERHUBER sieht die einzelne Strategie durch mehrere Dimensionen bestimmt, die erst in ihrer Gesamtheit ein zutreffendes Bild der Strategieproblematik abgeben:

- die politische Dimension,

- die kulturelle, ethische und soziale Dimension,

- die psychologische Dimension,

- die wirtschaftliche und finanzielle sowie technische bzw. zeitliche Dimension,

- die rationale und irrationale Dimension,

- die berechenbare und nicht-berechenbare Dimension,

- die nationale und internationale Dimension. ${ }^{371}$

Die von HINTERHUBER aufgezeigten Dimensionen geben einen Eindruck von den vielfältigen Ansprüchen, die an die Formulierung von Strategien gestellt werden. Sie leisten aber keine ausreichende Entscheidungshilfe für die Formulierung von Strategien. Etwas spezifischer wird GÄLWEILER, der für den praktischen Vollzug eindeutige, allgemein anwendbare und damit operationale Kriterien fordert. Dies bedeutet für ihn, daß sie in der Praxis einfach erkennbar, akzeptierbar, leicht und eindeutig zugänglich sowie leicht integrierbar sein müssen. ${ }^{372}$ Eine Spezifikation auf dieser übergeordneten Ebene unterbleibt in der Literatur weitgehend und soll auch in dieser Arbeit erst im Rahmen der einzelnen Strategietypen, d.h. der Innovationsbzw. Umweltstrategien, erfolgen.

\subsubsection{Ordnungskriterien des Strategiesystems}

Bereits in der Anfangsphase der Strategiediskussion in den sechziger und siebziger Jahren wurden zahlreiche Strategiekonzepte und -modelle entwickelt. ${ }^{373}$ Mittlerweile existiert eine unüberschaubare Ansammlung von Konzepten und Modellen zur Strategieformulierung. Folglich können auch Versuche, Strategien zu typologisieren, nur ein unvollständiges und grobes Abbild der in Theorie und Praxis vorfindbaren Strategien sein. $\mathrm{Zu}$ den bedeutendsten Ansätzen zur Typisierung von Strategien zählen die Vorschläge von ANSOFF ${ }^{374}$, aus dem BCG-Ansatz ${ }^{375}$, von Arthur D. Little ${ }^{376}$ sowie von PORTER ${ }^{377}$, denen in Abhängigkeit von der

\footnotetext{
${ }^{371}$ Vgl. dazu ausfuhrlich Hinterhuber, H.H. (1996), S. 142ff.

${ }^{372}$ Vgl. Gälweiler, A. (1981), S.34.

${ }^{373}$ Vgl. Hofer, C.W./Schendel, D. (1978), S. 16-19.

${ }^{374} \mathrm{Vgl}$. Ansoff, H.I. (1965).

${ }^{375} \mathrm{Vgl}$. Abschnitt 3.3.3.4.
} 
Fragestellung eine Vielzahl von weiteren Typisierungsversuchen folgte. Eine mögliche Systematik der wichtigsten Strategiearten zeigt die nachfolgende Tabelle:

Tab. 3-6: Strategien im Überblick

\begin{tabular}{|l|l|}
\hline Klassifikationskriterien & \multicolumn{1}{|c|}{ Strategiearten } \\
\hline $\begin{array}{l}\text { Organisatorischer Geltungsbe- } \\
\text { reich }\end{array}$ & $\begin{array}{l}\text { Unternehmensstrategie } \\
\text { Geschaftsbereichsstrategie } \\
\text { Funktionsbereichsstrategie }\end{array}$ \\
\hline Entwicklungsrichtung & $\begin{array}{l}\text { Wachstumsstrategie } \\
\text { Stabilisierungsstrategie } \\
\text { Schrumpfungstrategie }\end{array}$ \\
\hline $\begin{array}{l}\text { Produkt-Markt-Kombinationen } \\
\text { (ANSOFF) }\end{array}$ & $\begin{array}{l}\text { Marktdurchdringungsstrategie } \\
\text { Markterweiterungstrategie } \\
\text { Produkterweiterungsstrategie }\end{array}$ \\
\hline Diversifikationsstrategie
\end{tabular}

Quelle: vgl. Kreikebaum, H. (1997), S. 58 i.V.m. Bea, F.X./Haas, J. (1997), S. 156. ${ }^{378}$

Die Vielzahl strategischer Konzepte erschwert ihre empirische Überprüfung. Deshalb befassen sich empirische Arbeiten zur Strategieforschung lediglich mit einer begrenzten Anzahl von Strategien und/oder mit Strategien, die einen bestimmten Fokus aufweisen. Die Ergebnisse der empirischen Strategieforschung werden daher in dieser Arbeit auf Innovations- bzw. Umweltstrategien beschränkt (vgl. Kapitel 4.6 bzw. 5.6).

${ }^{376}$ Vgl. Mintzberg, H. (1988), S. 1f.; Hax, A.C./Majluf, N.S. (1991), S. 41 f.

${ }^{377}$ Vgl. Porter, M.E. (1980); Porter, M.E. (1985).

${ }^{378}$ Weitere Typisierungsansătze finden sich bei Schendel, D.E./Hofer, C.W. (Hrsg.) (1979), S. 11ff.; Pümpin, C. (1981), S. 22; Wiedmann, K.-P./Kreutzer, R. (1985), S. 113; Herbert, T.T./Deresky, H. (1987), S. 136ff.; Mintzberg, H. (1988), S. 62f.; Hax, A.C./Majluf, N.S. (1991), S. 41f. Vgl. daneben auch die 6 Typen strategischer Grundhaltungen nach Kirsch und Trux in Abschnitt 3.2.2. Einen Überblick uber strategische Grundverhaltensweisen bietet Hopfenbeck, W. (1997), S. 444-455. 
Wie bei den Unternehmenszielen läßt sich auch bei den Unternehmensstrategien eine Hierarchie bilden (siehe Abb. 3-11). HOFER UND SCHENDEL ${ }^{379}$ unterscheiden in bezug auf den organisatorischen Geltungsbereich drei verschiedene Ebenen eines strategischen Planungssystems:

- die Ebene der Unternehmensstrategie (corporate level),

- die Ebene der Geschäftsbereichsstrategie (business level) und

- die Ebene der Funktionsbereichsstrategie (functional area level). ${ }^{380}$

Im Rahmen der Unternehmensstrategie werden die unterschiedlichen Produkt- und Dienstleistungsbereiche festgelegt, in die intensiv oder weniger intensiv investiert werden soll. Parallel dazu sind Entscheidungen darüber zu treffen, auf welchen Märkten die Produkte und Dienstleistungen angeboten werden sollen. Zusammen bestimmen sie den Umfang bzw. die Reichweite der Unternehmenstätigkeit. Die grundsätzliche Frage, die in diesem Zusammenhang zu beantworten ist, lautet somit "what set of business should we be in" ${ }^{381}$. Durch die unmittelbare Verschränkung von Produkten und Märkten stehen Produkt-Markt-Strategien im Mittelpunkt der Strategieformulierung auf der Ebene der Unternehmensstrategie. Wesentlichen Einfluß auf diesen Strategiebereich hatte die Arbeit von ANSOFF. ${ }^{382}$ Die Unternehmensstrategie beinhaltet somit lediglich die strategische Grundorientierung des Unternehmens, d.h. allgemeine Verfahrensrichtlinien zur Erreichung der Unternehmensziele. ${ }^{383}$ Die Geschäftsbereichsstrategie hingegen beschäftigt sich mit dem "Wie", d.h. in welcher Art und Weise das Unternehmen in bestimmten Industriebereichen oder Produkt-Markt-Segmenten konkurrieren will. $^{384}$ Die zugrundeliegenden Wettbewerbsstrategien gehen auf PORTER zurück. ${ }^{385}$ Die Bildung eines Wettbewerbsvorteiles bedingt, wie bereits aufgezeigt, die Entwicklung unverwechselbarer Kompetenzen, d.h. bestimmter Ressourcen oder Fähigkeiten des Unternehmens. Diese können z.B. in bestimmten Distributionsformen, Forschungs- und Entwicklungs- oder Innovationskapazitäten, technologischen Fähigkeiten sowie in der Qualität oder Kombination der Produkte und Leistungen begründet sein. Auf der Ebene der Funktionsbereichsstrategie steht folglich die Maximierung der Ressourcenproduktivität in den einzelnen Funktionsbereichen im Vordergrund, indem Synergieeffekte genutzt sowie die Entwicklung der Kompetenzen vorangetrieben werden. ${ }^{386}$ Aber obwohl die drei Strategietypen sich deutlich unterschei-

\footnotetext{
${ }^{379}$ Vgl. Hofer, C.W./Schendel, D. (1978). Vgl. ferner Bamberger, J./Bonacker, R. (1994).

${ }^{380}$ Vgl. für eine Übersicht Hofer, C.W./Schendel, D. (1978), S. 27ff.

${ }^{381}$ Hofer, C.W./Schendel, D. (1978), S. 27.

${ }^{382}$ Siehe Abschnitt 3.6.3.1.

${ }^{383}$ Vgl. Meffert, H./Ostmeier, H. (1990), S. 112 i.V.m. Jahnes, S. (1997), S. 78.

${ }^{384} \mathrm{Vgl}$. dazu auch Abell, D.F. (1980), S. 18.

385 Siehe Abschnitt 3.6.3.2.

${ }^{386}$ Vgl. Hofer, C.W./Schendel, D. (1978), S. 29; Bamberger, J./Bonacker, R. (1994), S. 33.
} 
den, "they should all fit together to form a coherent and consistent whole for any particular organization if the organization is to be successful over the long run"387.

Werden die in Tab. 3-6 aufgezeigten Arten von Strategien nach Unternehmens-, Geschäftsbereichs- und Funktionsbereichsstrategie gruppiert ergibt sich folgendes Bild:

Abb. 3-11: Gliederung der Strategiearten nach den Ebenen des Planungssystems

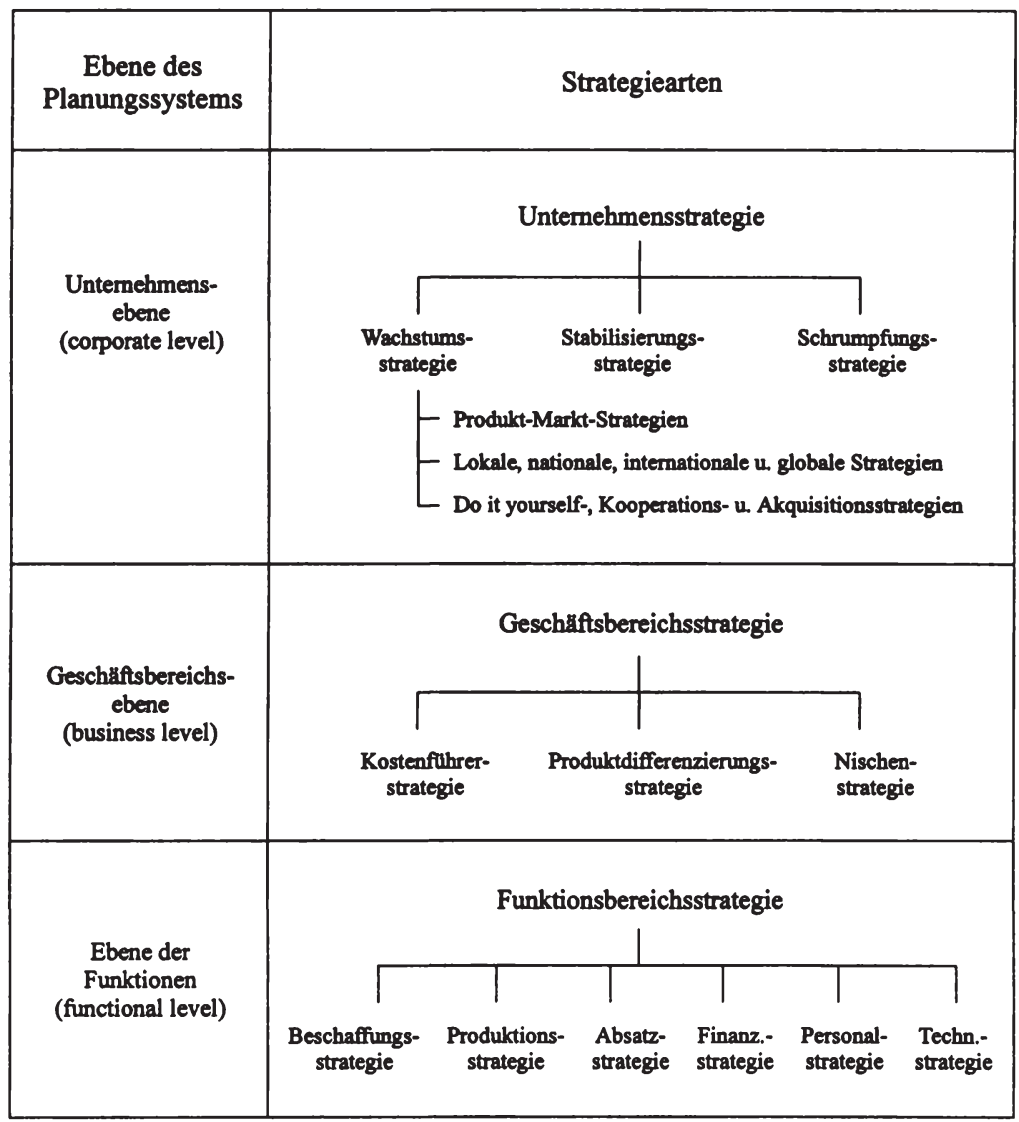

Quelle: Bea, F.X./Haas, J. (1997), S. 157.

${ }^{387}$ Hofer, C.W./Schendel, D. (1978), S. 29. 


\subsubsection{Strategieformulierung und ausgewählte Strategiearten}

Der vorstehend aufgezeigte Strategienkatalog kann auch als Menü verstanden werden, das in Abhängigkeit von der unternehmerischen Zielsetzung zusammengestellt wird. Es zeigt sich jedoch, daß die wenigsten Unternehmen eine strategische Planung besitzen. Dies ist die Folge einer lediglich rudimentären expliziten Dokumentation der wichtigsten Unternehmensziele. ${ }^{388}$ Zur langfristigen Sicherung der Wettbewerbsfähigkeit des Unternehmens sind aber sowohl Unternehmensziele als auch Unternehmensstrategien eine notwendige Voraussetzung. HEDLEY fuihrt dazu aus: "Clear and explicit considerations of long range strategy must be restored to our business consciousness and decision making, or we shall find that we have mortgaged the future irretrievably." ${ }^{389}$

Liegen formulierte Unternehmensziele (vgl. Kapitel 3.5) vor oder sind diese zumindest implizit vorhanden, bilden sie eine Komponente der Strategieformulierung. Eine weitere Komponente für die Formulierung von Strategien stellt die Unternehmenskultur (vgl. Kapitel 3.4) dar, da das Zusammenspiel von Kultur und Strategie einen wichtigen Ausgleich zwischen der eher vergangenheitsorientierten Kultur und den in die Zukunft gerichteten Strategien schafft. ${ }^{390}$ Mit Hilfe der Strategien sollen nachhaltige Wettbewerbsvorteile auf- und ausgebaut werden. Deshalb ist bei ihrer Formulierung ferner darauf $\mathrm{zu}$ achten, daß sie funktional (problembezogen), genau und zielgerichtet, erfullbar sowie anpassungsfähig bzw. robust gegenüber Veränderungen der externen und internen Bedingungen sind.

Der Prozeß der Strategieformulierung setzt sich aus drei Komponenten zusammen: ${ }^{391}$

1. Analyse der strategischen Ausgangsposition, d.h. Unternehmens- und Umfeldanalyse;

2. Entwicklung der strategischen Stoßrichtung, d.h. Bestimmung der zukünftigen Stellung der strategischen Geschäftseinheiten und des Unternehmens als Ganzes in seinem Umfeld;

\footnotetext{
${ }^{388}$ Vgl. Kirsch, W. (1991), S. 220. Zur Grundproblematik der strategischen Untemehmensfuhhrung in KMU vgl. Abschnitt 3.3.1.

${ }^{389}$ Hedley, B. (1977), S. 15.

${ }^{390}$ Vgl. Wolfrum, B. (1994b), S. 34f.; Hinterhuber, H.H. (1997), S. 237; Bromann, P./Piwinger, M. (1992), S. 14f.; Bleicher, K. (1993a), S. 178-182; Kremmel, D. (1996), S. 2f. (Trilogie von Strategie-Kultur-Struktur); Krüger, W. (1989), S. 16.

$\mathrm{Zu}$ diesem Zweck müssen die der Unternehmenskultur zugrundeliegenden Elemente erfaßt werden. Als sog. "weicher" Erfolgsfaktor bzw. intangible Ressource entzieht sich die Unternehmenskultur aber weitgehend einer Operationalisierung und somit einer objektiven Meßbarkeit. Einen Versuch, die dominierenden Werte der Unternehmenskultur zu gewichten und entsprechend ihrer Bedeutung verschiedenen Strategiearten zuzuordnen, unternimmt Hinterhuber, H.H. (1997), S. 238-243.

${ }^{391}$ Vgl. Macharzina, K. (1995), S. 233 bzw. ausfuhrlich S. 242-331; Hinterhuber, H.H. (1996), S. 18-22. Letzterer ergänzt noch einen vierten Punkt, und zwar die Festlegung kommunizierbarer und meßbarer Kriterien, d.h. die Evaluation der Strategie. Zur Strategieformulierung vgl. ferner z.B. Miller, A./Dess, G.G. (1996), Part II; Mugler, A./Schmidt, K.-H. (Hrsg.) (1995), S. 56
} 
3. Formulierung der (Produkt-Markt-) Strategie, d.h. Auswahl, Entwicklung und Allokation von Produkten, Technologien, Fähigkeiten und Ressourcen zur Schaffung von Wettbewerbsvorteilen und Synergieeffekten.

Die beiden ersten Komponenten wurden bereits im Rahmen der Abschnitte 3.3.2 und 3.3.3 angesprochen. Die dritte Komponente wird in den beiden nachfolgenden Abschnitten am Beispiel der von ANSOFF entwickelten Wachstumsstrategien (Produkt-Markt-Strategien) sowie der von PORTER entwickelten Wettbewerbsstrategien erläutert, welche zum einen die Strategiediskussion wesentlich beeinflußt haben und zum anderen mit Blick auf die Differenzierung kleiner und mittlerer Unternehmen hinsichtlich der Unternehmensgröße bzw. des Unternehmenserfolgs von besonderer Bedeutung sind.

\subsubsection{Wachstumsstrategien}

Ein Schema zur Darstellung von unterschiedlichen Wachstumsmöglichkeiten wurde von ANSOFF entwickelt. ${ }^{392}$ Ansoffs Konzept unterscheidet vier Typen von Produkt-MarktStrategien: die Marktdurchdringung, die Produkterweiterung, die Markterweiterung, die Diversifikation. ${ }^{393}$ Die Wahl der einzelnen Strategien wird von der grundsătzlichen Einstellung des Unternehmers bzw. der Unternehmensfuhrung bestimmt. Die Art der Marktbearbeitung wird daneben auch durch das vorhandene Know-how, die Finanzkraft, die Segmentattraktivităt und die Wettbewerbsintensităt beeinflußt. Vor diesem Hintergrund wurden die verfolgten Wachstumsstrategien auch bei den Unternehmen in der Region Neckar-Alb abgefragt. ${ }^{394}$

Hinter der Marktdurchdringungsstrategie steht die Uberlegung, mit dem derzeitigen Produktangebot den Marktanteil auf den derzeit bearbeiteten Märkten zu erhöhen. Dies kann z.B. über die Intensivierung der Nutzung bei bestehenden Kunden, über das Abwerben von Kunden bei Konkurrenten oder uber die Erschließung neuer Kundengruppen geschehen. Von den Unternehmen in der Region Neckar-Alb wählen 69,0\% die Strategie der Marktdurchdringung.

Bei der Produkterweiterungsstrategie werden durch das Unternehmen neue Produkte auf den bisher bearbeiteten Märkten (räumlich bzw. abnehmergruppenspezifisch) angeboten, indem beispielsweise eine Veränderung der Produktmerkmale oder -qualitäten stattfindet oder

${ }^{392}$ Vgl. Ansoff, H.I. (1957); Ansoff, H.I. (1965).

${ }^{393}$ Vgl. Ansoff, H.I. (1957), S. 114; Ansoff, H.I. (1965), S. 108ff. Vgl. zur Beschreibung der Strategien ferner Mintzberg, H. (1988), S. 31-38. Die Entwicklung der Wachstumsstrategien wurde stark durch die Kritik Ansoffs an Levitts Ansatz geprägt, den er als zu breit bzw. zu wenig zielgerichtet ansah. Vgl. Ansoff, H.I. (1965), S. 104-108 i.V.m. Levitt, T. (1960). Vgl. als Vorläufer auch Johnson, S.C./Jones, C. (1957).

Für die Erweiterung der vorgenannten Ansătze vgl. z.B. Abell, D.F. (1980), S. 14-18; West, A. (1992), S. 162-166.

${ }^{394}$ Siehe Frage 2/7 des Fragebogens im Anhang. Die Differenzierung nach den Erfolgstypen (vgl. Abschnitt 4.6.2) wird zeigen, daß sich die besonders erfolgreichen Unternehmen z.T. signifikant von den ubrigen unterscheiden, so daß die Intensităt der Verfolgung der Wachstumsstrategien Hinweise auf die Innovativităt zuläßt. 
in völlig neue Produktbereiche vorgestoßen wird. Die Strategie der Produkterweiterung wird von $54,0 \%$ der befragten Unternehmen in der Region Neckar-Alb verfolgt.

Die Markterweiterungsstrategie beinhaltet die Suche nach neuen Märkten für die bestehenden Produkte. Dabei kann eine Entwicklung des Marktes durch die Bearbeitung neuer Marktsegmente (z.B. neue Abnehmergruppen, neue Distributionskanäle) oder durch eine räumliche Erweiterung des Marktes (z.B. regional, national, international) erfolgen. Von den Unternehmen in der Region Neckar-Alb wird die Strategie der Markterweiterung von 44,8\% der befragten Unternehmen wahrgenommen.

Die Diversifikation stellt eine Verknüpfung der Markt- und Produkterweiterung dar. Hier werden die angestammten Betätigungsfelder verlassen, um mit neuen Produkten auf neue Märkte zu drängen. ${ }^{395}$ Die Strategie der Diversifikation bietet sich an, "wenn das Unternehmen außerhalb seiner gegenwärtigen Tätigkeitsfelder auf eine vielversprechende Marktchance stößt, also einen besonders attraktiven Markt entdeckt, für dessen Bearbeitung das Unternehmen genau die richtigen Wettbewerbsvorteile mitbringt ${ }^{\prime 396}$. Bei der Diversifikation lassen sich drei Arten unterscheiden: die horizontale, die vertikale und die laterale bzw. konglomerate Diversifikation. ${ }^{397}$ Eine horizontale Diversifikation liegt vor, wenn die Erweiterung des Leistungsprogrammes auf derselben Stufe stattfindet, d.h. die Produkte und Leistungen stehen noch in sachlichem Zusammenhang zu den bisherigen. Ziel ist dabei in der Regel die Realisierung von economies of scope sowie die Übertragung von Kernkompetenzen auf andere Bereiche. Die vertikale Diversifikation bezieht sich auf vor- oder nachgelagerte Wertschöpfungsstufen, wobei je nach Diversifikationsrichtung von Vorwärts- oder von Rückwärtsintegration geprochen wird. Unter lateraler bzw. konglomerater Diversifikation wird schließlich das Eindringen in für das Unternehmen neue Wirtschaftsbereiche verstanden. Die Gründe für die Wahl der Diversifikationsstrategie liegen hauptsächlich darin begründet, daß die Unternehmen in ihren angestammten Märkten ein nicht mehr ausreichendes Expansionspotential vorfinden. Ferner spielen Risikominimierung, Nutzung von Chancen, Wachstums- oder Technikfolgen und psychologische Faktoren eine Rolle. Diversifikation erfordert in der Regel den Einsatz neuer Fähigkeiten und Fertigkeiten, neuer Technologien und neuer Produktionsmöglichkeiten. Damit verbunden ist ein physischer und organisatorischer Wandel des Geschäftsfeldes, der einen Bruch mit den bisherigen Geschäftsfeldern bedeuten kann. ${ }^{398}$ Werden Diversifikationen

\footnotetext{
${ }^{395}$ Vgl. ausfuhrlich Brauchlin, E./Wehrli, H.-P. (1994), S. 123-135 und die dort angegebene Literatur. Vgl. ferner Brodbeck, H. (1995), S. 41-45, der insbesondere bei kleinen Unternehmen eine zu starke Konzentration auf eine Produktgruppe und damit eine Vernachlässigung der Diversifikation feststellt.

${ }^{396}$ Kotler, P./Bliemel, F. (1992), S. 68.

${ }^{397}$ In der Volkswirtschaftslehre wird ebenfalls zwischen horizontalen, vertikalen und diagonalen Zusammenschlüssen differenziert, wobei die diagonalen Zusammenschlusse weiter nach Markterweiterungszusammenschlüssen, Marktverkettungszusammenschlüssen und reinen Marktdiversifikationszusammenschlüssen gegliedert werden. In der volkswirtschaftlichen Diskussion stehen allerdings Konzentrationseffekte im Vordergrund. Vgl. Herdzina, K. (1993), S. $192 \mathrm{f}$.

${ }^{398}$ Vgl. Ansoff, H.I. (1957), S. 114.
} 
durchgefuihrt, sollten diese daher in verwandten Geschäftsbereichen getätigt werden, um Synergiepotentiale hoch und das Risiko niedrig zu halten. ${ }^{399}$ Die Verfolgung einer Diversifikationsstrategie stellt, im Vergleich zu den vorgenannten Strategietypen, die höchsten Ansprüche an den Unternehmer bzw. die Unternehmensführung. Dies spiegelt sich auch im Untersuchungsergebnis wider. Die Strategie der Diversifikation wird von ca. einem Drittel $(32,8 \%)$ der Unternehmen verfolgt.

Die vier Wachstumsstrategien lassen sich in Form einer Matrix zusammenfassen: ${ }^{400}$

\section{Tab. 3-7: Matrix der Produkt-Markt-Strategien und Intensität ihrer Anwendung} durch die Unternehmen in der Region Neckar-Alb

\begin{tabular}{|l|c|c|}
\hline Märkte & bestehende & neue \\
\hline bestehende & $\begin{array}{c}\text { Marktdurchdringung } \\
\text { (market penetration) } \\
69,9 \%\end{array}$ & $\begin{array}{c}\text { Produkterweiterung } \\
\text { (product development) } \\
54,0 \%\end{array}$ \\
\hline neue & $\begin{array}{c}\text { Markterweiterung } \\
\text { (market development) } \\
44,8 \%\end{array}$ & $\begin{array}{c}\text { Diversifikation } \\
\text { (diversification) } \\
32,8 \%\end{array}$ \\
\hline
\end{tabular}

Quelle: eigene Berechnungen.

Die Intensităt der Verfolgung der Produkt-Markt-Strategien durch die Unternehmen in der Region Neckar-Alb gibt bereits einen ersten groben Eindruck der Präferenzen kleiner und mittlerer Unternehmen. Ein deutlicher Schwerpunkt liegt dabei auf der Strategie der Marktdurchdringung, während Produkterweiterung, Markterweiterung und Diversifikation mit sinkender Intensität verfolgt werden.

Eine mögliche Begründung für die Strategiewahl kleiner und mittlerer Unternehmen kann darin gesehen werden, daß die Anforderungen, die an den Unternehmer bzw. die Unternehmensführung durch die Verfolgung der einzelnen Strategien gestellt werden von der Marktdurchdringung über die Produkt- und Markterweiterung bis zur Diversifikation kontinuierlich ansteigen. Je höher beispielsweise der Innovationsgrad der Produkte ist bzw. je entfernter die Märkte liegen, die erschlossen werden sollen, desto mehr Know-how ist erforderlich und desto schwieriger lassen sich die notwendigen Informationen beschaffen. Entsprechend sinken die Erfolgschancen bzw. steigen die Risiken der genannten Strategien je differenzierter Pro-

${ }^{399}$ Vgl. dazu die Diskussion bei Brauchlin, E./Wehrli, H.-P. (1994), S. 130.

${ }^{400}$ Eine Erweiterung der Matrix findet sich bei Abell, D.F. (1980) sowie bei Ansoff, H.I. (1988), S. 83ff. selbst. 
dukte und Märkte werden. ${ }^{401}$ Wie sich in der Untersuchung gezeigt hat, nimmt die Intensität, mit der die einzelnen Strategien verfolgt werden, mit steigender Unternehmensgröße zu. Die Begründung hierfür liegt u.a. darin, daß mit steigender Unternehmensgröße die Know-howund Informationsbasis zunimmt sowie die Möglichkeit besteht, auftretende Mißerfolge durch Erfolge an anderer Stelle leichter auszugleichen, und so eine Reduktion des auftretenden Risikos ermöglicht wird (vgl. Anlage 14). ${ }^{402}$

\subsubsection{Wettbewerbsstrategien}

Die Produkt-Markt-Strategie stellt einen ersten Schritt bei der Formulierung des unternehmerischen Strategiesystems dar, indem sie die generelle Stoßrichtung des Unternehmens vorgibt. In einem zweiten Schritt muß die Form festgelegt werden, in der das Unternehmen den Wettbewerbern gegenübertreten will.

Eine bedeutende Basisarbeit zur Systematisierung von Wettbewerbsstrategien hat PORTER geliefert. Er hebt hervor: "Der Wettbewerb stellt die Weichen zwischen Erfolg und Mißerfolg eines Unternehmens" ${ }^{\prime 03}$. Aus diesem Grund muß jedes Unternehmen seine Wettbewerbsstrategie definieren, um im Markt erfolgreich zu sein. Zwar verweist PORTER darauf, daß jedes im Wettbewerb stehende Unternehmen bewußt oder unbewußt über eine Wettbewerbsstrategie verfügt, diese aber ohne eine Koordinierung bzw. eine Systematisierung selten zu optimalen Ergebnissen führt. ${ }^{404} \mathrm{Um}$ sich im Wettbewerb behaupten zu können - PORTER geht dabei von einer Auseinandersetzung mit den fün Wettbewerbskräften aus, wie sie in Abschnitt 3.3.2.2 aufgezeigt wurden - stehen drei Grundstrategien ("generic competitive strategies") zur Verfügung: ${ }^{405}$

- die Strategie der Kostenführerschaft,

- die Strategie der Differenzierung,

- die Strategie der Konzentration auf Schwerpunkte (Nischenstrategie).

\footnotetext{
${ }^{401}$ Ansoff, H.I. (1965), S. 77ff. spricht in diesem Zusammenhang vom Gesetz der abnehmenden Synergie, wobei die höchsten Synergien bei der Marktdurchdringung und die niedrigsten bei der Diversifikation auftreten. Vgl. kritisch dazu Macharzina, K. (1995), S. 274ff. Hinsichtlich der Erfolgschancen der Produkt-MarktStrategien berichten Brauchlin, E./Wehrli, H.-P. (1994), S. 129f., daß die Marktdurchdringung eine Erfolgschance von 50\%, die Marktentwicklung von 30\%, die Produktentwicklung von 20-30\% sowie die Diversifikation von weniger als $10 \%$ besitzt. Wegen der unterschiedlichen Kosten vgl. ferner Bussiek, J. (1997), S. 19.

402 Die STRATOS-Studie kommt hinsichtlich der Verteilung der Strategietypen zu ganz änlichen Ergebnissen. Vgl. Fröhlich, E./Pichler, J.H. (1988), S. 106.

${ }^{403}$ Porter, M.E. (1996), S. 19.

${ }^{404}$ Vgl. Porter, M.E. (1995), S. 13.

${ }^{405}$ Vgl. auch im folgenden Porter, M.E. (1995), S. 62-77; Porter, M.E. (1996), S. 31-50.
} 
Abb. 3-12: Wettbewerbsstrategien

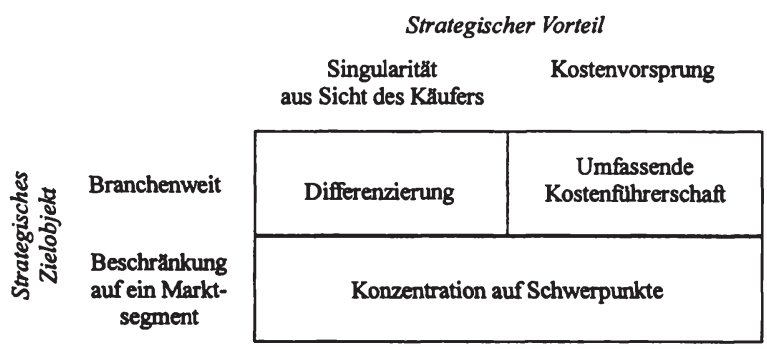

Quelle: Porter, M.E. (1995), S. 67.

Das Ziel der Kostenführerschaft ${ }^{406}$ ist, der kostengünstigste Wettbewerber auf dem Markt zu sein. Mit dieser Strategie ist eine rigorose Politik der Kostensenkung verbunden. Sie erfordert "den aggressiven Aufbau von Produktionsanlagen effizienter Größe, energisches Ausnutzen erfahrungsbedingter Kostensenkungen, strenge Kontrolle von variablen Kosten und Gemeinkosten, Vermeidung von marginalen Kunden und Kostenminimierung in Bereichen wie Forschung und Entwicklung, Service, Vertreterstab, Werbung usw." ${ }^{407}$. Ein umfassender Kostenvorsprung wird auch durch hohe Marktanteile oder andere Vorteile wie z.B. den günstigen Zugang zu Rohstoffen ermöglicht. Zur Verfolgung dieser Strategie bedarf es außerdem ständiger Innovationen im Verfahrens- und Technologiebereich zum Zweck der Prozeßrationalisierung und Standardisierung. Bereits an dieser überblickartigen Aufzählung zu den Bedingungen einer umfassenden Kostenfuhrerschaft offenbart sich, daß diese Strategie fur kleine und mittlere Unternehmen weitgehend ungeeignet ist. Dafür lassen sich mehrere Gründe aufzeigen. Im Rahmen der Kostenfuhrerstrategie werden Innovationen insbesondere im Verfahrensbereich zum Zweck der Prozeßrationalisierung getätigt. Produkte und Dienstleistungen von Kostenführern werden in der Regel nur von durchschnittlicher Qualität sein. Die Diskussion der Erfolgsfaktoren kleiner und mittlerer Untemehmen hat aber gezeigt, daß diese ihre Erfolgsfaktoren auf die Bereiche Qualität, Kundenorientierung, Innovativität und Qualifikation zurückführen, die besonders kostenintensiv sind und somit einer Übernahme der Kostenführerschaft im Wege stehen (vgl. Abschnitt 3.3.4.2). Zwar zielt auch die von den meisten kleinen und mittleren Unternehmen gewählte Art der Fertigung der Produkte bzw. Produkt-

\footnotetext{
${ }^{406}$ Vgl. zum Begriff der Kostenfuhrerschaft auch die Diskussion bei Mintzberg, der dem Begriff der Preisdifferenzierung den Vorzug gibt. Vgl. Mintzberg, H. (1988), S. 14ff.

${ }^{407}$ Porter, M.E. (1995), S. 63. Zu den Anforderungen an die einzelnen Strategietypen siehe dort auch die Übersicht auf S. $69 f$.
} 
gruppen auf die Herstellung möglichst hoher Stückzahlen $a b,{ }^{408}$ um auf diesem Wege "economies of scale" zu realisieren, es zeigt sich aber insgesamt, daß die produzierten Losgrößen kaum den oben genannten Erfordernissen entsprechen können. Diese Einschätzung wird auch dadurch unterstützt, daß die Unternehmen den Preis nicht als bedeutenden Wettbewerbsvorteil erkennen (vgl. Tab. 3-4).

Damit deutet sich bereits an, daß die beiden übrigen Wettbewerbsstrategien für kleine und mittlere Unternehmen eher geeignet sind. ${ }^{409}$ Bei der Differenzierungsstrategie ergeben sich Wettbewerbsvorteile, indem sich die Produkte und Leistungen des Unternehmens durch unverwechselbare Eigenschaften auszeichnen, die bei den Kunden eine hohe Wertschätzung genießen. Erfolgreich eingesetzt werden kann diese Strategie, wenn die mit der Einzigartigkeit der Anspruchserfüllung verbundene Anspruchsgruppenloyalität hoch ist bzw. eine in der Tendenz unelastische Reaktion der Nachfrager auf höhere Preise vorliegt. Als Mittel der Differenzierung kommen beispielsweise in Frage: ${ }^{410}$

- herausragende Produkt- oder Leistungsvorteile (Qualität, Technik, Gebrauchsnutzen, Marke, Design usw.),

- Unterhaltung eines gut ausgebauten Händlemetzes bzw. Angebot eines umfassenden Services,

- hohe Innovativität,

- intensive Öffentlichkeitsarbeit.

Ein Unternehmen, das die Differenzierung als strategische Option wählt, muß mindestens in einem dieser Punkte im Vergleich zu den Wettbewerbern einmalig sein oder für einmalig gehalten werden.

Während sich die Strategien der Kostenführerschaft bzw. der Differenzierung auf den Gesamtmarkt beziehen, ist die Nischenstrategie lediglich auf einen abgegrenzten Marktbereich ausgerichtet. Mit diesem Strategietyp findet eine Konzentration auf Marktnischen statt, d.h. auf eine bestimmte Abnehmergruppe, auf einen bestimmten Teil eines Produktprogrammes oder auf einen geographisch abgegrenzten Markt. Die Nischenstrategie basiert dabei auf der Prämisse, daß in der Nische die Anspruchserfüllung durch das Unternehmen effizienter und effektiver realisiert werden kann, als dies ein im Gesamtmarkt agierender Wettbewerber ver-

${ }^{408}$ Siehe Frage 2/2 des Fragebogens im Anhang. Nach eigenen Angaben stellen die Unternehmen ihre Produkte oder Produktgruppen zu 28,7\% durch Einzelfertigung (1-5 Stuck), zu 38,2\% durch Kleinserienfertigung (6-25 Stück), zu 52,3\% durch Großserienfertigung (26-500 Stück) und zu 41,0\% durch Massenfertigung $(>500$ Stück) her. Siehe dazu auch Anlage 16.

${ }^{409}$ Vgl. dazu auch Mugler, A./Schmidt, K.-H. (Hrsg.) (1995), S. 52 f.

${ }^{410}$ Vgl. Hax, A.C./Majluf, N.S. (1991), S. 50. Mintzberg unterscheidet 6 Hauptformen der Differenzierung: Qualităt, Design, Betreuung/Service, Image, Preis und undifferenzierte Produkte. Vgl. Mintzberg, H. (1988), S. 17-21. 
mag. ${ }^{411}$ Die Strategie der Konzentration kann mit den beiden vorgenannten Strategietypen kombiniert werden, indem das Unternehmen in seinem Zielsegment entweder einen Kostenvorteil anstrebt oder um Differenzierung bemüht ist. Die Nischenstrategie kann somit als Modifizierung der beiden anderen Strategien betrachtet werden.

Aufgrund der begrenzten Produktionskapazität können kleine und mittlere Unternehmen nur eingeschränkt "economies of scale" realisieren bzw. eine breite Produktpalette anbieten. Ihr Wettbewerbsvorteil liegt in der Differenzierung des Angebotes durch Fokussierung auf bestimmte Abnehmergruppen, Produktbereiche oder geographisch abgegrenzte Märkte. Erkennbar wird dies bei den untersuchten Unternehmen zum Beispiel daran, daß mit einer zunehmenden Unternehmensgröße auch die Absatzmarktreichweite steigt, d.h. je größer das Unternehmen ist, desto höher sind die Anteile entfernter liegender Märkte. ${ }^{412}$ Daneben zeigt sich auch, daß zwar durchschnittlich mehr als 50\% der Unternehmen ihr Produktprogramm an die spezifischen Bedürfnisse der Kunden anpassen. Bei einer Unterscheidung nach der Unternehmensgröße wird aber deutlich, daß mit einer zunehmenden Unternehmensgröße auch der Standardisierungsgrad des Produktprogrammes steigt (vgl. Anlage 16).

PORTER weist darauf hin, daß sich ein Unternehmen entweder für die Kostenführerschaft oder für die Differenzierung entscheiden muß. Die Mischung der Strategien bedeutet, daß das Unternehmen "zwischen den Stühlen sitzt" und somit kaum erfolgreich sein kann. ${ }^{413}$ Das heißt jedoch nicht, daß die Entscheidung für eine der Strategien eine dauerhafte Festlegung bedingt. Ein Wechsel der Strategien ist durchaus möglich. ${ }^{414}$

${ }^{411}$ Dabei ist jedoch zu beachten, daß die Konzentration auf die Bedürfnisse einer genau abgegrenzten Abnehmergruppe das Unternehmen zwar vor den Einflüssen bestimmter Marktsegmente schützen kann, dafur aber der Einflußgrad der relevanten Abnehmer innerhalb der gewahlten Marktnische stark an Bedeutung zunimmt. Vgl. dazu auch Achleitner, P. (1985), S. 165.

Hinder und Bartosch untersuchten in Damenoberbekleidung herstellenden Unternehmen inwieweit die von Porter vorgeschlagenen Strategien Anwendung finden. Die Studie zeigt, daß Unternehmen, die eine der von Porter beschriebenen Strategien verfolgen, im Durchschnitt erfolgreicher sind. Dabei bemerken sie allerdings einschränkend, daß dies überwiegend nicht auf geplante Strategiefindungsprozesse, sondern eher auf Intuition oder Gespür zurlickzufuhren ist. Vgl. Hinder, W./Bartosch, S. (1985), S. 98-102.

${ }^{412}$ Siehe Frage 2/8 im Fragebogen im Anhang sowie dort auch die Ergebnisse in Anlage 15. Die Anlage zeigt bei einer Unterscheidung der Unternehmensgröße nach BetriebsgroßBen (BG; Anzahl der Mitarbeiter) bzw. der Umsătze (U; Umsatz in Mio. DM) deutlich, daß die BG < 50 16,0\% ihres Umsatzes exportieren, während dies 32,4\% der BG $\geq 200$ tun. Bei der Differenzierung nach Umsätzen zeigt sich, daß 15,9\% der U $\leq 30$ aber $38,9 \%$ der $U>100$ exportieren.

${ }^{413}$ Vgl. Porter, M.E. (1995), S. 71-74. Zu weiteren Risiken der Strategien siehe dort S. 74-77 sowie Porter, M.E. (1996), S. 44 und ferner Hunger, J.D./Wheelen, T.L. (1996), S. 188f.

Die Einschătzung, daß sich ein Unternehmen furr eine Strategie (Kostenfuhrerschaft oder Differenzierung) entscheiden muß, gilt mittlerweile als widerlegt. Vgl. Meffert, H. (1994), S. $115 f$.

${ }^{414}$ Vgl. Macharzina, K. (1995), S. 229f. 


\subsubsection{Die Implementierung der Strategien im Unternehmen}

Die Umsetzung der Leitbilder und Ziele mit Hilfe der Strategien bereitet in jedem Unternehmen erhebliche Schwierigkeiten. Besonders deutlich wird dies in kleinen und mittleren Unternehmen. Hier existieren Leitbilder, Ziele und Strategien meist nur im Kopf des Unternehmers oder werden nur unzureichend dokumentiert und kommuniziert. Doch auch wenn dokumentierte strategische Pläne existieren, fuihren Implementierungszwang, politische Gegebenheiten und die Beschränkungsfaktoren des Machbaren immer zu einem System, das von der Idealvorstellung mehr oder weniger abweicht. Bedeutsam ist aber, den Implementierungsprozeß als kontinuierlichen Lernprozeß zu verstehen, in dem langfristig versucht wird, die Unvollkommenheiten und Unzulänglichkeiten auszuräumen und sich der Idealsituation anzunähern. ${ }^{415}$

In diesem Prozeß sind vier Komponenten von herausragender Bedeutung: die Organisationsstruktur des Unternehmens, der Führungsstil, die Mitarbeiter sowie die Unternehmenskultur. ${ }^{416}$ Innerhalb dieser Komponenten übernimmt die Strategie eine Schnittstellenfunktion. Sie soll im Hinblick auf den Unternehmenserfolg die Friktionen zwischen den genannten Komponenten möglichst gering halten. Die Art und Weise des Zusammenhangs zwischen der Strategie und der Struktur wird besonders deutlich von CHANDLER hervorgehoben: "Unless structure follows strategy, inefficiency results" ${ }^{\prime 17}$. Die Organisationsstruktur hat sich also der Strategie anzupassen und nicht umgekehrt. Folglich müssen auch die Führungssysteme den strategischen Erfordernissen angepaßt werden. Von strategischer Relevanz sind hier für AAKER vor allem Rechnungswesen und Finanzierung, das Informationssystem sowie das Beurteilungs- und Belohnungssystem. ${ }^{418}$ Das Scheitern von Strategien kann oftmals in der unzureichenden Durchsetzung der strategischen Konzepte im Unternehmen begründet sein. Ist die Umsetzung der Unternehmensstrategie allein auf den Unternehmer bzw. die Unternehmensführung beschränkt, entsteht eine "Implementierungslücke". Eine Strategie kann nur dann erfolgreich umgesetzt werden, wenn sie von allen Organisationsmitgliedern akzeptiert wird und wenn sie eine Leitlinie des täglichen Handelns darstellt. Beim Erarbeiten und Einführen von Strategien sind folglich alle Mitarbeiter des Unternehmens in den Prozeß mit einzubinden. ${ }^{419}$ Die starke Interdependenz zwischen Unternehmensstrategie und Unternehmenskultur stellt HINTERHUBER heraus, indem er darauf hinweist, daß das Zusammenspiel der beiden "aus einem durchschnittlichen Wettbewerber eine zielgerichtete, 'organisierte' Unternehmung

${ }^{415}$ Vgl. Kirsch, K./Roventa, P. (Hrsg.) (1983), S. 14; Pümpin, C. (1980), S. 64. Vgl. zur politischen Dimension der Veränderungen auch Thompson, A.A./Strickland, A.J. (1996), S. 546ff.

${ }^{416}$ Vgl. Aaker, D.A. (1995), S. 322-333.

${ }^{417}$ Chandler, A.D. (1962), S. 314. Diese Sichtweise ist allerdings umstritten. Im Rahmen des Strategischen Managements wird eher auf die gegenseitige Abstimmung von Strategie und Organisationsstruktur abgehoben. Von einer vertiefenden Diskussion wird hier jedoch abgesehen.

${ }^{418}$ Vgl. Aaker, D.A. (1995), S. 326f.

${ }^{419}$ Vgl. Meffert, H. (1988), S. 142f. Wird die Strategieimplementierung als Innovationsprozeß verstanden, können nach Witte zur Überwindung der Barrieren Macht- und Fachpromotoren eingesetzt werden. Vgl. Witte, E. (1973b), S. 14-22. Für eine genauere Darstellung des Promotorenmodells vgl. Abschnitt 4.4.1. 
macht" ${ }^{420}$. Dabei wirkt die Implementierung und Umsetzung der Strategie kulturgestaltend bzw.

-verändernd. Die Konsistenz zwischen Strategie und Kultur ist für HINTERHUBER eine zentrale Bedingung für das Erringen einer überlegenen Wettbewerbsposition. ${ }^{421}$

Der Ablauf des strategischen Planungsprozesses läßt sich in folgender Weise zusammenfassen: ${ }^{422}$

- Analyse der bislang im Unternehmen verfolgten Strategien,

- Analyse der externen und internen Bedingungen, um Stärken und Schwächen bzw. Chancen und Risiken deutlich zu machen,

- Identifikation strategischer Alternativen, auf die sich die neu entwickelten Strategien richten können,

- Strategieevaluation hinsichtlich der verfügbaren Ressourcen, der sich ergebenden Chancen und Risiken und der zu berilcksichtigenden Anspruchsgruppen (Stakeholder)

- Auswahl und Implementation geeigneter Strategien,

- Erarbeiten von Maßnahmen der strategischen Kontrolle und Bestimmung der Controlling-Zuständigkeiten.

Der vorstehend skizzierte Ablauf des strategischen Planungsprozesses macht erneut die fundamentale Bedeutung der Informationssuche, -aufbereitung und -interpretation deutlich. In Großunternehmen ist der Entwurf alternativer Zukunftsszenarien sowie die Entwicklung und Implementation entsprechender Strategien gängige Praxis. In kleinen und mittleren Unternehmen läßt sich dergleichen nur unzureichend belegen. Dabei sind vor allem kleine und mittlere Unternehmen durch die Begrenztheit ihres Tätigkeitsfeldes darauf angewiesen, besonders sensibel auf die Veränderungen in ihrem Umfeld zu reagieren. Bereits kleine Nachfrageverschiebungen, die bei einem Großunternehmen aufgrund des höheren Diversifizierungsgrades kaum ins Gewicht fallen, sind für kleine und mittlere Unternehmen deutlich spürbar. An den Unternehmer bzw. die Unternehmensführung stellt sich im Rahmen der strategischen Ausrichtung des Unternehmens somit die Forderung nach einer Systematisierung und Professionalisierung dieses Prozesses.

${ }^{420}$ Hinterhuber, H.H. (1990), S. 224.

${ }^{421}$ Vgl. Hinterhuber, H.H. (1990), S. 224-228.

${ }^{422}$ Vgl. Hofer, C.W./Schendel, D. (1978), S. 46f. Vgl. ferner Mintzberg, H. (1988), S. 3f.; Pümpin, C. (1981), S. 16-25. 


\subsection{Zwischenergebnis}

Intention dieses Kapitels war es, Besonderheiten und Problembereiche der Unternehmensführung in kleinen und mittleren Unternehmen darzustellen.

Diese sind meist durch eine Unternehmerpersönlichkeit und/oder eine Unternehmerfamilie geprägt. Ein besonderer Fokus lag daher zunächst auf der Charakterisierung des Unternehmers. Während noch in den Anfängen der Unternehmertheorie insbesondere auf die wirtschaftliche Bedeutung des Unternehmers (CANTLLON) oder etwa auf den Unternehmer als Innovator (SCHUMPETER) abgehoben und damit ein ganz bestimmter Unternehmertypus ins Zentrum der Betrachtung gestellt wurde, zeigen z.B. die Untersuchungen von MILES UND SNOw bzw. von KIRSCH UND TRUX eine ganze Reihe von unterschiedlichen Unternehmertypologien auf.

Hierbei wird ebenfalls deutlich, daß in kleinen und mittleren Unternehmen die Unternehmensführung eher intuitiv und situativ erfolgt. Eine systematische und zukunftsorientierte Unternehmensführung gewinnt aber vor dem Hintergrund zunehmend komplexerer und dynamischerer Markt- und Wettbewerbsprozesse an Bedeutung. Gleichzeitig wachsen auch innerhalb des Unternehmens die Anforderungen an die dispositiven und strategischen Fähigkeiten des Unternehmers. Um diesen Anforderungen gerecht zu werden, bedarf es geeigneter Informationen über die externen und internen Bedingungen des Unternehmens. Darin liegt ein Grund für die breite Diskussion der Umfeld- und Unternehmensanalyse. Daneben bildet diese Analyse auch die Basis für die Identifikation der unternehmenstypischen Erfolgsfaktoren. Die empirisch nachgewiesenen typischen Erfolgsfaktoren kleiner und mittlerer Unternehmen liegen hauptsächlich in der Qualität, der Kundenorientierung, der Innovativität und der Qualifikation der Mitarbeiter. Damit ist die Innovativität als ein zentraler Erfolgsfaktor identifiziert, der zugleich starke Interdependenzen zu den übrigen aufweist. Der Umweltschutz bzw. die Umweltorientierung wird auch als bedeutender Faktor herausgestellt, der einen ebenfalls hohen Beziehungszusammenhang zu den vorgenannten Erfolgsfaktoren aufweist. Hier ist allerdings noch zu prüfen, ob der Umweltschutz in die Reihe der Erfolgsfaktoren aufzunehmen ist oder ob ihm lediglich eine unterstützende Funktion zukommt. Werden die Erfolgsfaktoren zu einer stimmigen unternehmensspezifischen materiellen, finanziellen und personellen Ressourcenbasis gebündelt, entstehen daraus die Kernkompetenzen des Unternehmens, die ihrerseits die Wettbewerbsvorteile des Unternehmens am Markt ausmachen.

Weitere wichtige Teilaspekte der Unternehmensfuhrung in kleinen und mittleren Unternehmen sind die Unternehmenskultur, die Unternehmensphilosophie sowie die Unternehmenspolitik. Aus der Unternehmensgeschichte und -tradition entwickelt sich in den meisten Fällen eine unternehmensspezifische Kultur - ein Kern grundlegender Eigenschaften, durch den das 
Unternehmen eine unverwechselbare Identität erhält. Die Unternehmenskultur kann somit als die Gesamtheit der durch Evolution und Tradierung entstandenen Normen, Wertvorstellungen, Denk- und Handlungsweisen, die das Verhalten aller Organisationsmitglieder prägt und ihrerseits durch die Organisationsmitglieder geprägt wird, charakterisiert werden. Sie ist beispielsweise auch dafür verantwortlich, ob sich im Unternehmen eine innovative Atmosphäre, eine Innovationskultur bilden kann. Neben der Wirkung nach innen strahlt sie auch auf das Unternehmensumfeld aus und produziert in der Öffentlichkeit ein spezifisches "Image", ein Abbild ihrer Identität. Sie beeinflußt als Orientierungsrahmen die Unternehmensphilosophie und die Unternehmenspolitik. Während in der Unternehmensphilosophie noch allgemeine Zielvorstellungen und Werte, die eine Interpretation der wirtschaftlichen und gesellschaftlichen Funktion und Position des Unternehmens darstellen, zum Ausdruck kommen, werden diese innerhalb der Unternehmenspolitik weiter konkretisiert. Die Unternehmenspolitik umfaßt das Unternehmensleitbild, die Unternehmensziele und die Unternehmensstrategien.

Die Diskussion der Unternehmensziele ergab eine Dominanz des Ziels "Sicherung der Wettbewerbsfähigkeit". Hinsichtlich des Gewinnziels ergeben sich bei den angefuhrten Untersuchungen divergierende Ergebnisse. Sie bestätigen aber insgesamt die hohe Bedeutung dieses Ziels. Verstärkte Berücksichtigung in den Unternehmenszielen finden daneben auch Belange der Anspruchsgruppen, Innovations- und Umweltziele. Die Studien setzen sich zum Teil intensiv mit ökologischen Belangen auseinander. Die Ursachen, die hinter dem Bedeutungszuwachs des Umweltschutzes stehen, werden - von einigen Ausnahmen abgesehen - allerdings zu wenig kritisch hinterfragt. Die Bedeutung des Umweltschutzes in den Unternehmen bildet daher einen Schwerpunkt dieser Arbeit. Die Diskussion der Innovationsziele bleibt in allen Studien weitgehend ausgeblendet. Vor dem Hintergrund, daß die Bundesrepublik Deutschland insbesondere im Technologiebereich auf internationaler Ebene eine Spitzenposition im Wettbewerb zu verteidigen hat, ist dies nicht nachvollziehbar. Aus diesem Grund stellt die Innovativität der Unternehmen einen weiteren Schwerpunkt dieser Arbeit dar.

Nach der Festlegung der Unternehmensziele, sind geeignete Unternehmensstrategien zu entwickeln, mit deren Hilfe die angestrebten Ziele erreicht werden können. Hier offenbaren sich erneut Defizite in kleinen und mittleren Unternehmen. Das typische "Durchwursteln" muß einer Systematisierung und Professionalisierung der Unternehmensfuhrung weichen. Dies erfordert auch eine entsprechende strategische Ausrichtung des Unternehmens, um auf die Veränderungen der externen und internen Bedingungen angemessen reagieren zu können oder besser, sie zu antizipieren und gestaltend auf sie einzuwirken. Deshalb wurden verschiedene Strategietypen vorgestellt, die in den folgenden Kapiteln vertiefend diskutiert werden.

Mit den aufgezeigten Besonderheiten und Problembereichen der Unternehmensführung in kleinen und mittleren Unternehmen ist für das weitere Vorgehen eine breite Grundlage ge- 
schaffen worden, die eine vertiefte Diskussion zentraler Teilaspekte ermöglicht. Im Vordergrund soll dabei die Innovations- und Umweltorientierung kleiner und mittlerer Unternehmen stehen. Diese Unternehmensgruppe wurde gewählt, weil die deutsche Wirtschaft als mittelständisch bzw. kleinbetrieblich strukturiert charakterisiert werden kann. Unter Einschluß der Kleinst-, Klein- und Mittelunternehmen stellt der Mittelstand 99,8\% der Unternehmen und $65,7 \%$ der Beschäftigten. Diese Unternehmen gestalten damit in herausragender Weise den Wirtschaftsstandort Deutschland. Einen hohen Anteil daran haben die Unternehmen des Verarbeitenden Gewerbes, weshalb sich die Arbeit auf diesen Wirtschaftsbereich konzentriert.

Die Unternehmen des Verarbeitenden Gewerbes sind in besonderem Maße auf eine hochwertige Produkt- und Produktionstechnik angewiesen. Für die Aufrechterhaltung ihrer Wettbewerbsfähigkeit ist daher die Erneuerungsfähigkeit bzw. Innovativität von elementarer Bedeutung. Wie insbesondere die Unternehmen des Verarbeitenden Gewerbes in der Region Nekkar-Alb diese Herausforderung annehmen, wird in Kapitel 4 aufgezeigt.

Mit der Produktion eng verknüpft ist eine Belastung der Umwelt. Die Unternehmen des Verarbeitenden Gewerbes eigenen sich daher in besonderer Weise für eine Untersuchung ihrer Umweltziele sowie ihrer Strategien zur Vermeidung von Umweltbelastungen. Von hoher Bedeutung ist dabei auch, wann sich eine Umweltorientierung auf eine Verantwortung gegenüber der Gesellschaft und wann auf ökonomische Gründe zurückführen läßt bzw. wann sie aus ökonomischen Gründen hinter anderen Zielen zurückbleibt (Kapitel 5). 



\section{Innovationsmanagement}

\subsection{Begriff und Charakterisierung}

Die bisherige Analyse hat einerseits die wirtschaftliche Relevanz kleiner und mittlerer Unternehmen aufgezeigt sowie andererseits die Notwendigkeit einer systematischen und langfristig orientierten Unternehmensfuhrung in diesen Unternehmen verdeutlicht. Insbesondere vor dem Hintergrund einer steigenden Komplexität und Dynamik der Markt- und Wettbewerbsprozesse sowie z.B. verbesserter Transport- und Informationsmöglichkeiten, die die Märkte und Wettbewerber "zusammenrücken" lassen, wird die Verteidigung oder der Ausbau der eigenen Wettbewerbsposition immer schwieriger.

Als ein zentraler Erfolgsfaktor kleiner und mittlerer Unternehmen im Wettbewerb kristallisierte sich die Innovativität heraus. Die gesamt- und einzelwirtschaftliche Bedeutung der Innovation sowie die systematische Nutzung und Gestaltung der Innovationspotentiale im Umfeld und innerhalb des Unternehmens werden im folgenden genauer analysiert. Dieser Analyse vorangestellt ist die Erläuterung der dafür notwendigen Begriffe.

\subsubsection{Der Innovationsprozeß im Rahmen des technischen Fortschritts}

\subsubsection{Begriff und Arten der Technologie}

Für den Begriff der Technologie finden sich in der Literatur in Abhängigkeit der Zielsetzung unterschiedliche Begriffsverwendungen. Wird eher der technische Aspekt hervorgehoben, beinhaltet die Technologie das Wissen über naturwissenschaftlich-technische Zusammenhänge eines abgegrenzten Gebietes, das in materieller und immaterieller Form vorliegen kann und zur Lösung von technischen Problemen Anwendung findet. ${ }^{423}$ Weiter und damit beispielsweise auch für die Erfassung nicht-technischer Phänomene geeignet ist die Begriffsverwendung von ZAHN, der alle "Prinzipien, Mittel und Methoden zur wirtschaftlichen Herstellung von Produkten und Produktionsverfahren" ${ }^{424}$ unter den Technologiebegriff subsumiert. In Abgrenzung dazu wird unter Technik die konkrete Anwendung der Technologie zur Problemlösung in materieller Form verstanden. ${ }^{425}$

\footnotetext{
${ }^{423}$ Vgl. Zőrgiebel, W.W. (1983), S. 11; Perillieux, R. (1987), S. 12; Milling, P./Maier, F. (1996), S. 25; Specht, G./Beckmann, C. (1996), S. 14. Vgl. ferner Servatius, H.-G. (1985), S. 35, der dort Technologien weiter nach ihrem strukturalen, funktionalen und hierarchischen Aspekt charakterisiert.

${ }^{424}$ Zahn, E. (1986), S. 9.

${ }^{425}$ Vgl. Zðrgiebel, W.W. (1983), S. 11; Perillieux, R. (1987), S. 12; Milling, P./Maier, F. (1996), S. 25; Specht, G./Beckmann, C. (1996), S. 14.
} 
Daneben lassen sich Technologien auch nach ihren unterschiedlichen Arten charakterisieren: Hinsichtlich ihrer wettbewerbsstrategischen Bedeutung können Basis-, Schlüssel- und Schrittmachertechnologien unterschieden werden. Basistechnologien befinden sich in der Reife- oder sogar der Degenerationsphase des Lebenszyklus. Sie verkörpern das allgemein zugängliche Basis-Know-how, über das ein Unternehmen verfügen muß, wenn es am Wettbewerb teilnehmen will. Demgegenüber befinden sich Schlüsseltechnologien in der Wachstumsphase. Sie sind von wesentlicher Bedeutung für die gegenwärtige Wettbewerbsposition eines Unternehmens, da sie Differenzierungsmöglichkeiten zwischen den Wettbewerbern bieten. Schrittmachertechnologien stehen am Anfang des Lebenszyklus und lassen Auswirkungen auf Marktpotential und Wettbewerbsdynamik in der Zukunft erkennen. Sie besitzen daher noch keine Wettbewerbsrelevanz. Sofern sie sich erfolgreich am Markt durchsetzen, können sie selbst zur Schlüsseltechnologie werden und dabei entweder komplementär oder substitutiv zur bestehenden Schlüsseltechnologie wirken. ${ }^{426}$

Bezüglich der potentiellen Anwendungsbreite lassen sich spezifische Technologien mit eng begrenzten Einsatzmöglichkeiten und Querschnittstechnologien mit einem weiten Einsatzspektrum differenzieren. ${ }^{427}$ Im Hinblick auf den Einsatz lassen sich Produkt- und Prozeßtechnologien unterscheiden. ${ }^{428}$ ZAHN ergănzt diese beiden letztgenannten Technologiearten um die Informationstechnologien und bildet daraus ein technologisches Dreieck mit einem interdependenten Wirkungsgefüge.

\subsubsection{Begriff und Arten der Innovation}

Bei der Diskussion des Innovationsbegriffes zeigt sich ein uneinheitliches, vielschichtiges und mehrdimensionales Bild. Gemeinsames Element aller Definitionen der Innovation ist das Element der Neuheit. ${ }^{429}$ Die Vielfalt unterschiedlicher Definitionen gliedert HAUSCHIIDT nach sieben Kriterien: ${ }^{430}$

\footnotetext{
${ }^{426}$ Vgl. Zorgiebel, W.W. (1983), S. 12f.; Sommerlatte, T./Deschamps, J.-P. (1986), S. 50-56; Perillieux, R. (1987), S. 12f.; Arthur D. Little (Hrsg.) (1994), S. 74-80. Servatius erweitert diese Betrachtung durch "neue Technologien", deren wirtschaftliche Entwicklung noch nicht erkennbar bzw. unsicher ist, sowie durch "verdrängte Technologien", die durch andere substituiert werden. Vgl. Servatius, H.-G. (1985), S. 116. Siehe ferner auch die Erlăuterungen Brockhoffs zum Begriff der Spitzentechnik, der zwar als Schlag- und Schlusselwort in wirtschaftspolitischen und unternehmensstrategischen Diskussionen verwendet wird, sich aber kaum definitorisch festlegen läßt. Vgl. Brockhoff, K. (1994), S. 23-27.

${ }^{427}$ Vgl. Perillieux, R. (1987), S. 13.

${ }^{428}$ Vgl. Zahn, E. (1986), S. 31.

${ }^{429}$ Vgl. Perillieux, R. (1987), S. 14

${ }^{430}$ Vgl. Hauschildt, J. (1997), S. 4ff. Einen Überblick über verschiedene Definitionen bieten ferner Aregger, K. (1976), S. 101-119; Zaltman, G. u.a. (1973), S. 7-16.
} 
1. Tatsache und Ausmaß der Neuartigkeit, ${ }^{431}$

2. Wahrnehmung der Neuartigkeit, ${ }^{432}$

3. Erstmaligkeit der Neuartigkeit, ${ }^{433}$

4. Neuartige Kombination von Zweck und Mitteln, ${ }^{434}$

5. Verwertungsbezug, ${ }^{435}$

6. Prozeßaspekt ${ }^{436}$ und

7. Extension $^{437}$.

Diese Gliederung schafft lediglich eine vordergründige Klarheit. Bei Betrachtung der Definitionen fallen große Überschneidungen auf, so daß einzelne leicht auch hätten mehrfach genannt werden können. Zur Vereinfachung der weiteren Diskussion wird zunächst die Begriffsverwendung von KNIGHT in den Vordergrund gerückt: "An innovation is the adoption of a change which is new to an organization and to the relevant environment"438. Sie eignet sich dabei in mehrfacher Weise: Ihre Breite läßt ausreichend Interpretationsspielraum hinsichtlich der Innovationsarten; sie bringt den Prozeßcharakter von Innovationen zum Ausdruck; sie hebt die Neuartigkeit hervor und sie nimmt Bezug auf das Unternehmen bzw. sein relevantes Umfeld. Nachteilig ist jedoch, daß "adoption" (Übernahme, Einführung) impliziert, daß der Wandel bereits eingetreten ist. Damit wird ein enger Innovationsbegriff verwendet, der die Frage seiner Einbettung in den Prozeß des technischen Fortschritts, der mehrere Phasen umfaßt, noch nicht aufwirft. Wie im folgenden noch zu zeigen ist, ist es u.U. sinnvoll, einen weiten Innovationsbegriff zu verwenden, der sich über mehrere Phasen des Fortschritts erstreckt.

Die Diskussion der Innovationsarten zeigt sich ähnlich vielschichtig wie die des Innovationsbegriffes selbst. Nach ScHUMPETER kann das Schaffen von etwas Neuem bzw. die Durchsetzung neuer Kombinationen in

${ }^{431}$ Vgl. Barnett, H.G. (1953), S. 7; Becker, S.W./Whisler, T.L. (1967), S. 463; Witte, E. (1973b), S. 2; Aregger, K. (1976), S. 118; Mensch, G. (1979), S. 74.

${ }^{432}$ Vgl. Rogers, E.M (1983), S. 11; Zaltman, G. u.a. (1973), S. 10.

${ }^{433}$ Vgl. Schmookler, J. (1966), S. 2; Knight, K.E. (1967), S. 478; Kieser, A. (1975), Sp. 742 und (1970), S. 290; Cooper, R.G. (1979), S. 98; Strebel, H. u.a. (1979), S. 3; Walter, H. (1970), S. 37; Vedin, B.-A. (1980), S. 22; Moore, W.L./Tushman, M.L. (1982), S. 132; Zörgiebel, W.W. (1983), S. 13; Hübner, H./Jahnes, S. (1992), S. 1630.

${ }^{434}$ Vgl. Johnson, S.C./Jones, C. (1957), S. 52; Schumpeter, J.A. (1961), S. 95; Pfeiffer, W./Staudt, E. (1975), Sp. 1943f.; Moore, W.L./Tushman, M.L. (1982), S. 132; Nydegger, A. u.a. (1983), S. 13; Rickards, T. (1985), S. 10 und S. 28f.

${ }^{435}$ Vgl. Uhlmann, L. (1970), S. 49; Witte, E. (1973a), S. 17; Pfeiffer, W. (1980), S. 421f.; Zahn, E. (1986), S. 16; Roberts, E.B. (1987), S. 3; Servatius, H.-G. (1988), S. 20; Brockhoff, K. (1993), S. 173; Lang, H.-C. (1995), S. 179; U.S. Small Business Administration (1995), S. 110.

${ }^{436}$ Vgl. Uhlman, L. (1978), S. 41; Goldhar, J.D. (1980), S. 284; Thom, N. (1980), S. 28f.; Baumol, W.J. (1993), S. 6; Mugler, A./Schmidt, K.-H. (Hrsg.) (1995), S. 56.

${ }^{437}$ Vgl. Schumpeter, J.A. (1912), S. 159; Knight, K.E. (1967), S. 478; Becker, F.G. (1991), S. 569; Chmielewicz, K. (1991), S. 84; Damanpour, F. (1991), S. 556; U.S. Small Business Administration (1995), S. $119 f$.

${ }^{438}$ Knight, K.E. (1967), S. 478. 
- der Produktion eines bisher noch nicht bekannten Gutes,

- der Einführung einer neuen Qualität oder einer neuen Verwendung eines bereits bekannten Gutes,

- der Einfuhrung einer neuen Produktionsmethode,

- der Erschließung eines neuen Marktes sowie

- der Änderung der wirtschaftlichen Organisation

liegen. ${ }^{439}$

Das Schema von KNIGHT umfaßt vier Typen, die in einem engen Beziehungszusammenhang stehen. Er unterscheidet

- product or service innovations,

- production-process innovations,

- organizational-structure innovations sowie

- people innovations. $^{440}$

Produktinnovationen umfassen das Loistungsangebot des Unternehmens. Sie setzen sich aus den Neuerungen im Sachgüter- und Dienstleistungsbereich zusammen. Prozeß- bzw. Verfahrensinnovationen bezeichnen hingegen Neuerungen bei den Leistungserstellungsprozessen. ${ }^{441}$ Organisations- oder Sozialinnovationen beziehen sich auf Veränderungen im Humanbereich. Sie stellen entweder Normveränderungen und/oder Veränderungen der Interaktionsformen zwischen den einzelnen Mitgliedern oder Gruppen des Unternehmens dar. ${ }^{442}$ Sie beziehen sich beispielsweise auf die Einführung veränderter Arbeitsablăufe, Weisungsbefugnisse, Kommunikationssysteme oder Entlohnungssysteme. ${ }^{443}$ Neuerungen auf der Mitarbeiterebene (people innovations) beziehen sich einerseits auf die Veränderung der Zusammensetzung durch Einstellung bzw. Freisetzung von Mitarbeitern sowie andererseits auf Verhaltens- oder Einstellungsänderungen bei den Mitarbeitern. ${ }^{444}$

${ }^{439}$ Vgl. Schumpeter, J.A. (1912), S. 159, wobei er in der Gründung eines Unternehmens alle Morglichkeiten reprásentiert sieht. Spăter differenziert Schumpeter die Erschließung eines neuen Marktes nach Bezugsquellen bzw. Absatzmärkten. Vgl. Schumpeter, J.A. (1928), S. 483; Schumpeter, J.A. (1934b), S. $100 f$.

${ }^{440}$ Vgl. Knight, K.E. (1967), S. 482. Vgl. bez. weiterer Gliederungen Kieser, A. (1975), Sp. 743; Pfeiffer, W. (1980), S. 424; Thom, N. (1983), S. 5f.; Lang, H.-C. (1995), S. 179ff.; U.S. Small Business Administration (1995), S. $109 \mathrm{f}$.

${ }^{441}$ Vgl. Perillieux, R. (1987), S. 15. Für die Darstellung des Zusammenhangs zwischen erfolgreichen Produktinnovationen und einer entsprechenden Weiterentwicklung der Produktionsprozesse vgl. die Modelle von Utterback, J.M./Abernathy, W.J (1975) sowie von Hayes, R.H./Wheelwright, S.C. (1979a) und (1979b).

${ }^{442}$ Vgl. Thom, N. (1980), S. 37f.; Perlitz, M./Lobler, H. (1985), S. 425; Marr, R. (1993), Sp. 1797. Zahn hebt in diesem Zusammenhang insbesondere die Katalysator- und Wegbereiterfunktion sozialer Innovationen hervor. Soziale Innovationen sind dabei zugleich Folge und Voraussetzung technischer Innovationen. Vgl. Zahn, E. (1986), S. 14 sowie auch Albach, H. (1983), S. 10ff.

${ }^{443}$ Vgl. Knight, K.E. (1967), S. 482.

${ }^{444}$ Vgl. Knight, K.E. (1967), S. 482. 
Für das weitere Vorgehen wird lediglich zwischen Produkt- und Prozeßinnovationen unterschieden. Dagegen könnte eingewandt werden, daß bei volkswirtschaftlicher Betrachtung nicht oder nur schwerlich zwischen Produkt- und Prozeßinnovationen unterschieden werden kann, da die Produktinnovation eines Unternehmens (z.B. Werkzeugmaschine) die Prozeßinnovation eines anderen Unternehmens ist. Prozeßinnovationen erstrecken sich aber nicht ausschließlich auf den technischen Bereich. Auch nicht-technische Innovationen, d.h. Organisations- bzw. Sozialinnovationen sowie Neuerungen auf der Mitarbeiterebene haben einen direkten Einfluß auf den Produktionsprozeß und tragen letztlich zu einer Stückkostensenkung bei den bestehenden Produkten bei oder schaffen die Möglichkeit, ein neues Produkt zu einem besseren Preis-/Leistungsverhältnis anbieten zu können, als dies vor der Einführung der Innovation möglich gewesen wäre. ${ }^{445}$ Nicht-technische Innovationen werden daher ebenfalls unter die Prozeßinnovationen subsumiert, so daß eine Trennung zwischen Produkt- und Prozeßinnovationen sinnvoll ist.

\subsubsection{Phasen des technischen Fortschritts}

"Neben einer gesicherten Rohstoff- und Energiebasis wird technischer Fortschritt zunehmend zum bestimmenden Faktor hochentwickelter Volkswirtschaften im internationalen Wettbewerb, denn nur durch kostensenkende und ressourcensparende Prozeß- und Produktinnovationen sind neue Märkte zu erschließen. ${ }^{446}$ Damit sind die Unternehmen in einer Volkswirtschaft gefordert, auf die durch den technischen Fortschritt induzierten Wandlungsprozesse zu reagieren oder sogar selbst diese Prozesse aktiv zu initiieren. Wird der technische Fortschritt durch konsequente Innovationen genutzt, bilden sich daraus Wettbewerbsvorteile, die beispielsweise aus einer Kostensenkung bei der Leistungserstellung, einer Differenzierungsmöglichkeit am Markt oder einer Führungsposition im Innovationswettbewerb ${ }^{447}$ entstehen können. $^{448}$

Der Vorgang des technischen Fortschritts läßt sich in mehrere Phasen einteilen. Nach HERDZINA können vier Phasen unterschieden werden: der Erkenntnisprozeß, der Inventionsprozeß, der Informations- und Lernprozeß sowie der Innovations- und Diffusionsprozeß. ${ }^{449}$ Die prozessuale Sichtweise bringt bereits die mit dem technischen Fortschritt verbundene Dynamik zum Ausdruck. Im folgenden soll jedoch der Informations- und Lernprozeß aus dieser Abfolge herausgelöst werden, da er die drei anderen Phasen überspannt. Faßt man den Er-

${ }^{445}$ Vgl. Zorgiebel, W.W. (1983), S. 13 i.V.m. Keßler, U. (1992), S. 48f.

${ }^{446}$ BMFT (Hrsg.) (1990), S. 12. Zur Entstehung des technischen Fortschritts vgl. ausfuhrlich Herdzina, K. (1981), S. 64-82 sowie auch Strebel, H. (1968), S. 21-32.

${ }_{447}$ Eine ausfulhrliche Darstellung zum Innovationswettbewerb findet sich bei Elßer, S. (1993).

${ }^{448}$ Vgl. Zahn, E. (1986), S. 34.

${ }^{449}$ Vgl. Herdzina, K. (1981), S. 85-88. Vgl. auch Walter, H. (1970), S. 37ff. Zum Begriff des technischen Fortschritts vgl. z.B. Walter, H. (1969), S. 231-238. 
kenntnis- und den Inventionsprozeß zur Inventionsphase i.w.S. zusammen und differenziert man zwischen Innovation und Diffusion, so umfaßt der Prozeß des technischen Fortschritts in seiner Gesamtheit somit die Erfindungstätigkeit (Invention) als eine Vorstufe zur Markteinfuihrung von Neuerungen (Innovation i.e.S.) sowie deren anschließende Verbreitung (Diffusion). ${ }^{450}$ Parallel zu diesen drei Phasen erfolgt ein kontinuierlicher Informations- und Lernprozeß. ${ }^{451}$

\section{Abb. 4-1: Die Phasen des technischen Fortschritts}

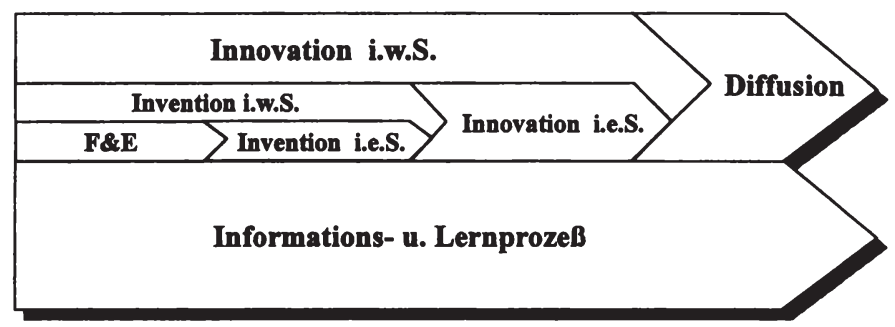

Die Phase der Invention läßt sich in zwei Teilphasen untergliedern. Die erste Teilphase umfaßt die Forschung und Entwicklung (F\&E), d.h. die Wissensgenerierung bzw. den Erkenntnisprozeß. In der zweiten Teilphase, der Inventionsphase i.e.S., kommt es zu technologischem Fortschritt, weil die Entdeckungen und Erfindungen aus dem F\&E-Prozeß beispielsweise in Form eines Prototyps angewandt werden. ${ }^{452}$ Forschung und Entwicklung umfaßt den planvoll, systematisch und methodisch durchgefuihrten Prozeß zum Erwerb neuen Wissens durch die Kombination dazu geeignet erscheinender Produktionsfaktoren. ${ }^{453}$ Entsprechend ihrem Ziel wird nach Grundlagenforschung, angewandter Forschung und experimenteller Entwicklung differenziert: Die Grundlagenforschung besteht aus experimenteller oder theoretischer Arbeit, die in erster Linie auf die Gewinnung neuer Erkenntnisse über den zugrundeliegenden Ursprung von Phänomenen und beobachtbaren Tatsachen gerichtet ist, ohne daß dadurch auf

${ }^{450}$ Vgl. z.B. Schumpeter, J.A. (1961), S. 91 ff. und S. 140; Witte, E. (1973b), S. 2; Brockhoff, K. (1993), S. 173; Brockhoff, K. (1994), S. 27-30. Vgl. daneben auch ElBer, S. (1993), S. 11.

Mit Blick auf das Produktlebenszykluskonzept (vgl. Abschnitt 3.3.3.3) kann die Inventionsphase mit dem Entstehungszyklus und die Innovations- bzw. die Diffusionsphase mit dem Marktzyklus - und hier insb. mit der Markteinfuhrungs- und Wachstumsphase - in Verbindung gebracht werden.

${ }^{451}$ Vgl. daneben auch z.B. Thom, N. (1980), S. 46-53; Trommsdorff, V./Schneider, P. (1990), S. 8-13. Vgl. dazu auch Abschnitt 4.4.3.

${ }^{452}$ Vgl. Walter, H. (1970), S. 37ff.; Herdzina, K. (1981), S. 85-88; Hübner, H./Jahnes, S. (1992), S. 1630.

${ }^{453}$ Zum F\&E-Begriff vgl. RKW (Hrsg.) (1976), Kapitel 2020; Brockhoff, K. (1993), S. 173-176; Brockhoff, K. (1994), S. 35ff.; Milling, P./Maier, F. (1996), S. 23; Specht, G./Beckmann, C. (1996), S. 15f. Von besonderer praktischer Bedeutung ist das "Frascati-Manual" der OECD, das z.B. in der Bundesrepublik Deutschland u.a. für die Erhebung der F\&E-Aktivităten und als Abgrenzung der Berechnungsgrundlage für Subventionen Anwendung findet. Vgl. OECD (1981). 
eine besondere Anwendung oder Verwendung abgezielt wird. In der angewandten Forschung werden auf der Grundlage bekannten theoretischen Grundlagenwissens neue Erkenntnisse im Hinblick auf ein spezifisches, praktisches Ziel oder eine bestimmte Zielsetzung erarbeitet. ${ }^{454}$ Inhalt der experimentellen Entwicklung ist die systematische, auf vorhandenen Erkenntnissen aus Forschung und/oder praktischer Erfahrung aufbauende Arbeit, die auf die Herstellung neuer Materialien, Produkte und Geräte und die Einfuihrung neuer Verfahren, Systeme und Dienstleistungen sowie deren wesentliche Verbesserung abzielt. ${ }^{455}$ Hier erfolgt die Umsetzung der Ergebnisse der angewandten Forschung in praktische Problemlösungen, um Produktoder Prozeßinnovationen hervorzubringen. Damit ist der Übergang zur Invention geschaffen. Inventionen i.e.S. können in einer breiten Definition nach ARROW "as the production of knowledge" 456 interpretiert werden. Sie gelten als das Ergebnis von F\&E-Aktivitäten und stellen durch die zugrundeliegende Erfindung oder Entdeckung bisher unbekannter Problemlösungen technologischen Fortschritt ${ }^{457}$ und damit eine Nutzungschance ${ }^{458}$ dar.

Die Phase der Innovation i.e.S. umfaßt lediglich die Einführung neuer Produkte und Prozesse am Markt, d.h. die erstmalige wirtschaftliche Verwertung der Inventionen. In einer erweiterten Betrachtung wird der bis in diese Phase anhaltende "Kreationsprozeß", 459 bestehend aus der Inventions- und der Innovationsphase im folgenden vereinfachend als InnovationsprozeB bezeichnet. ${ }^{460}$ Die aus diesem Prozeß resultierende Innovation kann nach SCHUMPETER die Einführung neuer Güter, die technologische Veränderung in der Produktion von Gütern, die verbesserte Materialbehandlung, die Einrichtung neuer Geschäftsorganisationen, d.h. jedes "Andersmachen" im wirtschaftlichen Bereich sein. ${ }^{461}$

Ist die Einfuhrung eines neuen Produktes oder Prozesses erfolgreich, kommt es zur Diffusion, d.h. zur Ausbreitung der Innovation auf dem Markt bzw. in einem sozialen System oder zur Imitation bzw. Nachahmung, wenn dieses Wissen unverändert Eingang in den unternehmerischen Problemlösungsprozeß findet ("Diffusionsprozeß"). ${ }^{462}$

\footnotetext{
${ }^{454}$ In der Literatur findet sich eine unterschiedliche Einschätzung der Bedeutung der F\&E und insbesondere der Grundlagenforschung furr technologische Innovationen. Vgl. dazu beispielsweise die bei Corsten, H. (1985) aufgezeigten Fallstudien.

${ }^{455}$ Vgl. OECD (1981), S. 25 und S. 54f. Vgl. dazu auch Zorgiebel, W.W. (1983), S. 213; Brockhoff, K. (1993), S. 175.

${ }^{456}$ Arrow, K.J. (1962), S. 609.

${ }^{457}$ Vgl. Walter, H. (1970), S. 37ff.; Herdzina, K. (1981), S. 85-88; Pfeiffer, W. (1980), S. 421.

${ }^{458} \mathrm{Vgl}$. Witte, E. (1973b), S. 2.

${ }^{459}$ Vgl. Walter, H. (1970), S. 38.

${ }^{460}$ Folgt man der Phaseneinteilung des Lebenszykluskonzeptes, dann umspannt der Innovationsprozeß den Entstehungszyklus und die Einfuhrungsphase im Marktzyklus. Vgl. Abb. 3-7.

${ }^{461} \mathrm{Vgl}$. Schumpeter, J.A. (1961), S. 91.

${ }^{462}$ Vgl. Herdzina, K. (1981), S. 187; Milling, P./Maier, F. (1996), S. $17 f$.
} 
Auch wenn die vorstehend aufgezeigte Phaseneinteilung eine logische Abfolge impliziert, kommt es in der Praxis sowohl zu zyklischen Rückkopplungen innerhalb der Phasenabfolge als auch zu einem teilweise parallelen Ablauf der Phasen. Angestoßen werden diese Prozesse durch die Veränderung der externen und internen Bedingungen, die durch Informations- und Lernprozesse als neues Wissen Eingang in das System finden und Einfluß auf die stattfindenden Inventions-, Innovations- und Diffusionsprozesse nehmen. Diese werden als Reaktion auf die Bedingungsänderungen in Ziel, Inhalt und Ausmaß angepaßt. Aus der Verbindung von Kreations- und Diffusionsproze $B$ bzw. Innovation und Diffusion resultiert technischer Fortschritt.

\subsubsection{Innovationsmanagement - eine Begriffsabgrenzung}

Im Rahmen der Unternehmensfuihrung stellt das Innovationsmanagement ein Führungskonzept dar, das auf funktioneller und institutioneller Ebene die Zukunft des Unternehmens sichert, indem dessen Fähigkeiten, sich weiterzuentwickeln, systematisch ausgebaut und gefördert werden. ${ }^{463}$ Gegenstand des Innovationsmanagements ist somit die "Planung, Umsetzung und Kontrolle von zielorientierten Neuerungsstrategien zum Zwecke des Aufbaus und der Nutzung von Wertschöpfungspotentialen"464. In Anlehnung an die vorstehende Phaseneinteilung des technischen Fortschritts kann nun die Abgrenzung von Technologie-, F\&E- und Innovationsmanagement erfolgen (vgl. Abb. 4-2).

Entsprechend der hier gewählten weiten Definition von Innovation umfaßt das Innovationsmanagement das F\&E-Management sowie die Produktion und die Markteinführung. ${ }^{465}$ Das F\&E-Management erstreckt sich von der Grundlagenforschung über die Technologie- und Vorentwicklung bis in die Produkt- und Prozeßentwicklung. Obwohl das F\&E-Management insoweit integraler Bestandteil des Innovationsmanagements ist, lassen sich möglicherweise auch wesentliche Unterschiede erkennen. Es wird nämlich vielfach die Meinung geäußert, daß sich Forschung und Entwicklung ausschließlich auf naturwissenschaftlich-technische Prozesse beziehen, die sich in der Regel institutionalisieren und organisieren lassen. Sie werden in vielen Unternehmen systematisch durchgeführt. Das Innovationsmanagement hingegen beinhaltet zusätzlich administrative Prozesse, die sich aufgrund ihrer Einmaligkeit bzw. NichtWiederholbarkeit schwerer institutionalisieren und organisieren lassen und damit nicht systematisierbar sind. ${ }^{466}$ Hierauf ist später zurückzukommen.

\footnotetext{
${ }^{463}$ Vgl. Witt, J. (1996), S. 169 sowie ergänzend Kapitel 3.1.

${ }^{464}$ Marr, R. (1993), Sp. 1796 (im Original teilweise kursiv). Vgl. dazu auch Pichler, J.H. u.a. (Hrsg.) (1997), S. 95; Hauschildt, J. (1997), S. 25f.

${ }^{465}$ Hierzu finden sich zahlreiche abweichende Gliederungen. Beispielsweise geht Brockhoff von einem alles umfassenden Technologiemanagement aus, unter das dann das Innovationsmanagement i.w.S. und darunter wiederum das F\&E- und das Innovationsmanagement i.e.S. subsumiert werden. Vgl. Brockhoff, K. (1993), S. 177. Vgl. ferner Bürgel, H.D. u.a. (1996), S. $13 \mathrm{ff}$.

${ }^{466}$ Vgl. Hauschildt, J. (1997), S. $27 f$.
} 
Abb. 4-2: Abgrenzung von Technologie-, F\&E- und Innovationsmanagement

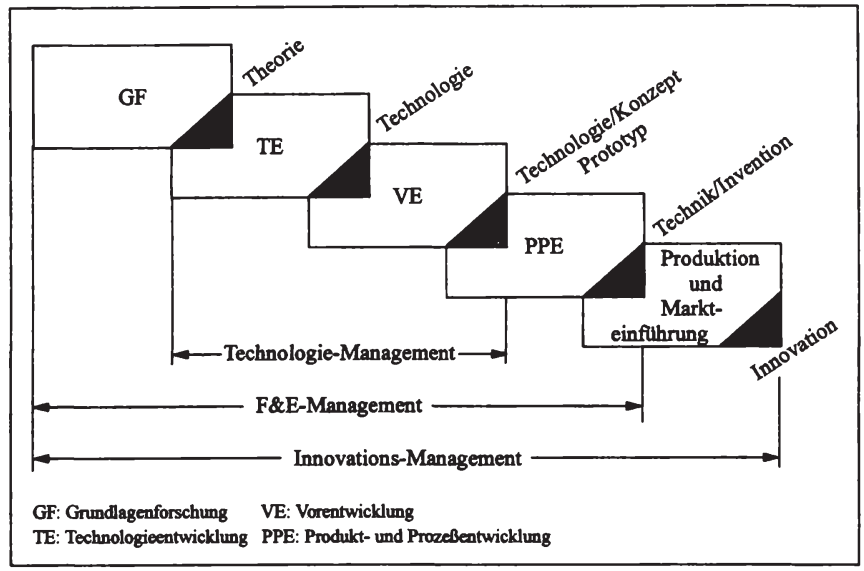

Quelle: Specht, G./Beckmann, C. (1996), S. 18.

Das Technologiemanagement kann zunächst als ein Teilbereich des F\&E-Managements betrachtet werden (vgl. Abb. 4-2). Als zentrale Aufgabe des Technologiemanagements wird in der Regel der Aufbau und die Aufrechterhaltung der technologischen Wettbewerbsfähigkeit gesehen, so z.B. durch

- eine systematische Konkurrenzbeobachtung,

- die Erstellung von Technologieportfolios und die Ableitung von Technologieprognosen, -bewertungen und -folgenabschätzungen,

- die Konzentration auf Schlüsseltechnologien oder Technologieverknüpfungen,

- die Sicherung der Technologiepotentiale durch Patentierung, Lizenzierung und Personalpolitik,

- das Eingehen von technologischen Allianzen etc. ${ }^{467}$

Eine derartige Interpretation zeigt, daß sich das Technologiemanagement nicht ausschließlich auf neue Technologien konzentriert, sondern auch auf die strategische Erhaltung und Weiter-

\footnotetext{
${ }^{467}$ Vgl. Hübner, H./Jahnes, S. (1992), S. 1631; Hauschildt, J. (1997), S. 28. Vgl. dazu auch die von Freeman aufgezeigten Charakteristika erfolgreicher Unternehmen: "1. Strong in-house professional R\&D. 2. Performance of basic research or close connections with those conducting such research. 3 . The use of patents to gain protection and to bargain with competitors. 4. Large enough size to finance fairly heavy R\&D expenditures over long periods. 5. Shorter lead-times than competitors. 6 . Readiness to take high risks. 7. Early and imaginative identification of a potential market. 8. Careful attention to the potential market and substantial efforts to involve, educate and assist users. 9. Entrepreneurship strong enough effectively to coordinate R\&D, production and marketing. 10. Good communication with the outside scientific world as well as with customers." Freeman, C. (1982), S. 112.
} 
führung vorhandener Technologien gerichtet ist. Darin besteht der Unterschied zum Innovationsmanagement, das sich vornehmlich auf neue Technologien bezieht, aber über die technologische Komponente hinaus insbesondere den damit verbundenen Wandlungsprozeß ("Change Management") zu bewältigen hat. ${ }^{468}$

Mittels Innovationsmanagement sollen im Unternehmen die Grundlagen für eine systematische und wettbewerbsorientierte Weiterentwicklung geschaffen werden. Letzteres gilt es noch einmal zu betonen, da Abb. 4-2 lediglich die technische Komponente des Innovationsmanagements beleuchtet. Diese spielt in kleinen und mittleren Unternehmen des Verarbeitenden Gewerbes sicherlich eine überragende Rolle. Erinnert sei aber nochmals daran, daß Innovationen über die rein technische Emeuerung hinausgehen und sich nach SCHUMPETER auf jedes "Andersmachen" beziehen. ${ }^{469}$ Das Innovationsmanagement erstreckt sich auf den gesamten unternehmerischen Neuerungsprozeß, nimmt also Einfluß auf alle Funktionsbereiche des Unternehmens.

\subsection{Innovationen im gesamt- und einzelwirtschaftlichen Kontext}

\subsubsection{Die gesamtwirtschaftliche Bedeutung von Innovationen}

Im Zusammenhang mit der Erlăuterung der Phasen des technischen Fortschritts wurde bereits die gesamt- bzw. die einzelwirtschaftliche Bedeutung von Innovationen angedeutet. Im Zentrum gesamtwirtschaftlicher Betrachtungen steht das Wirtschaftswachstum. Dessen exponierte Stellung wurde in der Bundesrepublik Deutschland im Jahre 1967 durch das "Gesetz zur Förderung der Stabilität und des Wachstums der Wirtschaft" (StWG) verdeutlicht.

Über die Quellen des Wachstums - und im Zuge dessen auch über den Einfluß des Wachstums auf die Beschäftigung - wird seit langem ausfuhrlich diskutiert. Maßgeblich angestoßen wurde die Debatte durch Solow. ${ }^{470}$ Er entwickelte auf der Basis der Produktionsfunktion ein Rechenschema zur Messung der Hauptfaktoren des wirtschaftlichen Wachstums, d.h. wie das Wachstum des Outputs dem der zugrundeliegenden Faktoren Kapitalstock, Arbeitseinsatz und Stand der Technik zugemessen werden kann. ${ }^{471}$ Danach ergibt sich die Wachstumsrate des Outputs aus der Summe (1) der Wachstumsrate des Kapitals, gewichtet mit dem Anteil des

\footnotetext{
${ }^{468}$ Vgl. Specht, G./Beckmann, C. (1996), S. 18; Hauschildt, J. (1997), S. $28 f$.

${ }^{469}$ Innovationsmanagement verfolgt in erster Linie die Neuerung. Dabei besteht die Gefahr, daß die Qualitat ein weiterer Erfolgsfaktor kleiner und mittlerer Unternehmen - vernachlässigt wird. Es ist damit notwendig, den Prozeß des Innovationsmanagements mit dem Qualitătsmanagement zu verknüpfen. Vgl. dazu Abschnitt 4.3.1.2.

${ }^{470}$ Vgl. Solow, R.M. (1957). Vgl. ergănzend Solow, R.M. (1994).

${ }^{471}$ Solows Arbeit sowie die weiteren in dieser Tradition abgefaßten Arbeiten werden als "Growth-AccountingAnsatz" bezeichnet.
} 
Kapitals am Output, (2) der Steigerungsrate des Arbeitseinsatzes, gewichtet mit dem Anteil der Arbeit am Output sowie (3) der Rate des technischen Fortschritts. Problematisch ist dabei, daß sich der technische Fortschritt im Gegensatz zu den anderen Faktoren nicht direkt beobachten läßt. Solow nahm daher an, daß der technische Fortschritt den Teil des Wirtschaftswachstums ausmacht, der nicht durch feststellbare Faktoren erklärt ist ("Solow-Residuum"). In seiner empirischen Untersuchung zu den Quellen des Wachstums in den USA zwischen 1909 und 1949 ließen sich lediglich 12\% durch die Ausweitung des Kapitals pro Arbeitskraft erklären. Entsprechend wurden die übrigen $88 \%$ dem Solow-Residuum, d.h. dem technischen Fortschritt, zugerechnet. Weitgehende Bestätigung fand dieses Ergebnis durch die Untersuchungen von DENISON, obwohl dieser eine weitaus differenziertere Vorgehensweise wählte. ${ }^{472}$ Beide Untersuchungen machen damit die primäre Abhängigkeit des Wachstums vom technischen Fortschritt deutlich.

Wie oben bereits dargestellt, gliedert sich der technische Fortschritt in verschiedene Phasen. In Abhängigkeit der Abgrenzung nimmt dabei die Innovation einen unterschiedlich breiten Raum ein. Wird die enge Sichtweise, die die Innovationsphase auf die Markteinführung bzw. Marktreife begrenzt, aufgegeben und Innovation in einem weiten Sinne verstanden, so wird durch die Einbeziehung von Forschung und Entwicklung, Invention und Innovation i.e.S. in dieser weiten Betrachtung, zum einen der Prozeßcharakter der Innovation hervorgehoben und zum anderen die herausragende Stellung der Innovation im Rahmen des technischen Fortschritts verdeutlicht. Folglich sind Innovationen als zentraler Wachstumsmotor zu charakterisieren.

Die Stärke des Einflusses der Innovationen auf das Wachstum sowie die Beschäftigung wurde im Gefolge der Arbeiten Solows und Denisons vielfach theoretisch und empirisch untersucht. Wenn auch nicht immer die gleiche Intensität des Zusammenhangs festgestellt werden konnte, so wird dennoch durchgängig die positive Wirkung der Innovation auf Wirtschaftswachstum und Beschäftigung hervorgehoben. ${ }^{473}$

${ }^{472}$ Vgl. Denison, E.F.. (1962); Denison, E.F. (1985). Bei Denison betrug die Zunahme des Kapitals pro Arbeitseinheit ca. 15\%. Daneben hebt er die wesentliche Bedeutung der Ausbildung beim Anstieg des Outputs pro Arbeitskraft hervor und zeigt damit, wie wichtig Investitionen in das Humankapital als Quelle des Wirtschaftswachstums sind. Darauf wird an verschiedenen Stellen noch eingegangen. Zur Kritik an Denison vgl. z.B. McCombie, J.S.L./Thirlwall, A.P. (1994).

${ }^{473}$ Bereits Schumpeter hat darauf hingewiesen, daß Innovationen der Motor der wirtschaftlichen Entwicklung sind. Vgl. Schumpeter, J.A. (1950), S. 136ff.

Zum Zusammenhang zwischen Wachstum und Beschäftigung vgl. Verdoorn, P.J. (1949); Verdoom, P.J. (1980); Hof, B. (1994); Seiter, S. (1997), S. 193-224; Hagemann, H./Seiter, S. (1998).

Für die Wirkung der Innovation auf Wirtschaftswachstum und Beschäftigung vgl. z.B. Albach, H. (1983); Hagemann, H. (1985); Klauder, W. (1986); Leontief, W.W./Duchin, F. (1986); Europåische Kommission (1994); OECD (1994), Kapitel 4; König, H. (1995); Grossman, G.M./Helpman, E. (1997); Grupp, H. (1997); Rottmann, H./Ruschinski, M. (1997); Schmalholz, H./Penzkofer, H. (1997) sowie die jeweils angegebene vertiefende Literatur. 
Die Globalisierung der Wirtschaft und das damit verbundene "Zusammenrücken" der Märkte führt zu einer Intensivierung des Wettbewerbs. Da der zwischen den Industrieländern bestehende Wettbewerb im wesentlichen ein Innovationswettbewerb ist, lassen sich Marktpositionen nur durch ständige Produkt- und Prozeßinnovationen verteidigen oder aufbauen. Demgemäß wird die internationale Wettbewerbsfähigkeit ${ }^{474}$ einer hochentwickelten Industrienation - wie z.B. der Bundesrepublik Deutschland - nach Auffassung des Sachverständigenrats durch die physischen Investitionen sowie die Ausgaben für Forschung und Entwicklung bestimmt. Daher sind zur Erhaltung der Wettbewerbsfähigkeit u.a. die Ausgaben für Forschung und Entwicklung auf einem hohen Stand zu halten oder sogar zu steigern. ${ }^{475}$ In Verbindung mit dem Erhalt der Wettbewerbsfähigkeit nehmen die Ausgaben für Forschung und Entwicklung Einfluß auf die Innovation und damit auch auf das Wirtschaftswachstum.

Die bislang erfolgreiche Wirtschaftsentwicklung in der Bundesrepublik Deutschland ist hauptsächlich auf die Innovationskraft deutscher Unternehmen zurückzufuihren. Daher ist es um so folgenreicher, wenn die Innovationskraft und damit die internationale Wettbewerbsfáhigkeit neuerdings abzunehmen scheint. ${ }^{476}$ Kennzeichnend für deutsche Unternehmen war lange Zeit die Innovativität auf breiter Front, d.h. es wurden zahlreiche kleine, schrittweise (inkrementelle) Verbesserungen vorhandener Produkte und Verfahren und diverse große bedeutende Basisinnovationen getätigt. ${ }^{477}$ Problematisch ist neuerdings, daß "die Bundesrepublik auf den meisten der uberdurchschnittlich wachsenden Weltmärkten zurückgefallen [ist, der Verf.], während sie ausgerechnet auf den nur langsam expandierenden Märkten stark war und Anteilsgewinne erzielte" ${ }^{478}$. Zum anderen nimmt Deutschland eine schwache Wettbewerbsposition in bestimmten Bereichen der Spitzentechnologie ${ }^{479}$ ein oder hat den anfänglichen Innovationsvorsprung aufs Spiel gesetzt. ${ }^{480}$ Damit werden aber langfristige Wachstumspotentiale aufgegeben. Betroffen sind vor allem der Bereich der Mikroelektronik und die auf dieser Querschnittstechnologie basierenden Branchen. Die technologischen Defizite im Bereich der Mikroelektronik strahlen zunehmend auch auf Branchen aus, die teilweise zu den

${ }^{474}$ Zur internationalen Wettbewerbsfahigkeit sowie der damit in Verbindung stehenden Qualităt des Wirtschaftsstandorts Deutschland vgl. Lobbe, K. (1991) und (1994); Klodt, H. u.a. (1994); Kantzenbach, E. (1997); Kromphardt, J. (1997); Thomasberger, C. (1997). Vgl. insb. auch Krugman, P. (1996).

Für eine Analyse der Wettbewerbsfahigkeit der europăischen Industrie vgl. Europäische Kommission (1996b) und (1997a).

${ }^{475}$ Vgl. Sachverstăndigenrat (1988), S. 113. Vgl. ferner Zahn, E. (1986), S. 10 f.

${ }^{476}$ Vgl. Lobbe, K. (1994), S. 35; Ottnad, A. u.a. (1995), S. 131; Perlitz, M./Lobler, H. (1985), S. 424.

${ }^{477}$ Vgl. Matraves, C. (1997), S. 1. Die deutsche Wirtschaft hat sich in der Vergangenheit vor allem darauf konzentriert, vorhandene Marktpositionen zu behaupten und auszubauen. Vgl. Ottnad, A. u.a. (1995), S. 132. Dies spiegelt auch das Ergebnis der eigenen Untersuchung wider. Wie in Abschnitt 3.6.3.1 aufgezeigt, wird die Strategie der Marktdurchdringung von $69,9 \%$ der untersuchten KMU gewăhlt.

${ }^{478}$ Löbbe, K. (1991), S. 59.

${ }^{479} \mathrm{Vgl}$. FN 426.

${ }^{480}$ Vgl. Klodt, H. u.a. (1994), S. 27; Gerybadze, A./Reger, G. (1997), S. 9. Gerybadze und Reger führen als Beispiele Flüssigkristalle und das Telefax an. 
Schlüsselbereichen der deutschen Wirtschaft gehören. ${ }^{481}$ Kritisch ist diese Entwicklung weniger auf europäischer Ebene, wo Deutschland noch immer in zahlreichen Branchen eine Marktführerposition einnimmt, als vielmehr im Vergleich zu den USA bzw. zu Japan. Beide erreichen sowohl absolut als auch relativ einen größeren Anteil am gesamten Welthandel mit Spitzentechnik als Deutschland. ${ }^{482}$

Für eine genauere Betrachtung der Situation Deutschlands werden die Innovationsintensität sowie die Attraktivität als Innovationsstandort herangezogen. ${ }^{483}$ Zur Abschätzung der Innovationsintensität können zwei Indikatoren verwendet werden, und zwar die F\&E-Intensität, d.h. der Anteil der F\&E-Ausgaben am Bruttoinlandsprodukt (BIP), und die gesamtwirtschaftliche Patentintensität. Ein Vergleich der F\&E-Intensität verschiedener OECD-Länder zeigt, daß Deutschland mit 2,3\% nach Japan (3,0\%) und den USA (2,6\%) den dritten Rang einnimmt:

Abb. 4-3: F\&E-Ausgaben (in \% des BIP) in verschiedenen Låndern der OECD (1995)

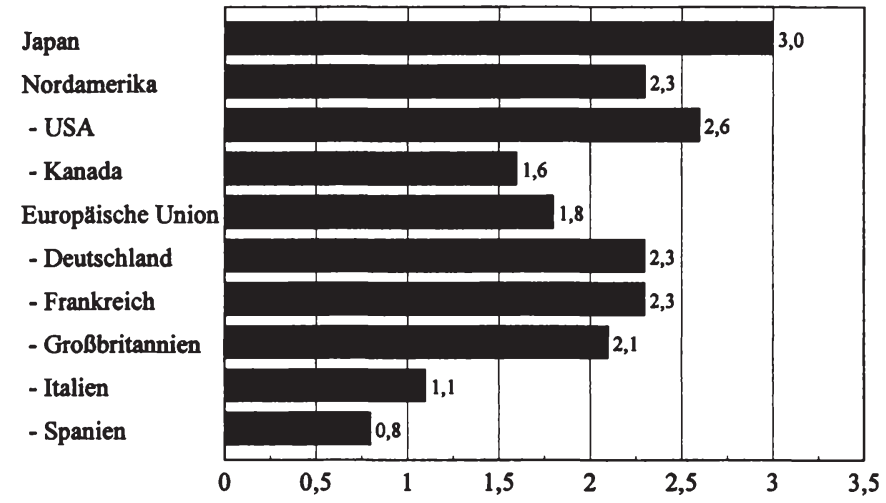

Quelle: OECD (1997), S. $16 .^{484}$

Innerhalb der Europäischen Union (1995: 1,91\%) nimmt Deutschland sogar eine Spitzenstellung ein, wobei allerdings zu berücksichtigen ist, daß die F\&E-Ausgaben vereinigungsbedingt

${ }^{481}$ Vgl. Ottnad, A. u.a. (1995), S. 133-144.

${ }^{482}$ Dabei ist jedoch zu beachten, daß die Europäische Union insgesamt gegenuber den "Benchmarks" USA bzw. Japan zuruckgefallen ist. Vgl. Europäische Kommission (1996b); Ottnad, A. u.a. (1995), S. 132f. Zu den Bestimmungsfaktoren der amerikanischen und japanischen Erfolge vgl. Europăische Kommission (1996c), S. 15.

${ }^{483}$ Vgl. Klodt, H. u.a. (1994); Lobbe, K. (1991) und (1994); Ottnad, A. u.a. (1995), S. 144-150. Vgl. zum Standort Deutschland ferner IW (Hrsg.) (1996).

${ }^{484}$ Zur Entwicklung der F\&E-Ausgaben zwischen 1990 und 1995 vgl. Anlage 17. Vgl. dazu ferner Europäische Kommission (1997b), S. 26. Die Werte in den angegebenen Quellen weisen dabei kleinere Differenzen auf. 
in Deutschland zwischen 1991 und 1993 deutlich zurückgingen (-3,4\%). Zum Vergleich: In diesem Zeitraum sanken in Japan die F\&E-Ausgaben um 2,8\%, in der EU um 1,6\%, während sie in den USA um $1,8 \%$ anstiegen. ${ }^{485}$ Die F\&E-Intensität sagt jedoch wenig über den Erfolg der Forschungsanstrengungen aus. Deswegen wird als weiterer Indikator die gesamtwirtschaftliche Patentintensität, d.h. die Anzahl der pro Jahr angemeldeten Patente in Relation zur Zahl der Erwerbstätigen, herangezogen, da zur Patentanmeldung ausschließlich erfolgreiche Innovationsprozesse fuihren. Wie verschiedene Patentstatistiken zeigen, hatte Deutschland bis in die Mitte der achtziger Jahre die höchste Patentintensität. Seit 1987 nimmt Deutschland hinter Japan, das im Gegensatz zu Deutschland seinen Anteil an Patenten in hohem Maße ausgedehnt hat, den zweiten Rang ein. ${ }^{486}$

Die weiterhin gute Position der Bundesrepublik Deutschland bezüglich der F\&E- und der Patentintensität einerseits und die neuerdings gefährdete internationale Wettbewerbsfähigkeit andererseits machen deutlich, daß Forschung und Entwicklung sowie Pantentanmeldungen eine möglicherweise notwendige, nicht aber schon hinreichende Bedingung für erfolgreiche Innovationstätigkeit sind. Es kommt offensichtlich darauf an, in welchen Bereichen die Aktivitäten anfallen. So verfügt Deutschland uber eine im internationalen Maßstab gesehen hohe Innovationsintensität im Mitteltechnologiesektor. Durch die Konzentration auf die Herstellung technologisch hochwertiger Produkte konnte in diesem Technologiesektor die internationale Wettbewerbsfähigkeit behauptet werden. ${ }^{487}$ Damit fand allerdings eine Spezialisierung in Be-

${ }^{485}$ Vgl. Europaische Kommission (1997b), S. 26-31. Vgl. ferner Kurz, R. (1994a), S. 92f.; Brockhoff, K. (1994), S. 59-70; Specht, G./Beckmann, C. (1996), S. 7-13; Paasi, M. (1997), S. 37-43; Europäische Kommission (1997a), S. 90ff. Gegen die Verwendung der F\&E-Intensităt als Maß für die Innovativităt wenden Klodt u.a. vor allem ein, daß die F\&E-Ausgaben nur einen Teil der gesamten Innovationsaufwendungen darstellen. Sie betrugen beispielsweise 1991 im Verarbeitenden Gewerbe lediglich 23\%. Daneben bildeten die Ausgaben für Konstruktion und Produktdesign (26\%), Produktionsvorbereitung (18\%) und Prozeßinnovation (28\%) weitere 486 Innovationsaufwendungen. Vgl. Klodt, H. u.a. (1994), S. 42f. sowie ferner Rottmann, H. (1995), S. $137 f$.

${ }^{V}$ gl. Klodt, H. u.a. (1994), S. 43ff.; Lobbe, K. (1994), S. 42f.; Matraves, C. (1997), S. 11-14.

Allerdings erscheint die deutsche Position durch eine Zunahme der Patentanmeldungen in der jüngeren Vergangenheit in einem deutlich positiveren Licht. Über die Eignung von Patenten als Maß für die Innovationsintensitat werden jedoch unterschiedliche Meinungen vertreten. Brockhoff sieht in Patenten zwar kein ideales, aber doch das beste verfügbare Outputmaß für F\&E. Vgl. Brockhoff, K. (1993), S. 183f Dagegen wenden Klodt u.a. ein, "daß aus der Anzahl der angemeldeten Patente nicht ohne weiteres auf die tatsăchlich in neue Produkte und Herstellungsverfahren umgesetzten Patente geschlossen werden kann". Klodt, H. u.a. (1994), S. 43. Vgl. dazu auch Acs, Z.J./Audretsch, D.B. (1992), S. 56f.; Rottmann, H. (1995), S. 137f. Perillieux spricht ferner von einer geringen Bedeutung von Patenten im Wettbewerb, da der kritische Erfolgsfaktor weniger in der rechtlichen Absicherung von Innovationsführerpositionen als in der frühen Einfuhrung technisch anspruchsvoller Produkte liegt. Dies zeigt sich deutlich bei Produkten in sich schnell entwickelnden Märkten, die teilweise bereits vor Erteilung des Patents obsolet sind. Vgl. Perillieux, R. (1987), S. 108. Mit Blick auf KMU kann mit Scherer festgestellt werden "that patenting is an increasing function of firm size", Scherer, F.M. (1965), S. 1103. KMU verzichten hăufig auf die Anmeldung von Patenten, da zum einen die Anwaltshonorare und Patentgebühren furr die Erteilung von Patenten als zu hoch betrachtet werden und zum anderen die Durchsetzung der Patentrechte ebenfalls zu aufwendig erscheint. Vgl. Albach, H. (1983), S. 47. Da Patente auch als Ideenpool furr Neu- oder Weiterentwicklungen herangezogen werden, werden Innovationen aus Geheimhaltungsgruinden teilweise gerade nicht als Patente angemeldet. Zur Funktion von Patenten als Indikator innovativer Aktivităten vgl. z.B. Merkle, E. (1989), S. 398-414; Konig, H./Licht, G. (1995), S. 524-528.

487 Vgl. Klodt, H. u.a. (1994), S. 43ff. Vgl. zur technologischen Wettbewerbsposition dort auch die Fallstudie Maschinenbau, S. 46-57. 
reichen statt, die sich in einer Stagnations- bzw. sogar Degenerationsphase befinden. Durch die im deutschen Innovationssystem stärker inkrementellen als grundlegenden Innovationen werden Hochtechnologiebranchen vernachlässigt und damit vor allem bei wichtigen Schlüsseltechnologien zukünftige Wettbewerbspositionen aufgegeben. ${ }^{488}$

Bezüglich der Abschätzung der Attraktivität als Innovationsstandort dient als Indikator vor allem die internationale Verteilung des weltweiten Investitionskapitals. Sie zeigt, in welchem Ausmaß es den einzelnen Ländern gelungen ist, mobiles Kapital anzulocken und im Land zu halten. Als Maß hierfür kann die Bilanz der Direktinvestitionen herangezogen werden. Direktinvestitionen sind eine Form der Auslandsinvestition zur Absicherung der Wettbewerbsfähigkeit und der Präsenz auf wachsenden Märkten, bei der der Kapitalexport dazu genutzt wird, z.B. neue Produktionsstätten zu errichten bzw. eine maßgebliche Beteiligung an einem Unternehmen im Ausland zu erwerben. Die Bilanz der Direktinvestitionen der Bundesrepublik Deutschland weist seit längerem einen negativen Saldo aus. "Die Passivierung der Direktinvestitionsbilanz wird im allgemeinen als Anzeichen einer Verschlechterung der relativen Standortqualität eines Landes gewertet. ${ }^{489}$

Die Ursachen für eine Verlagerung der Investitionsströme und damit des Innovationspotentials liegen u.a.

- in hohen Abgabenlasten in Form von Steuern und Sozialbeiträgen,

- in vorhandenen Strukturdefiziten, da der Schwerpunkt der deutschen Industrie im Mitteltechnologiebereich und nicht im wachstumsstarken Hochtechnologiebereich - wie z.B. der Mikroelektronik - liegt,

- in innovationshemmenden staatlichen Regulierungen, die sich z.B. in langen Anmeldungs- und Genehmigungsverfahren äußern, wie dies etwa bei bio- und gentechnischen Verfahren der Fall ist,

- in vielfältigen Starrheiten und Inflexibilitäten am Arbeitsmarkt und im Anstieg der Lohnkosten auch im Zusammenhang mit der Aufwertung der D-Mark,

- in der wachsenden Mobilität und schnelleren Verbreitung des technischen Wissens sowie der zunehmenden Entkopplung von Forschung und Entwicklung, so

${ }^{488}$ Vgl. Matraves, C. (1997), S. 13ff; Ottnad, A. u.a. (1995), S. 145ff. Vgl. dazu ferner die Beispiele Mikroelektronik bei Ottnad, A. u.a. (1995), S. 133-144 bzw. Biotechnologie bei Klodt, H. u.a. (1994), S. 57-68 und Ottnad, A. u.a. (1995), S. $148 \mathrm{ff}$.

${ }^{489}$ Klodt, H. u.a. (1994), S. 16. Zur Entwicklung der Kapitalverflechtung deutscher Unternehmen mit dem Ausland vgl. Deutsche Bundesbank (1997a), S. 63-77 und Deutsche Bundesbank (1997b), S. 63-82 sowie ferner Kromphardt, J. (1997), S. 13-20; Löbbe, K. (1994), S. 38-41; Ottnad, A. u.a. (1995), S. 147f. Für eine Darstellung der Situation auf europăischer Ebene vgl. Europäische Kommission (1997a), S. 40-46.

Zur Problematik internationaler Vergleiche von Direktinvestitionsstromen und den daraus resultierenden Einwänden gegen diesen Standortindikator vgl. Deutsche Bundesbank (1997a), S. 79-86 i.V.m. Klodt, H. u.a. (1994), S. 17f. Letzterer plådiert daher für die Verwendung des Saldos der gesamten Kapitalbilanz, da dieser sich aus der Summe des Direktinvestitionssaldos und des Portfolioinvestitionssaldos zusammensetzt. 
daß sich die Qualifikationsvorsprünge des Humankapitals in Deutschland gegenüber den Wettbewerbern verringern,

- in einer gewissen gesellschaftlichen Technikfeindlichkeit (z.B. Bio- und Gentechnologie), wobei die Sensibilisierung der Gesellschaft bezüglich der Technikfolgen für Ressourcen- und Umweltsituation sowie für den sozialen Bereich zu einer teilweisen Ablehnung bzw. zu der bereits genannten Aufstellung bzw. Verschärfung staatlicher Regelungen geführt hat sowie

- in der Verschiebung internationaler Mărkte von Europa bzw. den USA in den asiatisch-pazifischen Raum. $^{490}$

Werden die Aussagen über die Innovationsintensität und den Innovationsstandort zusammengefaßt, kann Deutschland mittelfristig durch seine starke Position im Bereich der Mitteltechnologie seine große Leistungs- und Wettbewerbsfähigkeit aufrechterhalten. Die strukturellen Anpassungsdefizite, die Schwächen im Bereich der Hochtechnologie und die abnehmende Innovationskraft beeinträchtigen jedoch die langfristige Leistungs- und Wettbewerbsfähigkeit und somit auch das langfristige Wachstumspotential.

Die gesamtwirtschaftliche Bedeutung kleiner und mittlerer Unternehmen im deutschen Innovationssystem ist schwer zu quantifizieren. ${ }^{491}$ Als Anhaltspunkt soll daher eine Aufstellung bei C. FREEMAN dienen, die den prozentualen Anteil von Unternehmen mit weniger als 500 Mitarbeitern an den zwischen 1945 und 1980 in Großbritannien angemeldeten Patenten auf durchschnittlich $21 \%$ beziffert. ${ }^{492}$ Damit würde die Neo-Schumpeter-Hypothese, "daß vor allem die Großunternehmen als Träger des Fortschritts figurieren, der Fortschritt also eine Funktion der Unternehmensgröße ist (Unternehmensgrößenhypothese)"1493, neue Nahrung erhalten.

Die Überprüung dieser Hypothese wurde auch in der zugrundeliegenden Untersuchung in der Region Neckar-Alb angestrengt und wird im Verlauf dieses vierten Kapitels mehrfach thematisiert. Für die Region Neckar-Alb stellt KosCHATZKY ${ }^{494}$ eine weit unterdurchschnittliche F\&E-Personalquote fest. Der Anteil der in Forschung und Entwicklung tätigen Mitarbeiter am Gesamtpersonal liegt in der Region mit 2,72\% deutlich unter dem baden-württembergischen Durchschnitt (4,24\%) sowie auch unter dem bundesdeutschen Durchschnitt (West: 3,23\%).

\footnotetext{
${ }^{490}$ Vgl. Deutsche Bundesbank (1997a), S. 66; Deutsche Bundesbank (1997b), S. 76; Ottnad, A. u.a. (1995), S. 147-151; Klodt, H. u.a. (1994), S. 18-27; Lobbe, K. (1994); Dieter, W.H. (1991), S. 35.

${ }^{491} \mathrm{Vgl}$. Kurz, R. (1994a), S. 95. Allgemein wird davon ausgegangen, daß sie eine bedeutende aber schwer zu quantifizierende Rolle im gesamtwirtschaftichen Innovationsprozeß spielen. Vgl. u.a. U.S. Small Business Administration (1983), S. 121-128.

492 Vgl. Freeman, C. (1982), S. 140.

${ }^{493}$ Herdzina, K. (1981), S. 79. Vgl. dazu auch Elßer, S. (1993) sowie die jeweils angegebene Literatur zur Diskussion dieser Hypothese.

${ }^{494}$ Vgl. Koschatzky, K. (1997).
} 
Daneben liegen die Patentkennziffern für die Region ebenfalls weit unter dem Landesschnitt. Die Stärken der Region in Form eines breiten wissenschaftlichen Potentials, besonders im Bereich der Biotechnologie-, der Gesundheits- und der Materialforschung sowie der physikalischen Technologien werden somit nicht in eine entsprechend große Erfindertätigkeit umgesetzt. $^{495}$

\subsubsection{Die einzelwirtschaftliche Bedeutung von Innovationen}

Ein sich beschleunigender Wandel der externen und internen Bedingungen des Unternehmens ist ein Merkmal moderner Industriegesellschaften. Dieser Wandlungsprozeß stellt hohe Anforderungen an die Wandlungsfähigkeit und -willigkeit derjenigen Unternehmen, die sich diesem Prozeß erfolgreich stellen wollen. Die Basis für einen Erfolg ist die Innovativität des Unternehmens, d.h. die Entwicklung und Durchsetzung neuer Produkte und Verfahren auf dem Markt. Dabei steht außer Zweifel, daß Innovationen Kosten verursachen und sie sind, "da sie mit erheblich größeren Unsicherheiten behaftet sind als die Produktion bekannter Güter und die Verwendung bekannter Produktionsprozesse, extrem risikoreich. Bei den Wirtschaftssubjekten dürfte daher eine Neigung bestehen, derartige Kosten und Risiken zu vermeiden. Sie werden diese Aktivitäten dennoch entfalten (müssen), wenn für sie ein Verlust oder gar ein Existenzrisiko bei Unterlassung besteht, wenn also zu befïchten ist, daß andere ihnen zuvorkommen und sie verdrängen. Sie werden möglicherweise auch dann aktiv werden, wenn sie eine Chance sehen, durch Erreichen einer Vorsprungsposition vor anderen nicht nur die Kosten von Forschung und Entwicklung wieder vergütet zu bekommen, sondern darüber hinaus zusätzliche Gewinne zu erzielen" ${ }^{\text {496 }}$. Daneben kann es durch eine Differenzierung des Leistungsangebotes mittels Innovationen zumindest temporär gelingen, sich dem Wettbewerbsdruck zu entziehen bzw. eine strategisch günstige Position im Wettbewerb einzunehmen.

Innovation ist somit kein Selbstzweck, sondern sie dient als strategische Schlüsselressource der Herbeifuhrung von Markterfolgen, indem sie die Erringung von Wettbewerbsvorteilen und damit die Stärkung der Wettbewerbsposition sowie die Erreichung und Sicherung von Volumens- und Ertragszielen ermöglicht. ${ }^{497}$ Die Bedeutung von Innovationen für den Unternehmenserfolg "zeigt sich daran, daß der Anteil neuer Produkte an Umsatz und Gewinn ständig zunimmt" ${ }^{498}$. Die Einbindung der Innovation in die Unternehmensplanung ist somit von existentieller Bedeutung, da sie den schnellen und reibungslosen Transfer von Wissen und

\footnotetext{
${ }^{495}$ Vgl. Koschatzky, K. (1997), S. 48-53. Dabei stellt Koschatzky ferner fest, daß die in der Region Neckar-Alb z.T. vorfindbaren ländlichen Strukturmerkmale nicht unbedingt im Widerspruch zu den regionalen Inventionsaktivităten stehen. Vgl. dazu auch Fritsch, M. (1990), S. 117f.; Vaessen, P./Keeble, D. (1995), S. 489-505.

${ }^{496}$ Herdzina, K. (1993), S. 28. Vgl. dazu auch Zahn, E. (1986), S. 34.

${ }^{497}$ Vgl. Dieter, W.H. (1991), S. 28.

${ }^{498}$ Perillieux, R. (1991), S. 23.
} 
Fähigkeiten in das Unternehmen und auch innerhalb des Unternehmens erleichtert und so dem Aufbau von Leistungs- und Wettbewerbspotentialen dient. ${ }^{499}$ Von großer Bedeutung ist, ob und wie ein Unternehmen seine speziellen Innovationspotentiale in marktfähige Produkte umsetzen kann, wie es die Risiken der Innovation diversifiziert und nach welchen Prioritäten die Ressourcen des Unternehmens auf welche Schwerpunkte verteilt werden. ${ }^{500}$ Die Bewältigung dieser Aufgabe, d.h. die effiziente Gestaltung der Entstehung, Übernahme und Verbreitung von Neuerungen, ist Inhalt des Innovationsmanagements. ${ }^{501}$

Der Innovativität sowie dem effizienten Management von Innovationen kommt in kleinen und mittleren Unternehmen des Verarbeitenden Gewerbes eine mehrdimensionale Bedeutung zu. Zum einen sind Innovationen naturgemäß in technologieintensiven Industrien, zu denen insbesondere auch das Verarbeitende Gewerbe zählt, von herausragender Bedeutung. Hier wird der Wettbewerb in erster Linie über das Produkt bzw. über die eingesetzte Technologie entschieden, wodurch die übrigen Elemente des Marketing-Mix, also Preis, Distribution oder Kommunikation, etwas in den Hintergrund treten. ${ }^{502}$ Zum anderen wird vor allem von kleinen und mittleren Unternehmen eine hohe Anpassungsfähigkeit gefordert. Die Innovationsorientierung ist damit eine notwendige Voraussetzung für den Unternehmenserfolg, wobei ihrer Systematisierung in Form eines Innovationsmanagements eine hohe Bedeutung eingeräumt werden muß, da Innovationsmißerfolge vor allem in kleinen und mittleren Unternehmen zu einer Existenzgefährdung werden können.

Die Bedeutung der Innovation als ein zentraler Erfolgsfaktor kleiner und mittlerer Unternehmen wurde bereits herausgestellt. Wie nun das Innovationsmanagement zur Stärkung dieses Erfolgsfaktors beitragen kann, ist Ziel der nachfolgenden Kapitel. ${ }^{503}$ Dazu wird analog zur Vorgehensweise in Kapitel 3 zunächst das Innovationsmanagement in kleinen und mittleren Unternehmen global dargestellt (Kapitel 4.3). Anschließend werden die wesentlichen Komponenten, d.h. die Innovationskultur (Kapitel 4.4), die Innovationsziele (Kapitel 4.5) sowie die Innovationsstrategien (Kapitel 4.6) einer genaueren Analyse unterzogen.

\footnotetext{
${ }^{499}$ Vgl. Specht, G./Zörgiebel, W.W. (1985), S. 492; Specht, G. (1989), S. 148; Liessmann, K. (1987), S. 101; Perillieux, R.Wittkemper, G. (1991), S. 13; Krubasik, E.G. (1982), S. 33.

${ }^{500}$ Vgl. Liessmann, K. (1987), S. 101.

${ }^{501}$ Vgl. Bierfelder, W.H. (1994), S. 180.

502 Vgl. Perillieux, R. (1991), S. 23.

${ }^{503}$ In Analogie zur Vorgehensweise bei der gesamtwirtschaftlichen Betrachtung, wăren an dieser Stelle Aussagen zur Innovationsintensităt der untersuchten Unternehmen in der Region Neckar-Alb sowie zu den dortigen Standortbedingungen zu treffen. Um Überschneidungen zu vermeiden, wird auf die Darstellung in den nachfolgenden Kapiteln verwiesen.
} 


\subsection{Innovationsmanagement in kleinen und mittleren Unternehmen}

\subsubsection{Gestaltungsbereiche des Innovationsmanagements}

\subsubsection{Notwendigkeit des Innovationsmanagements}

Die Erneuerung und Verbesserung von Produkten und Leistungen ist die Voraussetzung für das Bestehen auf dem Markt. Dies gilt auch für kleine und mittlere Unternehmen des Verarbeitenden Gewerbes, zumal ihre Produkte und Leistungen die zentrale Basis darstellen, auf der sie ihren Bestand begründen und die ihre Existenzberechtigung im Markt ausmacht. Kleine und mittlere Unternehmen sind aber auch durch ihr eingeschränktes Produkt- und Leistungsprogramm in besonderem Maße von ständigen Innovationen abhängig. Die Abhängigkeit von Innovationen wird in der Diskussion über kleine und mittlere Unternehmen jedoch oftmals mit dem grundsätzlichen Vermögen zu Innovationen gleichgesetzt, indem stereotyp auf ein herausragendes Anpassungs- und Erneuerungsvermögen kleiner und mittlerer Unternehmen verwiesen wird. Zwar verfügen kleine und mittlere Unternehmen über eine Reihe von Eigenschaften wie z.B. über eine Unternehmerpersönlichkeit mit umfassender Entscheidungskompetenz, überschaubare Einheiten, flache Hierarchien, kurze Entscheidungs- und Kommunikationswege etc., die allesamt Innovationen begünstigen. Sie sind damit aber nicht automatisch innovativ. Das Anpassungs- und Erneuerungsverhalten hängt auch hier von der Innovationsfähigkeit, -fertigkeit und -neigung des Unternehmers bzw. aller Organisationsmitglieder ab und muß systematisch und gezielt gefördert werden, damit Innovationen möglich sind. Dies ist Aufgabe des Unternehmers bzw. der Unternehmensführung.

Die Notwendigkeit einer strategischen Unternehmensfuhrung in kleinen und mittleren Unternehmen wurde in Kapitel 3 damit begründet, daß zur langfristigen Überlebenssicherung des Unternehmens eine systematische Nutzung des sich wandelnden oder gestaltbaren Handlungsspielraumes erforderlich ist. Die Unternehmensführung wird dazu Unternehmens- und/oder Umfeldänderungen, also Realitätsänderungen, induzieren müssen. Dazu ist es notwendig, sich abzeichnende Veränderungen und Trends frühzeitig zu erkennen und sie daraufhin zu untersuchen, ob diese Prozesse Innovationen anregen, die beispielsweise die bestehende technologische Basis substituieren können, zusätzliche Leistungsmerkmale ermöglichen, die Kosten/Leistungsrelationen verändern oder die Überwindung bestehender Produkt- oder Leistungsbegrenzungen gestatten. ${ }^{504}$

Die Systematisierung und zielorientierte Gestaltung des Innovationsprozesses im Rahmen der Unternehmensführung leistet das Innovationsmanagement, indem

$\overline{504}$ Vgl. Arthur D. Little (Hrsg.) (1994), S. 74. 
- Wertschöpfungspotentiale mit zentraler Bedeutung für den Unternehmenserfolg identifiziert werden und in Produkt- und Prozeßideen einfließen,

- operative Handlungsprogramme zu einer zielorientierten Umsetzung der Ideen in ein konkretes Produkt - unter Beachtung der Rahmenbedingungen - entwikkelt werden;

- Organisationsstrukturen, Führungs- und Anreizkonzeptionen gestaltet werden, die die Innovationsbereitschaft fördern und

- innovatives Denken und Handeln der Mitarbeiter und insb. der Führung gefördert werden, ${ }^{505}$

so daß eine Weiterentwicklung und Anpassung des Unternehmens möglich wird. Mit Hilfe des Innovationsmanagements sollen im Unternehmen die Grundlagen für diese Weiterentwicklung geschaffen werden. ${ }^{506}$ Das Innovationsmanagement umfaßt damit alle strategischen und operativen Aufgaben, die diesen Gestaltungsproze $ß$ im Unternehmen begünstigen und fördern. Ansatzpunkte der Gestaltung sind die Unternehmenskultur, die Organisation, die Personalpolitik, die Informations- und Kommunikationspolitik, die Finanzierung sowie das Controlling. ${ }^{507}$ In diesen Bereichen sind mit Hilfe des Innovationsmanagements die Voraussetzungen für erfolgreiche Innovationen zu schaffen. Daneben besteht die Aufgabe des Innovationsmanagements darin, "innerhalb der vorhandenen Industriestruktur Wege zur Erreichung verteidigungsfähiger Wettbewerbspositionen aufzuzeigen oder durch ... Innovationen die Industriestruktur zugunsten der eigenen Unternehmung zu verändern und so die Spielregeln des Wettbewerbs neu zu definieren" ${ }^{508}$.

Innovationsmanagement verfolgt in erster Linie die Neuerung. Dabei entsteht die Gefahr, daß die Qualität vernachlässigt wird. Es ist daher notwendig, die Prozesse des Innovations- und des Qualitätsmanagements miteinander so zu verknüpfen, daß ein einheitlicher und übergreifender Gestaltungsprozeß entsteht. ${ }^{509}$

\footnotetext{
${ }^{505}$ Vgl. Marr, R. (1993), Sp. 1797f.

${ }^{506}$ Vgl. Witt, J. (1996), S. 169.

${ }^{507}$ Eine ausfuhrliche Behandlung aller genannten Gestaltungsbereiche wulrde den Rahmen dieser Arbeit sprengen. Der Fokus liegt daher auf dem Gestaltungsbereich der Unternehmenskultur, d.h. genauer der Innovationskultur. Sie prägt das Verhalten aller Organisationsmitglieder sowie die formalen Regelungen. Damit bildet sie die Basis innovativen Verhaltens im Unternehmen und strahlt zugleich auf die übrigen Bereiche stark aus.

${ }^{508}$ Servatius, H.-G. (1985), S. 7.

${ }^{509} \mathrm{Vgl}$. Witt, J. (1996), S. $182 \mathrm{f}$.
} 


\subsubsection{Das Qualitätsmanagement als Komponente des Innovationsmanagements}

Qualität als "Komponente" der Innovation zu betrachten, kann mit dem Schumpeterschen Innovationsbegriff begründet werden, der u.a. auch die Erzeugung neuer Qualitäten von Produkten beinhaltet. ${ }^{510}$ Qualität bezieht sich jedoch nicht ausschließlich auf Produkte, sondern um$\mathrm{fa}$ ßt das gesamte Leistungsspektrum eines Unternehmens. Sie ist die Gesamtheit von Eigenschaften und Merkmalen eines Produktes oder einer Tätigkeit, die sich auf deren Eignung zur Erfüllung festgelegter und vorausgesetzter Erfordernisse bezieht. ${ }^{511}$

In Abschnitt 3.3.4.2 wurde die Qualität als Erfolgsfaktor kleiner und mittlerer Unternehmen identifiziert. Wie jedoch die zahlreichen Veröffentlichungen japanischen und amerikanischen Ursprungs zeigen, hat sich mittlerweile eine eigenständige Qualitätswissenschaft entwickelt, deren Konzepte vor allem auf Erfahrungen aus Großunternehmen basieren und meist auch auf die Belange von Großunternehmen zugeschnitten sind. ${ }^{512}$ Soll also die Qualität auch weiterhin ein zentraler Erfolgsfaktor kleiner und mittlerer Unternehmen bleiben, müssen sie sich diesen Konzepten öffnen und sie ihren Belangen anpassen.

Ausgangspunkt der unterschiedlichen Qualitätsmanagementkonzepte ist das KAIZEN. ${ }^{513}$ Das KAIZEN-Konzept richtet sich auf die gesamte Wertschöpfungskette des Unternehmens und bedeutet "die ständige Verbesserung von Prozessen und Produkten in kleinen Schritten durch Einbeziehung sämtlicher Mitarbeiter und Führungskräfte" ${ }^{514}$. Dieses Konzept zeichnet sich somit durch zwei wesentliche Gestaltungskomponenten aus, nämlich die Mitarbeiterorientierung und die Prozeßorientierung. Beide Komponenten zielen letztlich auf die Zufriedenstellung des Kunden $a b .{ }^{515}$ Die Kundenorientierung wird dabei global betrachtet, d.h. neben den externen werden auch die internen Kunden-Lieferantenbeziehungen durch das Konzept erfaßt. Die Kundenorientierung im internen Bereich soll zu einem gesteigerten Verantwortungsbe-

${ }^{510}$ Vgl. Schumpeter, J.A. (1912), S. 159; Schumpeter, J.A. (1928), S. 483.

511 Vgl. dazu Elter, V.-C. (1997), S. 207f.; Seghezzi, H.D. (1995), S. 145; Seghezzi, H.D. (1996), S. 92-95; Steinbach, R.F. (1997), S. 74ff. und die dort zitierten Normen DIN ISO 8402 und 55350. Vgl. ferner Specht, G. (1989), S. 143; Feigenbaum, A.V. (1991), S. 7; Garvin, D.A. (1984), S. 25-28; Garvin, D.A. (1988), S. 39-46.

512 Eine umfassende und erschöpfende Diskussion der für das Qualitătsmanagement relevanten Konzepte und Ansătze kann in dieser Arbeit nicht geleistet werden. Für einen Überblick siehe Kamiske, G.F./Brauer, J.-P. (1995) sowie die dort angegebene Literatur.

${ }^{513}$ Vgl. Imai, M. (1994); BMWi u.a. (Hrsg.) (1995); Teufel, P. (1996). Kritisch zu dem von Imai vorgestellten Konzept åußert sich Zink, K.J. (1995), S. 15-19. Als Grundlage des KAIZEN gilt die von Deming seit den 50er Jahren entwickelte und zunächst in Japan eingefuhrte Unternehmensphilosophie, die auf Qualităt und ständige Verbesserung des Produktionsprozesses ausgerichtet ist und in die alle Mitarbeiter des Unternehmens einbezogen werden müssen. Vgl. Deming, W.E. (1994). Nach Tominaga bedeutet KAIZEN wörtlich übersetzt "Wandel zum Besseren". Da der Begriff KAIZEN in Deutschland patentrechtlich geschützt ist, verwendet er die deutsche Übersetzung "Kontinuierlicher Verbesserungsprozeß - KVP". Vgl. Tominaga, M. (1997), S. 15-25. Bei der Anwendung des Konzeptes hat sich aus der Region Neckar-Alb vor allem die Mettler-Toledo (Albstadt) GmbH hervorgetan. Vgl. Tikart, J. (1997); Tominaga, M. (1997), S. 75f.

514 Teufel, P. (1996), S. 526. Vgl. auch BMWi u.a. (Hrsg.) (1995), S. 3.

${ }^{515}$ Vgl. Imai, M. (1994), S. 39; Teufel, P. (1996), S. 527. 
wußtsein für die eigene Tätigkeit führen, indem sich der Mitarbeiter als Unternehmer im Unternehmen (Intrapreneur) versteht. ${ }^{516}$

Zur Umsetzung des KAIZEN im Unternehmen werden nach TEUFEL eine Vielzahl eigenständiger Methoden und Konzepte eingesetzt.

Zweck der 5A-Kampagne ist, das Unternehmen in einen sauberen, aufgeräumten Zustand zu versetzen und diesen beizubehalten. Die ursprüngliche Bezeichnung lautet "5S", nach den japanischen Begriffen Seiri (Aussortieren unnötiger Dinge), Seiton (Aufräumen), Seiso (Arbeitsplatz sauberhalten), Seiketsu (Anordnungen zur Regel machen) und Shitsuke (Alle Punkte einhalten und ständig verbessern). ${ }^{517}$

Das Total Productive Maintenance (TPM) ist ein Ansatz, der durch die systematische und kontinuierliche Verbesserung der Nutzleistung von Produktionsanlagen auf die Anlageneffizienz abzielt. Die Anlageneffizienz setzt sich aus drei Faktoren zusammen, der Verfügbarkeit, der Leistung und der Qualität. Innerhalb dieser Faktoren existieren sechs Fehlerquellen, auf deren Vermeidung der Ansatz abzielt. Die potentiellen Fehlerquellen liegen beim Verfügbarkeitsfaktor in Maschinenausfällen bzw. Rüstzeiten und Justierungen, beim Leistungsfaktor im Leerlauf bzw. in kleineren Störungen sowie beim Qualitătsfaktor in fehlerhaften Teilen bzw. Anlaufverlusten. ${ }^{518}$

In Bezug auf die Qualität können zwei Ansätze unterschieden werden, das Total Quality Control (TQC) und das Company Wide Quality Control (CWQC). Das TQC geht auf ein von FEIGENBAUM 1961 entwickeltes Konzept zurlick und ist eine das gesamte Unternehmen umfassende Qualitätsstrategie, die sich an den Kundenbedürfnissen ausrichtet. ${ }^{519}$ Das CWQC geht auf den Japaner IsHIKAWA zurück und gilt als eine Weiterentwicklung des TQC. ${ }^{520}$ Es stellt vor allem die Beteiligung der Mitarbeiter bei der Einfuhrung und Stabilisierung des Qualitätskonzeptes heraus. $^{521}$

${ }^{516} \mathrm{Vgl}$. Teufel, P. (1996), S. 528. Als ein herausragendes Beispiel aus der Unternehmerbefragung ist die Bizerba $\mathrm{GmbH} \&$ Co. KG, Werk Balingen, zu nennen. Kundenorientierung ist dort ein gewichtiger Kernpunkt der Unternehmensphilosophie, die aktiv zur Innovation genutzt wird.

${ }^{517}$ Vgl. Teufel, P. (1996), S 534f.; Tominaga, M. (1996), S. 139-154.

${ }^{518}$ Vgl. Teufel, P. (1996), S. 536f.; Kamiske, G.F./Brauer, J.-P. (1995), S. 237-240.

${ }^{519}$ Vgl. Feigenbaum, A.V. (1991). Er definiert TQC als "an effective system for integrating the qualitydevelopment, quality-maintenance, and quality-improvement efforts of the various groups in an organization so as to enable marketing, engineering, production, and service at the most economical levels which allow for full customer satisfaction". Feigenbaum, A.V. (1991), S. 6.

${ }^{520}$ Vgl. Ishikawa, K. (1994); Ishikawa, K. (1990); Ishikawa, K. (1985).

521 Über das TQC und das CWQC hinaus geht das Total Quality Management (TQM), das die Qualität in die Unternehmensphilosophie einbezieht und sogar auf das Unternehmensumfeld ausdehnt. Das TQM wird damit zur umfassendsten Qualitătsstrategie. Die Grundprinzipien des TQM sind externe und interne Kundenorientierung, Prozeßorientierung, Mitarbeiterorientierung, erkennen und fordern von Problemlossungspotentialen, kontinuierliche Verbesserung (dynamische Komponente des TQM) sowie präventives Verhalten (prozeßbegleitende Überwachung). Sie bilden die instrumentelle Basis für die Umsetzung des TQM, deren Grundlage wiederum die Normenreihe DIN EN ISO 9000fr. darstellt. Die Normen beschreiben also die An- 
Das Just in Time (JT) ist "ein Organisationsprinzip, das die verschwendungsfreie und bedarfsgerechte Realisierung unternehmensinterner und -übergreifender Güteraustauschprozesse zum Inhalt hat" ${ }^{1522}$. Die unternehmensinternen Austauschprozesse werden durch das KanbanPrinzip gesteuert, das nach dem Pull-System (Zug-System) funktioniert. Die im Fertigungsprozeß benötigten Teile werden jeweils bei der vorgelagerten Stelle im Moment des Bedarfs abgerufen (Pull), d.h. die nachgelagerten Prozesse steuern die vorgelagerten. ${ }^{523} \mathrm{Ziel}$ des Kanban ist einerseits die Senkung der Auftragsdurchlaufzeiten und der Bestandsarten sowie andererseits die Erhöhung der Lieferbereitschaft und der Flexibilität gegenüber Nachfrageschwankungen. ${ }^{524}$ Die unternehmensübergreifenden Austauschprozesse führen zu einer Synchronisation von Belieferungs- und Produktionsprozeß. Dies bedeutet, wie im internen Bereich, die bedarfssynchrone Anlieferung der im Produktionsprozeß benötigten Teile.

Wird nun das KAIZEN der Innovation gegenübergestellt, so zeigen sich nach IMAI eine Reihe divergierender Merkmale, die er u.a. auch auf das jeweilige soziale und kulturelle Erbe zurückfuhrt (vgl. Tab. 4-1). ${ }^{525}$ Die Übersicht in Tabelle 4-1 stellt allerdings eine sehr stark polarisierende Sichtweise des KAIZEN bzw. der Innovation dar, wie sie lediglich idealtypisch in Großunternehmen westlicher bzw. fernöstlicher Prägung vorgefunden werden kann. Eine genauere Betrachtung der angefuihrten Kriterien zeigt allerdings an einigen Stellen durchaus fließende Übergänge zwischen den beiden Systemen. So hat z.B. bereits SCHUMPETER darauf hingewiesen, daß Innovation nicht unbedingt etwas aufsehenerregend Wichtiges sein muß, wodurch etwa die Punkte 1, 2 und 8 aufgeweicht werden. ${ }^{526}$ Wird ferner der Fokus auf die Innovationstätigkeit in kleinen und mittleren Unternehmen gerichtet, könnten die für das KAIZEN typischen Merkmale 1 bis 11 durchaus für die Beschreibung der dortigen Innovationstätigkeit herangezogen werden. Letztlich ist beiden Systemen das Ziel der Erneuerung gemeinsam, für dessen Erreichen die Qualität eine wesentliche Komponente darstellt.

forderungen an ein Qualitătssicherungssystem und sind damit für die Reorganisation von Produktions- und Dienstleistungsunternehmen von großer Hilfe. Vgl. zum TQM ausfuhrlich Butterbrodt, D. (1997), S. 106113; Betzl, K. (1996), S. 40-43; Elter, V.-C. (1997), S. 207-210; Seghezzi, H.D. (1995); Steinbach, R.F. (1997), S. 216-272; Kamiske, G.F./Brauer, J.-P. (1995), S. 243-247; Zink, K.J. (1995); Zink, K.J./Hauer R. (1995), S. 116-121; 0.V. (1995), S. 58-74. Beispielhaft fur konsequentes TQM aus der Reihe der untersuchten Unternehmen ist die Mettler-Toledo (Albstadt) GmbH.

Zur DIN EN ISO 9000ff. vgl. z.B. Pfeifer, T./Heine, J. (1992), S. 21f.; Seghezzi, H.D. (1996), S. 111f.; Steinbach, R.F. (1997), S. 96f.; Butterbrodt, D. (1997), S. 108 und S. 118; Kostka, S. (1997), S.151-154.

522 Teufel, P. (1996), S. 537f. Vgl. auch Kamiske, G.F./Brauer, J.-P. (1995), S. 84-93; 0.V. (1995), S. $570-573$ und S. $583 \mathrm{ff}$.

${ }^{523}$ Beim konventionellen Push-System (Schub-System) erfolgt der Materialtransfer entlang dem Produktionsprozeß. Vgl. Teufel, P. (1996), S. 537.

${ }^{524}$ Vgl. Imai, M. (1994), S. 24; Tominaga, M. (1996), S. 178-181; Stahlmann, V. (1988), S. 130-134.

${ }^{525} \mathrm{Vgl}$. auch im folgenden Imai, M. (1994), S. 47-66 sowie ferner Imai, M. (1996), S. $27 \mathrm{f}$.

${ }^{526}$ Vgl. Schumpeter, J.A. (1961), S. 99. 
Tab. 4-1: Die Merkmale von KAIZEN und Innovation

\begin{tabular}{|c|c|c|}
\hline & KAIZEN & Innovation \\
\hline 1. Effekt & $\begin{array}{l}\text { langfristig und andauernd, aber undra- } \\
\text { matisch }\end{array}$ & kurzfristig, aber dramatisch \\
\hline 2. Tempo & kleine Schritte & große Schritte \\
\hline 3. zeitlicher Rahmen & kontinuierlich und steigend & unterbrochen und befristet \\
\hline 4. Erfolgschance & gleichbleibend hoch & abrupt und unbeständig \\
\hline 5. Protagonisten & jeder Firmenangestellte & wenige "Auserwảhlte" \\
\hline 6. Vorgehensweise & $\begin{array}{l}\text { Kollektivgeist, Gruppenarbeit, Systema- } \\
\text { tik }\end{array}$ & $\begin{array}{l}\text { "Ellbogenverfahren", individuelle Ideen } \\
\text { und Anstrengungen }\end{array}$ \\
\hline 7. Devise & Erhaltung und Verbesserung & Abbruch und Neuaufbau \\
\hline 8. Erfolgsrezept & $\begin{array}{l}\text { konventionelles Know-how und jeweili- } \\
\text { ger Stand der Technik }\end{array}$ & $\begin{array}{l}\text { technologische Errungenschaften, neue } \\
\text { Erfindungen, neue Theorien }\end{array}$ \\
\hline $\begin{array}{l}\text { 9. praktische Vorausset- } \\
\text { zungen }\end{array}$ & $\begin{array}{l}\text { kleines Investment, großer Einsatz zur } \\
\text { Erhaltung }\end{array}$ & $\begin{array}{l}\text { großes Investment, geringer Einsatz zur } \\
\text { Erhaltung }\end{array}$ \\
\hline 10. Erfolgsorientierung & Menschen & Technik \\
\hline 11. Bewertungskriterien & $\begin{array}{l}\text { Leistung und Verfahren fur bessere Er- } \\
\text { gebnisse }\end{array}$ & Profitresultate \\
\hline 12. Vorteil & $\begin{array}{l}\text { hervorragend geeignet fir eine langsam } \\
\text { ansteigende Wirtschaft }\end{array}$ & $\begin{array}{l}\text { hauptsächlich geeignet für eine rasch } \\
\text { ansteigende Wirtschaft }\end{array}$ \\
\hline
\end{tabular}

Quelle: Imai, M. (1994), S. $48^{527}$

\subsubsection{Innovationsorientierte Analyse des Unternehmensumfeldes}

Sinnvolle strategische Unternehmensführung bedarf der Information. Diese elementare Bedeutung der Information im Führungs- und Entscheidungsprozeß wurde bereits mehrfach hervorgehoben. Die Fähigkeit eines Unternehmens, sich erfolgreich auf dynamischen Märkten zu entwickeln und diese mitzugestalten, hängt davon $a b$, inwieweit die eigenen Kompetenzen durch die Nutzung externer und interner Informationen gesichert und ausgebaut werden können. ${ }^{528}$ Die bereitgestellte Information muß hierzu rechtzeitig und in adäquatem Umfang und adäquater Qualität zur Verfügung stehen, um Pläne und Programme anpassen bzw. Ziele,

527 Vgl. ergänzend Imai, M. (1994), S. 57 sowie daneben Tominaga, M. (1997).

${ }^{528}$ Vgl. z.B. Ansoff, H.I. (1975), S. 22; Heinen, E. (1976), S. 24; Harhoff, D. u.a. (1996), S. 22; Cohen, W.M./Levinthal, D.A. (1990), S. 128. Müller hebt in diesem Zusammenhang hervor, daß bei mittelstăndischen Unternehmen Informationsdefizite im Zusammenhang mit Problemen der Unternehmensfuihrung als wichtigste Entstehungsquelle für Insolvenzen gelten. Vgl. Müller, K. (1990), S. 357. 
Strategien, Szenarien oder Vorhersagen ableiten zu können. Dies gilt in besonderem Maße für Informationen, die das Innovationspotential des Unternehmens bestimmen. Sie beeinflussen die Wahrnehmung von Innovationsmöglichkeiten sowie die Qualität der Innovationsentscheidungen und -realisierungen und wirken damit direkt auf die zukünftige Wettbewerbsposition des Unternehmens.

Wird Innovation als ein Verbindungsprozeß betrachtet, der zunächst nur in der Vorstellungskraft existiert, impliziert dies, daß ein Unternehmen dann erfolgreich innoviert, wenn Umfeldveränderungen, technologische Entwicklungen oder Trends aufgegriffen und die daraus ableitbaren Informationen sinnvoll mit den eigenen Kompetenzen verknüpft werden. Voraussetzung dafür ist die Sammlung, Analyse und entscheidungsorientierte Verknüpfung von Informationen. ${ }^{529}$ COHEN UND LEVINTHAL bezeichnen die Fähigkeit eines Unternehmens, den Wert externer Informationen zu erkennen, sie aufzunehmen und sie im Unternehmen zu verwenden als "absorptive capacity". ${ }^{530}$ Sie argumentieren, daß mit der Verbreiterung der Informationsbasis auch die Wissensabsorptionsfähigkeit zunimmt und dadurch eine Erweiterung der Grenzen der Kernkompetenzen möglich ist. ${ }^{531}$

Die Grundlage der Suche nach innovationsrelevanten Informationen bilden die Ergebnisse aus der Umfeldanalyse, wie sie in Abschnitt 3.3.2 dargestellt wurde. Für die Verbreiterung der Informationsbasis aus der Analyse des Makro-Umfeldes, der Branchen-, Wettbewerbs- und Marktanalyse sowie der Interessenanalyse der Stakeholder steht dem Unternehmen eine Reihe spezifischer, innovationsrelevanter Informationsquellen zur Verfügung. Da kleine und mittlere Unternehmen nicht die personellen und finanziellen Ressourcen aufbringen können, eigene Abteilungen für die Beschaffung von Informationen einzurichten, muß die Funktion der Informationsversorgung nach außen verlagert werden. Damit kommt den externen Informationsquellen im Innovationsprozeß der kleinen und mittleren Unternehmen eine Schlüsselfunktion zu. Eine wesentliche Informationsquelle ergibt sich durch den Aufbau von langfristig angelegten formellen oder informellen Beziehungen zu geschäftlichen und wissenschaftlichen Partnern. Die daraus entstehenden Informationsnetzwerke bilden einen Ideenpool, den es zu nutzen gilt. ${ }^{532}$ Impulse für Innovationen gehen beispielsweise von Kunden, Lieferanten, Wettbewerbern und Kooperationspartnern aus. Zu diesem selbst zu schaffenden Netzwerk zählen auch informelle Kontakte zu den Mitarbeitern anderer Unternehmen. ${ }^{533}$ Daneben halten auch

${ }^{529}$ Vgl. Freeman, C. (1982), S. 111.

${ }^{530} \mathrm{Vgl}$. Cohen, W.M./Levinthal, D.A. (1990).

${ }^{531}$ Vgl. Cohen, W.M./Levinthal, D.A. (1989), S. 569.

${ }^{532}$ Dabei steigt die Erfolgswahrscheinlichkeit einer Unternehmensinnovation mit zunehmendem Grad der AuBenbeziehungen, des Kontaktreichtums und des Zugriffs auf die Informationsmărkte. Utterback, J.M. (1971), S. 85 fuhrt dazu aus, "that the greater the degree of communication between the firm and its environment at each stage of the process of innovation ... the more effective the firm will be in generating, developing, and implementing new technology. Vgl. ferner Mensch, G. (1979), S. 74-78; Schmidt, A. (1995), S. 123.

${ }^{533} \mathrm{Da}$ in-house-Entwicklungen oftmals zeitaufwendig und teuer sind, sieht von Hippel insbesondere in informellen Kontakten im Bereich der Forschung und Entwicklung Anreize, die eigene Know-how-Basis zu verbrei- 
zahlreiche Institutionen der Innovationsinfrastruktur Informationen bereit. So ermöglichen z.B. die Ministerien, die Landesgewerbeämter, die Industrie- und Handelskammern, die Fachverbände und die Transfer- und Forschungseinrichtungen die Vermittlung neuen Wissens. Dabei wird der Zugang zu Informationen über elektronische Netzwerke zunehmend leichter und kostenglinstiger, ${ }^{534}$ so daß auch kleine und mittlere Unternehmen immer besser in die Lage versetzt werden, das externe Informations- und Beratungsangebot zur Lösung organisatorischer bzw. produkt- oder prozeßbezogener Probleme zu nutzen. Schließlich zeigen auch Messen, Kongresse und Ausstellungen sowie die Fachliteratur neue Trends und Entwicklungen auf.

Dem Informationsverhalten über marktrelevante und technische Entwicklungstrends sowie dem Stellenwert dieser Informationsquellen wurde auch in der zugrundeliegenden Untersuchung nachgegangen. ${ }^{535}$

Abb. 4-4: Nutzung innovationsrelevanter Informationsquellen durch die Unternehmen in der Region Neckar-Alb

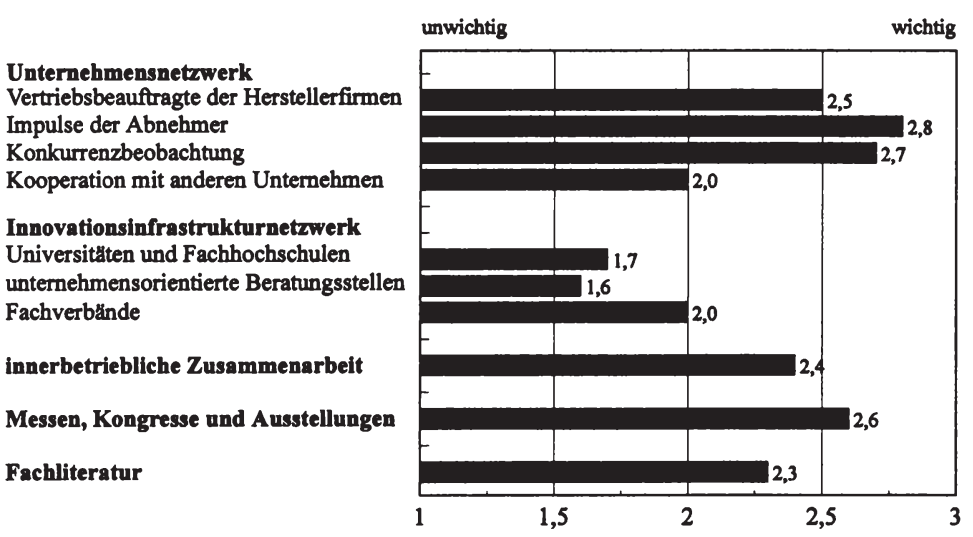

Quelle: eigene Berechnungen. ${ }^{536}$

tern. Gleichzeitig bieten sich hierdurch auch Möglichkeiten, die entstehenden Innovationskosten (und -gewinne) zu teilen. Er zeigt Beispiele auf, wo diese Kontakte auch zwischen direkten Konkurrenten stattfinden. Eine erste Kontaktaufnahme bzw. das Knupfen eines Netzwerkes erfolgt meist uber Messen, Austellungen und Kongresse, was auch die zugrundeliegende Untersuchung bestătigt. Vgl. von Hippel, E. (1988), S. 76-92.

${ }^{534}$ Vgl. Feldman, M.P./Audretsch, D.B. (1996), S. 3f.; Feldman, M.P./Audretsch, D.B. (1997), S. 14. Vgl. ferner Porter, M.E./Millar, V.E. (1986), S. 29; Abernathy, W.J./Utterback, J.M. (1988), S. 143.

${ }^{535}$ Vgl. Frage 3/14 des Fragebogens im Anhang sowie Anlage 18.

${ }^{536}$ Die Ergebnisse der innerbetrieblichen Zusammenarbeit werden im folgenden Abschnitt (4.3.3) diskutiert. 
Die bedeutendsten Informationsquellen im Innovationsprozeß der Unternehmen des Verarbeitenden Gewerbes in der Region Neckar-Alb sind erwartungsgemäß im Unternehmensnetzwerk zu finden. Vor allem den Impulsen durch die Abnehmer $(2,8)^{537}$ und der Konkurrenzbeobachtung $(2,7)$ wird eine herausragende Bedeutung beigemessen. Die große Bedeutung, die den Abnehmern beigemessen wird, ist darauf zurückzuführen, daß kleine und mittlere Unternehmen vielfach auf Märkten agieren, auf denen ein enger Kontakt zu den Abnehmern wichtig ist. Daneben spielt der Dialog mit den Vertriebsmitarbeitern der Lieferanten $(2,5)$ sowie die Informationsaufnahme bei Messen, Kongressen und Ausstellungen $(2,6)$ eine ebenfalls große Rolle. Diese enge Einbettung erlaubt es, zumal Entwick-lungs-, Produktionsund Verkaufsentscheidungen in kleinen und mittleren Unternehmen oft von einem überschaubaren Personenkreis getroffen werden und daher eng miteinander verknüpft sind, Innovationsentscheidungen relativ rasch umzusetzen. Als weiteres Ergebnis zeigt sich zwar, daß 44,3\% der besonders erfolgreichen Unternehmen bei der Einführung neuer Verfahren und Produkte mit anderen Unternehmen kooperieren (übrige: 27,9\%), insgesamt wird diese Komponente des Innovationsprozesses mit einem Wert von 2,0 aber als weniger wichtig erachtet. Hier scheint somit die Befürchtung, einem Wettbewerber wertvolle Informationen preiszugeben, schwerer zu wiegen als der positive Effekt der Gewinnung von Innovationsideen aus gemeinsamer Arbeit. Allerdings ist darauf hinzuweisen, daß der sich auch für kleine und mittlere Unternehmen verschärfende Wettbewerbsdruck ein situatives, vorteilwahrendes und strategisches Handeln erfordert und daß damit zeitlich begrenzte Kooperationen oder Leistungsverbünde zur erfolgreichen Abgrenzung gegenüber den Mitbewerbern eine immer stärkere Bedeutung erlangen. 538

Gerade kleine und mittlere Unternehmen, die nicht oder nur in begrenztem Maße über eigene Forschungsabteilungen verfügen, sind auf den Dialog und die Zusammenarbeit mit Hochschulen, Beratungsstellen und Fachverbänden angewiesen. ${ }^{539}$ Diese Option spielt bei den Unternehmen in der Region Neckar-Alb jedoch eine eher untergeordnete Rolle. Lediglich die Fachverbände nehmen noch eine Mittelposition bei der Wichtigkeit der Informationsquellen ein $(2,0)$. Universitäten und Fachhochschulen $(1,7)$ bzw. Beratungsstellen $(1,6)$ betrachten die

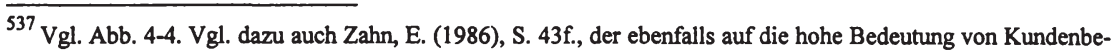
fragungen und Konkurrenzanalysen fur Innovationsimpulse hinweist, gleichzeitig aber auch deren Begrenztheit bezulglich der Identifikation zukünttiger Innovationen betont. Bez. der Bedeutung innovationsrelevanter Informationsquellen vgl. auch die Ergebnisse bei Strebel, H. u.a. (1979), S. 11f. und S. 167f. sowie bei Schmalholz, H./Penzkofer, H. (1997), S. 31.

${ }^{538} \mathrm{Vgl}$. Betzl, K. (1996), S. $52 \mathrm{f}$.

${ }^{539}$ Auch vor dem Hintergrund einer dynamischen Entwicklung im Bereich des Umweltschutzes ist es für KMU notwendig, einen Überblick uber problemrelevante Bereiche und technische Lösungsmöglichkeiten zu wahren. Hier sollten die zunehmend besser ausgebauten Datenbanken und Informationen von Verbänden sowie Erfahrungen anderer Unternehmen aktiv genutzt werden. Beispielsweise stellen Unternehmensverbănde, wie der Bundesdeutsche Arbeitskreis fur umweltbewußtes Management e.V. (B.A.U.M.) oder future e.V., Informationen über branchenbezogene Problemlठsungen, Checklisten sowie kompetente Ansprechpartner zur Verfugung. Vgl. z.B. BMU/Umweltbundesamt (Hrsg.) (1995).
} 
Unternehmen als eher unwichtig. ${ }^{540}$ Vor dem Hintergrund einer gut ausgebauten Hochschulund Forschungsinfrastruktur in der Region Neckar-Alb liegt hier noch ein hohes ausschöpfbares Potential für die Unternehmen. Notwendig ist hierzu allerdings eine höhere Transparenz der Forschungsleistungen und der ständige Dialog zwischen Wissenschaft und Wirtschaft.

Generell zeigt die Unternehmensbefragung, daß die Aussagen der besonders erfolgreichen und der weniger erfolgreichen Unternehmen bezüglich der Nutzung innovationsrelevanter Informationsquellen nur unwesentlich voneinander abweichen. Lediglich bei der Konkurrenzbeobachtung ( 2,8 vs. 2,6$)$ lagen die Werte etwas deutlicher auseinander (vgl. zusätzlich Anlage $18) .{ }^{541}$

Ein an einigen Stellen anderes Bild zeigt sich bei der Differenzierung nach der Unternehmensgröße. Vor allem bei der Nutzung von Informationen aus dem Innovationsinfrastrukturnetzwerk ergeben sich signifikante bzw. hoch signifikante Unterschiede in Abhängigkeit von der Unternehmensgröße. Dies bedeutet, daß mit steigender Beschäftigtenzahl bzw. mit zunehmendem Umsatz die Bedeutung der Nutzung von Universitäten und Fachhochschulen, ${ }^{542}$ von außeruniversitären Forschungseinrichtungen ${ }^{543}$ sowie von Technologietransfer- und Innovationsberatungsstellen ${ }^{544}$ ebenfalls zunimmt. Ein zwar nicht signifikanter, aber dennoch deutlicher Unterschied zeigt sich bei der Nutzung von Informationen von seiten des Patentamtes, ${ }^{545}$ wăhrend sich bei den übrigen Informationsquellen nur schwache, unternehmensgrößenbedingte Unterschiede erkennen lassen.

Die vorstehenden Ergebnisse verdeutlichen, daß sich hinsichtlich des Informationsverhaltens der untersuchten Unternehmen innerhalb der "gewohnten" Informationskanăle, d.h. des Unternehmensnetzwerkes, keine Unterschiede aufgrund der Innovativität bzw. der Unternehmensgröße feststellen lassen. Unterschiede zeigen sich allerdings bei der Bedeutung der Informationen aus dem Innovationsinfrastrukturnetzwerk, die eher durch die Unternehmensgröße und weniger durch die Innovativität des Unternehmens bestimmt werden. Mit zunehmender Unternehmensgröße wächst offensichtlich der Stellenwert wissenschaftlich orientierter

${ }^{540} \mathrm{Zu}$ ganz ăhnlichen Ergebnissen gelangen auch Staudt, E. u.a. (1992). Für den Fall, daß Forschungseinrichtungen als Informationsquellen genutzt werden, kommen auch Harhoff u.a. zu dem Ergebnis, daß Hochschulen die bedeutsamsten Informationsgeber sind, gefolgt von offentlichen und privaten wissenschaftlichen Forschungseinrichtungen und Instituten. Vgl. Harhoff, D. u.a. (1996), S. 58-64.

${ }^{541}$ Defizite in der Vernetzung zwischen Forschungs- und Transfereinrichtungen und Unternehmen stellt auch Koschatzky fest. Ferner zeigt seine Untersuchung der regionalen Patentanmeldungen, daß "das breite wissenschaftliche Potential der Region Neckar-Alb nicht in eine entsprechend große Erfindertătigkeit umgesetzt" wird. Koschatzky, K. (1997), S. 51.

542 Sig.: 0,004 bzw. 0,004.

${ }^{543}$ Sig.: 0,038 bzw. 0,007 .

${ }^{544}$ Sig.: 0,084 bzw. 0,042 .

${ }^{545}$ Sig.: 0,120 bzw. 0,081 . 
Informationen, die Hochschulen, Forschungseinrichtungen und Transferstellen anbieten können bzw. bereithalten.

Ähnliches gilt auch für die Nutzung von Informationen aus Patentdaten (vgl. Anlage 18), die als Informationsquelle insgesamt zwar nachrangig sind $(1,6),{ }^{546}$ mit steigender Unternehmensgröße aber in ihrer Bedeutung ebenfalls zunehmen.

Eine mögliche Begründung für die Bedeutungszunahme der Informationen aus dem Innovationsinfrastrukturnetzwerk ist darin zu sehen, daß mit der Unternehmensgröße auch die Heterogenität der Produkte steigt, zu deren Herstellung einerseits zunehmend fachspezifisches Know-how benötigt wird, das innerhalb des Unternehmens nicht vorgehalten werden kann. Andererseits müssen aufwendige Versuchsreihen durchgeführt werden, die ebenfalls die Kompetenzen bzw. die räumlichen und finanziellen Möglichkeiten des Unternehmens übersteigen. Eine weitere Begründung findet sich in persönlichen, weitgehend qualifikationsbedingten Berührungsängsten. Wie sich in der Untersuchung gezeigt hat, nimmt der Anteil höher qualifizierter kaufmännischer Angestellter und der Anteil an Hochschulingenieuren mit steigender Unternehmensgröße zu. ${ }^{547}$ Die vermehrte Nutzung wissenschaftlicher Informationsquellen läßt darauf schließen, daß der Zugang zu wissenschaftlichen Einrichtungen mit zunehmender Qualifikation leichter fällt. Dies kann darauf zurückzuführen sein, daß höher qualifizierte Unternehmer bzw. Mitarbeiter bei der ersten Kontaktaufnahme durch die in der Ausbildung gemachten Erfahrungen weniger zurückhaltend sind als geringer qualifizierte und daß sie zum Teil noch über Kontakte zu ihren Ausbildungseinrichtungen verfügen, die sich nun nutzen lassen.

\subsubsection{Innovationsorientierte Analyse der internen Unternehmenssituation}

Für die Systematisierung der Analyse der internen Unternehmenssituation wurden in Kapitel 3 mit der Wertketten-, der Funktionsbereichs-, der Produktlebenszyklus- sowie der Portfolioanalyse vier mögliche Instrumente dargestellt. ${ }^{548}$ Bei der Darstellung des Modells der Wertkette

${ }^{546}$ Im Abschnitt 4.2.1 wurde auf die begrenzte Eignung von Patenten als Maß für die Innovativităt hingewiesen. Das hier abgebildete Ergebnis schrănkt daneben auch die praktische, d.h. anwendungsbezogene Bedeutung von Patenten zur Generierung von Innovationsideen in KMU ein.

${ }^{547}$ Siehe Frage 1/4 des Fragebogens sowie Anlage 19. Vgl. dazu auch Pohl, H.-J./Rehkugler, H. (1986), S. 68; Pfeiffer, F. (1997), S. 12ff.

${ }^{548}$ Der Prozeß der Informationsbeschaffung und -aufbereitung sowie die Bereitstellung geeigneter Steuerungsund Kontrollmechanismen sind Aufgaben des betrieblichen Controlling. Controlling als Führungsaufgabe umfaßt sowohl den Prozeß der Datenerhebung, Planung, Budgetierung, Steuerung, Implementierung und Kontrolle etc. als auch das Set von Instrumenten zur Unterstuttzung dieses Prozesses und dient damit der Erkennung von Signalen, die auf Erfolgs- und Wachstumsengpässe hindeuten. Eine ausfuhrliche Darstellung und Diskussion des Controlling als Fuhrungsinstrument wilrde den hier gesteckten Rahmen ubersteigen. Daher sei auf die einschlägige Literatur verwiesen, wie beispielsweise Mayer, E. (1987); Liessmann, K. (1987); Horváth, P. (1996b); Mayer, F. (1997) sowie grundsătzlich Horváth, P. (1996a); Küpper, H.-U. (1997). Zum Controlling in KMU vgl. z.B. Horváth, P. (1981) und Horváth, P./Weber, J. (1990) sowie zum Innovationscontrolling z.B. Schroder, H.-H. (1996). 
(siehe Abschnitt 3.3.3.1) wurde der Produkt- und Prozeßentwicklung (Technologieentwicklung) eine Schlüsselrolle für Unternehmen des Verarbeitenden Gewerbes zugewiesen, da ihre Wettbewerbsfähigkeit in starkem Maße von der verwendeten Technologie abhängig ist. Daneben besitzt jede Aktivität in der Wertkette eine technologische Komponente, die weit über das unmittelbare Produkt hinausgeht. ${ }^{549}$ Für eine Analyse der Innovativität eines Unternehmens reicht der Hinweis darauf, daß jede Wertkettenaktivität eine Vielzahl technologischer Komponenten aufweist, noch nicht aus. Diesem Zweck werden die drei übrigen Instrumente eher gerecht, weshalb sie im Zentrum der nachfolgenden Ausführungen stehen.

\subsubsection{Die Funktionsbereichsanalyse}

Die Funktionsbereiche Unternehmensführung, Personalwesen, Forschung und Entwicklung sowie Finanzwesen sind für die Innovativität eines Unternehmens von besonderer Bedeutung.

Die Unternehmensführung in kleinen und mittleren Unternehmen ist durch die zentrale Stellung des Unternehmers geprägt, der in der Regel zugleich Risikoträger, Kapitalgeber und Leiter ist. Darüber hinaus übernimmt der Unternehmer neben den Führungstätigkeiten auch Aufgaben im operationalen Bereich, d.h. er ist oftmals "Chef"-einkäufer, -verkäufer und/oder -entwickler. Letztere Aufgabe ist vor allem in den Unternehmen des Verarbeitenden Gewerbes - durch die oftmals überwiegend technische Orientierung des Unternehmers - von großer Bedeutung. Auf seinen Ideen bzw. auf seinem technischen Wissen und Können sowie deren Umsetzung in marktfähige Produkte basiert der hauptsächliche Unternehmenserfolg. In kleinen Unternehmen mag diese stark unternehmerzentrierte Sichtweise noch erfolgreich sein. Angesichts der beschleunigten Technologieentwicklung und der zunehmenden Komplexität der Marktprozesse sieht sich der Unternehmer in immer kürzer werdenden Abständen vor Entscheidungen für neue Produkte, neue Produktionstechnologien und neue Managementprozesse gestellt, die auch in kleinen Unternehmen immer seltener von ihm allein bewältigt werden können. Diese Tendenzen erfordern die aktive Auseinandersetzung des Unternehmers mit Innovationen und die Entwicklung entsprechender Managementqualifikationen sowie daneben auch die notwendige Einbindung weiterer Mitarbeiter in Entscheidungsprozesse. Noch deutlicher wird dies mit zunehmender Größe des Unternehmens. Mit den dann wachsenden administrativen Aufgaben wird vom Unternehmer weit mehr als fachspezifisches (technisches) Wissen und Können gefordert, d.h. es treten zielorientierte Gestaltungs-, Lenkungs- und Entwicklungsaufgaben in sach- und personenbezogener Hinsicht in den Vordergrund. ${ }^{550}$ Der Unternehmer muß also zunehmend in der Lage sein, neben den technischen Kompetenzen

\footnotetext{
${ }^{549}$ Vgl. dazu Porter, M.E. (1996), S. 219-234. Bei der Darstellung typischer Technologien in der Wertkette eines Unternehmens nennt Porter im wesentlichen Logistik-, Kommunikations- und Informationstechnologien sowie spezifische aktivitätsbezogene Technologien.

${ }^{550}$ Vgl. Kapitel 3.1.
} 
auch Management- bzw. soziale Kompetenzen zu entwickeln. ${ }^{551}$ Dies bedeutet, daß die Einbindung der Mitarbeiter sowie deren aktive Führung an Bedeutung zunimmt.

Im Hinblick auf den Erfolgsfaktor Innovativität bedeutet dies für den Unternehmer bzw. die Unternehmensführung, daß zunächst im Zuge einer Selbstreflexion die eigene Wandlungsund Innovationsfähigkeit sowie die eigene Qualifikation, Leistungs- und Lernfähigkeit kritisch auf den Prüfstand gestellt werden. ${ }^{552}$ Nur wenn hier optimale Voraussetzungen bestehen und diese sich auch in der Unternehmenskultur, den Führungssystemen, der Organisation und Verwaltung sowie den Informations- und Kommunikationssystemen wiederfinden, läßt sich ein innovatives Umfeld aufbauen. ${ }^{553}$

Neben der Unternehmensführung haben die Mitarbeiter entscheidenden Einfluß auf den langfristigen Erfolg des Unternehmens am Markt. Aus diesem Grund muß für ein funktionierendes betriebliches Personalwesen (Personalmanagement) gesorgt werden. ${ }^{554}$ Im Zentrum des Personalmanagements steht die Versorgung des Unternehmens mit adäquat ausgebildeten bzw. qualifizierten Mitarbeitern bzw. die Organisation einer anforderungsgerechten Qualifizierung $^{555}$ und Förderung. Allerdings weist das Personalmanagement gerade in kleinen und mittleren Unternehmen zahlreiche Defizite auf. Systematisches und kontinuierliches Personalmanagement findet sich nur in Ausnahmefällen. Darüber hinaus wird weitgehend darauf verzichtet, moderne Hilfsmittel der Personalarbeit, wie beispielsweise Stellenbeschreibungen, Bedarfspläne, Fragebögen oder Beurteilungsverfahren, zu nutzen. Oftmals ist sogar das Fehlen einer entsprechenden Abteilung oder einer Person mit Personalentwicklungskompetenz sowie eines entsprechenden Konzeptes zu bemängeln. Um diesen Mängeln entgegenzuwirken,

551 Zum Kompetenzbegriff vgl. Wilsdorf, D. (1991), S. 41 ff. Zur Diskussion des Begriffes der sozialen Kompetenz vgl. Schuler, H./Barthelme, D. (1995).

552 Prahalad und Hamel fuhren dazu aus: "... top executives were judged on their ability ... to identify, cultivate, and exploit the core competencies that make growth possible ..." Prahalad, C.K./Hamel, G. (1990), S. 79.

$553 \mathrm{Vgl}$. dazu ausfuhrlich Kapitel 4.4.

${ }^{554}$ Die Begriffe Personalwesen, Personalwirtschaft, Personalpolitik, Personalmanagement oder Human Resource Management werden in Literatur und Praxis teilweise synonym verwandt, obwohl sie für höchst unterschiedliche historische und inhaltliche Phasen des Arbeitsgebietes stehen. Eine Differenzierung würde jedoch hier zu weit fuhren. Das Personalwesen umfaßt die Rekrutierung, die Bereitstellung, den Einsatz, die Entwicklung, die Führung und Verwaltung sowie die Freisetzung der Mitarbeiter und stellt damit eine wesentliche Komponente der strategischen Unternehmensfuhrung dar. Da dabei der Mensch stärker als wertvolle Ressource und weniger als Kostenfaktor begriffen werden soll und insbesondere der Human-Resource-Management-Ansatz auf eine ganzheitliche Sichtweise der Integration von Personal und Arbeit bei allen unternehmerischen Entscheidungen abstellt, wird nachfolgend - auch mit Blick auf die neuere Literatur - den Begriffen Personalmanagement und Human Resource Management (Management der Humanressourcen) der Vorzug gegeben. Vgl. u.a. Laukamm, T. (1985); Servatius, H.-G. (1988), S. 96; Wăchter, H. (1992); Staehle, W.H. (1994), S. 718 828; Oechsler, W.A. (1997), S. 16-21 und S. 83-93.

555 Der Begriff der Qualifikation wird abhängig vom Untersuchungsschwerpunkt unterschiedlich definiert. Wird er als bestimmendes Merkmal für die Verwertbarkeit und Anwendbarkeit von Wissen in konkreten Situationen herangezogen, dann sind Qualifikationen die Gesamtheit aller fachlichen und überfachlichen Kenntnisse, Fähigkeiten und Fertigkeiten, über die eine Person zur Erfullung von (beruflichen) Aufgaben verfugt oder verfugen muß. Vgl. Wilsdorf, D. (1991), S. 44; Schneider, H. (1994), S. 69ff.; Heberer, J./Grap, R. (1995), S. 6; Beck, H. (1995), S. 12; Gilardi, S. (1995), S. 138; Pawlowsky, P./Baumer, J. (1996), S. 7; Blessin, B. (1996), S. 7; Weiß, R. u.a. (1997), S. 80ff. 
wird eine Systematisierung des Personalmanagements notwendig, die das "Wollen" und die Benennung einer hierfür verantwortlichen Person voraussetzt. Darauf aufbauend sind die im Unternehmen vorhandenen Qualifikationen zu erfassen, die Aufschluß über das potentiell verfügbare Know-how der Mitarbeiter geben. ${ }^{556}$ Neben der Qualifikationsstruktur sind ferner z.B. auch die Altersstruktur und die Fluktuationsrate zu erfassen. Zur Visualisierung der Ergebnisse aus der Situationsanalyse und Prognose kann auch hier das Portfoliokonzept herangezogen werden. Aus den Schlüsselfaktoren Potential und Leistung leitet z.B. ODIORNE ein Personalportfolio ab. ${ }^{557}$ Entsprechend der Plazierung in der Matrix können dann individuelle Programme und Entwicklungsmaßnahmen geplant und durchgeführt werden, die ein Erreichen der unternehmerischen Ziele ermöglichen.

Im Rahmen der zugrundeliegenden Untersuchung wurde daher geprüft, ob sich die angesprochenen Unternehmensführer grundsätzlich mit dem Qualifizierungsbedarf in ihrem Unternehmen auseinandersetzen, in welchen Bereichen sie einen solchen feststellen und ob sich Unterschiede des Qualifizierungsbedarfs in Abhängigkeit der Innovativität bzw. der Größe des Unternehmens aufzeigen lassen. Zunächst kann festgehalten werden, daß der weit überwiegende Teil der untersuchten kleinen und mittleren Unternehmen $(80,3 \%)$ einen Qualifizierungsbedarf bei den derzeitigen Mitarbeitern sieht (vgl. Abb. 4-5). Aus dem hohen Qualifizierungsbedarf ist zu schließen, daß sich die untersuchten Unternehmen zumindest implizit mit dem Personalmanagement auseinandersetzen. Die Ergebnisse (Durchschnitte) zeigen ferner, daß vor allem die technische Qualifizierung im Vordergrund steht, d.h. der technische Bereich im allgemeinen mit 50,6\%, die Produktqualität mit 36,0\% sowie die Prozeßqualität mit 25,8\% der Nennungen. Dieses Ergebnis ist im Hinblick auf die untersuchte Branche, das Verarbeitende Gewerbe, nicht weiter erstaunlich. Bemerkenswert sind dennoch die durchgängigen Unterschiede zwischen den beiden Erfolgstypen. Bei den weniger erfolgreichen Unternehmen ist vor allem der geringe Bedarf an kaufmännischen Qualifikationen auffallend. Der höhere Bedarf an diesen Qualifikationen bei den besonders erfolgreichen Unternehmen steht in engem Zusammenhang mit deren intensiveren Marktbearbeitungsstrategien (vgl. Abschnitt 4.6.1), die offensichtlich neben den höheren technischen Qualifikationen einen höheren Aufwand an Management- und Organisations-Know-how sowie vermehrte Sprachkenntnisse erfordern. Der insgesamt höhere Bedarf an Qualifikationen bei den besonders erfolgreichen Unternehmen läßt darauf schließen, daß sie dieses Instrument bewußt zum Erhalt ihrer Innovativität einsetzen.

\footnotetext{
${ }^{556}$ Siehe Frage 1/4b des Fragebogens und Anlage 19, die eine erste grobe Übersicht uber die formalen Qualifikationen geben. Diese muß dann durch eine individuelle Betrachtung der zusătzlich erworbenen Qualifikationen erweitert werden. Die Summe der Qualifikationen, d.h. alle Erfahrungen, Kenntnisse, Făhigkeiten und Fertigkeiten stellen das individuelle bzw. - auf das gesamte Unternehmen bezogen - das Humankapital des Unternehmens dar. Zum Begriff des Humankapitals vgl. Gaugler, E. (1994), S. 91f.; Schoenfeld, H.M. (1993). Auf die wirtschaftliche Bedeutung des Humankapitals ("education") hat bereits Denison hingewiesen. Vgl. Denison, E.F. (1962). Vgl. dazu auch Walter, H. (1969), S. 166-171.

${ }^{557}$ Vgl. Odiorne, G.S. (1989), S. 66. Vgl. dazu auch Blessin, B. (1996), S. $28 f$.
} 


\section{Abb. 4-5: Qualifizierungsbedarf der beiden Erfolgstypen}

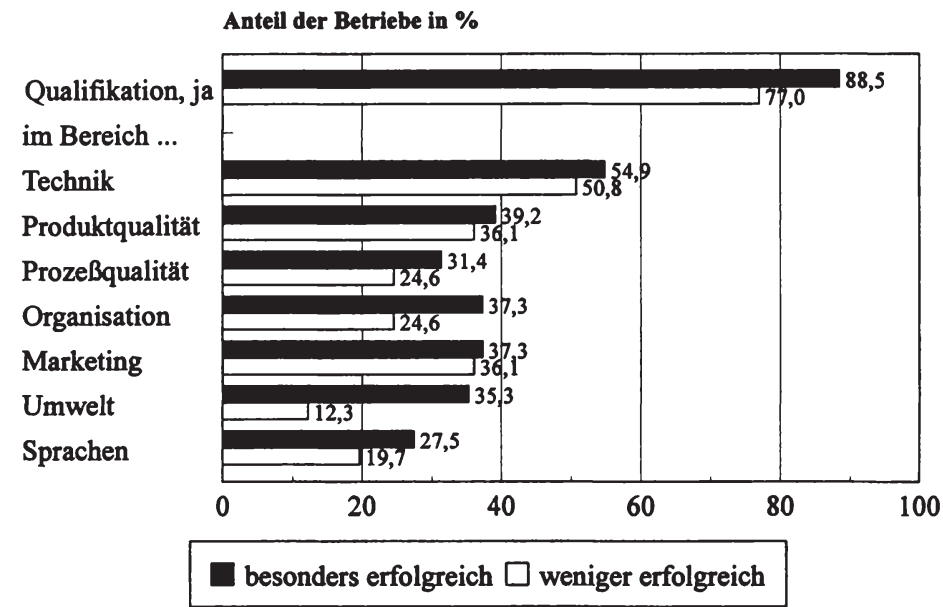

Quelle: eigene Berechnungen. ${ }^{558}$

Noch deutlicher treten die Unterschiede beim Qualifizierungsbedarf hervor, wenn nach der Unternehmensgröße (Beschäftigtenzahl bzw. Umsatz) differenziert wird. Hier zeigt sich, daß mit steigender Unternehmensgröße auch der Qualifizierungsbedarf zum Teil signifikant bzw. hoch signifikant ansteigt (vgl. Anlage 20). Hervorstechend sind besonders die Ergebnisse in den Bereichen Informationstechnik, ${ }^{559}$ Prozeßqualität, ${ }^{560}$ Organisation und Management, ${ }^{561}$ Umwelt $^{562}$ sowie Sprachen ${ }^{563}$. Die Unterschiede lassen darauf schließen, daß mit steigender Unternehmensgröße eine Systematisierung des Personalmanagements stattfindet und/oder generell eine intensivere Auseinandersetzung mit der Thematik erfolgt, wodurch auch eine präzisere Angabe des Qualifikationsbedarfs möglich wird.

Nach der Feststellung des Bedarfs, ist uber dessen Deckung zu entscheiden. Diese kann im Rahmen der betrieblichen Weiterbildung erfolgen, die nach interner bzw. externer Weiterbildung differenziert werden kann. ${ }^{564}$ Die interne Weiterbildung beinhaltet Maßnahmen, die im Unternehmen durch eigenes bzw. fremdes Lehrpersonal durchgefuhrt werden. Bei der exter-

558 Siehe Frage 3/12 des Fragebogens und Anlage 20.

559 Sig.: 0,006 bzw. 0,045 .

${ }^{560}$ Sig.: 0,009 bzw. 0,084 .

561 Sig.: 0,001 bzw. 0,001 .

562 Sig.: 0,085 bzw. 0,049 .

563 Sig.: 0,006 bzw. 0,001.

${ }^{564}$ Vgl. zum Begriff der Weiterbildung Pawlowsky, P./Băumer, J. (1996), S. 8-11. 
nen Weiterbildung finden die Maßnahmen außerhalb des Unternehmens bei einem nicht zum Unternehmen gehörenden Träger oder Institut statt. ${ }^{565} \mathrm{Da}$ sich Schulungsmaßnahmen durch den Hersteller nicht eindeutig den internen - sofern sie im eigenen Haus stattfinden - bzw. den externen - sofern sie beim Hersteller selbst stattfinden - Weiterbildungsmaßnahmen zurechnen lassen, sind diese gesondert zu erfassen. Die Analyse der Aktivităten betrieblicher Weiterbildung in den untersuchten Unternehmen des Verarbeitenden Gewerbes ergab, daß insgesamt über $70 \%$ der Unternehmen mindestens eine der vorgenannten Weiterbildungsoptionen nutzen. Differenziert nach den Erfolgstypen zeigt sich eine wesentlich intensivere Nutzung durch die besonders erfolgreichen Unternehmen. ${ }^{566}$ Sie folgen damit der Einsicht, daß die Mitarbeiter eine wertvolle Ressource darstellen, die mit Hilfe von Bildungsmaßnahmen gestärkt wird und dadurch wiederum die Innovativität des Unternehmens fördert.

\section{Abb. 4-6: Nutzung der betrieblichen Weiterbildung durch die beiden Erfolgstypen}

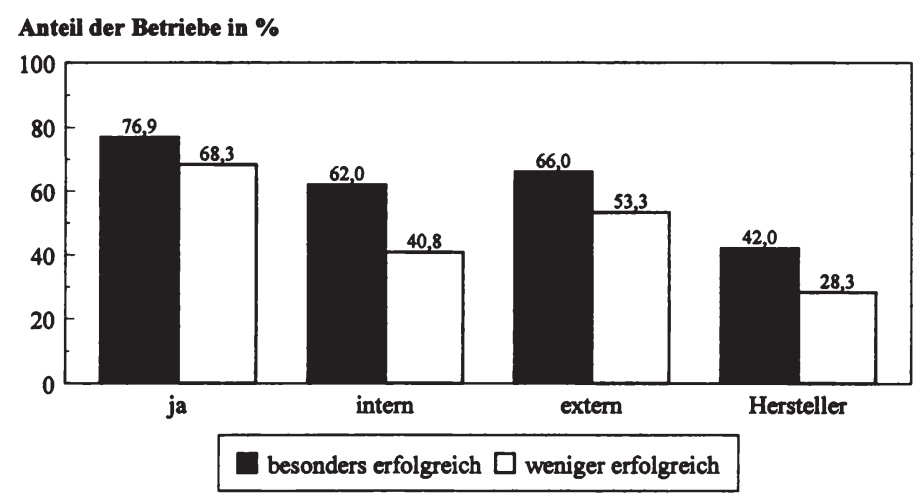

Quelle: eigene Berechnungen.

Trotz der deutlichen Unterschiede zwischen den besonders erfolgreichen und den weniger erfolgreichen Unternehmen bei einer Aufgliederung der betrieblichen Weiterbildung nach internen, externen sowie Maßnahmen durch den Hersteller ${ }^{567}$ zeigen die Zahlen dennoch, daß bei den Weiterbildungsaktivitäten ein erhebliches Entwicklungspotential bei allen Unternehmen besteht. Bei einer Differenzierung nach der Unternehmensgröße wird dies noch deutlicher und es bestätigen sich die im Rahmen der Qualifizierung aufgezeigten Ergebnisse. Mit ansteigender Unternehmensgröße (Beschäftigtenzahl bzw. Umsatz) intensiviert sich auch die

${ }_{565}$ Vgl. Pawlowsky, P./Băumer, J. (1996), S. 9.

${ }^{566}$ Siehe Frage 3/11 des Fragebogens sowie Anlage 21.

${ }^{567}$ Sig.: (intern) 0,012; (extern) 0,128 sowie (Hersteller) 0,083. 
Nutzung der einzelnen Komponenten der betrieblichen Weiterbildung (vgl. Anlage 21). ${ }^{568}$ Aus diesen Ergebnissen folgt, daß sowohl für die Unternehmen selbst als auch für die regionalen und überregionalen Bildungsanbieter ein Handlungsbedarf in Richtung auf eine Intensivierung der betrieblichen Weiterbildung besteht, da innovative Unternehmen Mitarbeiter benötigen, die kreativ, engagiert, qualifiziert und lernfähig sowie zu selbständigem bzw. unternehmerischem Handeln fähig sind. Dies setzt aber geeignete Qualifizierungs- und Weiterbildungsmaßnahmen voraus. ${ }^{569}$

In dem Maße, wie Innovationen für die Wettbewerbsfähigkeit des Unternehmens immer wichtiger geworden sind, hat auch die Bedeutung der Forschung und Entwicklung (F\&E) in den Unternehmen an Bedeutung zugenommen. Im Rahmen des Innovationsmanagements muß über die Beibehaltung vorhandener Produkte und Technologien und deren Weiterentwicklung bzw. die Entwicklung neuer Produkte und Technologien entschieden werden. Für den Unternehmer steht die Entscheidung im Zentrum, mit welchem Produkt und mit welcher Prozeßtechnologie die Wettbewerbsfähigkeit gesichert werden soll, wie sich das Unternehmen an veränderte Rahmenbedingungen anpassen kann und inwieweit es gelingen soll, das relevante Umfeld mitzugestalten. Bei dieser Gestaltungsaufgabe spielt die Forschung und Entwicklung des Unternehmens eine aktive Rolle.

Die Intensität, mit der Forschung und Entwicklung betrieben werden, wird häufig als Maßstab für die Innovativität eines Unternehmens betrachtet. Zur Messung der F\&E-Intensität in personeller und finanzieller Hinsicht bzw. der Generierung von Patenten und Lizenzen greift die Analyse des F\&E-Bereichs auf der einzelwirtschaftlichen Ebene ebenfalls auf die schon im Rahmen der gesamtwirtschaftlichen Analyse verwendeten Indikatoren zurück (vgl. Abschnitt 4.2.1). Die dort aufgezeigten Schwierigkeiten hinsichtlich der Erfassung bzw. der Aussagekraft gelten auch für die einzelwirtschaftliche Betrachtung unvermindert. Deshalb ist erneut auf die Nachteile der F\&E-Indikatoren hinzuweisen, die darin bestehen, "daß sie lediglich Aufschluß über die für die Innovation eingesetzten Mittel geben, nicht jedoch über die resultierende Innovationsaktivität" ${ }^{570}$. Ebenso fraglich ist die Zuverlässigkeit des Indikators $\mathrm{Pa}$ tentdaten, da - wie bereits erwähnt - einerseits nicht alle patentierten Erfindungen in marktfähige Produkte umgesetzt bzw. andererseits nicht alle Innovationen als Patent angemeldet werden. Die Aussagekraft der Indikatoren in Bezug auf kleine und mittlere Unternehmen wird zusätzlich dadurch erschwert, daß sich ein großer Teil der Innovationsaktivitäten nicht der

\footnotetext{
${ }^{568}$ Beschaftigtengrőßenklassen Sig.: (intern) 0,001; (extern) 0,001 sowie (Hersteller) 0,001; Umsatzgrößenklassen Sig.: (intern) 0,001; (extern) 0,022 sowie (Hersteller) 0,068.

${ }^{569}$ Eine tiefergehende Analyse und Darstellung des Personalmanagements lag nicht im engeren Fokus der Untersuchung. Diesbezüglich sei daher auf die einschlägige Literatur verwiesen, wie beispielsweise Heberer, J./Grap, R. (1995); Mugler, A. (1995), S. 326-377; Hornsby, J.S./Kuratko, D.F. (1990); Gebert, D./Steinkamp, T. (1990); Mank, P. (1991); Maier, W./Fröhlich, W. (1992); Meier, H. (1992); Staehle, W.H. (1994), S. 718-828; Nagel, K. (1993); Stiefel, R.T. (1991) und die dort angegebene Literatur.

570 Acs, Z.J./Audretsch, D.B. (1992), S. 56.
} 
Forschung und Entwicklung zurechnen läßt oder von den Unternehmen nicht als F\&EAufwand aufgefaßt wird. "Während in größeren Unternehmen Innovationsaktivitäten zu einem Großteil in spezialisierten Abteilungen durchgeführt und daher über die Abteilungsausgaben erfaßt werden, entstehen im KMU-Sektor häufig neue oder verbesserte Produkte und Prozesse aus der Produktionserfahrung, der Konstruktionsarbeit und dem Engagement des Unternehmers." ${ }^{571}$ Dadurch entsteht die Schwierigkeit, den Innovationsaktivitäten in kleinen und mittleren Unternehmen die damit verbundenen F\&E-Aufwendungen zuzurechnen.

Zweifelsohne sind Investitionen in F\&E-Bemühungen eine notwendige Voraussetzung für die Innovativität eines Unternehmens. Dennoch können aus der Höhe der Aufwendungen für Forschung und Entwicklung keine direkten Rückschlüsse auf die Innovativität des Unternehmens gezogen werden, da der finanzielle Aufwand a priori noch nichts darüber aussagt, wie effizient und erfolgreich im Unternehmen geforscht und entwickelt wird. In Abhängigkeit des gewählten F\&E-Maßes zeigen sich zwischen den Erfolgstypen deutliche Unterschiede. Werden beispielsweise die F\&E-Aufwendungen je Betrieb bzw. je Mitarbeiter betrachtet, weisen die weniger erfolgreichen Unternehmen hier zum Teil deutlich höhere Aufwendungen auf.

Tab. 4-2: Entwicklung der Aufwendungen für Forschung und Entwicklung der beiden Erfolgstypen von 1990 bis 1995

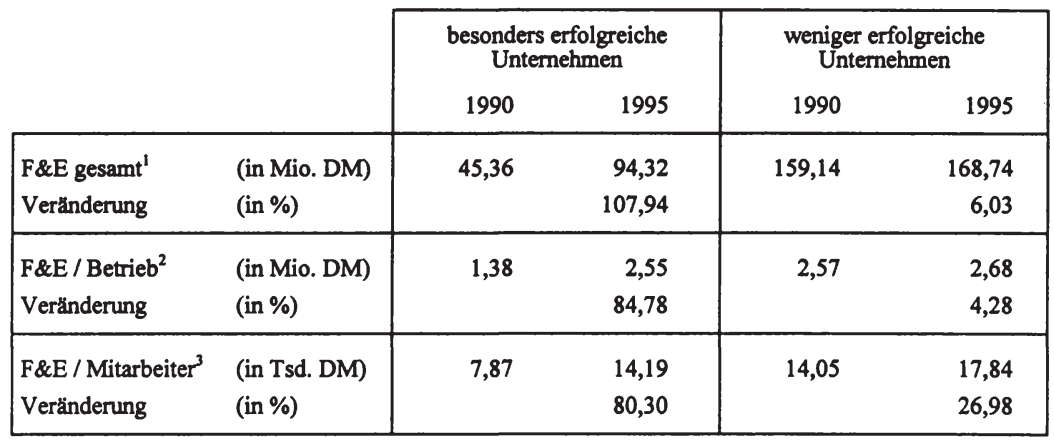

1 fur diese Auswertung wurden nur diejenigen Unternehmen herangezogen, die Angaben zur Entwicklung des F\&E-Aufwands und zur Mitarbeiterentwicklung machten

2 Anzahl der Unternehmen 90/95: besonders erfolgreiche 33/37, ubrige 62/63

3 Anzahl der Mitarbeiter 90/95: besonders erfolgreiche 5.767/6.649, ubrige 11.324/9.458

Quelle: eigene Berechnungen. ${ }^{572}$

${ }^{571}$ Harhoff, D. u.a. (1996), S. 24.

${ }^{572}$ Vgl. in Ergänzung dazu Anlage 22, die die Entwicklung des F\&E-Anteils zwischen 1990 und 1995 nach Wachstumsklassen darstellt. 
Entsprechend dieser Ergebnisse liegt die Vermutung nahe, daß die weniger erfolgreichen Unternehmen aufgrund der höheren F\&E-Aufwendungen je Betrieb bzw. je Mitarbeiter eher in der Lage sind, Innovationen hervorzubringen. Dies trifft jedoch nicht zu. Das Bild verändert sich, wenn der allgemein übliche Indikator des F\&E-Anteils am Umsatz gewählt wird. Die untersuchten Unternehmen investierten 1995 durchschnittlich 4,95\% ihres Umsatzes in die Forschung und Entwicklung (1990 waren es 4,38\%). Differenziert nach den beiden Erfolgstypen ergeben sich 5,30\% (4,45\%) bei den besonders erfolgreichen bzw. $4,75 \%(4,34 \%)$ bei den weniger erfolgreichen Unternehmen. Die besonders erfolgreichen Unternehmen geben also einen höheren Anteil ihres Umsatzes für die Forschung und Entwicklung aus. Darüber hinaus zeigen die jeweiligen Zuwächse zwischen 1990 und 1995 deutlich, daß sich die Aufwendungen für Forschung und Entwicklung in den besonders erfolgreichen Unternehmen wesentlich positiver entwickelt haben als in den weniger erfolgreichen Unternehmen (vgl. Tab. 4-2). Dies ist insgesamt ein Hinweis darauf, daß die besonders erfolgreichen Unternehmen die in die Forschung und Entwicklung investierten Mittel effizienter nutzen, daß sie diese strategisch wichtige Position weiter ausbauen und sich so ein "junges" Produktprogramm erhalten. ${ }^{573}$ Dies bedeutet dann aber auch, daß mit einer weiteren Zunahme der Lücke zwischen den besonders erfolgreichen und den weniger erfolgreichen Unternehmen zu rechnen ist.

Darüber hinaus trägt nach COHEN UND LEVINTHAL Forschung und Entwicklung nicht nur zur Generierung neuen technologischen Wissens bei, sondern hat auch die Aufgabe der Integration und Nutzung existierenden Wissens: "We suggest that R\&D not only generates new information, but also enhances the firm's ability to assimilate and exploit information. ... Accordingly, we argue that while R\&D obviously generates innovations, it also develops the firm's ability to identify, assimilate, and exploit knowledge from the environment - what we call the firm's 'learning' or 'absorptive' capacity" ${ }^{574}$. Betrachtet man jedoch den Stellenwert dieser innovationsrelevanten Informationsquelle bei den untersuchten Unternehmen, so fällt deren nachrangige Bewertung auf. ${ }^{575}$ Mit einem durchschnittlichen Wert von 2,4 rangieren die als innovationsrelevant eingeschätzten Informationen aus der innerbetrieblichen Zusammenarbeit lediglich auf Platz fün, die aus der eigenen F\&E-Abteilung mit einem Wert von 2,1 gar nur auf Platz sieben. ${ }^{576}$ Bei einer Differenzierung nach Erfolgstypen verschiebt sich dieses Bild. Die besonders erfolgreichen Unternehmen schätzen sowohl die Information aus der innerbe-

${ }^{573}$ Albach kommt sogar zu dem Ergebnis, daß die auf den Umsatz bezogenen Aufwendungen erfolgreicher Unternehmen für F\&E geringer sind als bei weniger erfolgreichen Unternehmen und daß erfolgreiche Unternehmen sehr schnell wachsende Aufwendungen für F\&E aufweisen. Vgl. Albach, H. (1989), S. 1345.

${ }^{574}$ Cohen, W.M./Levinthal, D.A. (1989), S. 569. Vgl. dazu auch Cohen, W.M./Levinthal, D.A. (1990) sowie Acs, Z.J./Audretsch, D.B. (1993a), S. 2.

${ }^{575}$ Vgl. Frage 3/14 des Fragebogens im Anhang, Abb. 4-4 sowie Anlage 18. Vor allem bei KMU rücken nach Einschătzung der Europäischen Kommission "externe Quellen stärker in den Vordergrund, da hier - anders als in größeren Firmen - von der internen Entwicklungsarbeit und wissenschaftlichen Forschung nicht so starke Impulse ausgehen". Europäische Kommission (1997a), S. 100.

${ }^{576}$ Skala von 1 = "unwichtig" bis 3 = "wichtig". 
trieblichen Zusammenarbeit (2,6; übrige: 2,3$)^{577}$ als auch die Informationen aus der eigenen F\&E-Abteilung (2,3; übrige: 2,1$)$ höher ein. ${ }^{578}$ Die Unterschiede in der innerbetrieblichen Information und Kommunikation sind damit eine mögliche Begründung für die Effizienzunterschiede zwischen den F\&E-Anstrengungen der untersuchten Erfolgstypen.

Die Verbesserung der innerbetrieblichen Information und Kommunikation ist Aufgabe des Unternehmers. Sein Vorbild und seine Initiative sind entscheidend für die Gestaltung einer offenen Information und Kommunikation. Begünstigt wird dieser Gestaltungsprozeß in kleinen und mittleren Unternehmen durch die im Vergleich zu Großunternehmen geringere Organisationskomplexität, die durch flache Hierarchien und engere Beziehungen gekennzeichnet ist. Diese Eigenschaften sind zu fördern und auszunutzen, indem beispielsweise der Austausch zwischen Vertrieb und F\&E gezielt intensiviert wird. Da der Unternehmer in kleinen und mittleren Unternehmen in der Regel in beiden Aufgabenbereichen stark involviert ist, müssen von ihm - und hier sind besonders die Unternehmer in den weniger erfolgreichen Unternehmen gefordert - die entsprechenden Impulse ausgehen. ${ }^{579}$

Der Finanzierungsbereich ist eine weitere wichtige Komponente bei der Realisierung von Innovationsvorhaben. Die Finanzierung umfaßt dabei "alle Formen der internen und externen Geld- und Kapitalbeschaffung einschließlich Kapitalfreisetzungseffekte" ${ }^{1580}$. Entsprechend läßt sich der Finanzierungsbedarf des Unternehmens nach dem Kriterium der Mittelherkunf in Innen- und Außenfinanzierung einteilen. ${ }^{581}$ Bei der Innenfinanzierung werden die Mittel vom Unternehmen selbst (von "innen heraus") aufgebracht. Die wichtigste Form ist die Selbstfinanzierung (interne Eigenfinanzierung), die aus Gewinnen heraus erfolgt. Daneben besteht die Möglichkeit der internen Fremdfinanzierung, d.h. aus Rückstellungen bzw. aus freigesetztem Kapital. Letztere wird auch als "Umfinanzierung" bezeichnet. Da hier keine zusätzlichen Mittel beschaff werden, sondern lediglich das Vermögen umgeschichtet wird, liegt streng genommen keine Finanzierungsmaßnahme vor. Vielmehr handelt es sich um "Uminvestierung". Bei der Außenfinanzierung fließen die Mittel dem Unternehmen von "außen" zu: Entweder durch die Eigentumer bzw. Gesellschafter des Unternehmens und zwar

577 Sig.: 0,037 .

${ }^{578}$ Die Unterscheidung nach Unternehmensgroßenklassen zeigt keine großßenbedingten Differenzen hinsichtlich der Informationen aus der innerbetrieblichen Zusammenarbeit. Hoch signifikante Unterschiede (Sig.: 0,001) ergeben sich in Bezug auf die Informationen aus der eigenen F\&E-Abteilung. Die ausgesprochen stark zunehmende Bedeutung der eigenen F\&E-Abteilung mit steigender UnternehmensgröBe ist auf den ebenfalls steigenden Organisationsgrad der Forschung und Entwicklung zurückzuführen. Da kleinere Unternehmen oftmals uber keine oder eine lediglich unzureichend abgegrenzte F\&E-Abteilung verfugen, kann sie auch kaum als Informationsquelle dienen. Bestătigung findet dies darin, daß mit steigender Unternehmensgroßße F\&E zunehmend im eigenen Hause durchgefuhrt wird und die F\&E-Ausgaben tendenziell zunehmen (vgl. Anlage 23 und Anlage 22).

${ }^{579} \mathrm{Vgl}$. dazu ausfuhrlich Kapitel 4.4.

${ }^{580}$ Perridon, L./Steiner, M. (1997), S. 341.

${ }^{581}$ Bez. der unterschiedlichen Systematisienungsansătze der Finanzierungsformen vgl. Perridon, L./Steiner, M. (1997), S. 341-345. 
als Beteiligungsfinanzierung (externe Eigenfinanzierung) oder durch die Aufnahme von Kreditkapital von Dritten (externe Fremdfinanzierung).

Die Finanzplanung von Innovationsprojekten stellt an das Innovationsmanagement kleiner und mittlerer Unternehmen beträchtliche Anforderungen. Zum einen ist die Quantität des Kapitalbedarfs, d.h. die Höhe der in den einzelnen Innovationsphasen benötigten Mittel, und zum anderen die Qualität des Kapitalbedarfs, d.h. das mit der Innovation verbundene Risiko, abzuschätzen. ${ }^{582}$ Daneben sind Möglichkeiten der Kapitalbeschaffung auszuloten. Allerdings sehen sich kleine und mittlere Unternehmen bei der Beschaffung von Kapital für Innovationsprojekte eingeschränkten Optionen der Innen- und Außenfinanzierung gegenüber. ${ }^{583}$

Diesen Hemmnissen wurde auch in dieser Untersuchung nachgegangen, ${ }^{584}$ indem Probleme bei der Beschaffung von Eigenkapital bzw. Probleme bei der Kreditfinanzierung abgefragt wurden. Beide Problembereiche scheinen für die untersuchten kleinen und mittleren Unternehmen von geringer Bedeutung zu sein. Lediglich 2,5\% sehen Probleme bei der Eigenkapitalbeschaffung und 21,1\% haben Schwierigkeiten bei der Kreditfinanzierung. Eine Differenzierung zwischen den beiden Erfolgstypen ist zunächst nur von geringem Aussagewert, da sich bei der Einschätzung hinsichtlich der Eigenkapitalbeschaffung keine Unterschiede und hinsichtlich der Fremdkapitalbeschaffung zwar deutliche, aber keineswegs signifikante (besonders erfolgreiche: $12,2 \%$; übrige: $25,6 \%)^{585}$ Unterschiede ergeben. Daraus könnte der Schluß gezogen werden, daß die untersuchten kleinen und mittleren Unternehmen des Verarbeitenden Gewerbes im Hinblick auf die Innovationsfinanzierung keine Hemmnisse sehen.

Allerdings ist darauf hinzuweisen, daß diese Frage von $31 \%$ der befragten Unternehmen nicht beantwortet wurde. Dies ist sicherlich darauf zurückzuführen, daß Fragen zur Finanzierungs-, Umsatz- oder Gewinnsituation grundsätzlich zurückhaltend beantwortet werden. ${ }^{586}$ Folglich ist eher darauf zu schließen, daß Unternehmen, die in diesen Bereichen starke Schwierigkeiten haben, diese nicht zum Ausdruck brachten. Zieht man ergänzend dazu ins Kalkül, daß aufgrund der Selbstselektion diejenigen Unternehmen von einer Teilnahme an der Untersuchung Abstand nahmen, die der Thematik der Untersuchung weniger aufgeschlossen gegenüberstanden, so ist zu vermuten, daß sich der Prozentsatz der Unternehmen, die sich Hemmnissen bei

\footnotetext{
${ }^{582} \mathrm{Vgl}$. Thomas, H. (1989), S. 85-88.

${ }^{583}$ Vgl. Harhoff, D. u.a. (1996), S. 74f.; Mugler, A./Schmidt, K.-H. (Hrsg.) (1995), S. 46f. Zu den Problemen mittelständischer Unternehmen beim Zugang zum Kapitalmarkt vgl. Gerke, W. u.a. (1995) sowie auch Stützle-Leinmuller, S. (1997).

Deutlich wird die Bedeutung einer ausreichenden Liquidität und Finanzierung auch bei Betrachtung der Insolvenzstatistik. Bei insgesamt 22.344 Insolvenzen im Jahr 1995 entfielen auf das Verarbeitende Gewerbe 3.384 Insolvenzen (14,98\%, bei einem Anteil von $16,04 \%$ an allen Unternehmen). Vgl. Statistisches Bundesamt (Hrsg.) (1996), S. 132 und S. 136; eigene Berechnungen.

${ }^{584} \mathrm{Vgl}$. Frage $3 / 9$ des Fragebogens im Anhang.

585 Sig.: 0,086 .

${ }^{586}$ Vgl. Pfohl, H.-C./Kellerwessel, P. (1990), S. 13f.
} 
der Finanzierung gegenübersehen, deutlich erhöhen würde, wenn diese Unternehmen mit einbezogen werden könnten. Von einer tiefergehenden Analyse der (Innovations-) Finanzierung wird abgesehen und auf die entsprechende Literatur verwiesen. ${ }^{587}$

\subsubsection{Die Produktlebenszyklusanalyse}

Eine der bedeutendsten Aufgaben der Unternehmensführung ist, dafür Sorge zu tragen, daß aus dem Markt ausscheidende Produkte durch neue ersetzt werden. Dieser Zyklus kann, wie bereits im Kapitel Unternehmensführung (Abschnitt 3.3.3.3) ausführlich beschrieben, in Anlehnung an den biologischen Zyklus in drei Phasen oder Teilzyklen gegliedert werden, nämlich den Entstehungs-, den Markt- und den Recyclingzyklus. Zur Vereinfachung der Frage nach dem Umsatzanteil der Produkte in den einzelnen Phasen des Produktlebenszyklus wurde in der zugrundeliegenden Untersuchung der Entstehungs- und der Recyclingzyklus vernachlässigt und lediglich der Marktzyklus betrachtet. ${ }^{588}$

Bei einer Analyse der Marktzyklen der untersuchten kleinen und mittleren Unternehmen fällt der gleichmäßigere Verlauf der Kurve bei den besonders erfolgreichen Unternehmen auf. Das Verhältnis der innovativen und produktverändernden Phasen (Markteinführung: 13,8\%; Wachstum: $31,9 \%)$ zur Reife- bzw. Schrumpfungsphase (40,2\% bzw. $14,1 \%)$ ist nahezu ausgeglichen (45,7\% zu 54,3\%). Es besteht lediglich ein geringer Überhang der Produkte in der Schrumpfungsphase gegenuber denen in der Einfuhrungsphase. Hier sollte daher noch eine weitere Verschiebung hin auf junge, innovative Wachstumsprodukte angestrebt werden. Gleichzeitig fällt die extreme Rechtslastigkeit der Kurve der weniger erfolgreichen Unternehmen ins Auge. Das Verhältnis der ersten beiden zu den letzten beiden Phasen beträgt hier ca. 25 : 75 und zeigt damit einen deutlichen Überhang bei den "alten" Produkten. ${ }^{589}$

\footnotetext{
${ }^{587}$ Vgl. bez. der Finanzierungsproblematik in KMU z.B. Kaufmann, F. (1997); Pichler, J.H. u.a. (Hrsg.) (1997), S. 157-206; Harhoff, D. u.a. (1996), S. 74-88; Fischer, T.R. (1997); Nolte, B. (1997); Nolte, B. (1996), S. 102-114; Nopper, H. (1997); Gerke, W. u.a. (1995); Thomas, H. (1989), S. 85-94 sowie ferner Maas, C. (1990), S. 185-202. Einen Gesamtüberblick über die Unternehmensfinanzierung vermitteln Perridon, L./Steiner, M. (1997). Zur Innovationsforderung kleiner und mittlerer Unternehmen vgl. z.B. BMBF/BMWi (Hrsg.) (1997); IHK (1997) und Zieger, S. (1997).

${ }^{588}$ Vgl. Frage $2 / 4$ des Fragebogens im Anhang.

${ }^{589}$ Tendenziell ăhnliche Ergebnisse werden aufgezeigt bei Arthur D. Little (Hrsg.) (1994), S. 123f. Vgl. dazu auch die von Gälweiler, A. (1974), S. 240 vorgeschlagene Idealverteilung des Umsatzes in den einzelnen Phasen.
} 


\section{Abb. 4-7: Die Marktzyklen der beiden Erfolgstypen}

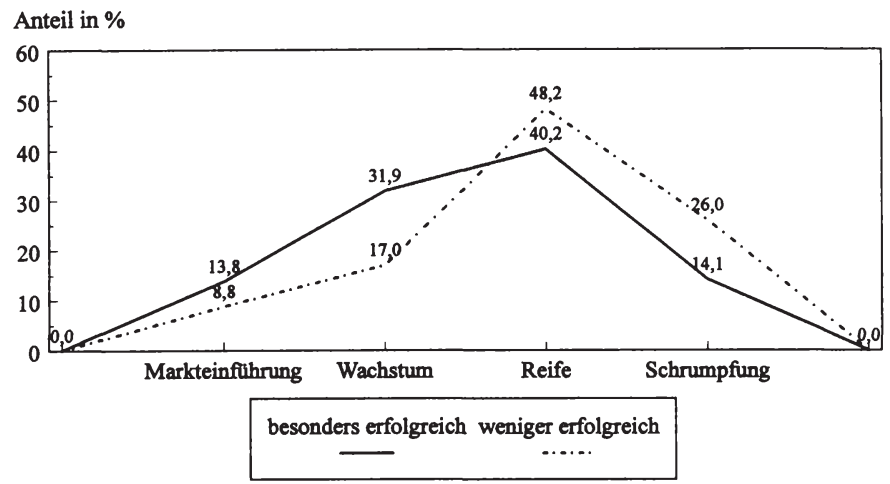

Anteil in \%

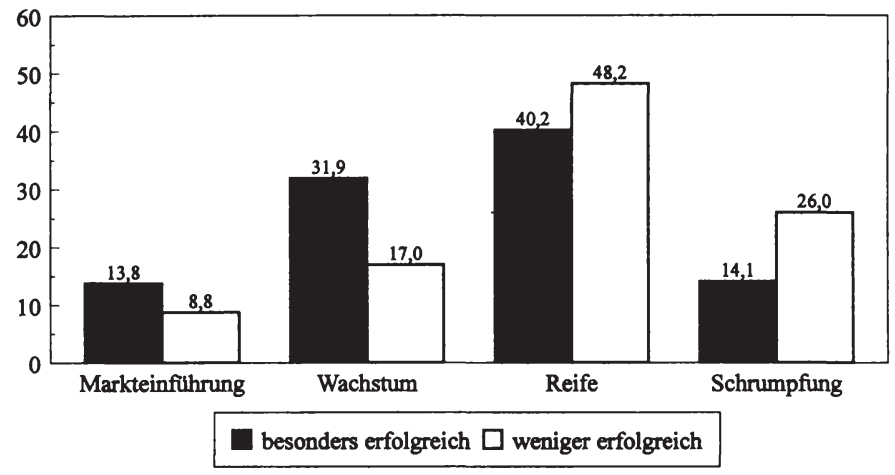

Quelle: eigene Berechnungen.

Wie die Ergebnisse deutlich zeigen, gelingt es den besonders erfolgreichen Unternehmen weitaus besser, aus dem Markt ausscheidende Produkte durch neue zu ersetzen. Sie können das Ausscheiden von Produkten aus der Schrumpfungsphase (Sättigungs- bzw. Degenerationsphase) durch die Einführung neuer Produkte kompensieren, d.h. sie sind in der Lage, ihr Produktprogramm ständig zu verjüngen. ${ }^{590}$

590 Vgl. dazu auch Knight, der ebenfalls zu dem Ergebnis kommt "that the successful firms made more radical and more frequent product and process innovations than the unsuccessful firms", Knight, K.E. (1967), S. 485. 
Werden die verschiedenen Unternehmensgrößenklassen in die Betrachtung mit einbezogen, so zeigt sich mit steigender Unternehmensgröße (Beschäftigtenzahl bzw. Umsatz) ebenfalls eine Zunahme der Produkte in den ersten beiden Phasen (vgl. Anlage 24). Herausstechend sind vor allem die sehr geringen Anteile der Produkte in der Markteinführungsphase bei den Unternehmen mit weniger als 50 Beschäftigten $(8,6 \%)$ und den Unternehmen mit weniger als 30 Mio. DM Umsatz (9,5\%) bei gleichzeitig sehr hohen Anteilen in der Schrumpfungsphase (27,0\% und 26,2\%). In Kontrast dazu steht das Ergebnis der Unternehmen mit mehr als 100 Mio. DM Umsatz, die in diesen beiden Phasen ein Verhältnis von 14,5\% zu 12,3\% aufweisen.

Diese Ausschnittsbetrachtung scheint darauf hinzuweisen, daß mit steigender Unternehmensgröße die Innovativität zunimmt, die sich wiederum auf die unternehmensgrößenbedingte Steigerung der F\&E-Aufwendungen zurückfuhren läßt. Dieser Schluß greift jedoch zu kurz, da sich die Ergebnisse unter Einbeziehung aller Phasen stark relativieren, wobei unternehmensgrößenbedingte Verhältnisdifferenzen zwischen den ersten beiden und den letzten beiden Marktphasen bestehen bleiben. Allerdings wird in keiner der Unternehmensgrößenklassen ein ähnlich ausgeglichenes Verhältnis zwischen den ersten beiden und den letzten beiden Phasen erzielt, wie dies bei den besonders erfolgreichen Unternehmen der Fall ist. ${ }^{591}$ Damit ist bereits an dieser Stelle zum einen der Nachweis erbracht, daß die Innovativität eines Unternehmens nur unzureichend auf die Unternehmensgröße zurückzuführen und nicht direkt abhängig vom F\&E-Aufwand ist. ${ }^{592}$ Zum anderen verdeutlicht die Lebenszyklusanalyse, daß die besonders erfolgreichen Unternehmen die von ihnen aufgewendeten F\&E-Mittel effizienter nutzen als die weniger erfolgreichen Unternehmen. Halten die weniger erfolgreichen Unternehmen an Produkten (und Technologien) mit abnehmenden Wachstumsaussichten fest, erleichtert dies den Innovatoren sogar die Einfuhrung neuer Produkte. Neu am Markt eingeführte Produkte verschaffen den Innovatoren kurzfristige Monopolstellungen gegenüber den Wettbewerbern, die sog. Pioniergewinne ${ }^{593}$ ermöglichen. Es zeigt sich, daß die hohe Wettbewerbsfähigkeit der besonders erfolgreichen Unternehmen auf deren Innovativität zurückzufuihren ist. Diese Folgerungen finden auch durch die Ergebnisse bei den verfolgten Produkt-/Marktstrategien der Unternehmen Bestätigung (vgl. Abschnitt 4.6.1).

${ }^{591}$ Die deutlichste Abweichung zwischen den ersten und den letzten beiden Phasen zeigen erwartungsgemäß die nicht-innovativen Unternehmen mit einem Verhältnis von $15,2 \%$ zu $84,8 \%$ (zu deren Charakterisierung vgl. Abschnitt 2.3.3). Aber auch die Gegengruppe, d.h. die Unternehmen, die neue Produkte oder Prozesse einfuhrten, weisen lediglich ein Verhältnis von $34,7 \% \mathrm{zu} 66,3 \%$ auf.

592 So sieht Brockhoff die Größenvorteile in bezug auf F\&E im wesentlichen in der Fähigkeit zur Ausnutzung von ungeplanten Erfindungen. Vgl. Brockhoff, K. (1993), S. 174. Auf einen weiteren Vorteil der Unternehmensgröße hat bereits Arrow hingewiesen: $\mathrm{Da}$ Neuerungen mit hohen Risiken verbunden sind, trăgt eine steigende Unternehmensgroßße zur Minimierung dieses Problems bei, da dann die steigende Zahl der Projekte einen Risikoausgleich gewăhrleisten und sich damit gegenseitig absichern. Vgl. Arrow, K.J. (1962), S. 616.

593

Die Realisation von Pioniergewinnen bei Produkt- und Verfahrensinnovationen setzt eine möglichst kurze Prozeßzeit voraus, um eine "first-to-market"-Position zu gewăhrleisten oder/und Rationalisierungpotentiale schnellstmöglich nutzen zu können. Vgl. Thom, N. (1983), S. 7. 


\subsubsection{Die Portfolioanalyse}

Die Portfoliotechnik ist eines der bekanntesten und in der Praxis am häufigsten verwendeten Instrumente zur Verknüpfung der Informationen aus dem Unternehmensumfeld mit denen der Unternehmensanalyse. Ihr Ziel ist die methodische Unterstützung von Auswahlentscheidungen. Dazu werden in einer zweidimensionalen Matrix Umfeldeinflüsse auf das Unternehmen und Unternehmensvariable einander gegenübergestellt und die zu betrachtenden Produkte bzw. Technologien in der Matrix positioniert. Damit sollen Ist-Situationen und Zukunftssituationen einzelner Geschäftsfelder eines Unternehmens abgebildet werden.

Die in Kapitel 3 dargestellten Portfolio-Konzepte der Boston Consulting Group bzw. von McKinsey berücksichtigen den Faktor Technologie nicht oder nur implizit. ${ }^{594} \mathrm{Da}$ aber die Technologie ein wesentliches Potential des Unternehmens darstellt, wurden seit Beginn der achtziger Jahre Technologie-Portfolio-Ansätze entwickelt, die dieses Defizit ausräumen sollen und dabei dem F\&E-Bereich ein Kommunikations- und Koordinationsinstrument zur Verfigung stellen. Hervorzuheben ist in diesem Zusammenhang das Konzept von PFEIFFER u.a. ${ }^{595}$ Das von ihnen entwickelte Technologie-Portfolio besitzt die beiden Hauptdimensionen Technologieattraktivität und Ressourcenstärke, die sich ihrerseits aus einer Reihe von Faktoren generieren. Die Technologieattraktivität als unternehmensexterne und damit weitgehend unbeeinflußbare Größe bildet die technischen und wirtschaftlichen Vorteile ab, die durch die Realisierung der in diesem Technologiegebiet noch steckenden strategischen Weiterentwicklungspotentiale wirksam werden. ${ }^{596}$ Die Ressourcenstärke als unternehmensinterne Variable erfaßt die technische und wirtschaftliche Beherrschung der Technologie im Vergleich zum stärksten Wettbewerber (Vgl. Abb. 4-8). ${ }^{597}$

\footnotetext{
${ }^{594}$ Vgl. Pfeiffer, W. u.a. (1983), S. 252f. Eine Verbindung des Marktportfolios mit F\&E-Normstrategien stellt z.B. Brockhoff, K. (1994), S. 160f. her.

${ }^{595}$ Vgl. Pfeiffer, W. u.a. (1982); Pfeiffer, W. u.a. (1983); Pfeiffer, W. u.a. (1986). Vgl. ferner Krubasik, E.G. (1982); Servatius, H.-G. (1985), S. 112-144 und die bei letzterem diskutierten Ansătze der Beratungsunternehmen Arthur D. Little, McKinsey bzw. Booz, Allen \& Hamilton. Für einen Überblick vgl. auch Brockhoff, K. (1994), S. 155-177; Specht, G./Beckmann, C. (1996), S. 91-102, wobei Specht und Beckmann mit dem von Michel, Ewald und Specht entwickelten "Darmstädter Portfolio-Ansatz" ein weiteres Konzept vorstellen (S. 95-99). Kritisch zu letzterem äußert sich Wolfrum. Vgl. Wolfrum, B. (1994b), S. 215.

596 Vgl. Pfeiffer, W. u.a. (1982), S. 85-88.

${ }^{597}$ Vgl. Pfeiffer, W. u.a. (1982), S. 89-92.
} 
Abb. 4-8: Das Technologie-Portfolio nach PFEIFFER u.a.

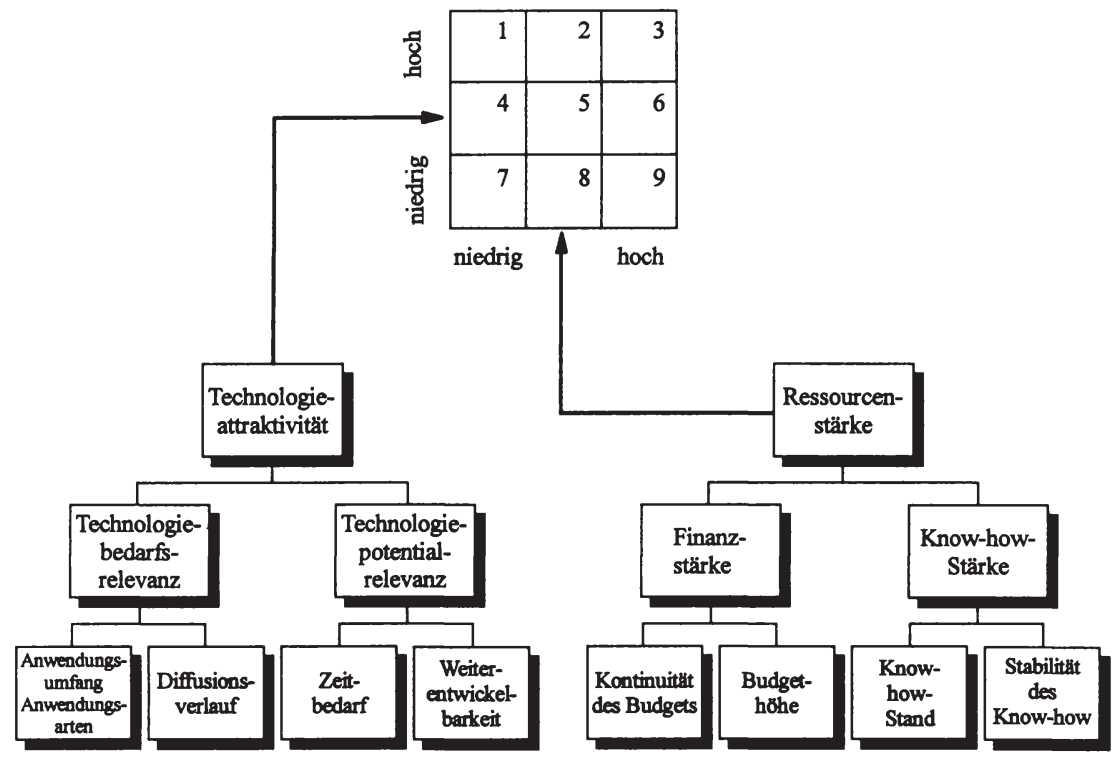

Quelle: in Anlehnung an Pfeiffer, W. u.a. (1982), S. 88 und 91.

Zur Ableitung des Technologie-Portfolios lassen sich folgende Schritte unterscheiden: ${ }^{598}$

1. Identifikation der genutzten Produkt- und Prozeßtechnologien durch Zerlegung des Produktes in seine Subsysteme, Baugruppen und Elemente und Kennzeichnung der Ressourcenkonzentration und Synergieeffekte zwischen den Produkten.

2. Bewertung der einzelnen Technologien hinsichtlich ihrer Attraktivität. Dazu werden die technischen und wirtschaftlichen Erfolgsaussichten (Technologiepotential und -bedarf) erfaßt. Die Technologieattraktivität beschreibt den Reifegrad der jeweiligen Technologie.

3. Bewertung der unternehmerischen Ressourcen. Sie setzen sich aus den Faktoren Know-how- und Finanzstärke zusammen.

4. Positionierung der einzelnen Produkt- und Prozeßtechnologien im Portfolio entsprechend der bewerteten Hauptdimensionen (Ist-Portfolio).

${ }^{598}$ Vgl. Pfeiffer, W. u.a. (1982), S. 80-98; Pfeiffer, W. u.a. (1986), S. 115-123. 
5. Transformation des Ist-Portfolios, indem die einzelnen Produkt- und Prozeßtechnologien in Relation zu potentiellen Konkurrenztechnologien gesetzt werden, um zuküntige Chancen und Risiken aufzuzeigen.

Auf diese Weise können produkt-, prozeß-, geschäftsfeld- und unternehmensspezifische Portfolios erstellt werden. Entsprechend der Positionierung im Portfolio lassen sich auf der Basis der Normstrategien - Investieren, Selektieren und Desinvestieren - Handlungsempfehlungen für die Ressourcenallokation im Rahmen des Innovationsmanagements ableiten. ${ }^{599}$

Zur Kritik am Technologie-Portfolio von PFEIFFER u.a. äußern SPECHT UND BECKMANN, daß erstens mit der Einbeziehung des Faktors "Technologiebedarfsrelevanz" in die PortfolioAnalyse eine unzureichende Ausrichtung an marktstrategischen Aspekten erfolgt, so daß das gesamte Konzept eine weitgehend isolierte Analyse der Technologiekomponente darstellt. Außerdem sind kaum Hinweise zur notwendigen Integration der Technologiefeldplanung in die strategische Gesamtplanung zu finden. Zweitens ergeben sich besonders im Technologieattraktivitätsbereich aggregative, einzelne Ausprägungen nivellierende Effekte, weil die marktbezogenen Daten der Technologiebedarfsrelevanz auf mehreren Produkten bzw. Produktgruppen basieren, denen jedoch die gleiche Technologie zugrundeliegen kann. Schließlich erfüllen drittens die betrachteten Komponenten z.T. nicht das für die Portfolio-Analyse geforderte Kriterium der Unabhängigkeit. So bestimmen beispielsweise die finanziellen Mittel die erklärende Dimension "Ressourcenstärke", obwohl als Ergebnis Ressourcenallokationsstrategien generiert werden sollen. Außerdem erfordert eine Technologie, die mit einer hohen Attraktivität bewertet wird, einen relativ hohen Finanzmitteleinsatz, so daß sich ein kumulativer Effekt ergibt. ${ }^{600}$

Abgesehen von der vorstehenden Kritik erfüllt das Technologie-Portfolio seine Grundfunktion als Analyseinstrument, nämlich die Generierung und Verdichtung relevanter Daten, die als Informationsbasis für die Entwicklung strategischer Programme geeignet sind. Daneben lassen sich weitere Eigenschaften des Technologie-Portfolios hervorheben. Zunächst verläßt das Technologie-Portfolio den eingeschränkten Betrachtungsabschnitt des Marktzyklus und bezieht den gesamten Produktlebenszyklus mit ein. ${ }^{601}$ Dadurch werden neben den am Markt befindlichen Basis-, Schlüssel- und Schrittmachertechnologien zusätzlich potentielle Substitutionstechnologien berücksichtigt, die für das Unternehmen zur Chance oder zum Risiko werden können. Die Betrachtung der einzelnen Elemente der Produkt- und Prozeßtechnologien bietet ferner die Möglichkeit, rechtzeitig eventuelle (ökologische) Risiken aufzudecken, die

${ }^{599}$ Für eine Beschreibung der Normstrategien vgl. Pfeiffer, W. u.a. (1982), S. 99-102; Pfeiffer, W. u.a. (1986), S. 120-123.

${ }^{600}$ Siehe Specht, G./Beckmann, C. (1996), S. 100. Vgl. zur Kritik ferner Servatius, H.-G. (1985), S. 137f. Der bei Specht und Beckmann diskutierte "Darmstädter Ansatz" berücksichtigt diese Kritik zwar, erhält dadurch aber eine sehr hohe Komplexität, die speziell eine Anwendung in KMU erschwert.

601 Vgl. Pfeiffer, W. u.a. (1986), S. 109-112. 
zu einer Verkürzung des Marktzyklus oder im Laufe des Recyclingzyklus zu Problemen führen könnten. Durch diese ganzheitliche Betrachtungsweise berlicksichtigt das Instrument die prinzipielle Dynamik des technischen Fortschritts. Daneben ermöglicht das TechnologiePortfolio den Brückenschlag zu den Kernkompetenzen des Unternehmens. ${ }^{602}$ Angesichts sich schnell wandelnder Märkte und Technologien stellt das Technologie-Portfolio auf die langfristig stabilen Ressourcen sowie die Synergien zwischen den Geschäftsfeldern und den Produkten ab, um dadurch schneller und billiger als die Wettbewerber Fähigkeiten aufzubauen, aus denen neue Produkte oder Verfahren resultieren. Das Konzept der Kernkompetenzen setzt ebenfalls an den langfristig stabilen Kompetenzen des Unternehmens bzw. den entstehenden Synergien an, geht dann allerdings über die Beherrschung von Produkt- und Verfahrenstechnologien hinaus und verlangt zusätzlich, daß die Kompetenzen einmalig und schwer imitierbar sind. Dies geschieht durch die systematische Integration von Produkt, Technologie und Mitarbeitern (Know-how, Einstellungen) zu einem stimmigen Ganzen. ${ }^{603}$

Kernkompetenzen sind der Ursprung innovativer Produkte und Prozesse. In den kleinen und mittleren Unternehmen des Verarbeitenden Gewerbes sind es genau diese Komponenten - Produkt, Technologie und Mitarbeiter -, deren entsprechende Kombination die Basis ihrer Wettbewerbsstärke bildet. Der Einsatz des Technologie-Portfolios in kleinen und mittleren Unternehmen würde somit dazu beitragen, die Kernkompetenzen des Unternehmens eindeutig zu bestimmen, wodurch ein gezielter Ausbau möglich und dadurch auch die Innovativität des Unternehmens aufrechterhalten wird.

\subsection{Innovationskultur}

\subsubsection{Die Rolle des Unternehmers}

Die Unternehmenskultur umfaßt in der Summe alle wahmehmbaren Merkmale eines Unternehmens, die durch Evolution und Tradierung entstanden sind. Sie erhöht auf der Unternehmensebene die allgemeine Leistungsfähigkeit und besitzt auf der individuellen Ebene eine motivierende und verhaltensleitende Funktion. ${ }^{604}$ Obwohl alle Mitarbeiter dazu beitragen, die Kultur zu bilden und zu erhalten, kommt der Unternehmensfuhrung eine herausragende Rolle $\mathrm{zu}$. Besonders deutlich wird dies in kleinen und mittleren Unternehmen, die durch die zentrale

\footnotetext{
${ }^{602}$ Vgl. Osterloh, M. (1994), S. 50. Zu den Kernkompetenzen eines Unternehmens vgl. grundsătzlich Prahalad, C.K./Hamel, G. (1990), die dazu u.a. ausfuhren: "The real sources of advantage are to be found in management's ability to consolidate corporatewide technologies and production skills into competencies that empower individual businesses to adapt quickly to changing opportunities. ... Core competencies are the collective learning in the organization, especially how to coordinate diverse production skills and integrate multiple ${ }^{603} \mathrm{Vgl}$. auch Anlage 11.

${ }^{604}$ Vgl. Kieser, A. (1986), S. $44 f$.
} 
Stellung des Unternehmers geprägt sind. Sein Persönlichkeitsprofil und das durch ihn verkörperte Wertesystem bestimmen maßgeblich die Kultur des Unternehmens. Die Inhalte der Unternehmenskultur lassen sich damit auf zwei Komponenten zurückführen, auf Schlüsselpersonen im Unternehmen - wie beispielsweise den Unternehmer oder eine Unternehmerfamilie und auf den Lernprozeß, im Rahmen dessen die Unternehmenskultur weiterentwickelt wurde. ${ }^{605}$ Entwicklung und Wandel sind damit bereits impliziter Bestandteil der Unternehmenskultur.

Als grundlegende Voraussetzung für die langfristige Sicherung des Unternehmenserfolgs wird die Fähigkeit angesehen, Innovationen zu initiieren und umzusetzen. Die Innovationsorientierung sollte sich folglich auch in der Unternehmenskultur wiederfinden. Ist sie bereits ein fester Bestandteil der Unternehmensentwicklung bzw. -geschichte, kann sie als Innovationskultur bezeichnet werden. ${ }^{606}$ Die Entstehung einer Innovationskultur setzt die Herausbildung einer bestimmten Denkhaltung voraus. Zu den Merkmalen einer innovationsförderlichen Unternehmenskultur, die den langfristigen Unternehmenserfolg sicherstellt, gehören

- eine Führung, die sich offen gegenüber neuen Entwicklungen zeigt und die auch die Mitarbeiter in diesen Wandlungs- und Anpassungsprozeß miteinbezieht;

- Mitarbeiter, die den Wandel und die Anpassung als Herausforderung und Chance betrachten, Innovation also als eigenen Wert akzeptieren, und sich als Unternehmer im Unternehmen (Intrapreneure) verstehen;

- eine Informations- und Kommunikationskultur, die intern die Verbindung zwischen Führung und Mitarbeitern sowie zwischen den einzelnen Funktionsbereichen herstellt und die extern den Kontakt zu und den Austausch mit innovationsrelevanten Quellen sowie den Anspruchsgruppen (Stakeholder) fördert.

Aus diesen Komponenten muß sich ein Umfeld formieren, in dem Initiative, Kreativität und Risikobereitschaft sowie ein vernetztes, ganzheitliches Denken gefördert und in dem Innovativität - und mit ihr die Unternehmensentwicklung - als dynamischer (Lern-) Prozeß verstanden wird. ${ }^{607}$

Der initiierende Anstoß für die Herausbildung einer Innovationskultur in kleinen und mittleren Unternehmen muß vom Unternehmer ausgehen. Innovationsbereitschaft stellt sich nur dann ein, wenn Innovativität von seiten des Unternehmers als eigenständiger Wert vorgelebt und nicht nur verbal oder über vereinzelte Aktivitäten signalisiert wird. Erleichtert wird dies

605 Vgl. Gussmann, B. (1988), S. 226f.

${ }^{606}$ Zur Innovationskultur vgl. z.B. Kieser, A. (1986); Arthur D. Little (1988); Gussmann, B. (1988); Thom, N. (1992), S. $20 \mathrm{f}$.

${ }^{607}$ Zur Gestaltung eines innovativen Umfeldes (einer innovativen Atmosphäre) bzw. einer Lernkultur vgl. die beiden nachfolgenden Abschnitte 4.4.2 und 4.4.3. 
in kleinen und mittleren Unternehmen dadurch, daß er in der Regel selbst an der Planung und Realisation von Innovationen beteiligt ist, seine Vorbildfunktion in Verbindung mit der hohen Kontaktdichte in kleinen und mittleren Unternehmen also multiplikative Wirkungen entwikkeln kann. Die enge Einbindung ermöglicht die Übernahme einer Promotorenrolle.

Werden Innovationsprozesse als Entscheidungsprozesse ${ }^{608}$ verstanden, so bedarf es nach WITTE neben deren intellektueller Beherrschung zusätzlich der Aktivität von Promotoren (Prozeßförderern), die den Innovationsprozeß fortlaufend unterstützen. ${ }^{609}$ Diese Notwendigkeit ergibt sich zum einen daraus, daß innovative Entscheidungsprozesse unter tendenziell geringer Strukturiertheit des Problems sowie in einem schlecht strukturierten Prozeß verlaufen und somit ein Koordinator erforderlich wird. Zum anderen bilden sich im Innovationsproze $B$ sachliche und personelle Barrieren, die WITTE nach Willens- und Fähigkeitsbarrieren differenziert. ${ }^{610}$ Innovationsbarrieren in Form von Willensbarrieren (das Nicht-Wollen) erklären sich aus den Beharrungskräften des Status quo. Die Bekanntheit und Vertrautheit des gegenwärtigen Zustandes und der sich daraus ergebenden Chancen und Risiken schafft ein Gleichgewicht, das durch Innovationen verändert wird. ${ }^{611}$ Innovationen bedeuten zusätzlich "stets den Verzicht auf Realisierung anderer Pläne, so daß diejenigen Kräfte, die sich mit anderen Plänen identifizieren, notwendigerweise in eine Opponentenrolle gedrängt werden" ${ }^{612}$. Die Veränderung dieses Gleichgewichts, d.h. die Durchbrechung der Willensbarrieren der Innovation und die Integration der Opponenten, kann mit Hilfe des Sanktionssystems des Unternehmens erfolgen. Dies bedeutet, daß instantielle Macht ausgeubt wird, um den Innovationsprozeß zielorientiert durchzusetzen. ${ }^{613}$ Eine weitere Innovationsbarriere, die Fähigkeitsbarriere (das Nicht-Wissen), resultiert aus der Neuartigkeit des Produktes bzw. Prozesses sowie aus den Anforderungen an die intellektuelle Anpassungsfähigkeit. Diese Barriere wächst mit dem

${ }^{608}$ Witte versteht unter einer Entscheidung "die Wahl einer Handlungsmoglichkeit aus zwei oder mehreren, sich gegenseitig ausschließenden Alternativen". Witte, E. (1992), S. 552. Der Entscheidungsprozeß ist folglich der geistige Ablauf, der zur Wahl einer Alternative fuhrt. Innerhalb dieses Entscheidungsprozesses lassen sich einander überlappende bzw. parallel zueinander verlaufende Phasen unterscheiden: die Problemidentifizierung, die Informationssammlung, die Alternativengenerierung, die Alternativenbewertung sowie die Entscheidung. Vgl. Witte, E. (1992), S. 553f.

${ }^{609} \mathrm{Vgl}$. zu den Grundlagen des Promotoren-Konzeptes Witte, E. (1973a); Witte, E. (1973b). Wittes Untersuchung bezog sich auf die empirische Analyse von 233 Innovationsentscheidungen zur Erstinstallation einer EDV-Anlage in Unternehmen und Behörden.

Das Promotorenmodell findet in der wissenschaftlichen Literatur eine starke Beachtung und wurde vielfach variiert und verfeinert. Der Untersuchungsansatz und die aus den Ergebnissen gezogenen Schlüsse weisen jedoch zahlreiche Schwachpunkte auf. Zu kritisieren sind insbesondere konzeptionelle, empirische, praxeologische und methodische Aspekte des Konzeptes. Vgl. fur eine zusammenfassende Darstellung der Kritik Wicher, H. (1995).

${ }^{610}$ Vgl. Witte, E. (1973b), S. 6-9.

${ }^{611}$ Vgl. hierzu erneut den von Schumpeter beschriebenen "Prozeß der schð̋ferischen Zerstorung", der die Überwindung dieses Gleichgewichts zum Ausdruck bringen soll. Bei Verlassen dieses Gleichgewichts formieren sich jedoch i.d.R. Widerstănde auf Seiten der Organisationsmitglieder. Vgl. dazu z.B. auch Zaltman, G. u.a. (1973), S. 85-103; Strebel, P. (1996).

${ }^{612}$ Witte, E. (1973b), S. 7.

${ }^{613}$ Witte spricht hier von Energie, "die in der Lage ist, das Sanktionssystem der Unternehmung zu mobilisieren und damit die Bereitschaft zur Teilnahme am Innovationsprozeß zu veranlassen". Witte, E. (1973a), S. 20. 
Grad der Neuartigkeit bzw. der Komplexität des Innovationsproblems. Für die Überwindung dieser Barriere bedarf es eines oder mehrerer Experten, die ihr Fachwissen zur Lösung des Innovationsproblems und "gegenüber Innovationswilligen und Opponenten als Argumentationskraft" ${ }^{614}$ einsetzen.

Die für die Überwindung der Innovationsbarrieren notwendigen Energien teilen sich in die Energie der Macht und in die Energie des Fachwissens auf. Daraus ergeben sich nach WITTE zwei personale Elemente, der Macht- bzw. der Fachpromotor. Promotoren starten den Innovationsproze $\beta$ "und treiben ihn unter Überwindung von Barrieren bis zum Innovationsentschluß voran" ${ }^{1615}$. Dabei erfolgt die aktive und intensive Förderung des Innovationsprozesses durch den Machtpromotor mittels seines hierarchischen Potentials, während der Fachpromotor sein objektspezifisches Wissen einbringt. In Wittes Untersuchung ließen sich fünf Strukturformen identifizieren: die Gespannstruktur (als signifikant häufigster Wert), die einseitige Machtstruktur, die einseitige Fachstruktur, die Personalunion-Struktur sowie die Struktur ohne Promotoren. ${ }^{616}$ Das organisatorische Modell der Gespannstruktur erwies sich insgesamt als überlegen, d.h. sowohl hinsichtlich der Einwirkung auf den Verlauf des Neuerungsprozesses als auch auf die Qualität der Entscheidungen. ${ }^{617}$

Eine Erweiterung erfährt das Promotorenmodell durch HAUSCHIIDT UND CHAKRABARTI, die den Prozeßpromotor als eine Zwischeninstanz hinzufügen und die Aufgaben der Promotoren umfassender charakterisieren. ${ }^{618}$ Sie behaupten, "daß der Einsatz der unterschiedlichen Machtquellen am wirksamsten in einer Drei-Personen-Arbeitsteilung erfolgt. Diese kann auf ein Zwei-Personen-Modell reduziert werden, wenn das Problem weniger komplex oder die Unternehmung kleiner ist." ${ }^{619}$ Der Prozeßpromotor nimmt in diesem Modell eine Vermittler-

${ }^{614}$ Witte, E. (1973b), S. 19.

${ }^{615}$ Witte, E. (1973b), S. 16.

${ }^{616}$ Vgl. Witte, E. (1973a), S. 20-24; Witte, E. (1973b), S. 17-22. Zur Beschreibung des Promotorenmodells vgl. ferner z.B. Aregger, K. (1976), S. 142-145; Servatius, H.-G. (1988), S. 108f.; Eschenbach, R./Müller, C. (Hrsg.) (1992), S. 243-247; Wicher, H. (1995), S. 820f.; Hauschildt, J. (1997), S. 160-167.

Hervorzuheben ist auch, daß sich der Fachpromotor in einem dauerhaften Lemprozeß befindet, in dem er zugleich Lernender und Lehrender ist und so die Fähigkeitsbarrieren der Innovation uberwindet. Vgl. Witte, E. (1973b), S. 19. Wie sich spăter noch zeigen wird, findet das Promotorenkonzept auch Anwendung auf Entscheidungsprozesse im Rahmen des Umweltmanagements.

${ }^{617}$ Vgl. Witte, E. (1973b), S. 55.

${ }^{618}$ Vgl. Hauschildt, J./Chakrabarti, A. (1988); Hauschildt, J. (1997), S. 167-178. Vgl. dazu ferner Töpfer, A. (1986), S. 399, der in diesem Zusammenhang von einem "Koordinationspromotor" spricht sowie Kirchmann, E. (1994), S. 225 und S. $232 \mathrm{ff}$.

Im Hinblick auf den fortlaufenden organisatorischen Wandel nimmt Hauschildt weitere Anpassungen am Promotorenmodell vor. Er stellt fest, daß Unternehmen "offener, konflikttoleranter, prozeßorientierter, projektbewußter, informationsaktiver und kooperationsbereiter geworden" sind und somit auch "eine deutliche Veränderung des Managements von Projekten" stattfinden muß. Hauschildt, J. (1997), S. 180. Darüber hinaus erfordert die Verwirklichung einer Innovationskultur im Unternehmen auch einen entsprechenden Einsatz von seiten der Promotoren, deren genaue Rolle allerdings noch im Unklaren liegt. Vgl. Hauschildt, J. (1997), S. $185 \mathrm{ff}$.

${ }^{619}$ Hauschildt, J. (1997), S. 167. 
rolle ein. Dieser Promotorentyp wird notwendig, nachdem HAUSCHILDT UND CHAKRABARTI den Handlungsbereich der beiden übrigen Promotoren auf einen eng umrissenen Kern reduzieren. Der Handlungsbereich des Machtpromotors umfaßt die Verfügungsmacht über die Ressourcen des Unternehmens und die Kenntnis über dessen strategische Ausrichtung. Der Fachpromotor ist Träger des objektspezifischen Fachwissens und er verfügt über funktionale Autorität. Damit wird ein Verbindungsglied erforderlich, das zwischen dem Fach- und dem Machtpromotor vermittelt und durch seine Organisationskenntnis und seine Informationsbeziehungen für eine adäquate Kommunikation des Innovationsprozesses im Unternehmen sorgt. $^{620}$

Bei der Übertragung des Promotorenkonzeptes auf die spezielle Situation in kleinen und mittleren Unternehmen wird deutlich, daß eine wichtige Quelle innovativer Tätigkeiten der Unternehmer selbst ist. Seine direkte Einbindung in den Innovationsprozeß kann zu einer Verschmelzung mehrerer Promotorenrollen in seiner Person führen. In diesen Fällen besitzt er zugleich die Verfügungsmacht über die Ressourcen des Unternehmens, den Überblick über die (zumindest implizite) strategische Zielsetzung des Unternehmens, das objektspezifische Fachwissen, die umfassende Kenntnis der organisatorischen Strukturen und Kommunikationskanäle sowie die Koordinationskompetenz, die in ihrer Gesamtheit für das Vorantreiben eines erfolgreichen Innovationsprozesses notwendig sind. Dieser Zustand würde dem Schumpeterschen Unternehmerbild, das im "Erkennen und Durchsetzen neuer Möglichkeiten"621 liegt, entsprechen. Allerdings zeigt sich - und dies wird erneut durch das Promotorenkonzept deutlich -, daß die Initiative zu bzw. die Durchsetzung und Umsetzung von Innovationen zwar durchaus auf einzelne Personen oder in Sonderfällen auf die Person des Unternehmers zurückgefuhrt werden kann, daß aber in der Regel mehrere Personen am Innovationsprozeß beteiligt sind. Dadurch gewinnt die Sichtweise an Bedeutung, daß Innovationen als gesamtunternehmerische, organisationsweite Such-, Lern- und Problemlösungsprozesse verstanden werden müssen, die von allen Mitarbeitern mitzutragen sind.

Insbesondere im Zuge der Human-Relations-Bewegung rückten die Mitarbeiter und ihr Potential in den Mittelpunkt des Innovationsprozesses. ${ }^{622} \mathrm{Da}$ sie die Träger des organisationalen Handelns sind, sind sie auch Träger des Veränderungsprozesses. Zur Steigerung der Innovationsbereitschaft und -fähigkeit der Mitarbeiter ist die Schaffung eines innovationsfreundlichen Umfeldes notwendig. Ein solches Umfeld ist die Voraussetzung für innovatives Entscheiden

${ }^{620}$ Vgl. Hauschildt, J. (1997), S. 167-172. Die am Konzept von Witte geäußerte Kritik wird durch die Erweiterungen bzw. Verfeinerungen durch Hauschildt und Chakrabarti keineswegs ausgerăumt. Die Ausdehnung um einen Prozeßpromotor - der in Großunternehmen etwa die Rolle eines Innovationsmanagers/Leiters eines Venture-Teams übernimmt - berilcksichtigt zwar grundsătzlich, daß mehrere Personen am Innovationsprozeß beteiligt sind. Aus dem Modell lassen sich aber keine prăzisen Handlungsempfehlungen für die Anwendung in der Praxis ableiten.

${ }^{621}$ Vgl. Schumpeter, J.A. (1928), S. 483. Zur Kritik an dieser Sichtweise vgl. Leder, M. (1989), S. $19 \mathrm{ff}$.

${ }^{622}$ Vgl. Gussmann, B. (1988), S. 4; Corsten, H. (1989), S. 11. 
und Handeln der Mitarbeiter. Die Initiative hierfür muß aber maßgeblich vom Unternehmer als dem zentralen Gestalter des Unternehmens - und folglich auch der (Innovations-) Kultur ausgehen.

\subsubsection{Die Schaffung eines innovativen Umfeldes}

Wird von seiten des Unternehmers bzw. der Unternehmensführung die Errichtung einer Innovationskultur im Unternehmen angestrebt, müssen dafür auch die organisatorischen Voraussetzungen geschaffen werden. Für die Charakterisierung innovationsfördernder Organisationsformen oder Zustände im Unternehmen finden sich in der Literatur zahlreiche Umschreibungen, wie beispielsweise "innovative Atmosphäre", "innovatives Klima", "innovative Kultur" oder "innovatives Milieu". ${ }^{623}$ Bereits durch die Wortwahl wird jedoch deutlich, daß diese Begriffe wohl eher einen Zustand auf der Gefühlsebene kennzeichnen als ein in seiner Komplexität exakt beschreibbares Phänomen. Dennoch lassen sich einige Kernelemente aufzeigen, die durch ihr Zusammenwirken ein innovatives Umfeld schaffen, das die Innovativität des Unternehmens zumindest potentiell positiv beeinflußt. ${ }^{624}$

Im Gefolge der Typologien von BURNS UND STALKER aus dem Jahre 1961, die mit dem mechanistischen und dem organischen Managementsystem zwei entgegengesetzte Typen von Organisationen unterscheiden, ${ }^{625}$ wurden zahlreiche weitere Ansätze entwickelt, die innovative Organisationsstrukturen beschreiben. Die Diskussion wurde außerdem durch die Thesen von PETERS UND WATERMAN beeinflußt, ${ }^{626}$ die eine durchgehende Innovativität des Unternehmens für lohnend erachten. Im Extremfall würde dies bedeuten, daß es die Aufgabe eines jeden Mitarbeiters ist, innovativ zu sein, d.h. ständig nach neuen Produkten oder Verfahren zu suchen, wie dies beispielsweise beim KAIZEN bzw. KVP der Fall ist.

${ }^{623}$ Vgl. z.B. Knight, K.E. (1967), S. 481; Pfeiffer, W. u.a. (1986), S. 123f.; Kasper, H. (1986), S. 118-123; Servatius, H.-G. (1988), S. 10; Specht, G. (1989), S. 153; Quévit, M. (1991), S. 55; Bromann, P./Piwinger, M. (1992), S. 35; Wolfrum, B. (1994a), S. 1018; BMWi u.a. (Hrsg.) (1995), S. 1-13; Lang, H.-C. (1995), S. 183f.; Hinterhuber, H.H. (1996), S. 26; Hunger, J.D./Wheelen, T.L. (1996), S. 350-354; Pawlowsky, P.Băumer, J. (1996), S. 6; Europäische Kommission (1997b), S. 3; Tominaga, M. (1997), S. 169f. Aufgrund der Vielzahl von Autoren, die sich mit diesem Thema auseinandersetzen, ist es nicht weiter verwunderlich, daß auch gänzlich neue Wortschöpfungen entstehen, wie dies etwa bei Mintzberg ("adhocracy") der Fall ist. Vgl. Mintzberg, H. (1989), S. 196-199.

${ }^{624}$ Dem Begriff des "innovativen Umfeldes" wird hier der Vorzug gegeben, da er sowohl fur die Beschreibung der Situation innerhalb als auch außerhalb des Unternehmens geeignet ist. Auf die Darstellung der letzteren wird hier allerdings verzichtet. Vgl. dazu Aydalot, P. (Hrsg.) (1986); Nolte, B. (1996), S. 88ff. Daneben wird nicht verkannt, daß auch hinter diesem Begriff kein allgemein gültiges Organisationskonzept steht.

${ }^{625}$ Vgl. Burns, T./Stalker, G.M. (1961). Das mechanistische System entspricht dem einer geordneten Bürokratie in einem stabilen Umfeld und ist u.a. durch Zentralisierung, Hierarchie und vertikale Kommunikationsbeziehungen gekennzeichnet. Das organische Managementsystem ist nicht eindeutig definierbar, da ein veränderliches Umfeld besteht, so daß keine exakte Aufgaben- oder Stellenbeschreibung möglich ist, sondern problemorientiertes Denken und Handeln notwendig wird. Die Kommunikation verlauft vertikal und horizontal. Vgl. zur Beschreibung und Kritik ferner Hauschildt, J. (1997), S. 115-118.

${ }^{626}$ Vgl. die aufgezeigten Merkmale innovativer Unternehmen in Abschnitt 3.3.4.1. 
Die Frage nach besonders innovativen Organisationsformen nimmt ihren Ausgang in der Betrachtung bestimmter Strukturgrößen der Organisation, die innovationsorientiert gestaltet werden müssen. Entsprechend formuliert MINTZBERG: "To innovate means to break away from established patterns. Thus the innovative organization cannot rely on any form of standardization for coordination. In other words, it must avoid all the trappings of bureaucratic structure, notably sharp division of labor, extensive unit differentiation, highly formalized behaviors, and the emphasis on planning and control systems. Above all, it must remain flexible. ${ }^{1627}$ Als innovationsbegünstigend werden folglich erachtet: ${ }^{628}$

- eine flache hierarchische Struktur,

- ein geringer Formalisierungsgrad,

- die Dominanz von Generalisten,

- eine dezentrale Entscheidungsbildung,

- ein geringer Standardisierungsgrad und

- eine intensive Information und Kommunikation.

Allerdings ist darauf hinzuweisen, daß in den verschiedenen Phasen des Innovationsprozesses unterschiedliche Ausprägungen bestimmter Organisationsmerkmale sowie auch unterschiedliche Führungsstile erforderlich sind. Bereits WILsON ${ }^{629}$ hat darauf hingewiesen, daß es die innovationsdienlichste Organisationsform gar nicht gibt, das Unternehmen sich also in einem "organisatorischen Dilemma" befindet. ${ }^{630}$ In der Ideenphase ("the conception of the change") sind unbürokratische Strukturen, ein geringer Zentralisierungsgrad und eine geringe Funktionsdifferenzierung sowie der breite Zugang zu internen und externen Informationen Voraussetzung für innovatives Denken und das Zustandekommen von Neuerungsvorschlägen. ${ }^{631}$ Mit Eintritt in die Konkretisierungs- und Entwicklungsphase ("the proposing of the change") nimmt die Konzentration auf das Projektziel zu. Folglich steigen auch Standardisierung, Formalisierung, Arbeitsteilung und Entscheidungszentralisation langsam an. Die Einfuihrung der

${ }^{627}$ Mintzberg, H. (1989), S. 199.

${ }^{628}$ Vgl. Arthur D. Little (1988), S. 46-68; Geschka, H. (1990), S. 163; Trommsdorff, V./Schneider, P. (1990), S. 17. Vgl. ferner die generischen Erfolgskonstellationen für Innovationsprozesse bei Gerybadze, A. (1995), S. 833. Kennzeichen einer innovativen Organisation zeigt auch Kirsch auf, der die Gedanken Etzionis hinsichtlich der Fähigkeit einer aktiven Gesellschaft zur Selbsttransformation auf die Unternehmensebene überträgt. Die fortschrittsfähige bzw. innovative Organisation ist demnach dadurch gekennzeichnet, daß Handlungsfähigkeit, Empfänglichkeit und Erkenntnisfortschritt gleichermaßen hoch ausgeprägt sind und keinerlei Inkompatibilităten zwischen diesen Făhigkeiten bzw. einzelnen ihrer Dimensionen existieren. Vgl. Etzioni, A. (1969) und Etzioni, A. (1975) i.V.m. Kirsch, K./Trux, W. (1981), 371-384; Kirsch, W. (1991), S. 271ff. und S. 315; Kirsch, W. (1997b), S. 21-24.

${ }^{629}$ Vgl. Wilson, J.Q. (1966).

${ }^{630}$ Vgl. Zaltman, G. u.a. (1973), S. 134-154; Trommsdorff, V./Schneider, P. (1990), S. 15f.; Köhler, R. (1991), S. 159ff; Geschka, H. (1990), S. 163ff. Für eine kritische Diskussion des Ansatzes von Wilson vgl. Thom, N. (1980), S. 305-323; Tebbe, K. (1990), S. 49ff.

${ }^{631}$ Möglichkeiten der Ideen- und Lossungsfindung bieten die verschiedenen Kreativitătstechniken. Eine ausfuhrliche Beschreibung findet sich bei Schlick, G.H. (1995) bzw. Higgins, J.H./Wiese, G.G. (1996). Vgl. auch Bullinger, H.-J. (1996), S. 229-250. 
Neuerung ("the adoption and implementation of the change") erfordert eine weitgehend straffe Organisation, die eine hohe Handlungsfähigkeit gewährleistet.

Die meisten der o.g. Organisationsformen werden in kleinen und mittleren Unternehmen zu einem großen Teil erfullt. ${ }^{632}$ Der vielfach unternehmerzentrierte Aufbau steht einer dezentralen Entscheidungsbildung jedoch entgegen. Die Übertragung von Eigenverantwortlichkeit an die Mitarbeiter, also die Verschiebung von Kompetenz und Verantwortung, wird zugleich als ein Machtverlust interpretiert. Ein partizipativer, kooperativer Führungsstil, über dessen innovationsförderliche Wirkung zu Beginn des Innovationsprozesses in der Literatur weitgehend Einigkeit herrscht, ${ }^{633}$ bedeutet aber gerade nicht, daß die Mitarbeiter nach dem "Laissezfaire"-Prinzip gefuhrt werden, sondern daß sie, dort wo es sinnvoll ist, in die Entscheidungsfindung eingebunden werden. Dem Unternehmer kommt weiterhin die Aufgabe zu, die strategische Ausrichtung vorzugeben, Entscheidungen herbeizuführen und in kritischen Situationen unterstützend einzuspringen. D.h. er fungiert als Koordinator bzw. Promotor des Innovationsprozesses und muß folglich in Abhängigkeit der Situation partizipativ kooperativ oder autoritär entscheiden. Dies verlangt hohes Einfühlungs- und Anpassungsvermögen und folglich eine hohe soziale Kompetenz.

Eigenverantwortlichkeit und Entscheidungspartizipation schaffen Freiräume für die Entwicklung von Kreativität und Initiative und vermindern eventuelle Widerstände der Mitarbeiter gegenüber Neuerungen. Die Übertragung von Verantwortung und das ihnen damit entgegengebrachte Vertrauen verdeutlicht die Wertschätzung ihrer Arbeit. Als Beispiel kann die Mettler-Toledo (Albstadt) $\mathrm{GmbH}$ angefuhrt werden, in der Eigenverantwortung ein wichtiges Teilziel im Rahmen der Mitarbeiterorientierung darstellt. Eigenverantwortung bedeutet hier die weitgehende Selbstgestaltung des Arbeitsprozesses und die selbständige Zusammenstellung der für die Erledigung der Auftäge notwendigen Teams. Grundlage für die Entstehung kontinuierlicher Innovationen ist bei Mettler-Toledo auch die Schaffung von Freiräumen innerhalb des Unternehmens, in denen Lernprozesse gefördert werden. Das Konzept der "Fabrik als Labor" bzw. der "Lernstatt" soll den Mitarbeitern diese Freiräume schaffen, indem sie die Möglichkeit erhalten, Neuerungen auszuprobieren. ${ }^{634}$

${ }^{632}$ Vgl. Anlage 5.

${ }^{633}$ Vgl. Strebel, H. u.a. (1979), S. 78f.; Thom, N. (1980), S. 317f.; Trommsdorff, V./Schneider, P. (1990), S. 15. Zur Beschreibung von Führungssystemen und Führungsstilen vgl. Macharzina, K. (1995); Oechsler, W.A. (1997); Bullinger, H.-J. (1996), S. 113-121.

${ }^{634}$ Die Konzepte verlangen ferner, daß Arbeitsstrukturen von den Mitarbeitern mitgestaltet, d.h. daß Kompetenzen und Verantwortlichkeiten dezentralisiert werden. Die Mitarbeiter haben damit verstärkt die Möglichkeit, bei der Erfullung ihrer Aufgaben eigene Schwerpunkte zu setzen und eigene Problemlösungskonzepte einzubringen. Die gewährten Freiheiten können Wissenspotentiale offenlegen, die durch die Weitergabe der Informationen und der kreativen Kombination des Wissens für das Unternehmen nutzbar gemacht werden. 
Darüber hinaus kommt es darauf an, durch Anreizsysteme ${ }^{635}$ den Werten Innovation, Kreativität und Initiative sowie auch der Toleranz gegenüber Fehlschlägen einen hohen Stellenwert zuzuweisen, um dadurch die Experimentierfreudigkeit anzuregen. Ziel ist der durch das Anreizsystem induzierte, aber letztlich eigenmotivierte Leistungsbeitrag. Analog zu den unterschiedlichen menschlichen Bedürfnissen, die sich grob nach materiellen und immateriellen Bedürfnissen differenzieren lassen, können auch materielle und immaterielle Anreize unterschieden werden. ${ }^{636}$ Materielle Leistungsanreize in Form von Geld- oder Sachprämien sind wesentliche Inhalte z.B. des Betrieblichen Vorschlagswesens, ${ }^{637}$ der qualifikationsorientierten Entlohnung oder des innovationsfördernden Erfolgsbeteiligungssystems. Materiellen Entgeltelementen kommt aber letztlich eine geringere motivationale Bedeutung $\mathrm{zu}$ als den immateriellen Elementen. Innovationsfördernde Anreizsysteme immaterieller Natur sind beispielsweise Maßnahmen der Personalentwicklung. Sie ermöglichen durch den beruflichen Aufstieg die Übernahme höher qualifizierter Tätigkeiten, die zugleich mit einem höheren Ansehen bzw. Image verbunden sind, die letztlich aber auch mit einer höheren materiellen Belohnung verbunden sein können. ${ }^{638}$ Weitere immaterielle Motivatoren zur Leistungssteigerung finden sich in den Arbeitsbedingungen und dem sozialen Gefüge, d.h. den sozialen Beziehungen und den sozialen Einrichtungen. Sie befriedigen insbesondere die sozialen Bedürfnisse sowie das Bedürfnis nach Selbsterfullung und tragen so zur Arbeitszufriedenheit bei, ${ }^{639}$ die eine der Grundlagen innovativen Denkens und Handelns ist.

Insgesamt läßt sich zwar keine optimale innovationsfördernde Organisationsform darstellen, mit der aktiven und bewußten Einbindung der Mitarbeiter in den Innovationsprozeß kann aber ein zusätzliches Innovationspotential erschlossen werden. Die Mitarbeiter sind dazu am Entscheidungsproze $ß \mathrm{zu}$ beteiligen und in die unternehmerische Verantwortung einzubinden. In Verbindung mit einem entsprechenden Anreizsystem und einer offenen Information und Kommunikation wirken diese Komponenten motivierend und letztlich innovationsfördernd.

${ }^{635}$ Betriebliche Anreizsysteme sind bewußt gestaltete Arbeitsbedingungen, die bestimmte Verhaltensweisen durch positive Anreize bzw. Belohnungen verstärken und dadurch die Wahrscheinlichkeit des Auftretens unerwilnschter Verhaltensweisen mindern. Vgl. Becker, F.G. (1991), S. 569 sowie ausfuhrlich Schanz, G. (Hrsg.) (1991).

${ }^{636}$ Die Einteilung menschlicher Bedürfnisse in eine Hierarchie ist auf Maslow zurückzufuhren. Vgl. Maslow, A.H. (1954). Vgl. dazu auch Comelli, G./von Rosenstiel, L. (1995), S. 12f. sowie für einen Überblick über die Kritik an diesem Modell Bullinger, H.-J. (1996), S. 43f.

${ }^{637}$ Das Betriebliche Vorschlagswesen beinhaltet daneben auch immaterielle Komponenten, wie etwa persőnliche Anerkennung, schöpferische Mitarbeit, Arbeitserleichterung und -sicherung. Vgl. zum Betrieblichen Vorschlagswesen und dessen Weiterentwicklung Bullinger, H.-J. (1996), S. 257-279.

${ }^{638}$ Vgl. Becker, F.G. (1991), S. 573-584.

${ }^{639}$ Arthur D. Little (Hrsg.) (1997), S. 280f., spricht in diesem Zusammenhang vom Motivationsfaktor Spaß - neben den Faktoren Geld bzw. Titel, Ruhm und Verantwortung. Arbeit wird quasi als Belohnung betrachtet und setzt dadurch zusătzliche Leistungspotentiale frei. 


\subsubsection{Die Schaffung einer Lernenden Organisation}

Das derzeit breit diskutierte Konzept der Lernenden Organisation ist bestrebt, eine ganze Reihe von Ansätzen unter einem Dach zusammenzuführen, um dadurch das Unternehmen noch wettbewerbsfähiger zu gestalten. ${ }^{640}$ Die große Bedeutung organisationalen Wissens und Lernens bringen NONAKA sowie DE GEUS deutlich zum Ausdruck: "In an economy where the only certainty is uncertainty, the one sure source of lasting competitive advantage is knowledge. ${ }^{1641}$ Und: "The ability to learn faster than your competitors may be the only sustainable competitive advantage. ${ }^{1642}$ Die Generierung, Akkumulation und Diffusion von Wissen und Kompetenz im Unternehmen ist somit die entscheidende Basis bei der Lösung technologischer und organisatorischer Probleme. Auf ihr beruht die Fähigkeit, erfolgreiche Innovationen zu tätigen. ${ }^{643}$

Organisationales Lernen setzt individuelles Lernen voraus. Das individuelle Lernen ist ein Prozeß, in dessen Verlauf sich die Wissensbasis verändert, d.h. Kenntnisse und Wissensstrukturen erworben werden, die entweder zu einer effizienteren Ausführung bekannter Aufgabenstellungen oder zur Erkennung neuer Aufgaben befähigen. Dennoch kann organisationales Lernen nicht als die Summe individueller Lemprozesse betrachtet werden, da einerseits individuelle Wissensbestandteile vorhanden sind, die der Organisation weder bekannt noch zugänglich sind, und da andererseits Organisationen über Wissensbestandteile verfügen, die bei den einzelnen Individuen nicht mehr vorhanden sind ("überdauerndes Gedächtnis des Unternehmens"). Nach PROBST UND BÜCHEL stellt organisationales Lemen somit "eine unternehmenseigene Größe" dar, die sich quantitativ und qualitativ von der Summe des individuellen Lernens unterscheidet. ${ }^{644}$ Sie definieren organisationales Lernen als einen "Prozeß der Erhöhung und Veränderung der organisationalen Wert- und Wissensbasis, die Verbesserung der Problemlösungs- und Handlungskompetenz sowie die Veränderung des gemeinsamen Bezugsrahmens von und für Mitglieder innerhalb der Organisation" ${ }^{1645}$.

${ }^{640}$ Einen ausführlichen Überblick bieten u.a. Probst, G.J.B./Büchel, B. (1994); Bullinger, H.-J. (Hrsg.) (1996); Sattelberger, T. (Hrsg.) (1996); Sonntag, K. (1996); Wildemann H. (Hrsg.) (1996); Dr. Wieselhuber \& Partner (Hrsg.) (1997).

${ }^{641}$ Nonaka, I. (1991), S. 96.

${ }^{642}$ De Geus, A.P. (1988), S. 71.

${ }^{643}$ Vgl. von Hayek, F.A. (1969), S. 251; Dosi, G. (1988), S. 1163. Auf die grundsătzliche Bedeutung der Information und der Verwertung des Wissens in der Gesellschaft hat von Hayek bereits fruher hingewiesen. Vgl. von Hayek, F.A. (1945).

${ }^{644}$ Vgl. Probst, G.J.B./Büchel, B. (1994), S. 18; Zahn, E. (1996), S. 47. Vgl. ferner Argyris, C./Schön, D.A. (1978), S. 20.

${ }^{645}$ Probst, G.J.B./Büchel, B. (1994), S. 17. Eine mehr innovations- bzw. wettbewerbsorientierte Definition findet sich bei Miller, A./Dess, G.G. (1996), S. 371: "Organizational learning is the combination of discovering new things and acting in new ways that allows an organization to adapt to changes and thereby sustain or improve competitiveness". Vgl. ferner die bei Garvin, D.A. (1993), S. 80 angefuhrten Definitionen. 
Organisationales Lernen kann sich auf verschiedenen Ebenen vollziehen. Zur Verdeutlichung der unterschiedlichen Lernniveaus differenzieren ARGYRIS UND SCHÖN ${ }^{646}$ :

- Single-Loop-Learning (Anpassungs- bzw. Verbesserungslernen) beschreibt einen Lernvorgang, bei dem die Organisationsmitglieder auf interne und externe Abweichungen reagieren, indem sie die Fehlerquelle identifizieren und beseitigen, so daß sich das System wieder im Einklang mit der vorgegebenen Norm befindet. Es findet also eine Bewegung innerhalb der durch die Handlungsmuster vorgegebenen Grenzen statt.

- Double-Loop-Learning (Veränderungs- bzw. Erneuerungslernen) bedeutet das Infragestellen des organisationalen Bezugsrahmens. Sofern die für die Bewältigung des Problems vorgegebenen Werte und Normen nicht adäquat sind, eröffnet das Hinterfragen der Wertvorstellungen und Normen und deren daraus resultierende Anpassung wieder einen angemessenen Handlungsrahmen. DoubleLoop-Learning stellt das Lernen auf einer höheren Ebene und somit das eigentliche organisationale Lernen dar.

- Deutero-Learning (Prozeßlernen bzw. Lernen des Lernens) beinhaltet die Verbesserung der Lemfähigkeit dadurch, daß das Lernen selbst zum Gegenstand des Lernens wird. Dies bedeutet "die Analyse bisheriger Lernvorgänge, die Identifikation von Erfolgen und Mißerfolgen, das Beseitigen von Lernbarrieren und die Förderung der organisationalen Lernfähigkeit" ${ }^{647}$ und damit das Einschwenken in einen zyklischen Lemprozeß.

Das erfolgreiche Handhaben und zielfuhrende Steuern dieser Lernzyklen im Unternehmen setzt den Umbau des Unternehmens in eine Lernende Organisation voraus. Ein Unternehmen stellt dann eine Lernende Organisation dar, wenn es die Fähigkeit besitzt, Wissen zu schaffen, zu erwerben und weiterzugeben sowie sein Verhalten aufgrund des neuen Wissens zu verändern. ${ }^{648}$ Das Unternehmen dehnt damit beständig seine Fähigkeit aus, die eigene Zukunft zu gestalten.

Für die Initiierung von Lernprozessen im Unternehmen müssen eine Reihe von Bedingungen geschaffen werden, zu deren Verwirklichung größtenteils auf Instrumente und Konzepte zurückgegriffen werden kann, die auch an anderer Stelle zum Tragen kommen. WILdEMANN hebt in diesem Zusammenhang vor allem die Bedeutung der Konzentration auf Kernkompe-

${ }^{646}$ Vgl. Argyris, C. (1977), S. 116f.; Argyris, C./Schön, D.A. (1978), S. 18-29. Vgl. dazu ferner Probst, G.J.B./Büchel, B. (1994), S. 35-39; Zahn, E. (1996), S. 53-56.

${ }^{647}$ Zahn, E. (1996), S. 55.

${ }^{648}$ Vgl. Garvin, D.A. (1993), S. 80. Eine mitarbeiterorientierte Sichtweise vertritt Senge, der Lernende Organisationen als Organisationen betrachtet "where people continually expand their capacity to create the results they truly desire, where new and expansive patterns of thinking are nurtured, where collective aspiration is set free, and where people are continually learning how to learn together". Senge, P.M. (1990), S. 3. 
tenzen, das Lernen vom Besten (Benchmarking), den Lerntransfer durch Visualisierung und Auditierung sowie eine auf Intrapreneurship abgestellte Führung hervor. ${ }^{649}$ Kernkompetenzen resultieren aus einer bestimmten Kombination von Fähigkeiten und Technologien, die durch eine hohe Wettbewerbswirksamkeit auf den Märkten und einen großen Wettbewerbsvorteil gegenüber den Wettbewerbern gekennzeichnet sind. Ihre Identifikation und ihr Ausbau stellen einen Lernprozeß dar, dessen zentraler Inhalt die Erzeugung eng auf die Kundenwünsche zugeschnittener Problemlösungen ist. Wesentlich ist dabei der intensive Austausch mit den Kunden, um daraus zukünftige Anforderungen abzuleiten. Eine weitere Facette des Lernprozesses stellt der Austausch mit anerkannten Benchmarks dar. Das Lernen von Unternehmen, die Bestleistungen bei der Herstellung von Produkten, der Beherrschung von Prozessen oder der Bereitstellung von Dienstleistungen erbringen, ermöglicht das Schließen eigener Leistungslücken. Neben den Lernprozessen, die aus Informationen von bzw. der Kommunikation mit externen Quellen angestoßen werden, sind auch im Unternehmen selbst geeignete Voraussetzungen zu schaffen. Darin eingeschlossen ist eine Verbesserung der internen Informationsund Kommunikationsstrukturen sowie auch eine Verbesserung der Humanressourcenbasis, die aber über reine Qualifizierungsmaßnahmen im Zuge der Personalentwicklung hinausgehen muß. Als ein geeignetes Konzept schlägt WILDEMANN hierfür die Visualisierung und gegenseitige Auditierung vor. Visualisierung bedeutet in diesem Zusammenhang, daß sowohl die Kundenanforderungen als auch die Leistungsbeiträge eines jeden einzelnen transparent gemacht werden. Das damit verfolgte Ziel ist die Zunahme der Identifikation der Mitarbeiter mit dem Unternehmen sowie der Motivation zur Zielerreichung und kontinuierlichen Verbesserung. Die Auditierung als Führungsinstrument geht über deren Nutzung als Qualitätssicherungs- oder Lieferantenbewertungsinstrument hinaus. Sie soll Daten über den Fortgang der Verbesserungsprozesse liefern sowie eine Beurteilung der Kundenzufriedenheit ermöglichen. In Verbindung mit der Visualisierung soll dadurch ein interner Markt für Innovationen geschaffen werden. Dieses Bestreben wird ferner durch eine auf Intrapreneurship abgestellte Führung unterstützt. Die wesentlichen Inhalte sind die Partizipation der Mitarbeiter bei der Festlegung von Aufgabeninhalten und Zielvereinbarungen, ${ }^{650}$ die Einbindung in Verantwortung und Risiko sowie die Förderung von Gruppen- und Teamarbeit. Intention der stark auf die Mitarbeiter ausgerichteten Führung ist die Entwicklung unternehmerisch denkender und

${ }^{649}$ Vgl. auch im folgenden Wildemann, H. (1995); Wildemann, H. (1996a), (1996b) und (1996c). Vgl. dazu ferner Garvin, D.A. (1993), S. 81-89, der funf Bereiche herausstellt, die eine Lernende Organisation charakterisieren: systematische Problemlø̈sung, experimentieren mit neuen Ansätzen, lernen aus der eigenen Erfahrung und von Benchmarks sowie schneller und effizienter Transfer des Wissens im gesamten Unternehmen. Vgl. ferner Sommerlatte, T. (1990); Gibb, A.A. (1997).

${ }^{650}$ Damit verbunden ist auch eine Veränderung des Entlohnungskonzeptes, d.h. eine Flexibilisierung, die die unterschiedlichen Zielerreichungsgrade berücksichtigt. Anders als bei der Zielvorgabe ist bei einer gemeinsamen Zielvereinbarung mit einer höheren Motivation der Mitarbeiter zu rechnen, da sie selbst an der Festlegung der entgeltrelevanten Leistungen beteiligt sind. 
handelnder Mitarbeiter (Intrapreneure). ${ }^{651}$ Die Verwirklichung einer Lernenden Organisation zieht somit den Nutzen aus den individuellen Qualifikationen und Kompetenzen der Organisationsmitglieder, indem deren Fähigkeiten kombiniert mit denen des Unternehmens zu schwer imitierbaren Kernkompetenzen ausgebaut werden.

Die Vorzüge des Ansatzes von WILDEMANN liegen darin, daß auf bekannte und im Rahmen der Unternehmensführung vielfach eingesetzte Instrumente und Konzepte zurückgegriffen wird. Dies erleichtert den ersten Schritt in Richtung auf ein Lernendes Unternehmen. Der zweite Schritt wäre die Integration der Einzelkomponenten in ein in sich geschlossenes Konzept. Dieser Schritt wird jedoch nicht vollzogen. Die aufgezeigten Instrumente und Konzepte bleiben weitgehend isoliert nebeneinander stehen, ohne daß eine Verzahnung erfolgt, die eine handlungsorientierte Umsetzung des Konzeptes erlaubt. Als ein Schritt in diese Richtung kann der Ansatz von SENGE betrachtet werden. Er entwickelte eine mehrdimensionale Theorie organisationalen Lernens, bei der er fünf Disziplinen unterscheidet, deren Zusammenwirken die erfolgreiche Realisierung organisationalen Lernens ermöglichen. ${ }^{652}$

\section{Abb. 4-9: Die funf Disziplinen nach SENGE}

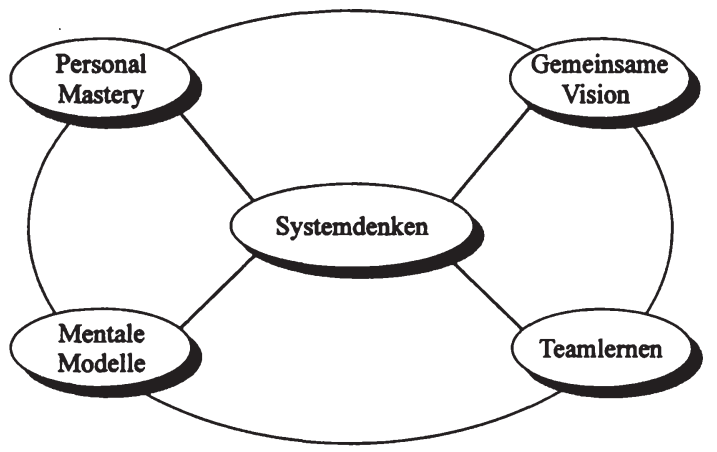

${ }^{651}$ Zur Unterstützung dieser Entwicklung konnen weitere Konzepte, wie beispielsweise das Lernstatt-Konzept, die Fabrik als Labor oder die Produktklinik herangezogen werden. Durch sie sollen Freirăume geschaffen werden, um eigene Ideen auszuprobieren (Lernstatt, Fabrik als Labor), bzw. um eine Auseinandersetzung mit konkreten Losungen (der Wettbewerber) zu ermőglichen (Produktklinik). Bullinger und Zinser gehen einen Schritt weiter. Teams oder Gruppen sind nicht auf das Unternehmen zu beschränken, sondern in netzwerkorientierte Organisationsstrukturen uber das Unternehmen hinaus einzubinden. Dieses Netzwerk besteht aus Mitarbeitern, Lieferanten, Kunden, weiteren Dienstleistern und Wettbewerbern, deren gemeinsames Ziel die Herstellung eines Produktes ist, das die Kundenanforderungen erfullt. Vgl. Bullinger, H.-J./Zinser, S. (1997), S. 20ff. Vgl. ferner Warnecke, H.-J. (1996).

${ }^{652}$ Vgl. Senge, P.M. (1990); Senge, P.M. u.a. (1994). Vgl. ferner Senge, P.M./Scharmer, C.O. (1996); Arthur D. Little (Hrsg.) (1997), S. 327-331. Senge spricht von Disziplinen, da hiermit bewußt gemacht werden soll, daß Lernen ein lebenslanger, nie endender Prozeß ist. Die hier vorgenommene Darstellung kann den Ansatz lediglich in groben Zügen wiedergeben. Für eine intensive Betrachtung sei daher auf die vorstehende Originalliteratur verwiesen. Eine kritische Würdigung findet sich bei Fassbender, P. (1997). 
Das zentrale, verbindende Element bei der Realisierung einer Lernenden Organisation ist die Fähigkeit, in Systemzusammenhängen zu denken, d.h. das kategoriale Verständnis von Unternehmensstrukturen zu verlassen und verstärkt den Fokus auf die Wechselbeziehungen und Veränderungsprozesse im Unternehmen zu legen, also das Ganze zu betrachten. Die Unternehmensvision liefert dafür das Bezugssystem. Das Hinarbeiten auf diese Vision bindet und verbindet die Mitarbeiter zugleich, es entwickelt sich ein Wir-Gefühl, aus dem selbstmotiviertes Denken und Handeln resultiert. Dadurch wird die Teambildung erleichtert und die Bereitschaft gefördert, gemeinsam ein Ergebnis erreichen zu wollen. Dies setzt den Dialog voraus, d.h. u.U. eigene Positionen zugunsten gemeinsamer aufzugeben. Eine Barriere bei der Umsetzung der Vision können mentale Modelle sein. Mentale Modelle sind tief verwurzelte persönliche Wertvorstellungen und Annahmen über Zusammenhänge, die einen spezifischen Kontext bilden. Aufgrund dieses Kontextes entstehen bestimmte Erwartungen, die großen Einfluß auf die Wahrnehmung des Umfeldes bzw. des Handelns haben. Erst wenn die durch die individuellen Normen und Werte entstandenen mentalen Modelle nicht mehr im Widerspruch zur gemeinsamen (Unternehmens-) Vision stehen, ist die wichtigste Voraussetzung der Personal Mastery geschaffen. Personal Mastery bedeutet das ständige Klären der eigenen Vision und die Entwicklung der eigenen Persönlichkeit, um einen bestimmten Grad an Professionalität zu erzielen. Sind also die eigenen Ziele vereinbar mit denen des Unternehmens, ist die innere Bereitschaft geschaffen, "sich unter Anstrengung persönlich im und mit dem Unternehmen zu entwickeln. Erst mit dieser Bereitschaft fallen Weiterbildungsmaßnahmen auf fruchtbaren Boden." 653

In kleinen und mittleren Unternehmen bestehen zumindest grundsätzlich günstige Bedingungen für die Verwirklichung einer Lernenden Organisation. Die Unternehmensgröße erleichtert ein Denken in Systemzusammenhängen, da durch die Überschaubarkeit der Prozesse die Leistungen des Einzelnen und dessen Anteil am Ganzen nachvollzogen und Wechselbeziehungen direkt wahrgenommen werden können. Die sichtbare Wirkung einer Handlung endet nicht an Abteilungsgrenzen und beschränkt sich damit auf einen Ausschnitt, sondern kann in ihrer ganzen Breite und Tiefe als Veränderungsprozeß nachvollzogen werden. Daraus resultiert eine enge Einbindung des Einzelnen in die Organisation, die zum einen die Kommunikation sowie das Verfolgen einer gemeinsamen Unternehmensvision begünstigt und zum anderen die Möglichkeit bietet, sich verstärkt einzubringen. ${ }^{654}$

In den Reihen der untersuchten Unternehmen in der Region Neckar-Alb findet sich kein Unternehmen, das diesen Idealzustand erreicht hat. Dies kann jedoch auch nicht erwartet werden, da sich das vergleichbar "neue" Konzept der Lernenden Organisation in seiner Ge-

${ }_{653}$ Arthur D. Little (Hrsg.) (1997), S. 329.

${ }^{654}$ Ansätze zur Realisierung einer Lernenden Organisation in den Unternehmen der untersuchten Region zeigen sich z.B. bei der Bizerba GmbH \& Co. KG, Werk Balingen. Vgl. dazu auch Weger, H.-J. (1995); Böttler, E. (1997). Vgl. ferner Klinger, H.J. (1997). 
samtheit erst noch durchsetzen und nachhaltig unter Beweis stellen muß. Für die einzelnen Komponenten (Disziplinen) des Konzeptes gilt dies nicht. Sie stehen bereits länger in der Diskussion und über ihre positiven Wirkungen herrscht weitgehend Konsens. Doch auch hier zeigt sich in kleinen und mittleren Unternehmen deutlicher Nachholbedarf. Hervorzuheben aus der Untersuchungsregion sind allerdings die Unternehmen Bizerba und Mettler-Toledo, die an den einzelnen Komponenten arbeiten und bereits ein gutes Wegstück zum Erreichen des Idealzustands zurückgelegt haben. Insgesamt zeigt sich aber, daß vor allem die Mitarbeiter als wesentliche Ressource erst von einem Teil der Unternehmen vollständig erkannt und entsprechend gefördert werden. Deutlich wird dies in einer hinter dem festgestellten Qualifikationsbedarf zurückbleibenden Rate an Weiterbildungsmaßnahmen und einer nachrangigen Einschätzung der Mitarbeiter als innovationsrelvante Informationsquelle. ${ }^{655}$ Daneben ist auch nur bei wenigen Unternehmen erkennbar, daß durch die Schaffung von Freiräumen, die zu explorierendem Verhalten anregen, und durch breit gefächerte Informations- und Kommunikationsmöglichkeiten die Innovativität gefördert wird. Dies ist wohl auch auf das weitgehende Fehlen einer verbindenden Vision (Philosophie) zurückzuführen, die u.a. die Innovations- und die Lernbereitschaft als zentrale Gestaltungsparameter beinhaltet.

Zusammenfassend ist erkennbar, daß durch die enge Verbindung von Innovations- und Lernbereitschaft das Schaffen eines innovativen Umfeldes bzw. das Schaffen eines Lernenden Unternehmens wichtige Zwischenschritte bei der Steigerung der Innovativität sind. Soll Innovativität des Unternehmens auf diesem Weg gesteigert werden, ist erneut auf die Forderung zurückzukommen, daß von seiten des Unternehmers bzw. der Unternehmensführung die entscheidenden Impulse ausgehen müssen.

${ }^{655}$ Wie in Abschnitt 4.3.3.1 aufgezeigt, weisen 80,3\% der befragten Unternehmen einen Qualifikationsbedarf aus, aber nur 70,8\% der Unternehmen betreiben betriebliche Weiterbildung, wobei in beiden Fällen deutliche Unterschiede zwischen den beiden Erfolgstypen erkennbar sind. Darüber hinaus zeigt sich bei der Betrachtung der Qualifikationsstruktur in den Unternehmen (vgl. Frage 1/4 des Fragebogens sowie Anlage 19), daß mit steigender Unternehmensgröße sowohl das Qualifikationsniveau als auch die Bereitschaft steigt, Ausbildung zu betreiben. 


\subsection{Innovationsziele}

\subsubsection{Die Bildung von Innovationszielen}

Innovationszielen wird in der Entscheidungstheorie kein eigener Platz eingeräumt, da sie als Spezialfälle von Entscheidungen gelten. Zwar entspricht auch das nachfolgend angedeutete Zielsystem nicht den Anforderungen der Entscheidungstheorie. Die zentrale Bedeutung der Innovation für den Unternehmenserfolg sowie ihre Komplexität rechtfertigen es allerdings, die Entwicklung von Zielen für innovative Problemstellungen als eine eigenständige Aufgabe der Unternehmensfuhrung im Innovationsprozeß zu betrachten. ${ }^{656}$ In Abschnitt 3.5.1 wurden Ziele als in der Zukunft liegende Zustände bezeichnet, die nach Inhalt, Ausmaß und Zeitbezug spezifiziert werden können. So kann beispielsweise beim Umsatz, Gewinn oder Marktanteil von einem quantifizierbaren Ausgangszustand aus ein gewünschter Endzustand formuliert werden. Dies ist bei Innovationen wegen ihres Neuigkeitsgehaltes nur schwer möglich. Im Rahmen der gewählten Definition gibt es strenggenommen keine Innovationsziele, da diese nicht hinreichend operationalisiert werden können. Eine Operationalisierung ist jedoch notwendig, um eine Steuerungsfunktion erfulllen zu können. Deshalb ist die Definition dahingehend zu erweitern, daß die Zielbildung ebenso wie die Innovation als evolutorischer Prozeß zu betrachten ist. Innovationsziele liegen also auch dann vor, wenn sie den Endzustand a priori nicht eindeutig spezifizieren und daher im Evolutionsprozeß ihre Revision notwendig wird. Dies impliziert ferner eine Parallelisierung von Ziel- und Strategienbildung, wodurch - zumindest im Fall der Innovation - davon abgewichen werden muß, daß die Zielbildung im wesentlichen vor der Strategiebildung stattfindet. ${ }^{657}$

Der Bildung von Zielen in der Produkt- und Prozeßentwicklung liegen äußerst komplexe Probleme zugrunde, die hinsichtlich ihrer sachlichen Struktur und zeitlichen Entwicklung unklar und ungewiß sind. Innovationziele müssen folglich Komponenten enthalten, die eine Zielanpassung im Evolutionsprozeß ermöglichen. Möglich wird dies durch Verwendung von Nutzenkomponenten, wie etwa dem Oberziel "Steigerung des Kundennutzens", das beispielsweise mit Hilfe der Unterziele "Verbreiterung der Anwendungsmöglichkeiten", "Erhöhung des Bedienungskomforts", "Reduktion des Energieverbrauchs beim Einsatz", "Wiederverwertbarkeit nach Gebrauch" etc. zwar näher spezifiziert, letztlich aber nicht präzise quantifiziert werden kann. Da hier lediglich ein "Mehr" oder "Weniger" zum Ausdruck kommt, wird ebenfalls deutlich, daß Innovationsziele ordinal skaliert sind, während sich technische und wirtschaftliche Ziele weitgehend kardinal skalieren lassen. Aber auch bei Verwendung einer Or-

\footnotetext{
${ }^{656}$ Vgl. Hauschildt, J. (1997), S. 273. Hauschildt führt die Komplexităt von Innovationszielen auf drei Ursachen zurück, die Unklarheit der Problemstruktur, die Unübersehbarkeit der Problemkomponenten sowie das Entstehen andersartiger Konflikte. Vgl. auch im folgenden Hauschildt, J. (1977); Hauschildt, J. (1997), S. 273292.

${ }^{657}$ Vgl. dazu auch FN 370.
} 
dinalskala ergeben sich unterschiedliche Ebenen, die eine erste Ordnung herbeiführen, einen Vergleich ermöglichen und eine grobe Zielrichtung angeben. Wesentlich bei der Formulierung von Innovationszielen ist daher die Berücksichtigung von Freiheitsgraden, die die Handlungsautonomie im Innovationsprozeß aufrechterhalten. Mit fortschreitendem Grad des Entwicklungsprozesses kann dann auch der Detaillierungsgrad des Zielsystems zunehmen, "bis hin zum detaillierten Pflichtenheft, das die Realisierungsphase der Produkt- und Prozeßentwicklung begleitet" ${ }^{158}$.

\subsubsection{Innovation im Zielsystem der Unternehmen}

Der vorangegangene Abschnitt verdeutlicht die Problematik, daß Innovationsziele - anders als ökonomische oder auch ökologische Unternehmensziele - a priori nur schwer operationalisiert werden können. Dadurch wird auch die empirische Erfassung von Innovationszielen erschwert. Angesichts dieser Tatsache mußte von einer expliziten Erfassung von Innovationszielen in der zugrundeliegenden Untersuchung abgesehen werden. ${ }^{659} \mathrm{Um}$ dennoch Anhaltspunkte über die Intention der Innovationsbemühungen zu erhalten, wird auf die Unternehmensziele i.V.m. den geäußerten Beweggründen für die getätigten Innovationen zurückgegriffen. ${ }^{660}$

Bei näherer Betrachtung der Unternehmensziele (vgl. Tab. 3-5 in Abschnitt 3.5.3) zeigt sich, daß die hier befragten Unternehmen innovationsorientierten Zielen einen hohen Stellenwert einräumen. Bereits dicht auf die Unternehmensziele "Sicherung der Wettbewerbsfähigkeit" und "langfristige Gewinnerzielung" folgen die Ziele "Kosteneinsparungen" und "Produktivitätssteigerungen" sowie mit etwas Abstand das Ziel "Erschließung neuer Märkte". Eine direkte Verbindung dieser Ziele zur Innovation kann zum einen dadurch hergestellt werden, daß die Verwirklichung von Kosteneinsparungen und Produktivitätssteigerungen die Veränderung von Produktionsprozessen oder der Produkte selbst voraussetzt und die Erschließung neuer Märkte bereits direkt auf die Innovation hinweist. Zum anderen ergibt sich eine Verbindung daraus, daß diese Ziele auch bei der Begründung für die Einführung von Innovationen eine

${ }^{658}$ Specht, G./Beckmann, C. (1996), S. 125. Die Autoren greifen bei der Systematisierung von Objektzielen auf das Konzept des Produktlebenszyklus zurück und verdeutlichen dies am Beispiel der Qualităt. "Qualität i.w.S. zielt auf einen moglichst hohen Grad der grundsătzlichen Anforderungserfullung aller Lebensphasen; Qualităt i.e.S. [Zuverlăssigkeit, der Verf.] richtet sich bei gegebener grundsătzlicher Erfullung auf die Minimierung von Funktionsausfallen und Leistungsminderungen in jeder einzelnen Lebensphase. Des weiteren lassen sich Produkt- und Prozeßziele auch aus Innovativităts-, Kosten- und Zeitanforderungen der individuellen Lebensphasen ableiten." Specht, G./Beckmann, C. (1996), S. 128.

${ }^{659}$ In diesem Umstand liegt wohl u.a. auch die Begrulndung dafür, daß Innovationsziele im Rahmen der empirischen Zielforschung ausgeklammert sind. Die explizite Erfassung von Innovationszielen in der zugrundeliegenden Untersuchung hătte eine umfangreiche Erweiterung des Fragebogens notwendig gemacht. Damit wäre aber auch eine weitere Ausdehnung der Bearbeitungszeit des Fragebogens durch den Befragten verbunden gewesen. Aufgrund der in vergleichbaren Untersuchungen am EFLR gemachten Erfahrungen hätte eine Ausweitung der Fragen unverhăltnismäßig hohe Einbußen beim Rücklauf nach sich gezogen. Deshalb wurde von der expliziten Erfassung der Innovationsziele abgesehen.

${ }^{660} \mathrm{Vgl}$. Frage 4/1 i.V.m. Frage 3/5 des Fragebogens im Anhang und ferner die Ergebnisse in Tab. 3-5 und in Anlage 13 i.V.m. Anlage 25. 
wichtige Rolle spielen. Mit einem deutlichen Abstand werden Kostensenkungspotentiale (76,9\%), Verbesserung der Produktqualität (69,2\%) und Absatzchancen (59,8\%) als Begründung für Innovationen benannt. ${ }^{661}$

Die Erschließung neuer Märkte wird hingegen nicht als wesentlicher Innovationsgrund eingeschätzt (29,9\%). Zurückzuführen ist dies darauf, daß auch die Produkt-Markt-Strategien der Markterweiterung bzw. Diversifikation mit einer geringeren Intensität verfolgt werden als die Strategie der Marktdurchdringung oder der Produkterweiterung (vgl. Abschnitt 3.6.3.1).

Die vorstehenden Ausführungen zeigen, daß die Formulierung von Innovationszielen als ein eigenständiger Prozeß im Rahmen der Unternehmensführung zu betrachten ist. Da dieser Prozeß aber von einer immensen Komplexität geprägt ist, wird er sowohl auf der theoretischen wie auch auf der praktischen Ebene weitgehend ausgeklammert. Hier besteht somit eine Lükke, die es zu schließen gilt.

\subsection{Innovationsstrategien}

\subsubsection{Ansătze zur Ableitung von Innovationsstrategien}

Der technische Fortschritt beeinflußt maßgeblich die Wettbewerbsposition eines Unternehmens. Dem Unternehmen muß daher bewußt werden, welcher Veränderungsdynamik die eingesetzten Technologien und die hergestellten Produkte unterliegen. Zur herausragendsten Aufgabe des Innovationsmanagements gehört die Suche nach, die Identifikation sowie die anschließende Optimierung von neuen Produkten oder Produktionsprozessen. Strategisches Innovationsmanagement hat darüber hinaus das Ziel, das Unternehmen und seine Potentiale an sich ändernde Bedingungen und Anforderungen des Umfeldes anzupassen oder durch eigene Gestaltung sein unmittelbares bzw. relevantes Umfeld zu beeinflussen. Soll also der Unternehmenserfolg nicht dem Zufall überlassen werden, ist der Einsatz zielgerichteter Strategien erforderlich.

Für die Entwicklung einer geeigneten Innovationsstrategie eines Unternehmens bedarf es der folgenden beiden Voraussetzungen:

${ }^{661}$ Vgl. dazu ausfuhrlich Anlage 25. Hervorzuheben ist dabei insbesondere das Ergebnis, daß mit steigender Unternehmensgröße eine Verringerung des Ressourcen- oder Materialverbrauchs als Innovationsbegrinndung signifikant an Bedeutung zunimmt: Sig. Betriebsgrőßenklasse: 0,002 bzw. Sig. Umsatzgrößenklasse: 0,013. 
- Das Unternehmen muß die Fähigkeit besitzen, die Notwendigkeit für einen Wechsel seiner Produkte bzw. seiner Technologiebasis wahrzunehmen.

- Das Unternehmen muß die Fähigkeit und den Willen besitzen, den wahrgenommenen Veränderungsbedarf auch umzusetzen.

Grundlage dieser beiden Komponenten ist das Vorliegen adäquater Informationen, d.h. eine aktive Nutzung innovationsrelevanter Informationsquellen für das rechtzeitige und richtige Erkennen von Bedarfsentwicklungen und Nachfragepotentialen sowie eine Analyse der externen und internen Bedingungen, die die Stärken und Schwächen, d.h. die unternehmenseigenen Potentiale offenbaren. Darauf aufbauend lassen sich dann konsequente Innovationsstrategien entwickeln.

In der Literatur findet sich eine ganze Reihe von Ansätzen zur Formulierung von Innovationsstrategien, die einen Bezug zwischen wettbewerbs- und innovationsstrategischen Sachverhalten herzustellen versuchen. ${ }^{662}$ Bei diesen Ansätzen gilt es jedoch zweierlei zu beachten: Aufgrund des Versuchs, die Komplexität der Realität zu reduzieren, berücksichtigt keiner der Ansätze sämtliche innovationsstrategische Optionen. Darüber hinaus ist es kaum möglich, die differenten Strategieempfehlungen voneinander abzugrenzen. Eine detaillierte Diskussion der einzelnen Ansătze würde den Rahmen dieser Arbeit sprengen. Aus diesem Grund werden nachfolgend lediglich die wesentlichen Gemeinsamkeiten aufgezeigt. Für eine ausführliche und kritische Darstellung wird daher auf WOLFRUM verwiesen. ${ }^{663}$

Zunächst können zwei generelle strategische Alternativenpaare unterschieden werden. Das erste Alternativenpaar orientiert sich daran, von welcher Marktseite der Antrieb für die Innovation ausgeht. Bei der Push-Strategie (market-push) kommt der Antrieb für die Innovation von seiten des Unternehmens, d.h. z.B. aus der eigenen Forschung und Entwicklung. Entsprechend muß furr die Innovation (Produkt oder Verfahren) erst ein neuer Markt oder Anwendungsbereich (ein Bedarf) geschaffen werden. Kommt der Antrieb für die Innovation aus dem Markt, liegt eine Pull-Strategie (market-pull) vor. Der Bedarf existiert bereits und kann durch ein neues Produkt oder Verfahren gedeckt werden. Im Rahmen des zweiten Alternativenpaars wird nach dem Maß der Eigenständigkeit differenziert, mit dem die Innovation durchgefuihrt

${ }^{662}$ Vgl. z.B. Ansoff, H.I./Stewart, J.M. (1967), S. 81 ff.; Maidique, M.A./Patch, P. (1982), S. 276f.; Freeman, C. (1982), S. 169-186 und Freeman, C./Soete, L. (1997), S. 265-285; Zörgiebel, W.W. (1983), S. 206-212 erweitert durch Specht, G./Zörgiebel, W.W. (1985), S. 494-511; Porter, M.E. (1980) erweitert durch Servatius, H.-G. (1985), S. 106-111; Zahn, E. (1986), S. 35-43.

Im Gegensatz dazu wăhlt z.B. Weidler, A. (1997) eine nach innen gerichtete Vorgehensweise bei der Formulierung von Innovationsstrategien, indem er Innovationsstrategien aus dem Zusammenspiel von technischen, ${ }^{6}$ organisationalen und geschăftsbezogenen
${ }^{6 g l}$. Wolfrum, B. (1994b), S. 253-270. 
wird. Die Extreme bewegen sich hier zwischen der Eigenentwicklung und dem Fremdbezug der notwendigen Technologien. Einen Sonderfall stellt die Kooperationsstrategie ${ }^{664}$ dar. $^{665}$

Darüber hinaus zeichnen sich im wesentlichen sechs Innovationsstrategien ab, die jeweils auf Produkt- und Prozeßinnovationen gerichtet sein können.

Die offensive Innovationsstrategie zielt auf die Marktführerschaft ab. Das Unternehmen versucht als Pionier (first-to-market) grundlegende Neuerungen zu entwickeln, um dadurch eine Vorreiterrolle zu übernehmen sowie ein temporäres Quasimonopol aufzubauen. Bei dieser sehr risikoreichen Strategie spielt aufgrund der Forschungsintensität der F\&E-Bereich eine Schlüsselrolle. Zusätzlich ergänzt werden müssen die weitreichenden F\&E-Kompetenzen durch eine ausgeprägte Kommunikation mit internen und externen Quellen, um so den technischen Fortschritt selbst gestalten zu können.

Mit einer aktiven Innovationsstrategie (fruher Nachfolger; follow-the-leader) sucht das Unternehmen zwar auch permanent nach Neuerungen, stellt aber nicht den Anspruch, eine Vorreiterrolle zu übernehmen. Ziel ist eher die anwendungsbezogene Weiterentwicklung bereits im Markt eingefuhrter Produkte, wodurch sowohl aus den Fehlern der Pionierunternehmen gelernt als auch das Risiko der eigenen Produkt- oder Verfahrensentwicklung reduziert werden kann. Diese Strategie erfordert folglich eine hohe Flexibilität und Reaktionsfähigkeit im Entwicklungsbereich.

Im Zuge einer reaktiven Innovationsstrategie erfolgt keine aktive eigenständige Suche nach Produkt- oder Verfahrensinnovationen, sondern ein bewußtes, zeitversetztes Nachfolgen hinter den Innovatoren. Die Adaption erfolgt erst, wenn die Funktionsweise bzw. die Wirtschaftlichkeit der Innovationen gesichert ist. Wie schon bei der aktiven Innovationsstrategie erfordert auch dieser Strategietyp hohe Flexibilität und Reaktionsfähigkeit im Entwicklungsbereich, um den Wettbewerbern keinen allzu großen Vorsprung zu gewähren.

Im Vordergrund einer imitativen Innovationsstrategie (late-to-market; me-too) steht die Imitation erfolgreicher Neuerungen und ihre möglichst kostengünstige Produktion, sobald sich das Risiko vermindert hat. Durch die Imitation weitgehend ausgereifter Produkte und Verfahren lassen sich vor allem die Kosten für F\&E, Patente und Schulungen sowie für den Service reduzieren. Damit die Kostenvorteile der Imitation ausgenutzt werden können, ist der Aufbau

\footnotetext{
${ }^{664}$ Vgl. insb. Zahn, E. (1986), S. 40-43. Zahn bezieht in diese Betrachtung sowohl Möglichkeiten des externen Bezugs technologischen Wissens, wie beispielsweise Lizenznahme, Technologiekauf oder verschiedene Formen strategischer Allianzen (z.B. Venture Management), als auch Möglichkeiten der alternativen Verwertung von Technologien, wie beispielsweise Lizenzvergabe oder Technologieverkauf, ein.

${ }^{665}$ Bei den untersuchten Unternehmen wird die Einführung von Innovationen (insb. die Entwicklungsarbeit) überwiegend eigenständig ausgeführt (besonders erfolgreiche Unternehmen: 82,7\%; übrige: $75,8 \%$ ). Kooperationen z.B. mit anderen Unternehmen gehen lediglich $25,5 \%$ der besonders erfolgreichen Unternehmen und $15,6 \%$ der weniger erfolgreichen Unternehmen ein (vgl. Anlage 26).
} 
kapitalintensiver, großvolumiger Produktionssysteme notwendig. Hierin liegt auch das besondere Risiko, da bei technischem Fortschritt bzw. Produktwechsel die Produktionssysteme schnell obsolet werden können.

Unternehmen, die eine passive Innovationsstrategie verfolgen, richten ihre Innovationen strikt an den Anforderungen der Abnehmer aus (application engineering). Hinsichtlich der Entwicklungsintensität gehen hier die Meinungen in der Literatur auseinander. Während ANSOFF UND STEWART noch "substantial product design and engineering resources but no research and little development" ${ }^{1666}$ als Merkmal hervorheben, stellt C. FREEMAN fest - vor allem mit Blick auf Zulieferunternehmen und kleine und mittlere Unternehmen in kapitalintensiven Wirtschaftszweigen -, daß ein passiver Innovator "has lost all initiative in product design and has no R\&D facilities" ${ }^{\prime 667}$.

Bei einer traditionellen Strategie besteht für das Unternehmen kein Grund für eine Produktoder Prozeßveränderung, da dies weder der Markt noch die Wettbewerber verlangen. Möglich wird dies, wenn sich das Unternehmen in einer Marktnische (Segmentierungs- oder Nischenstrategie) befindet und dort eine monopolartige Stellung einnimmt.

Die vorstehenden Typisierungen zeigen strategische Vorgehensweisen im Innovationsprozeß. Dabei wird mehreres deutlich: Zunächst handelt es sich um idealtypische Vorstellungen, die sich in dieser Form kaum in der Praxis wiederfinden lassen und die folglich auch nicht die Vielfalt der in der Praxis auffindbaren Kombinationsmöglichkeiten zeigen können. Entsprechend ist ferner davon auszugehen, daß ein Unternehmen in Abhängigkeit vom bearbeiteten Marktfeld oder von der Wettbewerbssituation verschiedene der genannten Strategien zugleich verfolgt, so daß sich letztlich keine Aussagen über die "richtige" Strategie treffen lassen. Darüber hinaus ist $\mathrm{zu}$ bezweifeln, ob die traditionelle Strategie als Innovationsstrategie gelten kann. Konnte bei der reaktiven, der imitativen bzw. der passiven Innovationsstrategie noch argumentiert werden, daß es sich um eine Neuerung für das Unternehmen handelt, ${ }^{668}$ muß dies bei der traditionellen Strategie zunächst in Frage gestellt werden. Lediglich für den Fall des Vorliegens einer Nischen- oder Segmentstrategie ergibt sich eine Innovationsstrategie, wobei hier wiederum die Abgrenzung zur Pionierstrategie schwierig wird, da auch letztere auf die Realisierung einer monopolartigen Stellung abzielt. Ähnlich fließende Übergänge können auch für die übrigen Innovationsstrategien aufgezeigt werden.

\footnotetext{
${ }^{666}$ Ansoff, H.I./Stewart, J.M. (1967), S. 82.

${ }^{667}$ Freeman, C. (1982), S. 180. Freeman und Soete ergănzen dazu: "However, small subcontract firms may also move from a dependent status to the category of innovative firms by the upgrading of their specialized knowledge in a narrow field. They may also lessen their dependence by enlarging their customer network once they strengthen their own innovative competence". Freeman, C./Soete, L. (1997), S. 280.

${ }^{668}$ Im Falle der offensiven und der aktiven Innovationsstrategie erfolgt die Innovation durch das Unternehmen.
} 
Angesichts des Interpretationsspielraums, der sich bei den vorgenannten Strategien im Rahmen einer empirischen Untersuchung ergeben würde, wurde von einer direkten Erhebung abgesehen. Dennoch kann davon ausgegangen werden, daß sich ein Großteil der hier untersuchten Unternehmen im Bereich der aktiven Innovationsstrategie bewegt. Dieser Schluß ergibt sich daraus, daß die untersuchten Unternehmen zu 68,5\% die Forschung und Entwicklung sowie $\mathrm{zu} 75,3 \%$ die Konstruktion und Gestaltung im Unternehmen selbst ausführen und dies zu 78,1\% selbständig, d.h. ohne Kooperationspartner tun. ${ }^{669}$ Ferner wird die Einführung neuer Produktionsverfahren, nachdem sie bei den Wettbewerbern bereits installiert sind (Adaption), in der Regel rasch vollzogen. Bei 43,3\% der Unternehmen erfolgt eine Übernahme von Technologien. Aus diesem Kreis übernehmen 48,1\% die Technologie sofort, 46,9\% warten weniger als fünf Jahre und lediglich $4,9 \%$ zögern länger als fünf Jahre. ${ }^{670}$ Die Unternehmen können demnach, sofern sie nicht selbst mit einer Innovation auf den Markt treten, als frühe Folger charakterisiert werden. Schließlich findet sich die traditionelle Strategie auch nur bei einem Bruchteil der Unternehmen. Von denjenigen Unternehmen, die keine neuen Verfahren und/oder Produkte eingeführt haben, bestand bei 11,1\% keine Innovationsnotwendigkeit (z.B. aufgrund eines stabilen Marktes) und bei 7,9\% keine Innovationsmöglichkeit (z.B. aufgrund ausgereifter Technik). ${ }^{671}$

Um zusätzliche Aussagen uber das Innovationsverhalten der untersuchten kleinen und mittleren Unternehmen treffen zu können, wird im folgenden Abschnitt auf die Wachstumsstrategien (Produkt-Markt-Strategien) nach ANSOFF zurückgegriffen und eine Verbindung zu den Unternehmertypologien von MIIES UND SNOw bzw. KIRSCH UND TRUX hergestellt. ${ }^{672}$

${ }^{669}$ Die beiden Erfolgstypen unterscheiden sich in folgender Weise: F\&E: besonders erfolgreiche Unternehmen: 78,9\%; übrige: 64,3\%; Konstruktion und Gestaltung: besonders erfolgreiche Unternehmen: 78,9\%; übrige: 73,8\%. Vgl. Frage 1/6 des Fragebogens und Anlage 23. Eigenständige Ausfuhrung von Entwicklungsarbeiten: besonders erfolgreiche Unternehmen: 82,7\%; abrige: 75,8\%. Vgl. Frage 3/7 des Fragebogens und Anlage 26.

${ }^{670}$ Vgl. Frage 3/3 des Fragebogens. Da die weniger erfolgreichen Unternehmen in geringerem Ausmaß eigene F\&E betreiben, müßten sie eigentlich verstärkt Technologien adaptieren, um den Anschluß an den technischen Fortschritt halten zu können. Dies spiegelt sich in den Ergebnissen nicht eindeutig wider. Sie übernehmen lediglich zu 38,9\% neue Technologien (besonders erfolgreiche Unternehmen: 53,9\%). Sie gehen dann aber bei der Einfulhrung rascher als die besonders erfolgreichen Unternehmen (in Klammern) vor: Sie adaptieren zu 52,9\% (40,0\%) sofort, zu 43,1\% (53,3\%) innerhalb von fün Jahren und zu 3,9\% (6,7\%) nach mehr als fünf Jahren. Die Begründung für die zeitlich etwas verzögertere Übernahme fremder Technologien durch die besonders erfolgreichen Unternehmen kann darin gesehen werden, daß sie aufgrund ihrer eigenen F\&EBemühungen es sich eher leisten können, fremde Technologien erst dann zu übernehmen, wenn diese sich am Markt bewăhrt haben. Nachrichtlich: Eine Abhängigkeit der Adaption von der Unternehmensgroße läßt sich nicht feststellen.

${ }^{671}$ Auf die Gesamtheit der befragten Unternehmen bezogen wären dies 7,9\% bzw. 5,6\%. Vgl. Frage 3/10 des Fragebogens. Nachrichtlich: Ein zu hohes Risiko sehen 10,3\% (auf Gesamtheit bezogen: 7,3\%).

${ }^{672} \mathrm{Vgl}$. Abschnitt 3.6.3.1 i.V.m. Abschnitt 3.2.2. Die in Abschnitt 3.6.3.2 beschriebenen Wettbewerbsstrategien nach Porter wurden unter die o.g. Innovationsstrategien subsumiert, so daß hier keine gesonderte Diskussion erfolgt. 


\subsubsection{Wachstumsstrategien als Maßstab der Innovativität}

Die unternehmerische Leistung besteht in der zielorientierten Ausrichtung des Unternehmens auf die Anforderungen des Marktes. Dies bedingt die Entwicklung eines hierfür adäquaten Produkt- und Leistungsprogrammes. Durch die Festlegung spezifischer Produkt-MarktKombinationen erfolgt die strategische Ausrichtung des Unternehmens. Sie spiegelt die grundsätzliche Einstellung des Unternehmers bzw. der Unternehmensführung wider. Aus der Kombination von Produkten und Märkten sowie deren Unterscheidung in "bestehend" bzw. "neu" entstehen vier unterschiedliche Strategietypen: die Marktdurchdringung, die Produkterweiterung, die Markterweiterung und die Diversifikation.

Bei der Marktdurchdringung sollen mit Hilfe des bestehenden Produktprogrammes auf den bereits bearbeiteten Märkten die Marktanteile bzw. -volumina ausgebaut werden. In Frage kommt hierfür die Intensivierung der bisherigen Marktbeziehungen sowie die Erschließung neuer Kundengruppen. Da mit dieser Strategie für das Unternehmen im wesentlichen - abgesehen von der Akquirierung neuer Kunden - keine Neuerungen verbunden sind, und man sich somit auf bekanntem Terrain bewegt, kann die Marktdurchdringung als nicht-innovative "Sicherheitsstrategie" bezeichnet werden. Von den untersuchten kleinen und mittleren Unternehmen verfolgen $72,6 \%$ der besonders erfolgreichen Unternehmen und $67,5 \%$ der weniger erfolgreichen Unternehmen diese Sicherheitsstrategie (vgl. Abb. 4-10). Bemerkenswert ist hierbei der hohe und nur wenig differierende Anteil beider Erfolgstypen. Die Verteidigung der aktuellen Märkte nimmt damit großen Raum ein.

Im Gegensatz zur vorgenannten Strategie handeln Unternehmen innovativ, wenn die verfolgte Strategie auf einer Neuerung basiert. Die Strategien der Produkterweiterung, Markterweiterung und Diversifikation werden folglich als "Innovationsstrategien" bezeichnet. Ein signifikanter Unterschied zwischen den beiden Erfolgstypen zeigt sich bei der Strategie der Produkterweiterung. Während die besonders erfolgreichen Unternehmen die Intensität bei der Verfolgung dieser Strategie $(68,6 \%)$ im Vergleich zur Marktdurchdringung nur unwesentlich vermindern, ist der Rückgang bei den weniger erfolgreichen Unternehmen deutlich $(48,0 \%) .{ }^{673}$ Wie bereits festgestellt, ist die Erschließung neuer Märkte als Begründung für Innovationen lediglich von untergeordneter Bedeutung. ${ }^{674}$ Folglich wird die Strategie der Markterweiterung von beiden Erfolgstypen auf einem niedrigen Niveau wahrgenommen. Die besonders erfolgreichen Unternehmen wählen diese Option zu 43,1\% und die weniger erfolgreichen Unternehmen zu 45,5\%. ${ }^{675}$ Bei der dritten Innovationsstrategie, der Diversifi-

${ }^{673}$ Sig.: 0,013 .

${ }^{674} \mathrm{Vgl}$. Anlage 25.

${ }^{675}$ Allerdings bestehen große qualitative Unterschiede in der Marktbearbeitung zwischen den beiden Erfolgstypen. Die besonders erfolgreichen Unternehmen weisen eine höhere Absatzmarktreichweite auf als die weniger erfolgreichen Unternehmen. Sie erwirtschaften 22,3\% ihres Umsatzes (übrige: 17,7\%) auf ausländischen Mărkten. Vgl. Frage 2/8 des Fragebogens i.V.m. Anlage 15 sowie Herdzina, K./Blessin, B. (1996), S. 40f. 
kation, ergeben sich erneut signifikante Unterschiede. Nur noch $26,8 \%$ der weniger erfolgreichen Unternehmen, aber $47,1 \%$ der besonders erfolgreichen Unternehmen verfolgen diese Strategie. ${ }^{676}$

\section{Abb. 4-10: Verfolgung der Produkt-Markt-Strategien durch die beiden Erfolgstypen}

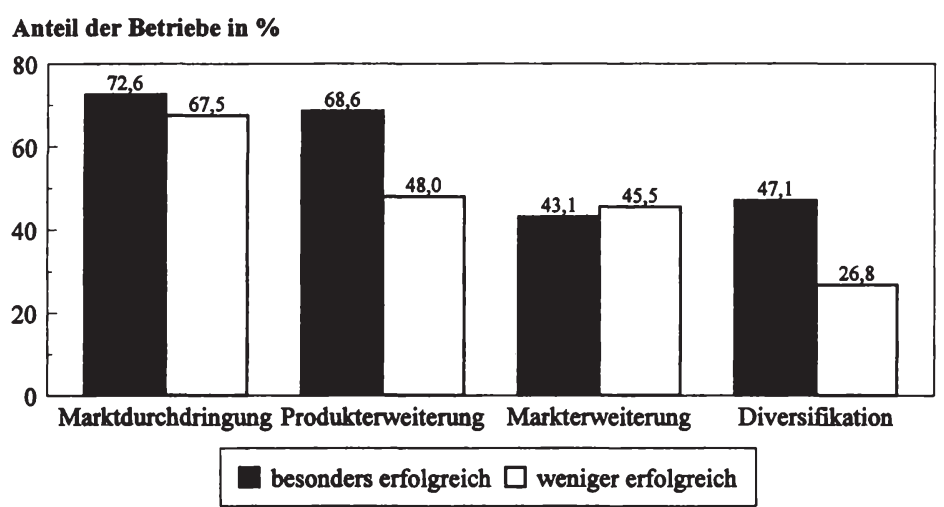

Quelle: eigene Berechnungen.

Die untersuchten kleinen und mittleren Unternehmen sind aufgrund der ausgeprägten Verfolgung der Strategie der Marktdurchdringung zunächst als Verteidiger zu charakterisieren. ${ }^{677}$ Die ausgeprägte Bewegung in angestammten Geschäftsfeldern bringt eine stark konservative Haltung zum Ausdruck. Der deutliche Fokus auf Bekanntes dient den beiden untersuchten Erfolgstypen als Ausgangsbasis für die Wahmehmung weiterer strategischer Optionen. Die weniger erfolgreichen Unternehmen weisen eine schwache Tendenz in Richtung Risikostreuer auf. Sie sind zwar bestrebt, nach neuen Geschäftsfeldern zu suchen, was die Anteile der Produkterweiterungs- bzw. Marktentwicklungsstrategie zum Ausdruck bringen. Sie erreichen dabei allerdings nicht die fur einen Risikostreuer typische Ausgeglichenheit des ProduktMarkt-Portfolios. Hierfur sind zum einen die Anteile der Diversifikationsstrategie zu gering und, wenn die Ergebnisse der Produktlebenszyklusanalyse ebenfalls berïcksichtigt werden, zum anderen der Überhang bei den "alten" Produkten zu hoch. ${ }^{678}$ Die besonders erfolgrei-

Aus Anlage 27 i.V.m. Anlage 28 wird ferner deutlich, daß der Anteil des Exports am Umsatz und die Ent676 wicklung des Exports von der Große des Unternehmens abhăngig sind.

${ }^{676}$ Sig.: 0,010 .

${ }^{677}$ Vgl. dazu ausfuhrlich Abschnitt 3.2.2 i.V.m. Miles, R.E./Snow, C.C. (1978) und Kirsch, K./Trux, W. (1981).

Allerdings ist ausdrücklich darauf hinzuweisen, daß die von Miles und Snow bzw. Kirsch und Trux aufgezeigten Unternehmertypologien Idealvorstellungen sind. Die Einordnung der Erfolgstypen in diese Schemata kann nur grob und pausch
${ }^{678} \mathrm{Vgl}$. Abschnitt 4.3.3.2. 
chen Unternehmen weisen insgesamt eine deutlich höhere Intensität bei der Verfolgung der einzelnen Strategien bei einem gleichzeitig ausgeglichenen Produktportfolio auf. Neben der Beibehaltung traditioneller Produkte und Märkte streben sie stärker als die weniger erfolgreichen Unternehmen die Erschließung neuer Produkt- und Marktpotentiale an. Aufgrund ihrer deutlich progressiveren Einstellung in Verbindung mit der Ausgeglichenheit des Produktportfolios können sie grob als Analysierer bzw. Architekten gekennzeichnet werden. Daneben weisen beide Erfolgstypen auch Merkmale des Reagierers auf, die sich hauptsächlich in der für diesen Typ charakteristischen Eigenschaft nicht explizit formulierter Strategien äußert. Diese vermeintliche "Strategielosigkeit" ist kennzeichnend für kleine und mittlere Unternehmen und kann mit dem Streben nach größtmöglicher Flexibilität in Verbindung gebracht werden.

Eine Untersuchung der Ergebnisse in Abhängigkeit von der Unternehmensgröße zeigt nur einen schwachen Zusammenhang zwischen steigender Unternehmensgröße und steigender Intensität der Verfolgung der Produkt-Markt-Strategien. ${ }^{679}$

Damit stellt sich an dieser Stelle erneut die Frage nach der Eignung der gewählten Indikatoren für die Messung der Innovativität und dem damit eng verbundenen Unternehmenserfolg. Wie sich bis hierhin gezeigt hat, können bei einigen Fragestellungen deutliche Unternehmensgrößeneffekte nachgewiesen werden. ${ }^{680}$ Solche Effekte zeigen sich beispielsweise bei der Nutzung innovationsrelevanter Informationsquellen, der betrieblichen Weiterbildung sowie bei der Umsatz-, Export- und F\&E-Entwicklung. Nur in wenigen Fällen erweist sich das Merkmal "Unternehmensgröße" als überlegen, d.h. es differenziert besser als die Unterscheidung nach Erfolgstypen. Letztere erweist sich vor allem dann als ubberlegen, wenn es darum geht, eine Begründung für die Entwicklung des Unternehmens zu finden. Definitionsgemäß zeichnen sich die besonders erfolgreichen Unternehmen durch die Einführung von Produktund/oder Prozeßinnovationen, die Betrachtung der Innovativität als Wettbewerbsvorteil und die positive Entwicklung des Umsatzes aus. Sie zeigen dabei bei den o.g. Fragestellungen zum Teil wesentlich deutlichere Unterschiede zur Gegengruppe der weniger erfolgreichen Unternehmen, als dies die Differenzierung nach der Unternehmensgröße zuläßt. Werden darüber hinaus die Ergebnisse der Lebenszyklusanalyse sowie der verfolgten Produkt-MarktStrategien in die Überlegungen mit einbezogen, zeigt sich insgesamt die Überlegenheit der gewählten Merkmalskombination.

\footnotetext{
${ }^{679}$ Nur im Fall der Produkterweiterung kommt es bei einer Differenzierung nach Umsatzgrößenklassen zu einem signifikanten Ergebnis (Sig.: 0,003). Vgl. Anlage 14. Daraus läßt sich schließen, daß für die Steigerung des Umsatzes die Entwicklung neuer Produkte die am besten geeignete Strategie darstellt.

${ }^{680}$ Dies gilt selbstverständlich nur für die hier untersuchten Unternehmensgrößen, d.h. Unternehmen zwischen 20 und 500 Mitarbeitern. Eine Verallgemeinerung ist somit nur bedingt zulässig.
} 
Damit kann folgender Schluß gezogen werden: Der Unternehmenserfolg hängt von der Innovativität des Unternehmens ab. Die Innovativität wiederum wird wesentlich bestimmt

- durch den Aufbau externer und interner Informations- und Kommunikationsnetzwerke,

- durch eine innovationsorientierte Unternehmensfuhrung, die ein innovatives Umfeld schafft und Lemprozesse initiiert,

- durch den effizienten Einsatz der F\&E.

Diese Voraussetzungen werden von den besonders erfolgreichen Unternehmen wesentlich besser erfullt als von den weniger erfolgreichen Unternehmen. Besonders hervorzuheben ist daneben, daß aus der positiven Entwicklung des Unternehmenserfolges auch positive Beschäftigungseffekte resultieren. Bei $65,4 \%$ der besonders erfolgreichen Unternehmen (übrige: 25,4\%) konnte im betrachteten Zeitraum zwischen 1990 und 1995 eine Zunahme der Beschäftigten festgestellt werden, was letztlich ein Beschäftigungswachstum von 5,6\% (übrige: $-18,1 \%$ ) bedeutet. Die besonders erfolgreichen Unternehmen entwickelten sich somit entgegen dem Trend sowohl in der Region Neckar-Alb als auch in Baden-Württemberg bzw. der Bundesrepublik Deutschland. ${ }^{681}$ Folglich wird zusätzlich deutlich: Innovation schafft Arbeitsplätze.

${ }^{681}$ Vgl. Herdzina, K./Blessin, B. (1996), S. 7ff.; Regionalverband Neckar-Alb (1995). Die in Anlage 29 dargestellte Entwicklung der Beschätigten in den untersuchten Unternehmen verdeutlicht den positiven Zusammenhang zwischen Innovativităt und Beschäftigung noch einmal und zeigt darüber hinaus, daß sich zwischen der Unternehmensgroßße und der Beschäftigtenentwicklung kein Zusammenhang ableiten läßt. 


\subsection{Zwischenergebnis}

Innovationen sind eine wesentliche Komponente des Unternehmenserfolges. Mit Hilfe des Innovationsmanagements als Führungskonzept soll dieser Erfolg sichergestellt werden, indem die Anpassungsfähigkeit des Unternehmens systematisch ausgebaut und gefördert wird. Die Anpassungsfähigkeit eines Unternehmens resultiert aus dem Ausgleich zwischen Stabilisierung und Veränderung. In diesem Spannungsfeld fällt dem Innovationsmanagement einerseits die Aufgabe zu, Veränderungen im Umfeld wahrzunehmen und als Chance zu begreifen, um durch die Generierung neuen Wissens und neuer Problemlösungen die Wettbewerbsfähigkeit des Unternehmens zu stärken. Dies bedingt andererseits auch die Schaffung geeigneter Strukturen und Prozesse im Unternehmen selbst, die durch ihre Stabilität und Effizienz erst die Voraussetzungen für den erfolgreichen Wandel schaffen.

Zentrales Ziel des vierten Kapitels war es daher, die Komponenten und Instrumente des Innovationsmanagements in kleinen und mittleren Unternehmen aufzuzeigen und deren Relevanz mit Hilfe empirischer Ergebnisse nachzuweisen.

Um die Bedeutung von Innovationen vollständig erfassen zu können, muß zunächst auf die Vielschichtigkeit des Begriffes hingewiesen und die Innovation als wesentlicher Bestandteil des technischen Fortschrittes gekennzeichnet werden. Innovation wird hier in einem sehr weiten Sinne als ein Prozeß verstanden, der sich auf Neuerungen jeglicher Art, also auf jedes "Andersmachen" (vgl. SCHUMPETER) bezieht. Das Innovationsmanagement erstreckt sich damit auf den gesamten unternehmerischen Neuerungsprozeß und nimmt Einfluß auf alle Bereiche des Unternehmens.

Neben der reinen Begrifflichkeit ist auch die gesamt- und einzelwirtschaftliche Bedeutung von Innovationen zu erfassen. Die Diskussion um den Beitrag des technischen Fortschrittes zum Wirtschaftswachstum (Growth-Accounting-Ansatz) wurde maßgeblich durch SoLOw angestoßen. Wenn auch der von Solow festgestellte starke Einfluß des technischen Fortschrittes - und damit der Innovation - auf das Wachstum sowie auf die Beschäftigung in Folgearbeiten nicht immer in gleicher Höhe nachvollzogen werden konnte, so wird dennoch durchgängig die positive Wirkung der Innovation auf das Wirtschaftswachstum und die Beschäftigung hervorgehoben. Problematisch bleiben aber die Indikatoren, mit denen die Innovativität bzw. die Attraktivität einer Volkswirtschaft als Innovationsstandort gemessen werden können. Ganz ähnliche Probleme ergeben sich auch auf der einzelwirtschaftlichen Ebene. Die Messung der Innovativität mit Hilfe von F\&E- und Patentintensitäten bzw. der getätigten Investitionen ergeben hier ebenfalls nur ein unvollständiges Bild. Zu seiner Vervollständigung werden daher die Unterschiede im Innovationsverhalten besonders erfolgreicher und weniger erfolgreicher Unternehmen herausgearbeitet. 
Wie bereits die Unternehmensfuhrung, erfordert auch der Innovationsprozeß eine systematische und zielorientierte Gestaltung. Die Aufgabe des Innovationsmanagements ist es dabei, Wertschöpfungspotentiale zu erkennen und erfolgreich $\mathrm{zu}$ nutzen. Letzteres ist vor allem für kleine und mittlere Unternehmen von großer Bedeutung, da Mißerfolge nicht nur die Wettbewerbsfähigkeit, sondern im Extremfall auch die Existenz gefährden können. Grundvoraussetzung für ein erfolgreiches Innovationsmanagement in kleinen und mittleren Unternehmen ist die Informationsbeschaffung durch die Analyse der externen und internen Bedingungen. Neben den in Kapitel 3 bereits dargestellten externen Informationsquellen stehen dem Unternehmen eine Reihe weiterer, innovationsrelevanter Informationsquellen zur Verfügung, deren Verknüpfung zu einem Informationsnetzwerk einen Ideenpool darstellt, den es zu nutzen gilt. Während kleine und mittlere Unternehmen zu ihren Lieferanten, Abnehmern und Wettbewerbern vielfach Kontakte aufgebaut haben, werden Hochschulen, Beratungsstellen und Verbände deutlich nachrangig eingeschätzt, obwohl gerade hier ein hohes ausschöpfbares Potential für sie besteht. Für die interne Analyse sind zunächst die Funktionsbereiche Unternehmensführung, Personalwesen, Forschung und Entwicklung sowie Finanzen von Bedeutung. Dabei können vor allem im Personalwesen und im F\&E-Bereich deutliche Unterschiede zwischen den Erfolgstypen festgestellt werden. Bei den besonders erfolgreichen Unternehmen wird erkennbar, daß sie ihre Mitarbeiter als eine wertvolle Ressource betrachten, die mit Hilfe der Qualifizierung gestärkt wird und dadurch wiederum die Innovativität des Unternehmens fördert. Daneben geben sie auch einen höheren Anteil ihres Umsatzes für F\&E aus. Daß sie das eingesetzte Kapital effizienter nutzen, kann anhand der Produktlebenszyklusanalyse gezeigt werden. Den besonders erfolgreichen Unternehmen gelingt es, ein ausgewogenes Verhältnis zwischen "jungen" und "alten" Produkten zu schaffen. Demgegenüber weisen die weniger erfolgreichen Unternehmen einen deutlichen Überhang bei den "alten" Produkten auf.

Durch seine zentrale Rolle in kleinen und mittleren Unternehmen hat der Unternehmer maßgeblichen Einfluß auf die Bildung einer Innovationskultur. Seiner Einstellung und Initiative unterliegt zum einen die Schaffung eines innovativen Umfeldes. Dieses ist im wesentlichen gekennzeichnet durch einen kooperativen, partizipativen Fürungsstil, Übertragung von Verantwortung, Gewährung von Freiräumen sowie die Entwicklung geeigneter Anreizsysteme. Zur Aufrechterhaltung der Wettbewerbsfähigkeit wird die Generierung, Akkumulation und Diffusion des Wissens im Unternehmen immer wichtiger. Die Schaffung einer Lernenden Organisation soll zum anderen das Unternehmen in die Lage versetzen, schneller als die Wettbewerber innovative Problemlösungen anzubieten. Die von WILDEMANN bzw. von SENGE entwickelten Konzepte zeigen Ansatzpunkte der Realisierung auf. In der Praxis finden sich jedoch erst wenige Unternehmen, die eine Umsetzung des Konzeptes anstreben.

Eine weitere Komponente des Innovationsmanagements ist die Formulierung von Innovationszielen. Dabei ergibt sich die Schwierigkeit, daß Innovationszielen im Rahmen der Ent- 
scheidungstheorie kein eigener Platz eingeräumt wird. Die Bedeutung der Innovation für den Unternehmenserfolg sowie die Notwendigkeit eines Orientierungsrahmens für die Formulierung von Strategien rechtfertigen die Entwicklung eines eigenständigen Zielsystemes. Innovationsziele müssen dabei die Komplexität und Unbestimmtheit von Innovationen berücksichtigen, so daß die Ansprüche an ihre Spezifikation entsprechend anzupassen sind. Dann zeigt sich, daß im Rahmen der Unternehmensziele vor allem die innovationsrelevanten Ziele Kosteneinsparung, Produktivitätssteigerung sowie Erschließung neuer Märkte einen hohen Rang einnehmen.

Bei der Verfolgung von Innovationsstrategien zeichnen sich im wesentlichen sechs Vorgehensweisen ab: offensiv, aktiv, reaktiv, imitativ, passiv und traditionell. Ein Großteil der hier untersuchten Unternehmen bewegt sich im Bereich der aktiven Innovationsstrategie, wobei allerdings darauf hinzuweisen ist, daß mehrere der Strategien in Kombination verfolgt werden. Zusätzliche Aussagen über das Innovationsverhalten der Unternehmen können durch die Analyse der verfolgten Produkt-Markt-Strategien getroffen werden. Die besonders erfolgreichen Unternehmen weisen im Vergleich zu den weniger erfolgreichen Unternehmen dabei eine insgesamt höhere Intensität bei der Verfolgung der einzelnen Strategien auf.

Schließlich zeigt sich aufgrund der theoretischen und empirischen Analyse, daß Innovation sicherlich zum Teil von der Unternehmensgröße beeinflußt wird, da hier auf ein breites Potential unterschiedlicher Ressourcen zurilckgegriffen werden kann. Die vorstehenden Ausführungen machen aber zusätzlich deutlich, daß die grundsätzliche Einstellung eines Unternehmens zur Innovation die Unternehmensgrößeneffekte deutlich überlagert, was die Ergebnisse der besonders erfolgreichen Unternehmen klar zum Ausdruck bringen. Die bei ihnen festgestellten Eigenschaften lassen folgende Schlüsse zu: Mit dem Aufbau externer und interner Informations- und Kommunikationsnetzwerke, einer innovationsorientierten Unternehmensführung sowie dem effizienten Einsatz der Forschung und Entwicklung wird die Innovativität des Unternehmens entscheidend gefördert. Sie ist eine zentrale Voraussetzung für den Unternehmenserfolg und damit auch die Voraussetzung für Wachstum und Beschäftigung. 


\section{Umweltmanagement}

\subsection{Begriff und Charakterisierung}

Unternehmerisches Handeln ist zwangsläufig mit einer Beeinflussung der Umwelt verbunden. ${ }^{682}$ Unternehmen sind damit einerseits wertschöpfende Erzeuger von Sachgütern und Dienstleistungen, indem sie Produktionsfaktoren vereinen und organisieren. Andererseits wirken sie in entscheidender Weise auf die Umwelt durch den Verbrauch von Rohstoffen und Energie sowie durch die Produktion von Abfällen aller Art ein. Ein Spannungsverhältnis zwischen Ökonomie und Ökologie wird sich folglich immer dann aufbauen, wenn den Einschränkungen der unternehmerischen Handlungsfreiheit bzw. den Kosten der Umweltschutzmaßnahmen keine entsprechenden ökonomischen Erträge oder Erfolgspotentiale gegenüberstehen. Damit scheinen ökonomische und ökologische Ziele des Unternehmens in einer konkurrierenden Beziehung zueinander zu stehen, die offensichtlich zu einer Entscheidung zwischen einer wettbewerbsorientierten und einer nachhaltigen, ökologieorientierten Unternehmensführung führt.

Dieses Spannungsverhältnis existiert aber nur vordergründig. Wie im vorangegangenen Kapitel nachgewiesen wurde, sind Innovationen eine zentrale Voraussetzung, um sich den Veränderungen externer und interner Rahmenbedingungen des Unternehmens anzupassen bzw. gestaltend auf sie einzuwirken. Innovationen können also dazu beitragen, das zuvor skizzierte Spannungsfeld zu vermindern. Im Hinblick auf den betrieblichen Umweltschutz erfordert dies eine aktive und systematische Auseinandersetzung mit den von verschiedenen Seiten an das Unternehmen herangetragenen Ansprüchen. Diese Ansprüche bestehen beispielsweise aus einer wachsenden Anzahl umweltschutzbezogener Normen und Gesetze, aus gestiegenen Erwartungen der Gesellschaft bzw. der Abnehmer an die Umweltverträglichkeit der Produktionsprozesse bzw. der Produkte oder aus der Entwicklungsdynamik innerhalb der eigenen Branche. Ökologisch motivierte Innovationen gewinnen somit in zunehmendem $\mathrm{Maße}$ an $\mathrm{Be}-$ deutung. Die Wettbewerbsfähigkeit des Unternehmens wird also wesentlich davon abhängen, wie ausgeprägt die Anpassungs- und Neuerungsfähigkeit des Unternehmens an die veränder-

${ }^{682}$ Der Begriff "Umwelt" wird in vielfalltiger Weise und in unterschiedlicher Weite verwendet. In einer weiten Begriffsverwendung umfaßt die Umwelt die spezifische Umgebung, mit der ein System bzw. eine Lebenseinheit in wechselseitigen Beziehungen steht. Eine engere, anthropozentrische Verwendung des Begriffes unterscheidet zwischen der soziologischen, der räumlichen und der naturlichen Umwelt. Zur Vereinfachung wurde die soziologische Umwelt in dieser Arbeit als Umfeld bezeichnet (vgl. FN 118). Folglich werden die beiden übrigen als Umwelt bezeichnet. Vgl. zum Begriff "Umwelt" auch SRU (1988); Wicke, L. (1993), S. 5f.; Hartwig, K.-H. (1995), S. 125. Der "Umweltschutz" bezieht sich demnach auf alle Maßnahmen, "durch die Umweltmedien bzw. -bereiche vor den nachteiligen Wirkungen menschlicher Eingriffe geschützt werden sollen". Halstrick-Schwenk, M. u.a. (1994), S. 24. 
ten Bedingungen ist. Eine wettbewerbsorientierte Unternehmensführung schließt somit ökologische Gesichtspunkte mit ein.

Damit wird die enge Verbindung zwischen Innovation und Umweltschutz deutlich sichtbar. Die Komplexität und Multikausalität der Umweltthematik bedingt jedoch eine eigenständige Berücksichtigung im Rahmen der Unternehmensführung. Darüber hinaus erfordert allein schon eine ganzheitliche, vernetzte und langfristige Sichtweise der Unternehmensführung die Integration umweltorientierter Inhalte und somit ihre gesonderte Beachtung. Dies bedeutet eine gleichberechtigte Behandlung leistungswirtschaftlicher, finanzieller, sozialer und eben auch ökologischer Ziele. Folglich kann erst dann von einer umweltorientierten Unternehmensführung (im folgenden auch Umweltmanagement) gesprochen werden, wenn der Umweltschutz als Bestandteil der Unternehmensführung betrachtet und als eigenständiges Ziel im Zielsystem des Unternehmens integriert wird. Zur Erreichung der Umweltziele nimmt das Umweltmanagement Einfluß auf die Gestaltung, Lenkung und Entwicklung der Unternehmenstätigkeit, so daß eine Verminderung oder Vermeidung der Umweltbelastung durch das Unternehmen sowie eine langfristige Sicherung des Unternehmenserfolges möglich wird. ${ }^{683}$ Bereits an dieser Stelle wird deutlich, daß das Umweltmanagement im Unternehmen eine Querschnittsaufgabe darstellt. Sie erfordert Anpassungsmaßnahmen in allen Unternehmensfunktionen und -bereichen wie Forschung und Entwicklung, Beschaffung, Produktion, Lagerhaltung, Absatz bzw. Redistribution und Logistik sowie Planung, Finanzierung, Information, Organisation und Führung. Daraus ergibt sich die Notwendigkeit, das Umweltmanagement als Führungsaufgabe zu begreifen und aus einer konzeptionellen Gesamtsicht heraus umzusetzen. Das Umweltmanagement erhält damit unternehmensstrategische Relevanz.

Im Vergleich zur volkswirtschaftlichen Literatur, die sich bereits seit geraumer Zeit mit dem Umweltproblem auseinandersetzt, ${ }^{684}$ findet sich in der betriebswirtschaftlichen Literatur erst in jüngerer Zeit eine umfassende Diskussion. ${ }^{685}$ Die hierbei entwickelten Ansätze berücksichtigen jedoch nur in unzureichender Weise die spezifische Situation kleiner und mittlerer Unternehmen und lassen sich folglich auch nicht ohne Schwierigkeiten übertragen. Dieses De-

${ }^{683}$ Zum Begriff "Umweltmanagement" existiert in der Literatur kein einheitlicher Vorstellungsinhalt. Als konstitutive Merkmale der unterschiedlichen Definitionsansätze lassen sich nach Meffert, H./Kirchgeorg, M. (1993), S. 15f., der mehrdimensionale Zielbezug, der funktions- und unternehmensübergreifende Charakter sowie die proaktive Verhaltensausrichtung herausfiltern. Damit scheint allerdings das "Umweltmanagement" kein grundsätzlich neuer Ansatz zu sein, sondern vielmehr die Erweiterung bestehender Ansätze um die ökologische Dimension. Für eine Definition des Begriffes vgl. z.B. FUUF (1991), S. 74; Dyllick, T./Belz, F. (1993), S. 22; Steger, U. (1993), S. 66; Butterbrodt, D. u.a. (1995), S. 4; Kreikebaum, H. (1995), S. 6; Tischler, K. (1996), S. 24. Vgl. ferner auch die Begriffsbestimmung im Rahmen der EG-Umwelt-AuditVerordnung.

${ }^{684}$ Vgl. z.B. Pigou, A.C. (1923); Coase, R.H. (1960); Dales, J.H. (1968); Baumol, W.J./Oates, W.E. (1975) sowie die bei Oates, W.E. (Hrsg.) (1992) aufgezeigte Literatur. Vgl. daneben u.a. die Arbeiten von H. Bonus bzw. H. Siebert.

${ }^{685}$ Vgl. z.B. die Arbeiten von Strebel, H. (1980); Senn, J.F. (1986); Brenken, D. (1988); Pfriem, R. (1989); Kirchgeorg, M. (1990); Wicke, L. u.a. (1992); Meffert, H./Kirchgeorg, M. (1993); Steger, U. (1993); Hopfenbeck, W. (1994). Für einen Literaturüberblick siehe Clausen, J. u.a. (1995). 
fizit eröffnet ein weitreichendes Forschungsfeld sowohl auf theoretischer wie auch auf empirischer Ebene. Die nachfolgenden Kapitel setzen daher an dieser Lücke an. Die vorliegende Arbeit erhebt dabei nicht den Anspruch, einen umfassenden und in sich geschlossenen Ansatz zur umweltorientierten Unternehmensführung in kleinen und mittleren Unternehmen zu entwickeln. Auf der Basis der empirischen Ergebnisse können aber die wesentlichen Eckpunkte für die Entwicklung eines solchen Ansatzes aufgezeigt werden.

\subsection{Umweltschutz im gesamt- und einzelwirtschaftlichen Kontext}

\subsubsection{Die gesamtwirtschaftliche Bedeutung des Umweltschutzes}

Die grundsätzliche Notwendigkeit des Umweltschutzes steht außer Frage. Dies wird bereits im Umweltprogramm der Bundesregierung von 1971 deutlich. Dessen Ziele sind die Sicherung einer menschenwürdigen Umwelt, der Schutz von Boden, Luft und Wasser, Pflanzenund Tierwelt vor der nachteiligen Wirkung menschlicher Eingriffe sowie die Beseitigung von Schäden und Nachteilen aufgrund menschlicher Eingriffe. ${ }^{686}$ Die Umweltpolitik wird dabei gleichrangig zu anderen Politikbereichen wie beispielsweise der sozialen Sicherheit, der Bildungspolitik oder der inneren und äußeren Sicherheit gesehen. Aufgrund der weitreichenden ökonomischen Wirkungen des Umweltschutzes steht auf der gesamtwirtschaftlichen Ebene der Einfluß auf das Wirtschaftswachstum und auf die Beschäftigung im Zentrum theoretischer und empirischer Untersuchungen.

In der Literatur scheint mittlerweile weitgehend Konsens darüber zu bestehen, daß sich zumindest auf lange Sicht eine Zielharmonie zwischen Umweltschutz und Wirtschaftswachstum entwickelt. ${ }^{687}$ Auf kurze Sicht können die in der Bundesrepublik Deutschland politisch gesetzten Umweltstandards jedoch in bestimmten Branchen die internationale Wettbewerbsfähigkeit beeinträchtigen, da die erforderlichen Umweltschutzinvestitionen sowie die laufenden Umweltschutzkosten zunächst eine Verteuerung der Produkte verursachen. Demgegenüber stehen zum einen die aus einer Modernisierung der Anlagen resultierenden Einsparpotentiale an Energie, Material und Abfällen, die kostenreduzierend wirken, zum anderen trägt der Umweltschutz auch zu einer Verbesserung der Standortbedingungen bei. ${ }^{688}$ Darüber

${ }^{686}$ BMI (Hrsg.) (1971), S. 6. Für eine Quantifizierung der Kosten der Umweltzerstornung vgl. Wicke, L. (1986) und (1993), S. 60-119; Leipert, C. (1989) und (1992). Daneben finden Bemühungen um die Modifizierung der Volkswirtschaftichen Gesamtrechnung durch im Umweltbereich auftretende Effekte statt. Vgl. für eine kurze Darstellung der Diskussion sowie der jüngeren Literatur SRU (1996), S. 87f.

${ }^{687}$ Vgl. u.a. Meißner, W. (1982), S. 63ff.; Sprenger, R.-U. (1982), S. 69-74; Zimmermann, K. (1982), S. 17ff.; Wicke, L. (1993), S. 557-563; SRU (1996), S. 88 sowie die jeweils angegebene weitreichende nationalökonomische Literatur zum Themenkreis "Umweltschutz und Wirtschaftswachstum".

${ }^{688}$ Die Reinhaltung der Umweltmedien Boden, Wasser und Luft ist dabei nicht allein als Standortbedingung fur die Produktion von Bedeutung, sondern auch wenn es darum geht, neue Mitarbeiter anzuwerben. Insbesondere für Fachkräfte spielen neben den ökonomischen auch die sozialen und okologischen Bedingungen eine zu- 
hinaus hat sich durch die Nachfrage nach Umweltschutzgütern und -diensten in Deutschland ein eigenständiger Wirtschaftszweig entwickelt, der auf dem Weltmarkt eine führende Position einnimmt. Von diesem Markt sind gleichzeitig "per Saldo positive Effekte auf die ökonomische Entwicklung ausgegangen". ${ }^{699}$ Der Umweltschutzindustrie bzw. den -dienstleistern werden auch weiter, sowohl auf dem nationalen als auch auf dem internationalen Markt, überdurchschnittliche Wachstumsraten prognostiziert, da es - zumindest in den Industrieländern verstärkt zu einer Verschärfung der Umweltstandards und damit zu einer Angleichung an die deutschen Normen und Gesetze kommt. Aus den durch die deutsche Umweltpolitik bereits frühzeitig freigesetzten innovativen Kräften und dem daraus entwickelten Know-how resultieren Vorteile für die internationale Wettbewerbsfähigkeit. Diese erstrecken sich nicht allein auf Umweltindustrie bzw. -dienstleister, sondern auch auf die Produkte und Prozesse, die bereits heute Standards genügen, an die sich Anbieter anderer Länder erst noch anpassen müssen. ${ }^{690}$

Der Zusammenhang zwischen Umweltschutz und Beschäftigung ist in den vergangenen zwei Jahrzehnten in mehreren theoretischen und empirischen Untersuchungen kontrovers diskutiert worden. Während z.B. ZIMMERMANN darauf hinweist, daß die Umlenkung der Ressourcen durch eine auf dem Verursacherprinzip basierende Umweltpolitik kurz- bis mittelfristig zu einer Gefährdung der Vollbeschäftigung bzw. zu einer Steigerung der Unterbeschäftigung führen kann, ${ }^{691}$ zeigen andere Arbeiten eine überwiegend positive Beziehung zwischen Umweltschutz und Beschäftigung auf. $\mathrm{Zu}$ nennen sind hier vor allem die Studien von SPRENGER sowie von BLAZEJCZAK u.a. ${ }^{692}$ Auch wenn letztlich keine genauen Abschätzungen möglich sind, prognostizieren BLAZEJCZAK u.a. bis zum Jahr 2000 eine umweltschutzinduzierte Beschäftigung von 1,1 Mio. Personen. Werden die umweltschutzinduzierten negativen Beschäftigungseffekte gegen die positiven Beschäftigungseffekte aufgerechnet, so ergibt sich im Zeitraum 1990 bis 2000 ein positiver Nettoeffekt von 185.000 Personen. ${ }^{693}$

nehmende Rolle bei der Entscheidung für oder gegen ein Unternehmen. Vgl. zur Wirkung des Umweltschutzes auf den Industriestandort ausfuhrlich Sprenger, R.-U. (1992); Blazejczak, J. u.a. (1993c) sowie ferner Prătorius, G. (1992).

689

SRU (1996), S. 88. Nachfrage und Angebot von Umweltschutzgutern und -diensten wurde von HalstrickSchwenk, M. u.a. (1994) untersucht und quantifiziert. Dabei zeigt sich, daß 87,1\% der Unternehmen in der umwelttechnischen Industrie weniger als 500 Mitarbeiter aufweisen und mit einem Weltmarktanteil von ca. $21 \%$ deutlich vor den USA und Japan fuhren. Vgl. Halstrick-Schwenk, M. u.a. (1994), S. $113 \mathrm{ff}$. und S. $118 f$. Vgl. ferner Schafhausen, F. (1988), S. 284; Kurz, R. (1994b), S. 155; Helbig, J. (1997), S. 16-19.

${ }^{690}$ Auf diese durch eine strikte nationale Umweltpolitik langfristig entstehende technologische Vorsprungsrente haben bereits Ullmann, A.A./Zimmermann, K. (1982), S. 34 bzw. Zimmermann, K. (1982), S. 21 hingewiesen.

${ }^{691}$ Vgl. Zimmermann, K. (1982), S. 16. Allerdings hebt auch er die positiven Zielbeiträge der Umweltschutzindustrie hervor (S. 22-28).

${ }^{692}$ Vgl. Sprenger, R.-U. (1989); Blazejczak, J. u.a. (1993a) i.V.m. Blazejczak, J. u.a. (1993b). Eine kurze Darstellung der Diskussion findet sich bei Löbbe, K./Wenke, M. (1995). Vgl. ferner auch den Überblick bei Blazejczak, J. u.a. (1993a), S. 6-9 über die gesamtwirtschaftlich, regional bzw. sektoral angelegten einschlägigen Untersuchungen, die seit 1977 in der Bundesrepublik Deutschland erarbeitet worden sind. Vgl. daneben auch den Beitrag von Binswanger, H.C. u.a. (1988), die in einer okologieorientierten Wirtschaftspolitik u.a. Ansatzpunkte zur Bekämpfung der Arbeitslosigkeit sehen.

693 Blazejczak, J. u.a. (1993a), S. 1-4. 
Sowohl die Abschätzungen der Wachstums- als auch der Beschäftigungseffekte sind mit erheblichen methodischen Problemen verbunden. Die vorgenannten Betrachtungen beziehen sich vornehmlich auf die Wirkung additiver Umweltschutztechnik. Die bereits hier bestehenden Abgrenzungsschwierigkeiten und die daraus resultierende Prognoseunsicherheit würden sich bei der Erfassung des Marktpotentials integrierter Umwelttechnologien noch weiter verschärfen. Gerade aber die zusätzliche Erfassung integrierter Umwelttechnologien ist für eine umfassende Darstellung von Wachstums- und Beschäftigungseffekten notwendig und könnte zusätzlich verdeutlichen, wie es zum einen "um die Art und Qualität der geschaffenen Arbeitsplätze steht, und zum anderen, wie sich die Verlagerung von additiven Umweltschutztechnologien hin $\mathrm{zu}$ integrierten Technologien auf den Beschäftigungsstand auswirken wird"694. Daneben zeigen die Prognosen zwar deutlich positive Beschäftigungseffekte des ökologischen Modernisierungsprozesses auf, diese sind allerdings in ihrer Quantität nicht dazu geeignet, eine nennenswerte Entspannung auf dem Arbeitsmarkt herbeizufuhren. Letzteres ist jedoch auch nicht die Intention der Umweltpolitik. Das von ihr verfolgte Ziel einer Verbesserung der Lebensbedingungen reicht als Begrundung aus, sie bedarf also keiner wachstumsoder beschäftigungspolitischen Begründung. ${ }^{695}$

\subsubsection{Die einzelwirtschaftliche Bedeutung des Umweltschutzes}

Das Verhältnis des Unternehmens zu seiner natürlichen Umwelt wird wesentlich durch die im Faktorkombinationsprozeß stattfindende Umweltnutzung bestimmt. Die dabei entstehenden Nutzungs-, Entnahme- und Verbrauchsansprüche gehen als Inputelemente in die Faktorkombination ein. Daneben dient die Umwelt als Aufnahmemedium für die während der Produktion, des Produktge- oder -verbrauchs sowie die nach Beendigung der Produktnutzung entstehenden Abfälle im weitesten Sinn (Output).

Wie im vorangegangenen Abschnitt deutlich wurde, zielt die Umweltpolitik in der Bundesrepublik Deutschland auf eine Vermeidung bzw. Verminderung umweltbelastender Produkte und Prozesse ab. Die zur Erreichung dieses Zieles von seiten der Umweltpolitik angestrengten Maßnahmen setzen dabei sowohl am Input wie auch am Output an. Die daraus resultierenden Restriktionen stellen für das Unternehmen zunächst eine zusätzliche Kostenkomponente dar, die entweder den Marktpreis erhöht oder, falls sich dies nicht durchsetzen läßt, gewinnmindernd wirkt. Dies gilt allerdings nur dann, wenn eine Anpassung an die geforderten Normen

${ }^{694}$ SRU (1996), S. 92.

${ }^{695}$ Vgl. Meißner, W./Hödl, E. (1978), S. 183; SRU (1994), S. 62f. und (1996), S. 92. 
und Gesetze in Form von nachgeschalteten bzw. additiven Technologien ${ }^{696}$ erfolgt. In diesem Fall stellt der betriebliche Umweltschutz eine zusätzliche, unproduktive Investition dar. ${ }^{697}$

Innovatives, unternehmerisches Handeln wird dagegen auf eine Vermeidung bzw. Verminderung der Kosten durch integrierte Problemlösungen abzielen. Durch die effizientere Nutzung der Produktionssysteme, die Veränderung von Produktionsprozessen, die Substitution umweltgefährdender Materialien oder die Ressourcenrückgewinnung werden Rationalisierungspotentiale freigesetzt, die oftmals weit über die umweltschutzinduzierten Kosten hinausgehen. Dies bedeutet neben einem verminderten Aufwand für Energie, Rohstoffe und Abfälle auch eine Verminderung des Gefahrenpotentials, woraus wiederum eine Verminderung der Kosten für die Risikoabsicherung oder eine Verkürzung von Genehmigungsfristen resultieren kann. Schließlich bedeutet die frühzeitige innovative Reaktion auf umweltschutzbezogene Forderungen die Aufrechterhaltung des unternehmerischen Flexibilitätsspielraumes. Neben diesen quantitativen Aspekten ergeben sich noch eine Reihe qualitativer Aspekte. $\mathrm{Zu}$ diesen zählt beispielsweise der Zusatznutzen, den umweltverträglichere Produkte und Prozesse beinhalten und der sich bei entsprechender Kommunikation als ergänzender Wettbewerbsfaktor einsetzen läßt und somit die Markt- und Absatzchancen erhöht. Darüber hinaus ergeben sich Möglichkeiten, das Image des Unternehmens weiter zu verbessern und damit auch seine gesellschaftiche Akzeptanz zu erhöhen. Für das Unternehmen bedeutet dies zum einen eine steigende Attraktivität als Arbeitgeber, die sich einerseits in der Loyalität und dem Engagement der Mitarbeiter ausdrückt und andererseits die Rekrutierung neuer Mitarbeiter erleichtert. Zum anderen schlägt sich die gesellschaftliche Akzeptanz auch in der Zusammenarbeit mit verschiedenen Anspruchsgruppen bzw. der Zusammenarbeit mit öffentlichen Stellen nieder. ${ }^{698}$

Umweltorientiertes Unternehmensverhalten bedeutet also auch auf der einzelwirtschaftlichen Ebene nicht zwangsläufig einen Zielkonflikt zwischen Umweltschutz und Kostensenkung bzw. zwischen Umweltschutz und Wettbewerbsfähigkeit. Der Zusammenhang verhält sich vielmehr analog zu dem zwischen Qualitätsverbesserung und Kostensenkung. Diese beiden Ziele wurden ursprünglich ebenfalls als konkurrierend betrachtet, ihre gleichzeitige Erreichbarkeit steht aber mittlerweile außer Frage. Ebenso wie die Qualitätssicherung zur Grundlage der Unternehmensphilosophie gemacht wird, ist auch der betriebliche Umweltschutz in gleichwertiger Weise zu verankern. Dies erfordert allerdings auch die systematische Einbindung des Umweltschutzes in die Unternehmensführung.

\footnotetext{
${ }^{696}$ In der Literatur finden sich auch die Begriffe "End-of-pipe-Technologien" oder kurz "EOP-Technologien".

${ }^{697}$ Vgl. ferner Abschnitt 5.3.4.1. Für weitere Gründe, die gegen die Berücksichtigung 8kologischer Aspekte sprechen vgl. Bleis, C. (1996), S. 54ff.

${ }^{698} \mathrm{Vgl}$. zu den betriebswirtschaftlichen Gründen, die für eine umweltorientierte Ausrichtung der Unternehmensfuhrung sprechen, ferner Pfriem, R. (1989), S. 14-18; Zabel, H.-U. (1994), S. 14; Bleis, C. (1996), S. 47-54.
} 
Das Ziel der nachfolgenden Kapitel ist es daher, die Einbindung des Umweltschutzes in die Unternehmensfuhrung darzustellen. Dabei werden neben den Nutzenpotentialen, die sich aus dem betrieblichen Umweltschutz ergeben, auch eine Reihe von Hemmnissen besonders für kleine und mittlere Unternehmen offenbar, zu deren Beseitigung bislang lediglich unzureichende Ansätze bestehen.

\subsection{Umweltmanagement in kleinen und mittleren Unternehmen}

\subsubsection{Gestaltungsbereiche des Umweltmanagements}

Strategisches Management richtet sich im Rahmen von Lernprozessen auf die schrittweise Schaffung und Sicherung von Erfolgsfaktoren. Eine systematische, ganzheitliche und zukunftsorientierte Unternehmensführung müßte somit neben der ökonomischen und sozialen Dimension auch die ökologische Dimension bei der Entscheidungsfindung berücksichtigen. Dieser Automatismus scheint aber noch immer keine Selbstverständlichkeit zu sein.

Umweltmanagement ist in kleinen und mittleren Unternehmen mit einer Reihe von Problemen behaftet, die sich weitgehend schon im Zuge des Strategischen Managements offenbarten, sich allerdings durch die Komplexität der Umweltthematik weiter verschärfen. ${ }^{699}$ Die Komplexität ergibt sich zum einen aus der hohen Regelungsdichte im Umweltschutz und zum anderen aus den auf die speziellen Belange kleiner und mittlerer Unternehmen nur unzureichend angepaßten Instrumenten des Umweltmanagements. Mit der Konzentration der unternehmerischen Funktion auf eine Person bzw. auf einen kleinen Personenkreis kommt es aufgrund der zusätzlichen Anforderungen durch das Umweltmanagement zu einer Aufgabenüberfrachtung der Unternehmensfuhhrung. Daneben fehlen aber auch speziell für Umweltschutzangelegenheiten qualifizierte Mitarbeiter, die zu einer Entlastung beitragen könnten. Dies hat zur Folge, daß umweltschutzrelevante Informationen kaum systematisch und vorausschauend gesammelt und bewertet werden. Weil der Handlungs- und der Informationsbedarf somit vielfach erst unter Vollzugsdruck entsteht, beraubt sich die Unternehmensführung jedoch der Möglichkeit, aus einer Reihe von Handlungs- und Anpassungsoptionen auswählen zu können.

Die grundlegende Voraussetzung für die Überwindung der vorgenannten Problembereiche ist die Überzeugung, daß eine umweltorientierte Unternehmensführung mit positiven Wertschöpfungswirkungen verbunden ist. Wertschöpfungssteigernde Effekte des Umweltmanagements resultieren aus der systematischen Ermittlung und Ausschöpfung von Rationalisierungspotentialen. Dies erfordert ferner neben einer adäquaten Zielsetzung vor allem eine systematische, funktions- und bereichsübergreifende Betrachtung und Umsetzung umweltorientierter Maß-

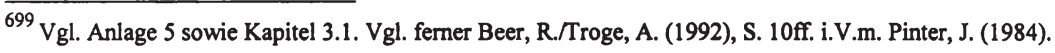


nahmen. Erst mit einer ganzheitlichen, vernetzten Sichtweise wird die Einbeziehung der Querschnittsaufgabe Umweltschutz in alle Handlungsfelder des Unternehmens ermöglicht. ${ }^{700}$ Daneben bedarf es einer zeitlich erweiterten Perspektive, da sich die Strategische Unternehmensführung im wesentlichen an der Beeinflußbarkeit der einzelwirtschaftlich relevanten Zukunft durch heutiges Handeln orientiert und sich folglich auf einen Zeitraum von wenigen Jahren erstreckt. Zur Sicherung des ökonomischen Überlebens orientiert sie sich ausschließlich am ökonomisch meßbaren Erfolg und bewertet die Umwelt danach, wie sie betriebswirtschaftliche Ziele fördert oder hemmt. Umweltmanagement hat als Zeithorizont mehrere Generationen vor Augen, wobei die Umwelt selbst einen Eigenwert besitzt und damit eine Sonderstellung unter den Produktionsfaktoren einnimmt. ${ }^{701}$ Ein der Umwelt zugewiesener Eigenwert impliziert ein differenziertes Umwelt-Verständnis, durch das sie neben dem ökonomischen Wert auch einen sozialen bzw. emotionalen Wert erhält. Folglich stellt sich hier die Überlebensfrage doppelt: Neben dem Überleben des Unternehmens selbst geht es ferner um das Überleben der natürlichen Umwelt. ${ }^{702}$

Die genannten Voraussetzungen für eine erfolgreiche und funktionsfähige Implementierung des Umweltmanagements im Rahmen der Unternehmensführung lassen deutlich erkennen, daß Umweltschutz als eine Führungsaufgabe verstanden werden muß. Ohne die grundsätzlich positive Einstellung der Führung gegenüber dem betrieblichen Umweltschutz sowie der Übernahme einer Promotorenrolle lassen sich keine geeigneten internen Rahmenbedingungen und Strukturen schaffen, die die Bedürnisse und Ziele des Unternehmens und der in ihm tätigen Mitarbeiter zum Ausgleich bringen.

Aufgrund der oben angeführten Problembereiche sind in den wenigsten der kleinen und mittleren Unternehmen Ansätze einer umweltorientierten Unternehmensführung erkennbar, von einer ganzheitlichen Lösung kann sogar nur in Einzelfällen berichtet werden. Die Intention der nachfolgenden Kapitel ist es daher, die wesentlichen Gestaltungsbereiche des Umweltmanagements und die damit verbundenen Problembereiche in kleinen und mittleren Unternehmen aufzuzeigen. Die Gestaltungsaufgabe Umweltmanagement bezieht sich dabei auf den Aufbau eines adäquaten Informationssystems, die technische und organisatorische Einbindung des Umweltschutzes, die Transformation der Unternehmenskultur sowie die Berücksichtigung des Umweltschutzes im Rahmen der Festlegung von Unternehmenszielen und von Unternehmensstrategien. In diesem Zusammenhang liegt die Vermutung nahe, daß es vor allem die besonders erfolgreichen Unternehmen sind, die sich aufgrund ihrer Innovativität auch hin-

\footnotetext{
700 Vgl. FUUF (1991), S. $51 \mathrm{f}$.

${ }^{701}$ Zur Umwelt als Produktionsfaktor vgl. z.B. Immler, H. (1990), S. 49-52; Dyckhoff, H. (1991), S. 275-304; Hartwig, K.-H. (1995), S. 125ff.; Haasis, H.-D. (1996), S. 16; Hahlen, J. (1997), S. 93. Steven, M. (1991), S. 521 , zeigt in diesem Zusammenhang jedoch auf, "daß 'Umwelt' nicht gleichrangig zu den klassischen Faktoren in ein Produktionsfaktorensystem integriert werden kann, da sie grundsätzlich unterschiedliche Eigenschaften aufweist: natürliche Ressourcen sind in sämtlichen Produktionsfaktoren implizit enthalten".

${ }^{702}$ Vgl. Stitzel, M./Wank, L. (1990), S. 109-112.
} 
sichtlich der Umweltorientierung und dem Einsatz von Instrumenten des Umweltmanagements deutlich von den übrigen Unternehmen absetzen. ${ }^{703}$.

\subsubsection{Umweltorientierte Analyse des Unternehmensumfeldes}

Ausgangspunkt für die Entwicklung eines Umweltmanagementsystems als Teilaufgabe der Unternehmensführung ist die Bereitstellung entscheidungsrelevanter Informationen. Das Ziel ist auch hier das frühzeitige Erkennen von Trendbrüchen und Diskontinuitäten. Zu diesem Zweck müssen die in Abschnitt 3.3.2 vorgestellten Instrumente zur Analyse der unternehmensexternen Einflußfaktoren um ökologische Belange erweitert werden, so daß sie in der Lage sind, auch die ökologischen Chancen und Risiken der Unternehmensaktivitäten abzubilden. Der Rückgriff auf externe Informationsquellen ist dabei für kleine und mittlere Unternehmen deshalb von besonderer Bedeutung, weil sich in ihnen umweltrelevante Kompetenzen vielfach erst noch entwickeln müssen.

Für die Sammlung umweltrelevanter Informationen über die unternehmensexternen Rahmenbedingungen können die bereits diskutierten innovationsrelevanten Informationsquellen herangezogen werden. ${ }^{704}$ Mit ihrer systematischen Nutzung lassen sich ökologierelevante Veränderungen im Makro-Umfeld des Unternehmens erkennen. ${ }^{705}$ Von hoher Bedeutung für kleine und mittlere Unternehmen des Verarbeitenden Gewerbes sind in diesem Zusammenhang Informationen über die unternehmensrelevanten Umweltvorschriften sowie Möglichkeiten ihrer technologischen Erfüllung (Ökologie-Pull). ${ }^{706}$ Die Beobachtung, Analyse sowie letztlich auch die Einhaltung der Normen und Gesetze im Umweltschutz sind aufgrund des Umfangs der Regelwerke bzw. der Vielzahl der Änderungen mit großen Schwierigkeiten verbunden. Dennoch bildet ihre Einhaltung das Fundament des Umweltmanagements und dient gleichzeitig der Sicherung der rechtlichen Legitimität des Unternehmens. Im Zuge eines innovativ verstandenen Umweltmanagements kann somit die Antizipation von Normen und Gesetzen wettbewerbsstrategische Bedeutung erlangen. Informationen über umweltrelevante Normen und Gesetze halten beispielsweise Kammern und Verbände vor. Sie informieren auch über staatli-

${ }^{703}$ Vgl. dazu auch Schmidheiny, S. (1992), S. 38: "Gerade die wettbewerbsfähigsten und erfolgreichsten Unternehmen stehen bezüglich Öko-Effizienz in vorderster Reihe". Ähnlich äußert sich auch Fritz, W. (1995), S. 350.

${ }^{704}$ Aus diesem Grund wird von einer detaillierten Darstellung abgesehen. Daraus ist jedoch nicht auf eine untergeordnete Bedeutung umweltrelevanter Informationen zu schließen. Umweltschutz ist ein wesentlicher Bestandteil von Produkt- und Prozeßinnovationen, für deren Erfolg wiederum Informationen die Grundlage bilden. $\mathrm{Zu}$ den innovationsrelevanten Informationsquellen vgl. Abschnitt 4.3.2. sowie ferner Beer, R./Troge, A. (1992), S. 52-76, die umweltrelevante Informationsquellen untersuchten und zu ganz ähnlichen Ergebnissen wie die vorliegende Untersuchung gelangen.

${ }^{705}$ Vgl. dazu ausfuhrlich Meffert, H./Kirchgeorg, M. (1993), S. 62-86 sowie ferner Hopfenbeck, W. (1997), S. 779ff.; Jahnes, S. (1997), S. 33-36.

${ }^{706}$ Die Erfassung und Dokumentation von Umweltvorschriften sowie die Ermittlung des Informations- und Bildungsbedarfs im Umweltschutz sind beispielsweise auch zentrale Bestandteile der ersten Umweltprüfung im Rahmen des EG-Öko-Audits (vgl. Abschnitt 5.3.3.1). 
che Mittel zur Förderung von Umweltschutzmaßnahmen. Gerade hier zeigen sich jedoch massive Informationsdefizite bei kleinen und mittleren Unternehmen. So haben ca. $90 \%$ der in der Region Neckar-Alb befragten Unternehmen noch keine staatlichen Mittel zur Förderung von Umweltschutzmaßnahmen erhalten bzw. beantragt, da u.a. Fördermöglichkeiten, -voraussetzungen und -konditionen unbekannt sind oder die Einschätzung der Attraktivität zu schwierig ist. ${ }^{707}$ Informationen über Umweltschutztechnologien lassen sich auch über den Besuch von Messen, Kongressen und Ausstellungen, über die Fachliteratur oder über Hochschulen und Berater gewinnen. Ein weiterer Schwerpunkt der Informationssammlung ist die Analyse gesellschaftlicher Entwicklungen. Da die gesellschaftliche Legitimität des Unternehmens zunehmend durch dessen Haltung in Fragen des Umweltschutzes bestimmt wird, erhält der Informationsaustausch mit den gesellschaftlichen Anspruchsgruppen hohe Relevanz. ${ }^{708}$

In Ergänzung zur globalen Analyse des Umfeldes müssen auch umweltschutzinduzierte Veränderungen der Branchen-, Wettbewerbs- bzw. Marktsituation erfaßt werden. Sie resultieren zum Teil aus der Reaktion auf die Veränderung der Rahmenbedingungen. Beispielsweise führt das Verbot bestimmter Produkte, wie dies beispielsweise bei FCKW oder Asbest der Fall war, zu einem "Wegbrechen" der Märkte für diese Produkte. Dies und die Suche nach geeigneten Alternativen führt zum Entstehen neuer Märkte, aber auch zu Verschiebungen der Wettbewerbskräfte bzw. der Branchenstruktur. Teilweise sind Veränderungen aber auch selbstmotiviert (Ökologie-Push). Dann nämlich, wenn latent vorhandener Bedarf von innovativen Unternehmen mit entsprechenden Produkten gedeckt wird. Die Nutzung der sich daraus ergebenden Marktpotentiale beeinflußt erneut zum einen die Wettbewerbsverhältnisse und zum anderen die Branchenstruktur.

\subsubsection{Umweltorientierte Analyse der internen Unternehmenssituation}

Die Beurteilung und adressatengerechte Bereitstellung von Informationen über die Umweltverträglichkeit von Produkten oder Produktionsprozessen erfordert adäquate Informationssysteme im Unternehmen. Dabei lassen sich die in Abschnitt 3.3.3 dargestellten Instrumente - die Wertkettenanalyse, die Funktionsbereichsanalyse und die Portfolioanalyse - an die Erfordernisse umweltorientierter Entscheidungen anpassen. Neben diesen zukunftsgerichteten und damit strategisch orientierten Planungsverfahren haben sich in den letzten Jahren weitere, die spezifischen Belange des Umweltmanagements berücksichtigende Informations- und Planungsinstrumente entwickelt. Die eher auf einer ex post-Betrachtung aufbauenden, operativ ausgerichteten Analyseinstrumente eignen sich sowohl für Diagnose- und Kontrollzwecke als auch zur Berichterstattung über die Maßnahmen und Wirkungen umweltorientierten unter-

${ }_{707}^{7 g l . ~ F r a g e ~} 4 / 13$ des Fragebogens im Anhang sowie Anlage 30.

${ }^{708}$ Dabei wird die Kommunikation mit den gesellschaftlichen Anspruchsgruppen z.B. durch den Einsatz von Öko-Bilanzen oder das EG-Öko-Audit erleichtert. 
nehmerischen Handelns. Zu ihnen zählt die Erweiterung des betrieblichen Rechnungswesens durch die ökologische Buchhaltung nach MüLLER-WENK sowie die Erweiterung des Controlling z.B. durch den Umweltbericht, die Öko-Bilanz und das EG-Öko-Audit. ${ }^{709}$

$\mathrm{Da}$ es sich bei den Instrumenten zur umweltorientierten Analyse der internen Unternehmenssituation nicht ausschließlich um Adaptionen bereits vorhandener Instrumente handelt, erscheint ihre ausführliche Darstellung gerechtfertigt. Dazu werden in einem ersten Schritt die operativen und in einem zweiten Schritt die strategischen Instrumente des Umweltmanagements aufgezeigt.

\subsubsection{Operative Instrumente des Umweltmanagements}

Das betriebliche Rechnungswesen stellt das zentrale Element eines betrieblichen Informationssystems zur Unterstützung der Planung, Steuerung und Kontrolle unternehmerischen Handelns dar. Für die Abbildung umweltrelevanter und quantifizierbarer Beziehungen und Vorgänge im Unternehmen, muß das betriebliche Rechnungswesen auf diese Anwendung hin adaptiert bzw. ökologisch erweitert werden. ${ }^{710}$ Erste Anpassungsversuche wurden von MüLLER-WENK ${ }^{711}$ vorgenommen. Sein System einer ökologischen Buchhaltung stellt die erste umfassende Konzeption eines Meß- und Informationssystems dar, mit dessen Hilfe auch derjenige Teil unternehmerischen Handelns kontinuierlich überprüft werden soll, dessen Auswirkungen nicht durch den Markt sanktioniert werden. Daruber hinaus soll kenntlich gemacht werden, inwieweit dieses Handeln zu einer Erhöhung bzw. zu einer Reduzierung von gesellschaftlichen Kosten bzw. Nutzen führt. ${ }^{712}$

Entsprechend lassen sich Umweltkosten in zwei Gruppen untergliedern. Sie werden einmal durch das Umweltmanagement induziert und fallen damit zusätzlich an, um mittels prozeßin-

${ }^{709}$ Neben der Unterscheidung nach Zielhorizont und Zukunftgerichtetheit, die die Instrumente in strategisch und operativ ausgerichtete einteilt, lassen sie sich auch nach ihren Funktionen bzw. nach ihrem Objektbezug differenzieren. Vgl. dazu sowie für eine Aufstellung weiterer Ansătze 8kologisch orientierter Informations- und Planungsinstrumente Meffert, H./Kirchgeorg, M. (1993), S. 105f. sowie ferner Günther, E./Wagner, B. (1993), S. 147-156; Stahlmann, V. (1994), S. 156-171; Schaltegger, S./Kempke, S. (1996), S. 150-160.

${ }^{710}$ Bez. der Unzulänglichkeiten des betrieblichen Rechnungswesens im Hinblick auf okologische Belange vgl. z.B. Stahlmann, V. (1994), S. 147-150.

711 Vgl. Müller-Wenk, R. (1978).

${ }^{712}$ Vgl. Müller-Wenk, R. (1978), S. 10 sowie ferner Zahn, E./Schmid, U. (1992), S. 43.

Zentrales Element des Konzeptes der ökologischen Buchhaltung nach Maller-Wenk ist die Berechnung von Äquivalenzkoeffizienten, die ökologische Knappheiten widerspiegeln. Für eine ausführliche Darstellung sowie die Wirkungen des Einsatzes dieses Instrumentes vgl. Müller-Wenk, R. (1978), S. 35-48 und 69-105. Kritische Anmerkungen finden sich bei Steger, der in Muller-Wenks Konzept prinzipielle Probleme ausmacht: "Wenn die Informationen bekannt sind, die zur Bestimmung der Äquivalenzkoeffizienten notwendig sind, können auch (Knappheits-) Preise bestimmt werden, mithin wäre ein separates (Öko-) Rechnungssystem überflüssig. Letztlich läuft es auch bei Müller-Wenk darauf hinaus, daß eine staatliche Instanz nach normativen Vorgaben die Äquivalenzkoeffizienten und damit die Knappheiten bestimmt, was lediglich eine Verlagerung, aber keine Lösung des Problems bedeutet." Steger, U. (1988), S. 205. Vgl. bez. der Kritik ferner Pfriem, R. (1986), S. 221 ff.; Meffert, H./Kirchgeorg, M. (1993), S. 121f.; Stahlmann, V. (1994), S. $167 f$. 
tegrierten oder nachsorgenden Technologien ein bestimmtes Ziel an Ökologieverträglichkeit der Produkte und Prozesse zu erreichen. Daneben fallen vom Unternehmen zu tragende, d.h. $\mathrm{zu}$ internalisierende, Kosten der Umweltbeanspruchung an. Sie umfassen Kosten aus unterlassenen Umweltschutzmaßnahmen bzw. aus unzulänglicher Ökologieverträglichkeit wie beispielsweise Umwelt- und Produkthaftungen, Opportunitätskosten aus entgangenen Erlösen, Mehraufwand, Entsorgungsaufwand oder sunk costs. ${ }^{713}$

Das betrieblich-ökologische Rechnungswesen fungiert im Rahmen einer umweltorientierten Unternehmensfuhrung als Steuerungshilfe zu einer immer besseren, annähernd idealen Kreislaufwirtschaft. Indem es den gesamten Produktlebenszyklus steuernd begleitet, fuihrt es letztlich von der Entsorgung über die Verwertung zur Verminderung und Vermeidung von Abfall. Es ist im Sinne eines "environmental auditing" ferner geeignet, z.B. auch Eingang in die Kreditwürdigkeitsprüfung der Banken zu finden. Ökologisches Wirtschaften, dokumentiert im Rechnungswesen des Unternehmens, erhält im Hinblick auf die langfristige Investitions- und Finanzplanung sowie die Offenlegung umweltbezogener Risiken dann auch strategisch bedeutende Dimensionen. Hinzu kommen positive Auswirkungen auf das Image in der Öffentlichkeit. $^{714}$

Mit der Abbildung komplexer umweltrelevanter Informationen ist das traditionelle Controlling durch seine Beschränkung auf im Rechnungswesen abgebildete oder abbildbare Informationen überfordert. Will das Unternehmen aktiv den zuküntigen ökologisch induzierten Herausforderungen begegnen, ist ein Instrumentarium notwendig, das frühzeitig auf diese Entwicklungen hinweist. Für eine adäquate Informations- und Komplexitătsreduktion umweltrelevanter Daten im betrieblichen Entscheidungsprozeß bietet das ökologieorientierte Controlling bzw. Umweltcontrolling ${ }^{715}$ eine Reihe von Instrumenten an. Mittels ihrer quantitativen und qualitativen Ergebnisse werden Entscheidungsträger in die Lage versetzt, ökologische Schwachstellen und Risiken zu erkennen bzw. Chancen, Leistungen und Vorsprünge des Unternehmens gegenüber Wettbewerbern aufzuzeigen.

Zum Begriff des "Umweltcontrolling" findet sich in der Literatur ein ähnlich breites Spektrum an Definitionen wie zum Begriff des "Controlling". ${ }^{116}$ Das Umweltcontrolling soll die beste-

${ }^{713}$ Vgl. Zabel, H.-U. (1994), S. 22. Für eine Aufstellung der Kostenarten im betrieblichen Rechnungswesen vgl. Müller, C. (1995), S. 144-149. Eine allgemeinere Definition bietet Hamm an, indem er als umweltrelevante Kosten "diejenigen Kosten bezeichnet, die dem Unternehmen aus Großen entstehen, die am Markt mit Umweltschutz in Verbindung gebracht werden". Hamm, U. (1997), S. 271 bzw. S. 276-280, wo weitere Definitionen aufgezeigt und diskutiert werden.

${ }^{714}$ Vgl. Malinsky, A.H./Seidel, E. (1994), S. 42-45.

${ }^{715}$ Untersuchungen zum Umweltcontrolling v.a. in mittelständischen Unternehmen des Produzierenden und Verarbeitenden Gewerbes wurden beispielsweise von Hallay, H. (1990); Hallay, H./Pfriem, R. (1992); Hummel, J. (1997) durchgeführt.

${ }^{716}$ Die große Bandbreite von Ansătzen zum ökologieorientierten Controlling wird begleitet von einer umfangreichen Varietăt der verwendeten Begriffe, wie z.B. Umwelt-Controlling, Öko-Controlling, ökologisches Con- 
henden Verfahren und Instrumente des betrieblichen Controlling durch eine ökologische Dimension erweitern und auf alle Funktionsbereiche und Prozesse des Unternehmens übertragen, um ein ressourcenorientiertes Handeln aller Mitarbeiter sowohl unter Unternehmens- als auch unter Umweltgesichtspunkten zu ermöglichen. Das Umweltcontrolling ist damit entscheidend an der nachhaltigen Entwicklung des Unternehmens beteiligt. ${ }^{717}$

Ziel bei der Entwicklung eines geeigneten Instrumentariums des Umweltcontrolling ist es, ein managementorientiertes Planungs-, Steuerungs- und Kontrollinstrument zur Verfügung zu stellen, mit dessen Hilfe auf allen betrieblichen Ebenen umweltorientierte Entscheidungen getroffen werden können. Das Umweltcontrolling übernimmt somit die auf umweltspezifische Belange angepaßten Funktionen der Analyse, Planung und Koordination, Durchsetzung und Steuerung sowie Kontrolle und Regelung. ${ }^{718}$

Die erfolgreiche Implementation des Umweltcontrolling im Unternehmen muß sich an den bestehenden Produktions- und Organisationsstrukturen orientieren und ist an verschiedene Voraussetzungen gebunden. Für die Schaffung der notwendigen formalen Strukturen innerhalb des Unternehmens mulssen gegebenenfalls interne oder externe Promotoren eingesetzt werden, die diesen Prozeß begleiten und unterstützen. Daneben ist die frühzeitige Einbindung aller Organisationsmitglieder anzustreben, da hierdurch Durchsetzungsbarrieren verringert bzw. Motivations- und Innovationspotentiale freigesetzt werden können. Ferner muß das Umweltcontrollinginstrumentarium in einem evolutorischen Prozeß auf Alternativen zu bestehenden Strukturen und Strategien hinweisen und Schwachstellen und Optimierungspotentiale aufzeigen. ${ }^{719}$ Dadurch erhält das Umweltcontrolling auch eine strategische Bedeutung.

In der Praxis zeigt sich allerdings, daß die verfügbaren Instrumente des Umweltcontrolling zu komplex und damit zu wenig anwendungsorientiert sind. Sie werden somit ihrer ursprünglichen Aufgabe, der Komplexitätsreduktion, kaum gerecht. Da die Vielschichtigkeit des Themas Umweltschutz sowie die ungewohnten Bewertungsunsicherheiten viele Unternehmen überfordern, wiegt dieser Nachteil um so schwerer. ${ }^{720}$ Vor allem für kleine und mittlere Un-

trolling, 8kologisch orientiertes Controlling etc. In dieser Arbeit wird der Begriff "Umweltcontrolling" gewăhlt, ohne daß damit die Prăferenz für ein bestimmtes Konzept zum Ausdruck kommen soll.

${ }^{717}$ Vgl. Schaltegger, S./Kempke, S. (1996), S. 150. Zur Definition des Umweltcontrolling vgl. stellvertretend den Vorschlag von Pfriem, R./Hallay, H. (1992), S. 296 i.V.m. Günther, E./Wagner, B. (1993), S. 144: Umweltcontrolling ist ein Instrument zur Analyse, Planung, Steuerung und Kontrolle aller umweltrelevanten Aktivităten des Unternehmens das durch 8kologieorientierte, funktionen- und unternehmensübergreifende Informationsgewinnung sowie durch quantitative und/oder qualitative Informationsauswertung eine Grundlage für zukunftsorientierte, operative und strategische Entscheidungen der Unternehmensführung liefert. Vgl. ferner Butterbrodt, D. u.a. (1995), S. 17.

${ }^{718}$ Vgl. Hallay, H./Pfriem, R. (1992), S. 33; Günther, E./Wagner, B. (1993), S. 144-147; Steinhilper, R./Friedel, A. (1996), S. 398. Vgl. dazu allgemein Bleis, C. (1996), S. 75-86.

${ }^{719}$ Zur Implementation eines Umweltcontrollingsystems in der Praxis vgl. insb. Hallay, H./Pfriem, R. (1992), S. 47-56; Pfriem, R/Hallay, H. (1992), S. 308. Vgl. ferner BMU/Umweltbundesamt (Hrsg.) (1995).

${ }^{720}$ Vgl. Günther, E./Wagner, B. (1993), S. 156. 
ternehmen erwachsen aus dieser Situation besondere Probleme. Fehlendes Expertenwissen bzw. mangelnde Zeit, sich mit der Thematik auseinanderzusetzen, oder Finanzierungsprobleme führen zu Ablehnung oder Aufschub. Dies spiegelt sich auch in den Ergebnissen der zugrundeliegenden Untersuchung wider. Nur wenige Unternehmen waren in der Lage, Investitionen in den Umweltschutz zu quantifizieren bzw. hinsichtlich der Emissionsart zu differenzieren, was auf ein unzureichendes Umweltcontrolling - und damit letztlich auch auf ein generell unzureichendes Controlling - schließen läßt. ${ }^{721}$

Neben Informationen über die entstehenden Emissionen und Abfälle muß das betriebliche Controlling auch Daten uber den Ressourcenverbrauch, die eingesetzten Stoffe und deren Verbleib sowie potentielle Gefahrenquellen liefern. Voraussetzung dafür, daß der Analyseprozeß zu aussagefähigen Ergebnissen führt, ist die wirkungsvolle Vernetzung der einzelnen Unternehmensbereiche sowie die Initiierung von Lernprozessen, um eine evolutorische Weiterentwicklung des Unternehmens zu ermöglichen. ${ }^{722}$ Der Nutzen eines Umweltcontrolling liegt zusammengefaßt in der

- Deckung der Informationsbedürfnisse von seiten der Banken, Kapitalgeber, Versicherungen bzw. von Kunden und Abnehmern,

- Nachweismöglichkeit der Umweltschutzanstrengungen gegenüber ökologieorientierten Anspruchsgruppen,

- Offenlegung betrieblicher Chancen und Risiken,

- Offenlegung von Ressourceneinsparungspotentialen und damit Kostensenkungspotentialen sowie

- Erhöhung der Effizienz von Umweltinvestitionen.

Das betriebliche Controlling und mit ihm das Umweltcontrolling benötigen ein funktionsspezifisches Informationsversorgungssystem, das eine systembildende und systemkoppelnde Koordination der Daten und Informationen ermöglicht. ${ }^{723}$ Vor diesem Hintergrund wurde im Rahmen der Untersuchung u.a. auf die Instrumente Umweltbericht, Öko-Bilanz und EG-ÖkoAudit abgehoben. Von diesen Instrumenten konnte erwartet werden, daß sie den höchsten Bekanntheitsgrad und damit auch den höchsten Verbreitungsgrad aufweisen.

Umweltberichte oder Umwelterklärungen stellen die einfachsten der hier dargestellten Informations- und Kommunikationsinstrumente im Rahmen der Umweltpolitik eines Unternehmens dar. Im Gegensatz zum "Umweltbericht", der noch nicht gesetzlich definiert oder

\footnotetext{
${ }^{721}$ Vgl. Frage 4/12 des Fragebogens im Anhang. Da lediglich ein Drittel der befragten Unternehmen zu dieser Frage Angaben machten, mußte von einer Auswertung abgesehen werden.

${ }^{722}$ Vgl. Servatius, H.-G. (1992), S. 103.

${ }^{723}$ Vgl. Butterbrodt, D. u.a. (1995), S. 23.
} 
normiert ist, liegen für die "Umwelterklärung" mit der EG-Öko-Audit-Verordnung Kriterien über Ziel und Inhalt vor. ${ }^{724}$

Als Instrument zur Unterstützung der Unternehmensführung dient der Umweltbericht einerseits der Dokumentation der betrieblichen Umweltaktivitäten sowie andererseits der Erfolgskontrolle und Planungshilfe. Neben diesen unternehmensplanerischen Aspekten unterstützt die Erstellung und Dokumentation des Berichts auch den Dialog mit externen und internen Anspruchsgruppen. Hervorzuheben ist in diesem Zusammenhang der starke Einfluß, den das in dieser Weise dokumentierte Engagement des Unternehmens auf die Motivation der Mitarbeiter haben kann.

$\mathrm{Zu}$ den notwendigen Voraussetzungen für die Erstellung des Berichts zählen das Vorliegen von Umweltleitlinien, -programmen und -zielen, eines etablierten bzw. im Aufbau befindlichen Umweltmanagementsystems, von Informationen und Daten zu Stoff- und Energieströmen sowie von Ergebnissen bereits durchgefuhrter Audits. Auf der Basis dieser Daten lassen sich dann die vom Unternehmen ausgehenden Umweltwirkungen analysieren und bewerten.

Für die Veröffentlichung sollte der Umweltbericht verschiedenen Anforderungen gerecht werden, zumal das Unternehmen dadurch in einen Dialog mit den relevanten Anspruchsgruppen tritt. Der Bericht sollte folglich in der Lage sein, diesen Dialog zu unterstützen, indem eine glaubwürdige und erschöpfende Darstellung der Daten, die den unterschiedlichen Ansprüchen der Zielgruppen gerecht wird, erfolgt. Letztlich sollte auch eine Integration in das Kommunikationskonzept des Unternehmens stattfinden, um Überschneidungen oder Widersprüche zu vermeiden. Der Umweltbericht als Vorstufe oder Teil einer Öko-Bilanz bzw. des EG-Öko-Audit zielt auf die Schaffung eines Vertrauensverhältnisses mit den internen und externen Anspruchsgruppen ab, das letztlich auch der Existenzsicherung des Unternehmens dient.

Betriebliche Tätigkeiten beeinflussen direkt oder indirekt die natürliche Umwelt. Als Orientierungshilfe zur Komplexitätsreduktion, Thematisierung und Akzentuierung seines ökologischen und ökonomischen Handelns benötigt der Unternehmer Informationen über diese Eingriffe. Mit der Öko-Bilanz ${ }^{725}$ steht ein Instrument zur Verfügung, mit dem die ökologischen

${ }^{724}$ Die Anforderungen, die die EG-Öko-Audit-Verordnung an die Erstellung einer Umwelterklărung stellt, finden sich in Artikel 5 i.V.m. Anhang I B Nr. 3 der Verordnung. Sie stellen eine sinnvolle und fundierte Grundstruktur eines Umweltberichts dar. Vgl. bez. Ziel, Inhalt und Vorgehensweise bei der Erstellung von Umweltberichten bzw. -erklärungen auch im folgenden Clausen, J./Fichter, K. (1994). Für Praxisbeispiele zur Umweltberichterstattung vgl. z.B. Hopfenbeck, W./Jasch, C. (1993).

Teilweise besteht durch bestimmte Gesetze und Verordnungen auch die Verpflichtung zur Bereitstellung umweltrelevanter Daten. Regelungen hierzu finden sich im Immissionsschutzgesetz (BImSchV, BImSchG), im Wasserreinhaltungsgesetz (AbwAG), im Abfallwirtschaftsgesetz (Landesgesetze) sowie in der Störfallverordnung (StörfallVO).

${ }^{725}$ Die Literatur zur Thematik "Öko-Bilanz" hat trotz der erst seit kurzem bestehenden Diskussion bereits umfangreiche Ausmaße angenommen. Eine ausfuhrliche Beschreibung des Instruments findet sich z.B. bei 
Wirkungen der Unternehmensaktivitäten abgebildet und bewertet werden können. Die ÖkoBilanz dient im Hinblick auf eine strategisch, ökologisch orientierte Unternehmenspolitik als Kontroll- und Planungsinstrument und als Entscheidungshilfe. Intern unterstützt sie die Planung und Entwicklung umweltverträglicher Produkte und Produktionsverfahren sowie die Steuerung und Kontrolle. Als Kommunikationsinstrument unterstützt sie den externen Dialog zwischen Unternehmen und Umfeld. Die verschiedenen Öko-Bilanz-Ansätze gehen dabei auf eine gemeinsame Grundlage zurück, den ersten Hauptsatz der Thermodynamik - den Energieund Massenerhaltungssatz -, nach dem die Menge des Inputs der des Outputs entsprechen muß. Die in den betrachteten Bilanzraum einfließenden Stoffe und Energien werden unmittelbar oder über Vorstufen aus der Umwelt entnommen. Im Produktionssystem werden sie durch Produktionsprozesse transformiert und verlassen das System als erwünschter Output, d.h. als Hauptprodukt oder warenförmige Kuppelprodukte oder als unerwünschter Output, d.h. als nicht warenförmige Kuppelprodukte wie z.B. Abfälle, Abwasser, Abluft oder Abwärme.

\section{Abb. 5-1: Schema einer Stoff- und Energiebilanz ${ }^{726}$}

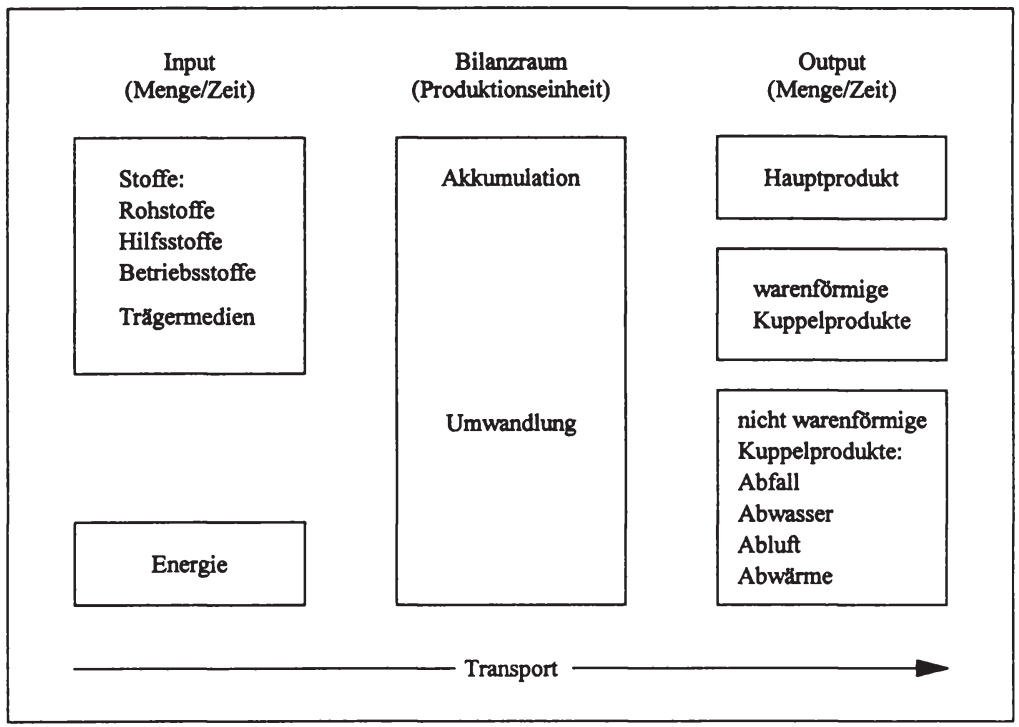

Hallay, H. (1990), S. 30-40 und Hallay, H./Pfriem, R. (1992), S. 57-90. Für eine Diskussion verschiedener Ansätze als Basis für Unternehmensőkobilanzen vgl. Pfriem, R. (1986); Kaimer, M./Schade, D. (1994). Vgl. ferner die Beispiele in Beschorner, D. (1990) insb. für Verpackungssysteme, in Stolting, P./Rubik, F. (1992) und in Umweltbundesamt (Hrsg.) (1992) insb. für Produktokobilanzen, in Ehrnsperger, F. (1994), S.19-31 und Stahlmann, V. (1994), S. 169-216 für die Neumarkter Lammsbrău, in Schaltegger, S./Sturm, A. (1995), S. 94-113 für die Mohndruck Graphische Unternehmen GmbH sowie zahlreiche weitere Beispiele in Hopfenbeck, W./Jasch, C. (1993).

${ }^{726}$ Vgl. z.B. Beschorner, D. (1990), S. 164; Hopfenbeck, W. (1994), S. 499; Prammer, H.K. (1996), S. 212. 
Wie die vorstehende Abbildung zeigt, lassen sich Öko-Bilanzen für verschiedene Betrachtungsebenen aufstellen (Teilbilanzen). Sie können das Unternehmen als Ganzes (Input-/ Output- bzw. Betriebsbilanz), einzelne Prozesse (Prozeßbilanz) oder einzelne Produkte (Produktbilanz) umfassen. Daneben lassen sich in einer Substanzbetrachtung weitere ökologisch relevante Aspekte wie beispielsweise Bebauung oder Altlastensanierung aufzeigen. Grundlage für die Erstellung der einzelnen Stoff- und Energiebilanzen sind Informationen aus internen und externen Informationsquellen. ${ }^{727}$

\section{Abb. 5-2: Das Konzept der Stoff- und Energiebilanzierung}

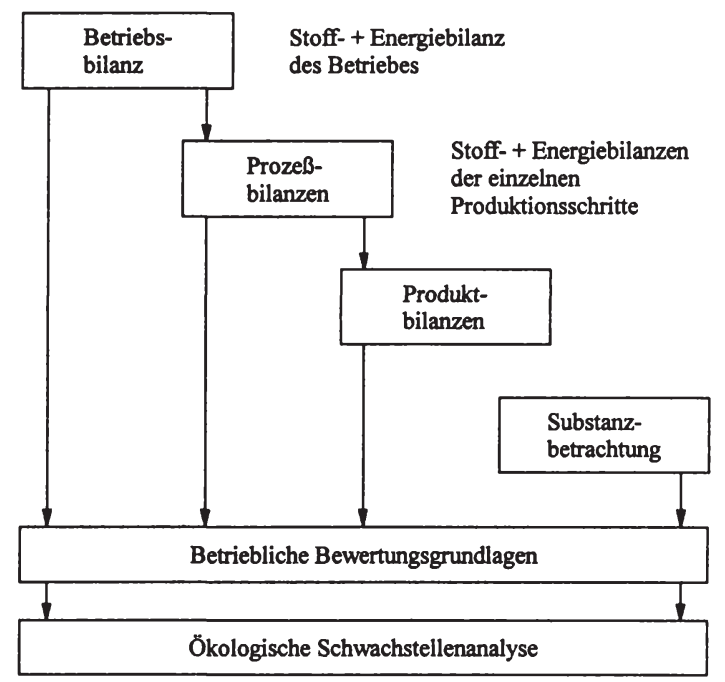

Quelle: $\quad$ Hallay, H./Pfriem, R. (1992), S. 59.

Die Betriebsbilanz dient als Ausgangspunkt der Betrachung. In ihr werden auf höchster Aggregationsebene der stoffliche und energetische Input dem Output aus Produkten sowie stofflichen und energetischen Emissionen eines Unternehmens gegenübergestellt. Eine Teilbilanz der Betriebsbilanz ist die Abfallbilanz, in der nicht mehr im Produktionsprozeß verwendbarer Output Eingang findet. Innerbetriebliche Prozesse werden in der Betriebsbilanz nicht berücksichtigt (Black-box). Die Betriebsbilanz bietet damit einen gesamthaften Überblick über Art und Menge der durchfließenden Stoffe und Energien und erlaubt durch die ökologische Bewertung der Input-Output-Relationen die Erstellung einer Schwachstellenanalyse bzw. die

${ }^{727}$ Vgl. auch im folgenden Hallay, H./Pfriem, R. (1992). 
Erarbeitung eines Maßnahmenkatalogs. Beide können dann als Orientierungshilfen für den betrieblichen Umweltschutz dienen.

Bei der Betrachtung betrieblicher Prozesse (Prozeßbilanzen) stehen stofflich-energetische Umweltwirkungen, die von den Transformationsprozessen ausgehen, im Vordergrund. In Abhängigkeit des gewählten Bezugsrahmens reicht die Betrachtungsdimension vom gesamten betrieblichen Umwandlungsprozeß über bestimmte Teilprozesse (Produktion, Lagerhaltung, Verwaltung etc.) bis zu einzelnen Maschinen oder einzelnen Arbeitsplätzen.

Produktbilanzen erfassen die Umweltwirkungen, die von Produkten ausgehen. In einer verkürzten Betrachtung kann ausschließlich der Herstellungsprozeß innerhalb des Unternehmens einbezogen sein. Da die ökologische Produktverantwortung des Produzenten über den direkten Einflußbereich hinausgeht, sind auch die der im eigenen Unternehmen stattfindenden Produktion vor- und nachgelagerten Produktions-, Distributions- und Konsumtionsphasen zu berücksichtigen. Das heißt, Produktbilanzen bilden die erzeugten Produkte uber ihren gesamten Lebenszyklus hinweg ab. ${ }^{728}$

In der Substanz- oder Standortbilanz werden die zeitraumübergreifenden, strukturellen Belastungen des Naturhaushalts durch das Unternehmen erfaßt. Hierzu gehören dauerhafte betriebliche Umweltnutzungen (wie z.B. Flächennutzung oder Bebauung ${ }^{729}$ ) und dauerhafte Beeinträchtigungen der Umwelt durch den Betrieb (wie z.B. Boden- oder Gewässerverunreinigungen).

Das Instrumentarium der Ökobilanzen verschafft einen Überblick über die umweltrelevanten Wirkungen unternehmerischen Handelns. Analog zur traditionellen Bilanzierung sollten ökobilanzielle Bewertungsverfahren ebenfalls den Anforderungen Vollständigkeit, Transparenz, Nachvollziehbarkeit und Einheitlichkeit sowie Flexibilität, Praktikabilität und Wirtschaftlichkeit gerecht werden. ${ }^{730}$ Damit wird es u.a. möglich, ökologische Qualitätskriterien $\mathrm{zu}$ berücksichtigen, Schwachstellen aufzudecken und $\mathrm{zu}$ analysieren, den Informationsbedarf der internen und externen Anspruchsgruppen zu decken sowie Soll-/Ist-Vergleiche durchzuführen.

\footnotetext{
${ }^{728}$ Bei der Betrachtung des Produktlebenszyklus unterscheiden Hallay, H./Pfriem, R. (1992), S. 39f., fünf Wirkungsphasen: Stoff- und Energieentnahme aus der Natur, Produktion (Vorproduktion, Produktion im betrachteten Unternehmen und Weiterverarbeitung), Verbrauch bzw. Konsum, Entsorgung sowie Transport zwischen und innerhalb der Phasen.

${ }^{729}$ Beispiele zur Verminderung von Umweltbeeinträchtigungen durch baubiologischen Industriebau zeigt Winter, G. (1988), S. 31f., auf.

${ }^{730}$ Vgl. dazu ausführlich Prammer, H.K. (1996), S. 233-241, der zugleich eine Evaluation ökobilanzieller Bewertungsverfahren vornimmt. Zu den Anwendungsproblemen von Ökobilanzen vgl. z.B. Stölting, P./Rubik, F. (1992), S. 3-12.
} 
Ein weiteres Instrument im Rahmen des Umweltcontrolling stellt das EG-Öko-Audit dar. Die EG-Verordnung zum Umwelt-Audit unterstreicht die Rolle und die Verantwortung der Unternehmen sowohl für die Stärkung der Wirtschaft als auch für den Schutz der Umwelt in der Europäischen Gemeinschaft. Vor diesem Hintergrund entstand die EG-Verordnung Nr. 1836/93 (EG-Öko-Audit-Verordnung) zur gemeinschaftlichen Umweltmanagement- und Betriebsprüfungsregelung. ${ }^{731}$ Die Verordnung ermöglicht die selbständige Implementierung des Umweltschutzes im Unternehmen und schafft gleichzeitig einen Rahmen für die Teilnahme an einem Umweltmanagement- und Betriebsprüfungssystem.

Die Umwelt-Audit-Verordnung steht unter der Leitidee des "sustainable development" ${ }^{\prime 732}$. Sie greift die Eigenverantwortung der Unternehmen für den Umweltschutz auf und strebt die Berücksichtigung des Umweltschutzes im Rahmen der Unternehmensführung an. Die schriftliche Dokumentation erhöht dabei die Transparenz nach innen und außen. Das EG-Öko-Audit als Teil eines Umweltmanagementsystems wird somit Teil des gesamten übergreifenden Managementsystems. Dieses Umweltmanagementsystem schließt die Organisationsstruktur,

${ }^{731}$ Vgl. Verordnung (EWG) des Rates vom 29. Juni 1993 uber die freiwillige Beteiligung gewerblicher Unternehmen an einem Gemeinschaftssystem furr das Umweltmanagement und die Umweltbetriebsprüfung, Amtsblatt der Europaischen Gemeinschaften Nr. L 168/1 vom 10.7.1993. Ein Abdruck der Verordnung findet sich z.B. auch in Landesanstalt für Umweltschutz (Hrsg.) (1995a), S. 22-46. Eine weitere Rechtsgrundlage ist das bundesdeutsche Umwelt-Audit-Gesetz (UAG), Gesetz vom 7.12.1995, BGBI. I, S. 1591. Neben dem Begriff "EG-Ōko-Audit" ist vor allem auf internationaler Ebene die Bezeichnung "EMAS" (Environmental Management and Audit Scheme) gebrăuchlich. Vgl. Europäische Kommission (1996a), S. 13.

Eine ausfuhrliche Darstellung des Instruments findet sich z.B. in: Săchsisches Staatsministerium (Hrsg.) (1994); Waskow, S. (1997). Einen v.a. für mittelständische Unternehmen geeigneten Einstieg in die Thematik bieten z.B. Bayerisches Staatsministerium (Hrsg.) (1995); Landesanstalt für Umweltschutz (Hrsg.) (1995a), (1995b), (1995c) und (1997). Vgl. darüber hinaus u.a. Hopfenbeck, W./Willig, M. (1995), S. 123-129; Butterbrodt, D. u.a. (1995), S. 8-15 sowie Alijah, R/Heuvels, K. (Hrsg.) (1995); BMU/Umweltbundesamt (Hrsg.) (1995); Fichter, K. (1995); Gallert, H./Clausen, J. (1996); Oberrath, J.-D. (1997). Ferner unternimmt der NAGUS (Normenausschuß Grundlagen des Umweltschutzes) Anstrengungen, Unternehmen bei der Umsetzung der Verordnungsinhalte zu helfen.

Bereits vor Verabschiedung der EG-Őko-Audit-Verordnung existierten unterschiedliche nationale Entwürfe für Umweltmanagementnormen. Hervorzuheben ist dabei der 1992 vom British Standard Institute veröffentlichte British Standard 7750, der auch als Grundlage für die ersten EG-Verordnungsentwürfe diente. Um eine Homogenisierung auf europäischer wie auch auf internationaler Ebene zu erreichen, richtet sich die Aufmerksamkeit verstarkt auf die internationale ISO-Normungsebene und hier insbesondere auf die ISOUmweltmanagementnorm Nr. 14000 (ISO 14000). Die ISO 14000 zeichnet sich gegenüber der EGVerordnung durch einen wesentlich strafferen und logischeren Aufbau sowie die dynamischere Ablauffolge von "Environmental Policy, Environmental Planning, Implementation and Operations, Monitoring, Corrective Actions, Management Review" aus, Peglau, R. (1995), S. 22f. Vgl. dazu ferner Waskow, S. (1997), S. 86101; Jasch, A. (1995).

${ }^{732}$ Das Konzept des "sustainable development" (dauerhafte bzw. nachhaltige Entwicklung) stammt ursprünglich aus der Forstwirtschaft und beinhaltet die Bewirtschaftung von Forstflächen in einer Weise, die den langfristigen, kontinuierlichen Ertrag über mehrere Generationen ohne Aufzehrung der natürlichen Ressourcen gewährleistet. In die ökonomische Diskussion wurde der Begriff 1987 durch die Weltkommission für Umwelt und Entwicklung (sog. "Brundtland-Kommission") eingeführt. Die grundlegende Forderung ist eine Entwicklung, die den Bedarf der Gegenwart deckt, ohne zukünftigen Generationen die Grundlage für deren Bedürfnisbefriedigung zu nehmen. Vgl. Hauff, V. (1987), S. 46-69 sowie ferner SRU (1994), S. 9 und S. 45-49. Mit dem Leitbild des "sustainable development" erhält der Umweltschutz eine gesellschaftliche und politische Bedeutung und einen neuen Stellenwert, der ihn vom Begrenzungsfaktor zum Zielfaktor gesellschaftlicher Entwicklung werden läßt. Vgl. SRU (1996), S. 50-58. Vgl. darüber hinaus Schmidheiny, S. (1992); Europäische Kommission (1996a); Georgescu-Roegen, N. (1974), S. 26f. Für eine kritische Betrachtung des Begriffes unter ökonomischen Gesichtspunkten vgl. Binswanger, M. (1995). 
Zuständigkeiten, Verhaltensweisen, förmliche Verfahren, Abläufe und Mittel für die Festlegung und Durchführung der Umweltpolitik des Unternehmens ein. Von grundlegender Bedeutung ist dabei, daß systematisch, objektiv und regelmäßig der Nachweis über die Einhaltung aller gesetzlichen Vorschriften erbracht wird und die Festlegung auf eine kontinuierliche Verbesserung des betrieblichen Umweltschutzes erfolgt. Das Öko-Audit dient neben der Feststellung des ökologischen Ist-Zustandes auch der Erfassung und Bewertung in den Betrieb eingehender und ausgehender Stoff- sowie Energiearten und -mengen. Es fungiert damit als ein betriebsinternes bzw. externes Kontrollinstrument. Das Audit läßt sich in mehrere Teilaudits gliedern, nämlich in Bestands-, in Input- und Output- sowie in Produkt-, Verbrauchs- und Prozeß-Audits. ${ }^{733}$ Damit kann z.B. eine Analyse entlang der Wertschöpfungskette ${ }^{734}$ stattfinden. Mittels des Bestands-Audits werden alle vorhandenen Materialien und Substanzen erfaßt. Daraus können u.U. erste Hinweise darauf abgeleitet werden, in welchen Bereichen eine Substitution ökologisch bedenklicher Stoffe anzustreben ist. Input- und Output-Audits dienen ebenfalls der Lokalisation von Schwachstellen, Substitutionsalternativen und Einsparungsmöglichkeiten. Sie erfassen die jährlichen Zu- und Abgänge an Rohstoffen, Energie, Produkten sowie Kuppelprodukten bzw. Abfällen. Im Rahmen der Produkt-, Verbrauchs- und Prozeß-Audits findet eine vertiefte Betrachtung einzelner Produkte (z.B. mit Hilfe der Produktlinienanalyse oder des Produktlebenszyklus), von Verbrauchsmengen und -arten sowie einzelnen Prozessen (z.B. mit Hilfe von Ablaufanalysen) statt. Das Gesamtergebnis des Audits fließt in einen Umweltbericht ein, der die Grundlage für die Erstellung eines betrieblichen Umwelt-Handbuches bildet. ${ }^{735}$ Als Abschluß des Auditing findet eine Umweltbetriebsprüfung und Zertifizierung statt. ${ }^{736}$ Die Informationen über den betrieblichen Umweltschutz sollen dann der Öffentlichkeit in Form einer "Umwelterklärung" bereitgestellt werden. ${ }^{737}$ Das Auditing sollte im Abstand von zwei bis drei Jahren wiederholt werden und gewährleistet dann das Erreichen folgender Ziele:

- die Erfullung von gesetzlichen Auflagen und Normen,

- die Sicherung einer effizienten Technologie,

- das Erkennen und Bewerten von Umweltrisiken sowie die Reduktion des Haftungsrisikos,

- die Organisation und Strukturierung des Managements sowie

- die Verminderung von Problemen durch internen und externen Informationstransfer.

\footnotetext{
${ }^{733}$ Ein Überblick findet sich bei Günther, E./Wagner, B. (1993), S. 159-162.

${ }^{734} \mathrm{Vgl}$. Abschnitt 5.3.3.2.

${ }^{735}$ Vgl. Sächsisches Staatsministerium (Hrsg.) (1994), S. 46-54.

${ }^{736}$ Vgl. Sächsisches Staatsministerium (Hrsg.) (1994), S. 55-64.

${ }^{737}$ Ein Ablaufschema des EG-Őko-Audits zeigt Anlage 31.
} 
Daneben werden durch ein ganzheitliches (Umwelt-) Management ${ }^{738}$ die isolierte Stellung des Umweltschutzbeauftragten aufgehoben und Umweltbelange in allen betrieblichen Funktionen und auf allen Ebenen der Unternehmenshierarchie integriert. Die positiven Effekte des EGÖko-Audit können vor allem in folgenden Punkten zusammengefaßt werden: ${ }^{739}$

- aktive Auseinandersetzung mit ökologischen Anforderungen,

- Informationen über die umweltrelevanten Stärken und Schwächen des Unternehmens,

- Transparenz über Umweltkosten bzw. Umweltbeeinträchtigungen und dadurch

-- Kostenreduzierung durch umweltorientierte Produktion (Ressourcen- und Energieeinsparung),

-- Kostenreduzierung durch Risikoreduzierung bzw. Vermeidung von Störfällen und damit weniger Verletzungen von Umweltgesetzen, niedrigere Versicherungsprämien und günstigere Kreditkonditionen,

- Innovationsvorsprung durch umweltorientierte Produkt- und Verfahrensentwicklung,

- Angebotsvorteile am Markt durch Imagegewinn und Erschließung ökologischer Differenzierungspotentiale,

- Förderung durch öffentliche Mittel,

- Qualifizierung der Mitarbeiter,

- Steigerung der Motivation und Arbeitszufriedenheit der Mitarbeiter,

- langfristige Existenzsicherung des Unternehmens.

Zusätzlich eröffnet die Normierung des betrieblichen Umweltmanagementsystems die zwischenbetriebliche und europaweite Vergleichbarkeit und Überprüfbarkeit unternehmerischen Handelns. Aus der Überprüfbarkeit entsteht jedoch auch das Risiko, aufgrund festgestellter Mängel verfolgt bzw. haftbar gemacht zu werden, da im Audit "Gesetzesverstöße, Austritte von oder unsachgemäßer Umgang mit gefährlichen Stoffen oder Vorkommen von Altlasten dokumentiert" ${ }^{140}$ werden. Ein weiterer Nachteil der Transparenz ist, daß auch Wettbewerbern Unternehmensdaten zugänglich gemacht werden, die diese auf anderem Wege nicht erhalten würden.

Obwohl zwischenzeitlich zur EG-Öko-Audit-Verordnung umfangreiche Literatur und zahlreiche Hilfestellungen zu ihrer Umsetzung auch von öffentlicher Seite zur Verfügung stehen, verbleiben gerade für kleine und mittlere Unternehmen eine Reihe von Umsetzungspro-

\footnotetext{
${ }^{738}$ Vgl. hierzu die in Anhang I, Teil D der EG-Öko-Audit-Verordnung aufgezeigten "guten Managementpraktiken", die als Handlungsgrundsătze zur stetigen Verbesserung des betrieblichen Umweltschutzes dienen sollen.

${ }^{739}$ Vgl. Sächsisches Staatsministerium (Hrsg.) (1994), S. 1ff. und S. 67. Vgl. daneben auch Bartsch, T. (1995), S. 17f.; Hopfenbeck, W. u.a. (1995), S. $51 \mathrm{ff}$.

${ }^{740}$ Bartsch, T. (1995), S. 18.
} 
blemen. ${ }^{741}$ Ursache hierfür sind zum einen KMU-typische Defizite. Diese setzen sich zusammen aus Informationsdefiziten, einem Mangel an finanziellen und personellen Ressourcen und dem Mangel an der notwendigen Zeit. Kleine und mittlere Unternehmen sind über das EGÖko-Audit nur unzureichend informiert. Die Informationsdefizite beziehen sich hauptsächlich darauf, den Nutzen des Audits zu erkennen. Folglich werden aufgrund eines eher kurzfristigen Planungshorizontes ausschließlich die Durchfuihrungskosten, nicht aber die aus dem Audit resultierenden Rationalisierungspotentiale betrachtet. Hinzu kommt, daß die zum Teil angespannte finanzielle Situation diese Investition nicht zuläßt. Die Informationsdefizite beziehen sich aber auch auf die weitgehende Unkenntnis der Hilfestellung gebenden Einrichtungen sowie der speziell für die Durchführung des Audits aufgelegten Förderprogramme. ${ }^{742}$ Daneben fehlen oftmals auch die notwendigen personellen Ressourcen sowohl in quantitativer wie auch in qualitativer Hinsicht. ${ }^{743}$ Deswegen sowie aufgrund der ohnehin knappen Ressource Zeit unterbleibt meist die Akkumulation und Auswertung von Informationen und Kenntnissen. Gerade die systematische Erfassung und Dokumentation externer und interner Informationen sowie auch der Ziele und Strategien sind zentrale Komponenten des Audits. Sie sind aber auch offenkundige Defizite kleiner und mittlerer Unternehmen. Die Verordnung scheint somit eher auf größere Unternehmen mit ausgeprägten Organisationsstrukturen, die bereits Erfahrungen mit anderen Managementinstrumenten gesammelt haben, zugeschnitten zu sein. Fraglich ist daher, ob die Implementierung eines systematischen Managementsystems in kleinen und mittleren Unternehmen, wie sie durch die Verordnung gefordert wird, ausgerechnet mit einem Umweltmanagementsystem begonnen wird. Allerdings bietet sich gerade hier für kleine und mittlere Unternehmen die Chance, einen ersten und entscheidenden Schritt in Richtung einer systematischen, zielorientierten und damit Strategischen Unternehmensführung zu tun. Die zahlreichen vorhandenen, auf die Belange von kleinen und mittleren Unternehmen zugeschnittenen Leitfäden zur Einführung und Umsetzung eines Umweltmanagementsystems bieten auch Anhaltspunkte für den Ausbau zu einem umfassenden Managementsystem. $^{744}$

Eine breite Anwendung ökologieorientierter Managementmethoden ist in kleinen und mittleren Unternehmen bislang noch nicht zu beobachten. Bei den untersuchten Unternehmen des Verarbeitenden Gewerbes findet nur in wenigen Fällen ein Einsatz der zuvor beschriebenen Instrumente des Umweltcontrolling statt. Insgesamt haben lediglich 9,6\% der befragten

${ }^{741}$ Vgl. Kottmann, H./Franke, W. (1994), S. 51; van Someren, T. (1994), S. 19-31; Meffert, H./Kirchgeorg, M. (1995), S. 31; Tischler, K. (1996), S. 356f.

${ }^{742}$ Diese Informationsdefizite sind aber nicht allein den KMU anzulasten. Hier besteht auch von seiten der Kammern und Fachverbände eine Bringschuld hinsichtlich des Angebotes von Unterstützung und der aktiven Versorgung der KMU mit den notwendigen Informationen zu den Inhalten, dem Nutzen und den existieren-

den Förderprogrammen.

${ }^{743} \mathrm{Zu}$ den Qualifikationsanforderungen, die das EG-Öko-Audit als Managementinstrument an die Mitarbeiter stellt, vgl. u.a. Hopfenbeck, W./Willig, M. (1995), S. $126 \mathrm{f}$.

${ }^{744}$ Vgl. dazu beispielsweise die diversen Leitfaden der Landesanstalt für Umweltschutz Baden-Württemberg. 
Unternehmen in der Region Neckar-Alb Ökobilanzen oder Umweltberichte angefertigt oder ein Audit durchgefuhrt (vgl. Tab. 5-1). ${ }^{745}$ Dabei zeigen die besonders erfolgreichen Unternehmen nur bei der Erstellung von Umweltberichten einen erkennbaren Vorsprung gegenüber den weniger erfolgreichen Unternehmen:

Tab. 5-1: Nutzung von Instrumenten des Umweltcontrolling durch die beiden Erfolgstypen

\begin{tabular}{|l|c|c|}
\hline Instrument (in \%) & $\begin{array}{c}\text { besonders erfolgreiche } \\
\text { Unternehmen }\end{array}$ & $\begin{array}{c}\text { weniger erfolgreiche } \\
\text { Unternehmen }\end{array}$ \\
\hline Ökobilanzen & 2,2 & 1,8 \\
\hline EG-Öko-Audit & 0,0 & 2,8 \\
\hline Umweltberichte & 8,7 & 5,5 \\
\hline
\end{tabular}

Quelle: eigene Berechnungen.

Dieses wenig befriedigende Ergebnis ist auf die oben genannten Probleme zurückzuführen. Vor allem in den Unternehmergesprächen wurde zum Teil deutlich zum Ausdruck gebracht, daß die Instrumente zu komplex sind - einzelnen Gesprächspartnern war z.B. das EG-ÖkoAudit sogar gänzlich unbekannt ${ }^{746}$-, eine zu hohe Investitition darstellen und der aus ihnen resultierende ökonomische Nutzen zu ungewiß ist. Der Nutzen wird auch deswegen in Frage gestellt, weil beispielsweise das Audit einen hohen zeitlichen und personellen Aufwand erfordert und darüber hinaus mit einer zunehmenden Bürokratisierung in Verbindung gebracht wird, unter der die Flexibilität des Unternehmens leiden könnte. Schließlich wurde auch das unzureichende Angebot an Unterstützung und Information von seiten der Kammern und Fachverbände bemängelt. ${ }^{747}$

${ }^{745}$ Vgl. Frage 4/9 des Fragebogens im Anhang sowie Anlage 32. Die Anlage verdeutlicht, daß tendenziell die Nutzung von Umweltcontrollinginstrumenten mit der Unternehmensgröße steigt. $\mathrm{Zu}$ dieser Einschätzung gelangt auch Günther, K. (1996), S. 166ff.

${ }^{746}$ Ein diesbezüglich deutlich positiveres Bild zeichnet die Studie des Unternehmerinstitut e.V. (1997), in der $53,5 \%$ der antwortenden KMU das EG-Öko-Audit implementiert haben. Obwohl die Untersuchung methodische Mängel aufweist und nicht repräsentativ ist, kann dennoch festgehalten werden, daß sich das Instrument weiter durchsetzt.

${ }^{747}$ Obwohl zu bemerken ist, daß insbesondere von seiten der EU umfangreiche Maßnahmen zur Information und Beratung eingeleitet und auch von den einzelnen Mitgliedsstaaten aufgegriffen wurden. Vgl. Europäische Kommission (1996a), S. 13f.

Als Unternehmensbeispiel aus der Region Neckar-Alb kann die Bizerba GmbH \&Co.KG herangezogen werden. Hier konnte nachgewiesen werden, daß die im Rahmen eines Umweltmangementsystems durchgeführte Schwachstellenanalyse Kosteneinsparungsmöglichkeiten aufzeigte, deren Realisierung die Kosten der Analyse bei weitem überdeckte. Bei der Implementierung des Umweltmanagements fand u.a. eine intensive Zusammenarbeit zwischen dem Unternehmen und der Industrie- und Handelskammer statt. 
Als die grundlegende Ursache für die ausgesprochen zurückhaltende Anwendung der Instrumente kann jedoch ein umfassendes Informationsdefizit identifiziert werden. Für diesen $\mathrm{Zu}$ stand zeichnen sowohl die Unternehmen als auch die (öffentlichen) Informationsanbieter verantwortlich: die Unternehmen, indem sie nicht ausreichend um Informationen nachsuchen (Holschuld), und die Informationsanbieter, indem sie die in großem Umfang vorhandenen Informationen nicht problem- bzw. kundenbezogen kleinen und mittleren Unternehmen nahebringen (Bringschuld).

\subsubsection{Strategische Instrumente des Umweltmanagements}

Das festgestellte Defizit kleiner und mittlerer Unternehmen beim Einsatz operativer Instrumente des Umweltmanagements schafft denkbar ungünstige Voraussetzungen für die Anwendung strategischer Instrumente. ${ }^{748}$ Letztere stehen zum einen in einer engen Wechselbeziehung zu den operativen Instrumenten und bilden zum anderen die Grundlage für die Entwicklung einer ökologieorientierten Unternehmenskultur, von Umweltzielen und von Umweltstrategien, d.h. also eines systematischen Umweltmanagements. Dafür müssen die in Abschnitt 3.3.3 dargestellten Instrumente - die Wertkettenanalyse, die Funktionsbereichsanalyse (Stärken-/Schwächenanalyse) und die Portfolioanalyse - um die hierfür notwendige ökologische Dimension erweitert werden.

Mit dem Instrument der Wertkette (Wertschöpfungskette) lassen sich die Synergien zwischen den Unternehmensfunktionen analysieren sowie kostensenkende bzw. ertragssteigernde Aktivitäten identifizieren und dadurch die Quellen dauerhafter Wettbewerbsvorteile feststellen. Hierbei gilt es zu beachten, daß der Fokus des Porterschen Konzeptes ausschließlich auf die innerbetrieblichen Phasen gerichtet ist. Zwar findet sich auch eine Erweiterung der Betrachtungsweise auf die vorgelagerten Aktivitäten von Lieferanten bzw. die nachgelagerten Vertriebswege, doch richtet diese sich erneut lediglich auf deren Wirkung auf Kosten und Differenzierung. ${ }^{749}$ Die Wertkette sollte daher in Anlehnung an den erweiterten Produktlebenszyklus (vgl. Abb. 3-7) um ökologische Dimensionen ergänzt werden. Das bedeutet, die Phasen der Rohstoff- und Energiegewinnung, der Produktion und des Konsums sowie des Recycling bzw. der Entsorgung mit den dazwischenliegenden Transport- und Lagerproblemen sind als ein ganzheitlicher Kreislaufprozeß aufzufassen und in die unternehmerische Entscheidung miteinzubeziehen. ${ }^{750}$ Ein Konzept zu einer ökologischen Erweiterung der Wertkette findet

\footnotetext{
${ }^{748}$ Der geringe Einsatz strategischer Planungsinstrumente wird auch in der Untersuchung der FUUF (1991), S. $210 \mathrm{ff}$., deutlich.

749 Vgl. Porter, M.E. (1996), S. 60-67 und S. $79 \mathrm{ff}$.

${ }^{750} \mathrm{Zu}$ den umweltrelevanten stofflichen und energetischen Wirkungen der einzelnen Produktlebensphasen vgl. Türck, R. (1991), S. 36-41 und (1992), S. 64-70 sowie ferner Winter, G. (1988), S. 146ff. und S. 156-165; Eschenbach, R./Müller, C. (Hrsg.) (1992), S. 215-223; Wicke, L. u.a. (1992), S. 662-666.
} 
sich beispielsweise bei ZAHN UND SCHMm. ${ }^{751}$ Der von ihnen vorgestellte "Ökologiebezogene Wertschöpfungsring" versetzt das Unternehmen in die Lage, "alle ökologierelevanten (Wert-) Aktivitäten, die einen Beitrag zur Unternehmungsleistung liefern, gezielt unter Umweltschutzaspekten identifizieren, beschreiben, analysieren und gestalten zu können" ${ }^{752}$. Hilfreich ist dabei, wenn durch die Erstellung einer Öko-Bilanz bzw. aufgrund der Durchführung eines Audits bereits eine breite Wissensbasis geschaffen wurde. Für die Ermittlung wettbewerbsstrategisch relevanter, ökologiebezogener Differenzierungs- und Kostenvorteile stehen darüber hinaus eine Vielzahl praxisorientierter, handlungsleitender Checklisten zur Verfügung, die hier jedoch nicht näher dargestellt werden sollen. ${ }^{753}$

Damit ist eine enge Verbindung zur Funktionsbereichsanalyse geschaffen. Die aus der Wertkettenanalyse gewonnenen Informationen über die einzelnen Funktionsbereiche des Unternehmens bilden zusammen mit den Informationen über externe Einflußgrößen bzw. über Wettbewerber die Grundlage einer Ressourcenanalyse zur Ermittlung der Stärken und Schwächen des Unternehmens. Im Hinblick auf die umweltrelevanten Stärken und Schwächen des Unternehmens lassen sich beispielsweise im Führungs-, Versorgungs- und Vollzugsbereich die folgenden Schlüsselfaktoren hervorheben: ${ }^{754}$

- im Führungsbereich: die Aufgeschlossenheit und Flexibilität des Unternehmers gegenüber umweltrelevanten Problemen sowie die aktive Unterstützung der ökologischen Ausrichtung des Unternehmens;

- im Versorgungsbereich: die Fähigkeiten und Fertigkeiten sowie die Motivation der Mitarbeiter, das Alter und die Umrüstbarkeit der Anlagen, die Substitutionsmöglichkeit umweltgefährdender Materialien, die zur Verfügung stehenden finanziellen Mittel, das Vorliegen umweltrelevanter Informationen;

- im Vollzugsbereich: das umweltrelevante Know-how in der F\&E, die Möglichkeiten einer ökologischen Ausrichtung der Produktion, die Absatzmöglichkeiten bzw. die Durchsetzbarkeit umweltschonender hergestellter Produkte am Markt.

${ }^{751}$ Vgl. Zahn, E./Schmid, U. (1992), S. 74-78. Thr Konzept basiert auf den Überlegungen von Schmid, U. (1989), S. 76f.; Dyllick, T. (1989), S. 16f. und (1990), S. 24-27 sowie der von Schaltegger, S./Sturm, A. (1992) entwickelten Schadschöpfungskette. Vgl. ferner auch Macharzina, K. (1995), S. 837ff.

752 Zahn, E./Schmid, U. (1992), S. 76.

${ }^{753}$ Vgl. dazu z.B. Dyllick, T. (1990), S. 29-33; BMU/Umweltbundesamt (Hrsg.) (1995), S. 77-95 und die bei letzteren angegebene Literatur.

${ }^{754} \mathrm{Vgl}$. dazu auch Meffert, H./Kirchgeorg, M. (1993), S. 107. Entscheidend ist in diesem Zusammenhang auch der Exponiertheitsgrad bzw. die Betroffenheit eines Unternehmens in Bezug auf okologische Problemstellungen. Auf diesen Aspekt wird an spăterer Stelle eingegangen. 
Zur Ableitung von Ansatzpunkten für die Formulierung von Umweltstrategien sind die aus der Stärken-/Schwächen-Analyse gewonnenen Informationen mit denen aus der Umfeldanalyse zu verknüpfen. Die sich daraus ergebenden Chancen und Risiken zeigen künftige, umweltrelevante Entwicklungs- und Bedrohungspotentiale für das Unternehmen auf. ${ }^{755}$

Ein weiteres Hilfsmittel zur Bestimmung der ökologiebezogenen Ausgangslage und zur Ableitung von Umweltstrategien steht mit dem Öko-Portfolio zur Verfügung. ${ }^{756}$ Das Portfolio wird durch die beiden Dimensionen "Vorteile umweltorientierten Unternehmensverhaltens" und "Umweltgefährdung durch das eigene Unternehmen" aufgespannt. Die Dimension der Vorteile umweltorientierten Unternehmensverhaltens setzt sich aus quantitativen und qualitativen Elementen zusammen. Als quantitative, meßbare Elemente können beispielsweise Kosteneinsparungen, Produktivitätsverbesserungen sowie Gewinn- oder Marktanteilssteigerungen einfließen. Als qualitative, meßbare Elemente sind Imageverbesserungen, Steigerung der Markentreue, Verbesserung der Zusammenarbeit mit öffentlichen Stellen sowie die Steigerung der Motivation und der Loyalität der Mitarbeiter denkbar. Die zweite Dimension generiert sich • aus der bei der Beschaffung, Produktion, Verwendung und Beseitigung des Produktes entstehenden Umweltgefährdung durch das Unternehmen. Die einzelnen SGE lassen sich nun entsprechend ihrer Umweltrelevanz im Portfolio positionieren. In Abhängigkeit der Positionierung können dann strategische Stoßrichtungen abgeleitet werden. ${ }^{757}$ Die Positionierung der untersuchten kleinen und mittleren Unternehmen des Verarbeitenden Gewerbes in einem solchen Öko-Portfolio ist in Abb. 5-3 dargestellt. Diese stark vereinfachte und daher nur eingeschränkt aussagefähige Positionierung verdeutlicht dennoch, daß die untersuchten kleinen und mittleren Unternehmen des Verarbeitenden Gewerbes

- die Chancen, die aus einer Umweltorientierung erwachsen, eher mittelmäßig einschätzen ${ }^{758}$ und

- die vom eigenen Unternehmen ausgehende Umweltgefährdung als eher gering einstufen. ${ }^{759}$

\footnotetext{
${ }^{755} \mathrm{Vgl}$. Anlage 10 sowie die umweltorientierte Erweiterung bei Macharzina, K. (1995), S. 849.

${ }^{756}$ Vgl. z.B. die Ansätze bei Meffert, H. u.a. (1986), S. 152f.; Antes, R. (1988), S. 109ff.; Meffert, H. (1988), S. 320f.; Steger, U. (1988), S. 150f. sowie die Modifikation in (1993), S. 206ff.; Dyllick, T. (1990), S. 34-37; Türck, R. (1991), S. 159-165; Schaltegger, S./Sturm, A. (1992), S. 74f.; Servatius, H.-G. (1992), S. 104; Meffert, H./Kirchgeorg, M. (1993), S. 111-113.

${ }^{757}$ Die einzelnen Quadranten des Portfolios enthalten unterschiedliche Strategiealternativen. Für eine Zusammenführung der "Normstrategien" von Steger, U. (1988), S. 150f., der "okologieorientierten Wettbewerbsstrategien" von Meffert, H. u.a. (1986), S. 152f.; Brenken, D. (1988), S. 246-249; Steger, U. (1988), S. $152-$ 155 und Kirchgeorg, M. (1990), S. 109-115 sowie der "ðkologieorientierten Basisstrategien" von Kirchgeorg, M. (1990), S. 45-51, vgl. Zahn, E./Schmid, U. (1992), S. 65ff. Zur Formulierung von Umweltschutzstrategien vgl. ferner Kapitel 5.6.

${ }^{758}$ Vgl. Frage 4/2 des Fragebogens im Anhang sowie die Ausfuhrungen in Kapitel 5.5.

${ }^{759}$ Vgl. Frage 4/7 des Fragebogens im Anhang sowie die Ausfuhrungen in Kapitel 5.4.
} 


\section{Abb. 5-3: Positionierung der untersuchten Unternehmen im Öko-Portfolio}

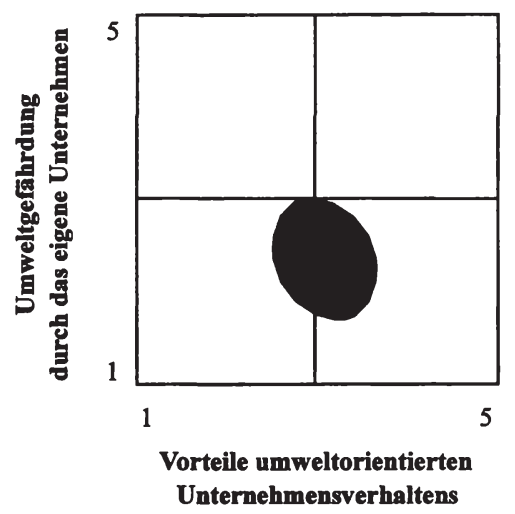

Quelle: eigene Berechnungen.

Hervorzuheben ist dabei ebenfalls die geringe Streuung der untersuchten Unternehmen. Dies bedeutet, daß sich keine wesentlichen erfolgs- bzw. größenbedingten Differenzen zwischen den Unternehmen feststellen lassen. Die Positionierung liefert darüber hinaus eine erste Begründung für die nur in wenigen Fällen vorhandenen Umweltmanagementsysteme. Aufgrund der eher mittelmäßigen Chancen, die aus einer Umweltorientierung resultieren, sowie der als eher gering eingeschätzten Umweltgefährdung durch das eigene Unternehmen ergibt sich kaum die Notwendigkeit für deren Einfuihrung.

Die Unzulänglichkeiten der Portfolioanalyse wurden bereits an anderer Stelle ausführlich erörtert (vgl. Abschnitt 3.3.3.4). Ergänzende Kritik ergibt sich einerseits aus der Komplexität der zugrundegelegten Dimensionen: Die Beurteilung und Quantifizierung umweltschädigenden Handelns ist beispielsweise abhängig vom wissenschaftlichen Erkenntnisstand bzw. von der politischen Einschätzung, während die Ermittlung quantitativer und qualitativer Vorteile eine genaue Kenntnis der eigenen Situation und die der Wettbewerber erfordert. ${ }^{760}$ Andererseits erscheint in dem hier relevanten Zusammenhang besonders das dieser Konzeption zugrundeliegende Postulat der Ausgewogenheit und Risikostreuung problematisch. Ein solches eher konservatives Wettbewerbsverhalten weist auf eine starke Gegenwartsorientierung hin. In Verbindung mit einer mangelnden Suche nach neuen umweltorientierten Produkt-MarktKombinationen kommen Zweifel an einer zukunftsorientierten innovativen Annahme der ökologischen Herausforderung auf. ${ }^{761}$

\footnotetext{
${ }^{760}$ Vgl. Dyllick, T. (1990), S. 35f.

${ }^{761} \mathrm{Vgl}$. Zahn, E./Schmid, U. (1992), S. $67 \mathrm{f}$.
} 


\subsubsection{Technische und organisatorische Einbindung des Umweltschutzes}

Der zentrale Inhalt umweltorientierten Unternehmensverhaltens ist die Lösung des Stoff- und Energieproblems. Hierfür stehen zunächst eine Reihe von Technologien zur Verfügung, die durch additive oder integrierte Maßnahmen auf eine Lösung dieser Probleme abzielen. Darüber hinaus ist neben der Schaffung einer geeigneten technologischen Basis und der im vorigen Abschnitt dargestellten informatorischen Basis auch für eine geeignete organisatorische bzw. personelle Basis zu sorgen, damit eine umfassende Implementierung des Umweltmanagements im Unternehmen möglich wird.

\subsubsection{Technische Einbindung des Umweltschutzes}

Produktionsprozesse tangieren die Umwelt einerseits durch die Entnahme von Ressourcen als Inputfaktoren für Produkte und Prozesse und andererseits durch den dabei entstehenden Output, der sich aufgliedert in verkaufsfähige Erzeugnisse sowie nicht warenförmige Kuppelprodukte und Abfälle. ${ }^{762}$ Die Herstellung von Produkten sollte daher ressourcenschonend, emissionsarm und möglichst risikofrei gestaltet werden. Für das Erreichen dieser Ziele steht eine breite Palette nachsorgender bzw. vorsorgender und integrierter Technologien zur Verfügung.

Nachgeschaltete bzw. additive Technologien sind Maßnahmen zur nachträglichen Verminderung oder Vermeidung der Umweltbelastung und basieren auf den Grundprinzipien der Abscheidung, Rückhaltung, Umwandlung, Diffusion oder Speicherung von Fremdstoffen. Beispiele hierfür wären Katalysatoren, Filtereinsätze oder Kläranlagen. Sie sind größtenteils Modifikationen bekannter Prinzipien der chemischen, mechanischen oder thermischen Verfahrenstechnik sowie biotechnischer Verfahren. Durch additive Technologien werden folglich keine Schadstoffe verringert, sondern lediglich in ein anderes Medium überführt. ${ }^{763} \mathrm{Da}$ sie somit die bestehenden Produktionseinrichtungen unverändert lassen, setzen sie nicht an der Entstehungsquelle der Umweltbelastung an, sondern tragen erst nach Beendigung des eigentlichen Produktionsprozesses zur Entlastung der Umwelt bei. ${ }^{764}$ Die Erfolgswirkungen ihres Einsatzes hängen von den Nettoeffekten der Kostenauswirkungen ab. Oftmals sind Investitions- und Umstellungskosten bei additiven Technologien niedriger als bei integrierten Verfahren, da bei ihnen nicht in den gesamten Produktionsprozeß eingegriffen wird, sondern dieser

762 Vgl. Abb. 5-1 sowie Adam, D. (1993), S. 6.

${ }^{763}$ Bei der anschließenden Entsorgung des Abproduktes stehen dem Unternehmen nun grundsätzlich zwei Möglichkeiten zur Verfuggung: die Fremd- bzw. die Eigenentsorgung. Dyckhoff, H./Souren, R. (1994), S. 85-103 zufolge bringen beide Entsorgungsarten Ausweitungsmoglichkeiten der Abproduktion im eigentlichen Produktionsprozeß mit sich, deren Vorteilhaftigkeit jedoch im Einzelfall betrachtet werden muß. Für die hier angestrengte Betrachtung fulhrt diese Diskussion jedoch zu weit und wird daher nicht weiter verfolgt.

764 Additive Technologien entsprechen damit nur bedingt den Forderungen des Vorsorgeprinzips, da sie letzlich nicht zu einer Vermeidung bzw. Verminderung von Rohstoff- und Energieeinsatz führen und den Prozeß der Entropie fordern. Zur Bedeutung der Entropie im Wirtschafts- und Produktionsprozeß vgl. GeorgescuRoegen, N. (1971); Georgescu-Roegen, N. (1974). 
lediglich um eine weitere Stufe verlängert wird. ${ }^{765}$ Für den bislang vorrangigen Einsatz additiver Technologien lassen sich nach HARTJE folgende Gründe angeben: ${ }^{766}$

- geringer Grad an Unsicherheit hinsichtlich der Eigenschaften der Emissionsminderung,

- niedrigere Zugangskosten infolge der erfolgreichen Erprobung bzw. eines gröBeren Marktes,

- geringere Umstellungskosten der "Standard"-Technologien gegenüber integrierten Umweltschutztechnologien sowie Vermeidung von "sunk costs",

- geringere Ausfallwahrscheinlichkeiten (technische und ökonomische Risiken) der erprobten additiven Systeme,

- besser entwickelte Absatzchancen für Reststoffe (Kuppelprodukte),

- stärkere Auswirkung von Lerneffekten (steigender Ausnutzungsgrad der Anlage und sinkende Stückkosten).

Additive Technologien eignen sich deshalb vor allem für eine kurzfristig erforderliche, etwa auflagenbedingte Reduzierung von Emissionen. Sie sind als Zwischenlösung oft unverzichtbar, bis grundlegende Innovationen realisiert werden können. Letztlich stoßen additive Umweltschutzmaßnahmen aber an ökonomische Grenzen, da sie für den Anwender unproduktive, die Kosten erhöhende Investitionen darstellen. Zudem verringern sie nicht den Rohstoff- und Energieeinsatz von Produktionsprozessen.

Im Zuge einer erfolgreichen Unternehmensentwicklung muß daher "Umweltschutz über den additiven Charakter von EOP-Lösungen hinausgehen und als eine innovative Aufgabe des gesamten Unternehmens verstanden werden" ${ }^{167}$. Dies kann durch die Implementierung eines integrierten Umweltschutzes im Unternehmen ermöglicht werden. Dabei stehen alle Unternehmensangehörigen in der Verantwortung, in ihrem jeweiligen Aufgabenbereich durch ihr Verhalten Umweltbeeinträchtigungen zu vermindern bzw. zu vermeiden. Integrierte Umweltschutzverfahren sind also das Ergebnis umweltbezogenen Verhaltens und haben das Ziel, Reststoffe und Emissionen durch umweltgerechte Produktionsverfahren zu vermindern bzw. auf lange Sicht zu vermeiden. Kennzeichnend für diese Technologieform ist eine ganzheitliche und systemische Denkweise, die versucht, alle relevanten Umweltprobleme zu erfassen und bei der technologischen Problemlösung eventuell bestehende Synergiepotentiale zu

${ }^{765}$ Vgl. Kreikebaum, H. (1994), S. 107 f.

${ }^{766}$ Vgl. Hartje, V.J. (1990), S. 144-161. Die Auffassung, daß Unternehmen auf staatliche Umweltschutzmaßnahmen ubberwiegend mit Investitionen in additive Technologien reagieren, ist in der betriebswirtschaftlichen Literatur breit vertreten, vgl. hierzu Maas, C. (1986), S. 113 bzw. Steger, U. (1992), S. 34-37 und die dort angegebene Literatur.

${ }^{767}$ Pfriem, R./Hallay, H. (1992), S. 297. Integrierter Umweltschutz wird damit zu einer Querschnittsaufgabe des Innovationsmanagements. Vgl. Kreikebaum, H. (1992a), S. 46.

Nachgeschaltete Technologien werden auch als End-of-Pipe-Technologien (EOP-Technologien) bezeichnet. 
nutzen. ${ }^{768}$ In den Produktionsprozeß integrierte Technologien orientieren sich am Vorsorgeprinzip und sind damit auf einen präventiven Umweltschutz im Unternehmen ausgerichtet. ${ }^{769}$ Da sie Teil des Produktionsprozesses sind, leistet die ökologische Modernisierung der Produktion einen Beitrag zum technischen Fortschritt und wirkt damit zugleich strukturverändernd.

Integrierte Technologien erfordern im Vergleich zu additiven Technologien im allgemeinen einen höheren Investitionsaufwand, da die Produktionsanlage und die Prozeßführung insgesamt vollständig verändert werden muß. ${ }^{770}$ Auf lange Sicht weisen integrierte Technologien aufgrund ihrer geringeren Kosten Vorteile auf, da sie z.B. bereits im Prozeßablauf zur Verminderung des Ressourcen- und Energieverbrauchs beitragen. Durch die Substitution umweltgefährdender durch ökologieverträglichere Einsatzstoffe verändern sie ferner Strukturen im Produktions- und Konsumtionsprozeß. So ist es möglich, einerseits die Kosten der Einsatzstoffe und andererseits die Kosten einer eventuellen Verwertung oder Entsorgung der Prozeßrückstände - wie sie z.B. auch bei additiven Technologien auftreten würden - zu senken. Sie wirken damit unmittelbar betriebskostensenkend und ermöglichen dadurch, die Erfolgsverringerung durch Umweltschutzanforderungen so gering wie möglich zu halten. Durch die ökologische Modernisierung des Unternehmens sowie die Verwirklichung des Prinzips eines geschlossenen Kreislaufs werden Strukturveränderungen angestoßen, die aufgrund technischer Innovationen zu einer umweltfreundlichen Gestaltung von Produkten und Prozessen führen. ${ }^{771}$ Positive Erfolgswirkungen lassen sich vor allem durch den sparsameren Ressourceneinsatz und die Antizipation von Umweltschutzstandards und -gesetzen, die ein späteres, teures Nachrüsten vermeiden, erzielen. Darüber hinaus kann ein Transaktionsnutzen in Form der sozialen Anerkennung bzw. einer steigenden Motivation der Mitarbeiter erzielt werden. Schließlich

${ }^{768}$ Konkrete Maßnahmen des integrierten Umweltschutzes in der Produktion umfassen beispielsweise die Produktionsfaktorplanung (Input), die Produktionsprozeßplanung (Throughput) sowie die Produktionsprogrammplanung (Output). Vgl. hierzu ausfuhrlich Kaluza, B./Pasckert, A. (1994), S. 122ff. Problematisch bleibt aber, daß fir einzelne Anwendungsbereiche keine oder lediglich unzureichende integrierte Problemlosungen zur Verfügung stehen, was den Einsatz nachgeschalteter Technologien erfordert.

${ }^{769} \mathrm{DaB}$ integrierte Technik nicht automatisch mit vorsorgendem Umweltschutz gleichzusetzen ist, zeigt Troge, A. (1988), S. 98f., auf.

${ }^{770}$ Integrierte Umweltschutztechnologien konkurrieren mit additiven Verfahren um die knappen Finanzierungsmittel. Bei der Planung einer Neuanlage wird das Unternehmen die integrierte Technologie demnach nur dann einsetzen, wenn deren Gesamtkosten niedriger sind als die der Standardtechnologie. Es kommt daher entscheidend auf den kostensparenden technologischen Fortschritt an, der bei einer Investitionsentscheidung für die integrierte Technologie spricht. Geht es dagegen um bestehende Anlagen, so sind deren Kosten als "sunk costs" anzusehen, wenn sie kurz- und mittelfristig nicht verănderbare Kapitalkosten einer spezialisierten Anlage darstellen. Die Altanlage wird demnach nur dann substituiert, wenn die integrierte Technologie die Vorteile einer additiven Lősung uberkompensiert. Für eine ausführliche Darstellung siehe Hartje, V.J. (1990), S. 146-151; Hartje, V.J./Lurie, R.L. (1984), S. 9-14. Zu den Determinanten von Umweltschutzinnovationen vgl. ferner Maas, C. (1986) und (1990).

${ }^{771}$ Vgl. Kreikebaum, H. (1992b), S. 10; Kreikebaum, H. (1994), S. 105f. und S. 110. Vgl. ferner Vieregge, R. (1992), S. $90 \mathrm{f}$. 
werden durch den Einsatz integrierter Prozeßtechnologien auch Verstöße gegen Auflagen und Gesetze z.B. „durch Ausschaltung von Nachsorgeeinrichtungen" ${ }^{172}$ ausgeschlossen. ${ }^{773}$

Anwendung finden Vermeidungstechniken vor allem in den Bereichen Luft, Wasser, Boden, Abfall und Lärm. Bei den hier untersuchten kleinen und mittleren Unternehmen des Verarbeitenden Gewerbes zeigt sich bezüglich der Anwendung additiver bzw. integrierter Technologien ein uneinheitliches Bild. Die besonders erfolgreichen Unternehmen, bei denen Vermeidungstechnologien zur Anwendung kommen, arbeiten in den Bereichen Boden, Abfall und Lärm überwiegend mit integrierten Techniken. In den weniger erfolgreichen Unternehmen ist dies in den Bereichen Luft, Abfall und Lärm der Fall. Lediglich im Bereich Wasser wird bei beiden Erfolgstypen überwiegend mit additiven Technologien (z.B. Filter, Reinigungsanlagen, Rückhaltebecken) gearbeitet.

Tab. 5-2: Nutzung von Emissionsvermeidungstechnologien durch die beiden Erfolgstypen

\begin{tabular}{|c|c|c|c|c|c|}
\hline Emissionsvermeidungs- & \multicolumn{5}{|c|}{ im Bereich ... } \\
\hline technologien & Luft & Wasser & Boden & feste Abralle & Lărm \\
\hline additive Technologien & & & & & \\
\hline $\begin{array}{l}\text { besonders erfolgreiche } \\
\text { Unternehmen }\end{array}$ & $79,0 \%$ & $56,3 \%$ & $0,0 \%$ & $44,4 \%$ & $42,9 \%$ \\
\hline $\begin{array}{l}\text { weniger erfolgreiche } \\
\text { Unternehmen }\end{array}$ & $47,8 \%$ & $80,0 \%$ & $100,0 \%$ & $44,3 \%$ & $33,3 \%$ \\
\hline integrierte Technologien & & & & & \\
\hline $\begin{array}{l}\text { besonders erfolgreiche } \\
\text { Unternehmen }\end{array}$ & $21,0 \%$ & $43,7 \%$ & $100,0 \%$ & $55,6 \%$ & $57,1 \%$ \\
\hline $\begin{array}{l}\text { weniger erfolgreiche } \\
\text { Unternehmen }\end{array}$ & $52,2 \%$ & $20,0 \%$ & $0,0 \%$ & $55,7 \%$ & $66,7 \%$ \\
\hline
\end{tabular}

Quelle: eigene Berechnungen. ${ }^{774}$

Werden über alle Bereiche hinweg die Durchschnitte gebildet, so zeigt sich, daß die besonders erfolgreichen Unternehmen überwiegend (55,5\%) integrierte Technologien zum Einsatz bringen. Die weniger erfolgreichen Unternehmen geben hingegen additiven Techno-

\footnotetext{
772 Kreikebaum, H. (1992b), S. 6.

${ }^{773}$ Zur Erfolgswirkung integrierten Umweltschutzes vgl. Troge, A. (1988), S. 99-120.

${ }^{774} \mathrm{Vgl}$. Frage 4/11 des Fragebogens im Anhang sowie ergånzend Anlage 33.
} 
logien den Vorzug $(61,1 \%){ }^{775}$ Die Differenzierung der Unternehmen nach der Unternehmensgröße ergibt keine unternehmensgrößenabhängigen Unterschiede beim Einsatz von Vermeidungstechnologien (vgl. Anlage 33). Werden auch hier die Durchschnitte über die Bereiche hinweg gebildet, zeigt sich jedoch in nahezu allen Unternehmensgrößenklassen ein Übergewicht bei den additiven Technologien. ${ }^{776}$

Integrierte Technologien wurden oben als die innovative Antwort auf betriebliche Umweltschutzprobleme charakterisiert. Die vorstehenden Ergebnisse deuten darauf hin, daß ein zwar schwacher, aber dennoch erkennbarer Zusammenhang zwischen der Innovativität des Unternehmens und dem Einsatz integrierter Technologien besteht, d.h., die besonders erfolgreichen Unternehmen haben das Nutzenpotential integrierter Technologien eher erkannt und haben dadurch die Chance, ihre Position gegenüber den weniger erfolgreichen Unternehmen weiter $\mathrm{zu}$ verbessern.

\subsubsection{Organisatorische Einbindung des Umweltschutzes}

Die Einführung von Umweltmanagementsystemen im Unternehmen ist mit organisatorischen und personellen Veränderungen verbunden. Dabei stellen die einschlägigen rechtlichen Rahmenbedingungen die zu erfüllenden Mindestanforderungen dar. ${ }^{777}$ Ferner erfordert die Einbindung des Umweltschutzes in das Unternehmen die uneingeschränkte Unterstützung durch die Unternehmensführung. Ohne ihr Engagement bleiben die notwendigen weitreichenden Bemühungen um die Implementierung des Umweltschutzes marginal. Wird darliber hinaus die Implementierung als Innovationsprozeß verstanden, so kommt auch der bereichsübergreifenden Zusammenarbeit höchste Bedeutung zu. Das hierfür erforderliche "Schnittstellenmanagement" wird in kleinen und mittleren Unternehmen jedoch durch ihre Überschaubarkeit sowie ihren geringeren Strukturierungsgrad erleichtert.

Bei der Einführung eines Umweltmanagementsystems lassen sich nach KOSTKA drei chronologische Phasen unterscheiden: ${ }^{778}$

1. Vorbereitung,

2. Implementierung und

3. Aufrechterhaltung.

$\overline{775}$ Vgl. dazu auch die Ergebnisse von Kirchgeorg, M. (1990), S. 157f. Er stellt fest, daß im Produktbereich in erster Linie EOP-Technologien Anwendung finden, daß aber über zwei Drittel der Unternehmen bereits Recyclingtechnologien und integrierte Umweltschutztechnologien einsetzen.

${ }^{776}$ Additive Technologien finden durschnittlich in den vier Betriebsgrößenklassen zu 51,6\%,51,6\%,57,4\% und $58,5 \%$ bzw. in den drei Umsatzgroßenklassen zu 49,3\%, 63,6\% und 55,9\% Anwendung.

${ }^{777} \mathrm{Vgl}$. zu den rechtlichen Grundlagen des betrieblichen Umweltschutzes Sondermann, W.D. (1992); Freimann, J. (1996), S. 114-125; Kostka, S. (1997), S. 133-144 sowie allgemein Schmidt, R./Müller, H. (1995).

${ }^{778}$ Vgl. Kostka, S. (1997), S. 161-172. Vgl. hierzu auch die Vorgehensweise beim EG-Öko-Audit. 
In den beiden ersten Phasen besteht die wichtigste Aufgabe darin, alle Unternehmensmitglieder vom Sinn und Zweck des betrieblichen Umweltschutzes zu überzeugen. Aufgrund der Einmaligkeit und der zeitlichen Begrenztheit schlägt KOSTKA für die Vorbereitung und Implementierung eines Umweltmanagementsystems den Einsatz von Projektteams vor. Um ferner etwaiger Betriebsblindheit vorzubeugen, empfiehlt sich die Einbindung externer Berater. Auf diese Weise lassen sich die Kenntnisse und Erfahrungen auf allen Hierarchieebenen gezielt aktivieren und bestmöglich nutzen. Durch konsequente Aus- und Weiterbildung lassen sich noch bestehende Know-how-Defizite ausräumen. Ausgehend von der Initiative der Unternehmensleitung erfolgt in der Vorbereitungsphase der Aufbau des Projektmanagements, die Formulierung der Umweltpolitik und die Durchführung der Umweltprüfung. In der Implementierungsphase wird ein erstes Umweltprogramm aufgestellt sowie die Unternehmensorganisation den Erfordernissen des Umweltmanagements angepaßt. Vor allem in diesen beiden Phasen können aktive und passive Widerstände (Durchsetzungsbarrieren) von seiten der Mitarbeiter auftreten, da z.B. die Aufdeckung von Unzulänglichkeiten oder notwendige Organisationsveränderungen zu Unsicherheiten führen können. ${ }^{779}$ Aus diesem Grund ist auch eine sukzessive Einführung des Umweltmanagements denkbar. ${ }^{780}$ Dabei werden zunächst Umweltschutzmaßnahmen durchgeführt, die gesetzlich vorgeschrieben sind, die eine hohe Rentabilität aufweisen oder die besondere umweltrelevante "Brennpunkte" des Unternehmens betreffen. Sind die Umweltschutzmaßnahmen in diesen Bereichen erfolgreich, wird auf der Basis dieser Beispiele eine unternehmensweite Einführung erleichtert.

Zusätzlich erfordern organisatorische Gestaltungsmaßnahmen zur Durchsetzung des betrieblichen Umweltschutzes sowohl zweckmäßige aufbauorganisatorische Strukturen als auch eine sinnvolle Gestaltung der Ablaufprozesse. ${ }^{781}$ Sie sorgen gleichzeitig für die erforderliche Transparenz, die notwendig ist, um Umweltmanagementaufgaben strukturiert und effektiv wahrzunehmen. Dabei ist erneut zu beachten, daß Maßnahmen der Organisationsentwicklung, wenn sie gesicherte Verhaltensweisen und Besitzstände in Frage stellen, Widerstände hervorrufen können, die letztlich auch die Innovationsfähigkeit des Unternehmens hemmen. Eine umweltinduzierte Modifikation der Unternehmensorganisation muß reaktives Verhalten anti-

\footnotetext{
${ }^{779}$ Neben den internen Durchsetzungsbarrieren bestehen eine Reihe weiterer Gegebenheiten, die den umweltorientierten Anpassungsprozeß verhindern oder erschweren. Es sind dies z.B. hohe Investitions-, Folge- und Betriebskosten, fehlende Informationen über technologische oder rechtliche Entwicklungen, hoher Zeitdruck oder mangelnde Nachfrage. Vgl. dazu auch Meffert, H. u.a. (1989), S. 38-45; Kirchgeorg, M. (1990), S. 116 120 und S. 262-271; Meffert, H./Ostmeier, H. (1990), S. 93-100; Meffert, H. u.a. (1990), S. 48; Kreikebaum, H. (1992b), S. 104ff.

${ }^{780}$ Vgl. z.B. Wicke, L. u.a. (1992), S. 643-646; Winter, G. (1988), S. 82-88.

${ }^{781}$ Vgl. Kreikebaum, H. (1992b), S. 100. Zur Betrachtung aufbau- und ablauforganisatorischer Aspekte vgl. ferner Wöhe, G. (1996), S. 183-198; Nissen, U. (1995), Kapitel 5.8; Kreikebaum, H. (1992b), S. 108. Die Unterscheidung von Aufbau- und Ablauforganisation, ist eine in der deutschen Literatur zu findende Trennung, die sich in der Praxis nicht aufrechterhalten läßt. Dort sind die Organisationsstruktur und die darin vollzogenen Abläufe untrennbar miteinander verbunden. Aufbau- und Ablauforganisation bilden zusammen die formelle Organisationsstruktur eines Unternehmens, vgl. z.B. Wöhe, G. (1996), S. 182.
} 
zipieren und daher evolutorisch angelegt sein. ${ }^{782}$ Nach der Einfuihrung muß eine periodische Überprüfung erfolgen, um die erarbeiteten Strukturen aufrechtzuerhalten bzw. gegebenenfalls anzupassen.

Hinsichtlich der zu bildenden Organisationsstruktur ist auch für den Umweltschutz die grundlegende Frage nach dem Ausmaß an Delegation von Entscheidungs- bzw. Handlungskompetenzen, also nach einer Zentralisation (Konzentration) oder einer Dezentralisation (Diffusion) der Aufgaben, zu beantworten. In Abhängigkeit von der Größe des Unternehmens muß somit der für den betrieblichen Umweltschutz optimale Zentralisationsgrad gefunden werden. Eine dezentrale Verteilung der Aufgaben auf mehrere Stellen erfordert einerseits eine größere Zahl von Fachkräften, die den übertragenen Aufgaben gerecht werden müssen. Andererseits wird durch die Einbindung das Verantwortungsgefulhl und die Motivation der Mitarbeiter erhöht, was zu einer unternehmensumfassenden Umweltverantwortlichkeit führt. Daneben vermindert sich durch Dezentralisation der Verwaltungsapparat an der Spitze und entlastet diese. Eine zentrale Aufgabenverteilung ist dann angezeigt, wenn die Gefahr besteht, daß der Überblick verlorengeht bzw. wenn Aufgabenabgrenzungen zunehmend verwischen. Ferner wird eine Zentralisation notwendig, wenn nicht genügend geeignete Fachkräfte im Unternehmen zur Verfügung stehen. ${ }^{783}$ Für den betrieblichen Umweltschutz - und dies vor allem mit Blick auf die spezifische Situation in kleinen und mittleren Unternehmen - ist wegen der Komplexität und den Interdependenzen bei Umweltschutzentscheidungen eine Aufteilung in Partialaufgaben nur beschränkt möglich. "Personengebundenes Know-how und Professionalität lassen sich in einer zentralen Einheit respektive in einer Person besser nutzen. ${ }^{784}$

Unabhängig vom Zentralisationsgrad läßt das Ausmaß der organisatorischen Einbindung des Umweltschutzes in das Unternehmen erkennen, ob eine kontinuierliche oder lediglich fallweise Berücksichtigung von Umweltschutzaufgaben angestrebt wird. Umweltschutzeinheiten gewinnen in diesem Zusammenhang "den Charakter eines Maintenance-Subsystems, welches das Verhalten des Unternehmens und seiner Vorhaben im Hinblick auf die Umwelteinwirkungen kontinuierlich überprüft, die Implementierung externer Auflagen sicherstellt und Neuentwicklungen in der Gesellschaft beziehungsweise auf bestimmten Märkten im Hinblick auf Umweltschutzbelange verfolgt" ${ }^{1785}$. Die untersuchten Unternehmen weisen jedoch in Bezug auf das Ausmaß der organisatorischen Einbindung des Umweltschutzes einen sehr geringen Organisationsgrad auf. Nur 23,6\% der Unternehmen weisen institutionalisierte Umweltschutzeinheiten aus (besonders erfolgreiche Unternehmen: 25,0\%; übrige: 23,0\%). Lediglich $15,7 \%$ der besonders erfolgreichen Unternehmen haben zentrale Organisationseinheiten mit

\footnotetext{
${ }^{782}$ Einen solchen Organisationsentwicklungsprozeß zeigt z.B. Günther, K. (1992), S. 20f., auf.

${ }^{783}$ Vgl. Wöhe, G. (1996), S. $187 f$.

${ }^{784}$ Steinle, C. u.a. (1994), S. 421.

${ }^{785}$ Ullmann, A.A. (1982), S. 101.
} 
Umweltschutzaufgaben eingerichtet (übrige: 17,6\%). Dezentrale Umweltschutzeinheiten haben nur $12,2 \%$ der besonders erfolgreichen Unternehmen (übrige: $7,5 \%$ ) berücksichtigt. ${ }^{786}$

Besonders deutlich tritt bei dieser Fragestellung die Abhängigkeit institutionalisierter Umweltschutzstellen von der Unternehmensgröße hervor. Mit zunehmender Betriebsgröße bzw. zunehmendem Umsatz finden sich auch immer mehr Unternehmen, die Umweltschutzeinheiten eingerichtet haben (vgl. Anlage 34). ${ }^{787}$ Dies kann u.a. darauf zurückgeführt werden, daß mit zunehmender Unternehmensgröße auch die Anlagengröße und damit die Emissionstätigkeit steigt, woraus wiederum die Notwendigkeit zur Bestellung eines Betriebsbeauftragten für Umweltschutz entsteht. Der Betriebsbeauftragte für Umweltschutz (kurz: "Umweltschutzbeauftragter") ist eine gesetzlich vorgeformte umweltbezogene Organisationseinheit. Mit dieser personalpolitischen Vorgabe von staatlicher Seite ist die Absicht verbunden, im Unternehmen einen Spezialisten einzusetzen, der zum einen die Komplexität der Normen und Gesetze zu reduzieren und daraus konkrete Anforderungen für die einzelnen Betriebsbereiche abzuleiten vermag. Dem Unternehmen wird also die Selbstkontrolle zur Pflicht gemacht - ein Aspekt, der sich auch in der EG-Öko-Audit-Verordnung wiederfindet. Zum anderen soll der Umweltschutzbeauftragte den kontinuierlichen Verbesserungsprozeß des betrieblichen Umweltschutzes fördern. Daraus lassen sich eine Reihe von Funktionen ableiten, die der Umweltschutzbeauftragte wahrzunehmen hat. Im wesentlichen sind dies Innovations-, Kontroll-, Informations- und Berichtsfunktionen. ${ }^{788}$ Aus diesem breiten Funktionsspektrum resultieren hohe Anforderungen in fachlicher und persönlicher Hinsicht an den Umweltschutzbeauftragten. $^{789}$

Von gesetzlicher Seite entsteht für eine Vielzahl kleiner und mittlerer Unternehmen nicht die Notwendigkeit zur Berufung eines Umweltschutzbeauftragten, weshalb in der zugrundeliegenden Untersuchung von einer Erfassung abgesehen wurde. Aufgrund der hohen Komplexität und Dynamik sowie der mangelnden Routinisierbarkeit der Umweltschutzaufgaben ist die Einrichtung einer vergleichbaren Funktion mit einer Reihe von Vorteilen verbunden. Diese

\footnotetext{
${ }^{786} \mathrm{Vgl}$. Frage 4/3 des Fragebogens im Anhang sowie Anlage 34.

$\mathrm{Zu}$ ähnlichen Ergebnissen gelangen Beer, R./Troge, A. (1992), S. 88f. Kirchgeorg, M. (1990), S. 158-161. zeigt hingegen in seiner Untersuchung höhere Organisationsgrade auf. Sie liegen bei ihm zwischen $33 \%$ und 83\%. Dieses Ergebnis könnte aber darauf zurilckzufuhren sein, daß vom Umweltschutz in besonderer Weise betroffene Unternehmen untersucht wurden.

${ }^{787} \mathrm{Sig}$. jeweils 0,001 . Es zeigt sich ferner, daß mit steigender Unternehmensgrőße die Umweltschutzeinheiten zunehmend direkt der Unternehmensfuhrung bzw. Betriebsleitung unterstellt sind (Sig. jeweils 0,001). Vgl. hierzu auch die Ergebnisse von Ullmann, A.A. (1982), S. 101f.

${ }^{788}$ Vgl. dazu und zu weiteren Funktionen z.B. Ullmann, A.A. (1982), S. 104; Senn, J.F. (1986), S. 310f.; Seidel, E. (1990), S. 217f.; Wicke, L. u.a. (1992), S. 35f. und S. 73f; Malinsky, A.H. (1996), S. 47f.; Freimann, J. (1996), S. 133. Allerdings weist Ullmann, A.A. (1982), S. 110, darauf hin, daß der innovativen Funktion im Vergleich zu den anderen eine relativ untergeordnete Bedeutung zukommt.

${ }^{789}$ Für eine ausführliche Beschreibung des Umweltschutzbeauftragten vgl. Ullmann, A.A. (1982), S. 102-114; Senn, J.F. (1986), S. 310-321; Wicke, L. u.a. (1992), S. 68-90; Tischler, K. (1996), S. 563-572.
} 
Vorteile resultieren zunächst aus der Übernahme der oben genannten Funktionen. Dadurch könnte

- die Sammlung, Verarbeitung und Weitergabe umweltrelevanter Informationen systematisiert,

- die Einhaltung von Gesetzen, Verordnungen und behördlichen Anordnungen verbessert sowie

- auf die Entwicklung umweltfreundlicher Verfahren und Produkte hingewirkt (Fachpromotor)

werden. Auf die daraus entstehenden positiven ökologischen und ökonomischen Effekte wurde bereits hingewiesen (vgl. Abschnitt 5.2.2). Hinzu kommt die Signalwirkung, die von einer derartigen Implementierung des Umweltschutzes ausgeht. Sie verdeutlicht die Unterstützung durch die Unternehmensfuihrung und wirkt dadurch motivierend auf alle Mitarbeiter.

\subsection{Der Umweltschutz in der Unternehmenskultur}

"Nachhaltige Entwicklung steht im Mittelpunkt eines globalen wirtschaftlichen, technologischen, sozialen, politischen und kulturellen Wandels, der die Grenzen des Möglichen und Wünschenswerten neu definiert. Für die Wirtschaft bedeutet dies einen tiefgreifenden Wandel: einen Wandel in den Zielen und Wertvorstellungen, von denen ein Unternehmen sich in seinen Aktivitäten leiten läßt, und einen Wandel im täglichen Handeln sowie im Umgang mit neuen Prozessen und Instrumenten. ${ }^{1790}$ Dieser durch das Umfeld an das Unternehmen herangetragene sowie durch die Organisationsmitglieder in das Unternehmen hineingetragene Wandel erfordert eine umweltorientierte Anpassung der Unternehmenskultur. Sie steckt als Orientierungs- und Verhaltensmuster den Rahmen für Entscheidungsprozesse und das Handeln im Unternehmen ab. Indem sie die Identifikation der Mitarbeiter mit dem Unternehmen fördert und ein "Wir-Gefühl" schaff, ist ihre Anpassung somit auch eine Erfolgsvoraussetzung für die im vorangegangenen Abschnitt aufgezeigte organisatorische Einbindung des Umweltschutzes in das Unternehmen.

Von grundlegender Bedeutung sind in diesem Anpassungsprozeß zunächst zwei Komponenten, nämlich die umweltbezogenen Wertvorstellungen der Unternehmensführung und die aktive Einbeziehung der Mitarbeiter. Die umweltbezogenen Wertvorstellungen bringen die kulturprägenden Überzeugungen der Unternehmensführung zum Ausdruck. Eine umweltorientierte Unternehmenskultur findet aber erst durch das sichtbare Vorleben der ihr zugrundeliegenden Werte Eingang in das Denken und Handeln der Organisationsmitglieder und erhält

${ }^{790}$ Schmidheiny, S. (1992), S. 124. 
nach außen das notwendige $\mathrm{Maß}$ an Glaubwürdigkeit. Für Akzeptanz und Wirkung umweltbezogener Bestandteile der Unternehmenskultur ist darüber hinaus die aktive Einbeziehung der Mitarbeiter wichtig, weil eine vollständige Identifikation mit dem Unternehmen nur dann erfolgt, wenn sich das individuelle Umweltbewußtsein mit dem des Unternehmens deckt, und weil auch sie durch ihr Denken und Handeln die Glaubwürdigkeit des Unternehmens nach außen hin bestimmen. Analog zur Innovations- oder Qualitätsorientierung löst dann die Umweltorientierung ebenfalls einen kontinuierlichen Verbesserungsproze $ß$ aus, der neben positiven ökologischen Effekten auch positive ökonomische Effekte nach sich zieht.

Transparent wird die umweltorientierte Transformation der Unternehmenskultur in der Unternehmenspolitik durch die Formulierung von Umweltleitbildern, Umweltzielen und Umweltstrategien. Als Orientierungshilfe zur Formulierung der Inhalte der betrieblichen Umweltpolitik können beispielsweise die sogenannten "guten Managementpraktiken" des EG-Öko-Audits verwendet werden. ${ }^{791}$ Die Inhalte sollen alle Bereiche des Unternehmens betreffen, wobei die angeführten Ziele nicht utopisch sein dürfen, da sie sonst unglaubwürdig wirken und ihre Akzeptanz verlieren. Die Inhalte der betrieblichen Umweltpolitik können z.B. in der in Abb. 5-4 dargestellten Weise formuliert werden.

In einer Vielzahl kleiner und mittlerer Unternehmen sind die Bestandteile der Unternehmenspolitik nicht schriftlich fixiert. Folglich finden sich auch nur in wenigen Fällen ausformulierte Umweltleitbilder oder -grundsätze, Umweltziele und Umweltstrategien. ${ }^{792}$ Doch selbst wenn das Unternehmen für alle Beschäftigten uberschaubar und die umweltpolitische Orientierung erlebbar ist, ermöglicht die eindeutige Formulierung der Umweltpolitik den zielorientierteren und konzentrierteren Einsatz der in kleinen und mittleren Unternehmen knappen personellen und finanziellen Ressourcen. Eine schriftliche Fassung hat darüber hinaus den Vorzug, daß sie eine höhere Verbindlichkeit der Umweltschutzmaßnahmen zum Ausdruck bringt und dadurch ein Problembewußtsein schafft sowie umweltorientiertes Denken und Handeln fördert.

${ }_{791}$ Vgl. Anhang I D der EG-Ǒko-Audit-Verordnung.

792 Als positives Beispiel aus der Region Neckar-Alb vgl. beispielsweise die umweltpolitischen Grundsătze der Bizerba GmbH \& Co.KG in Anlage 35 sowie ferner auch die Ergebnisse der FUUF (1991), S. $200 \mathrm{f}$. 


\section{Abb. 5-4: Exemplarische Inhalte betrieblicher Umweltpolitik}

\begin{tabular}{|c|}
\hline Umweltpolitik \\
\hline Wir wollen: \\
\hline $\begin{array}{l}\text { - den Umweltschutz gleichwertig wie wirtschaftliche } \\
\text { und soziale Belange des Unternehmens behandeln, }\end{array}$ \\
\hline $\begin{array}{l}\text { - den Schutz unserer Umwelt verantwortlich } \\
\text { fordern und mitgestalten, }\end{array}$ \\
\hline $\begin{array}{l}\text { - die Ressourcen der Natur auf allen Gebieten } \\
\text { schonend einsetzen. Dies beginnt bei der Produkt- } \\
\text { entwicklung und endet beim Recycling des Produktes. }\end{array}$ \\
\hline $\begin{array}{l}\text { - die Umweltauswirkungen jedes Produktes, } \\
\text { jeder neuen Tătigkeit und jedes neuen Verfahrens } \\
\text { vor ihrer Anwendung beurteilen und somit Umwelt- } \\
\text { schäden und Sicherheitsrisiken vorbeugend vermeiden, }\end{array}$ \\
\hline $\begin{array}{l}\text { - Reststoffe in die Stofflkreisläufe zurdckführen, } \\
\text { soweit es möglich und wirtschaftlich vertretbar ist, }\end{array}$ \\
\hline $\begin{array}{l}\text { - das Verantwortungsbewußtsein fur die Umwelt } \\
\text { bei unseren Mitarbeitern auf allen Ebenen fordern }\end{array}$ \\
\hline und \\
\hline $\begin{array}{l}\text { - den offenen, sachlichen Dialog mit unseren Kunden, } \\
\text { den Behörden und der Öffentlichkeit pflegen, der zum } \\
\text { besseren gegenseitigen Verständnis beitragen soll. }\end{array}$ \\
\hline Unternehmensleitung der Firma Metall GmbH \\
\hline
\end{tabular}

Quelle: Landesanstalt für Umweltschutz (Hrsg.) (1995b), S. 17.

Mögliche Begründungen für die mangelnde schriftliche Fixierung ergeben sich aus den allgemeinen Charakteristika kleiner und mittlerer Unternehmen (vgl. Abschnitt 2.1.2 und Anlage 5) sowie ferner aus der Exponiertheit des Unternehmens ${ }^{793}$ und der subjektiven Einschätzung der vom Unternehmen ausgehenden Umweltprobleme. Da kleine und mittlere Unternehmen im Vergleich zu Großunternehmen in der Regel eine geringe Exponiertheit aufweisen und somit von seiten der Anspruchsgruppen nur wenig Druck ausgeübt wird, schätzen sie auch die Notwendigkeit einer (öffentlichkeitswirksamen) schriftlichen Fixierung der Umweltpolitik, die die umweltorientierte Einstellung des Unternehmens dokumentiert, als sehr gering ein. Desweiteren ist die subjektive Einschätzung der vom Unternehmen ausgehenden Umweltprobleme bedeutsam. Gelangt die Unternehmensführung zu der Einschätzung, daß von seiten

${ }^{793}$ Die Exponiertheit des Unternehmens wird bestimmt durch das ihm in der Öffentlichkeit entgegengebrachte Interesse. 
des Unternehmens keine wesentlichen Umweltprobleme entlang des Produktlebenszyklus entstehen, ergibt sich ebenfalls kaum ein Handlungsbedarf in Richtung auf die Formulierung einer expliziten Umweltpolitik. Diese beiden Sachverhalte bilden somit die dritte konstituierende Komponente der betrieblichen Umweltpolitik.

Die letztere der vorgenannten Komponenten findet in der vorliegenden Untersuchung Bestätigung. Von den befragten Unternehmen geht nach eigener Einschätzung bei der Beschaffung, bei der Produktion, beim Vertrieb sowie bei der Entsorgung der Ressourcen bzw. der Produkte übereinstimmend so gut wie keine Umweltgefährdung aus. Im einzelnen ergibt sich das folgende Bild:

Tab. 5-3: Einschätzung der Umweltprobleme entlang des Produktlebenszyklus durch die beiden Erfolgstypen

\begin{tabular}{|l|c|c|c|}
\hline \multicolumn{1}{|c|}{ Umweltprobleme } & Gesamt & $\begin{array}{c}\text { besonders erfolgreiche } \\
\text { Unternehmen }\end{array}$ & $\begin{array}{c}\text { weniger erfolgreiche } \\
\text { Unternehmen }\end{array}$ \\
\hline $\begin{array}{l}\text { bei der Beschaffung der Rohstoffe } \\
\text { und Vorprodukte } \\
\text { bei der Produktion mit umwelt- } \\
\text { belastenden Verfahren }\end{array}$ & 1,9 & 2,0 & 1,8 \\
$\begin{array}{l}\text { im Vertrieb wegen der Umwelt- } \\
\text { belastung der Produkte } \\
\text { bei der Entsorgung }\end{array}$ & 1,6 & 2,3 & 2,1 \\
\hline
\end{tabular}

Quelle: eigene Berechnungen. ${ }^{794}$

Mit dem vorstehenden Ergebnis scheint darüber hinaus auch eine Begründung für den schwachen Einsatz operativer und strategischer Instrumente des Umweltmanagements in kleinen und mittleren Unternehmen gefunden zu sein (vgl. die Abschnitte 5.3.3.1 und 5.3.3.2).

Vor diesem Hintergrund stellt sich die Frage, ob und in welchem Ausmaß der Umweltschutz Eingang in das Ziel- und Strategiensystem der untersuchten kleinen und mittleren Unternehmen des Verarbeitenden Gewerbes findet. Mit der Beleuchtung dieser Aspekte befassen sich die beiden folgenden Kapitel.

\footnotetext{
${ }^{794}$ Vgl. Frage 4/7 des Fragebogens im Anhang sowie Anlage 36. Skala von $1=$ "überhaupt nicht" bis $5=$ " in hohem Maße". Die Anlage verdeutlicht, daß sich auch bei einer Differenzierung nach der Unternehmensgröße keine wesentlichen unternehmensgroßßenspezifischen Abweichungen bei der Einschätzung der Umweltprobleme entlang des Produktlebenszyklus ergeben.
} 


\subsection{Umweltschutzziele}

\subsubsection{Die Integration von Umweltschutzzielen in das Zielsystem des Unternehmens}

Das Unternehmen steht in einem vielfältigen Bedingungs- und Wirkungsgefüge mit seinem spezifischen Umfeld. Dies verlangt die Übernahme von Verantwortung für dessen ökonomische und ökologische Entwicklung. Entsprechend muß das Unternehmen einen eigenständigen Beitrag zur Lösung ökonomischer und ökologischer Problemstellungen erbringen. Folglich muß ein Weg gefunden werden, wie durch die Verknüpfung ökonomischer und ökologischer Ziele Erfolgsfaktoren aufgebaut werden können, die eine nachhaltige Wettbewerbsfähigkeit des Unternehmens sicherstellen.

Das traditionelle Zielsystem des Unternehmens versteht die Umweltfreundlichkeit der Produkte und Prozesse lediglich als Restriktion, die entsprechend der rechtlichen Rahmenbedingungen einzuhalten ist und die den Gewinn bzw. die Rentabilität einschränkt. Von dieser Sichtweise muß sich die Unternehmensführung lösen. Die besondere Herausforderung liegt somit in der Verknüpfung ökologischer und ökonomischer Unternehmensziele, so daß Umweltschutz zu einer Wachstumsvoraussetzung und nicht zu einer Wachstumsbegrenzung wird. Umweltschutz kann dann zum Aufbau von Wettbewerbsvorteilen gegenüber denjenigen Wettbewerbern führen, die bisher auf eine explizite Berücksichtigung des Umweltschutzes verzichtet haben, die keine umweltgerechten Produktinnovationen anbieten können und/oder die nicht in der Lage sind, umweltschädigende Einsatzstoffe und Energien durch umweltverträglichere oder sogar regenerative Ressourcen und Energien zu substituieren. Mit der Wahrnehmung dieser Profilierungschancen eröffnen sich neue Markt- und Gewinnpotentiale. Der betriebliche Umweltschutz wird dann zu einem wettbewerbsstrategischen Instrument. ${ }^{795}$

Die mit einem systematischen Umweltmanagement verbundene konzeptionelle Gesamtsicht erleichtert ferner die Anpassung der Unternehmensziele an die dynamischen Veränderungen der ökologischen, gesellschaftlichen und wettbewerbsstrategischen Rahmenbedingungen unter Berücksichtigung der eigenen Ressourcen. Die Formulierung von Umweltschutzzielen ist folglich kein statischer, sondern ein kontinuierlicher, dynamischer Prozeß.

${ }^{795}$ Vgl. Meffert, H./Kirchgeorg, M. (1989b), S. 180ff. 


\subsubsection{Die Formulierung von Umweltschutzzielen}

Die zentralen Elemente des Umweltschutzes als Unternehmensziel betreffen den Ressourcenschutz, die Emissionsbegrenzung und die Risikobegrenzung. Aufgabe des Umweltmanagements ist es nun, im Einklang mit der betrieblichen Umweltpolitik konkrete Umweltschutzziele für die einzelnen Unternehmensfunktionen, Geschäftsbereiche, Produkte, Einsatzstoffe, Trägermedien und Energieträger zu formulieren. Die Ziele sollten dabei die Verpflichtung zur kontinuierlichen Verbesserung des betrieblichen Umweltschutzes enthalten und nach Inhalt, Ausmaß und Zeitbezug präzisiert werden. ${ }^{796}$

Das Oberziel "Umweltschutz" kann in eine Reihe von Zwischen- und Unterziele zerlegt werden, die sich wiederum nach Input-, Output- und Risikozielen differenzieren lassen. ${ }^{797}$ Inputorientierte Ziele stellen auf die für die Leistungserstellung notwendigen Produktionsfaktoren ab. Da der Einsatz von Ressourcen bzw. der Energieverbrauch grundsätzlich umweltwirksam ist, sind am Input ansetzende Ziele auf die Reduzierung der von den eingesetzten Produktionsfaktoren ausgehenden Umweltwirkungen gerichtet. Durch Maßnahmen der Vermeidung, Verminderung oder Substitution der Einsatzfaktoren bzw. nicht regenerativer Energieträger kann direkt Einfluß auf die Umweltwirksamkeit der Produktion genommen werden. Eine indirekte Einflußnahme liegt vor, wenn die Gestaltung der Produktionsbedingungen auf der vorgelagerten Stufe stattfindet. Da bei der Produktion von Gütern Kuppelprodukte (Emissionen) entstehen, setzen outputorientierte Ziele an dieser Stelle an. Sie haben die Reduktion nicht warenförmiger, d.h. nicht marktfähiger bzw. unerwünschter Kuppelprodukte wie z.B. Abfall, Abwasser, Abluft, Lärm usw. zum Inhalt. Am Output ansetzende Umweltschutzziele richten sich auf eine Begrenzung der vorgenannten Emissionen durch Vermeidung, Verminderung, Verwertung oder Entsorgung. Risikoorientierte Ziele richten sich auf eine Verminderung, Begrenzung oder Verhinderung von Gefahrenpotentialen und Störfällen.

Das Erreichen input-, output- sowie risikoorientierter Umweltschutzziele steht somit in engem Zusammenhang mit der technischen Einbindung des Umweltschutzes im Unternehmen (vgl. Abschnitt 5.3.4.1). Durch die Reduktion des Ressourcen- und Energieverbrauchs sowie der Emissionen in Verbindung mit einer Reduktion bzw. Substitution von Gefahrstoffen und der sich daraus ergebenden Absenkung des vom Unternehmen ausgehenden Risikopotentials trägt vor allem der innovative, produktionsintegrierte Umweltschutz entscheidend zum Erreichen von Umweltschutzzielen bei.

\footnotetext{
${ }^{796}$ Die Formulierung von Unternehmens- bzw. Umweltschutzzielen ist auch eine notwendige Voraussetzung furr die Implementierung eines funktionsfahigen Umweltcontrolling. Vgl. Pfriem, R./Hallay, H. (1992), S. 298 sowie Abschnitt 5.3.3.1.

${ }^{797}$ Vgl. Strebel , H. (1980), S. 94-97, i.V.m. Dyllick, T. (1990), S. 23ff.
} 


\subsubsection{Die Zielbeziehungen zwischen ökonomischen und ökologischen Unternehmenszielen}

Über die Zusammenhänge zwischen ökologischen und ökonomischen Unternehmenszielen herrschen unterschiedliche Auffassungen. Dabei wird oftmals die These vertreten, daß mit einer konsequenten Verfolgung von Umweltschutzzielen das Erreichen ökonomischer Ziele schwieriger wird. Allerdings ist darauf hinzuweisen, daß dem Umweltschutz im Rahmen der empirischen Zielforschung erst in jüngerer Zeit explizite Aufmerksamkeit geschenkt wird. Die Vernachlässigung des Umweltschutzes als Unternehmensziel in den frühen Phasen der empirischen Zielforschung ist zum einen auf die lange Zeit untergeordnete Bedeutung des Umweltschutzes und zum anderen auf die Komplexität der Ziele und ihrer Interdependenzen zurückzufuihren. Erst in den achtziger und zu Beginn der neunziger Jahre widmeten sich verschiedene Studien verstärkt dem Stellenwert des Umweltschutzes. Mit Blick auf diese Studien wird nachfolgend der Stellenwert des Umweltschutzes im Zielsystem der hier untersuchten Unternehmen sowie dessen Interdependenzen mit den übrigen Unternehmenszielen aufgezeigt.

Die Einordnung der Unternehmensziele durch die kleinen und mittleren Unternehmen des Verarbeitenden Gewerbes in der Region Neckar-Alb zeigt, daß das Unternehmensziel "Umweltschutz" einen eher untergeordneten Rang einnimmt (vgl. Tab. 5-4). Insgesamt wird der Umweltschutz im Rahmen der Unternehmensziele auf den zwölften Platz gesetzt. Wie aus Tab. 5-4 ersichtlich wird, plazieren die besonders erfolgreichen Unternehmen den Umweltschutz auf den 14. Rang. Die weniger erfolgreichen Unternehmen hingegen setzen den Umweltschutz auf den elften Platz. Damit kommt diese Untersuchung zu ganz ähnlichen Ergebnissen wie vergleichbare Studien, die sich allerdings ausschließlich mit dem Thema "Betrieblicher Umweltschutz" auseinandergesetzt haben. So lag der Umweltschutz bei RAFFÉE, FÖRSTER UND KRUPP 1988 auf dem zehnten bzw. elften Rang, bei MEFFERT UND KIRCHGEORG 1989 auf dem achten Rang und bei RAFFÉE UND FRTTZ 1990 auf dem 19. Rang. ${ }^{798}$

${ }^{798}$ Vgl. hierzu ausfuhrlich die Studien von Raffée, H. u.a. (1988); Meffert, H./Kirchgeorg, M. (1989a); Raffée, H./Fritz, W. (1990) sowie ferner die in Abschnitt 3.5.3 darüber hinaus vorgestellten Untersuchungen. Für eine Gegenüberstellung der Ergebnisse der empirischen Zielforschung sei erneut auf Tab. 3-5 verwiesen. 
Tab. 5-4: Inhalt und Rangordnung von Unternehmenszielen bei den beiden Erfolgstypen

\begin{tabular}{|l|c|c|c|}
\hline \multicolumn{1}{|c|}{ Unternehmensziel (Rang) } & Gesamt & $\begin{array}{c}\text { besonders erfolgreiche } \\
\text { Unternehmen }\end{array}$ & $\begin{array}{c}\text { weniger erfolgreiche } \\
\text { Unternehmen }\end{array}$ \\
\hline $\begin{array}{l}\text { Sicherung der Wettbewerbsfähig- } \\
\text { keit }\end{array}$ & 4,8 & $4,8(1)$ & $4,8(1)$ \\
langfristige Gewinnerzielung & 4,8 & $4,8(1)$ & $4,7(2)$ \\
Kosteneinsparungen & 4,6 & $4,6(4)$ & $4,6(3)$ \\
Produktivitătssteigerungen & 4,6 & $4,7(3)$ & $4,6(3)$ \\
Unternehmens-/ Produktimage & 4,4 & $4,5(5)$ & $4,4(5)$ \\
Mitarbeitermotivation & 4,4 & $4,4(6)$ & $4,4(5)$ \\
Erschließung neuer Märkte & 4,2 & $4,0(11)$ & $4,3(7)$ \\
Umsatz & 4,2 & $4,2(8)$ & $4,2(8)$ \\
Kooperation mit Abnehmern/ & 4,1 & $4,1(9)$ & $4,2(8)$ \\
Handel & 4,1 & $4,3(7)$ & $3,9(10)$ \\
Erhaltung von Arbeitsplătzen & 3,9 & $4,1(9)$ & $3,8(1)$ \\
Marktanteil & 3,7 & $3,6(14)$ & $3,8(11)$ \\
Umweltschutz & 3,7 & $3,9(12)$ & $3,7(13)$ \\
Unternehmenswachstum & 3,7 & $3,8(13)$ & $3,7(13)$ \\
Kooperation mit Lieferanten & 3,3 & $3,1(15)$ & $3,4(15)$ \\
kurzfristige Gewinnerzielung & & & \\
\hline
\end{tabular}

Quelle: eigene Berechnungen. ${ }^{799}$

Bei der Einordnung der einzelnen Ziele im Rahmen der zugrundeliegenden Untersuchung ist allerdings anzumerken, daß zwar die Plazierungen zum Teil stark voneinander abweichen, daß aber die Bewertungsunterschiede (Skalenwerte) zwischen den besonders erfolgreichen bzw. den weniger erfolgreichen Unternehmen nicht besonders ausgeprägt sind. Ein ähnliches Bild ergibt sich auch bei einer Differenzierung nach der Unternehmensgröße (vgl. Anlage 13). Der Umweltschutz als Unternehmensziel ist entsprechend der hier erzielten Ergebnisse weder von der Innovativität des Unternehmens noch von seiner Größe abhängig. ${ }^{800}$

Für die nachrangige Einordnung des Umweltschutzes als Unternehmensziel lassen sich zunächst zwei Erklärungen anführen. In Anbetracht der bislang im Rahmen des Kapitels Umweltmanagement aufgezeigten Ergebnisse ist die vorgenommene Plazierung nicht weiter verwunderlich. Aus dem zurückhaltenden Einsatz von Instrumenten des Umweltmanagements und dem niedrigen Organisationsgrad i.V.m. der geringen Exponiertheit sowie der vorherr-

${ }^{799}$ Vgl. Frage 4/1 des Fragebogens im Anhang sowie Anlage 13. Skala von 1 = "uberhaupt kein Stellenwert" bis $5=$ "sehr hoher Stellenwert".

${ }^{800}$ Wie Anlage 13 zeigt, ergeben sich auch für die übrigen Unternehmensziele sowohl bei einer Differenzierung nach den Erfolgstypen als auch bei einer Differenzierung nach der Unternehmensgröße weitgehend ähnliche Skalenwerte. 
schenden Überzeugung, daß vom eigenen Unternehmen keine Belastung der Umwelt ausgeht, resultiert konsequenterweise die nachrangige Einordnung. Hinzu kommt die Überlegung, da $\beta$ auch die wirtschaftlichen Rahmenbedingungen eine Rolle spielen könnten, die wettbewerbsund wachstumsorientierte Ziele verstärkt in den Vordergrund rücken und daß dadurch der Umweltschutz als Unternehmensziel an Stellenwert einbüßt. ${ }^{801}$

Bedeutender als die absolute Plazierung des Umweltschutzes im Zielsystem des Unternehmens, ist die Einschätzung, inwiefern die Verfolgung des Umweltschutzzieles eine positive bzw. negative Wirkung auf das Erreichen der übrigen Unternehmensziele hat. Von einer Zielkomplementarität kann dann gesprochen werden, wenn durch umweltorientiertes Wirtschaften ein Beitrag zum Unternehmenserfolg geleistet wird, d.h. mit der Verfolgung ökologischer Ziele wird das Erreichen ökonomischer Ziele begünstigt. Erweist sich hingegen die Realisation ökologischer Ziele als eine Beeinträchtigung des Erreichens der ökonomischen Ziele, so liegt ein konkurrierendes Verhältnis vor. Zielindifferenz oder -neutralität ist gegeben, wenn sich ökologische und ökonomische Ziele weitgehend unbeeinflußt voneinander verfolgen lassen. $^{802}$

Wird die Gesamtheit der untersuchten kleinen und mittleren Unternehmen betrachtet, so stehen die Ziele

- Unternehmens- bzw. Produktimage,

- Mitarbeitermotivation und

- Kooperation mit Abnehmern bzw. dem Handel

in einem komplementären Verhältnis zum Umweltschutz (vgl. Abb. 5-5). Wird der Bogen weiter gespannt, sehen die befragten Unternehmen eine zumindest neutrale Beziehung zwischen dem Umweltschutz und den Unternehmenszielen

- Sicherung der Wettbewerbsfähigkeit,

- Erschließung neuer Märkte,

- Marktanteil,

- Kooperation mit Lieferanten,

- Umsatz,

- langfristige Gewinnerzielung,

- Arbeitsplatzerhaltung und

- Unternehmenswachstum.

${ }^{801} \mathrm{Vgl}$. zu den wirtschaftlichen Rahmenbedingungen Abschnitt 2.3.1 sowie die dort angegebene Literatur. Vgl. ferner Kurz, R. (1994b), der die Problematik des Umweltschutzes in Krisenzeiten diskutiert.

${ }^{802} \mathrm{Vgl}$. dazu auch Abschnitt 3.5.2.2. 


\section{Abb. 5-5: Förderung bzw. Beeinträchtigung von Unternehmenszielen durch die Verfolgung von Umweltschutzielen}

Sich. Wettbewerbsf. langfr. Gewinnerz. Kosteneinsparung Produktivitätsstg. Untern./Produktimage Mitarb.motivation Erschl. neuer Märkte Umsatz

Koop. m. Abnehmern Arbeitsplatzerhaltg. Marktanteil Umweltschutz Untern.wachstum Koop. m. Lieferanten kurzfr. Gewinnerz.

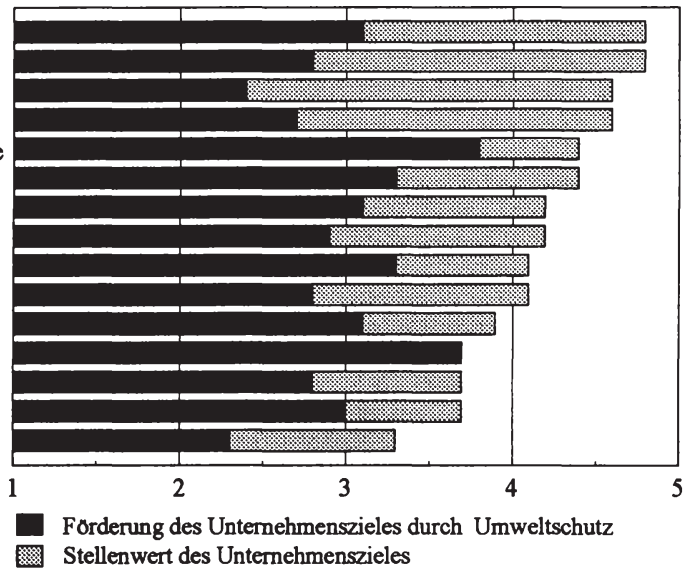

Quelle: eigene Berechnungen. ${ }^{803}$

Damit ist deutlich zu erkennen, daß alle auf den Markt bezogenen Ziele in einem positiven, zumindest aber einem neutralen Verhältnis zum Umweltschutzziel stehen. Ferner ist die positive Beeinflussung mitarbeiterbezogener Unternehmensziele hervorzuheben, die über eine steigende Motivation und Arbeitszufriedenheit wiederum fördernd auf die ökonomischen Ziele zurückwirken. ${ }^{804}$

Auffällig ist darüber hinaus, daß in der Tendenz mit steigender Unternehmensgröße dem Umweltschutz auch eine zunehmende Unterstützungswirkung der ökonomischen Ziele beigemessen wird (vgl. Anlage 37). Werden ausschließlich die Unternehmen mit mehr als 200 Mitarbeitern bzw. mit mehr als 100 Mio. DM Umsatz betrachtet, findet eine starke Erweiterung der ökonomischen Unternehmensziele statt, die durch die Verfolgung des Umweltschutzzieles positiv beeinflußt werden. In einem komplementären Verhältnis zum Umweltschutzziel stehen dann die Unternehmensziele

${ }^{803}$ Vgl. Frage 4/2 des Fragebogens im Anhang sowie Anlage 37. Skala von 1 = "sehr große Beeinträchtigung" bis 5 = "sehr große Förderung".

${ }^{804}$ An dieser Stelle sei erneut u.a. auf die Studien von Meffert, H./Kirchgeorg, M. (1989a) und Raffée, H. u.a. (1992) sowie die vergleichende Analyse von Fritz, W. (1995) verwiesen. Vgl. dazu ferner FUUF (1991), S. 204-207. 
- Unternehmens- bzw. Produktimage,

- Mitarbeitermotivation,

- Kooperation mit Abnehmern bzw. dem Handel,

- langfristige Gewinnerzielung,

- Sicherung der Wettbewerbsfähigkeit,

- Erschließung neuer Märkte,

- Marktanteil,

- Umsatz und

- Kooperation mit Lieferanten.

Lediglich bei den Unternehmenszielen "Kosteneinsparungen" und "kurzfristige Gewinnerzielung" wird eine Beeinträchtigung der Zielerreichung festgestellt. Das konkurrierende Zielverhältnis der Kosteneinsparungen mit dem Umweltschutz kann weitgehend auf das Informationsdefizit zurlickgeführt werden, das hinsichtlich der Rationalisierungswirkungen durch Umweltschutzmaßnahmen besteht. Der weit verbreiteten Auffassung "Umweltschutz kostet!", müßte deshalb von seiten der Informationsanbieter entschiedener entgegengetreten und es müßten positive Unternehmensbeispiele wirksamer hervorgehoben werden. Die zweite Konkurrenzbeziehung wird durch FRITZ relativiert. ${ }^{805}$ Nach seinen Erkenntnissen ergibt sich auch hier eher eine Zielkomplementarität, da die meisten Unternehmen nicht in der Lage sind, die wirtschaftlichen Vor- und Nachteile von Umweltschutzmaßnahmen quantitativ zu ermitteln und ihre Wirkung auf den Gewinn exakt anzugeben. Darliber hinaus wird zwar eine direkte negative Wirkung des Umweltschutzes auf den kurzfristigen Gewinn festgestellt, aber zugleich darauf hingewiesen, daß diese durch positive indirekte Wirkungszusammenhänge überkompensiert werden.

Angesichts der vorstehenden Ergebnisse ist kein Zielkonflikt zwischen ökonomischen und ökologischen Unternehmenszielen erkennbar, sondern vielmehr eine weitreichende Komplementarität zwischen ökonomischen und ökologischen Unternehmenszielen. Der betriebliche Umweltschutz leistet als Querschnittsaufgabe damit alles in allem einen nicht zu unterschätzenden Beitrag für die Sicherstellung des ökonomischen Unternehmenserfolges. Die ihm im Rahmen der Wettbewerbsvorteile und der Unternehmensziele zugewiesene nachrangige Einschätzung ${ }^{806}$ deutet jedoch darauf hin, daß die untersuchten Unternehmen erst in unzureichendem Maße das Chancenpotential des Umweltschutzes erkennen. Folglich kommt dem Umweltschutz in kleinen und mittleren Unternehmen des Verarbeitenden Gewerbes bislang noch nicht die Bedeutung eines eigenständigen Erfolgsfaktors zu.

${ }^{805}$ Vgl. Fritz, W. (1995), S. 352f.

${ }^{806}$ Vgl. hierzu die in Tab. 3-4 sowie Tab. 3-5 i.V.m. Tab. 5-4 zusammengestellten Ergebnisse. 


\subsection{Umweltschutzstrategien}

\subsubsection{Ansätze zur Ableitung von Umweltschutzstrategien}

Das Erzielen innovativer Lösungen erfordert nach der Implementierung des Umweltschutzes auf der Zielebene die Entwicklung geeigneter umweltorientierter Strategien. Unternehmensstrategien bilden damit ein zentrales Bindeglied zwischen den Unternehmenszielen und den abgeleiteten operativen Maßnahmen. Entscheidend für die Umsetzung umweltorientierter Strategien ist die Unterstützung durch die Unternehmensführung sowie der Wille und die Fähigkeit zum geplanten Wandel. Neben der Sensibilität des Managements gegenüber der ökologischen Herausforderung zählt auch die tatsächliche ökologische Betroffenheit sowie die Exponiertheit des Unternehmens bzw. der Branche zu den Bestimmungsfaktoren der Intensität und Form, mit der der potentielle Erfolgsfaktor "Umweltschutz" das Wettbewerbsverhalten des Unternehmens beeinflußt. ${ }^{807}$

In Abhängigkeit dieser Bestimmungsfaktoren bildet sich im Unternehmen eine strategische Grundeinstellung heraus, für deren Beschreibung in der Literatur eine Reihe von Begriffspaaren angeboten werden. Eine Zusammenstellung von ANTES enthält z.B. die Begriffspaare passiv-aktiv, reaktiv-aktiv, antizipativ/beeinflussend-adaptiv sowie defensiv-offensiv. ${ }^{808}$ Als Ausgangsbasis für eine erste Charakterisierung der von einem Unternehmen ergriffenen Umweltschutzstrategien wird in der zugrundeliegenden Untersuchung das Kontinuum defensivoffensiv als adäquat angesehen. ${ }^{809}$

Bei einer defensiven strategischen Grundeinstellung ${ }^{810}$ wird der Umweltschutz als eine von außen gesetzte Restriktion bzw. Nebenbedingung betrachtet, die den Handlungsspielraum des Unternehmens einengt und in Konkurrenz zum Gewinn- und Rentabilitätsziel steht. Als Begründungen für die Herausbildung defensiver Strategien lassen sich beispielsweise

${ }^{807}$ Vgl. Kapitel 5.4 sowie auch Kirchgeorg, M. (1990), S. 180-200; Meffert, H. (1990), S. 77-80; Zahn, E./Schmid, U. (1992), S. $57 \mathrm{ff}$.

${ }^{808} \mathrm{Vgl}$. Antes, R. (1988), S. 21 und die dort angegebene Literatur sowie ferner Kirchgeorg, M. (1990), S. 37; Meffert, H./Kirchgeorg, M. (1993), S. 150; Türck, R. (1991), Kapitel 5.3., insb. S. 152-159.

${ }^{809}$ Vgl. hierzu u.a. Schmid, U. (1989), S. 98-108; Wicke, L. u.a. (1992), S. 41-45; Steger, U. (1988), S. 150-171 sowie die von ihm vorgenommene Modifikation in der 2. Aufl., (1993), S. 206-225. Zur Einstellung des Unternehmens zu den Notwendigkeiten des Umweltschutzes vgl. ferner Schmidt, R.-B. (1991), S. 190.

Untersuchungen zum betrieblichen Umweltmanagement beziehen sich oftmals auf Märkte von Umwelt(schutz)gütern, wie dies z.B. bei Steger der Fall ist. Da sich die vorliegende Untersuchung auf Unternehmen bezieht, die zumeist nicht in diesen Märkten tătig sind, werden nicht Erfolgspotentiale im Umweltschutzbereich begutachtet, sondern Erfolgspotentiale, die sich durch die zusătzliche Berilcksichtigung von Aspekten des Umweltschutzes auftun.

${ }^{810}$ Vgl. Steger, U. (1988), S. 156-161; Wicke, L. (1988), S. 13-21; Eschenbach, R./Müller, C. (Hrsg.) (1992), S. 51-54; Wicke, L. u.a. (1992) S. 41 f. und S. 597-611. 
- unzureichende Erfolgsfaktoren umweltorientierter Produkte und Prozesse auf den gegenwärtig bearbeiteten Märkten,

- zu hohe Umweltrisiken im eigenen Unternehmen,

- fehlende staatliche Anreize zur innovativen Begegnung von Umweltschutzproblemen,

- mangelndes Wissen zur Lösung betrieblicher Umweltschutzprobleme sowie

- Möglichkeiten der Externalisierung von Umweltbelastungs- und Entsorgungskosten

anführen. ${ }^{811}$ Defensive Umweltstrategien zielen nicht darauf ab, die sich durch den Umweltschutz bietenden Chancen wahrzunehmen sowie die sich abzeichnenden Risiken zu vermeiden bzw. zu vermindern. Dementsprechend reicht das Spektrum defensiver Umweltstrategien von der Erfullung normativ vorgegebener Mindestanforderungen ohne bzw. mit Änderung von Produktion und Produkten bis zu umweltbelastendem Verhalten in Form von Nichterfüllung von Auflagen und Gesetzen, Verzögerung der Umsetzung oder Verlagerung der Umweltproblematik auf einen anderen Produktionsstandort, Absatzmarkt oder Einsatzstoff. Ferner wird unmittelbar von seiten des Unternehmens bzw. mittelbar über diverse Verbände der Versuch unternommen, die Gestaltung der Umweltpolitik mit dem Ziel der Senkung von Standards zu beeinflussen. Darüber hinaus fuhrt die defensive Ausrichtung von Umweltschutzstrategien dazu, daß Umweltschutzmaßnahmen in der Regel fallweise, d.h. isoliert vorgenommen werden. Das hinter dieser Strategieform stehende Umweltmanagement besteht lediglich in der "Mindestreaktion auf umweltbezogene Vorschriften und Notwendigkeiten"812 und kann damit nicht als Umweltschutz i.e.S. bezeichnet werden.

Einer langfristigen und nachhaltigen Sicherung des Unternehmens ist defensives Umweltmanagement jedoch nicht förderlich. Dies kann nur durch ein offensives Umweltmanagement geleistet werden. Im Zuge einer offensiven strategischen Grundeinstellung ${ }^{813}$ wird das Umweltproblem als Herausforderung erkannt, akzeptiert und proaktiv angegangen, d.h. es wird versucht, die betrieblichen Zielsetzungen mit den Erfordernissen des Umweltschutzes in Einklang zu bringen. Hier werden Maßnahmen ergriffen, bevor sie zur Pflicht geworden sind. Teilweise geht der betriebliche Umweltschutz dabei über das gesetzlich verlangte Maß hinaus. Mit dieser Handlungsweise kommt eine fundamental andere Auffassung zum Tragen, als dies bei einer defensiven Ausrichtung der Fall wäre. Die offensive Strategie verfolgt eine bewußte

\footnotetext{
${ }^{811}$ Vgl. Nüßgens, K.H. (1974), S. 124; Steger, U. (1988), S. 156; Wicke, L. (1988), S. 13-21; Kirchgeorg, M. (1990), S. 13.

812 Türck, R. (1991), S. 148.

${ }^{813}$ Vgl. Nüßgens, K.H. (1974), S. 124; Steger, U. (1988), S. 161-165; Wicke, L. (1987), S. 80ff.; Wicke, L. (1988), S. 21-32; Wicke, L. u.a. (1992), S. 43ff. und 640-670; Eschenbach, R./Müller, C. (Hrsg.) (1992), S. 54-57; Butterbrodt, D. u.a. (1995), S. 5. Vgl. darüber hinaus Kirchgeorg, M. (1990), S. 232-246, der in seiner Untersuchung eine positive Beziehung zwischen dem Stellenwert des Umweltschutzzieles und der Verfolgung offensiver Umweltschutzstrategien feststellt.
} 
und antizipative Auseinandersetzung mit der Thematik "Umweltschutz" und betrachtet diese als strategische Herausforderung und Wettbewerbschance zur Absicherung bestehender bzw. Erschließung neuer Märkte und nicht in erster Linie als Kostenfaktor oder Risiko. ${ }^{814}$

Auf der Basis der vorgenannten Grundeinstellungen lassen sich verschiedene Umweltschutzstrategien ableiten. Im Vordergrund stehen dabei markt- bzw. wettbewerbsorientierte Unternehmensstrategien, die um eine ökologische Dimension zu erweitern sind. ${ }^{815}$ Die marktorientierten Umweltschutzstrategien werden nachfolgend in Anlehnung an MEFFERT UND KIRCHGEORG als "umweltorientierte Basisstrategien" bezeichnet. Sie können die Ausprägungen Widerstand, Passivität, Rückzug, Anpassung und Innovation annehmen. In einem sich anschlieBenden Schritt werden die Porterschen Wettbewerbsstrategien - Kostenführerschaft, Differenzierung und Konzentration auf Schwerpunkte - auf ihre ökologische Erweiterbarkeit hin überprüft.

\subsubsection{Umweltorientierte Basisstrategien}

Auf den beiden vorgenannten Verhaltensweisen aufbauend, lassen sich verschiedene umweltorientierte Strategien entwickeln. In Abhängigkeit der verfolgten Umweltpolitik bzw. der Umweltziele des Unternehmens lassen sich verschiedene strategische Optionen aufzeigen, die sich vor allem in der Intensität, mit der sie den Umweltschutz integriert haben bzw. mit der sie zum Schutz der Umwelt beitragen, unterscheiden. ${ }^{816}$ Eine differenziertere Betrachtung umweltorientierten Verhaltens kann anhand der umweltorientierten Basisstrategien Widerstand, Passivität, Rückzug, Anpassung sowie Innovation erfolgen. ${ }^{817}$

Mittels der Widerstandsstrategie wird situationsabhängig versucht, gesellschafts- und marktbezogenen Umweltschutzforderungen entgegenzuwirken. Diese eher als defensiv zu charakterisierende Umweltschutzsstrategie - wenngleich auch der Widerstand an sich durchaus offensiv betrieben werden kann - dient nicht dem Erreichen umweltorientierter Ziele. Wird Widerstand offensiv betrieben, kann dies in Abhängigkeit der Betriebsgröße allein oder

$\overline{814}$ Vgl. Dyllick, T./Belz, F. (1994), S. 54. Vgl. ferner Meffert, H. (1991b), S. 95.

${ }^{815}$ Vgl. dazu Meffert, H./Kirchgeorg, M. (1993), S. 145-174; Steger, U. (1993), S. 203-234. Vgl. ferner Kirchgeorg, M. (1990), S. 45-50; Ostmeier, H. (1990), S. 123-135; Zahn, E./Schmid, U. (1992), S. 57-60. Zu alternativen Einteilungen vgl. Krüger, W. (1974), S. 64-70; Müller, C. (1995), S. $166 \mathrm{f}$.

${ }^{816}$ Siehe Türck, R. (1991), S. 152.

${ }^{817}$ Die zuvor dargestellte Unterscheidung in defensive und offensive Umweltschutzstrategien betrachtet Kirchgeorg, M. (1990), S. 50, als Verdichtung der nachfolgend beschriebenen Basisstrategien. Entsprechend lassen sich die Widerstands-, Passivităts-, Rückzugs- und Anpassungsstrategie unter die defensive bzw. die Innovations- und Antizipationsstrategie unter die offensive Umweltschutzstrategie subsumieren.

Aus den umweltorientierten Basisstrategien generieren Meffert u.a. branchenübergreifende Typologien $8 \mathrm{ko-}$ logischer Grundhaltungen. Wegen der zugrundeliegenden Strategie, der angewandten Umweltschutzmaßnahmen und der spezifischen Situation unterscheiden sie vier okologische Grundhaltungstypen von Unternehmen: selektiv-økologieorientierte, ठkologieorientiert-passive, innengerichtet-aktive und ökologieorientiertinnovative. Vgl. hierzu ausführlich Meffert, H. (1990), S. 86-89, bzw. Meffert, H. u.a. (1989), S. 28-32; Meffert, H. u.a. (1990), S. 45-48, bzw. ăhnlich Meffert, H./Ostmeier, H. (1990), S. 130-137. 
im Verbund mit anderen Unternehmen erfolgen. Kurzfristig lassen sich durch eine Verhinderung der Internalisierung von Umweltkosten eventuell Wettbewerbsvorteile erhalten, vor allem gegenüber internationalen Wettbewerbern, die geringeren Umweltschutzanforderungen unterliegen. Allerdings ist nicht auszuschließen, daß diese Verhaltensweise (national) zu Imageschäden führen kann und damit kontraproduktiv ist. Das Unternehmen läuft sogar Gefahr, die Glaubwürdigkeit bzw. gesellschaftliche Legitimität zu verlieren, wenn nicht ein geeignetes Management der Anspruchsgruppen erfolgt. ${ }^{818}$ Auch unter Wettbewerbsaspekten kann sich das Verfolgen dieser Strategie besonders dann nachteilig auswirken, wenn sie nicht von allen Unternehmen der Branche mitgetragen wird, sondern einzelne Unternehmen sich bestehenden Umweltschutzforderungen anpassen oder sie bereits frühzeitig antizipieren. ${ }^{819}$

Der Widerstand gegen umweltschutzbezogene Forderungen im hier dargestellten Sinne spielt im Kalkül der untersuchten Unternehmen allerdings kaum eine Rolle. Diese Strategie nimmt mit 1,8 Punkten ${ }^{820}$ die insgesamt geringste Bedeutung unter den umweltorientierten Basisstrategien ein, was sicherlich auch darauf zurückzuführen ist, daß einer Widerstandsstrategie ob der eigenen Unternehmensgröße kaum Erfolgschancen eingeräumt werden.

Passives strategisches Verhalten gegenüber Umweltproblemen ist dadurch gekennzeichnet, daß im Unternehmen keine Problemlösungsstrategien entwickelt werden. Dabei lassen sich drei Formen passiven Verhaltens unterscheiden: Isolation, Ignoranz bzw. Indifferenz. ${ }^{821} \mathrm{Im}$ Falle der Isolation wird der Umweltschutz von seiten des Unternehmens gänzlich mißachtet. Als mögliche Ursachen kommen mangelnde Einsicht oder Fehleinschätzung der eigenen Betroffenheit in Frage. Bei der Ignoranz von Umweltschutzaspekten findet zwar eine Beobachtung der Umwelt statt, unternehmensrelevante Änderungen werden aber z.B. aufgrund fehlender Qualifikation oder Frühwarnsysteme nicht wahrgenommen bzw. ubersehen. Im Rahmen der dritten Verhaltensweise, der Indifferenz, werden Wandlungen des Unternehmensumfeldes beobachtet und wahrgenommen, ohne daß dies jedoch $\mathrm{zu}$ handlungsauslösenden Reaktionen führt. Sofern tatsächlich nur geringe Umweltbelastungen vom eigenen Unternehmen ausgehen oder sich lediglich unwesentliche Vorteile aus Umweltschutzmaßnahmen ergeben, bietet sich diese Strategie durchaus an. Sie bedarf jedoch einer ständigen Überprüfung. Unter wettbe-

${ }^{818}$ Praxisbeispiele zum Verlust der Legitimität zeigt z.B. Achleitner, P. (1985), S. 98-102, auf. Vgl. dazu ferner Türck, R. (1991), S. 154; Meffert, H./Kirchgeorg, M. (1993), S. 17. Zur ökologischen Betroffenheit von Unternehmen durch Anspruchsgruppen vgl. die Untersuchung von Meffert, H./Ostmeier, H. (1990), S. 55f. Ein Beispiel aus der jüngeren Vergangenheit ist die versuchte Versenkung einer Ölbohrinsel in der Nordsee durch die Shell AG. Auf die Weigerung des Unternehmens, sich um eine umweltvertrăglichere Entsorgung zu bemühen, folgten umfangreiche internationale Proteste und Boykottaufrufe.

${ }^{819}$ Unter wettbewerbsstrategischen Gesichtspunkten gilt es auch zu beachten, daß Widerstandsstrategien finanzielle, materielle und vor allem personelle Ressourcen binden, die dann furr eine innovative Problemlösung fehlen.

${ }^{820}$ Die Punkteskala reicht von 1 = "spielt überhaupt keine Rolle" bis $5=$ "spielt eine sehr große Rolle". Vgl. Frage 4/8 des Fragebogens im Anhang sowie Abb. 5-6 i.V.m. Anlage 38.

${ }^{821}$ Vgl. Krüger, W. (1974), S. 65-68. 
werbsstrategischen Aspekten ist die Verfolgung einer Passivitätsstrategie wenig erfolgversprechend, u.U. sogar als existenzgefährdend einzustufen. Eine Messung dieser Strategieoption ist nur sehr schwer möglich, da sie nach außen nicht explizit kommuniziert wird.

Leichter fällt dagegen die Beobachtung der Rückzugsstrategie. Umweltschutzansprüche werden ebenfalls wie bei der Anpassungsstrategie als Datum angesehen. Allerdings sieht das Unternehmen keine adăquate Möglichkeit zur innovativen Lösung der anstehenden Umweltprobleme, weshalb auch hier noch nicht von einer offensiven Strategie zum Schutz der Umwelt gesprochen werden kann. Dem Betrieb stehen in Abhängigkeit der jeweiligen Situation zwei grundsätzliche Optionen zur Verfügung:

- die Verlagerung einzelner umweltbelastender Unternehmensfunktionen oder

- die vollständige Vermeidung von Umweltbelastungen.

Aufgrund der zunehmenden internationalen und weltweiten Anpassung der Gesetzgebung sowie Vernetzung der Anspruchsgruppen stellt die Produktion oder Entsorgung im Ausland lediglich eine kurzfristige Option dar. ${ }^{822}$ Der Rückzug aus ökologisch betroffenen Geschäftsfeldern bedeutet eine vollständige Vermeidung der mit der Produktion oder mit dem Gebrauch verbundenen Belastung. Durch diesen Eliminationseffekt kommt es zwar zum Umweltschutz, dies kann jedoch nicht als offensives Umweltmanagement bezeichnet werden. Darüber hinaus wird mit dieser Haltung das Feld zur innovativen Begegnung der marktbezogenen Chancen des Umweltschutzes den Wettbewerbern überlassen.

Die kleinen und mittleren Unternehmen in der Region Neckar-Alb haben diese Probleme erkannt. Dementsprechend ist bei ihnen die Verlagerung der Produktion $(1,9)$ und der Rückzug aus betroffenen Bereichen $(2,2)$ von untergeordneter Bedeutung. ${ }^{823}$ Dieses Ergebnis ist aber ebenfalls auf die spezifische Situation kleiner und mittlerer Unternehmen zurückführbar. So bestehen oftmals gar nicht die betrieblichen Voraussetzungen, die eine Verlagerung der Produktion ermöglichen, da noch immer ein wesentlicher Anteil der Produktion im Inland hergestellt wird. Daneben ist die Aufgabe ganzer Produktgruppen aufgrund des geringen Diversifikationsgrades nicht möglich, ohne das Unternehmen zu gefährden.

Bei der Anpassungsstrategie werden gesetzliche Regelungen und gesellschaftliche Forderungen ebenfalls als Datum angesehen. Es findet aber eine Adaption der Ansprüche und Ge-

\footnotetext{
${ }^{822}$ Vgl. hierzu beispielsweise auch den Export von Abfallen in die ehemalige Deutsche Demokratische Republik.

${ }^{823}$ Eine strategische Mittelposition zwischen der Rückzugsstrategie und der nachfolgend beschriebenen Anpassungsstrategie nehmen nachsorgeorientierte Strategien ein. Hierunter fallen Strategien der Nachsorge, Reparatur, Kompensation und Entsorgung sowie in einer erweiterten Sichtweise die Kostenminimierung, wenn nämlich versucht wird, okologische Ansprüche mit möglichst geringen Kosten zu erfüllen. Sie setzen sich offensiv mit dem Umweltmanagement auseinander und leisten dadurch einen positiven Beitrag zum Schutz der Umwelt, wobei die hier zum Einsatz kommenden nachträglichen Maßnahmen in Form von End-of-pipeTechnologien eigentlich als selbstverständlich zu betrachten sind.
} 
setze statt, ohne jedoch den Chancen des Umweltschutzes innovativ zu begegnen. Diese Strategie birgt die Gefahr in sich, von neuen Umweltschutznormen überrascht zu werden und damit Marktchancen zu verpassen. Daneben bedeutet ständiges Nachrüsten und Anpassen an neue Normen u.U. eine höhere finanzielle Belastung als eine einmalige größere Investition, die zu anfänglicher Übererfüllung geltender Normen führt. Für ein wettbewerbsorientiert handelndes Unternehmen läßt sich mit dieser Strategie letztlich kaum das Profil oder Image eines umweltorientierten und kompetenten Anbieters deutlich vermitteln bzw. aufbauen. Sie erscheint daher lediglich als kurzfristige Problemlösungsstrategie geeignet und führt langfristig zu einer Position des "stuck in the middle".

Verglichen mit den zuvor aufgezeigten Werten, weisen die Angaben der untersuchten Unternehmen tendenziell auf eine Präferenz der Anpassungsstrategie hin. Die sofortige Anpassung an neue Auflagen und Gesetze erhält mit 3,5 Punkten die höchste Wertung. An dieser Stelle ist jedoch darauf hinzuweisen, daß offensichtlich mit einer steigenden Unternehmensgröße eine zeitnahe Umsetzung neuer Normen und Strategien an Bedeutung gewinnt (vgl. Anlage 38). In Richtung einer Anpassungsstrategie deutet auch das mit einem Wert von 3,1 Punkten an die zweite Stelle gesetzte Abwarten, bis gesetzliche Regelungen sich konkretisiert haben.

Stellt sich das Unternehmen aktiv und innovativ gesellschaftlichen oder marktbezogenen Umweltschutzanforderungen, kann von einer umweltorientierten Innovationsstrategie gesprochen werden. Innerhalb dieser Strategieoption wird der Versuch unternommen, ökologische Problemfelder zu lokalisieren und mittels einer integrierten, auf alle Unternehmensbereiche ausgerichteten Strategie innovativ und rentabilitätsorientiert zu lösen. Da auf diese Weise Produkt- und Produktionsumstellungen selbstbestimmt vorgenommen werden, ist die Strategie im besonderen Maße zur Erreichung umweltorientierter - und damit auch ökonomischer Wettbewerbsvorteile geeignet. Die erzielte Pionierstellung eröffnet neue Marktchancen und schafft zusätzliche strategische Freiheitsgrade. Zugleich lassen sich Imagegewinne realisieren, die sich in einer steigenden Motivation und Einsatzbereitschaft der Mitarbeiter bzw. in einer einfacheren Anwerbung von qualifizierten Nachwuchskräften bemerkbar machen kann. ${ }^{824}$ Die Profilierung mit Hilfe einer umweltorientierten Innovationsstrategie wird besonders von solchen Unternehmen betrieben, die den Umweltschutz nicht als Bedrohung, sondern als poten-

${ }^{824}$ Bezuglich einer intensiveren Diskussion der Chancen und Risiken einer "ökologischen First-Position" vgl. Steger, U. (1993), S. 218-225, der als Konsequenz aus den zu erwartenden Vor- und Nachteilen des innovativen Leaders auch Anforderungen an eine Innovationsstrategie formuliert. So müssen Erfolgspotentiale dauerhaft gesichert sein, technische Alternativen sorgfaltig ermittelt werden, Umweltvorteile klar erkennbar und bewertbar sein und besondere Făhigkeiten und möglichst Synergieeffekte realisierbar sein (StärkenSchwächen-Analyse). Ferner dürfen die Konkurrenten keinen zeitlichen Vorsprung bei der Problemlösung haben (Konkurrentenanalyse) und letztlich darf die Implementierung der Innovationsstrategie nicht mit (Qualităts-) Ansprüchen der Abnehmer kollidieren. 
tiellen Erfolgsfaktor auffassen. Bei der Formulierung umweltorientierter Innovationsstrategien rücken die nachfolgenden Anforderungen in den Vordergrund: ${ }^{825}$

- Funktionsorientierung statt Produktorientierung;

- Reduzierung der Materialvielfalt durch Standardisierung, Vereinfachung und Normung;

- Eliminierung bzw. Substitution umweltschädigender Produktelemente sowie Substitution von Energieträgern durch regenerative Energiequellen;

- Verwendung von Sekundärrohstoffen;

- recycling- bzw. entsorgungsgerechte Konstruktion, das Ermöglichen von Nutzungskaskaden;

- Berücksichtigung des küntigen technischen Fortschritts durch Modulbauweise, Baukastensysteme und Teilefamilien mit homogenem Materialaufbau;

- Verbesserung der Materialausbeute und Energieeffizienz;

- Minimierung der Verpackung;

- Nutzungsdauerverlängerung durch Wiederverwertung, Reparatur oder Wiederinstandsetzung;

- Reduktion von Energieverbrauch und Emission beim Gebrauch der Produkte.

Damit muß bereits im Rahmen der F\&E eine umweltschädigende Wirkung der Produkte und Produktionsverfahren antizipiert (Vorsorgestrategie) und auf eine Verminderung oder Substitution umweltgefährdender Einsatzstoffe und Energieträger zur Verbesserung der Umweltqualität bzw. des Umweltschutzes durch Produkt- und Verfahrensgestaltung hingewirkt (Vermeidungsstrategie) werden.

Die umweltorientierte Innovationsstrategie nimmt bei den untersuchten kleinen und mittleren Unternehmen des Verarbeitenden Gewerbes eine mittlere Stellung ein. Sie setzt sich zusammen aus der Vorwegnahme gesetzlicher Forderungen $(2,6)$ sowie dem Erschließen neuer Märkte $(2,7)$. Bei diesen beiden Strategiekomponenten zeigen sich erneut unternehmensgrößenbedingte Unterschiede, wobei sich besonders deutlich die Unternehmen mit mehr als 200 Mitarbeitern bzw. die Unternehmen mit einem Umsatz von mehr als 200 Mio. von den übrigen Größenklassen absetzen (vgl. Anlage 38). Umweltschutzbezogene Innovationsimpulse können sich auch durch Veränderungen im Umfeld des Unternehmens ergeben. Zwei bedeutende Impulsgeber sind in diesem Zusammenhang die unmittelbaren Wettbewerber sowie umweltbewußte Konsumentengruppen bzw. Abnehmer. Die Orientierung an den Aktivitäten der unmittelbaren Konkurrenten nimmt dabei einen Wert von 2,7 Punkten und die Berücksichtigung umweltbewußter Konsumentengruppen einen Wert von 2,6 Punkten an.

${ }^{825}$ Vgl. Kreikebaum, H. (1992b), S. 29 sowie ferner Ullmann, A. (1976), S. 296-299; Müller-Wenk, R. (1978), S. 94-101; Adam, D. (1993), S. 28f.; Siegwart, H./Senti, R. (1995), S. $18 f$. 
Die von den kleinen und mittleren Unternehmen des Verarbeitenden Gewerbes in der Region Neckar-Alb präferierten umweltorientierten Basisstrategien weisen somit folgendes Bild auf:

\section{Abb. 5-6: Strategische Verhaltensweisen um Anforderungen des Umweltschutzes zu genügen}

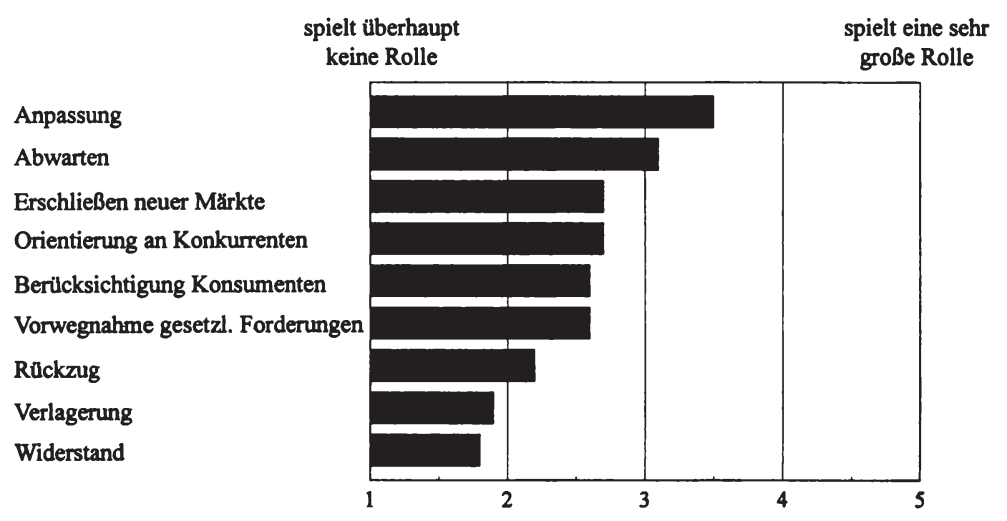

Quelle: eigene Berechnungen. ${ }^{826}$

Auffallend ist die insgesamt geringe Ausprägung umweltorientierter Basisstrategien. Damit verdeutlicht $\mathrm{Abb}$. 5-6 noch einmal, was sich in den Kapiteln 5.4 und 5.5 bereits abgezeichnet hat: Der betriebliche Umweltschutz ist bei kleinen und mittleren Unternehmen des Verarbeitenden Gewerbes augenblicklich kein wesentlicher Bestandteil der Unternehmenspolitik und ist folglich in den Unternehmenszielen und den Unternehmensstrategien von lediglich untergeordneter Bedeutung. Alles in allem zeigen die untersuchten Unternehmen in Bezug auf den Umweltschutz kein antizipatives bzw. innovatives Verhalten. Der Umweltschutz wird von ihnen bislang noch nicht in ausgeprägter Form als strategischer Wettbewerbsfaktor erkannt. Die angewandten umweltorientierten Strategien sind somit zusammenfassend eher als defensiv bzw. reaktiv-anpassend zu charakterisieren.

Allerdings führt auch eine Differenzierung nach Erfolgstypen bzw. nach der Unternehmensgröße nur vereinzelt zu Unterschieden innerhalb der Klassen. Dieses Ergebnis ist in zweierlei Hinsicht bemerkenswert. Zum einen ließen die Ergebnisse der besonders erfolgreichen Unternehmen in Kapitel 4 darauf schließen, daß sich deren ausgeprägte Innovationshaltung und der daraus resultierende Unternehmenserfolg auch auf den betrieblichen Umweltschutz überträgt. Dem ist offensichtlich nicht so. Das durch die Generierung betrieblicher Innovationen in verschiedenen Lemprozessen erworbene Wissen wird kaum auf den betrieblichen Umweltschutz

${ }^{826}$ Vgl. Frage 4/8 des Fragebogens im Anhang sowie Anlage 38. 
übertragen. Lediglich im Bereich integrierter Umweltschutztechnologien scheint ein solcher Transfer zu gelingen. Folglich ist ein enger Zusammenhang zwischen der Innovativität bzw. dem Unternehmenserfolg und dem betrieblichen Umweltschutz nicht gegeben. Im Vorfeld erschien zum anderen die Vermutung, betrieblicher Umweltschutz sei von der Größe des Unternehmens abhängig, als ebenfalls plausibel. Auch ein solcher Zusammenhang kann nur vereinzelt, nämlich bei der Anpassungsgeschwindigkeit an bzw. der Antizipation von Normen und Gesetzen sowie der Erschließung neuer Märkte, festgestellt werden.

\subsubsection{Umweltorientierte Wettbewerbsstrategien}

Die Entwicklung einer zukunftsorientierten Unternehmensstrategie unter Berücksichtigung des betrieblichen Umweltschutzes verlangt die Entwicklung und Kultivierung unternehmensspezifischer Kompetenzen, mit denen sich Wettbewerbsvorteile gegenüber der Konkurrenz aufbauen und langfristig sichern lassen. Den Porterschen Überlegungen folgend kann ein Unternehmen über zwei Typen von Wettbewerbsvorteilen verfügen: niedrige Kosten oder Differenzierung. Alle weiteren Stärken und Schwächen des Unternehmens lassen sich letztlich aus diesen beiden Optionen ableiten. Die sich ergebenden Strategietypen sind: umfassende Kostenfuhrerschaft, Differenzierung sowie Konzentration (Fokussierung) auf Nischen. Diese Strategien müssen nun auf die für eine umweltorientierte Ausrichtung des Unternehmens notwendigen Belange angepaßt werden.

Die Generierung okologieorientierter Wettbewerbsstrategien setzt die Fähigkeit des Unternehmens zur Innovation, Kooperation und Kommunikation voraus. Der Unternehmer muß diejenigen Möglichkeiten erkennen, die zu einer Belastungs- und damit zur Kostenreduktion beitragen, ${ }^{827}$ sowie auch solche, die dem Kunden bzw. Abnehmer Vorteile bringen und damit seine Wettbewerbsposition stärken können. Da sich die ökologische Belastung entlang der Wertschöpfungskette fortpflanzt, ist zur Bewertung der Beeinträchtigung die Zusammenarbeit mit vor- und nachgelagerten Stellen notwendig. Die Komplexität der Integration von Umweltschutzgesichtspunkten bei der Entwicklung neuer Produkte und Prozesse erfordert daneben auch die Kooperation mit Einrichtungen der Innovationsinfrastruktur. Damit eng verknüpft ist die Kommunikationsfähigkeit und Kommunikationskultur im Unternehmen selbst. Der Austausch von Informationen innerhalb des Unternehmens bzw. mit innovationsrelevanten Informationsquellen außerhalb des Unternehmens erhält im Kontext der ökologischen Herausforderung eine hohe unternehmensstrategische Bedeutung.

Verfolgt ein Unternehmen die Strategie der Kostenführerschaft, so besteht seine spezifische Kompetenz gegenüber den Wettbewerbern darin, daß durch eine konsequente Produkt- und

${ }^{827}$ Beispielsweise resultieren aus dem sparsamen und schonenden Einsatz knapper Ressourcen, der Begrenzung belastender Emissionen und Abfalle sowie der Risikobegrenzung positive Kosteneffekte. 
Prozeßoptimierung im Vergleich zu den Wettbewerbern niedrigere Stückkosten realisiert werden können und dieser Kostenvorteil in Form von geringeren Preisen an den Markt weitergegeben werden kann. Die Strategie der umfassenden Kostenführerschaft ist daran gebunden, ein einfaches, homogenes Produkt herzustellen, denn zu ihrer Umsetzung sind hohe Marktanteile erforderlich, um Erfahrungskurven- und Degressionseffekte nutzen zu können. Ferner dominiert bei den Abnehmern der Preis besondere Nutzenerwartungen als Kaufkriterium. Wie bereits an verschiedenen Stellen hervorgehoben wurde, können aus Umweltschutzmaßnahmen durch die Verminderung des Energie- und Ressourceneinsatzes sowie durch Verminderung oder Vermeidung von Abfällen Rationalisierungseffekte entstehen. In Verbindung mit der aus einer Verminderung oder Substitution umweltgefährdender Stoffe resultierenden Risikoabsenkung ergeben sich daraus positive Kosteneffekte. Allerdings hat bereits die Diskussion dieser Strategievariante in Abschnitt 3.6.3.2 gezeigt, daß sie für kleine und mittlere Unternehmen denkbar ungeeignet ist. Dies gilt im Hinblick auf eine umweltorientierte Erweiterung um so mehr. Produkt- bzw. prozeßintegrierter Umweltschutz hat sich als zusätzliches Qualitätsmerkmal bzw. als zusätzliche Nutzenkomponente noch nicht durchgesetzt. Dadurch erscheint das Erzielen von Massenproduktionsvorteilen, einer Grundvoraussetzung zur Realisierung von Erfahrungskurveneffekten, als eher unwahrscheinlich. Darüber hinaus erfordern Umweltschutzmaßnahmen durch den Zwang zu ständigen Anpassungen an sich verändernde rechtliche Rahmenbedingungen hohe F\&E-Investitionen und ein hohes Know-how und sind durch einen hohen Technologiedruck geprägt. Damit wird die Ausnutzung von Erfahrungskurveneffkten ähnlich wie bei spezialisierten technischen Produkten oder Verfahren zusätzlich eingeschränkt. Dies gilt insbesondere für die Entwicklung integrierter Umweltschutztechnologien, bei denen aufgrund individueller Anfertigung eine Senkung der Stückkosten durch Standardisierungen und hohe Stückzahlen nur begrenzt möglich ist. Zur Vermeidung von "sunk costs" kann es fermer kurzfristig ökonomisch rational sein, alte noch nicht vollständig abgeschriebene bzw. noch verwendungstaugliche Produktionsverfahren oder nachgeschaltete Anlagen weiter zu betreiben. Folglich ist davon auszugehen, daß die Realisierung einer kostenorientierten Wettbewerbsstrategie eine eher defensive Anpassung an Umweltschutzanforderungen nach sich zieht. $^{828}$

Die Strategie der Differenzierung mittels einer qualitätsorientierten Differenzierungs-, Service- oder Nischenstrategie als strategische Grundorientierungen fördert den Erfolg einer umweltorientierten Unternehmensführung. ${ }^{829}$ Die Erweiterung des bestehenden Angebotes durch die Herstellung umweltschutzorientierter Produkte bzw. die Verwendung umweltfreundlicher Verfahren stellt die Möglichkeit dar, das Angebot zu heterogenisieren. Die mit der Differenzierungsstrategie angestrebte Alleinstellung auf dem Markt zielt in diesem Fall gleichzeitig auf eine bessere Erfüllung der Anforderungen der Abnehmer bezüglich der Umweltverträg-

${ }^{828}$ Vgl. Türck, R. (1991), S. 175ff.; Kirchgeorg, M. (1995), Kapitel 8.6.

${ }^{829}$ Vgl. Meffert, H. u.a. (1990), S. 56. 
lichkeit von Produkten und Herstellungsprozessen als durch die Mitbewerber ab. Analog zur lateralen und diagonalen Diversifikation ${ }^{830}$ können im Zuge einer Differenzierungsstrategie ebenfalls bestehende Produkte durch umweltverträglichere Erzeugnisse ersetzt werden (lateral). Dem Hauptnutzen wird durch die Umweltverträglichkeit eine weitere Nutzenkomponente hinzugefügt. Lassen sich neue Bedürfnisse und Ansprüche bei den Abnehmern erkennen, steht für das Unternehmen u.U. grundsätzlich die Entwicklung neuer Produkte im Mittelpunkt (diagonal). Ziel einer erfolgreichen Differenzierung ist in beiden Fällen das Erreichen hoher Qualitäten, mit denen eine Abgrenzung zu den Wettbewerbern bzw. eine Steigerung der Loyalität und Preisbereitschaft der Abnehmer ermöglicht werden soll. Im Falle qualitätsorientierter Wettbewerbsstrategien paßt sich das Unternehmen offensiv an die Erfordernisse des Umweltschutzes an. ${ }^{831}$ Die Verfolgung der Differenzierungsstrategie stellt hohe Anforderungen an die Innovativität, Marktorientierung und Flexibilität des Unternehmens. Unternehmensfuhrung und Mitarbeiter sind daher gefordert, die hierfür notwendigen Anpassungspotentiale aufzubauen. ${ }^{832}$ Gerade in dieser Hinsicht weisen kleine und mittlere Unternehmen potentielle Stärken auf, wie bereits die Ergebnisse im Rahmen der Erfolgsfaktorenforschung deutlich gezeigt haben. Die identifizierten Erfolgsfaktoren kleiner und mittlerer Unternehmen unterstützen die Entwicklung und Herstellung von innovativen, qualitativ hochwertigen und auf die spezifischen Wünsche der Abnehmer zugeschnittenen Produkte. Eine umweltorientierte Differenzierung des Angebotes stellt also fur kleine und mittlere Unternehmen eine durchaus sinnvolle Strategie dar.

Die Spezialisierung eines Unternehmens auf ein abgegrenztes Wettbewerbsfeld innerhalb einer Branche charakterisiert die Strategie der Konzentration auf Marktnischen (Nischenstrategie). Die Grundüberlegung dieser Strategie geht davon aus, daß ein eng umrissenes strategisches Ziel wirkungsvoller erreicht werden kann, daß damit die vorhandenen Ressourcen effizienter eingesetzt werden können und daß somit dem Unternehmen Wettbewerbsvorteile gegenüber der auf dem Gesamtmarkt agierenden Konkurrenz gesichert werden. Die Konzentration auf eine Marktnische kann die jeweiligen Vorzüge der Kostenführerschaft bzw. Differenzierung ausschöpfen bzw. miteinander verbinden, indem segmentspezifisch günstigere Kostensituationen ausgenutzt und/oder Differenzierungsvorteile durch die bessere Befriedigung spezieller Kundenbedürnisse realisiert werden. Die Spezialisierung auf bestimmte Kundenbedürfnisse setzt auch hier eine individuelle Produktionsweise, wie sie in der Regel kleine und mittlere Unternehmen anbieten können, voraus. Gleichzeitig wird zur Herstellung umweltorientierter Produkte der Aufbau von Spezialkenntnissen und Fachkompetenz notwendig. Konsequente Spezialisierung und Fachwissen liefern aber ihrerseits wiederum Ansatzpunkte für Innovationen, die auch bei einer Marktnischenstrategie zur Sicherung der Marktposition

${ }^{830}$ Vgl. Ullmann, A. (1976), S. 295 und S. $301 \mathrm{ff}$.

${ }^{831}$ Vgl. Türck, R. (1991), S. 177 f.

${ }^{832}$ Vgl. in Abschnitt 4.4.2 die Ausfuhrungen zur Schaffung eines innovativen Umfeldes. 
notwendig sind. Die Marktnischenstrategie ist somit ein geeignetes Konzept, um speziellen ökologischen Bedürfnissen einzelner Marktsegmente gerecht werden zu können. Durch die intensive Auseinandersetzung mit den Bedürfnissen und Problemstellungen spezifischer Abnehmergruppen liegt der Fokus mehr auf der Befriedigung spezieller und damit auch umweltorientierter Bedürfnisse der Abnehmer als auf dem Absatz großer Mengen. Sie ist so lange geeignet, wie es um individuelle Problemlösungen geht. Setzen sich umweltorientierte Produkte auf breiter Front durch, ist der Schwenk auf die Strategie der Kostenfuihrerschaft bzw. der Differenzierung zu empfehlen. Die Differenzierungsstrategie bietet dabei den Vorteil, die im Rahmen der Nischenstrategie entwickelten spezifischen Eigenschaften weiterhin als Merkmale des Produktes im Wettbewerb einsetzen zu können.

An dieser Stelle könnte der verbindende Brückenschlag zwischen einer innovativen Ausrichtung des Unternehmens und einem offensiven Umweltmanagement stattfinden. Gerade durch die besonders erfolgreichen Unternehmen des Verarbeitenden Gewerbes in der Region Nekkar-Alb kann der Nachweis erbracht werden, daß Innovativität ein zentraler Erfolgsfaktor kleiner und mittlerer Unternehmen ist. Das hierbei in zahlreichen Lernprozessen gewonnene Know-how muß nun auch auf den produkt- und prozeßintegrierten Umweltschutz übertragen werden, da sich langfristig der Unternehmenserfolg ohne die Integration von Umweltschutzaspekten nicht gewährleisten läßt. Das heißt zunächst, daß der Umweltschutz zu einem zentralen Bestandteil technischer Innovationen wird, die dann dazu beitragen können, Umweltbelastungen weiter $\mathrm{zu}$ verringern und knappe Ressourcen effizienter zu nutzen. Umweltorientierte Innovationen weisen somit neben den ökologischen Nutzenpotentialen auch Kosteneinsparungspotentiale beim Ressourceneinsatz, bei Emissionen und Abfällen bzw. bei der Risikoabdeckung auf. Ferner rückt die Umweltverträglichkeit eines Produktes bzw. eines Herstellungsprozesses als differenzierendes Wettbewerbskriterium in den Vordergrund. ${ }^{833}$ Im Gefolge der technischen Innovationen sind dann auch unterstützende organisatorische Innovationen in Angriff zu nehmen, um den betrieblichen Umweltschutz auf ein breites Fundament zu stellen.

\footnotetext{
${ }^{833}$ Besonders deutlich werden umweltschutzinduzierte Wettbewerbsvorteile in der Umweltschutzgüter produzierenden Industrie. Sie kann als Wachstumsbranche und Innovationspol charakterisiert werden und ist damit eine wesentliche Triebkraft beim Vorantreiben des technischen Fortschritts und des Strukturwandels.
} 


\subsection{Zwischenergebnis}

Die Erzeugung von Sachgütern und Dienstleistungen ist zwangsläufig mit einer Beeinflussung der Umwelt verbunden. Erkennbar wird dies beispielsweise am Ausmaß und der Vielfalt ökologischer Schäden und Probleme, die sich in einer zunehmenden Ressourcenverknappung, einer an die Grenzen stoßenden Aufnahmefähigkeit von Luft, Wasser und Boden für industrielle Abfälle sowie den langfristig wirkenden Risiken einer globalen Klimaveränderung äußern.

Da kleine und mittlere Unternehmen einen wesentlichen Anteil an der Wirtschaftsleistung Deutschlands haben, sind sie auch zu einem großen Teil für die vorgenannten ökologischen Schäden und Probleme verantwortlich. Sie befinden sich dadurch in einem Spannungsfeld mit zahlreichen unternehmensinternen und -externen Anspruchsgruppen, die mit vielfältigen und teilweise gegensätzlichen Interessen an das Unternehmen herantreten. Für die Bewältigung dieser Herausforderung können sie auf eine Reihe von Erfolgsfaktoren zurückgreifen, die jedoch systematisch in eine aktive umweltorientierte Unternehmensfuihrung einzubinden sind.

Angesichts der Tatsache, daß die Innovativität als ein für kleine und mittlere Unternehmen zentraler Erfolgsfaktor (Abschnitt 3.3.4.2) und seine Bedeutung für den ökonomischen Erfolg durch eine Reihe von Faktoren auch empirisch nachgewiesen werden konnte (Kapitel 4), lag die Vermutung nahe, daß vor allem die innovativen Unternehmen sich der Herausforderung "Umweltschutz" in besonderer Weise annehmen. Ihre ausgeprägte Anpassungs- und Neuerungsfähigkeit schafft die Voraussetzungen, auf sich ändernde Rahmenbedingungen und Anforderungen innovativ zu reagieren. Diese Fähigkeit ist aufgrund der Komplexität und Multikausalität des betrieblichen Umweltschutzes in besonderer Weise erforderlich. Betrieblicher Umweltschutz stellt eine Querschnittsaufgabe dar. Seine Berücksichtigung im Rahmen der Unternehmensführung bedingt zahlreiche technische und organisatorische Anpassungs- und Neuerungsmaßnahmen in allen Unternehmensfunktionen und -bereichen.

Vor dem Hintergrund einer besonders in konjunkturschwachen Phasen aufkeimenden Diskussion um den Konflikt zwischen Ökonomie und Ökologie, ist der Umweltschutz zunächst im gesamt- und einzelwirtschaftlichen Kontext zu betrachten. Die Intention staatlicher Umweltpolitik ist eine Verbesserung der Lebensbedingungen. Das bedeutet, daß sie auch dann eine Berechtigung hätte, wenn ein Konflikt zwischen Ökonomie und Ökologie bestünde. Zahlreiche Arbeiten zeigen jedoch, daß aus einem gesamtwirtschaftlichen Blickwinkel zumindest auf lange Sicht eine Zielharmonie zwischen den Zielen Wachstum bzw. Beschäftigung sowie dem Ziel Umweltschutz besteht. Aber auch auf einzelwirtschaftlicher Ebene lassen sich positive Effekte ableiten. Durch innovatives unternehmerisches Handeln ergeben sich Rationalisierungspotentiale. Diese oftmals über die umweltschutzinduzierten Kosten hinaus- 
gehenden Rationalisierungseffekte resultieren beispielsweise aus einer Verminderung des Ressourcen- und Energieeinsatzes durch effizientere Nutzung der Produktionssysteme oder einer Veränderung von Produktionsprozessen, aus einer Substitution umweltgefährdender durch umweltschonendere Materialien sowie aus einer Verminderung oder Vermeidung von Abfällen. Hand in Hand mit einem zunehmenden Umweltschutz geht eine Absenkung des vom Unternehmen ausgehenden ökologischen Risikos, was neben sinkenden Kosten für die Risikoabsicherung auch positive Effekte auf die gesellschaftliche Akzeptanz und damit den Umgang mit den unterschiedlichen Anspruchsgruppen hat. Somit lassen sich auch auf der einzelwirtschaftlichen Ebene Zielkomplementaritäten zwischen dem betrieblichen Umweltschutz und der Wettbewerbsfähigkeit des Unternehmens herleiten.

Für eine Implementierung des Umweltmanagements in kleinen und mittleren Unternehmen gilt es zu beachten, daß die wesentlichen Impulse von der Unternehmensfuhrung ausgehen müssen (Führungsaufgabe). Sie muß eine breite Akzeptanzbasis schaffen, indem sie sich aktiv in diesen Prozeß einbringt, da für eine erfolgreiche Umsetzung des Umweltmanagements die Unterstutzung aus allen Bereichen und Funktionen des Unternehmens erforderlich ist (Querschnittsaufgabe). Daraus leitet sich ferner die Notwendigkeit des Aufbaus eines adäquaten Informationssystems, die technische und organisatorische Einbindung des Umweltschutzes, die Transformation der Unternehmenskultur sowie die Berücksichtigung des Umweltschutzes im Rahmen der Unternehmenspolitik ab (Gestaltungsaufgabe).

Ausgangspunkt für die Entwicklung eines Umweltmanagementsystems ist die Bereitstellung entscheidungsrelevanter Informationen. Zur systematischen Analyse der externen und internen Unternehmenssituation findet sich eine Reihe operativer und strategischer Instrumente. Hervorzuheben sind bei den operativen Instrumenten neben der Erweiterung des betrieblichen Rechnungswesens zu einer ökologischen Buchhaltung nach MÜLLER-WENK vor allem drei Instrumente des Umweltcontrolling: der Umweltbericht, die Öko-Bilanz sowie das EG-ÖkoAudit. Umweltberichte bzw. -erklärungen stellen die einfachste Form umweltorientierter Informations- und Kommunikationsinstrumente dar und finden sich als Vorstufe bzw. als Teil der Öko-Bilanz bzw. des EG-Öko-Audits wieder. Mit Hilfe der Öko-Bilanz lassen sich die umweltrelevanten Wirkungen der Unternehmensaktivitäten abbilden und bewerten. Sie dient damit zugleich der Schwachstellenanalyse, als Kontroll- und Planungsinstrument sowie als Entscheidungshilfe. Das EG-Öko-Audit zielt auf die freiwillige Implementierung eines systematischen und umfassenden Umweltmanagementsystems im Unternehmen ab. Hierdurch soll die Erfüllung gesetzlicher Normen und Auflagen, die Sicherung einer effizienten Technologie, das Erkennen und Bewerten von Umweltrisiken sowie die Reduktion von Haftungsrisiken, die Organisation und Strukturierung des Managements und die Verminderung von Problemen durch internen und externen Informationstransfer gewährleistet werden. Bei den untersuchten kleinen und mittleren Unternehmen haben allerdings bis 1995 lediglich 9,6\% Instrumente des 
Umweltcontrolling eingesetzt. Folglich finden auch die strategischen Instrumente kaum Anwendung.

Bei der technischen Einbindung des Umweltschutzes ist ein schwacher Zusammenhang zwischen der Innovativität des Unternehmens und dem Umweltschutz erkennbar, da die besonders erfolgreichen Unternehmen zu 55,5\% integrierte Umweltschutztechnologien nutzen, während die weniger erfolgreichen dies nur zu 38,9\% tun. Das Ergebnis wird jedoch durch einen äußerst geringen Organisationsgrad des Umweltschutzes bei beiden Erfolgstypen relativiert. Die besonders erfolgreichen Unternehmen verfügen zu $25,0 \%$, die übrigen zu $23,0 \%$ über feste Umweltschutzeinheiten.

Erforderlich für die Funktionstüchtigkeit eines Umweltmanagementsystems ist auch die Verankerung des Umweltschutzes in der Unternehmenskultur, die durch die Formulierung von Umweltleitbildern, Umweltzielen und Umweltstrategien transparent wird. Eine schriftliche Fixierung der drei Komponenten der betrieblichen Umweltpolitik findet in den untersuchten kleinen und mittleren Unternehmen des Verarbeitenden Gewerbes allerdings kaum statt. Zurückzufuhren ist dies auf die im Vergleich zu Großunternehmen geringere Exponiertheit sowie auf die Einschätzung, daß von seiten des eigenen Unternehmens keine wesentlichen Umweltbelastungen ausgehen. Folglich steht die betriebliche Umweltpolitik auch nicht im Zentrum unternehmerischen Denkens und Handelns.

Im Zielsystem der untersuchten kleinen und mittleren Unternehmen nimmt das Umweltschutzziel den zwölften Rang ein. Bedeutender als die absolute Einschätzung sind jedoch die Interdependenzen $\mathrm{zu}$ den übrigen Unternehmenszielen. Für die untersuchten Unternehmen steht das Umweltschutzziel in einem komplementären Verhältnis zu den Zielen Unternehmens- bzw. Produktimage, Mitarbeitermotivation sowie Kooperation mit Abnehmern bzw. dem Handel. Ferner besteht ein neutrales Verhältnis zu den Zielen Sicherung der Wettbewerbsfähigkeit, Erschließung neuer Märkte, Marktanteil, Kooperation mit Lieferanten, Umsatz, langfristige Gewinnerzielung, Arbeitsplatzerhaltung und Unternehmenswachstum.

Die von den untersuchten Unternehmen präferierten Umweltschutzstrategien können als defensiv bzw. reaktiv-anpassend bezeichnet werden. Antizipative bzw. innovative Umweltschutzstrategien finden sich auch bei den besonders erfolgreichen Unternehmen nicht. Gerade bei diesen hätten spill-over-Effekte vermutet werden können. Insgesamt wird damit der betriebliche Umweltschutz von den KMU noch nicht als eigenständiger strategischer Erfolgsfaktor erkannt. Darüber hinaus kann auch kein enger Zusammenhang zwischen der Innovativität bzw. dem Erfolg eines Unternehmens und dem betrieblichen Umweltschutz hergestellt werden. 



\section{Schlußbemerkungen}

Die in der vorliegenden Untersuchung vortetragenen Überlegungen basieren auf der herausragenden Bedeutung kleiner und mittlerer Unternehmen für die wirtschaftliche Entwicklung der Bundesrepublik Deutschland. In der derzeitigen Phase des tiefgreifenden strukturellen Umbruchs ist es vor allem ihre Anpassungs- und Wandlungsfähigkeit, die die deutsche Wirtschaft vor noch stärkeren Verwerfungen schützt.

Ziel der Untersuchung war es daher, die zentralen Bestimmungsgrößen der Anpassungs- und Wandlungsfähigkeit kleiner und mittlerer Unternehmen herauszufiltern. $\mathrm{Zu}$ diesem Zweck wurden kleine und mittlere Unternehmen des Verarbeitenden Gewerbes in der Region NeckarAlb (Baden-Württemberg, vgl. Anlage 1) zu Aspekten der Unternehmensführung sowie des Innovations- und Umweltmanagements befragt. Das Verarbeitende Gewerbe steht im Mittelpunkt der Untersuchung, da dieses traditionell eine hohe Bedeutung in der Bundesrepublik Deutschland hat, aber durch einen sich stetig verschärfenden Strukturwandel sowie ein Erstarken des Dienstleistungssektors zunehmend in Bedrängnis gerät. Die Region Neckar-Alb erwies sich deshalb als besonders geeignet, weil diese Region durch einen hohen Anteil an Unternehmen des Verarbeitenden Gewerbes in ausgeprägter Weise von der Strukturkrise betroffen ist. Innerhalb des Verarbeitenden Gewerbes ist in der Region Neckar-Alb vor allem die Dominanz des Leder-, Textil- und Bekleidungsgewerbes sowie des Stahl-, Maschinen- und Fahrzeugbaus auffallend. Durch die hohen Anteile dieser Wirtschaftszweige wurde die Bewältigung der Rezession im Jahre 1993 zusätzlich erschwert, da einerseits die wirtschaftliche Abwärtsbewegung früher und zugleich stärker einsetzte als auf Landes- bzw. Bundesebene, und da andererseits die Erholungstendenzen zum Teil noch immer geringer ausfallen als auf den genannten Vergleichsebenen.

Allerdings zeigt die Untersuchung auch, daß es eine Reihe von Unternehmen gibt, die sich von den regionalen Tendenzen in positiver Weise abheben und dabei sogar die Vergleichswerte auf Landes- und Bundesebene übertreffen. Charakteristisch für diese Unternehmen ist erstens ihre ausgeprägte Innovativität, d.h. sie haben im Untersuchungszeitraum zwischen 1990 und 1995 Produkt- oder Prozeßinnovationen im Unternehmen eingefuihrt. Zweitens betrachten sie die Innovativität als einen speziellen Wettbewerbsvorteil ihres Unternehmens und verzeichnen drittens innerhalb des Untersuchungszeitraumes eine positive Entwicklung in Form einer Umsatzsteigerung. Von den untersuchten Unternehmen wiesen ca. 30\% diese Charakteristika auf. Sie wurden als besonders erfolgreiche Unternehmen bezeichnet. Die Unternehmen, die eines oder mehrere der Kriterien nicht erfülten, wurden als weniger erfolgreiche Unternehmen typisiert. 
Als ein Erfolgsfaktor von zentraler Bedeutung für die Wandlungs- und Anpassungsfähigkeit kann folglich die Innovativität des Unternehmens betrachtet werden. Sie steht zugleich in einem engen Beziehungsgeflecht zu den übrigen Erfolgsfaktoren kleiner und mittlerer Unternehmen, nämlich der Qualität, der Kundenorientierung sowie der Qualifikation. Beispielsweise wirken sich höhere Qualifikationen positiv auf die Innovativität aus, und es entstehen im Gegenzug durch den Umgang mit Innovationen neue Qualifikationen.

Kleine und mittlere Unternehmen sind insgesamt durch eine weitgehend unsystematische, intuitiv-kreative Unternehmensfuihrung gekennzeichnet, die oftmals durch eine Unternehmerpersönlichkeit geprägt wird. Ein systematischer Einsatz von Unternehmensführungskonzepten bzw. -instrumenten entwickelt sich erst langsam. Dahinter steht der Glaube, daß das Befolgen von Konzepten und die einengende Wirkung von Instrumenten gerade die für kleine und mittlere Unternehmen typische Flexibilität gefährdet. Bei einer genaueren Betrachtung der empirisch nachgewiesenen Erfolgsfaktoren kleiner und mittlerer Unternehmen zeigt sich jedoch schnell, daß der Ausbau dieser Erfolgsfaktoren zu spezifischen Wettbewerbsvorteilen und letztlich zu Kernkompetenzen des Unternehmens ohne ein dafür geeignetes Instrumentarium nur schwer möglich ist. Die vorliegende Untersuchung verdeutlicht dies am zentralen Erfolgsfaktor Innovativität.

Im Rahmen der Unternehmensführung stellt das Innovationsmanagement ein Führungskonzept dar, das auf funktioneller und institutioneller Ebene die Zukunft des Unternehmens sichert, indem dessen Fähigkeiten, sich weiterzuentwickeln, systematisch ausgebaut und gefördert werden.

Eine wesentliche Grundlage hierfür ist der Aufbau eines adäquaten Informationsnetzwerkes. Im Verbund der innovationsrelevanten Informationsquellen kommt Informationen aus dem Unternehmensnetzwerk - und hier vor allem den Impulsen von seiten der Abnehmer - sowie von Messen, Kongressen und Ausstellungen die höchste Bedeutung zu. Der Dialog und die Zusammenarbeit mit Hochschulen, unternehmensorientierten Beratungseinrichtungen und Fachverbänden ist für die untersuchten Unternehmen von nachrangiger Bedeutung. Gerade diese Kontakte bieten aber eine nutzbringende Ergänzung zu den eigenen F\&E-Aktivitäten. Hier muß von beiden Seiten auf eine Intensivierung des Kontaktes hingewirkt werden, indem zum einen die Unternehmen sich aktiver diesen Informationsquellen zuwenden und sich das vorhandene Wissen erschließen und zum anderen die Informationsanbieter den Kontakt zu den Unternehmen suchen und aktiv auf die spezifischen Belange kleiner und mittlerer Unternehmen zugeschnittene Problemlösungen anbieten.

Neben den externen Informationsquellen sind als interne Informationsquelle die Mitarbeiter hervorzuheben. Die Nutzung sowie die Verbesserung der eigenen Humanressourcen wird von den besonders erfolgreichen Unternehmen intensiv betrieben. Sie legen deutlich mehr Wert 
auf die Qualifizierung ihrer Mitarbeiter als dies dit weniger erfolgreichen Unternehmen tun. Allerdings besteht auch bei ihnen noch ein erhebliches Entwicklungspotential.

Das Resultat intensiverer Qualifizierung zeigt sich auch in einer vergleichsweise hohen $F \& E$ Effizienz. Obwohl die besonders erfolgreichen Unternehmen absolut weniger Mittel für F\&E aufwenden als die weniger erfolgreichen Unternehmen, gelingt es ihnen wesentlich besser, ihr Produktprogramm ständig zu verjüngen. Bei ihnen befindet sich nahezu die Hälfte der Produkte in den innovativen und produktverändernden Phasen der Markteinführung und des Wachstums, während dies nur für ein Viertel der Produkte der weniger erfolgreichen Unternehmen zutrifft.

Eine weitere wesentliche Grundlage des Innovationsmanagements ist die Schaffung einer Innovationskultur. Hierbei kommt dem Unternehmer eine herausragende Rolle zu. Er muß sich offen gegenüber neuen Entwicklungen zeigen und den Mitarbeitern Freiräume zugestehen, in denen sie eigene Ideen entwickeln können. Die Mitarbeiter ihrerseits müssen den Wandel und die Anpassung als Herausforderung und Chance begreifen und Innovation als einen eigenen Wert ansehen. Intention ist dabei die Förderung unternehmerischen Denkens und Handelns der Mitarbeiter, so daß sie sich als Unternehmer im Unternehmen (Intrapreneure) verstehen. Innerhalb eines solchen innovativen Umfeldes kann die im Unternehmen vorhandene Humanressourcenbasis ausgeschöpft und über die dabei stattfindenden Lernprozesse weiter verbessert werden. Das Unternehmen stellt eine Lernende Organisation dar, wenn es im Rahmen dieser Lernprozesse in der Lage ist, Wissen zu schaffen, zu erwerben und weiterzugeben sowie sein Verhalten aufgrund des neuen Wissens zu verändern. Obwohl in kleinen und mittleren Unternehmen zumindest grundsätzlich günstige Bedingungen für die Schaffung einer Innovationskultur bzw. einer Lernenden Organisation herrschen, zeigen sich erst bei wenigen der untersuchten Unternehmen in der Region Neckar-Alb Ansätze zu einer expliziten Umsetzung. Implizit bestehen diese Strukturen durchaus.

Erkennbar ist dies an den stattfindenden Qualifizierungs- und Weiterbildungsaktivitäten und an den verfolgten Innovationsstrategien. Letztere sind zwar in den seltensten Fällen schriftlich fixiert, sie können aber dennoch insgesamt als "aktiv" bezeichnet werden. Aktive Innovationsstrategien zeichnen sich durch permanentes Suchen nach Neuerungen aus, wobei das Ziel eher die anwendungsorientierte Weiterentwicklung als die Übernahme einer Vorreiterrolle ist. Darüber hinaus zeigt die Analyse der verfolgten Wachstumsstrategien, daß neben einer intensiven Verteidigung der aktuellen Märkte (Marktdurchdringung) auch die Produkt- bzw. Markterweiterung sowie die Diversifikation breiten Raum einnehmen.

Für die besonders erfolgreichen Unternehmen ergibt sich daraus ein weitgehend stimmiges Innovationsmanagement. Darin eingeschlossen ist die umfassende Nutzung externer und interner innovationsrelevanter Informationsquellen, die zumindest implizite Entwicklung einer 
Innovationskultur bzw. das Anstoßen umfangreicher Lemprozesse sowie das Verfolgen aktiver Innovationsstrategien zur Erschließung neuer Produkt- und Marktpotentiale. Die sich daraus ergebende deutlich positive wirtschaftiche Entwicklung der besonders erfolgreichen Unternehmen ist darüber hinaus auch mit einem überdurchschnittlichen Beschäftigungszuwachs verbunden.

Unternehmen stehen in einem vielfältigen Bedingungs- und Wirkungsgefüge mit ihrem spezifischen Umfeld. Neben der Übernahme von Verantwortung für dessen ökonomische Entwicklung tritt zunehmend auch die Übernahme von Verantwortung für dessen ökologische Entwicklung ins Zentrum des Interesses. Entsprechend sind auch kleine und mittlere Unternehmen dazu aufgerufen, einen eigenständigen Beitrag zur Lösung ökonomischer und ökologischer Problemstellungen zu erbringen. In diesem Zusammenhang lag die Vermutung nahe, daß sich die Innovativität bzw. der ökonomische Erfolg eines Unternehmens auch auf dessen Umweltschutzmaßnahmen auswirkt.

Von grundlegender Bedeutung für die Implementierung des̀ Umweltmanagements im Rahmen der Unternehmensfuhrung ist auch hier die positive Einstellung des Unternehmers sowie die Übernahme einer Promotorenrolle durch ihn. Damit wird ebenfalls gewährleistet, daß der betriebliche Umweltschutz funktions- und bereichsübergreifend im Unternehmen verankert werden kann.

Die Einschätzung der befragten Unternehmer hinsichtlich der von seiten des eigenen Unternehmens ausgehenden Umweltprobleme entlang des Produktlebenszyklus zeigt jedoch, daß sie kaum Handlungsbedarf zur Verwirklichung eines aktiven und offensiven Umweltmanagements sehen. Eine Verstärkung erfährt diese Einschätzung durch zwei weitere Faktoren: durch die im Vergleich zu Großunternehmen geringere Exponiertheit kleiner und mittlerer Unternehmen und durch die in den Untersuchungszeitraum fallende Rezessionsphase. Beide Faktoren führen eher zu einer intensiveren Fokussierung der Kräfte auf ökonomische denn auf ökologische Belange des Unternehmens bzw. des relevanten Umfeldes.

Deutlich wird dies in mehrfacher Hinsicht. So zeigen sich unbefriedigende Ergebnisse im Hinblick auf die technische und organisatorische Einbindung des Umweltschutzes. Während die besonders erfolgreichen Unternehmen bei der technischen Einbindung durch die überwiegend zum Einsatz kommenden integrierten Technologien (55,5\%; weniger erfolgreiche Unternehmen: 38,9\%) ihre Innovativität zumindest in Ansätzen auf den Umweltschutz übertragen können, gelingt dies bei der organisatorischen Einbindung nicht. Zentrale bzw. dezentrale Umweltschutzeinheiten finden sich nur bei $25,0 \%$ der besonders erfolgreichen Unternehmen (weniger erfolgreiche Unternehmen: 23,0\%). Ferner finden auch die auf die Belange kleiner und mittlerer Unternehmen zugeschnittenen Instrumente des Umweltmanagements kaum Anwendung in den untersuchten Unternehmen des Verarbeitenden Gewerbes. Lediglich 9,6\% der 
Unternehmen nutzen die operativen Instrumente Umweltbericht, Öko-Bilanz oder EG-ÖkoAudit. Sehr deutlich wird die untergeordnete Bedeutıng des Umweltschutzes durch dessen Plazierung im Rahmen der Unternehmensziele. Das Umweltschutzziel nimmt dort den zwölften Rang ein, wobei jedoch zu bemerken ist, daß die den Unternehmenszielen beigemessenen Stellenwerte eng beieinanderliegen. Daneben ist ferner hervorzuheben, daß trotz der nachrangigen Einschätzung des Umweltschutzzieles ihm dennoch eine in vieler Hinsicht unterstützende Wirkung auf die ökonomischen Unternehmensziele beigemessen wird. Ein konfligierendes Verhältnis zwischen ökonomischen und ökologischen Zielen kann folglich nicht festgestellt werden. $\mathrm{Daß}$ der betriebliche Umweltschutz bei kleinen und mittleren Unternehmen des Verarbeitenden Gewerbes augenblicklich kein wesentlicher Bestandteil der Unternehmensführung ist, zeigen schließlich auch die verfolgten Umweltschutzstrategien. Die strategische Ausrichtung kann insgesamt als defensiv bzw. reaktiv-anpassend und nur in wenigen Fällen als antizipativ bzw. innovativ charakterisiert werden. Der Umweltschutz wird also von den untersuchten Unternehmen bislang noch nicht in ausgeprägter Form als strategischer Wettbewerbsfaktor erkannt.

Die theoretischen und empirischen Ergebnisse der vorliegenden Untersuchung greifen die insgesamt hohe Bedeutung kleiner und mittlerer Unternehmen im Wirtschaftsprozeß der Bundesrepublik Deutschland auf. Sie untermauern die positiven Effekte der Innovation sowohl auf die gesamt- wie auch auf die einzelwirtschaftliche Entwicklung von Wachstum und Beschäftigung, und sie zeigen ferner, daß die Innovativität ein zentraler Erfolgsfaktor kleiner und mittlerer Unternehmen ist. Dadurch findet zunächst die gängige Einschätzung, daß kleine und mittlere Unternehmen in besonderer Weise anpassungs- und wandlungsfähig sind, eine Bestätigung. Bei einer genaueren Betrachtung relativiert sich diese Einschätzung jedoch. Die empirische Analyse kann den Nachweis erbringen, daß sich eine Gruppe von Unternehmen abgrenzen läßt - die besonders erfolgreichen Unternehmen -, die aufgrund ihrer Innovativität tatsächlich über eine herausragende Anpassungs- und Wandlungsfähigkeit verfügt, daß aber die Mehrzahl der kleinen und mittleren Unternehmen diese Eigenschaften nicht besitzt. Aber auch bei den besonders erfolgreichen Unternehmen ergeben sich zahlreiche Defizite bei der Unternehmensfuihrung und dem Innovations- und Umweltmanagement. Diese Defizite resultieren vor allem aus der für kleine und mittlere Unternehmen typischen "hemdsärmeligen" Unternehmensführung. Dahinter verbirgt sich der Glaube, daß gerade hierdurch ein größtmöglicher Entscheidungsspielraum verbleibt, der Platz für Kreativität und Intuition läßt. Ein wirklicher Entscheidungsspielraum entsteht jedoch nur dann, wenn eine Auswahl aus einer Reihe von Handlungs- und Anpassungsoptionen getroffen werden kann. Diese lassen sich aber nur im Rahmen einer systematischen und vorausschauenden Unternehmensführung erarbeiten. An dieser Stelle ist verstärkt anzusetzen. 



\section{Anhang}

\section{Anlagenverzeichnis}

Anlage 1: Verwaltungseinteilung des Landes Baden-Württemberg

Anlage 2: Begleitschreiben der Unternehmensbefragung des Verarbeitenden Gewerbes in der Region Neckar-Alb

Anlage 3: Fragebogen zur Unternehmensbefragung

Anlage 4: Unternehmen, die an den Unternehmergesprächen teilgenommen haben

Anlage 5: Charakteristika kleiner und mittlerer Unternehmen und Großunternehmen

Anlage 6: Percentage of Number of Enterprises and of Employment by Size Class and Sector, EUR-12 1986

Anlage 7: Verteilung der Branchen sowie der Unternehmensgrößenklassen in der Grundgesamtheit und im Rücklauf

Anlage 8: Veränderung des Umsatzes im Verarbeitenden Gewerbe zwischen 1990 und 1995

Anlage 9: Verteilung der besonders erfolgreichen und der weniger erfolgreichen Unternehmen auf die Unternehmensgrößenklassen

Anlage 10: Zusammenführung der Umfeldanalyse und der Stärken-/Schwächenanalyse zur Chancen-/Risikenanalyse

Anlage 11: Erfolgsfaktoren und Wettbewerbsvorteile der August Beck GmbH \& Co., Winterlingen

Anlage 12: Klassifizierung der speziellen Wettbewerbsvorteile

Anlage 13: Inhalt und Rangordnung vorgegebener Unternehmensziele

Anlage 14: Verfolgte Wachstumsstrategien (Produkt-Markt-Strategien)

Anlage 15: Absatzmärkte der befragten Unternehmen nach Umsatzanteil

Anlage 16: Standardisierungsgrad des Produkt- und Leistungsangebotes

Anlage 17: F\&E-Ausgaben (in \% des BIP) in verschiedenen Ländern der OECD zwischen 1990 und 1995

Anlage 18: Stellenwert innovationsrelevanter Informationsquellen 
Anlage 21: Maßnahmen der betrieblichen Weiterbildung

Anlage 22: Entwicklung des F\&E-Anteils am Umsatz zwischen 1990 und 1995 nach Wachstumsklassen

Anlage 23: Im Unternehmen ausgefuhrte oder von anderen Unternehmen bezogene Unternehmensfunktionen

Anlage 24: Anteile der Produkte in den einzelnen Marktzyklusphasen

Anlage 25: Gründe für die Einführung von Innovationen

Anlage 26: Formen der Einführung neuer Produkte und Prozesse

Anlage 27: Entwicklung des Exportanteils am Umsatz zwischen 1990 und 1995 nach Wachstumsklassen

Anlage 28: Entwicklung des Exportes zwischen 1990 und 1995

Anlage 29: Entwicklung der Anzahl der Beschäftigten

Anlage 30: Nutzung staatlicher Mittel zur Förderung von Umweltschutzmaßnahmen

Anlage 31: Ablaufschema des EG-Öko-Audits

Anlage 32: Nutzung von Instrumenten des Umweltcontrolling

Anlage 33: Nutzung von Emissionsvermeidungstechnologien

Anlage 34: Organisationsgrad des Umweltschutzes

Anlage 35: Die Bizerba-Umweltpolitik

Anlage 36: Einschätzung der Umweltprobleme entlang des Produktlebenszyklus

Anlage 37: Förderung bzw. Beeinträchtigung von Unternehmenszielen durch die Verfolgung von Umweltschutzzielen

Anlage 38: Strategische Verhaltensweisen zur Begegnung der Anforderungen an den Umweltschutz 


\section{Anlage 1: Verwaltungseinteilung des Landes Baden-Württemberg}

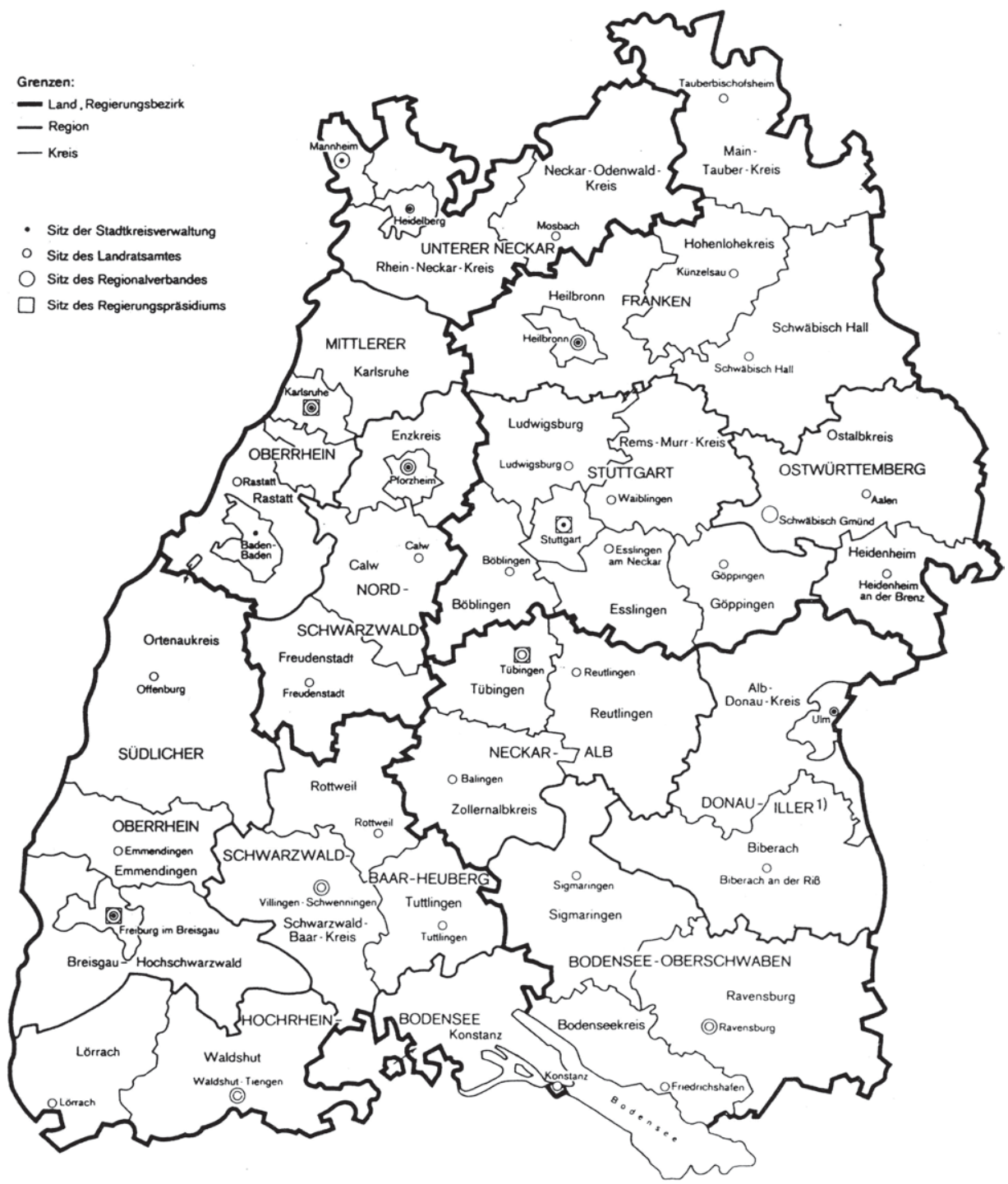

Quelle: Statistisches Landesamt Baden-Württemberg (1995). 


\section{Anlage 2: Begleitschreiben der Unternehmensbefragung des Verarbeitenden Gewer-} bes in der Region Neckar-Alb

Landratsamt Zollernalbkreis, 72334 Balingen Telefon: $07433 / 92-1001 / 1002$

An die

Geschäftsleitung

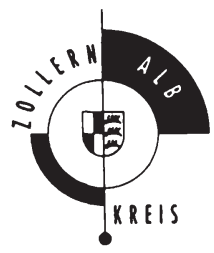

\section{Der Landrat}

Balingen, im November 1995

\section{Untersuchung zum Umwelt- und Technologiemanagement von Betrieben in Baden-Württemberg}

Sehr geehrte Damen und Herren,

die Wirtschaftsstruktur in unserem Land befindet sich unbestreitbar in einer Umbruchsituation. Diese ist u.a. durch tiefgreifende Verănderungen der internationalen Arbeitsteilung, eine Abschwăchung und Differenzierung der Nachfrageentwicklung und eine immense Dynamik an technologischen und organisatorischen Neuerungen gekennzeichnet. Dies bleibt natürlich nicht ohne Auswirkung auf die kleinen und mittelständischen Unternehmen des verarbeitenden Gewerbes in der Region Neckar-Alb.

Um die Entwicklungstendenzen im regionalen Verarbeitungsgewerbe für die Zukunft noch besser beurteilen zu kőnnen und um letztlich auch Threm Unternehmen Empfehlungen zu einem angepaßten Technotogieund Umweltmanagement geben zu kőnnen, benőtigen wir Ihre tatkräftige Unterstützung.

Die Europåische Forschungsstelle für den ländlichen Raum an der Universität Hohenheim führt deshalb mit unserer Unterstutzung auch im Zollernalbkreis eine spezielle Untersuchung über das Umwelt- und Technologiemanagement unserer Gewerbeunternehmen durch. Auf der Basis der auch von Ihnen dabei aufgezeigten Entwicklungen, Stărken und Schwächen sollen dann Ansatzpunkte zur Förderung kleiner und mittlerer Gewerbebetriebe abgeleitet werden.

Obwohl für Sie das Ausfallen des Fragebogens mit einer gewissen Arbeitsbelastung verbunden ist, möchten wir Sie angesichts der besonderen Bedeutung des Themas fur die zuklinftige weitere Entwicklung Ihres Wirtschaftsbereiches herzlich bitten, alle Fragen zu beantworten. Den ausgefullten Fragebogen senden Sie bitte in dem dafur vorgesehenen Freiumschlag zurück. Die Befragung erfolgt anonym. Die Ergebnisse und Handlungsempfehlungen der Studie werden von den Wissenschaftlern der Universität Hohenheim im Sommer 1996 in unserem Landkreis vorgestellt.

Für Nachfragen stehen Ihnen Herr Bernd Blessin von der Universităt Hohenheim unter der Rufnummer 0711/ 459-3498 oder Herr Dieter Gust, Verbandsdirektor des Regionalverbandes Neckar-Alb (07473/ 6004), als Ansprechpartner geme zur Verfügung.

Wir verbleiben mit bestem Dank fir Thre Mühe
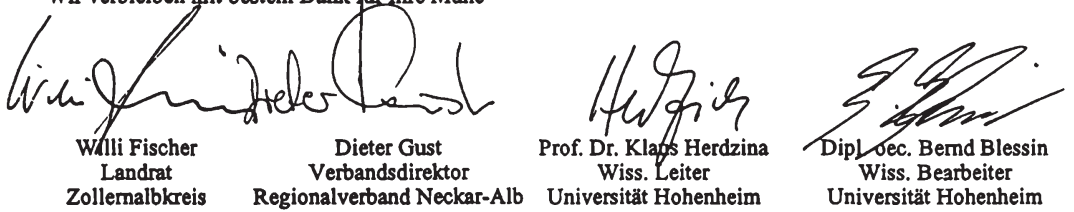


\section{Anlage 3: Fragebogen zur Unternehmensbefragung}

\section{Europåische Forschungsstelle für den Ländlichen Raum Universitåt Hohenheim}

\section{Erhebung zum Innovations- und Umweltmanagement von Betrieben in Baden-Württemberg}

Diese Befragung erfolgt im Rahmen des Forschungsprojekts

\section{Problemlagen und Entwicklungschancen der Region Neckar-Alb im Strukturwandel}

In dieser Untersuchung werden auf Betriebsebene die Anpassungs- und Neuerungsaktivităten in BadenWürttemberg in den letzten funf Jahren untersucht. Auf dieser Basis werden dann Ansatzpunkte zur Unterstïtzung und Förderung der Betriebe bei Innovations- und Neuerungsaktivitäten abgeleitet. Sie erhalten zudem durch den Vergleich mit den Stärken und Schwăchen Ihrer Branchenwettbewerber eine wertvolle Entscheidungshilfe.

Deshalb bitten wir Sie, die folgenden Fragen zu beantworten. Bitte kennzeichnen Sie die zutreffenden Kreise wie folgt $\otimes$ (Mehrfachnennungen sind in den meisten Fällen møglich und erwünscht). Bitte beantworten Sie alle Fragen.

Der „Europăische Forschungsschwerpunkt Låndlicher Raum“ garantiert bei der Umfrage die Einhaltung einer strengen Vertraulichkeit und Anonymităt Ihrer Angaben. Die Daten aus der Befragung werden ausschließlich in anonymisierter Form und stets nur zusammengefaßt mit den Angaben der anderen Befragungsteilnehmer ausgewertet. Damit kann niemand aus den Ergebnissen erkennen, von wem die Angaben gemacht worden sind.

Wenn Sie es wünschen, stehen wir Ihnen gerne für Rückfragen oder Hilfestellungen beim Beantworten der Fragen zur Verfügung:

Universităt Hohenheim:

Prof. Dr. Klaus Herdzina

Dipl. oec. Bernd Blessin
Tel.: (0711) 459-2593

Tel.: (0711) 459-3498

Fax: (0711) 459-3952

\section{Allgemeine Betriebsmerkmale}

1. Welcher Branche ist der Betrieb zuzuordnen?

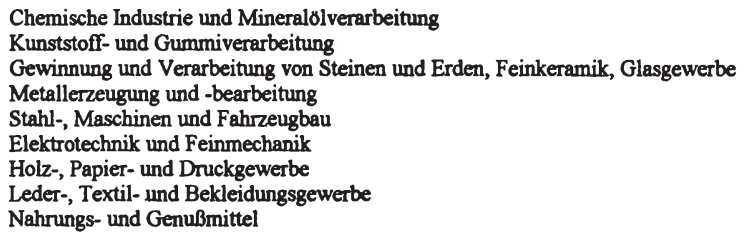


2. Jahr der Grilndung:

... als selbständiges Unternehmen $\bigcirc$

... als Zweigbetrieb

0

3. Organisatorischer Status des Betriebes

O der Betrieb wird ohne Filiale gefuhrt

$O$ der Betrieb hat eine/mehrere Filialen

$O$ der befragte Betrieb ist der Stammbetrieb/Unternehmenszentrale

$O$ der befragte Betrieb ist ein Filialbetrieb

4. Beschăftigtenstruktur und Lohnentwicklung des Betriebes

a. Die Gesamtzahl sowie die Lohnsamme der Beschăftigten im Untersuchungszeitraum:

Anzahl

Lohnsumme (in Mio.)

zum $\quad 31.12 .1990$

31.12.1991

31.12.1992

31.12 .1993

31.12.1994

31.12.1995

b. Die Gesamtzahl der Beschătigten im Jahr 1995 teilt sich auf in:

Anzahl

höhere kaufm. Angestellte:

Hochschulingenieure:

sonst. Angestellte:

Facharbeiter (Meister, Techniker):

Arbeiter:

Auszubildende:

5. Wie haben sich in Threm Betrieb Umsatz, Export, sowie Forschung und Entwicklung entwickelt (Schătzungen ausreichend)?

Umsatz (in Mio. DM, ohne Innenumsatz)

Exportanteil am Umsatz (\%)

Forschungs- und Entwicklungsanteil am Umsatz (\%) 
6. Werden die folgenden Unternehmensfunktionen in Ihrem Betrieb ausgefuhrt oder werden sie von anderen Betrieben bezogen (Mehrfachnennungen moglich)?

Die jeweilige Leistung wird ...

Forschung und Entwicklung

Konstruktion und Gestaltung

Produktionsplanung

Vertrieb und Verkauf

Qualitatssicherung

Umweltmanagement

Investitions- und Finanzplanung

Kostenrechnung im Betrieb
ausgefuhrt von anderen Betrieben des Unternehmens

bezogen von anderen Unternehmen gekauf (z.B. als Beratungsdienstleistung)

\section{Bauptprodukte (-gruppen) des Betriebes}

1. Welches sind die Hauptprodukte (-gruppen) Thres Betriebes (mit ca. Umsatzanteil)?
(1)
$\%$
(2)
$\%$
(3)
$\%$

2. Charakterisieren Sie bitte die uberwiegende Art der Fertigung Threr Produkte (-gruppen).

Einzelfertigung

(1-5)

Produkt

Produkt 2

Produkt 3

0
Kleinserienfertigung (6-25)

0
0
0
Großserienfertigung (25-500)

0
0

\section{$\circ$}

O

0

0

0

0

0

Massenfertigung $(>500)$

3. Wenn Sie Thre Produkte nach dem Alter betrachten, wieviel Umsatzanteil entfallt auf die Produkte, die seit ...

$$
\begin{aligned}
& \text { Umsatzanteil } \\
& \text { (Summe }=100 \%)
\end{aligned}
$$

... etwa 5 Jahren

... etwa 10 Jahren

... länger

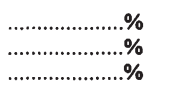

\section{Umsatzentwicklung}

$$
0
$$

0

0

0

produziert werden. 
4. In welcher Phase des Produktlebenszyklus befinden sich nach Threr Schätzung Ihre Produkte (ca. Umsatzanteile)?

* Markteinfuhrungsphase

$\%$

* Wachstumsphase

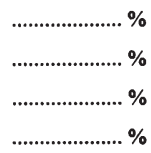

(Summe $=100 \%)$

5. Wie beurteilen Sie die Preiskonkurrenz auf Thren Mărkten?
stark
O mittel
O schwach

6. Welches sind Thres Erachtens die speziellen Wettbewerbsvorteile Thres Betriebes?

$\begin{array}{cc}\text { trifft } & \text { trifft gar } \\ \text { sehr zu } & \text { nicht zu }\end{array}$

günstige Preise

hohe Verarbeitungsqualităt

0

$\circ$

O

0

$0 \quad 0$

0

$\circ$

$\circ$

besonderes Design/ Gestaltung

$0 \quad 0$

$0 \quad 0$

besonderer Kundenservice

flexible Anpassung an Kundenwinsche

$0 \quad 0$

$0 \quad 0$

fortschrittliche Technologie/ Produkte

$\circ$

$\circ$

0

0

$\circ$

$\circ$

viele Produktinnovationen

o

0

0

o

hohe Umweltfreundlichkeit

o

o

o

0

Sonstiges

7. Wir haben in den letzten 5 Jahren folgende Wachstumsstrategie verfolgt:

mit dem bisherigen Produktionsprogramm Kundenbeziehungen auf den angestammten Märkten vertieft

O mit dem bisherigen Produktionsprogramm auf neue Absatzmärkte gegangen (z.B. neue Einsatzmöglichkeiten bestehender Produkte in anderen Branchen; räumlich neue Märkte)

mit neuen Produkten auf neue Märkte gegangen

mit neuen Produkten Kundenbeziehungen auf den angestammten Märkten erweitert 
8. Wo liegen Ihre Absatzmărkte (bitte geben Sie geschătzte Umsatzanteile an)?

\section{Umsatz in \%}

im Landkreis

in Baden-Württ.

in Deutschland

in der Europäischen Union

in Mittel- und Osteuropa

außerhalb Europas*

\section{wachsend}

O

0

0

0

0

o
Entwicklungstendenz seit 1990

konstant

O

$\circ$

$\circ$

$\circ$

$\circ$

$\circ$ schrumpfend

O

o

O

0

o

0

(Summe $=100 \%$ )

*(Bitte Lănder angeben!)

9. Welcher Anteil des Gesamtumsatzes enfallt

auf Thren wichtigsten Abnehmer

$\%$

auf Ihren zweitwichtigsten Abnehmer

\%

auf Thren drittwichtigsten Abnehmer

$\%$

10. Für unsere Abnehmer/ Kunden

haben wir ein standardisiertes Produkt- und Leistungsangebot

O haben wir ein standardisiertes Produkt- und Leistungsangebot, variieren unser Angebot jedoch haufig auf Kundenwunsch nach seinen spezifischen Bedürnissen

O erbringen wir in der Regel kundenspexifische Leistungen. Bei ihrer Entwicklung und Fertigung kooperieren wir eng mit dem jeweiligen Kunden.

11. Wo befinden sich Thre Lieferanten?

\begin{tabular}{|c|c|}
\hline Landkreis & Ba.-Wü. \\
\hline
\end{tabular}

Materialbezïge 0

Dienstleistungen
O

0

\begin{abstract}
o
0
\end{abstract}

0




\section{3 linoventinen}

1. Hat Thr Betrieb seit dem 1. 1. 1990 ein/mehrere neue Produkte (Produktinnovationen) eingefuhrt?

O nein ja, $\quad \mathrm{O}$ vollkommen neues Produkt am Markt eingefuhrt

O Aufnahme eines bereits am Markt befindlichen Produkts ins Angebot des Betriebes

2. Haben Sie seit dem 1. 1. 1990 neue oder wesentlich veranderte Produktionstechniken (ausgenommen neue Bürokommunikation) in Ihrem Betrieb eingefuhrt?

O ja $\quad O$ nein

3. Bei der Einfuhrung neuer Produktionsverfahren durch Konkurrenten haben wir ...

O diese neue Verfahrenstechnik auch in unserem Betrieb sofort eingefuhrt

$O$ weniger als 5 Jahre mit der Óbernahme gewartet

$O$ mehr als 5 Jahre mit der Obernahme gewartet

4. War die Einfuhrung neuer Produktionstechniken mit der Einfuhrung neuer Produkte verbunden?
0 immer
O hăufig
$O$ nein

5. Welches waren die Gründe fur die Einfuhrung dieser Innovationen?

O Absatzchancen

O Kostensenkungspotentiale

O Erschließung neuer Märkte

O Absatzprobleme bei vorhandenen Produkten

O Umweltschutzauflagen /-gesetze

$O$ Verbesserung der Produktqualităt

$O$ geringerer Ressourcen- oder Materialverbrauch

$O$ geringerer Energieverbrauch

O Sonstige 
6. Welche Auswirkungen hatte die Einfuhrung neuer Produkte und/ oder Produktionstechniken auf ...

$\begin{array}{llll} & \text { Zunahme } & \text { stabil } & \text { Abnahme } \\ \text { Herstellungskosten } & 0 & 0 & 0 \\ \text { Umsatz } & 0 & 0 & 0 \\ \text { Gewinn } & 0 & 0 & 0 \\ \begin{array}{l}\text { Beschaftigte (insg.) } \\ \text { darunter: }\end{array} & 0 & 0 & 0 \\ \quad \text { Hochqualifizierte } & 0 & 0 & 0 \\ \quad \text { Mittel-/Geringqualifizierte } & 0 & 0 & 0\end{array}$

7. Wenn Sie in den letzten 5 Jahren neue Verfahren bzw. neue Produkte eingefuhrt haben, die wesentliche technische Verbesserungen enthielten oder für Thr Untemehmen neu waren, welche Möglichkeiten hat thr Betrieb hierfür genutzat?

\begin{tabular}{|c|c|c|c|c|c|c|c|}
\hline \multirow{2}{*}{\multicolumn{2}{|c|}{ eigenständig }} & \multicolumn{6}{|c|}{ in Zusammenarbeit mit ... } \\
\hline & & $\begin{array}{l}\text { anderen } \\
\text { Untermehmen } \\
\text { (Kooperation) }\end{array}$ & $\begin{array}{l}\text { priv. Unter- } \\
\text { netmensenteratem } \\
\text { bzw. Ingenieur- } \\
\text { baros }\end{array}$ & $\begin{array}{l}\text { aubenniversi- } \\
\text { n taren Forschungs- } \\
\text { instituten } \\
\text { (z.B. Fraumhofer) }\end{array}$ & $\begin{array}{l}\text { Hochschul- } \\
\text { instituren }\end{array}$ & $\begin{array}{l}\text { Transfer- } \\
\text { einrichtungen } \\
\text { (2.B. Steinbeis) }\end{array}$ & RKW \\
\hline eigene Entwicklungsarbeiten & 0 & 0 & 0 & 0 & 0 & 0 & 0 \\
\hline Kauf neuer Anlagen & 0 & 0 & 0 & 0 & 0 & 0 & 0 \\
\hline $\begin{array}{l}\text { Kauf von Patenten, Lizenzen, } \\
\text { sonst. techn. Wissen }\end{array}$ & 0 & 0 & 0 & 0 & 0 & 0 & 0 \\
\hline $\begin{array}{l}\text { organisatorische und } \\
\text { logistische Änderungen der } \\
\text { Produktion }\end{array}$ & 0 & 0 & 0 & 0 & 0 & 0 & 0 \\
\hline $\begin{array}{l}\text { organisatorische und } \\
\text { logistische Änderungen der } \\
\text { Verwaltung }\end{array}$ & 0 & 0 & 0 & 0 & 0 & 0 & 0 \\
\hline
\end{tabular}

8. Haben Sie in den letzten 5 Jahren ein Innovationsvorhaben abgebrochen?
O nein
O ja
welche:

Grinde: 
9. In unserem Betrieb wurden seit dem 1. 1.1990 neue Verfahren und/ oder neue Produkte eingefuhrt, obwohl folgende Hemmnisse bestanden.

O Kreditfinanzierungsprobleme, wegen

O fehlender Sicherheiten

O fehlendem technischen Beurteilungsvermoggen der Bankmitarbeiter

$\mathrm{O}$ zu hohem Finanzierungsvolumen

O zentralisierter Kreditentscheidungsabläufe bei der Hausbank

O Probleme bei der Eigenkapitalbeschaffung wegen

O zu großer Mitspracheanspruche potentieller Kapitalgeber

$O$ Geheimhaltungsprobleme der Neuerung

O Ubernahmegefahr durch den Kapitalgeber

O schwierige Marktabschatzung

O fehlende Informationen uber technische Moglichkeiten

$O$ staatliche Auflagen und andere Vorschriften

$O$ mangelnde Qualifikation vorhandener Mitarbeiter

O Schwierigkeiten bei der Einstellung qualifizierter Mitarbeiter

$O$ ungenügendes Beratungsangebot

Organisatorische und logistische Änderung des Produktionsablaufs

$O$ organisatorische und logistische Änderungen des Verwaltungsablaufs

O sonstige Hemmnisse?

10. In unserem Betrieb wurden seit dem 1. 1. 1990 keine neuen Verfahren und/ oder Produkte eingefuhrt, weil ...

O keine Innovationsnotwendigkeit bestand (z.B. stabiler Markt)

O keine Innovationsmöglichkeit bestand (z.B. ausgereifte Technik)

O zu großes Risiko

O Sonstige

11. Betreiben Sie betriebliche Weiterbildung (z.B. Lehrgănge, Seminare)?
O nein
O ja

$O$ interne Weiterbildung

$O$ externe Weiterbildung

O Herstellerschulung 
12. Entsteht bei Ihren derzeitigen Mitarbeitern in den nächsten 3 Jahren ein Qualifizierungsbedarf ?

$O$ nein

$O$ ja, und zwar im Bereich ...

O Technik

O Informationstechnik

O Produktions-/ Fertigungstechnik

O Organisation/ Management

O Marketing/ Vertrieb

O Umwelt

O Produktqualitat

O Prozeßqualitatt

O Sprachen

O Sonstige:

13. Erwarten Sie von Thren zukănftigen Mitarbeitern hőhere Qualifikationen als von Thren derzeitigen?

O nein

$O \mathrm{ja}$, und zwar im Bereich ...

O Technik

O Informationstechnik

O Produktions-/ Fertigungstechnik

O Organisation/ Management

O Marketing/Vertrieb

O Umwelt

O Produktqualitatt

O Prozeßqualităt

O Sprachen

O Sonstige:

14. Wie informieren Sie sich ther marktrelevante und technische Entwicklungstrends und welchen Stellenwert haben die Informationsquellen für Sie?

- Vertriebsbeauftragte von Herstellerfirmen wichtig

- Impulse der Abnehmer

- aus innerbetrieblicher Zusammenarbeit

0

0

- eigene FuE-Abteilung

0

- Konkurrenzbeobachtung

- Kooperation mit anderen Untemehmen

0

0

0

- Messen, Kongresse, Ausstellungen

0

- private Unternehmensberater

- Fachliteratur

- Universitäten/ FHs

- außeruniversitäre Forschungseinrichtungen

0

0

0

- Technologietransfer- und

Innovationsberatungsstellen

O

weniger wichtig

unwichtig

- Fachverbănde

0

0

- Patentamt

- Sonstige

0

$\begin{array}{ll}0 & 0 \\ 0 & 0 \\ 0 & 0 \\ 0 & 0 \\ 0 & 0 \\ 0 & 0 \\ 0 & 0 \\ 0 & 0 \\ 0 & 0 \\ 0 & 0 \\ 0 & 0 \\ 0 & 0 \\ 0 & 0 \\ 0 & 0 \\ 0 & 0\end{array}$




\section{Uaterathrenambang und Um.}

1. Welchen Stellenwert raumen Sie den nachfolgend genannten Unternehmenszielen in Threm Betrieb ein?

Unternehmensziel

kurzfristige Gewinnerzielung

langfristige Gewinnerzielung

Umsatz

Marktanteil

Erschließung neuer Markte

Kosteneinsparungen

Produktivitătssteigerungen

Umweltschutz

Erhaltung von Arbeitsplatzen

Unternehmens-/ Produktimage

Mitarbeitermotivation

Kooperation mit Lieferanten

Kooperation mit Abnehmern/ Handel

Sicherung der Wettbewerbsfahigkeit

Unternehmenswachstum

\author{
sehr hoher \\ Stellenwert
}

$\begin{array}{ll}0 & 0 \\ 0 & 0 \\ 0 & 0 \\ 0 & 0 \\ 0 & 0 \\ 0 & 0 \\ 0 & 0 \\ 0 & 0 \\ 0 & 0 \\ 0 & 0 \\ 0 & 0 \\ 0 & 0 \\ 0 & 0 \\ 0 & 0 \\ 0 & 0 \\ 0 & 0\end{array}$

uberhaupt kein Stellenwert

0
0
0
0
0
0
0
0
0
0
0
0
0
0
0

2. Die Meinungen uber die gleichzeitige Erreichung von betriebswirtschaftlichen Zielen und Umweltschutzzielen gehen auseinander. Wenn Sie von Threm Betrieb ausgehen, inwieweit konnten die folgenden Unternehmensziele durch die Verfolgung von Umweltschutzmielen (wie z.B. Emissionsverminderung, Entwicklung umweltvertraglicher Produkte, Ressourcenschonung) gefordert oder beeintrïchtigt werden?

Unternehmensziel

kurzfristige Gewinnerzielung langfristige Gewinnerzielung

Umsatz

Marktanteil

Erschließung neuer Markte

Kosteneinsparungen

Produktivitatssteigerungen

Erhaltung von Arbeitsplatzen

Unternehmens-/ Produktimage

Mitarbeitermotivation

Kooperation mit Lieferanten

Kooperation mit Abnehmern/ Handel

Sicherung der Wettbewerbsfahigkeit

Unternehmenswachstum

\section{sehr gefordert}

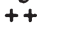

0

$\circ$

0

0

0

0

0

$\circ$

O

O

$\mathrm{O}$
... durch Umweltschutz

$$
+/-
$$
sehr beeinträchtigt

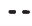


3. Gibt es in Threm Betrieb Organisationseinheiten, die sich speziell mit Umweltschutzaufgaben beschättigen (UWS-Einheiten)?

nein ja $\quad$... seit $\begin{gathered}\text { Anzahl der } \\ \text { Beschăftigten }\end{gathered}$

zentrale UWS-Einheiten mit ubergeordneten

Aufgaben für den Gesamtbetrieb

0

dezentrale UWS-Einheiten in den einzelnen

Betriebsbereichen

$0 \quad 0$

4. Welche Weisungsbefugnisse besitzen Thre Umweltschutz-Einheiten gegenuber anderen Organisationseinheiten?

$$
\begin{gathered}
\text { zentrale } \\
\text { UWS-Einheitentrale }
\end{gathered}
$$

keine

fachliche

disziplinarische

fachliche und disziplinarische

$\begin{array}{ll}0 & 0 \\ 0 & 0 \\ 0 & 0 \\ 0 & 0\end{array}$

5. Wie heißt die der Umweltschutz-Einheit vorgesetzte Stelle in Ihrem Betrieb?

$\begin{array}{cc}\text { zentrale } & \text { dezentrale } \\ \text { UWS-Einheiten } & \text { UWS-Einheiten }\end{array}$

Unternehmensleitung/ Vorstand

Betriebsleitung/ Geschätsfulhrer

$\begin{array}{ll}0 & 0 \\ 0 & 0 \\ 0 & 0 \\ 0 & 0 \\ 0 & 0 \\ 0 & 0\end{array}$

6. Wenn Sie Ihre Branche betrachten, in welchen Produktionsbereichen gibt es auf den folgenden Gebieten Umweltprobleme?
in hohem
uberhaupt
Maße
nicht

bei der Beschaffung der

Rohstoffe und Vorprodukte

O

O

O

O

O

bei der Produktion mit umweltbelastenden Verfahren

0

O

O

O

0

im Vertrieb wegen der Umweltbelastung der Produkte

0

0

O

0

O

bei der Entsorgung

o

o

o

o

o 
Denken Sie nun an Thren Betrieb: In welchem Maße gibt es in Threm Betrieb auf diesen Gebieten Umweltprobleme?

$$
\begin{gathered}
\text { in hohem } \\
\text { Maße }
\end{gathered}
$$

uberhaupt nicht

bei der Beschaffung der Rohstoffe und Vorprodukte
०

O

$\circ$

O

0

bei der Produktion mit umweltbelastenden Verfahren

$\circ$

0

$\circ$

O

im Vertrieb wegen der Umweltbelastung der Produkte

$\circ$

O

$\circ$

0

bei der Entsorgung

○

$\circ$

O

o

Nach welcher der folgenden Strategien gehen Sie in Ihrem Betrieb vor, um Anforderungen an den Umweltschutz (UWS) zu begegnen?

spielt eine sehr große Rolle

Ruckzug aus betroffenen Bereichen

Verlagerung der Produktion

Sofortige Anpassung an neue Auflagen und Gesetze

Widerstand gegen umweltschutzbezogene Forderungen (evt. in Kooperation mit anderen Untemehmen)

Berücksichtigung umweltbewußter Konsumentengruppen

$$
\circ
$$

$\circ$

O

O

0

0

0

0

0
Erschließen neuer Märkte mit umweltfreundlichen Produkten

Orientierung an den Aktivităten der unmittelbaren Konkurrenten

Abwarten, bis gesetzliche Regelungen sich konkretisiert haben

Vorwegnahme gesetzlicher Forderungen (Flexibilităt durch Innovation)
0

$\begin{array}{ll}0 & 0 \\ 0 & 0\end{array}$

$\circ$

o

0

O

O

$\circ$

O

$\circ$

0

$\circ$

O

$\circ$

0000

$\circ$

○

O

○

00000

○

o

○

○

Haben Sie fur Thren Betrieb seit 1990 Sozial- oder Umweltberichte angefertigt?
O nein
O ja, und zwar ...
O Ökobilanzen
O EG-Öko-Audit
O Umweltberichte
O Sozialbilanzen

Anzahl

spielt uberhaupt

keine Rolle 
10. Welche Belastungen oder/und Emissionen entstehen in Ihrem Betrieb?

O Abluft

O Abwasser

O Bodenbelastung

$O$ feste Abfalle

O Lărm

11. Welche Form der Emissionsvermeidungstechniken kommen dabei überwiegend zur Anwendung?

uberwiegend

(a)

... im Bereich Luft

... im Bereich Wasser

... im Bereich Boden

... bei festen Abrallen

... im Bereich Lärm
... integrierte Techniken (im Prozeßablauf, z.B. Techniken

zur Vermind. des Ressourcenund Energieverbrauchs)
... nachgeschaltete Techniken (am Ende des Prozeßablaufs, z.B. Filter, Rückhaltebecken)

$\begin{array}{ll}0 & 0 \\ 0 & 0 \\ 0 & 0 \\ 0 & 0 \\ 0 & 0\end{array}$

12. Wie hoch war die Summe der Investitionen zur Verminderung von Emissionen im Zeitraum 1. 1. 1990 bis 31.12.1995 (Schätzungen)?
O Abluft
O Abwasser
O Bodenbelastung
O feste Abfălle
O Lärm

13. Hat Thr Betrieb seit 1. 1.1990 staatliche Mittel zur Forderung von Umweltschutzmaßnahmen erhalten oder werden zur Zeit solche Mittel beantragt?

O ja

$O$ beantragt

O nein, weil

Investitionen stets aus eigenen Mitteln getătigt werden

O Fördermöglichkeiten unbekannt

O Fordervoraussetzungen und -konditionen unbekannt

O Möglichkeiten in Umweltschutz zu investieren unbekannt

O Einschătzung der Attraktivităt der Förderung zu schwierig (z.B. Zinsersparnis, Laufzeiten, Antragsstellen etc.)

14. Fand in Threm Betrieb seit dem 1. 1.1990 eine Prüfung auf Einhaltung der Emissionsvorschriften statt?

$O$ nein

$\mathrm{O}$ ja, und zwar ..................... Mal 


\section{Eine letzte Bitte!}

Um ein präzises Bild über den Ablauf der Strukturwandelungs- und Innovationsprozesse in der Region NeckarAlb zu bekommen, sind zusătzliche Interviews vorgesehen. Sie würden uns die Arbeit sehr erleichtern, wenn Sie zu einem Gespräch über diese Themenstellung bereit wären. Bitte vermerken Sie unter Angabe Ihrer Adresse, ob Sie zu einem solchen Gespräch bereit sind. Bitte seien Sie nochmals versichert, daß Ihre Angaben absolut vertraulich behandelt werden.

$\mathrm{Zu}$ einem Gesprăch bereit?

$O$ ja $\quad O$ nein Adresse (Firmenstempel)

Name:

Position:

Telefon-Nr.:

Wir danken Thnen an dieser Stelle noch einmal herzlich fur Thre Aufgeschlossenheit und Ihre Mitarbeit.

Bitte senden Sie den Fragebogen in beiliegendem Rückumschlag baldmöglichst an uns (Universităt Hohenheim, Europăische Forschungsstelle für den Lăndlichen Raum (521), 70599 Stuttgart) zurück.

Das Gutachten wird im Sommer 1996 allgemein zugănglich gemacht werden. In dieser Zeit werden wir Sie zu einer Vorstellung der Forschungsergebnisse in der Region Neckar-Alb recht herzlich einladen. 
Anlage 4: Unternehmen, die an den Unternehmergesprächen teilgenommen haben

1. auermöbel GmbH \& Co.KG

2. August Beck GmbH \& Co.

3. Bizerba $\mathrm{GmbH} \& \mathrm{Co} . \mathrm{KG}$

4. burger Behälterbau

5. CONRAD MAIER GmbH + Co.KG

6. disana

7. dixi \& mixi Kindermoden

CARL STREHLE GmbH \& Co.

8. effeff Fritz Fuss $\mathrm{GmbH} \& \mathrm{Co}$.

9. Elring Klinger $\mathrm{GmbH}$

10. ergo line

11. ETAPART

12. etifix ETIKETTEN GMBH

13. FLURO-Gelenklager $\mathrm{GmbH}$

14. Gebr. Buhl Papierfabriken $\mathrm{GmbH}$

15. GONSO SPORTMODEN GmbH + Co.KG

16. Hartschaumtechnik Götz

17. Holz-Hoerz $\mathrm{GmbH}$

18. Hüller Hille $\mathrm{GmbH}$

19. IDEAL-WERK

KRUG + PRIESTER GmbH + Co.KG

20. Imnauer Fürstenquellen $\mathrm{GmbH}$

21. JOCKEY VOLMA Wirkwaren GmbH/ MOONDAY underwear GmbH

22. KEMMLIT-Bauelemente-GmbH

23. $\mathrm{MaFu} \mathrm{GmbH}$

24. Mayer \& Cie. $\mathrm{GmbH} \& \mathrm{Co}$.

25. Mettler-Toledo (Albstadt) $\mathrm{GmbH}$

26. GEBRÜDER MEY GmbH \& Co.

27. Neckar-Alb-Zeitungsdruck GmbH \& Co.KG

28. Rampf Giessharzsysteme $\mathrm{GmbH}$

29. rüdt INDUSTRIELACKE GmbH

30. Spitta Verlag GmbH \& Co.KG

31. VILLFORTH Siebtechnik GmbH

32. Werner Fischer GmbH + Co.KG

33. Wilhelm Sülzle
Balingen-Stockhausen

Winterlingen

Balingen

Metzingen

Albstadt

Lichtenstein

Albstadt

Albstadt

Dettingen/Erms

Bitz

Rottenburg

Grafenberg

Rosenfeld

Dettingen

Albstadt

Reutlingen

Münsingen

Rottenburg

Balingen

Haigerloch-Bad Imnau

Hechingen

Dusslingen/Tübingen

Rosenfeld

Albstadt

Albstadt

Albstadt-Lautlingen

Balingen

Grafenberg

Dettingen/Erms

Balingen

Reutlingen

Albstadt

Rosenfeld 


\section{Anlage 5: Charakteristika kleiner und mittlerer Unternehmen und Großunternehmen}

\begin{tabular}{|c|c|}
\hline \multicolumn{2}{|c|}{ Unternehmensfïhrung } \\
\hline kleine und mittlere Unternehmen & Großunternehmen \\
\hline Eigentulmer - Unternehmer & Manager \\
\hline mangelnde Unternehmensfuhrungskenntnisse & fundierte Unternehmensfilhrungskenntnisse \\
\hline technisch orientierte Ausbildung & $\begin{array}{l}\text { gutes technisches Wissen in Fachabteilungen und Stä- } \\
\text { ben verfügbar }\end{array}$ \\
\hline $\begin{array}{l}\text { unzureichendes Informationswesen zur Nutzung vor- } \\
\text { handener Flexibilitătsvorteile }\end{array}$ & ausgebautes formalisiertes Informationswesen \\
\hline patriarchalische Führung & Führung nach Management-by-Prinzipien \\
\hline kaum Gruppenentscheidungen & hăufig Gruppenentscheidungen \\
\hline große Bedeutung von Improvisation und Intuition & geringe Bedeutung von Improvisation und Intuition \\
\hline kaum Planung & umfangreiche Planung \\
\hline $\begin{array}{l}\text { durch Funktionshäufung uberlastet, soweit Arbeitstei- } \\
\text { lung personenbezogen }\end{array}$ & hochgradig sachbezogene Arbeitsteilung \\
\hline unmittelbare Teilnahme am Betriebsgeschehen & Ferne zum Betriebsgeschehen \\
\hline $\begin{array}{l}\text { geringe Ausgleichsmöglichkeiten bei Fehlentscheidun- } \\
\text { gen }\end{array}$ & gute Ausgleichsmőglichkeiten bei Fehlentscheidungen \\
\hline Führungspotential nicht austauschbar & Führungspotential austauschbar \\
\hline
\end{tabular}

\begin{tabular}{l|l|}
\hline \multicolumn{1}{|c|}{ kleine und mittlere Unternehmen } & \multicolumn{1}{c|}{ Großunternehmen } \\
\hline geringe Zahl an Beschäftigten & $\begin{array}{l}\text { hohe Anzahl an Beschäftigten } \\
\text { häufig großer Anteil von ungelernten und angelernten } \\
\text { Arbeitskräften } \\
\text { häufig unbedeutender Anteil von ungelernten und ange } \\
\text { lernten Arbeitskrăften }\end{array}$ \\
$\begin{array}{l}\text { kaum Akademiker in größerem Umfang beschăftigt } \\
\text { uberwiegend breites Fachwissen vorhanden }\end{array}$ & $\begin{array}{l}\text { starke Tendenz zum ausgeprägten Spezialistentum } \\
\text { geringe Arbeitszufriedenheit }\end{array}$ \\
\hline
\end{tabular}




\section{Fortsetzung}

\begin{tabular}{|c|c|}
\hline \multicolumn{2}{|c|}{ Organisation } \\
\hline kleine und mittlere Unternehmen & Großunternehmen \\
\hline $\begin{array}{l}\text { auf den Unternehmer ausgerichtetes Einliniensystem, } \\
\text { von ihm selbst oder mit Hilfe weniger Führungsperso- } \\
\text { nen bis in die Einzelheiten überschaubar }\end{array}$ & $\begin{array}{l}\text { personenunabhängig an den sachlichen Gegebenheiten } \\
\text { orientierte komplexe Organisationsstruktur }\end{array}$ \\
\hline Funktionshäufung & Arbeitsteilung \\
\hline kaum Abteilungsbildung & umfangreiche Abteilungsbildung \\
\hline kurze direkte Informationswege & vorgeschriebene Informationswege \\
\hline starke persőnliche Bindungen & geringe persönliche Bindungen \\
\hline $\begin{array}{l}\text { Weisungen und Kontrolle im direkten personenbezoge- } \\
\text { nen Kontakt }\end{array}$ & $\begin{array}{l}\text { formalisierte unpersőnliche Weisungs- und Kontroll- } \\
\text { beziehungen }\end{array}$ \\
\hline Delegation in beschränktem Umfang & Delegation in vielen Bereichen \\
\hline kaum Koordinationsprobleme & große Koordinationsprobleme \\
\hline geringer Formalisierungsgrad & hoher Formalisierungsgrad \\
\hline hohe Flexibilităt & geringe Flexibilităt \\
\hline
\end{tabular}

\begin{tabular}{|l|l|}
\hline \multicolumn{2}{|c|}{ Absatz } \\
\hline \multicolumn{1}{|c|}{ kleine und mittlere Unternehmen } & \multicolumn{1}{|c|}{ Großunternehmen } \\
\hline $\begin{array}{l}\text { Deckung kleindimensionierter individualisierter Nach- } \\
\text { frage in einem răumlich und/oder sachlich schmalen } \\
\text { Marktsegment }\end{array}$ & $\begin{array}{l}\text { Deckung großdimensionierter Nachfrage' in einem } \\
\text { răumlich und/oder sachlich breiten Marktsegment }\end{array}$ \\
Wettbewerbsstellung sehr uneinheitlich & gute Wettbewerbsstellung \\
\hline
\end{tabular}

\begin{tabular}{|l|l|}
\hline \multicolumn{2}{|c|}{ Beschaffung und Materialwirtschaft } \\
\hline \multicolumn{1}{|c|}{ kleine und mittlere Unternehmen } & \multicolumn{1}{|c|}{ Großunternehmen } \\
\hline $\begin{array}{l}\text { schwache Position am Beschaffungsmarkt } \\
\begin{array}{l}\text { häufig auftragsbezogene Materialbeschaffung } \\
\text { (Ausnahme: Handel) }\end{array}\end{array}$ & $\begin{array}{l}\text { starke Position am Beschaffungsmarkt } \\
\text { uberwiegend auftragsunabhängige Materialbeschaf- } \\
\text { fung, abgesichert durch langfristige Vertrăge mit Liefe- } \\
\text { ranten }\end{array}$ \\
\hline
\end{tabular}


Fortsetzung

\begin{tabular}{|l|l|}
\hline \multicolumn{2}{|c|}{ Produktion } \\
\hline \multicolumn{1}{|c|}{ kleine und mittlere Unternehmen } & \multicolumn{1}{c|}{ Großunternehmen } \\
\hline arbeitsintensiv & kapitalintensiv \\
geringe Arbeitsteilung & hohe Arbeitsteilung \\
überwiegend Universalmaschinen & überwiegend Spezialmaschinen \\
geringe Kostendegression mit steigender Ausbringungs- \\
menge \\
$\begin{array}{l}\text { häufig langfristig gebunden an eine bestimmte Basisin- } \\
\text { novation }\end{array}$ & $\begin{array}{l}\text { starke Kostendegression mit steigender Ausbringungs- } \\
\text { keine langfristige Bindung an eine Basisinnovation }\end{array}$ \\
\hline
\end{tabular}

\begin{tabular}{|c|c|}
\hline \multicolumn{2}{|c|}{ Forschung und Entwicklung } \\
\hline kleine und mittlere Unternehmen & Großunternehmen \\
\hline $\begin{array}{l}\text { keine dauernd institutionalisierte Forschungs- und } \\
\text { Entwicklungsabteilung }\end{array}$ & $\begin{array}{l}\text { dauernd institutionalisierte Forschungs- und Entwick- } \\
\text { lungsabteilung }\end{array}$ \\
\hline $\begin{array}{l}\text { kurzfristig-intuitiv ausgerichtete Forschung und Ent- } \\
\text { wicklung }\end{array}$ & $\begin{array}{l}\text { langfristig-systematisch angelegte Forschung und Ent- } \\
\text { wicklung }\end{array}$ \\
\hline $\begin{array}{l}\text { fast ausschließlich bedarfsorientierte Produkt- und } \\
\text { Verfahrensentwicklung, kaum Grundlagenforschung }\end{array}$ & $\begin{array}{l}\text { Produkt- und Verfahrensentwicklung in engem } \mathrm{Zu} \text { - } \\
\text { sammenhang mit Grundlagenforschung }\end{array}$ \\
\hline $\begin{array}{l}\text { relativ kurzer Zeitraum zwischen Erfindung und wirt- } \\
\text { schaftlicher Nutzung }\end{array}$ & $\begin{array}{l}\text { relativ langer Zeitraum zwischen Erfindung und wirt- } \\
\text { schaftlicher Nutzung }\end{array}$ \\
\hline
\end{tabular}

\begin{tabular}{|c|c|}
\hline \multicolumn{2}{|c|}{ Finanzierung } \\
\hline kleine und mittlere Unternehmen & Großunternehmen \\
\hline im Familienbesitz & in der Regel breit gestreuter Besitz \\
\hline $\begin{array}{l}\text { kein Zugang zum anonymen Kapitalmarkt; dadurch nur } \\
\text { begrenzte Finanzierungsmöglichkeiten }\end{array}$ & $\begin{array}{l}\text { ungehinderter Zugang zum anonymen Kapitalmarkt; } \\
\text { dadurch vielfaltige Finanzierungsmöglichkeiten }\end{array}$ \\
\hline $\begin{array}{l}\text { keine unternehmensindividuelle, kaum allgemeine } \\
\text { staatliche Unterstiltzung in Krisensituationen }\end{array}$ & $\begin{array}{l}\text { unternehmensindividuelle staatliche Unterstützung in } \\
\text { Krisensituationen wahrscheinlich }\end{array}$ \\
\hline
\end{tabular}

Quelle: Pfohl, H.-C./Kellerwessel, P. (1990), S. 18ff.

Vgl. ergänzend Ostmeier, H. (1990), S. 197-208. 
Anlage 6: Percentage of Number of Enterprises and of Employment by Size Class and Sector, EUR-12 1986

\begin{tabular}{|l|rr|rr|rr|}
\hline & \multicolumn{2}{|c|}{ Micro } & \multicolumn{2}{c|}{ SMEs } & \multicolumn{2}{c|}{ Large } \\
& Germany & EUR-12 & Germany & EUR-12 & Germany & EUR-12 \\
\hline Enterprises: & & & & & & \\
All & 86,04 & 91,34 & 13,79 & 8,56 & 0,17 & 0,10 \\
Manufacturing & 73,59 & 82,70 & 25,59 & 16,91 & 0,82 & 0,39 \\
Construction & 79,25 & 91,28 & 20,71 & 8,68 & 0,05 & 0,04 \\
Services & 89,34 & 93,03 & 10,61 & 6,92 & 0,06 & 0,06 \\
\hline Employment: & & & & & & \\
All & 18,21 & 26,89 & 46,00 & 45,02 & 35,79 & 28,10 \\
Manufacturing & 6,20 & 11,14 & 41,15 & 45,95 & 52,65 & 42,91 \\
Construction & 22,66 & 39,53 & 67,21 & 50,75 & 10,13 & 9,90 \\
Services & 27,07 & 34,75 & 46,59 & 43,44 & 26,34 & 21,82 \\
\hline
\end{tabular}

Quelle: Commission of the European Communities (Hrsg.) (1990), S. 4.9.

Anlage 7: Verteilung der Branchen sowie der Unternehmensgrößenklassen in der Grundgesamtheit und im Rücklauf

a.

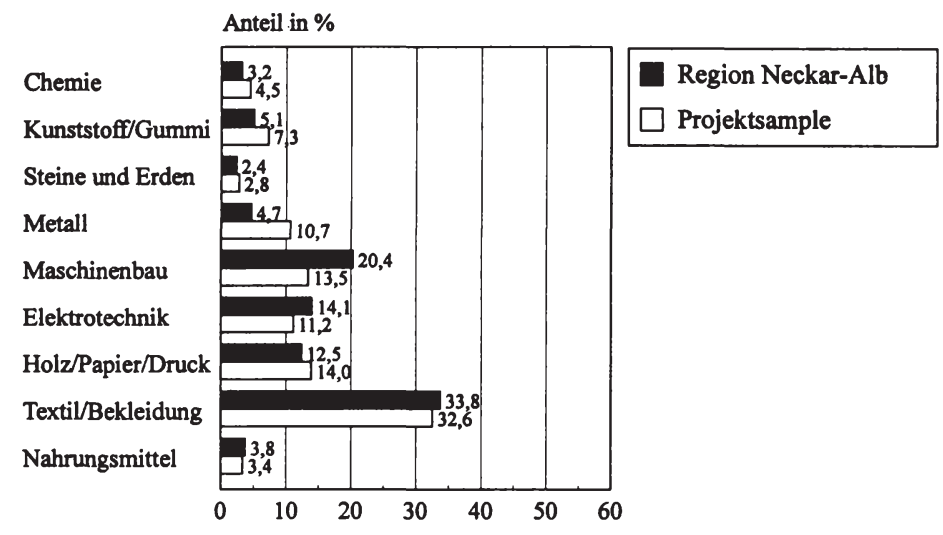


Fortsetzung

b.

\begin{tabular}{|c|c|c|c|c|c|}
\hline \multirow[b]{2}{*}{ Branche } & \multirow[b]{2}{*}{$\mathbf{U G K}^{1}$} & \multicolumn{2}{|c|}{ Grundgesamtheit } & \multicolumn{2}{|c|}{ Rücklauf } \\
\hline & & absolut & $\begin{array}{l}\text { relativ } \\
\text { (in \%) }\end{array}$ & absolut & $\begin{array}{l}\text { relativ } \\
\text { (in \%) }\end{array}$ \\
\hline \multirow[t]{4}{*}{ Chemie } & 12 & 15 & 2,12 & 6 & 3,37 \\
\hline & 13 & 3 & 0,42 & - & -- \\
\hline & 14 & 4 & 0,56 & 1 & 0,56 \\
\hline & 15 & 1 & 0,14 & 1 & 0,56 \\
\hline \multirow[t]{4}{*}{ Kunststoff/Gummi } & 12 & 21 & 2,96 & 9 & 5,06 \\
\hline & 13 & 8 & 1,13 & 1 & 0,56 \\
\hline & 14 & 6 & 0,85 & 2 & 1,12 \\
\hline & 15 & 1 & 0,14 & 1 & 0,56 \\
\hline \multirow{4}{*}{ Steine und Erden } & 12 & 8 & 1,13 & 1 & 0,56 \\
\hline & 13 & 5 & 0,71 & 1 & 0,56 \\
\hline & 14 & 1 & 0,14 & 2 & 1,12 \\
\hline & 15 & 3 & 0,42 & 1 & 0,56 \\
\hline \multirow[t]{4}{*}{ Metall } & 12 & 21 & 2,96 & 10 & 5,62 \\
\hline & 13 & 6 & 0,85 & 3 & 1,69 \\
\hline & 14 & 1 & 0,14 & 3 & 1,69 \\
\hline & 15 & 4 & 0,56 & 3 & 1,69 \\
\hline \multirow[t]{4}{*}{ Maschinenbau } & 12 & 53 & 7,48 & 14 & 7,87 \\
\hline & 13 & 38 & 5,36 & 5 & 2,81 \\
\hline & 14 & 31 & 4,37 & 1 & 0,56 \\
\hline & 15 & 22 & 3,10 & 4 & 2,25 \\
\hline
\end{tabular}


Fortsetzung

\begin{tabular}{|c|c|c|c|c|c|}
\hline \multirow[t]{4}{*}{ Elektrotechnik } & 12 & 43 & 6,06 & 7 & 3,93 \\
\hline & 13 & 20 & 2,82 & 2 & 1,12 \\
\hline & 14 & 22 & 3,10 & 4 & 2,25 \\
\hline & 15 & 17 & 2,40 & 7 & 3,93 \\
\hline \multirow[t]{4}{*}{ Holz/Papier/Druck } & 12 & 52 & 7,33 & 14 & 7,87 \\
\hline & 13 & 24 & 3,39 & 4 & 2,25 \\
\hline & 14 & 10 & 1,41 & 4 & 2,25 \\
\hline & 15 & 8 & 1,13 & 3 & 1,69 \\
\hline \multirow[t]{4}{*}{ Textil/Bekleidung } & 12 & 109 & 15,37 & 30 & 16,85 \\
\hline & 13 & 70 & 9,87 & 17 & 9,55 \\
\hline & 14 & 38 & 5,36 & 6 & 3,37 \\
\hline & 15 & 18 & 2,54 & 5 & 2,81 \\
\hline \multirow[t]{4}{*}{ Nahrungsmittel } & 12 & 16 & 2,26 & 4 & 2,25 \\
\hline & 13 & 4 & 0,56 & -- & -- \\
\hline & 14 & 4 & 0,56 & 2 & 1,12 \\
\hline & 15 & 2 & 0,28 & - & - \\
\hline Summen & & 709 & 100,00 & 178 & 100,00 \\
\hline \multicolumn{5}{|l|}{ Gesamtrücklauf } & 25,11 \\
\hline
\end{tabular}

$\begin{array}{llll}1 \text { Unternehmensgroßßenklassen (UGK): } & 12: & 20-49 & \text { Mitarbeiter } \\ & 13: & 50-99 & \text { Mitarbeiter } \\ & 14: & 100-199 & \text { Mitarbeiter } \\ & 15: & \text { ubber 200 } & \text { Mitarbeiter }\end{array}$

Quelle: eigene Berechnungen. 
Anlage 8: Veränderung des Umsatzes im Verarbeitenden Gewerbe zwischen 1990 und 1995

a.

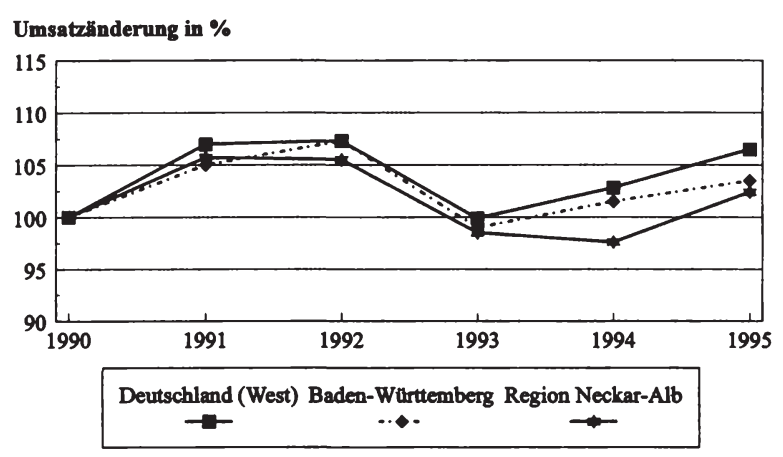

b.

\begin{tabular}{|l|c|}
\hline & Umsatzinderung \\
\hline Bundesrepublik Deutschland (West) & $+6,5 \%$ \\
Baden-Württemberg & $+3,5 \%$ \\
Region Neckar-Alb & $+2,4 \%$ \\
eigene Untersuchung & $+13,0 \%$ \\
- besonders erfolgreiche Unternehmen & $+54,4 \%$ \\
- weniger erfolgreiche Unternehmen & $-2,9 \%$ \\
\hline
\end{tabular}

Quelle: Statistisches Landesamt Baden-Württemberg (1996a), S. 1; Statistisches Landesamt Baden-Württemberg (1997a), S. 4 und S. 53; Herdzina, K./Blessin, B. (1996), S. 77; eigene Berechnungen. 
Anlage 9: Verteilung der besonders erfolgreichen und der weniger erfolgreichen Unternehmen auf die Unternehmensgrößenklassen

\begin{tabular}{|c|c|c|c|c|c|}
\hline Beschäftigtengrößenklassen & BG $<\mathbf{5 0}$ & $50 \leq B G<100$ & $100 \leq B G<200$ & $\mathbf{B G} \geq \mathbf{2 0 0}$ & Summe \\
\hline \multirow[t]{2}{*}{ besonders erfolgreiche Unternehmen } & $13,9 \%$ & $5,1 \%$ & $5,1 \%$ & $5,1 \%$ & \multirow[t]{2}{*}{$29,2 \%$} \\
\hline & $26,3 \%$ & $27,3 \%$ & $36,0 \%$ & $36,0 \%$ & \\
\hline \multirow[t]{2}{*}{ weniger erfolgreiche Unternehmen } & $39,3 \%$ & $13,5 \%$ & $9,0 \%$ & $9,0 \%$ & \multirow{2}{*}{$70,8 \%$} \\
\hline & $73,7 \%$ & $72,7 \%$ & $64,0 \%$ & $64,0 \%$ & \\
\hline Summe & $100,0 \%$ & $100,0 \%$ & $100,0 \%$ & $100,0 \%$ & $100,0 \%$ \\
\hline
\end{tabular}

\begin{tabular}{|c|c|c|c|c|}
\hline \multicolumn{1}{|c|}{ Umsatzgrößenklassen } & $\mathbf{U} \leq \mathbf{3 0}$ & $\mathbf{3 0 < U \leq 1 0 0}$ & $\mathbf{U}>\mathbf{1 0 0}$ & Summe \\
\hline besonders erfolgreiche Unternehmen & $\begin{array}{r}19,6 \% \\
25,9 \%\end{array}$ & $\begin{array}{r}6,2 \% \\
35,5 \%\end{array}$ & $\begin{array}{r}3,4 \% \\
50,0 \%\end{array}$ & $29,2 \%$ \\
\hline weniger erfolgreiche Unternehmen & $\begin{array}{r}56,2 \% \\
74,1 \%\end{array}$ & $\begin{array}{r}11,2 \% \\
64,5 \%\end{array}$ & $\begin{array}{r}3,4 \% \\
50,0 \%\end{array}$ & $70,8 \%$ \\
\hline Summe & $100,0 \%$ & $100,0 \%$ & $100,0 \%$ & $100,0 \%$ \\
\hline
\end{tabular}


Anlage 10: Zusammenführung der Umfeldanalyse und der Stärken-/Schwächenanalyse zur Chancen-/Risikenanalyse

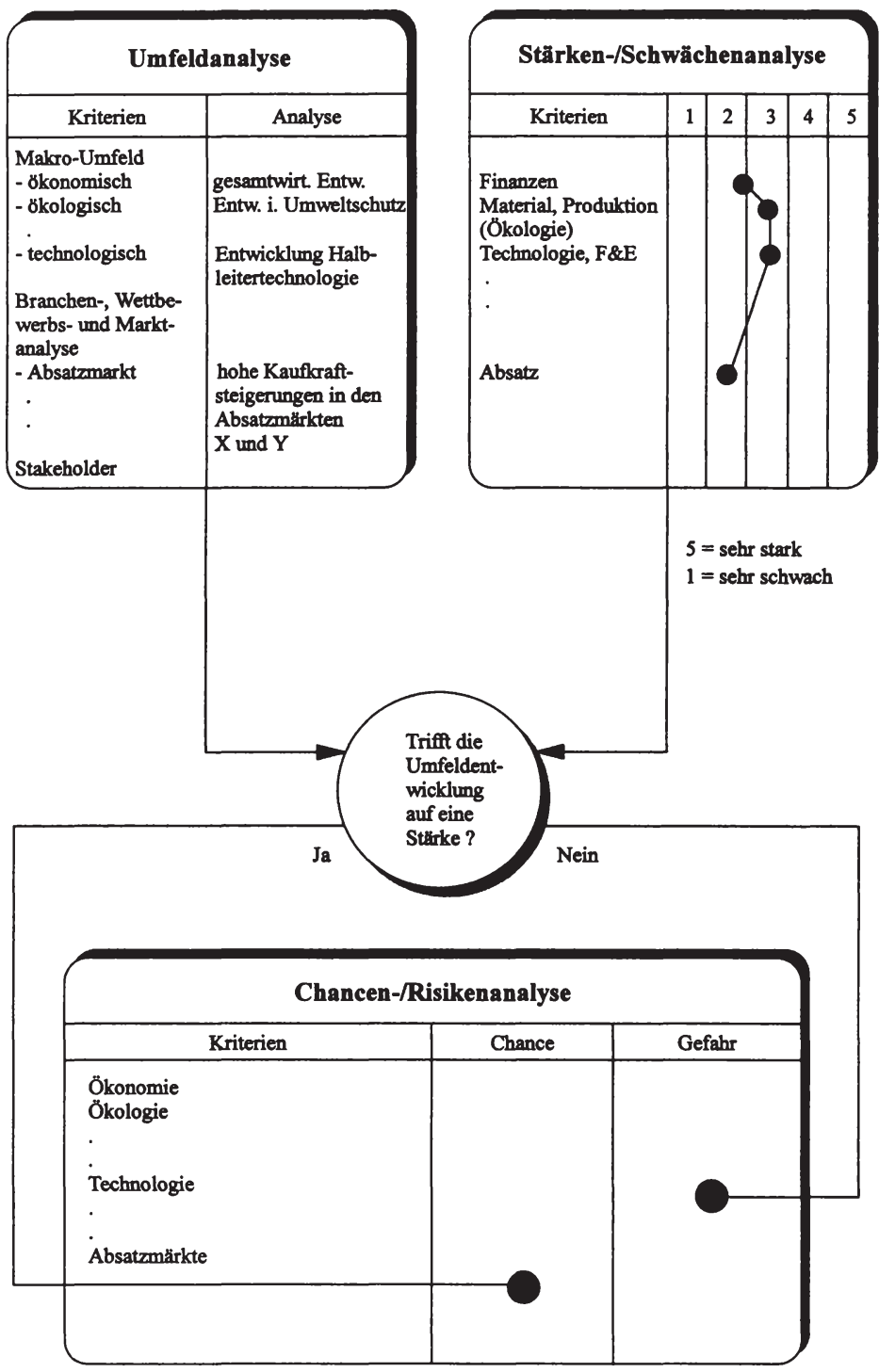

Quelle: in Anlehnung an Pümpin, C. (1980), S. 29. 
Anlage 11: Erfolgsfaktoren und Wettbewerbsvorteile der August Beck GmbH \& Co., Winterlingen

Die August Beck GmbH \& Co. ${ }^{1}$ wurde 1906 durch den Erfinder und Unternehmer August Beck gegründet. Das nunmehr in der dritten Generation geführte Familienunternehmen beschäftigt insgesamt 270 Mitarbeiter (davon 20 Auszubildende) und erzielte 1995 einen Umsatz von ca. 30 Mio. DM. Mit der Spezialisierung auf Zerspanungswerkzeuge erreicht das Unternehmen in Deutschland einen Marktanteil von ca. 30\% (Exportanteil ca. 25\%). Das Sortiment der "Beck-Präzisionswerkzeuge" umfaßt dabei über 500 Produktgruppen, bestehend aus 12.000 Einzelpositionen, die in Serie nach DIN- oder Werksnorm sowie als Sonderwerkzeuge nach spezifischen Kundenwünschen für nationale und internationale Kunden hergestellt werden.

Ganz so wie der Firmengründer fühlt sich das Unternehmen auch heute noch guter schwäbischer Tüftler- und Erfindertradition verpflichtet. Ständige Innovationen sind aber auch eine notwendige Voraussetzung, um im Markt zu bestehen und Wettbewerbsvorteile zu erzielen. Diese beiden Komponenten prägen seit jeher das Unternehmen und damit seine Unternehmenskultur. Aus dieser starken Unternehmenskultur heraus entwickelten sich die für das Unternehmen typischen Erfolgsfaktoren:

- die innovative Lősung von Kundenproblemen durch das Erfinden und Einführen neuer Produkte bzw. die ständige Weiterentwicklung von Produkten,

- die Verteidigung und Verbesserung der technologischen Spitzenposition,

- die Motivation und das Engagement der Mitarbeiter.

Die Verschmelzung von Produkt, Technologie und Mitarbeitern zu einer stimmigen Einheit bilden die wettbewerbsrelevanten Kernkompetenzen des Unternehmens. Mit diesen Kernkompetenzen ist das Unternehmen in der Lage, kundenspezifische Problemlösungen anzubieten, die in dieser Form von der (internationalen) Konkurrenz nicht erbracht werden können bzw. schwer imitierbar sind. Trotz der Spezialisierung auf ein enges Marktsegment öffnet sich dem Unternehmen durch das breite Sortiment und das vorhandene Know-how der potentielle $\mathrm{Zu}$ gang zu einer Vielzahl von Märkten. Aus dem unternehmensspezifischen Ressourcenbündel "Produkt - Technologie - Mitarbeiter" entsteht eine innovative, qualitativ hochwertige Marktleistung, die die Wettbewerbsvorteile der August Beck GmbH \& Co. begründet. Aus diesen Wettbewerbsvorteilen resultieren letztlich auch die Markterfolge des Unternehmens.

1 Vgl. auch Heim, G. (1997), S. 153f. 
Anlage 12: Klassifizierung der speziellen Wettbewerbsvorteile

\begin{tabular}{|l|c|c|c|}
\hline \multicolumn{1}{|c|}{ Wettbewerbsvorteil (Rang) } & Gesamt & $\begin{array}{c}\text { besonders erfolgreiche } \\
\text { Unternehmen }\end{array}$ & $\begin{array}{c}\text { weniger erfolgreiche } \\
\text { Unternehmen }\end{array}$ \\
\hline $\begin{array}{l}\text { flexible Anpassung an } \\
\text { Kundenwünsche } \\
\text { hohe Verarbeitungsqualität }\end{array}$ & 4,6 & $4,6(1)$ & $4,5(1)$ \\
besonderer Kundenservice \\
fortschrittliche \\
$\begin{array}{l}\text { Technologie/ Produkte } \\
\text { viele Produktinnovationen } \\
\text { besonderes Design/ }\end{array}$
\end{tabular}

\begin{tabular}{|l|c|c|c|c|c|}
\hline \multicolumn{1}{|c|}{ Wettbewerbsvorteil (Rang) } & Gesamt & $\mathbf{B G < 5 0}$ & $\mathbf{5 0 \leq B G}<\mathbf{1 0 0}$ & $\mathbf{1 0 0 \leq \mathbf { B } < \mathbf { 2 0 0 }}$ & $\mathbf{B G} \geq \mathbf{2 0 0}$ \\
\hline flexible Anpassung an & 4,6 & $4,7(1)$ & $4,5(1)$ & $4,6(1)$ & $4,3(3)$ \\
Kundenwünsche & 4,5 & $4,4(2)$ & $4,5(1)$ & $4,4(2)$ & $4,6(1)$ \\
hohe Verarbeitungsqualität & 4,2 & $4,3(3)$ & $4,0(3)$ & $4,2(4)$ & $4,3(3)$ \\
besonderer Kundenservice & 3,9 & $3,8(4)$ & $3,6(6)$ & $4,3(3)$ & $4,5(2)$ \\
fortschrittliche & 3,5 & $3,3(7)$ & $3,7(5)$ & $3,5(5)$ & $4,2(5)$ \\
Technologie/ Produkte & 3,5 & $3,3(7)$ & $3,8(4)$ & $3,3(6)$ & $3,6(7)$ \\
viele Produktinnovationen & 3,5 & $3,5(5)$ & $3,3(7)$ & $3,3(6)$ & $3,7(6)$ \\
besonderes Design/ & 3,2 & $3,4(6)$ & $3,0(8)$ & $3,3(6)$ & $2,7(8)$ \\
Gestaltung & & & & \\
hohe Umweltfreundlichkeit & günstige Preise & &
\end{tabular}

\begin{tabular}{|c|c|c|c|c|}
\hline Wettbewerbsvorteil (Rang) & Gesamt & $\mathbf{U} \leq \mathbf{3 0}$ & $30<U \leq 100$ & $U>100$ \\
\hline $\begin{array}{l}\text { flexible Anpassung an } \\
\text { Kundenwünsche }\end{array}$ & 4,6 & $4,6(1)$ & $4,4(2)$ & $4,0(5)$ \\
\hline hohe Verarbeitungsqualität & 4,5 & $4,5(2)$ & $4,5(1)$ & $4,7(1)$ \\
\hline besonderer Kundenservice & 4,2 & $4,3(3)$ & $4,2(3)$ & 4,1 (4) \\
\hline $\begin{array}{l}\text { fortschrittliche } \\
\text { Technologie/ Produkte }\end{array}$ & 3,9 & $3,8(4)$ & $4,1(4)$ & $4,7(1)$ \\
\hline viele Produktinnovationen & 3,5 & $3,4(5)$ & $3,9(5)$ & $4,3(3)$ \\
\hline $\begin{array}{l}\text { besonderes Design/ } \\
\text { Gestaltung }\end{array}$ & 3,5 & $3,4(5)$ & $3,6(6)$ & $3,5(7)$ \\
\hline hohe Umweltfreundlichkeit & 3,5 & $3,4(5)$ & $3,6(6)$ & $4,0(5)$ \\
\hline günstige Preise & 3,2 & $3,2(8)$ & $3,3(8)$ & $2,8(8)$ \\
\hline
\end{tabular}


Anlage 13: Inhalt und Rangordnung vorgegebener Unternehmensziele

(Skala von 1 = "überhaupt keine Stellenwert" bis 5 = "sehr hoher Stellenwert")

\begin{tabular}{|l|c|c|c|}
\hline \multicolumn{1}{|c|}{ Unternehmensziel (Rang) } & Gesamt & $\begin{array}{c}\text { besonders erfolgreiche } \\
\text { Unternehmen }\end{array}$ & $\begin{array}{c}\text { weniger erfolgreiche } \\
\text { Unternehmen }\end{array}$ \\
\hline $\begin{array}{l}\text { Sicherung der Wettbewerbsfähig- } \\
\text { keit }\end{array}$ & 4,8 & $4,8(1)$ & $4,8(1)$ \\
langfristige Gewinnerzielung & 4,8 & $4,8(1)$ & $4,7(2)$ \\
Kosteneinsparungen & 4,6 & $4,6(4)$ & $4,6(3)$ \\
Produktivitätssteigerungen & 4,6 & $4,7(3)$ & $4,6(3)$ \\
Unternehmens-/ Produktimage & 4,4 & $4,5(5)$ & $4,4(5)$ \\
Mitarbeitermotivation & 4,4 & $4,4(6)$ & $4,4(5)$ \\
Erschließung neuer Märkte & 4,2 & $4,0(11)$ & $4,3(7)$ \\
Umsatz & 4,2 & $4,2(8)$ & $4,2(8)$ \\
Kooperation mit Abnehmern/ & 4,1 & $4,1(9)$ & $4,2(8)$ \\
Handel & 4,1 & $4,3(7)$ & $3,9(10)$ \\
Erhaltung von Arbeitsplätzen & 3,9 & $4,1(9)$ & $3,8(11)$ \\
Marktanteil & 3,7 & $3,6(14)$ & $3,8(11)$ \\
Umweltschutz & 3,7 & $3,9(12)$ & $3,7(13)$ \\
Unternehmenswachstum & 3,7 & $3,8(13)$ & $3,7(13)$ \\
Kooperation mit Lieferanten & 3,3 & $3,1(15)$ & $3,4(15)$ \\
kurzfristige Gewinnerzielung & & & \\
\hline
\end{tabular}

\begin{tabular}{|c|c|c|c|c|c|}
\hline Unternehmensziel (Rang) & Gesamt & $\mathbf{B G}<\mathbf{5 0}$ & $50 \leq B G<100$ & $100 \leq \mathrm{BG}<200$ & $\mathbf{B G} \geq \mathbf{2 0 0}$ \\
\hline $\begin{array}{l}\text { Sicherung der Wettbewerbsfähig- } \\
\text { keit }\end{array}$ & 4,8 & $4,8(1)$ & $4,8(1)$ & $4,9(1)$ & $4,9(1)$ \\
\hline langfristige Gewinnerzielung & 4,8 & $4,8(1)$ & $4,7(2)$ & $4,8(2)$ & $4,6(3)$ \\
\hline Kosteneinsparungen & 4,6 & $4,5(4)$ & $4,6(3)$ & $4,8(2)$ & $4,7(2)$ \\
\hline Produktivitätssteigerungen & 4,6 & $4,6(3)$ & $4,5(5)$ & $4,8(2)$ & $4,5(4)$ \\
\hline Unternehmens-/ Produktimage & 4,4 & $4,4(5)$ & $4,5(5)$ & $4,4(5)$ & $4,4(5)$ \\
\hline Mitarbeitermotivation & 4,4 & $4,4(5)$ & 4,6 ( 3) & $4,4(5)$ & $4,2(7)$ \\
\hline Erschließung neuer Märkte & 4,2 & $4,2(9)$ & $4,3(7)$ & $4,2(7)$ & $4,2(7)$ \\
\hline Umsatz & 4,2 & $4,2(9)$ & $4,2(8)$ & $4,2(7)$ & $4,1(9)$ \\
\hline $\begin{array}{l}\text { Kooperation mit Abnehmern/ } \\
\text { Handel }\end{array}$ & 4,1 & $4,3(7)$ & $4,0(9)$ & $4,2(7)$ & $3,8(11)$ \\
\hline Erhaltung von Arbeitsplätzen & 4,1 & $4,3(7)$ & $3,7(12)$ & $3,9(12)$ & $3,7(12)$ \\
\hline Marktanteil & 3,9 & $3,3(14)$ & $4,0(9)$ & $4,0(10)$ & $4,3(6)$ \\
\hline Umweltschutz & 3,7 & $3,8(11)$ & $3,5(14)$ & $3,8(13)$ & $3,6(14)$ \\
\hline Unternehmenswachstum & 3,7 & $3,5(13)$ & 3,9 (11) & $4,0(10)$ & $4,0(10)$ \\
\hline Kooperation mit Lieferanten & 3,7 & $3,8(11)$ & $3,5(14)$ & $3,8(13)$ & $3,7(12)$ \\
\hline kurzfristige Gewinnerzielung & 3,3 & $3,3(14)$ & $3,7(12)$ & $3,5(15)$ & $2,9(15)$ \\
\hline
\end{tabular}




\section{Fortsetzung}

\begin{tabular}{|l|c|c|c|c|}
\hline \multicolumn{1}{|c|}{ Unternehmensziel (Rang) } & Gesamt & $\mathbf{U} \leq \mathbf{3 0}$ & $\mathbf{3 0 < U \leq 1 0 0}$ & $\mathbf{U}>\mathbf{1 0 0}$ \\
\hline Sicherung der Wettbewerbsfähig- & 4,8 & $4,8(1)$ & $4,9(1)$ & $4,8(1)$ \\
keit & 4,8 & $4,8(1)$ & $4,7(2)$ & $4,8(1)$ \\
langfristige Gewinnerzielung & 4,6 & $4,6(4)$ & $4,6(3)$ & $4,7(3)$ \\
Kosteneinsparungen & 4,6 & $4,7(3)$ & $4,3(5)$ & $4,7(3)$ \\
Produktivitătssteigerungen & 4,4 & $4,4(6)$ & $4,4(4)$ & $4,6(5)$ \\
Unternehmens-/ Produktimage & 4,4 & $4,5(5)$ & $4,2(8)$ & $4,5(6)$ \\
Mitarbeitermotivation & 4,2 & $4,2(8)$ & $4,1(9)$ & $4,0(11)$ \\
ErschlieBung neuer Mărkte & 4,2 & $4,2(8)$ & $4,3(5)$ & $3,8(14)$ \\
Umsatz & 4,1 & $4,3(7)$ & $3,8(11)$ & $4,1(9)$ \\
Kooperation mit Abnehmern/ & 4,1 & $4,2(8)$ & $3,7(12)$ & $4,0(11)$ \\
Handel & 3,9 & $3,7(12)$ & $4,3(5)$ & $4,3(7)$ \\
Erhaltung von Arbeitsplătzen & 3,7 & $3,8(11)$ & $3,5(14)$ & $4,2(8)$ \\
Marktanteil & 3,7 & $3,6(14)$ & $4,1(9)$ & $4,1(9)$ \\
Umweltschutz & 3,7 & $3,7(12)$ & $3,7(12)$ & $3,9(13)$ \\
Unternehmenswachstum & 3,3 & $3,3(15)$ & $3,5(14)$ & $2,8(15)$ \\
Kooperation mit Lieferanten & &
\end{tabular}

Anlage 14: Verfolgte Wachstumsstrategien (Produkt-Markt-Strategien)

\begin{tabular}{|l|c|c|c|}
\hline Produkt-Markt-Strategien & Gesamt & $\begin{array}{c}\text { besonders erfolgreiche } \\
\text { Unternehmen }\end{array}$ & $\begin{array}{c}\text { weniger erfolgreiche } \\
\text { Unternehmen }\end{array}$ \\
\hline Marktdurchdringung & $69,0 \%$ & $72,6 \%$ & $67,5 \%$ \\
Produkterweiterung & $54,0 \%$ & $68,6 \%$ & $48,0 \%$ \\
Markterweiterung & $44,8 \%$ & $43,1 \%$ & $45,5 \%$ \\
Diversifikation & $32,8 \%$ & $47,1 \%$ & $26,8 \%$ \\
\hline
\end{tabular}

\begin{tabular}{|l|c|c|c|c|c|}
\hline \multicolumn{1}{|c|}{ Produkt-Markt-Strategien } & Gesamt & BG<50 & 50 $\mathbf{B G}<\mathbf{1 0 0}$ & $\mathbf{1 0 0 \leq B G < 2 0 0}$ & BG $2 \mathbf{2 0 0}$ \\
\hline Marktdurchdringung & $69,0 \%$ & $70,3 \%$ & $63,6 \%$ & $76,0 \%$ & $64,0 \%$ \\
Produkterweiterung & $54,0 \%$ & $51,7 \%$ & $39,4 \%$ & $68,0 \%$ & $68,0 \%$ \\
Markterweiterung & $44,8 \%$ & $40,7 \%$ & $48,5 \%$ & $36,0 \%$ & $64,0 \%$ \\
Diversifikation & $32,8 \%$ & $31,9 \%$ & $24,2 \%$ & $44,0 \%$ & $36,0 \%$ \\
\hline
\end{tabular}


Fortsetzung

\begin{tabular}{|l|c|c|c|c|}
\hline \multicolumn{1}{|c|}{ Produkt-Markt-Strategien } & Gesamt & $\mathbf{U} \leq \mathbf{3 0}$ & $\mathbf{3 0}<\mathbf{U} \leq \mathbf{1 0 0}$ & $\mathbf{U}>\mathbf{1 0 0}$ \\
\hline Marktdurchdringung & $69,0 \%$ & $67,9 \%$ & $71,0 \%$ & $75,0 \%$ \\
Produkterweiterung & $54,0 \%$ & $47,3 \%$ & $67,7 \%$ & $91,7 \%$ \\
Markterweiterung & $44,8 \%$ & $42,8 \%$ & $45,2 \%$ & $66,7 \%$ \\
Diversifikation & $32,8 \%$ & $33,6 \%$ & $25,8 \%$ & $41,7 \%$ \\
\hline
\end{tabular}

Anlage 15: Absatzmärkte der befragten Unternehmen nach Umsatzanteil

\begin{tabular}{|l|c|c|c|}
\hline durchschnittlicher Umsatzanteil & Gesamt & $\begin{array}{c}\text { besonders erfolgreiche } \\
\text { Unternehmen }\end{array}$ & $\begin{array}{c}\text { weniger erfolgreiche } \\
\text { Unternehmen }\end{array}$ \\
\hline im Landkreis & $10,0 \%$ & $8,1 \%$ & $10,7 \%$ \\
in Baden-Württemberg & $22,5 \%$ & $23,6 \%$ & $22,2 \%$ \\
in Deutschland & $49,0 \%$ & $46,5 \%$ & $49,8 \%$ \\
in der Europäischen Union & $11,9 \%$ & $13,4 \%$ & $11,4 \%$ \\
in Mittel- und Osteuropa & $2,6 \%$ & $3,5 \%$ & $2,2 \%$ \\
außerhalb Europas & $4,0 \%$ & $4,9 \%$ & $3,7 \%$ \\
\hline
\end{tabular}

\begin{tabular}{|l|c|c|c|c|c|}
\hline durchschnittlicher Umsatzanteil & Gesamt & BG<50 & 50SBG<100 & $\mathbf{1 0 0 \leq B G < 2 0 0}$ & BG $2 \mathbf{2 0 0}$ \\
\hline im Landkreis & $10,0 \%$ & $14,0 \%$ & $2,6 \%$ & $14,1 \%$ & $0,5 \%$ \\
in Baden-Württemberg & $22,5 \%$ & $28,0 \%$ & $14,4 \%$ & $23,9 \%$ & $11,1 \%$ \\
in Deutschland & $49,0 \%$ & $42,0 \%$ & $63,3 \%$ & $49,9 \%$ & $55,9 \%$ \\
in der Europäischen Union & $11,9 \%$ & $40,5 \%$ & $14,5 \%$ & $7,0 \%$ & $18,6 \%$ \\
in Mittel- und Osteuropa & $2,6 \%$ & $1,9 \%$ & $3,6 \%$ & $2,7 \%$ & $3,6 \%$ \\
außerhalb Europas & $4,0 \%$ & $3,6 \%$ & $1,7 \%$ & $2,4 \%$ & $10,4 \%$ \\
\hline
\end{tabular}

\begin{tabular}{|l|c|c|c|c|}
\hline durchschnittlicher Umsatzanteil & Gesamt & $\mathbf{U} \leq \mathbf{3 0}$ & $\mathbf{3 0 < U \leq 1 0 0}$ & $\mathbf{U}>\mathbf{1 0 0}$ \\
\hline im Landkreis & $10,0 \%$ & $11,6 \%$ & $6,2 \%$ & $0,7 \%$ \\
in Baden-Württemberg & $22,5 \%$ & $24,9 \%$ & $18,8 \%$ & $5,6 \%$ \\
in Deutschland & $49,0 \%$ & $47,5 \%$ & $53,3 \%$ & $54,9 \%$ \\
in der Europăischen Union & $11,9 \%$ & $10,7 \%$ & $13,3 \%$ & $21,8 \%$ \\
in Mittel- und Osteuropa & $2,6 \%$ & $2,2 \%$ & $3,4 \%$ & $4,6 \%$ \\
außerhalb Europas & $4,0 \%$ & $3,0 \%$ & $4,9 \%$ & $12,5 \%$ \\
\hline
\end{tabular}


Anlage 16: Standardisierungsgrad des Produkt- und Leistungsangebotes

\begin{tabular}{|c|c|c|c|}
\hline Standardisierungsgrad & Gesamt & $\begin{array}{l}\text { besonders erfolgreiche } \\
\text { Unternehmen }\end{array}$ & $\begin{array}{c}\text { weniger erfolgreiche } \\
\text { Unternehmen }\end{array}$ \\
\hline Für unsere Abnehmer/ Kunden ... & & & \\
\hline $\begin{array}{l}\text { haben wir ein standardisiertes Pro- } \\
\text { dukt- und Leistungsangebot }\end{array}$ & $30,2 \%$ & $29,4 \%$ & $30,6 \%$ \\
\hline $\begin{array}{l}\text { haben wir ein standardisiertes Pro- } \\
\text { dukt- und Leistungsangebot, vari- } \\
\text { ieren unser Angebot häufig auf } \\
\text { Kundenwunsch nach seinen spezi- } \\
\text { fischen Bedürfnissen }\end{array}$ & $59,9 \%$ & $68,6 \%$ & $56,2 \%$ \\
\hline $\begin{array}{l}\text { erbringen wir in der Regel kunden- } \\
\text { spezifische Leistungen. Bei ihrer } \\
\text { Entwicklung und Fertigung ko- } \\
\text { operieren wir eng mit dem jeweili- } \\
\text { gen Kunden }\end{array}$ & $50,0 \%$ & $52,9 \%$ & $48,8 \%$ \\
\hline
\end{tabular}

\begin{tabular}{|c|c|c|c|c|c|}
\hline Standardisierungsgrad & Gesamt & $\mathbf{B G}<50$ & $50 \leq B G<100$ & $100 \leq B G<200$ & $\mathbf{B G} \geq \mathbf{2 0 0}$ \\
\hline Für unsere Abnehmer/ Kunden ... & & & & & \\
\hline $\begin{array}{l}\text { haben wir ein standardisiertes Pro- } \\
\text { dukt- und Leistungsangebot }\end{array}$ & $30,2 \%$ & $26,7 \%$ & $27,3 \%$ & $33,3 \%$ & $44,0 \%$ \\
\hline $\begin{array}{l}\text { haben wir ein standardisiertes Pro- } \\
\text { dukt- und Leistungsangebot, vari- } \\
\text { ieren unser Angebot häufig auf } \\
\text { Kundenwunsch nach seinen spezi- } \\
\text { fischen Bedürfnissen }\end{array}$ & $59,9 \%$ & $57,8 \%$ & $69,7 \%$ & $50,0 \%$ & $64,0 \%$ \\
\hline $\begin{array}{l}\text { erbringen wir in der Regel kunden- } \\
\text { spezifische Leistungen. Bei ihrer } \\
\text { Entwicklung und Fertigung ko- } \\
\text { operieren wir eng mit dem jeweili- } \\
\text { gen Kunden }\end{array}$ & $50,0 \%$ & $54,4 \%$ & $48,5 \%$ & $41,7 \%$ & $44,0 \%$ \\
\hline
\end{tabular}

\begin{tabular}{|c|c|c|c|c|}
\hline Standardisierungsgrad & Gesamt & $\mathbf{U} \leq \mathbf{3 0}$ & $30<\mathrm{U} \leq 100$ & $U>100$ \\
\hline Für unsere Abnehmer/ Kunden ... & & & & \\
\hline $\begin{array}{l}\text { haben wir ein standardisiertes Pro- } \\
\text { dukt- und Leistungsangebot }\end{array}$ & $30,2 \%$ & $23,9 \%$ & $46,7 \%$ & $58,3 \%$ \\
\hline $\begin{array}{l}\text { haben wir ein standardisiertes Pro- } \\
\text { dukt- und Leistungsangebot, vari- } \\
\text { ieren unser Angebot häufig auf } \\
\text { Kundenwunsch nach seinen spezi- } \\
\text { fischen Bedürfnissen }\end{array}$ & $59,9 \%$ & $60,0 \%$ & $60,0 \%$ & $58,3 \%$ \\
\hline $\begin{array}{l}\text { erbringen wir in der Regel kunden- } \\
\text { spezifische Leistungen. Bei ihrer } \\
\text { Entwicklung und Fertigung ko- } \\
\text { operieren wir eng mit dem jeweili- } \\
\text { gen Kunden }\end{array}$ & $50,0 \%$ & $53,9 \%$ & $43,3 \%$ & $25,0 \%$ \\
\hline
\end{tabular}


Anlage 17: F\&E-Ausgaben (in \% des BIP) in verschiedenen Ländern der OECD zwischen 1990 und 1995

\begin{tabular}{|l|c|c|c|c|c|c|}
\hline \multicolumn{1}{|c|}{ Land } & 1990 & 1991 & 1992 & 1993 & 1994 & 1995 \\
\hline Japan & 3,0 & 3,0 & 3,0 & 2,9 & 2,8 & 3,0 \\
Nordamerika & 2,7 & 2,5 & 2,5 & 2,4 & 2,3 & 2,3 \\
- USA & 2,8 & 2,8 & 2,8 & 2,6 & 2,5 & 2,6 \\
- Kanada & 1,5 & 1,5 & 1,6 & 1,6 & 1,6 & 1,6 \\
Europäische Union & 2,0 & 2,0 & 1,9 & 1,9 & 1,9 & 1,8 \\
- Deutschland & 2,8 & 2,6 & 2,5 & 2,4 & 2,3 & 2,3 \\
- Frankreich & 2,4 & 2,4 & 2,4 & 2,5 & 2,4 & 2,3 \\
- Großbritannien & 2,2 & 2,1 & 2,1 & 2,2 & 2,1 & 2,1 \\
- Italien & 1,3 & 1,3 & 1,3 & 1,3 & 1,2 & 1,1 \\
- Spanien & 0,9 & 0,9 & 0,9 & 0,9 & 0,9 & 0,8 \\
\hline
\end{tabular}

Quelle: OECD (1997), S. 16.

Anlage 18: Stellenwert innovationsrelevanter Informationsquellen (Skala von 1 = "unwichtig" bis 3 = "wichtig")

\begin{tabular}{|l|c|c|c|}
\hline \multicolumn{1}{|c|}{ Informationsquellen } & Gesamt & $\begin{array}{c}\text { besonders erfolgreiche } \\
\text { Unternehmen }\end{array}$ & $\begin{array}{c}\text { weniger erfolgreiche } \\
\text { Unternehmen }\end{array}$ \\
\hline $\begin{array}{l}\text { Vetriebsbeauftragte von Hersteller- } \\
\text { firmen }\end{array}$ & 2,5 & 2,4 & 2,5 \\
Impulse der Abnehmer & 2,8 & 2,9 & 2,8 \\
aus innerbetrieblicher Zusammen- & 2,4 & 2,6 & 2,3 \\
arbeit & 2,1 & 2,3 & 2,1 \\
eigene F\&E-Abteilung & 2,7 & 2,8 & 2,7 \\
Konkurrenzbeobachtung & 2,0 & 1,9 & 2,0 \\
Kooperation mit anderen Unter- \\
nehmen
\end{tabular}


Fortsetzung

\begin{tabular}{|c|c|c|c|c|c|}
\hline Informationsquellen & Gesamt & BG $<50$ & $50 \leq B G<100$ & $100 \leq B G<200$ & $\mathbf{B G} \geq \mathbf{2 0 0}$ \\
\hline $\begin{array}{l}\text { Vetriebsbeauftragte von Hersteller- } \\
\text { firmen }\end{array}$ & 2,5 & 2,4 & 2,5 & 2,5 & 2,7 \\
\hline Impulse der Abnehmer & 2,8 & 2,8 & 2,8 & 2,8 & 2,7 \\
\hline $\begin{array}{l}\text { aus innerbetrieblicher Zusammen- } \\
\text { arbeit }\end{array}$ & 2,4 & 2,4 & 2,4 & 2,5 & 2,6 \\
\hline eigene F\&E-Abteilung & 2,1 & 1,9 & 2,2 & 2,1 & 2,8 \\
\hline Konkurrenzbeobachtung & 2,7 & 2,8 & 2,6 & 2,9 & 2,6 \\
\hline $\begin{array}{l}\text { Kooperation mit anderen Unter- } \\
\text { nehmen }\end{array}$ & 2,0 & 2,0 & 1,8 & 2,1 & 1,9 \\
\hline Messen, Kongresse, Ausstellungen & 2,6 & 2,6 & 2,8 & 2,5 & 2,7 \\
\hline private Unternehmensberater & 1,4 & 1,3 & 1,6 & 1,6 & 1,5 \\
\hline Fachliteratur & 2,4 & 2,4 & 2,2 & 2,4 & 2,4 \\
\hline Universitäten/ FHs & 1,7 & 1,5 & 1,6 & 1,8 & 2,0 \\
\hline $\begin{array}{l}\text { außeruniversitäre Forschungsein- } \\
\text { richtungen }\end{array}$ & 1,6 & 1,5 & 1,5 & 1,7 & 2,0 \\
\hline $\begin{array}{l}\text { Technologietransfer- und Inno- } \\
\text { vationsberatungseinrichtungen }\end{array}$ & 1,6 & 1,5 & 1,4 & 1,9 & 1,8 \\
\hline Fachverbände & 2,0 & 2,0 & 2,1 & 2,3 & 2,1 \\
\hline Patentamt & 1,6 & 1,5 & 1,6 & 1,6 & 1,8 \\
\hline
\end{tabular}

\begin{tabular}{|c|c|c|c|c|}
\hline Informationsquellen & Gesamt & $\mathbf{U} \leq \mathbf{3 0}$ & $30<U \leq 100$ & $U>100$ \\
\hline $\begin{array}{l}\text { Vetriebsbeauftragte von Hersteller- } \\
\text { firmen }\end{array}$ & 2,5 & 2,4 & 2,5 & 2,7 \\
\hline Impulse der Abnehmer & 2,8 & 2,8 & 2,7 & 2,9 \\
\hline $\begin{array}{l}\text { aus innerbetrieblicher Zusammen- } \\
\text { arbeit }\end{array}$ & 2,4 & 2,4 & 2,5 & 2,5 \\
\hline eigene F\&E-Abteilung & 2,1 & 2,0 & 2,3 & 3,0 \\
\hline Konkurrenzbeobachtung & 2,7 & 2,7 & 2,7 & 2,8 \\
\hline $\begin{array}{l}\text { Kooperation mit anderen Unter- } \\
\text { nehmen }\end{array}$ & 2,0 & 2,0 & 1,9 & 1,9 \\
\hline Messen, Kongresse, Ausstellungen & 2,6 & 2,6 & 2,8 & 2,8 \\
\hline private Unternehmensberater & 1,4 & 1,4 & 1,4 & 1,7 \\
\hline Fachliteratur & 2,4 & 2,4 & 2,3 & 2,4 \\
\hline Universitäten/ FHs & 1,7 & 1,6 & 1,6 & 2,3 \\
\hline $\begin{array}{l}\text { außeruniversitäre Forschungsein- } \\
\text { richtungen }\end{array}$ & 1,6 & 1,5 & 1,7 & 2,2 \\
\hline $\begin{array}{l}\text { Technologietransfer- und Inno- } \\
\text { vationsberatungseinrichtungen }\end{array}$ & 1,6 & 1,5 & 1,7 & 2,0 \\
\hline Fachverbände & 2,0 & 2,1 & 2,0 & 2,4 \\
\hline Patentamt & 1,6 & 1,6 & 1,5 & 2,0 \\
\hline
\end{tabular}




\section{Anlage 19: Qualifikationsstruktur in den befragten Unternehmen}

\begin{tabular}{|l|c|c|}
\hline \multicolumn{1}{|c|}{ Qualifikationsstruktur } & $\begin{array}{c}\text { besonders erfolgreiche } \\
\text { Unternehmen }\end{array}$ & $\begin{array}{c}\text { weniger erfolgreiche } \\
\text { Unternehmen }\end{array}$ \\
\hline hőhere kaufmånnische Angestellte & $82,7 \%$ & $85,7 \%$ \\
Hochschulingenieure & $63,5 \%$ & $42,9 \%$ \\
sonstige Angestellte & $86,5 \%$ & $89,7 \%$ \\
Facharbeiter & $86,5 \%$ & $81,0 \%$ \\
Arbeiter & $88,5 \%$ & $96,8 \%$ \\
Auszubildende & $48,1 \%$ & $43,7 \%$ \\
\hline
\end{tabular}

Lesebeispiel:

82,7\% der besonders erfolgreichen Unternehmen beschăftigen höhere kaufmännische Angestellte.

\begin{tabular}{|c|c|c|c|c|}
\hline Qualifikationsstruktur & $\mathrm{BG}<\mathbf{5 0}$ & $50 \leq B G<100$ & $100 \leq B G<200$ & $\mathbf{B G} \geq \mathbf{2 0 0}$ \\
\hline höhere kaufmännische Angestellte & $81,5 \%$ & $90,9 \%$ & $92,0 \%$ & $92,0 \%$ \\
\hline Hochschulingenieure & $39,1 \%$ & $45,5 \%$ & $68,0 \%$ & $76,0 \%$ \\
\hline sonstige Angestellte & $87,0 \%$ & $93,9 \%$ & $92,0 \%$ & $96,0 \%$ \\
\hline Facharbeiter & $80,4 \%$ & $90,9 \%$ & $84,0 \%$ & $88,0 \%$ \\
\hline Arbeiter & $96,7 \%$ & $90,9 \%$ & $96,0 \%$ & $100,0 \%$ \\
\hline Auszubildende & $23,9 \%$ & $54,5 \%$ & $68,0 \%$ & $92,0 \%$ \\
\hline
\end{tabular}

\begin{tabular}{|l|c|c|c|}
\hline \multicolumn{1}{|c|}{ Qualifikationsstruktur } & $\mathbf{U} \leq \mathbf{3 0}$ & $\mathbf{3 0 < U \leq 1 0 0}$ & $\mathbf{U}>\mathbf{1 0 0}$ \\
\hline höhere kaufmännische Angestellte & $84,2 \%$ & $90,0 \%$ & $100,0 \%$ \\
Hochschulingenieure & $43,6 \%$ & $63,3 \%$ & $83,3 \%$ \\
sonstige Angestellte & $\mathbf{8 8 , 7 \%}$ & $96,7 \%$ & $91,7 \%$ \\
Facharbeiter & $84,2 \%$ & $83,3 \%$ & $83,3 \%$ \\
Arbeiter & $94,7 \%$ & $100,0 \%$ & $100,0 \%$ \\
Auszubildende & $35,3 \%$ & $73,3 \%$ & $91,7 \%$ \\
\hline
\end{tabular}


Anlage 20: Qualifizierungsbedarf bei den derzeitigen Mitarbeitern

\begin{tabular}{|l|c|c|c|}
\hline \multicolumn{1}{|c|}{ Qualifizierungsbedarf } & Gesamt & $\begin{array}{c}\text { besonders erfolgreiche } \\
\text { Unternehmen }\end{array}$ & $\begin{array}{c}\text { weniger erfolgreiche } \\
\text { Unternehmen }\end{array}$ \\
\hline nein & $19,7 \%$ & $11,5 \%$ & $23,0 \%$ \\
ja, und zwar im Bereich ... & $80,3 \%$ & $88,5 \%$ & $77,0 \%$ \\
Technik & $52,0 \%$ & $54,9 \%$ & $50,8 \%$ \\
- Informationstechnik & $34,1 \%$ & $49,0 \%$ & $27,9 \%$ \\
- Produktions-/Fertigungstechnik & $45,7 \%$ & $49,0 \%$ & $44,3 \%$ \\
Organisation/Management & $28,3 \%$ & $37,3 \%$ & $24,6 \%$ \\
Marketing/Vertrieb & $36,4 \%$ & $37,3 \%$ & $36,1 \%$ \\
Umwelt & $19,1 \%$ & $35,3 \%$ & $12,3 \%$ \\
Produktqualităt & $37,0 \%$ & $39,2 \%$ & $36,1 \%$ \\
Prozeßqualităt & $26,6 \%$ & $31,4 \%$ & $24,6 \%$ \\
Sprachen & $22,0 \%$ & $27,5 \%$ & $19,7 \%$ \\
Sonstige & $4,6 \%$ & $7,8 \%$ & $3,3 \%$ \\
\hline
\end{tabular}

\begin{tabular}{|c|c|c|c|c|c|}
\hline Qualifinierungsbedarf & Gesamt & BG $<50$ & $50 \leq B G<100$ & $100 \leq B G<200$ & BG 2200 \\
\hline nein & $19,7 \%$ & $24,2 \%$ & $24,2 \%$ & $12,0 \%$ & $4,0 \%$ \\
\hline ja, und zwar im Bereich ... & $80,3 \%$ & $75,8 \%$ & $75,8 \%$ & $88,0 \%$ & $96,0 \%$ \\
\hline Technik & $52,0 \%$ & $48,9 \%$ & $46,9 \%$ & $54,2 \%$ & $68,0 \%$ \\
\hline - Informationstechnik & $34,1 \%$ & $27,2 \%$ & $28,1 \%$ & $37,5 \%$ & $64,0 \%$ \\
\hline - Produktions-/Fertigungstechnik & $45,7 \%$ & $40,2 \%$ & $53,1 \%$ & $41,7 \%$ & $60,0 \%$ \\
\hline Organisation/Management & $28,3 \%$ & $14,1 \%$ & $37,5 \%$ & $41,7 \%$ & $56,0 \%$ \\
\hline Marketing/Vertrieb & $36,4 \%$ & $33,7 \%$ & $40,6 \%$ & $45,8 \%$ & $32,0 \%$ \\
\hline Umwelt & $19,1 \%$ & $12,0 \%$ & $25,0 \%$ & $29,2 \%$ & $28,0 \%$ \\
\hline Produktqualităt & $37,0 \%$ & $34,5 \%$ & $37,5 \%$ & $41,7 \%$ & $52,0 \%$ \\
\hline Prozeßqualităt & $26,6 \%$ & $20,7 \%$ & $18,8 \%$ & $33,3 \%$ & $52,0 \%$ \\
\hline Sprachen & $22,0 \%$ & $15,2 \%$ & $21,9 \%$ & $20,8 \%$ & $48,0 \%$ \\
\hline Sonstige & $4,6 \%$ & $1,1 \%$ & $12,5 \%$ & $12,5 \%$ & $0,0 \%$ \\
\hline
\end{tabular}


Fortsetzung

\begin{tabular}{|l|c|c|c|c|}
\hline \multicolumn{1}{|c|}{ Qualifizierungsbedarf } & Gesamt & U $\mathbf{3 0}$ & $\mathbf{3 0 < U \leq 1 0 0}$ & U>100 \\
\hline nein & $19,7 \%$ & $23,0 \%$ & $12,9 \%$ & $0,0 \%$ \\
ja, und zwar im Bereich ... & $80,3 \%$ & $77,0 \%$ & $87,1 \%$ & $100,0 \%$ \\
Technik & $52,0 \%$ & $50,8 \%$ & $45,2 \%$ & $83,3 \%$ \\
- Informationstechnik & $34,1 \%$ & $29,2 \%$ & $45,2 \%$ & $58,3 \%$ \\
- Produktions-/Fertigungstechnik & $45,7 \%$ & $43,9 \%$ & $45,2 \%$ & $66,7 \%$ \\
Organisation/Management & $28,3 \%$ & $20,0 \%$ & $54,8 \%$ & $50,0 \%$ \\
Marketing/Vertrieb & $36,4 \%$ & $35,4 \%$ & $35,5 \%$ & $50,0 \%$ \\
Umwelt & $19,1 \%$ & $15,4 \%$ & $25,8 \%$ & $41,7 \%$ \\
Produktqualităt & $37,0 \%$ & $33,1 \%$ & $51,6 \%$ & $41,7 \%$ \\
Prozeßqualităt & $26,6 \%$ & $22,3 \%$ & $38,7 \%$ & $41,7 \%$ \\
Sprachen & $22,0 \%$ & $15,4 \%$ & $32,3 \%$ & $66,7 \%$ \\
Sonstige & $4,6 \%$ & $4,6 \%$ & $6,5 \%$ & $0,0 \%$ \\
\hline
\end{tabular}

\section{Anlage 21: Maßnahmen der betrieblichen Weiterbildung}

\begin{tabular}{|l|c|c|c|}
\hline Weiterbildung findet statt ... & Gesamt & $\begin{array}{c}\text { besonders erfolgreiche } \\
\text { Unternehmen }\end{array}$ & $\begin{array}{c}\text { weniger erfolgreiche } \\
\text { Unternehmen }\end{array}$ \\
\hline nein & $29,2 \%$ & $23,1 \%$ & $31,7 \%$ \\
ja & $70,8 \%$ & $73,9 \%$ & $68,3 \%$ \\
- interne Weiterbildung & $47,1 \%$ & $62,0 \%$ & $40,8 \%$ \\
- externe Weiterbildung & $57,1 \%$ & $66,0 \%$ & $53,3 \%$ \\
- Herstellerschulung & $32,4 \%$ & $42,0 \%$ & $28,3 \%$ \\
\hline
\end{tabular}

\begin{tabular}{|l|c|c|c|c|r|}
\hline Weiterbildung findet statt ... & Gesamt & BG < 50 & 50 $\mathbf{B G}<\mathbf{1 0 0}$ & $\mathbf{1 0 0} \leq \mathbf{B G}<\mathbf{2 0 0}$ & BG $2 \mathbf{2 0 0}$ \\
\hline nein & $29,2 \%$ & $41,0 \%$ & $27,3 \%$ & $16,0 \%$ & $0,0 \%$ \\
ja & $70,8 \%$ & $59,0 \%$ & $72,7 \%$ & $84,0 \%$ & $100,0 \%$ \\
- interne Weiterbildung & $47,1 \%$ & $33,3 \%$ & $46,7 \%$ & $56,0 \%$ & $88,0 \%$ \\
- externe Weiterbildung & $57,1 \%$ & $44,4 \%$ & $63,3 \%$ & $64,0 \%$ & $88,0 \%$ \\
- Herstellerschulung & $32,4 \%$ & $22,2 \%$ & $26,7 \%$ & $52,0 \%$ & $56,0 \%$ \\
\hline
\end{tabular}


Fortsetzung

\begin{tabular}{|l|c|c|c|c|}
\hline Weiterbildung findet statt ... & Gesamt & $\mathbf{U} \leq \mathbf{3 0}$ & $\mathbf{3 0 < U \leq 1 0 0}$ & $\mathbf{U}>\mathbf{1 0 0}$ \\
\hline nein & $29,2 \%$ & $34,8 \%$ & $12,9 \%$ & $8,3 \%$ \\
ja & $70,8 \%$ & $65,2 \%$ & $87,1 \%$ & $91,7 \%$ \\
- interne Weiterbildung & $47,1 \%$ & $38,6 \%$ & $67,7 \%$ & $83,3 \%$ \\
- externe Weiterbildung & $57,1 \%$ & $51,2 \%$ & $71,0 \%$ & $83,3 \%$ \\
- Herstellerschulung & $32,4 \%$ & $27,6 \%$ & $45,2 \%$ & $50,0 \%$ \\
\hline
\end{tabular}

\section{Anlage 22: Entwicklung des F\&E-Anteils am Umsatz zwischen 1990 und 1995 nach Wachstumsklassen}

\begin{tabular}{|c|c|c|c|}
\hline Wachstumsklasse & Gesamt & $\begin{array}{c}\text { besonders erfolgreiche } \\
\text { Unternehmen }\end{array}$ & $\begin{array}{c}\text { weniger erfolgreiche } \\
\text { Unternehmen }\end{array}$ \\
\hline F\&E-Wachstumsklasse 1 & $49,4 \%$ & $42,3 \%$ & $52,4 \%$ \\
F\&E-Wachstumsklasse 2 & $3,4 \%$ & $7,7 \%$ & $1,6 \%$ \\
F\&E-Wachstumsklasse 3 & $26,4 \%$ & $25,0 \%$ & $27,0 \%$ \\
F\&E-Wachstumsklasse 4 & $4,5 \%$ & $1,9 \%$ & $5,6 \%$ \\
F\&E-Wachstumsklasse 5 & $6,2 \%$ & $5,8 \%$ & $6,3 \%$ \\
F\&E-Wachstumsklasse 6 & $1,7 \%$ & $3,8 \%$ & $0,8 \%$ \\
F\&E-Wachstumsklasse 7 & $8,4 \%$ & $13,5 \%$ & $6,3 \%$ \\
\hline
\end{tabular}

\begin{tabular}{|c|c|c|c|c|c|}
\hline Wachstumsklasse & Gesamt & BG<50 & $50 \leq B G<100$ & $100 \leq B G<200$ & $B G \geq 200$ \\
\hline F\&E-Wachstumsklasse 1 & $49,4 \%$ & $65,3 \%$ & $36,4 \%$ & $36,0 \%$ & $20,0 \%$ \\
\hline F\&E-Wachstumsklasse 2 & $3,4 \%$ & $3,2 \%$ & $0,0 \%$ & $8,0 \%$ & $4,0 \%$ \\
\hline F\&E-Wachstumsklasse 3 & $26,4 \%$ & $20,0 \%$ & $33,3 \%$ & $28,0 \%$ & $40,0 \%$ \\
\hline F\&E-Wachstumsklasse 4 & $4,5 \%$ & $1,0 \%$ & $6,1 \%$ & $4,0 \%$ & $16,0 \%$ \\
\hline F\&E-Wachstumsklasse 5 & $6,2 \%$ & $3,2 \%$ & $3,0 \%$ & $12,0 \%$ & $16,0 \%$ \\
\hline F\&E-Wachstumsklasse 6 & $1,7 \%$ & $1,0 \%$ & $0,0 \%$ & $4,0 \%$ & $4,0 \%$ \\
\hline F\&E-Wachstumsklasse 7 & $8,4 \%$ & $6,3 \%$ & $21,2 \%$ & $8,0 \%$ & $0,0 \%$ \\
\hline
\end{tabular}


Fortsetzung

\begin{tabular}{|c|c|c|c|c|}
\hline Wachstumsklasse & Gesamt & $\mathbf{U} \leq \mathbf{3 0}$ & $30<\mathrm{U} \leq 100$ & $U>100$ \\
\hline F\&E-Wachstumsklasse 1 & $49,4 \%$ & $56,3 \%$ & $29,0 \%$ & $25,0 \%$ \\
\hline F\&E-Wachstumsklasse 2 & $3,4 \%$ & $3,0 \%$ & $6,5 \%$ & $0,0 \%$ \\
\hline F\&E-Wachstumsklasse 3 & $26,4 \%$ & $21,4 \%$ & $38,7 \%$ & $50,0 \%$ \\
\hline F\&E-Wachstumsklasse 4 & $4,5 \%$ & $3,0 \%$ & $6,5 \%$ & $16,7 \%$ \\
\hline F\&E-Wachstumsklasse 5 & $6,2 \%$ & $5,2 \%$ & $9,6 \%$ & $8,3 \%$ \\
\hline F\&E-Wachstumsklasse 6 & $1,7 \%$ & $1,5 \%$ & $3,2 \%$ & $0,0 \%$ \\
\hline F\&E-Wachstumsklasse 7 & $8,4 \%$ & $9,6 \%$ & $6,5 \%$ & $0,0 \%$ \\
\hline
\end{tabular}

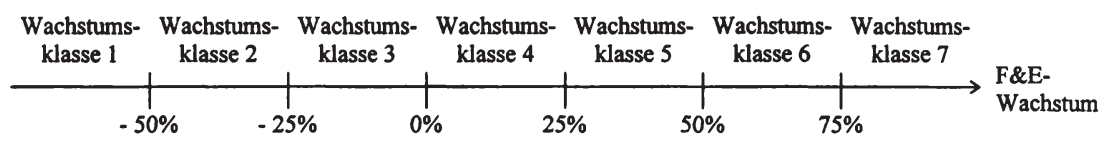

\section{Anlage 23: Im Unternehmen ausgeführte oder von anderen Unternehmen bezogene Unternehmensfunktionen}

\begin{tabular}{|l|c|c|c|}
\hline \multirow{2}{*}{ Unternehmensfunktionen } & \multicolumn{2}{|c|}{ Unternehmensfunktionen werden im Unternehmen ausgeftihrt } \\
& Gesamt & $\begin{array}{r}\text { vesonders erfolgreiche } \\
\text { Unternehmen }\end{array}$ & $\begin{array}{r}\text { weniger erfolgreiche } \\
\text { Unternehmen }\end{array}$ \\
\hline Forschung und Entwicklung & $68,5 \%$ & $78,9 \%$ & $64,3 \%$ \\
Konstruktion und Gestaltung & $75,3 \%$ & $78,9 \%$ & $73,8 \%$ \\
Produktionsplanung & $94,9 \%$ & $94,2 \%$ & $95,2 \%$ \\
Vertrieb und Verkauf & $94,9 \%$ & $98,1 \%$ & $93,7 \%$ \\
Qualitätssicherung & $92,7 \%$ & $90,4 \%$ & $93,7 \%$ \\
Umweltmanagement & $79,8 \%$ & $86,5 \%$ & $77,0 \%$ \\
Investitions- und Finanzplanung & $94,9 \%$ & $98,1 \%$ & $93,7 \%$ \\
Kostenrechnung & $91,6 \%$ & $92,3 \%$ & $91,3 \%$ \\
\hline
\end{tabular}


Fortsetzung

\begin{tabular}{|c|c|c|c|c|}
\hline \multirow[b]{2}{*}{ Unternehmensfunktionen } & \multicolumn{2}{|c|}{$\begin{array}{c}\text { von anderen Betrieben } \\
\text { des Unternehmens bezogen }\end{array}$} & \multicolumn{2}{|c|}{ von anderen Unternehmen gekauft } \\
\hline & $\begin{array}{c}\text { besonders } \\
\text { erfolgreiche } \\
\text { Unternehmen }\end{array}$ & $\begin{array}{c}\text { weniger } \\
\text { erfolgreiche } \\
\text { Unternehmen }\end{array}$ & $\begin{array}{c}\text { besonders } \\
\text { erfolgreiche } \\
\text { Unternehmen }\end{array}$ & $\begin{array}{c}\text { weniger } \\
\text { erfolgreiche } \\
\text { Unternehmen }\end{array}$ \\
\hline Forschung und Entwicklung & $3,9 \%$ & $9,6 \%$ & $26,9 \%$ & $24,8 \%$ \\
\hline Konstruktion und Gestaltung & $3,9 \%$ & $6,4 \%$ & $21,2 \%$ & $19,2 \%$ \\
\hline Produktionsplanung & $0,0 \%$ & $0,8 \%$ & $0,0 \%$ & $2,4 \%$ \\
\hline Vertrieb und Verkauf & $5,8 \%$ & $5,6 \%$ & $2,0 \%$ & $8,8 \%$ \\
\hline Qualitätssicherung & $1,9 \%$ & $1,6 \%$ & $13,5 \%$ & $48 \%$ \\
\hline Umweltmanagement & $5,8 \%$ & $0,8 \%$ & $7,8 \%$ & $4,8 \%$ \\
\hline Investitions- und Finanzplanung & $0,0 \%$ & $4,0 \%$ & $9,6 \%$ & $2,4 \%$ \\
\hline Kostenrechnung & $3,9 \%$ & $4,0 \%$ & $9,8 \%$ & $4,0 \%$ \\
\hline
\end{tabular}

\begin{tabular}{|c|c|c|c|c|c|}
\hline \multirow[b]{2}{*}{ Unternehmensfunktionen } & \multicolumn{5}{|c|}{ Unternehmensfunktionen werden im Unternehmen ausgefuhrt } \\
\hline & Gesamt & BG $<50$ & $50 \leq B G<100$ & $100 \leq B G<200$ & BG $\geq 200$ \\
\hline Forschung und Entwicklung & $68,5 \%$ & $60,0 \%$ & $78,8 \%$ & $72,0 \%$ & $84,0 \%$ \\
\hline Konstruktion und Gestaltung & $75,3 \%$ & $69,5 \%$ & $78,8 \%$ & $80,0 \%$ & $88,0 \%$ \\
\hline Produktionsplanung & $94,9 \%$ & $93,7 \%$ & $93,9 \%$ & $96,0 \%$ & $100,0 \%$ \\
\hline Vertrieb und Verkauf & $94,9 \%$ & $95,8 \%$ & $93,9 \%$ & $100,0 \%$ & $88,0 \%$ \\
\hline Qualitătssicherung & $92,7 \%$ & $92,6 \%$ & $84,9 \%$ & $96,0 \%$ & $100,0 \%$ \\
\hline Umweltmanagement & $79,8 \%$ & $81,1 \%$ & $66,7 \%$ & $80,0 \%$ & $92,0 \%$ \\
\hline Investitions- und Finanzplanung & $94,9 \%$ & $94,7 \%$ & $93,9 \%$ & $96,0 \%$ & $96,0 \%$ \\
\hline Kostenrechnung & $91,6 \%$ & $92,6 \%$ & $90,9 \%$ & $84,0 \%$ & $96,0 \%$ \\
\hline
\end{tabular}

\begin{tabular}{|l|c|c|c|c|}
\hline \multirow{2}{*}{ Unternehmensfunktionen } & \multicolumn{4}{|c|}{ Unternehmensfunktionen werden im Unternehmen ausgeführt } \\
& Gesamt & $\mathbf{U} \leq \mathbf{3 0}$ & $\mathbf{3 0 < U \leq 1 0 0}$ & U>100 \\
\hline Forschung und Entwicklung & $68,5 \%$ & $64,4 \%$ & $77,4 \%$ & $91,7 \%$ \\
Konstruktion und Gestaltung & $75,3 \%$ & $71,9 \%$ & $87,1 \%$ & $83,3 \%$ \\
Produktionsplanung & $94,9 \%$ & $94,1 \%$ & $96,8 \%$ & $100,0 \%$ \\
Vertrieb und Verkauf & $94,9 \%$ & $95,6 \%$ & $93,6 \%$ & $91,7 \%$ \\
Qualitätssicherung & $92,7 \%$ & $91,1 \%$ & $96,8 \%$ & $100,0 \%$ \\
Umweltmanagement & $79,8 \%$ & $78,5 \%$ & $77,4 \%$ & $100,0 \%$ \\
Investitions- und Finanzplanung & $94,9 \%$ & $94,1 \%$ & $96,8 \%$ & $100,0 \%$ \\
Kostenrechnung & $91,6 \%$ & $91,1 \%$ & $90,3 \%$ & $100,0 \%$ \\
\hline
\end{tabular}


Anlage 24: Anteile der Produkte in den einzelnen Marktzyklusphasen

\begin{tabular}{|c|c|c|c|c|c|}
\hline Marktphase & Gesamt & \multicolumn{2}{|c|}{$\begin{array}{c}\text { besonders erfolgreiche } \\
\text { Unternehmen }\end{array}$} & \multicolumn{2}{|c|}{$\begin{array}{c}\text { weniger erfolgreiche } \\
\text { Unternehmen }\end{array}$} \\
\hline Markteinführungsphase & $10,1 \%$ & $13,8 \%$ & & $8,8 \%$ & \\
\hline Wachstumsphase & $20,9 \% 31,0 \%$ & $31,9 \%$ & $45,7 \%$ & $17,0 \%$ & $25,8 \%$ \\
\hline Reifephase & $46,1 \%$ & $40,2 \%$ & & $48,2 \%$ & \\
\hline Schrumpfungsphase & $22,9 \% \quad 69,0 \%$ & $14,1 \%$ & $54,3 \%$ & $26,0 \%$ & $74,2 \%$ \\
\hline
\end{tabular}

\begin{tabular}{|c|c|c|c|c|c|}
\hline Marktphase & Gesamt & BG $<50$ & $50 \leq B G<100$ & $100 \leq B G<200$ & $B G \geq 200$ \\
\hline Markteinführungsphase & $10,1 \%$ & $8,6 \%$ & $13,6 \%$ & $9,8 \%$ & $11,2 \%$ \\
\hline Wachstumsphase & $20,9 \% 31,0 \%$ & $20,0 \% 28,6 \%$ & $19,6 \% 33,2 \%$ & $20,2 \% 30,0 \%$ & $26,0 \% 37,2 \%$ \\
\hline Reifephase & $46,1 \%$ & $44,4 \%$ & $47,0 \%$ & $48,7 \%$ & $48,8 \%$ \\
\hline Schrumpfungsphase & $22,9 \% \quad 69,0 \%$ & $27,0 \% 71,4 \%$ & $19,8 \% 66,8 \%$ & $21,3 \% 70,0 \%$ & $14,0 \% 62,8 \%$ \\
\hline
\end{tabular}

\begin{tabular}{|c|c|c|c|c|c|c|c|}
\hline Marktphase & Gesamt & \multicolumn{2}{|c|}{$\mathrm{U} \leq \mathbf{3 0}$} & \multicolumn{2}{|c|}{$30<\mathrm{U} \leq 100$} & \multicolumn{2}{|c|}{$\mathrm{U}>\mathbf{1 0 0}$} \\
\hline Markteinführungsphase & $10,1 \%$ & $9,5 \%$ & & $10,7 \%$ & & $14,5 \%$ & \\
\hline Wachstumsphase & $20,9 \% 31,0 \%$ & $21,0 \%$ & $30,5 \%$ & $19,1 \%$ & $29,8 \%$ & $24,5 \%$ & $39,0 \%$ \\
\hline Reifephase & $46,1 \%$ & $43,5 \%$ & & $56,2 \%$ & & $48,7 \%$ & \\
\hline Schrumpfungsphase & $22,9 \% \quad 69,0 \%$ & $26,2 \%$ & $69,5 \%$ & $14,0 \%$ & $70,2 \%$ & $12,3 \%$ & $51,0 \%$ \\
\hline
\end{tabular}


Anlage 25: Gründe für die Einführung von Innovationen

\begin{tabular}{l|c|c|c|}
\hline \multicolumn{1}{|c|}{ Innovationsgründe } & Gesamt & $\begin{array}{c}\text { besonders erfolgreiche } \\
\text { Unternehmen }\end{array}$ & $\begin{array}{c}\text { weniger erfolgreiche } \\
\text { Unternehmen }\end{array}$ \\
\hline Absatzchancen & $59,8 \%$ & $66,7 \%$ & $56,0 \%$ \\
Kostensenkungspotentiale & $76,9 \%$ & $71,4 \%$ & $80,0 \%$ \\
Erschließung neuer Mărkte & $29,9 \%$ & $33,3 \%$ & $28,0 \%$ \\
Absatzprobleme bei vorhandenen & $17,9 \%$ & $9,5 \%$ & $22,7 \%$ \\
Produkten & $24,8 \%$ & $26,2 \%$ & $24,0 \%$ \\
Umweltschutzauflagen/ -gesetze & $69,2 \%$ & $64,3 \%$ & $72,0 \%$ \\
Verbesserung der Produktqualităt & $26,5 \%$ & $26,2 \%$ & $26,7 \%$ \\
zeringerer Ressourcen- oder & $18,8 \%$ & $16,7 \%$ & $20,0 \%$ \\
Materialverbrauch & & & \\
geringerer Energieverbrauch & & & \\
\hline
\end{tabular}

\begin{tabular}{|c|c|c|c|c|c|}
\hline Innovationsgrunde & Gesamt & BG $<50$ & $50 \leq B G<100$ & $100 \leq B G<200$ & BG 2200 \\
\hline Absatzchancen & $59,8 \%$ & $61,7 \%$ & $63,2 \%$ & $52,9 \%$ & $57,1 \%$ \\
\hline Kostensenkungspotentiale & $76,9 \%$ & $70,0 \%$ & $73,7 \%$ & $82,4 \%$ & $95,2 \%$ \\
\hline Erschließung neuer Mărkte & $29,9 \%$ & $31,7 \%$ & $21,1 \%$ & $29,4 \%$ & $33,3 \%$ \\
\hline $\begin{array}{l}\text { Absatzprobleme bei vorhandenen } \\
\text { Produkten }\end{array}$ & $17,9 \%$ & $21,7 \%$ & $10,5 \%$ & $11,8 \%$ & $19,1 \%$ \\
\hline Umweltschutzauflagen/-gesetze & $24,8 \%$ & $28,3 \%$ & $26,3 \%$ & $17,7 \%$ & $19,1 \%$ \\
\hline Verbesserung der Produktqualität & $69,2 \%$ & $63,3 \%$ & $63,2 \%$ & $70,6 \%$ & $90,5 \%$ \\
\hline $\begin{array}{l}\text { zeringerer Ressourcen- oder } \\
\text { Materialverbrauch }\end{array}$ & $26,5 \%$ & $13,3 \%$ & $47,4 \%$ & $23,5 \%$ & $47,6 \%$ \\
\hline jeringerer Energieverbrauch & $18,8 \%$ & $20,0 \%$ & $10,5 \%$ & $23,5 \%$ & $19,1 \%$ \\
\hline
\end{tabular}

\begin{tabular}{|c|c|c|c|c|}
\hline Innovationsgrinde & Gesamt & $\mathbf{U} \leq \mathbf{3 0}$ & $30<\mathrm{U} \leq 100$ & $\mathrm{U}>100$ \\
\hline Absatzchancen & $59,8 \%$ & $60,0 \%$ & $58,3 \%$ & $62,5 \%$ \\
\hline Kostensenkungspotentiale & $76,9 \%$ & $69,4 \%$ & $95,8 \%$ & $100,0 \%$ \\
\hline Erschließung neuer Mărkte & $29,9 \%$ & $31,8 \%$ & $16,7 \%$ & $50,0 \%$ \\
\hline $\begin{array}{l}\text { Absatzprobleme bei vorhandenen } \\
\text { Produkten }\end{array}$ & $17,9 \%$ & $18,8 \%$ & $12,5 \%$ & $25,0 \%$ \\
\hline Jmweltschutzauflagen/ -gesetze & $24,8 \%$ & $25,9 \%$ & $20,8 \%$ & $25,0 \%$ \\
\hline Verbesserung der Produktqualität & $69,2 \%$ & $63,5 \%$ & $83,3 \%$ & $87,5 \%$ \\
\hline $\begin{array}{l}\text { jeringerer Ressourcen- oder } \\
\text { Materialverbrauch }\end{array}$ & $26,5 \%$ & $20,0 \%$ & $37,5 \%$ & $62,5 \%$ \\
\hline z̧eringerer Energieverbrauch & $18,8 \%$ & $17,7 \%$ & $25,0 \%$ & $12,5 \%$ \\
\hline
\end{tabular}


Anlage 26: Formen der Einführung neuer Produkte und Prozesse

\begin{tabular}{|l|c|c|c|}
\hline \multicolumn{1}{|c|}{ Formen } & Gesamt & $\begin{array}{c}\text { besonders erfolgreiche } \\
\text { Unternehmen }\end{array}$ & $\begin{array}{c}\text { weniger erfolgreiche } \\
\text { Unternehmen }\end{array}$ \\
\hline eigenständig & $78,1 \%$ & $82,7 \%$ & $75,8 \%$ \\
mit anderen Unternehmen & $19,0 \%$ & $25,5 \%$ & $15,6 \%$ \\
mit priv. Unternehmensberatern & $9,5 \%$ & $5,9 \%$ & $11,5 \%$ \\
bzw. Ingenieurbüros & $4,1 \%$ & $3,9 \%$ & $4,2 \%$ \\
mit außeruniversitären Forschungs- & & $3,9 \%$ & $6,3 \%$ \\
instituten & $5,4 \%$ & $0,0 \%$ & $3,1 \%$ \\
mit Hochschulinstituten & $2,0 \%$ & $2,0 \%$ & $1,0 \%$ \\
mit Transfereinrichtungen & $1,4 \%$ & & \\
mit RKW &
\end{tabular}

\begin{tabular}{|c|c|c|c|c|c|}
\hline Formen & Gesamt & $\mathbf{B G}<50$ & $50 \leq B G<100$ & $100 \leq \mathrm{BG}<200$ & $\mathbf{B G} \geq \mathbf{2 0 0}$ \\
\hline eigenstăndig & $78,1 \%$ & $75,0 \%$ & $81,5 \%$ & $73,9 \%$ & $88,0 \%$ \\
\hline mit anderen Unternehmen & $19,0 \%$ & $19,2 \%$ & $11,5 \%$ & $13,0 \%$ & $32,0 \%$ \\
\hline $\begin{array}{l}\text { mit priv. Unternehmensberatern } \\
\text { bzw. Ingenieurbüros }\end{array}$ & $9,5 \%$ & $6,9 \%$ & $7,7 \%$ & $17,4 \%$ & $12,0 \%$ \\
\hline $\begin{array}{l}\text { mit außeruniversităren Forschungs- } \\
\text { instituten }\end{array}$ & $4,1 \%$ & $0,0 \%$ & $3,9 \%$ & $0,0 \%$ & $20,0 \%$ \\
\hline mit Hochschulinstituten & $5,4 \%$ & $1,4 \%$ & $7,7 \%$ & $0,0 \%$ & $20,0 \%$ \\
\hline mit Transfereinrichtungen & $2,0 \%$ & $1,4 \%$ & $0,0 \%$ & $4,4 \%$ & $4,0 \%$ \\
\hline mit RKW & $1,4 \%$ & $0,0 \%$ & $0,0 \%$ & $4,4 \%$ & $4,0 \%$ \\
\hline
\end{tabular}

\begin{tabular}{|l|c|c|c|c|}
\hline \multicolumn{1}{|c|}{ Formen } & Gesamt & U $\mathbf{3 0}$ & $\mathbf{3 0 < U \leq 1 0 0}$ & $\mathbf{U}>\mathbf{1 0 0}$ \\
\hline eigenstăndig & $78,1 \%$ & $75,2 \%$ & $83,3 \%$ & $91,7 \%$ \\
mit anderen Unternehmen & $19,0 \%$ & $15,2 \%$ & $16,7 \%$ & $58,3 \%$ \\
mit priv. Unternehmensberatern & $9,5 \%$ & $8,6 \%$ & $10,0 \%$ & $16,7 \%$ \\
bzw. Ingenieurbüros & $4,1 \%$ & $1,9 \%$ & $3,3 \%$ & $25,0 \%$ \\
mit außeruniversitären Forschungs- & & $1,9 \%$ & $10,0 \%$ & $25,0 \%$ \\
instituten & $5,4 \%$ & $1,0 \%$ & $3,3 \%$ & $8,3 \%$ \\
mit Hochschulinstituten & $2,0 \%$ & $0,0 \%$ & $6,7 \%$ & $0,0 \%$ \\
mit Transfereinrichtungen & $1,4 \%$ & & & \\
mit RKW & &
\end{tabular}




\section{Anlage 27: Entwicklung des Exportanteils am Umsatz zwischen 1990 und 1995 nach Wachstumsklassen}

\begin{tabular}{|c|c|c|c|}
\hline Wachstumsklasse & Gesamt & $\begin{array}{c}\text { besonders erfolgreiche } \\
\text { Unternehmen }\end{array}$ & $\begin{array}{c}\text { weniger erfolgreiche } \\
\text { Unternehmen }\end{array}$ \\
\hline Exportwachstumsklasse 1 & $39,3 \%$ & $44,2 \%$ & $37,3 \%$ \\
Exportwachstumsklasse 2 & $6,2 \%$ & $3,9 \%$ & $7,1 \%$ \\
Exportwachstumsklasse 3 & $19,1 \%$ & $9,6 \%$ & $23,0 \%$ \\
Exportwachstumsklasse 4 & $14,6 \%$ & $19,2 \%$ & $12,7 \%$ \\
Exportwachstumsklasse 5 & $8,4 \%$ & $11,5 \%$ & $7,1 \%$ \\
Exportwachstumsklasse 6 & $2,3 \%$ & $3,9 \%$ & $1,6 \%$ \\
Exportwachstumsklasse 7 & $10,1 \%$ & $7,7 \%$ & $11,2 \%$ \\
\hline
\end{tabular}

\begin{tabular}{|c|r|r|r|r|r|}
\hline Wachstumsklasse & Gesamt & BG<50 & 50 $\mathbf{B G}<\mathbf{1 0 0}$ & $\mathbf{1 0 0} \leq \mathbf{B G}<\mathbf{2 0 0}$ & $\mathbf{B G} 2 \mathbf{2 0 0}$ \\
\hline Exportwachstumsklasse 1 & $39,3 \%$ & $50,5 \%$ & $24,2 \%$ & $44,0 \%$ & $12,0 \%$ \\
Exportwachstumsklasse 2 & $6,2 \%$ & $6,3 \%$ & $9,1 \%$ & $4,0 \%$ & $4,0 \%$ \\
Exportwachstumsklasse 3 & $19,1 \%$ & $14,8 \%$ & $36,3 \%$ & $12,0 \%$ & $20,0 \%$ \\
Exportwachstumsklasse 4 & $14,6 \%$ & $10,5 \%$ & $6,1 \%$ & $16,0 \%$ & $40,0 \%$ \\
Exportwachstumsklasse 5 & $8,4 \%$ & $8,4 \%$ & $9,1 \%$ & $4,0 \%$ & $12,0 \%$ \\
Exportwachstumsklasse 6 & $2,3 \%$ & $0,0 \%$ & $6,1 \%$ & $4,0 \%$ & $4,0 \%$ \\
Exportwachstumsklasse 7 & $10,1 \%$ & $9,5 \%$ & $9,1 \%$ & $16,0 \%$ & $\mathbf{8 , 0} \%$ \\
\hline
\end{tabular}

\begin{tabular}{|c|r|r|r|r|}
\hline Wachstumsklasse & Gesamt & $\mathbf{U} \leq \mathbf{3 0}$ & $\mathbf{3 0 <} \mathbf{0} \mathbf{1 0 0}$ & $\mathbf{U}>\mathbf{1 0 0}$ \\
\hline Exportwachstumsklasse 1 & $39,3 \%$ & $45,2 \%$ & $25,8 \%$ & $8,3 \%$ \\
Exportwachstumsklasse 2 & $6,2 \%$ & $6,7 \%$ & $3,2 \%$ & $8,3 \%$ \\
Exportwachstumsklasse 3 & $19,1 \%$ & $17,0 \%$ & $32,2 \%$ & $8,3 \%$ \\
Exportwachstumsklasse 4 & $14,6 \%$ & $11,8 \%$ & $9,7 \%$ & $58,4 \%$ \\
Exportwachstumsklasse 5 & $8,4 \%$ & $8,2 \%$ & $6,5 \%$ & $16,7 \%$ \\
Exportwachstumsklasse 6 & $2,3 \%$ & $1,5 \%$ & $6,5 \%$ & $0,0 \%$ \\
Exportwachstumsklasse 7 & $10,1 \%$ & $9,6 \%$ & $16,1 \%$ & $0,0 \%$ \\
\hline
\end{tabular}

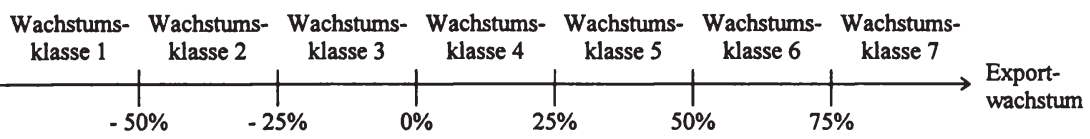


Anlage 28: Entwicklung des Exportes zwischen 1990 und 1995

\begin{tabular}{|l|c|c|c|}
\hline \multicolumn{1}{|c|}{ Exportentwicklung } & Gesamt & $\begin{array}{c}\text { besonders erfolgreiche } \\
\text { Unternehmen }\end{array}$ & $\begin{array}{c}\text { weniger erfolgreiche } \\
\text { Unternehmen }\end{array}$ \\
\hline Anstieg der Exportquote & $39,9 \%$ & $48,1 \%$ & $36,5 \%$ \\
Konstante Exportquote & $39,3 \%$ & $44,2 \%$ & $37,3 \%$ \\
Abnahme der Exportquote & $20,8 \%$ & $7,7 \%$ & $26,2 \%$ \\
\hline
\end{tabular}

\begin{tabular}{|l|c|c|c|c|c|}
\hline \multicolumn{1}{|c|}{ Exportentwicklung } & Gesamt & BG $<\mathbf{5 0}$ & 50 $\mathbf{B G}<\mathbf{1 0 0}$ & $\mathbf{1 0 0} \leq \mathbf{B G}<\mathbf{2 0 0}$ & BG $\geq \mathbf{2 0 0}$ \\
\hline Anstieg der Exportquote & $39,9 \%$ & $35,8 \%$ & $30,3 \%$ & $40,0 \%$ & $68,0 \%$ \\
Konstante Exportquote & $39,3 \%$ & $45,3 \%$ & $42,4 \%$ & $40,0 \%$ & $12,0 \%$ \\
Abnahme der Exportquote & $20,8 \%$ & $18,9 \%$ & $27,3 \%$ & $20,0 \%$ & $20,0 \%$ \\
\hline
\end{tabular}

\begin{tabular}{|l|c|c|c|c|}
\hline \multicolumn{1}{|c|}{ Exportentwicklung } & Gesamt & $\mathbf{U} \leq \mathbf{3 0}$ & $\mathbf{3 0 < U \leq 1 0 0}$ & $\mathbf{U > 1 0 0}$ \\
\hline Anstieg der Exportquote & $39,9 \%$ & $36,3 \%$ & $41,9 \%$ & $75,0 \%$ \\
Konstante Exportquote & $39,3 \%$ & $41,5 \%$ & $38,7 \%$ & $16,7 \%$ \\
Abnahme der Exportquote & $20,8 \%$ & $22,2 \%$ & $19,4 \%$ & $8,3 \%$ \\
\hline
\end{tabular}


Anlage 29: Entwicklung der Anzahl der Beschäftigten

\begin{tabular}{|l|c|c|c|}
\hline & \multicolumn{3}{|c|}{ Anzahl der Beschäftigten (Anzahl der Unternehmen) } \\
& Gesamt & $\begin{array}{c}\text { besonders erfolgreiche } \\
\text { Unternehmen }\end{array}$ & $\begin{array}{c}\text { weniger erfolgreiche } \\
\text { Unternehmen }\end{array}$ \\
\hline 31.12 .90 & $22372(174)$ & $7385(51)$ & $14987(123)$ \\
31.12 .95 & $20066(175)$ & $7796(52)$ & $12270(123)$ \\
\hline Verănderung & $-10,3 \%$ & $+5,6 \%$ & $-18,1 \%$ \\
\hline
\end{tabular}

\begin{tabular}{|c|c|c|c|c|c|}
\hline \multirow[b]{2}{*}{ Jahr } & \multicolumn{5}{|c|}{ Anzahl der Beschäftigten (Anzahl der Unternehmen) } \\
\hline & Gesamt & BG $<50$ & $50 \leq B G<100$ & $100 \leq B G<200$ & $\mathbf{B G} \geq \mathbf{2 0 0}$ \\
\hline 31.12 .90 & $22372(174)$ & $3158(91)$ & $2699(33)$ & $3642(25)$ & $12873(25)$ \\
\hline 31.12 .95 & $20066(175)$ & $2606(92)$ & $2411(33)$ & $3647(25)$ & $11582(25)$ \\
\hline Veränderung & $-10,3 \%$ & $-17,5 \%$ & $-10,7 \%$ & $+0,1 \%$ & $-10,0 \%$ \\
\hline
\end{tabular}

\begin{tabular}{|l|c|c|c|c|}
\hline \multirow{2}{*}{ Jahr } & \multicolumn{4}{|c|}{ Anzahl der Beschäftigten (Anzahl der Unternehmen) } \\
& Gesamt & U 30 & $30<U \leq 100$ & U>100 \\
\hline 31.12 .90 & $22372(174)$ & $8097(132)$ & $5569(30)$ & $8706(12)$ \\
31.12 .95 & $20066(175)$ & $6865(133)$ & $5546(30)$ & $7655(12)$ \\
\hline Verănderung & $-10,3 \%$ & $-15,2 \%$ & $-0,4 \%$ & $-12,1 \%$ \\
\hline
\end{tabular}

\section{Anlage 30: Nutzung staatlicher Mittel zur Förderung von Umweltschutzmaßnahmen}

\begin{tabular}{|l|c|}
\hline \multicolumn{1}{|c|}{ Nutzung staatlicher Mittel } & Gesamt \\
\hline ja bzw. beantragt & $10,9 \%$ \\
nein, weil ... & $89,1 \%$ \\
- Investitionen stets aus eigenen Mitteln getătigt werden & $55,7 \%$ \\
- Fördermöglichkeiten unbekannt & $31,6 \%$ \\
- Fördervoraussetzungen und -konditionen unbekannt & $22,4 \%$ \\
- Mőglichkeiten in Umweltschutz zu investieren unbekannt & $11,5 \%$ \\
- Einschătzung der Attraktivităt der Förderung zu schwierig & $20,1 \%$ \\
\hline
\end{tabular}




\section{Anlage 31: Ablaufschema des EG-Öko-Audits}

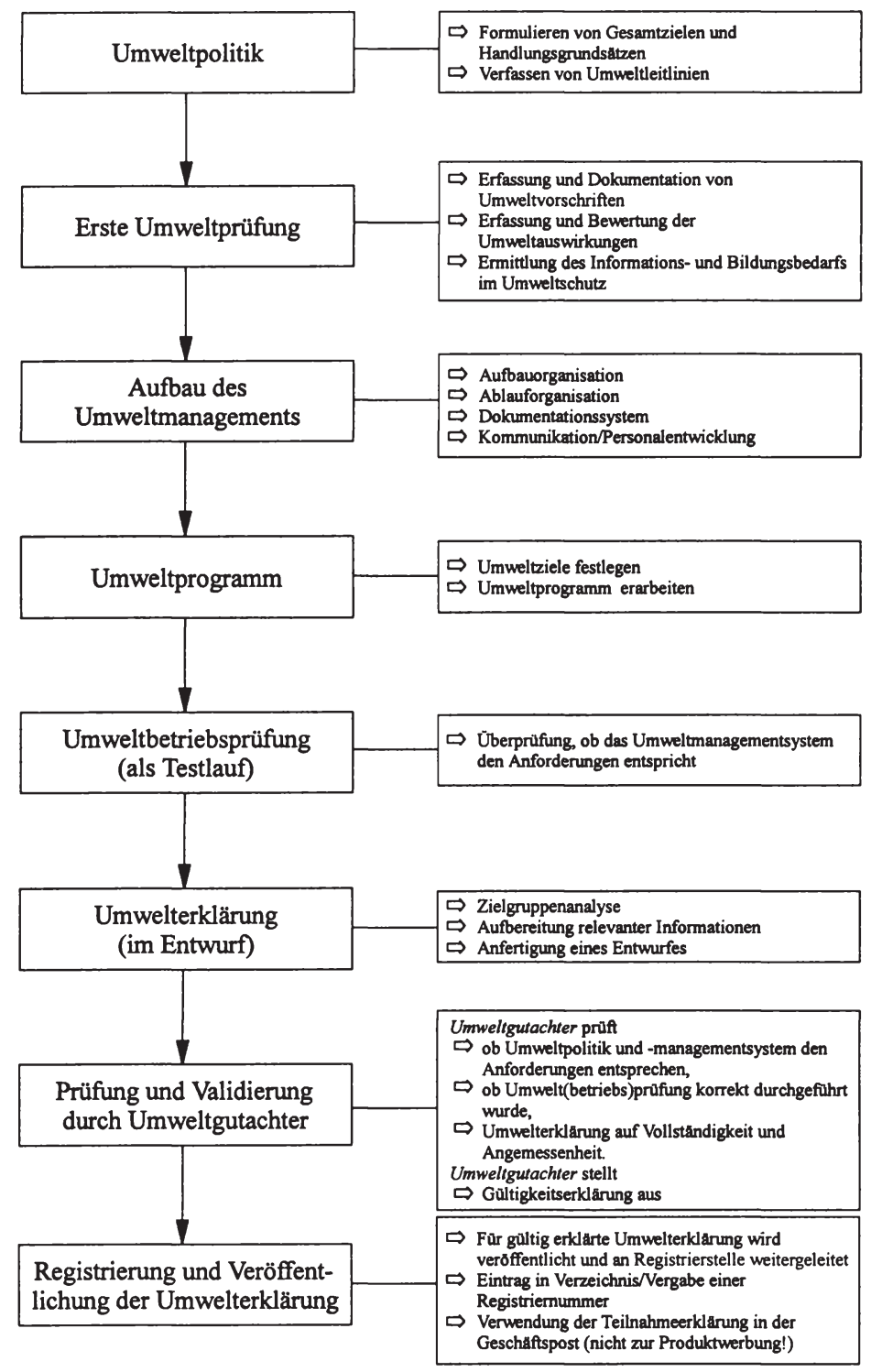

Quelle: $\quad$ Fichter, K. (1995), S. 56. 
Anlage 32: Nutzung von Instrumenten des Umweltcontrolling

\begin{tabular}{|l|c|c|c|}
\hline Umweltcontrollinginstrumente & Gesamt & $\begin{array}{c}\text { besonders erfolgreiche } \\
\text { Unternehmen }\end{array}$ & $\begin{array}{c}\text { weniger erfolgreiche } \\
\text { Unternehmen }\end{array}$ \\
\hline nein & $90,3 \%$ & $90,4 \%$ & $90,3 \%$ \\
ja, und zwar ... & $9,7 \%$ & $9,6 \%$ & $9,7 \%$ \\
- Ökobilanzen & $1,9 \%$ & $2,2 \%$ & $1,8 \%$ \\
- EG-Öko-Audit & $1,9 \%$ & $0,0 \%$ & $2,8 \%$ \\
- Umweltberichte & $6,5 \%$ & $\mathbf{8 , 7} \%$ & $5,5 \%$ \\
- Sozialbilanzen & $\mathbf{0 , 7 \%}$ & $0,0 \%$ & $0,9 \%$ \\
\hline
\end{tabular}

\begin{tabular}{|c|c|c|c|c|c|}
\hline Umweltcontrollinginstrumente & Gesamt & BG $<50$ & $50 \leq B G<100$ & $100 \leq B G<200$ & BG 2200 \\
\hline nein & $90,3 \%$ & $92,5 \%$ & $93,9 \%$ & $96,0 \%$ & $72,0 \%$ \\
\hline ja, und zwar ... & $9,7 \%$ & $7,5 \%$ & $6,1 \%$ & $4,0 \%$ & $28,0 \%$ \\
\hline - Ökobilanzen & $1,9 \%$ & $1,2 \%$ & $0,0 \%$ & $0,0 \%$ & $9,5 \%$ \\
\hline - EG-Öko-Audit & $1,9 \%$ & $1,2 \%$ & $0,0 \%$ & $4,8 \%$ & $4,8 \%$ \\
\hline - Umweltberichte & $6,5 \%$ & $2,4 \%$ & $6,5 \%$ & $4,8 \%$ & $23,8 \%$ \\
\hline - Sozialbilanzen & $0,7 \%$ & $1,2 \%$ & $0,0 \%$ & $0,0 \%$ & $0,0 \%$ \\
\hline
\end{tabular}

\begin{tabular}{|l|r|r|r|r|}
\hline Umweltcontrollinginstrumente & Gesamt & $\mathbf{U} \leq \mathbf{3 0}$ & $\mathbf{3 0 < U \leq 1 0 0}$ & $\mathbf{U}>\mathbf{1 0 0}$ \\
\hline nein & $90,3 \%$ & $91,7 \%$ & $96,8 \%$ & $58,3 \%$ \\
ja, und zwar ... & $9,7 \%$ & $8,3 \%$ & $3,2 \%$ & $41,7 \%$ \\
- Ökobilanzen & $1,9 \%$ & $0,8 \%$ & $0,0 \%$ & $20,0 \%$ \\
- EG-Öko-Audit & $1,9 \%$ & $1,7 \%$ & $0,0 \%$ & $10,0 \%$ \\
- Umweltberichte & $6,5 \%$ & $5,0 \%$ & $0,0 \%$ & $40,0 \%$ \\
- Sozialbilanzen & $0,7 \%$ & $0,8 \%$ & $0,0 \%$ & $0,0 \%$ \\
\hline
\end{tabular}


Anlage 33: Nutzung von Emissionsvermeidungstechnologien

\begin{tabular}{|c|c|c|c|c|c|}
\hline \multirow{2}{*}{$\begin{array}{c}\text { Emissionsvermeidungs- } \\
\text { technologien }\end{array}$} & \multicolumn{5}{|c|}{ im Bereich ... } \\
\hline & Luft & Wasser & Boden & feste Abfälle & Lärm \\
\hline additive Technologien & & & & & \\
\hline $\begin{array}{l}\text { besonders erfolgreiche } \\
\text { Unternehmen }\end{array}$ & $79,0 \%$ & $56,3 \%$ & $0,0 \%$ & $44,4 \%$ & $42,9 \%$ \\
\hline $\begin{array}{l}\text { weniger erfolgreiche } \\
\text { Unternehmen }\end{array}$ & $47,8 \%$ & $80,0 \%$ & $100,0 \%$ & $44,3 \%$ & $33,3 \%$ \\
\hline integrierte Technologien & & & & & \\
\hline $\begin{array}{l}\text { besonders erfolgreiche } \\
\text { Unternehmen }\end{array}$ & $21,0 \%$ & $43,7 \%$ & $100,0 \%$ & $55,6 \%$ & $57,1 \%$ \\
\hline $\begin{array}{l}\text { weniger erfolgreiche } \\
\text { Unternehmen }\end{array}$ & $52,2 \%$ & $20,0 \%$ & $0,0 \%$ & $55,7 \%$ & $66,7 \%$ \\
\hline
\end{tabular}

\begin{tabular}{|l|r|r|r|r|r|}
\hline \multicolumn{1}{|c|}{$\begin{array}{c}\text { Emissionsvermeidungs- } \\
\text { technologien }\end{array}$} & Luft & Wasser & Boden & feste Abralle & Lärm \\
\hline additive Technologien & & & & & \\
BG $<50$ & & & & & \\
$50 \leq \mathrm{BG}<100$ & $62,1 \%$ & $72,0 \%$ & $50,0 \%$ & $50,0 \%$ & $24,0 \%$ \\
$100 \leq \mathrm{BG}<200$ & $69,2 \%$ & $88,9 \%$ & $0,0 \%$ & $42,9 \%$ & $57,1 \%$ \\
BG 2200 & $36,4 \%$ & $81,8 \%$ & $100,0 \%$ & $40,0 \%$ & $28,6 \%$ \\
\hline integrierte Technologien & $50,0 \%$ & $54,5 \%$ & $100,0 \%$ & $33,3 \%$ & $54,5 \%$ \\
BG $<50$ & & & & & \\
$50 \leq \mathrm{BG}<100$ & $37,9 \%$ & $28,0 \%$ & $50,0 \%$ & $50,0 \%$ & $76,0 \%$ \\
$100 \leq \mathrm{BG}<200$ & $30,8 \%$ & $11,1 \%$ & $100,0 \%$ & $57,1 \%$ & $42,9 \%$ \\
BG 2200 & $63,6 \%$ & $18,2 \%$ & $0,0 \%$ & $60,0 \%$ & $71,4 \%$ \\
\hline
\end{tabular}


Fortsetzung

\begin{tabular}{|c|c|c|c|c|c|}
\hline \multirow{2}{*}{$\begin{array}{c}\text { Emissionsvermeidungs- } \\
\text { technologien }\end{array}$} & \multicolumn{5}{|c|}{ im Bereich ... } \\
\hline & Luft & Wasser & Boden & feste Abfalle & Lärm \\
\hline \multicolumn{6}{|l|}{ additive Technologien } \\
\hline $\mathrm{U} \leq 30$ & $58,3 \%$ & $75,6 \%$ & $33,3 \%$ & $48,6 \%$ & $30,6 \%$ \\
\hline $30<U \leq 100$ & $50,0 \%$ & $87,5 \%$ & $100,0 \%$ & $37,5 \%$ & $42,9 \%$ \\
\hline$U>100$ & $57,1 \%$ & $42,9 \%$ & $100,0 \%$ & $22,2 \%$ & $57,1 \%$ \\
\hline \multicolumn{6}{|l|}{ integrierte Technologien } \\
\hline $\mathrm{U} \leq 30$ & $41,7 \%$ & $24,4 \%$ & $66,7 \%$ & $51,4 \%$ & $69,4 \%$ \\
\hline $30<U \leq 100$ & $50,0 \%$ & $12,5 \%$ & $0,0 \%$ & $62,5 \%$ & $57,1 \%$ \\
\hline$U>100$ & $42,9 \%$ & $57,1 \%$ & $0,0 \%$ & $77,8 \%$ & $42,9 \%$ \\
\hline
\end{tabular}

\section{Anlage 34: Organisationsgrad des Umweltschutzes}

\begin{tabular}{|l|c|c|c|}
\hline & Gesamt & $\begin{array}{c}\text { besonders erfolgreiche } \\
\text { Unternehmen }\end{array}$ & $\begin{array}{c}\text { weniger erfolgreiche } \\
\text { Unternehmen }\end{array}$ \\
\hline $\begin{array}{l}\text { Unternehmen mit Umweltschutz- } \\
\text { einheiten }\end{array}$ & $23,6 \%$ & $25,0 \%$ & $23,0 \%$ \\
\hline
\end{tabular}

\begin{tabular}{|l|c|c|c|c|c|}
\hline & Gesamt & BG<50 & 50 $\mathbf{B}$ B $<100$ & $\mathbf{1 0 0}$ SBG $<200$ & BG $\geq 200$ \\
\hline $\begin{array}{l}\text { Unternehmen mit Umweltschutz- } \\
\text { einheiten }\end{array}$ & $23,6 \%$ & $13,7 \%$ & $18,2 \%$ & $36,0 \%$ & $56,0 \%$ \\
\hline
\end{tabular}

\begin{tabular}{|l|c|c|c|c|}
\hline & Gesamt & U 330 & $30<U \leq 100$ & U>100 \\
\hline $\begin{array}{l}\text { Unternehmen mit Umweltschutz- } \\
\text { einheiten }\end{array}$ & $23,6 \%$ & $17,8 \%$ & $29,0 \%$ & $75,0 \%$ \\
\hline
\end{tabular}




\section{Anlage 35: Die Bizerba-Umweltpolitik}

Die Grundsătze der Bizerba-Umweltpolitik sind:

\section{- Umweltschutz ist Aufgabe von Management und Mitarbeitern}

Umweltschutz ist eine wesentliche Führungsaufgabe. Alle Vorgesetzten und Mitarbeiter arbeiten daher gleichermaßen verantwortungsbewußt bei der tăglichen Umsetzung von Umweltschutzmaßnahmen mit. Schulung und Motivation der Mitarbeiter zum umweltbewußten Handeln am Arbeitsplatz ist ein zentrales Element der Umweltpolitik von Bizerba.

\section{- Umweltgerechte Produkte und Prozesse}

Bei der Entwicklung neuer Produkte und bei der Einfuhrung neuer Produktionsprozesse werden diese auf umweltkritische Stoffe und Verfahren untersucht. Dabei wird das System als Ganzes betrachtet, um die Verlagerung von Umweltproblemen in andere Bereiche zu vermeiden. Die gewonnenen Erkenntnisse werden zur Erarbeitung geeigneter organisatorischer und technischer Maßnahmen, einschließlich erforderlicher Notfallplăne, verwendet. Bizerba setzt unter Berücksichtigung des wirtschaftlichen Aufwandes die beste verfügbare Technik ein.

\section{- Schonung der Ressourcen}

Es werden Maßnahmen ergriffen, um den Einsatz an Energie, Rohstoffen und anderen natürlichen Ressourcen zu verringem.

\section{- Überprufung des Erfolges}

Die Auswirkungen von vorhandenen umweltrelevanten Einrichtungen werden regelmäßig überprüft. Bizerba verpflichtet sich, Sicherheitseinrichtungen und Organisation in der Form zu gestalten, daß negative Auswirkungen auf die Umwelt möglichst vermieden bzw. weitgehend minimiert werden.

Zur Sicherstellung der Einhaltung dieser Umweltpolitik und Erfullung vorgegebener Umweltziele werden interne und externe Produkt- und Systemaudits durchgefuhrt und die entsprechenden Maßnahmen eingeleitet.

\section{- Integration der Lieferanten}

Lieferanten und Auftragnehmer werden bei der Verbesserung ihres betrieblichen Umweltschutzes unterstützt. Lieferanten, welche auf dem Werksgelände von Bizerba tätig sind, werden zur Einhaltung der Bizerba betreffenden Umweltnormen verpflichtet.

\section{- Einhaltung und Umsetzung von Gesetzen und Vorschriften}

Bizerba verpflichtet sich zur Einhaltung aller einschlägigen Gesetze und Vorschriften. Die Zusammenarbeit mit den zuståndigen Behörden, Institutionen und qualifizierten Stellen wird laufend gepflegt. Es wird sichergestellt, daß der aktuelle Stand der Technik und die geltenden Umweltvorschriften in geeignetem Umfang beschaff, den Verantwortlichen zugånglich gemacht und eingehalten werden.

- Vermeidung von Abfallen und Emissionen

Abfalle, Reststoffe, Emissionen, Lărmbelästigung und Abwässer werden vermieden bzw. auf ein Mindestmaß reduziert.

- Verpnichtung gegenüber Kunden und Őffentlichkeit

Jeder Bizerba-Kunde hat das Recht auf die Gewißheit, ein umweltgerechtes Produkt erworben zu haben. Daher informieren wir uber die Umweltaspekte unserer Produkte im Zusammenhang mit Handhabung, Verwendung, Rücknahme, Verwertung und Entsorgung.

Quelle: Bizerba (1995), S. 8f. 
Anlage 36: Einschätzung der Umweltprobleme entlang des Produktlebenszyklus (Skala von 1 = "überhaupt nicht" bis 5 = " in hohem Maße")

\begin{tabular}{|l|c|c|c|}
\hline \multicolumn{1}{|c|}{ Umweltprobleme } & Gesamt & $\begin{array}{c}\text { besonders erfolgreiche } \\
\text { Unternehmen }\end{array}$ & $\begin{array}{c}\text { weniger erfolgreiche } \\
\text { Unternehmen }\end{array}$ \\
\hline $\begin{array}{l}\text { bei der Beschaffung der Rohstoffe } \\
\text { und Vorprodukte } \\
\text { bei der Produktion mit umwelt- } \\
\text { belastenden Verfahren } \\
\text { im Vertrieb wegen der Umwelt- } \\
\text { belastung der Produkte } \\
\text { bei der Entsorgung }\end{array}$ & 1,9 & 2,0 & 1,8 \\
\hline
\end{tabular}

\begin{tabular}{|c|c|c|c|c|c|}
\hline Umweltprobleme & Gesamt & BG $<50$ & $50 \leq B G<100$ & $100 \leq \mathrm{BG}<200$ & $B G \geq 200$ \\
\hline $\begin{array}{l}\text { bei der Beschaffung der Rohstoffe } \\
\text { und Vorprodukte }\end{array}$ & 1,9 & 1,6 & 2,6 & 1,8 & 2,0 \\
\hline $\begin{array}{l}\text { bei der Produktion mit umwelt- } \\
\text { belastenden Verfahren }\end{array}$ & 2,2 & 1,9 & 2,6 & 2,5 & 2,2 \\
\hline $\begin{array}{l}\text { im Vertrieb wegen der Umwelt- } \\
\text { belastung der Produkte }\end{array}$ & 1,6 & 1,5 & 1,8 & 1,9 & 1,5 \\
\hline bei der Entsorgung & 2,7 & 2,5 & 2,5 & 3,4 & 3,0 \\
\hline
\end{tabular}

\begin{tabular}{|l|c|c|c|c|}
\hline \multicolumn{1}{|c|}{ Umweltprobleme } & Gesamt & $\mathbf{U} \leq \mathbf{3 0}$ & $\mathbf{3 0 < \mathrm { U } \leq 1 0 0}$ & $\mathbf{U}>\mathbf{1 0 0}$ \\
\hline $\begin{array}{l}\text { bei der Beschaffung der Rohstoffe } \\
\text { und Vorprodukte }\end{array}$ & 1,9 & 1,8 & 1,9 & 2,3 \\
$\begin{array}{l}\text { bei der Produktion mit umwelt- } \\
\text { belastenden Verfahren } \\
\text { im Vertrieb wegen der Umwelt- } \\
\text { belastung der Produkte } \\
\text { bei der Entsorgung }\end{array}$ & 2,2 & 2,2 & 1,7 & 2,5 \\
\hline
\end{tabular}


Anlage 37: Förderung bzw. Beeinträchtigung von Unternehmenszielen durch die Verfolgung von Umweltschutzzielen

(Skala von 1 = "sehr große Beeinträchtigung" bis 5 = "sehr große Förderung")

\begin{tabular}{|l|c|c|c|}
\hline \multicolumn{1}{|c|}{ Unternehmensziel } & Gesamt & $\begin{array}{c}\text { besonders erfolgreiche } \\
\text { Unternehmen }\end{array}$ & $\begin{array}{c}\text { weniger erfolgreiche } \\
\text { Unternehmen }\end{array}$ \\
\hline Sicherung der Wettbewerbsfähig- & 3,1 & 3,1 & 3,1 \\
keit & 2,8 & 2,9 & 2,8 \\
langfristige Gewinnerzielung & 2,4 & 2,4 & 2,4 \\
Kosteneinsparungen & 2,7 & 2,6 & 2,7 \\
Produktivitătssteigerungen & 3,8 & 3,9 & 3,7 \\
Unternehmens-/Produktimage & 3,3 & 3,3 & 3,2 \\
Mitarbeitermotivation & 3,1 & 3,2 & 3,1 \\
Erschließung neuer Märkte & 2,9 & 3,1 & 2,9 \\
Umsatz & 3,3 & 3,1 & 3,3 \\
Kooperation mit Abnehmern/ & 2,8 & 2,8 & 2,7 \\
Handel & 3,1 & 3,2 & 3,1 \\
Erhaltung von Arbeitsplătzen & 2,8 & 2,8 & 2,8 \\
Marktanteil & 3,0 & 2,9 & 3,1 \\
Unternehmenswachstum & 2,3 & 2,2 & 2,4 \\
Kooperation mit Lieferanten & & & \\
kurzfristige Gewinnerzielung & & & \\
\hline
\end{tabular}

\begin{tabular}{|c|c|c|c|c|c|}
\hline Unternehmensziel & Gesamt & BG $<50$ & $50 \leq B G<100$ & $100 \leq B G<200$ & $\mathbf{B G} \geq \mathbf{2 0 0}$ \\
\hline $\begin{array}{l}\text { Sicherung der Wettbewerbsfähig- } \\
\text { keit }\end{array}$ & 3,1 & 3,1 & 2,8 & 2,9 & 3,4 \\
\hline langfristige Gewinnerzielung & 2,8 & 2,7 & 3,0 & 2,8 & 3,2 \\
\hline Kosteneinsparungen & 2,4 & 2,4 & 2,2 & 2,5 & 2,6 \\
\hline Produktivitätssteigerungen & 2,7 & 2,7 & 2,5 & 2,7 & 2,8 \\
\hline Unternehmens-/Produktimage & 3,8 & 3,7 & 3,8 & 3,8 & 4,0 \\
\hline Mitarbeitermotivation & 3,3 & 3,2 & 3,3 & 3,2 & 3,6 \\
\hline Erschließung neuer Märkte & 3,1 & 3,1 & 3,1 & 2,9 & 3,5 \\
\hline Umsatz & 2,9 & 2,9 & 3,0 & 2,8 & 3,1 \\
\hline $\begin{array}{l}\text { Kooperation mit Abnehmern/ } \\
\text { Handel }\end{array}$ & 3,3 & 3,3 & 3,1 & 3,0 & 3,6 \\
\hline Erhaltung von Arbeitsplätzen & 2,8 & 2,9 & 2,6 & 2,6 & 2,9 \\
\hline Marktanteil & 3,1 & 3,0 & 3,2 & 3,0 & 3,4 \\
\hline Unternehmenswachstum & 2,8 & 2,9 & 2,5 & 2,7 & 3,0 \\
\hline Kooperation mit Lieferanten & 3,0 & 3,0 & 3,0 & 2,9 & 3,2 \\
\hline kurzfristige Gewinnerzielung & 2,3 & 2,3 & 2,3 & 2,2 & 2,3 \\
\hline
\end{tabular}


Fortsetzung

\begin{tabular}{|c|c|c|c|c|}
\hline Unternehmensziel & Gesamt & $\mathbf{U} \leq \mathbf{3 0}$ & $30<\mathrm{U} \leq 100$ & $U>100$ \\
\hline $\begin{array}{l}\text { Sicherung der Wettbewerbsfähig- } \\
\text { keit }\end{array}$ & 3,1 & 3,0 & 3,1 & 3,4 \\
\hline langfristige Gewinnerzielung & 2,8 & 2,8 & 2,8 & 3,5 \\
\hline Kosteneinsparungen & 2,4 & 2,4 & 2,5 & 2,6 \\
\hline Produktivitätssteigerungen & 2,7 & 2,7 & 2,7 & 2,8 \\
\hline Unternehmens-/Produktimage & 3,8 & 3,7 & 3,8 & 4,3 \\
\hline Mitarbeitermotivation & 3,3 & 3,2 & 3,3 & 3,8 \\
\hline Erschließung neuer Märkte & 3,1 & 3,1 & 3,3 & 3,3 \\
\hline Umsatz & 2,9 & 2,9 & 2,8 & 3,3 \\
\hline $\begin{array}{l}\text { Kooperation mit Abnehmern/ } \\
\text { Handel }\end{array}$ & 3,3 & 3,2 & 3,3 & 3,7 \\
\hline Erhaltung von Arbeitsplätzen & 2,8 & 2,8 & 2,7 & 3,0 \\
\hline Marktanteil & 3,1 & 3,1 & 3,0 & 3,5 \\
\hline Unternehmenswachstum & 2,8 & 2,8 & 2,8 & 2,9 \\
\hline Kooperation mit Lieferanten & 3,0 & 3,0 & 3,2 & 3,1 \\
\hline kurzfristige Gewinnerzielung & 2,3 & 2,3 & 2,2 & 2,5 \\
\hline
\end{tabular}

\section{Anlage 38: Strategische Verhaltensweisen zur Begegnung der Anforderungen an den Umweltschutz}

(Skala von 1 = "spielt überhaupt keine Rolle" bis 5 = "spielt eine große Rolle")

\begin{tabular}{|c|c|c|c|}
\hline Strategien & Gesamt & $\begin{array}{l}\text { besonders erfolgreiche } \\
\text { Unternehmen }\end{array}$ & $\begin{array}{l}\text { weniger erfolgreiche } \\
\text { Unternehmen }\end{array}$ \\
\hline $\begin{array}{l}\text { Rückzug aus betroffenen } \\
\text { Bereichen }\end{array}$ & 2,2 & 2,2 & 2,2 \\
\hline Verlagerung der Produktion & 1,9 & 1,9 & 2,0 \\
\hline $\begin{array}{l}\text { Sofortige Anpassung an neue } \\
\text { Auflagen und Gesetze }\end{array}$ & 3,5 & 3,4 & 3,5 \\
\hline $\begin{array}{l}\text { Widerstand gegen umweltschutz- } \\
\text { bezogene Forderungen }\end{array}$ & 1,8 & 1,7 & 1,9 \\
\hline $\begin{array}{l}\text { Berücksichtigung umweltbewußter } \\
\text { Konsumentengruppen }\end{array}$ & 2,6 & 2,6 & 2,6 \\
\hline $\begin{array}{l}\text { Erschließen neuer Märkte mit } \\
\text { umweltfreundlichen Produkten }\end{array}$ & 2,7 & 2,7 & 2,8 \\
\hline $\begin{array}{l}\text { Orientierung an den Aktivitäten } \\
\text { der unmittelbaren Konkurrenten }\end{array}$ & 2,7 & 2,8 & 2,7 \\
\hline $\begin{array}{l}\text { Abwarten, bis gesetzliche } \\
\text { Regelungen sich konkretisieren }\end{array}$ & 3,1 & 2,8 & 3,2 \\
\hline $\begin{array}{l}\text { Vorwegnahme gesetzlicher } \\
\text { Forderungen }\end{array}$ & 2,6 & 2,7 & 2,6 \\
\hline
\end{tabular}


Fortsetzung

\begin{tabular}{|c|c|c|c|c|c|}
\hline Strategien & Gesamt & BG $<50$ & $50 \leq B G<100$ & $100 \leq B G<200$ & $\mathbf{B G} \geq \mathbf{2 0 0}$ \\
\hline $\begin{array}{l}\text { Rückzug aus betroffenen } \\
\text { Bereichen }\end{array}$ & 2,2 & 2,6 & 1,8 & 2,6 & 2,1 \\
\hline Verlagerung der Produktion & 1,9 & 2,0 & 2,1 & 1,9 & 1,7 \\
\hline $\begin{array}{l}\text { Sofortige Anpassung an neue } \\
\text { Auflagen und Gesetze }\end{array}$ & 3,5 & 3,4 & 3,3 & 3,5 & 3,9 \\
\hline $\begin{array}{l}\text { Widerstand gegen umweltschutz- } \\
\text { bezogene Forderungen }\end{array}$ & 1,8 & 1,8 & 2,2 & 1,7 & 1,6 \\
\hline $\begin{array}{l}\text { Berücksichtigung umweltbewußter } \\
\text { Konsumentengruppen }\end{array}$ & 2,6 & 2,7 & 2,4 & 2,9 & 2,3 \\
\hline $\begin{array}{l}\text { Erschließen neuer Märkte mit } \\
\text { umweltfreundlichen Produkten }\end{array}$ & 2,7 & 2,7 & 2,7 & 2,6 & 3,1 \\
\hline $\begin{array}{l}\text { Orientierung an den Aktivitäten } \\
\text { der unmittelbaren Konkurrenten }\end{array}$ & 2,7 & 2,7 & 2,9 & 2,9 & 2,5 \\
\hline $\begin{array}{l}\text { Abwarten, bis gesetzliche } \\
\text { Regelungen sich konkretisieren }\end{array}$ & 3,1 & 3,0 & 3,2 & 3,2 & 2,9 \\
\hline $\begin{array}{l}\text { Vorwegnahme gesetzlicher } \\
\text { Forderungen }\end{array}$ & 2,6 & 2,6 & 2,5 & 2,7 & 3,0 \\
\hline
\end{tabular}

\begin{tabular}{|l|c|c|c|c|}
\hline \multicolumn{1}{|c|}{ Strategien } & Gesamt & U $\leq 30$ & $30<\mathbf{U} \leq \mathbf{1 0 0}$ & U>100 \\
\hline $\begin{array}{l}\text { Rückzug aus betroffenen } \\
\text { Bereichen }\end{array}$ & 2,2 & 2,3 & 1,9 & 2,4 \\
Verlagerung der Produktion & 1,9 & 2,0 & 1,6 & 1,8 \\
Sofortige Anpassung an neue & 3,5 & 3,3 & 3,7 & 4,4 \\
Auflagen und Gesetze & 1,8 & 1,9 & 1,6 & 1,6 \\
$\begin{array}{l}\text { Widerstand gegen umweltschutz- } \\
\text { bezogene Forderungen }\end{array}$ & 2,6 & 2,6 & 2,7 & 2,8 \\
$\begin{array}{l}\text { Berücksichtigung umweltbewußter } \\
\text { Konsumentengruppen }\end{array}$ & 2,7 & 2,6 & 2,8 & 3,7 \\
$\begin{array}{l}\text { Erschließen neuer Märkte mit } \\
\text { umweltfreundlichen Produkten } \\
\text { Orientierung an den Aktivităten } \\
\text { der unmittelbaren Konkurrenten } \\
\text { Abwarten, bis gesetzliche }\end{array}$ & 2,7 & 2,7 & 2,7 & 3,0 \\
Regelungen sich konkretisieren & 3,1 & 3,1 & 3,1 & 2,9 \\
$\begin{array}{l}\text { Vorwegnahme gesetzlicher } \\
\text { Forderungen }\end{array}$ & 2,6 & 2,5 & 2,9 & 3,5 \\
\hline
\end{tabular}





\section{Literatur}

Aaker, D.A. (1989), Managing Assets and Skills: The Key to a Sustainable Competitive Advantage, in: Califomia Management Review, Winter 1989, S. 91-106

Aaker, D.A. (1995), Strategic Market Management, 4. Aufl., New York 1995

Abell, D.F. (1980), Defining the Business: The Starting Point of Strategic Planning, Englewood Cliffs 1980

Abernathy, W.J./Utterback, J.M. (1988), Patterns of Industrial Innovation, in: R.A. Burgelman, M.M. Maidique (Hrsg.), Strategic Management of Technology and Innovation, Homewood/Ill. 1988, S. 141-148

Achleitner, P. (1985), Sozio-politische Strategien multinationaler Unternehmungen, Bern 1985

Acs, Z.J./Audretsch, D.B. (1992), Innovation durch kleine Unternehmen, Berlin 1992

Acs, Z.J./Audretsch, D.B. (1993a), Firm Profitability, Growth, and Innovation, WZBDiscussion Papers, FS IV 93-11, Berlin 1993

Acs, Z.J./Audretsch, D.B. (1993b), Has the Role of Small Firms Changed in the United States?, in: Z.J. Acs, D.B. Audretsch (Hrsg.), Small Firms and Entrepreneurship: An East-West Perspective, Cambridge 1993, S. 55-77

Adam, D. (1993), Ökologische Anforderungen an die Produktion, in: D. Adam (Hrsg.), Umweltmanagement in der Produktion, Wiesbaden 1993, S. 5-31

Albach, H. (1979), Zur Wiederentdeckung des Unternehmers in der wirtschaftspolitischen Diskussion, in: Zeitschrift für die gesamte Staatswissenschaft, Band 135, Nr. 4, 1979, S. 533-552

Albach, H. (1983), Innovationen für Wirtschaftswachstum und internationale Wettbewerbsfähigkeit, in: Rheinisch Westfälische Akademie der Wissenschaften, Vorträge $\mathrm{N}$ 322, Köln 1983, S. 9-58

Albach, H. (1984), Die Innovationsdynamik der mittelständischen Industrie, in: H. Albach, T. Held (Hrsg.), Betriebswirtschaftslehre mittelständischer Unternehmen, Stuttgart 1984 , S. $35-50$

Albach, H. (1987), Investitionspolitik erfolgreicher Unternehmen, in: ZfB, 57. Jg. 1987, S. 636-661

Albach, H. (1989), Innovationsstrategien zur Verbesserung der Wettbewerbsfähigkeit, in: ZfB, 59. Jg., 1989, S. 1338-1352

Alijah, R./Heuvels, K. (Hrsg.) (1995), Praxishandbuch betriebliches Umweltmanagement: Systematische Umsetzung der EG-Öko-Audit-Verordnung, Augsburg 1995 
d'Amboise, G./Muldowney, M. (1986), Zur betriebswirtschaftlichen Theorie der kleinen und mittleren Unternehmung, in: H.J. Pleitner (Hrsg.), Aspekte einer Managementlehre für kleinere Unternehmen, Berlin 1986, S. 9-32

Ansoff, H.I. (1957), Strategies for Diversification, in: HBR, 35. Jg., Nr. 5, 1957, S. 113-124

Ansoff, H.I. (1965), Corporate Strategy, New York u.a. 1965

Ansoff, H.I. (1975), Managing Surprise and Discontinuity: Strategic Response to Weak Signals, in: California Management Review, Winter 1975, S. 21-33

Ansoff, H.I. (1980), Strategic Management, London u.a. 1980

Ansoff, H.I. (1988), The New Corporate Strategy, New York 1988

Ansoff, H.I./McDonnell, E.J. (1996), Implanting Strategic Management, London u.a. 1996

Ansoff, H.I./Stewart, J.M. (1967), Strategies for a Technology-Based Business, in: HBR, 45. Jg., Nr. 6, 1967, S. 71-83

Antes, R. (1988), Umweltschutzinnovationen als Chancen des aktiven Umweltschutzes für Unternehmen im sozialen Wandel, Schriftenreihe des IÖW, Nr. 16, Berlin 1988

Aregger, K. (1976), Innovation in sozialen Systemen. Band 1: Einfuhrung in die Innovationstheorie der Organisation, Bem, Stuttgart 1976

Argyris, C. (1977), Double Loop Learning in Organizations, in: HBR, 55. Jg., Nr. 5, 1977, S. 115-125

Argyris, C./Schön, D.A. (1978), Organizational Learning: A Theory of Action Perspective, Reading/Mass. 1978

Arrow, K.J. (1962), Economic Welfare and the Allocation of Resources for Innovation, in: R. Nelson (Hrsg.), The Rate and Direction of Inventive Activity: Economic and Social Factors, Princeton 1962, S. 609-626

Arthur D. Little (1988), Innovation als Führungsaufgabe, Frankfurt/M., New York 1988

Arthur D. Little (Hrsg.) (1994), Management erfolgreicher Produkte, Wiesbaden 1994

Arthur D. Little (Hrsg.) (1997), Management von Innovation und Wachstum, Wiesbaden 1997

Audretsch, D.B. (1995a), Innovation and Industry Evolution, Cambridge/Mass., London 1995

Audretsch, D.B. (1995b), The Innovation, Unemployment and Competitiveness Challenge in Germany, WZB-Discussion Papers, FS IV 95-6, Berlin 1995

Aydalot, P. (Hrsg.) (1986), Milieux Innovateurs en Europe, Paris 1986

Bade, F.-J. (1987), Die wachstumspolitische Bedeutung kleiner und mittlerer Unternehmen, in: M. Fritsch, C. Hull (Hrsg.), Arbeitsplatzdynamik und Regionalentwicklung, Berlin 1987, S. 71-99 
Bamberger, J./Bonacker, R. (1994), Strategies of Small and Medium-sized Enterprises and their Measurement, in: J. Bamberger (Hrsg.), Product/Market Strategies of Small and Medium-sized Enterprises, Aldershot 1994, S. 28-85

Bamberger, J./Pleitner, H.J (Hrsg.) (1988), Strategische Ausrichtung kleiner und mittlerer Unternehmen, Berlin 1988

Barnett, H.G. (1953), Innovation: The Basis of Cultural Change, New York 1953

Bartsch, T. (1995), Erfahrungen mit Umwelt-/Öko-Audits in den USA: Schutzschild vor Haftung oder gefährliches Schwert?, in: ZUR, Nr. 1, 1995, S. 14-19

Baumol, W.J. (1968), Entrepreneurship in Economic Theory, in: American Economic Review, 58. Jg., Nr. 2, 1968, S. 64-71

Baumol, W.J. (1993), Entrepreneurship, Management, and the Structure of Payoffs, Cambridge/Mass. 1993

Baumol, W.J. (1995), Formal Entrepreneurship Theory in Economics: Existence and Bounds, in: J. Bull, H. Thomas, G. Willard (Hrsg.), Entrepreneurship, Kidlington 1995, S. 17-33

Baumol, W.J./Oates, W.E. (1975), The Theory of Environmental Policy, Englewood Cliffs/NJ. 1975

Bayerisches Staatsministerium (Hrsg.) (1995), Das EG-Öko-Audit in der Praxis: Ein Leitfaden zur freiwilligen Beteiligung gewerblicher Unternehmen am Gemeinschaftssystem für das Umweltmanagement und die Umweltbetriebsprüfung, hrsg. vom Bayerischen Staatsministerium für Landesentwicklung und Umweltfragen, München 1995

Bea, F.X. u.a. (1993), Bea, F.X./Dichtl, E./Schweitzer, M., Allgemeine Betriebswirtschaftslehre, Band 2: Führung, 6. Aufl., Stuttgart, Jena 1993

Bea, F.X./Haas, J. (1997), Strategisches Management, 2. Aufl., Stuttgart 1997

Beck, H. (1995), Schlüsselqualifikationen: Bildung im Wandel, 2. Aufl., Darmstadt 1995

Becker, F.G. (1991), Innovationsfördernde Anreizsysteme, in: G. Schanz (Hrsg.), Anreizsysteme in Wirtschaft und Verwaltung, Stuttgart 1991, S. 567-593

Becker, S.W./Whisler, T.L. (1967), The Innovative Organization: A Selective View of Current Theory and Research, in: Journal of Business, 40. Jg., Nr. 4, 1967, S. $462-469$

Beer, R./Troge, A. (1992), Umweltschutz und Mittelstand: Modellversuch "Verstärkte Berücksichtigung mittelstandspolitischer Gesichtspunkte im Rahmen der Umweltpolitik", hrsg. vom Umweltbundesamt, Berichte 2/92, Berlin 1992

Berekoven, L. u.a. (1993), Berekoven, L./Eckert, W./Ellenrieder, P., Marktforschung, 6.Aufl., Wiesbaden 1993 
von Bertalanffy, L. (1950), An Outline of General Systems Theory, in: British Journal for the Philosophy of Science, 1, 1950, S. 134-165

Beschorner, D. (1990), Öko-Bilanz: Entscheidungshilfe für eine umweltfreundlichere Wirtschaftsweise, in: J. Freimann (Hrsg.), Ökologische Herausforderung der Betriebswirtschaftslehre, Wiesbaden 1990, S. 163-176

Betzl, K. (1996), Entwicklungsansătze in der Arbeitsorganisation und aktuelle Unternehmenskonzepte: Visionen und Leitbilder, in: H.-J. Bullinger, H.J. Warnecke (Hrsg.), Neue Organisationsformen im Unternehmen: Ein Handbuch für das moderne Management, Berlin u.a. 1996, S. 29-64

Bierfelder, W.H. (1994), Innovationsmanagement, 3. Aufl., München, Wien 1994

Binswanger, H.C. u.a. (1988), Binswanger, H.C./Frisch, H. u.a., Arbeit ohne Umweltzerst8rung: Strategien für eine neue Wirtschaftspolitik, Frankfurt/M. 1988

Binswanger, M. (1995), Sustainable Development: Utopie in einer wachsenden Wirtschaft?, in: ZfU, Nr.1, 1995, S. 1-19

Birch, D.L. (1981), Who Creates Jobs?, in: Public Interest, Nr. 65, Herbst 1981, S. 3-14

Birch, D.L. (1987), Job Creation in America: How our Smallest Companies put the most People to Work, New York 1987

Bircher, B. (1976), Langfristige Unternehmungsplanung, Bern, Stuttgart 1976

Bizerba (1995), Bizerba Umwelterklärung 1995, Bizerba GmbH Co.KG, Balingen 1995

Blank, P.-U. u.a. (1995), Blank, P.-U./Herdzina, K./Stützle-Leinmüller, S., Zur Problematik der Abgrenzung des relevanten Marktes mit Hilfe der Clusteranalyse: Das Beispiel des Automobilmarktes in Deutschland, Diskussionsbeiträge aus dem Institut für Volkswirtschaftslehre, Nr. 111, Universität Hohenheim, Stuttgart 1995

Blattner, N. (1977), Volkswirtschaftliche Theorie der Firma: Firmenverhalten, Organisationsstruktur, Kapitalmarktkontrolle, Berlin 1977

Blazejczak, J. u.a. (1993a), Blazejczak, J./Edler, D./Gornig, M., Beschäftigungswirkungen des Umweltschutzes: Stand und Perspektiven; Synthesebericht, hrsg. vom Umweltbundesamt, Berichte 5/93, Berlin 1993

Blazejczak, J. u.a. (1993b), Blazejczak, J./Edler, D. u.a., Beschäftigungswirkungen des Umweltschutzes: Abschätzung und Prognose bis 2000; Einzelanalysen, hrsg. vom Umweltbundesamt, Texte 42/93, Berlin 1993

Blazejczak, J. u.a. (1993c), Blazejczak, J./Kohlhaas, M. u.a., Umweltschutz und Industriestandort: Der Einfluß umweltbezogener Standortfaktoren auf Investitionsentscheidungen, hrsg. vom Umweltbundesamt, Berichte 1/93, Berlin 1993

Bleicher, K. (1971), Perspektiven für Organisation und Führung von Unternehmen, BadenBaden, Bad Homburg 1971 
Bleicher, K. (1979), Unternehmungsentwicklung und organisatorische Gestaltung, Stuttgart, New York 1979

Bleicher, K. (1990), Unternehmungskultur und strategische Unternehmungsführung, in: D. Hahn, B. Taylor (Hrsg.), Strategische Unternehmungsplanung, Strategische Unternehmungsfuihrung, 5. Aufl., Heidelberg 1990, S. 852-902

Bleicher, K. (1991), Organisation: Strategien, Strukturen und Kulturen, 2. Aufl., Wiesbaden 1991

Bleicher, K. (1993a), Organisation, in: F.X. Bea, E. Dichtl, M. Schweitzer (Hrsg.), Allgemeine Betriebswirtschaftslehre, Band 2: Führung, 6. Aufl., 1993, S. 103-186

Bleicher, K. (1993b), Unternehmenskultur, in: Gabler Wirtschaftslexikon , 13. Aufl., Wiesbaden 1993, S. 3404ff.

Bleicher, K. (1996), Das Konzept integriertes Management, 4. Aufl., Frankfurt/M., New York 1996

Bleis, C. (1996), Öko-Controlling: Betriebswirtschaftliche Analyse zur systematischen Berücksichtigung von ökologischen Aspekten durch Unternehmenscontrolling, 2. Aufl., Frankfurt/M. u.a. 1996

Blessin, B. (1996), Qualifikationsbedarf und Personalpolitik in kleinen und mittleren Betrieben: Das Beispiel kleiner und mittlerer Betriebe in der Region Neckar-Alb, EFLRDiskussionsbeiträge 7/1996, Hohenheim 1996

Blessin, B. (1997), Von der Lernenden Organisation zur Lemenden Region, EFLRDiskussionsbeitrăge 8/1997, Hohenheim 1997

BMBF/BMWi (Hrsg.) (1997), Innovationsförderung für kleine und mittlere Unternehmen: Gesamtkonzept der Bundesregierung, hrsg. vom Bundesministerium für Bildung, Wissenschaft, Forschung und Technologie (BMBF) und vom Bundesministerium für Wirtschaft (BMWi), Bonn 1997

BMFT (Hrsg.) (1990), Nachwachsende Rohstoffe: Konzept der Forschungsförderung 19901995, hrsg. vom Bundesminister für Forschung und Technologie, Bonn 1990

BMI (Hrsg.) (1971), Umweltprogramm der Bundesregierung, hrsg. vom Bundesministerium des Innern, Bonn 1971

BMU/Umweltbundesamt (Hrsg.) (1995), Handbuch Umweltcontrolling, hrsg. vom Bundesministerium für Umwelt, Naturschutz und Reaktorsicherheit, Umweltbundesamt, München 1995

BMWi u.a. (Hrsg.) (1995), Ideenmanagement für mittelständische Unternehmen: Mehr Innovation durch kreative Mitarbeiter, hrsg. vom Bundesministerium für Wirtschaft, Deutsches Institut für Betriebswirtschaft e.V., Wuppertaler Kreis e.V., Köln 1995

Booz, Allen \& Hamilton (1968), Management of New Products, New York 1968 
Bortz, J. (1993), Statistik für Sozialwissenschaftler, 4. Aufl., Berlin 1993

Böttler, E. (1997), Bizerba: Praxisbericht, in: Dr. Wieselhuber \& Partner (Hrsg.), Handbuch Lernende Organisation: Unternehmens- und Mitarbeiterpotentiale erfolgreich erschließen, Wiesbaden 1997, S. 359-365

Brauchlin, E. (1984), Schaffen auch Sie ein Unternehmungsleitbild, in: io Management Zeitschrift, 53. Jg., Nr. 7-8, 1984, S. 313-317

Brauchlin, E./Wehrli, H.-P. (1994), Strategisches Management: Lehrbuch mit Fallstudien, 2. Aufl., München 1994

Brenken, D. (1988), Strategische Unternehmensführung und Ökologie: Rekonstruktion eines ausgewählten Denkmodells und die Analyse seiner Anwendung am Beispiel ökonomisch-ökologischer Problemkomplexe, Bergisch Gladbach 1988

Brockhoff, K. (1974), Produktlebenszyklen, in: Handwörterbuch der Absatzwirtschaft, hrsg. von B. Tietz, Stuttgart 1974, Sp. 1763-1770

Brockhoff, K. (1993), Forschung und Entwicklung, in: Vahlens Kompendium der Betriebswirtschaftslehre, hrsg. von M. Bitz u.a., Band 1, 3. Aufl., München 1993, S. 171201

Brockhoff, K. (1994), Forschung und Entwicklung, 4. Aufl., München, Wien 1994

Brodbeck, H. (1995), Strategie, in: J. Sattes u.a. (Hrsg.), Erfolg in kleinen und mittleren Unternehmen: Ein Leitfaden für die Führung und Organisation in KMU, Zürich 1995, S. $31-48$

Bromann, P./Piwinger, M. (1992), Gestaltung der Unternehmenskultur: Strategie und Kommunikation, Stuttgart 1992

Bull, I./Willard, G. (1995), Towards a Theory of Entrepreneurship, in: J. Bull, T. Howard, G. Willard (Hrsg.), Entrepreneurship, Kidlington 1995, S. 1-16

Bullinger, H.-J. (1996), Erfolgsfaktor Mitarbeiter: Motivation, Kreativität, Innovation, Stuttgart 1996

Bullinger, H.-J. (Hrsg.) (1996), Lernende Organisationen: Konzepte, Methoden und Erfahrungsberichte, Stuttgart 1996

Bullinger, H.-J./Zinser, S. (1997), Die Notwendigkeit von Innovationen, in: W. Grosskopf u.a. (Hrsg.), Innovationen im Mittelstand: Strategisches Management, Finanzierung, Kooperation, Stuttgart 1997, S. 13-25

Burch, J.G. (1986), Entrepreneurship, New York 1986

Bürgel, H.D. u.a. (1996), Bürgel, H.D./Haller, C./Binder, M., F\&E-Management, München 1996

Burns, A.F. (1934), Productive Trends in the United States since 1870, New York 1934 
Burns, T./Stalker, G.M. (1961), The Management of Innovation, London 1961

Buß, E. (1988), Das Unternehmensimage: Der neue Produktionsfaktor, in: Manager-Magazin (Hrsg.), Imageprofile '88: Das deutsche Image-Jahrbuch, Düsseldorf 1988, S. 8-13

Busse von Colbe, W. (1964), Die Planung der Betriebsgröße, Wiesbaden 1964

Busse von Colbe, W. (1974), Betriebsgröße und Unternehmensgröße, in: Handwörterbuch der Betriebswirtschaft, hrsg. von E. Grochla, W. Wittmann, 4. Aufl., Band 1, Stuttgart 1974, Sp. 566-579

Bussiek, J. (1997), Erfolgsstrategien von kleinen und mittleren Unternehmen an der Schwelle zum 21. Jahrhundert, in: J. Bührens (Hrsg.), Management im Mittelstand, Berlin 1997 , S. $13-28$

Butterbrodt, D. (1997), Von traditionellen Unternehmenskonzepten zu modernen Managementkonzepten, in: G. Winter (Hrsg.), Ökologische Unternehmensentwicklung, Berlin u.a. 1997, S. 97-127

Butterbrodt, D. u.a. (1995), Butterbrodt, D./Dannich-Kappelmann, M./Tammler, U., Umweltmanagement: Moderne Methoden und Techniken zur Umsetzung, München, Wien 1995

Buzzell, R.D./Gale, B.T. (1989), Das PIMS-Programm: Strategien und Unternehmenserfolg, Wiesbaden 1989

Bygrave, W.D. (1995), Theory Building in the Entrepreneurship Paradigm, in: J. Bull, H. Thomas, G. Willard (Hrsg.), Entrepreneurship, Kidlington 1995, S. 129-155

Camp, R.C. (1994), Benchmarking, München, Wien 1994

Cantillon, R. (1755), Essai sur la Nature du Commerce en Général, London 1755, hrsg. i.R.d. Faksimile-Edition "Klassiker der Nationalökonomie" von W. Engels u.a., Frankfurt/M. 1987

Carland, J.W. u.a. (1984), Differentiating Entrepreneurs from Small Business Owners: A Conceptualization, in: Academy of Management Review, 9. Jg., Nr. 2, 1984, S. 354-359

Casson, M.C. (1982), The Entrepreneur: An Economic Theory, Oxford 1982

Casson, M.C. (1995), Entrepreneurship and Business Culture, Aldershot 1995

Chandler, A.D. (1962), Strategy and Structure, 19. Aufl, Cambridge/Mass. 1995

Chmielewicz, K. (1991), Unternehmensverfassung und Innovation, in: D. Müller-Böling u.a. (Hrsg.), Innovations- und Technologiemanagement, Stuttgart 1991, S. 83-101

Clausen, J./Fichter, K. (1994), Umweltberichte: Umwelterklärungen, Hinweise zur Erstellung und Verbreitung, München 1994 
Clausen, J. u.a. (1995), Clausen, J./Fichter, K. u.a., Materialien zum betrieblichen Umweltmanagement und Umweltcontrolling, hrsg. vom Umweltbundesamt, Texte 12/95, Berlin 1995

von Clausewitz, K. (1832), Vom Kriege, Berlin 1832, Ausgabe Leipzig 1917

Clifford, D.K. u.a. (1975), Clifford, D.K. jr./Bridgewater, B.A. jr./ Hardy, T., The Game has Changed, in: McKinsey Quarterly, Herbst 1975, S. 2-21

Coase, R.H. (1960), The Problem of Social Cost, in: Journal of Law and Economics, 3. Jg., Oktober 1960, S. 1-44

Cohen, W.M./Levinthal, D.A. (1989), Innovation and Learning: The two Faces of R\&D, in: Economic Journal, 99. Jg., Nr. 3, 1989, S. 569-596

Cohen, W.M./Levinthal, D.A. (1990), Absorptive Capacity: A New Perspective on Learning and Innovation, in: Administrative Science Quarterly, 35. Jg., März 1990, S. 128152

Comelli, G./von Rosenstiel, L. (1995), Führung durch Motivation: Mitarbeiter für Organisationsziele gewinnen, München 1995

Commission of the European Communities (Hrsg.) (1990), Enterprises in the European Community, Brüssel 1990

Cooper, R.G. (1979), The Dimensions of Industrial New Product Success and Failure, in: Journal of Marketing, 43. Jg., Nr. 3, 1979, S. 93-103

Cooper, R.G. (1984a), How New Product Strategies Impact on Performance, in: Journal of Product Innovation Management, 1. Jg., Nr. 1, 1984, S. 5-18

Cooper, R.G. (1984b), New Product Strategies: What Distinguishes the Top Performers?, in: Journal of Product Innovation Management, 1. Jg., Nr. 3, 1984, S. 151-164

Corsten, H. (1985), Die Bedeutung von Forschung und Entwicklung für technologische Innovationen: Eine Analyse empirischer Untersuchungen, in: WiSt, 14. Jg., Nr. 7, 1985, S. 363-367

Corsten, H. (1989), Überlegungen zu einem Innovationsmanagement: Organisationale und personale Aspekte, in: H. Corsten (Hrsg.), Die Gestaltung von Innovationsprozessen: Hindernisse und Erfolgsfaktoren im Organisations-, Finanz- und Informationsbereich, Berlin 1989, S. 1-56

Cox, W.E. jr. (1967), Product Life Cycles as Marketing Models, in: Journal of Business, 40. Jg., Nr. 4, 1967, S. 375-384

Dales, J.H. (1968), Land, Water, and Ownership, in: Canadian Journal of Economics, 1. Jg., Nr. 4, 1968, S. 791-804 
Damanpour, (1991), Organizational Innovation: A Meta-analysis of Effects of Determinants and Moderators, in: Academy of Management Journal, 34. Jg., Nr. 3, 1991, S. $555-590$

David, F.R. (1995), Strategic Management, 5. Aufl., Englewood Cliffs 1995

Day, G.S. (1981), The Product Life Cycle: Analysis and Application Issues, in: Journal of Marketing, 45. Jg., Nr. 4, 1981, S. 60-67

Deakins, D. (1996), Entrepreneurship and Small Firms, London 1996

Dean, J. (1950), Pricing Policies for New Products, in: HBR, 28. Jg., Nr. 6, 1950, S. 45-53

Deeks, J. (1973), The Small Firm: Asset or Liability?, in: Journal of Management Studies, 10. Jg., Nr. 1, S. 25-47

Deming, W.E. (1994), Out of the Crisis: Quality, Productivity, and Competitive Position, 19. Aufl., Cambridge/Mass, 1994

Denison, E.F. (1962), Sources of the Economic Growth in the United States and the Alternatives Before Us, Committee for Economic Development, Supplementary Paper No. 13, New York 1962

Denison, E.F. (1985), Trends in American Economic Growth: 1929-1982, Washington/DC 1985

Deutsche Bundesbank (1997a), Monatsbericht Mai 1997, 49. Jg., Nr. 5, Frankfurt/M. 1997

Deutsche Bundesbank (1997b), Monatsbericht August 1997, 49. Jg., Nr. 8, Frankfurt/M. 1997

Dieter, W.H. (1991), Technologiemanagement: Theorie und Praxis, in: D. Müller-Böling u.a. (Hrsg.), Innovations- und Technologiemanagement, Stuttgart 1991, S. 27-37

Dosi, G. (1988), Sources, Procedures and Microeconomic Effects of Innovation, in: Journal of Economic Literature, 26. Jg., 1988, S. 1120-1171

Dr. Wieselhuber \& Partner (Hrsg.) (1997), Handbuch Lernende Organisation: Unternehmensund Mitarbeiterpotentiale erfolgreich erschließen, Wiesbaden 1997

Dufner, J. u.a. (1992), Dufner, J./Jensen, U./Schumacher, E., Statistik mit SAS, Stuttgart 1992

Dyckhoff, H. (1991), Berücksichtigung des Umweltschutzes in der betriebswirtschaftlichen Produktionstheorie, in: D. Ordelheide, B. Rudolph, E. Büsselmann (Hrsg.), Betriebswirtschaftslehre und ökonomische Theorie, Stuttgart 1991, S. 275-309

Dyckhoff, H./Souren, R. (1994), Der Einfluß von Umweltschutzvorgaben auf betriebliche Produktionsentscheidungen, in: B. Kaluza (Hrsg.), Unternehmung und Umwelt, Hamburg 1994, S. 77-104

Dyllick, T. (1989), Ökologisch bewußte Unternehmensführung: Der Beitrag der Managementlehre, Schriftenreihe des Ö.B.U./A.S.I.E.G.E., 1/1989, St. Gallen 1989 
Dyllick, T. (1990), Ökologisch bewußtes Management, Schweizerische Volksbank (Hrsg.), Die Orientierung, Nr. 96, Bern 1990

Dyllick, T./Belz, F. (1993), Ökologie und Wettbewerbsfähigkeit von Unternehmen und Branchen in der Schweiz: Konzeption eines Forschungsprojektes, IWÖDiskussionsbeitrag, Nr. 1, St. Gallen 1993

Dyllick, T./Belz, F. (1994), Ökologische Unternehmensentwicklung: Die Entstehung einer dynamischen Perspektive, in: H. Kreikebaum, E. Seidel, H.-U. Zabel (Hrsg.), Unternehmenserfolg durch Umweltschutz: Rahmenbedingungen, Instrumente, Praxisbeispiele, Wiesbaden 1994, S. 53-69

Eberhardt, S. (1997), Sicherung der langfristigen wirtschaftlichen Leistungsfähigkeit von Unternehmungen mit Hilfe des modifizierten Stakeholder-Value-Ansatzes, Dissertation Universität Hohenheim, Stuttgart 1997

Ehrnsperger, F. (1994), Unternehmensgrundsätze: Plädoyer für eine neue Unternehmenskultur, in: K. Günther (Hrsg.), Erfolg durch Umweltmanagement: Reportagen aus mittelständischen Unternehmen, Neuwied 1994, S. 19-31

Elßer, S. (1993), Innovationswettbewerb: Determinanten und Unternehmensverhalten, Frankfurt/M. u.a. 1993

Elter, V.-C. (1997), Total Quality Management (TQM), in WISU, 26. Jg., Nr. 3, 1997, S. 207210

Engelhardt, W.H. (1989), Produktlebenszyklus- und Substitutionsanalyse, in: Handwörterbuch der Planung, hrsg. von N. Szyperski, U. Wienand, Stuttgart 1989, Sp. 1595ff.

Eschenbach, R./Kunesch, H. (1996), Strategische Konzepte: Managementansätze von Ansoff bis Ulrich, 3. Aufl., Stuttgart 1996

Eschenbach, R./Müller, C. (Hrsg.) (1992), Umweltmanagement in Österreich: State of the Art und Entwicklungstendenzen, Wien 1992

Etzioni, A. (1969), Elemente einer Makrosoziologie, in: W. Zapf (Hrsg.), Theorien des sozialen Wandels, Köln 1969, S. 147-176

Etzioni, A. (1975), Die aktive Gesellschaft, Opladen 1975

Europäische Kommission (1994), Wachstum, Wettbewerbsfähigkeit, Beschäftigung: Herausforderungen der Gegenwart und Wege ins 21. Jahrhundert, Weißbuch, Luxemburg 1994

Europäische Kommission (1995), Maßnahmen für die KMU und das Handwerk, Luxemburg 1995

Europäische Kommission (1996a), Bericht der Kommission über die Umsetzung des Programms der Europäischen Gemeinschaft für Umweltpolitik und Maßnahmen im Hinblick auf eine dauerhafte und umweltgerechte Entwicklung, Brüssel 1996 
Europäische Kommission (1996b), Die Wettbewerbsfähigkeit der europäischen Industrie: Eine Bewertung mittels Benchmarking, Luxemburg 1996

Europäische Kommission (1996c), Grünbuch zur Innovation, Beilage 5/95 zum Bulletin der Europäischen Union, Luxemburg 1996

Europäische Kommission (1997a), Die Wettbewerbsfähigkeit der europäischen Industrie, Luxemburg 1997

Europäische Kommission (1997b), Erster Aktionsplan für Innovation in Europa: Innovation im Dienste von Wachstum und Beschäftigung, Luxemburg 1997

Fabricant, S. (1940), The Output of Manufacturing Industries, 1899-1933, New York 1940

Fassbender, P. (1997), Auf dem Weg zum Lernenden Unternehmen, in: Dr. Wieselhuber \& Partner (Hrsg.), Handbuch Lernende Organisation: Unternehmens- und Mitarbeiterpotentiale erfolgreich erschließen, Wiesbaden 1997, S. 55-65

Feigenbaum, A.V. (1991), Total Quality Control, 3. Aufl., New York 1991

Feldman, M.P./Audretsch, D.B. (1996), Location, Location, Location: The Geography of Innovation and Knowledge Spillovers, WZB-Discussion Papers, FS IV 96-28, Berlin 1996

Feldman, M.P./Audretsch, D.B. (1997), Innovationen und ihr Standort: Informationstechnologien und Kleinunternehmen, in: WZB-Mitteilungen, Nr. 75, März 1997, S. 14f.

Fichter, K. (1995), Die EG-Öko-Audit-Verordnung: Mit Öko-Controlling zum zertifizierten Umweltmanagmentsystem, München, Wien 1995

Fischer, T.R. (1997), Innovationsförderung durch Risikokapital, in: W. Grosskopf u.a. (Hrsg.), Innovationen im Mittelstand: Strategisches Management, Finanzierung, Kooperation, Stuttgart 1997, S. 95-102

Flechtner, H.-J. (1966), Grundbegriffe der Kybernetik, Stuttgart 1966

Forrester, J.W. (1959), Advertising: A Problem in Industrial Dynamics, in: HBR, 37. Jg., Nr. 2 , S. $100-110$

Freeman, C. (1982), The Economics of Industrial Innovation, Cambridge/Mass. 1982

Freeman, C./Soete, L. (1997), The Economics of Industrial Innovation, 3. Aufl., London 1997

Freeman, R.E. (1984), Strategic Management: A Stakeholder Approach, Boston u.a. 1984

Freimann, J. (1996), Betriebliche Umweltpolitik: Praxis, Theorie, Instrumente, Bern u.a. 1996

Fritsch, M. (1990), Technologieförderung als regionalpolitische Strategie, in: RuR, Nr. 2-3, 1990, S. 117-123 
Fritsch, M. (1993), The Role of Small Firms in West Germany, in: Z.J. Acs, D.B. Audretsch (Hrsg.), Small Firms and Entrepreneurship: An East-West Perspective, Cambridge 1993, S. 38-54

Fritz, W. (1990), Marketing - Ein Schlüsselfaktor des Unternehmenserfolges: Eine kritische Analyse vor dem Hintergrund der empirischen Erfolgsfaktorenforschung, in: Marketing ZFP, 12. Jg., Nr. 2, 1990, S. 91-110

Fritz, W. (1995), Umweltschutz und Unternehmenserfolg: Eine empirische Analyse, in: Die Betriebswirtschaft, 55. Jg., Nr. 3, S. 347-357

Fritz, W. u.a. (1985), Fritz, W./Förster, F./Raffée, H./Silberer, G., Unternehmensziele in Industrie und Handel, in: Die Betriebswirtschaft, 45. Jg., Nr. 4, 1985, S. 375-394

Fritz, W. u.a. (1988), Fritz, W./Förster, F./Wiedmann, K.-P./Raffée, H., Unternehmensziele und strategische Unternehmensführung, in: Die Betriebswirtschaft, 48. Jg., Nr. 5, 1988, S. $567-586$

Fröhlich, E./Pichler, J.H. (1988), Werte und Typen mittelständischer Unternehmer, Berlin 1988

FUUF (1991), Forschungsgruppe Umweltorientierte Unternehmensführung (FUUF), Umweltorientierte Unternehmensführung: Möglichkeiten zur Kostensenkung und Erlössteigerung: Modellvorhaben und Kongreß, hrsg. vom Umweltbundesamt, Berichte 11/91, Berlin 1991

Gabele, E. (1989), Die Rolle der Werthaltungen von Führungskräften mittelständischer Unternehmen bei der Erringung strategischer Wettbewerbsvorteile, in: Die Betriebswirtschaft, 49. Jg., Nr. 5, 1989, S. 623-637

Gabler Wirtschaftslexikon (1993), 13. Aufl., Wiesbaden 1993

Gaitanides, M./Sjurts, I. (1995), Wettbewerbsvorteile durch Prozeßmanagement: Eine ressourcenorientierte Analyse, in: H. Corsten, T. Will (Hrsg.), Unternehmensfuihrung im Wandel, Strategien zur Sicherung des Erfolgspotentials, Stuttgart 1995, S. 6182

Gallert, H./Clausen, J. (1996), Leitfaden Öko-Controlling: Erfolgsorientierter Einstieg in die EG-Öko-Audit-Verordnung für kleine und mittlere Unternehmen, Düsseldorf 1996

Gälweiler, A. (1974), Unternehmensplanung: Grundlagen und Praxis, Frankfurt/M., New York 1974

Gälweiler, A. (1979a), Die Gestaltung geschäftspolitischer Grundsätze, in: Der kaufmännische Geschäftsführer, hrsg. von G. Haberland, 1979, S. 1-30

Gälweiler, A. (1979b), Strategische Geschäftseinheiten (SGE) und Aufbauorganisation der Unternehmung, in: zfo, 48. Jg., 1979, S. 252-260 
Gälweiler, A. (1981), Was ist Strategie? Was heißt strategisch Denken, Entscheiden und Handeln?, in: C. Pümpin u.a. (Hrsg.), Produkt-Markt-Strategien: Neue Instrumente erfolgreicher Unternehmensfuihrung, Bern 1981, S. 33-54

Gantzel, K.-J. (1962), Wesen und Begriff der mittelständischen Unternehmung, Köln 1962

Garvin, D.A. (1984), What does "Product Quality" Really Mean?, in: Sloan Management Review, 26. Jg., Nr. 1, 1984, S. 25-43

Garvin, D.A. (1988), Managing Quality: The Strategic and Competitive Edge, New York, London 1988

Garvin, D.A. (1993), Building a Learning Organization, in: HBR, 71. Jg., Nr. 4, 1993, S. 7891

Gaugler, E. (1994), Das Humankapital als Faktor der Wettbewerbsfähigkeit, in: E. Dichtl (Hrsg.), Standort Bundesrepublik Deutschland, Frankfurt/M. 1994, S. 91-112

Gebert, D./Steinkamp, T. (1990), Innovativität und Produktivität durch betriebliche Weiterbildung: Eine empirische Analyse mittelständischer Unternehmen, Stuttgart 1990

Georgescu-Roegen, N. (1971), The Entropy Law and the Economic Process, Cambridge/Mass., London 1971

Georgescu-Roegen, N. (1974), Was geschieht mit der Materie im Wirtschaftsprozeß?, in: Brennpunkte (gdi-topics), 5. Jg., Nr. 2, 1974, S. 17-28

Gerke, W. u.a. (1995), Probleme deutscher mittelständischer Unternehmen beim Zugang zum Kapitalmarkt: Analyse und wirtschaftspolitische Schlußfolgerungen, Baden-Baden 1995

Gerybadze, A. (1995), Innovationsmanagement, in: H. Corsten, M. Reiß (Hrsg.), Handbuch Unternehmensführung: Konzepte, Instrumente, Schnittstellen, Wiesbaden 1995, S. 829-845

Gerybadze, A./Reger, G. (1997), Executive Summary: Kernfragen und wesentliche Ergebnisse, in: A. Gerybadze u.a. (Hrsg.), Globales Management von Forschung und Innovation, Stuttgart 1997

Geschka, H. (1990), Innovationsmanagement, in: H.-C. Pfohl (Hrsg.), Betriebswirtschaftslehre der Mittel- und Kleinbetriebe: Größenspezifische Probleme und Möglichkeiten zu ihrer Lősung, 2. Aufl., Berlin 1990, S. 157-178

de Geus, A.P. (1988), Planning as Learning, in: HBR, 66. Jg., Nr. 2, 1988, S. 70-74

Gibb, A.A. (1997), Small Firm's Training and Competitiveness: Building upon the Small Business as a Learning Organization, in: International Small Business Journal, 15. Jg., Nr. 3, 1997, S. 13-29 
Gilardi, S. (1995), Qualifikation und Weiterbildung, in: J. Sattes u.a. (Hrsg.), Erfolg in kleinen und mittleren Unternehmen: Ein Leitfaden für die Führung und Organisation in KMU, Zürich 1995, S. 135-144

Goldhar, J.D. (1980), Some Modest Conclusions, in: B.V. Dean, J.L. Goldhar (Hrsg.), Management of Research and Innovation, New York u.a. 1980, S. $283 \mathrm{f}$.

Gomez, P./Weber, B. (1989), Strategien zur Steigerung des Unternehmenswertes, in: Budget, 58. Jg., Nr. 10, 1989, S. 27-29

Grochla, E. (1982), Grundlagen der organisatorischen Gestaltung, Stuttgart 1982

Grossman, G.M./Helpman, E. (1997), Innovation and Growth in the Global Economy, 6. Aufl., Cambridge/Mass. 1997

Grupp, H. (1997), Technischer Wandel und Beschäftigung, in: H. Schnabl (Hrsg.), Innovation und Arbeit: Fakten, Analysen, Perspektiven, Tübingen 1997, S. 1-24

Günther, E./Wagner, B. (1993), Ökologieorientierung des Controlling (Öko-Controlling), in: Die Betriebswirtschaft, 53. Jg., Nr. 2, 1993, S. 143-166

Günther, K. (1992), Umweltorientierte Organisationsentwicklung: Praktische Umsetzung des Umweltmanagements, in: M. Sietz (Hrsg.), Umweltbewußtes Management, Taunusstein 1992, S. 11-20

Günther, K. (1996), Das Öko-Audit aus der Sicht der Wirtschaft, in: Bertelsmann Stiftung u.a. (Hrsg.), Bausteine einer rationalen Umweltpolitik, Gütersloh 1996, S. 163-172

Günzel, D. (1975), Das betriebswirtschaftliche Größenproblem kleiner und mittlerer industrieller Unternehmen, Göttingen 1975

Gussmann, B. (1988), Innovationsfordernde Unternehmenskultur: Die Steigerung der Innovationsbereitschaft als Aufgabe der Organisationsentwicklung, Berlin 1988

Haasis, H.-D. (1996), Betriebliche Umweltökonomie: Bewerten, Optimieren, Entscheiden, Berlin, Heidelberg 1996

Haberfellner, R. u.a. (1994), Haberfellner, R./Nagel, P./Becker, M., Systems Engineering: Methodik und Praxis, 8. Aufl., Zürich 1994

Hagemann, H. (1985), Freisetzungs- und Kompensationseffekte neuer Technologien: Zur Gefahr einer technologischen Arbeitslosigkeit, in: F. Buttler, J. Kühl, B. Rahmann (Hrsg.), Staat und Beschäftigung: Angebots- und Nachfragepolitik in Theorie und Praxis, Nürnberg 1985, S. 291-335

Hagemann, H./Seiter, S. (1998), Verdoorn's Law, in: Encyclopedia of Political Economy, London, New York, erscheint 1998

Hahlen, J. (1997), Umweltprobleme und Statistik: Was kostet die Natur, in: WISU, 26. Jg., Nr. 2, 1997, S. $93 \mathrm{f}$. 
Hahn, D. (1990), Strategische Unternehmungsführung: Grundkonzept, in: D. Hahn, B. Taylor (Hrsg.), Strategische Unternehmungsplanung, Strategische Unternehmungsführung, 5. Aufl., Heidelberg 1990, S. 31-51

Hall, R. (1992), The Strategic Analysis of Intangible Resources, in: Strategic Management Journal, 13. Jg., 1992, S. 135-144

Hall, R. (1993), A Framework Linking Intangible Resources and Capabilities to Sustainable Competitive Advantage, in: Strategic Management Journal, 14. Jg., 1993, S. 607618

Hallay, H. (1990), Die Öko-Bilanz: Ein betriebliches Informationssystem, Schriftenreihe des IÖW, Nr. 27, Berlin 1990

Hallay, H./Pfriem, R. (1992), Öko-Controlling: Umweltschutz in mittelständischen Unternehmen, Frankfurt/M., New York 1992

Halstrick-Schwenk, M. u.a. (1994), Halstrick-Schwenk, M./Horbach, J./Löbbe, K./Walter, J., Die umwelttechnische Industrie in der Bundesrepublik Deutschland, Untersuchungen des Rheinisch-Westfälischen Instituts für Wirtschaftsforschung, Nr. 12, Essen 1994

Hamer, E. (1990a), Mittelständische Unternehmen: Gründung, Führung, Chancen, Risiken, Landsberg/L. 1990

Hamer, E. (1990b), Unternehmensfuhrung, in: H.-C. Pfohl (Hrsg.), Betriebswirtschaftslehre der Mittel- und Kleinbetriebe: Größenspezifische Probleme und Möglichkeiten zu ihrer Lösung, 2. Aufl., Berlin 1990, S. 43-74

Hamm, U. (1997), Die Ermittlung umweltrelevanter Kosten, in: G. Winter (Hrsg.), Ökologische Unternehmensentwicklung, Berlin u.a. 1997, S. 267-298

Harhoff, D. u.a. (1996), Harhoff, D./Licht, G./Beise, M., Innovationsaktivitäten kleiner und mittlerer Unternehmen: Ergebnisse des Mannheimer Innovationspanels, BadenBaden 1996

Harper, D.A. (1996), Entrepreneurship and the Market Process: An Inquiry into the Growth of Knowledge, London 1996

Hartje, V.J. (1990), Zur Struktur des "ökologisierten" Umweltkapitalstocks: Variablen und Determinanten umweltsparender technologischer Anpassungen in Unternehmen, in: K. Zimmermann, V.J. Hartje, A. Ryll (Hrsg.), Ökologische Modernisierung der Produktion, Berlin 1990, S. 135-198

Hartje, V.J./Lurie, R.L. (1984), Adopting Rules for Pollution Control Innovations: End-ofPipe versus Integrated Process Technology, WZB-Discussion Papers, IIUG 84-6, Berlin 1984

Hartwig, K.-H. (1995), Umweltökonomie, in: Vahlens Kompendium der Wirtschaftstheorie und Wirtschaftspolitik, Band 2, 6. Aufl., München 1995, S. 123-162 
Hauff, V. (1987), Unsere gemeinsame Zukunft: Der Brundtland-Bericht der Weltkommission für Umwelt und Entwicklung, Greven 1987

Hauschildt, J. (1977), Entscheidungsziele: Zielbildung in innovativen Entscheidungsprozessen, Tübingen 1977

Hauschildt, J. (1986), Das Innovationsbewußtsein, in: E. Staudt (Hrsg.), Das Management von Innovationen, Frankfurt/M. 1986, S. 62-68

Hauschildt, J. (1997), Innovationsmanagement, München 1997

Hauschildt, J./Chakrabarti, A. (1988), Arbeitsteilung im Innovationsmanagement: Forschungsergebnisse, Kriterien und Modelle, in: zfo, 57. Jg., Nr. 6, 1988, S. 378-388

Hax, A.C./Majluf, N.S. (1991), Strategisches Management: Ein integratives Konzept aus dem MIT, Frankfurt/M., New York 1991

von Hayek, F.A. (1945), The Use of Knowledge in Society, in: American Economic Review, 35. Jg., 1945, S. 519-530

von Hayek, F.A. (1969), Der Wettbewerb als Entdeckungsverfahren, in: F.A. von Hayek (Hrsg.), Freiburger Studien, Tübingen 1969, S. 249-265

Hayes, R.H./Wheelwright, S.C. (1979a), Link Manufacturing Process and Product Life Cycle, in: HBR, 57. Jg., Nr. 1, 1979, S. 133-140

Hayes, R.H./Wheelwright, S.C. (1979b), The Dynamics of Process-Product Life Cycle, in: HBR, 57. Jg., Nr. 2, 1979, S. 127-136

Heberer, J./Grap, R. (1995), Betriebliche Weiterbildung in kleinen und mittelständischen Unternehmen: Methoden und Vorgehensweise, Herzogenrath 1995

Hedley, B. (1977), Strategy and the "Business Portfolio", in: Long Range Planning, 10. Jg., Nr. 1, 1977, S. 9-15

Heim, G. (1997), Präzision mit Tradition, in: W. Grosskopf u.a. (Hrsg.), Innovationen im Mittelstand: Strategisches Management, Finanzierung, Kooperation, Stuttgart 1997 , S. $153 \mathrm{f}$.

Heinen, E. (1976), Grundlagen betriebswirtschaftlicher Entscheidungen, 3. Aufl., Wiesbaden 1976

Heinen, E. (1993), Unternehmungsziele, in: Gabler Wirtschaftslexikon, 13. Aufl., Wiesbaden 1993, S. 3442-3445

Heinrich, W. (1967), Wirtschaftspolitik, Band I/2, 2. Aufl., Berlin 1967

Helbig, J. (1997), Wirtschaftliche Relevanz von Umweltschutzgütern in Baden-Württemberg und in der Bundesrepublik Deutschland, in: IAW-Mitteilungen 1/97, Tübingen 1997, S. 16-25 
Henderson, B.D. (1974), Die Erfahrungskurve in der Unternehmensstrategie, Frankfurt/M. 1974

Henze, A. (1994), Marktforschung: Grundlage für Marketing und Marktpolitik, Stuttgart 1994

Herbert, T.T./Deresky, H. (1987), Generic Strategies: An Empirical Investigation of Typology Validity and Strategy Content, in: Strategic Management Journal, 8. Jg., 1987, S. 135-147

Herdzina, K. (1981), Wirtschaf:iches Wachstum, Strukturwandel und Wettbewerb, Berlin 1981

Herdzina, K. (1993), Wettbewerbspolitik, 4. Aufl., Stuttgart 1993

Herdzina, K./Blessin, B. (1996), Strategische Unternehmensführung als Erfolgsfaktor im Wettbewerb: Kleine und mittlere Unternehmen der Region Neckar-Alb im Strukturwandel, EFLR-Forschung 1996-1, Hohenheim 1996

Herdzina, K./Nolte, B. (1995), Regionalentwicklung und Strukturwandel: Problemlagen und Entwicklungschancen in der Region Neckar-Alb, EFLR-Forschung 1995-1, Hohenheim 1995

Herdzina, K. u.a. (1996), Herdzina, K./Nolte, B./Hegner, S., Innovation im Handwerk: Mit neuen Produkten und Leistungen die Zukunft meistern, Gutachten im Auftrag der Handwerkskammer Reutlingen, Hohenheim, Reutlingen 1996

Heuss, E. (1965), Allgemeine Markttheorie, Tübingen 1965

Higgins, J.H./Wiese, G.G. (1996), Innovationsmanagement: Kreativitätstechniken für Unternehmen, Berlin u.a. 1996

Hinder, W./Bartosch, S. (1985), Strategien in stagnierenden Märkten - DOB: Intuitiv oder geplant? Mittelbetriebe strategisch positioniert, in: Absatzwirtschaft, 10. Jg., Nr. 1,1985 , S. $98-102$

Hinterhuber, H.H. (1990), Wettbewerbsstrategie, 2. Aufl., Berlin 1990

Hinterhuber, H.H. (1992), Strategische Unternehmensführung, Band I: Strategisches Denken, 5. Aufl., Berlin, New York 1992

Hinterhuber, H.H. (1996), Strategische Unternehmensführung, Band I: Strategisches Denken, 6. Aufl., Berlin, New York 1996

Hinterhuber, H.H. (1997), Strategische Unternehmensführung, Band II: Strategisches Handeln, 6. Aufl., Berlin, New York 1997

von Hippel, E. (1988), The Sources of Innovation, Oxford u.a. 1988

Hof, B. (1994), Beschäftigungsschwelle und Wachstum: Was besagt die Empirie, in: ifoStudien, 40. Jg., 2/1994, S. 127-144 
Hofer, C.W./Schendel, D. (1978), Strategy Formulation: Analytical Concepts, St. Paul u.a. 1978

Hoffmann, W. (1940), Wachstum und Wachstumsformen der englischen Industriewirtschaft von 1700 bis zur Gegenwart, Jena 1940

Hopfenbeck, W. (1994), Umweltorientiertes Management und Marketing: Konzepte, Instrumente, Praxisbeispiele, 3. Aufl., Landsberg/L. 1994

Hopfenbeck, W. (1997), Allgemeine Betriebswirtschafts- und Managementlehre: Das Unternehmen im Spannungsfeld zwischen ökonomischen, sozialen und ökologischen Interessen, 11. Aufl., Landsberg/L. 1997

Hopfenbeck, W./Jasch, C. (1993), Öko-Controlling: Umdenken zahlt sich aus!, Landsberg/L. 1993

Hopfenbeck, W. u.a. (1995), Hopfenbeck, W./Jasch, C./Jasch, A., Öko-Audit: Der Weg zum Zertifikat, Landsberg/L. 1995

Hopfenbeck, W./Willig, M. (1995), Umweltorientiertes Personalmanagement: Umweltbildung, Motivation, Mitarbeiterkommunikation, Landsberg/L. 1995

Hornsby, J.S./Kuratko, D.F. (1990), Human Resource Management in Small Business: Critical Issues for the 1990's, in: Journal of Small Business Management, 28. Jg., Nr. 3, 1990, S. 9-18

Hörschgen, H. (1992), Grundbegriffe der Betriebswirtschaftslehre, 3. Aufl., Stuttgart 1992

Horváth, P. (1981), Controlling im Klein- und Mittelbetrieb, 3. Aufl., Eschborn/Ts. 1981

Horváth, P. (1996a), Controlling, 6. Aufl., München 1996

Horváth, P. (1996b), Emeuerung des Controlling, in: H.-J. Bullinger, H.J. Warnecke (Hrsg.), Neue Organisationsformen im Unternehmen: Ein Handbuch für das moderne Management, Berlin u.a. 1996, S. 937-944

Horváth, P./Herter, R.N. (1992), Vergleich mit den Besten der Besten, in: Controlling, 4. Jg., Nr. 1, 1992, S. 4-11

Horváth, P./Weber, J. (1990), Controlling, in: H.-C. Pfohl (Hrsg.), Betriebswirtschaftslehre der Mittel- und Kleinbetriebe: Größenspezifische Probleme und Möglichkeiten zu ihrer Lösung, 2. Aufl., Berlin 1990, S. 288-324

Hübner, H. (1996), Informationsmanagement und strategische Unternehmensführung: Vom Informationsmarkt zur Innovation, München, Wien 1996

Hübner, H./Jahnes, S. (1992), Ganzheitliches Innovations- und Technologiemanagement, in: Gablers Wirtschaftslexikon, 13. Aufl., Band 2, Wiesbaden 1992, S. 1628-1637

Hummel, J. (1997), Strategisches Öko-Controlling: Konzeption und Umsetzung in der textilen Kette, Wiesbaden 1997 
Hunger, J.D./Wheelen, T.L. (1996), Strategic Management, 5. Aufl., Reading/Mass. 1996

Ibrahim, A.B./Goodwin, J.R. (1986), Perceived Causes of Success in Small Business, in: American Journal of Small Business, 11. Jg., Nr. 2, 1986, S. 41-50

IHK (1997), Die Industrie- und Handelskammern in Baden-Württemberg, Innovationshilfen für kleine und mittlere Unternehmen: Die wichtigsten Fördermaßnahmen der Europäischen Union, der Bundesrepublik Deutschland, des Landes BadenWürttemberg und der Industrie- und Handelskammern, Arbeitskreis Technologie, 1997

Imai, M. (1994), Kaizen: Der Schlüssel zum Erfolg der Japaner im Wettbewerb, 12. Aufl., München 1994

Imai, M. (1996), GembaKaizen, in: io Management Zeitschrift, 65. Jg., Nr. 1/2, 1996, S. 27f.

Immler, H. (1990), Natur in der ökonomischen Theorie, 2. Aufl., Opladen 1990

Ishikawa, K. (1985), What is Total Quality Control?: The Japanese Way, Englewood Cliffs/NJ, 1985

Ishikawa, K. (1990), Guide to Quality Control, 2. Aufl., Tokyo, 1990

Ishikawa, K. (1994), Introduction to Quality Control, 3. Aufl., Tokyo 1994

IW (Hrsg.) (1996), Industriestandort Deutschland: Ein graphisches Porträt, hrsg. vom Institut der deutschen Wirtschaft Köln, 5. Aufl., Köln 1996

Jahnes, S. (1997), Umweltorientierte Unternehmensführung, in: G. Winter (Hrsg.), Ökologische Unternehmensentwicklung, Berlin u.a. 1997, S. 27-93

Jahnes, S./Tammler, U. (1997), Anforderungen an Unternehmen, in: G. Winter (Hrsg.), Ökologische Unternehmensentwicklung, Berlin u.a. 1997, S. 5-24

Jasch, A. (1995), Die ISO 14001-Norm und ihre Bedeutung für die EG-Öko-AuditVerordnung, in: K. Fichter, Die EG-Öko-Audit-Verordnung: Mit Öko-Controlling zum zertifizierten Umweltmanagementsystem, München, Wien 1995

Johnson, H.T./Kaplan, R.S. (1987), Relevance Lost, Boston/Mass. 1987

Johnson, S.C./Jones, C. (1957), How to Organize for New Products, in: HBR, 35. Jg., Nr. 3, S. 49-62

Kaimer, M./Schade, D. (1994), Ökobilanzen: Umweltorientierte Informations- und Bewertungsinstrumente, Akademie für Technikfolgenabschätzung in BadenWürttemberg, Arbeitsbericht Nr. 4, Stuttgart 1994

Kaluza, B./Pasckert, A. (1994), Kreislaufwirtschaft und umweltorientiertes Technologiemanagement, in: B. Kaluza (Hrsg.), Unternehmung und Umwelt, Hamburg 1994, S. 105-144 
Kamiske, G.F./Brauer, J.-P. (1995), Qualitätsmanagement von A bis Z, 2. Aufl., München 1995

Kantzenbach, E. (1997), Globalisierung und Verteilung, in: Friedrich-Ebert-Stiftung (Hrsg.), Globalisierung: Ende nationaler Wirtschaftspolitik?, Bonn 1997, S. 1-12

Kaplan, A.D.H. u.a. (1958), Kaplan, A.D.H./Dirlam, J.B./Lanzillotti, R.R., Pricing in Big Business: A Case Approach, Washington/DC 1958

Karlöf, B./Östblom, S. (1994), Das Benchmarking-Konzept, München 1994

Kasper, H. (1986), Widersprüche und Konflikte beim Innovationsmanagement, in: zfo, 55. Jg., Nr. 2, 1986, S. 115-123

Kaufmann, F. (1997), Besonderheiten der Finanzierung kleiner und mittlerer Unternehmen: Ein Überblick über die Problemlage, in: Kredit und Kapital, 30. Jg., Nr. 1, 1997, S. $140-155$

Keßler, U. (1992), Unternehmensgröße, Innovation und Wertschöpfungswachstum. Eine empirische Untersuchung im Lichte der Schumpeterschen Innovationsdiskussion, Frankfurt/M. u.a. 1992

Kets de Vries, M.F.R. (1977), The Entrepreneurial Personality: A Person at the Crossroads, in: Journal of Management Studies, Februar 1977, S. 34-57

Kets de Vries, M.F.R. (1985), The Dark Side of Entrepreneurship, in: HBR, 63. Jg., Nr. 6, 1985 , S. $160-167$

Kieser, A. (1970), Management von Innovationen, in: Innovationen in der Wirtschaft, hrsg. vom Ifo-Institut, München 1970, S. 290-307

Kieser, A. (1975), Innovationen, in: Handwörterbuch der Organisation, hrsg. von E. Grochla, 2. Aufl., Stuttgart 1975, Sp. 741-750

Kieser, A. (1986), Unternehmenskultur und Innovation, in: E. Staudt (Hrsg.), Das Management von Innovationen, Frankfurt/M. 1986, S. 42-50

Kirchgeorg, M. (1990), Ökologieorientiertes Unternehmensverhalten: Typologien und Erklärungsansätze auf empirischer Grundlage, Wiesbaden 1990

Kirchgeorg, M. (1995), Ökologische Herausforderung an die marktorientierte Unternehmensführung, in: R. Alijah, K. Heuvels (Hrsg.), Praxishandbuch betriebliches Umweltmanagement: Systematische Umsetzung der EG-Öko-Audit-Verordnung, Augsburg 1995, Kapitel 8.2

Kirchmann, E. (1994), Innovationskooperation zwischen Herstellern und Anwendern, Wiesbaden 1994

Kirsch, W. (1983), Fingerspitzengefühl und Hemdsärmeligkeit bei der Planung im Mittelstand, in: E. Gabele (Hrsg.), Märkte, Mitarbeiter, Management, Bamberg 1983, S. $150-176$ 
Kirsch, W. (1991), Unternehmenspolitik und Strategische Unternehmensführung, 2. Aufl., München 1991

Kirsch, W. (1997a), Betriebswirtschaftslehre: Eine Annäherung aus der Perspektive der Unternehmensfuhrung, 4. Aufl., München 1997

Kirsch, W. (1997b), Strategisches Management: Die geplante Evolution von Unternehmen, München 1997

Kirsch, K./Roventa, P. (Hrsg.) (1983), Bausteine eines Strategischen Managements: Dialoge zwischen Wissenschaft und Praxis, Berlin, New York 1983

Kirsch, K./Trux, W. (1981), Perspektiven eines Strategischen Managements, in: W. Kirsch (Hrsg.), Unternehmenspolitik: Von der Zielforschung zum Strategischen Management, München 1981, S. 290-396

Kirzner, I.M. (1974), Competition and Entrepreneurship, 2. Aufl., Chicago 1974

Kirzner, I.M. (1979), Perception, Opportunity and Profit: Studies in the Theory of Entrepreneurship, Chicago, London 1979

Kirzner, I.M. (1984), The Role of the Entrepreneur in the Economic System, Centre of Independent Studies, Occasional Papers, Nr. 10, St. Leonhard 1984

Klauder, W. (1986), Technischer Fortschritt und Beschäftigung: Zum Zusammenhang von Technik, Strukturwandel, Wachstum und Beschäftigung, in: Mitteilungen aus der Arbeitsmarkt- und Berufsforschung, Nr. 1, 1986, S. 1-19

Klinger, H.J. (1997), Lemorganisation in der Praxis, in: ASU/BJU NEWS, 13. Jg., Nr. 5, 1997, S. 78ff.

Klodt, H. u.a. (1994), Klodt, H./Stehn, J. u.a., Standort Deutschland: Strukturelle Herausforderungen im neuen Europa, Tübingen 1994

Knight, K.E. (1967), A Descriptive Model of the Intra-firm Innovation Process, in: Journal of Business, 40. Jg., 1967, S. 478-496

Kobi, J.-M./Wütherich, H.A. (1986), Unternehmenskultur: Eine Schlüsselgröße des Erfolgs wird faßbar, in: Der kaufmännische Geschäftsführer, hrsg. von G. Haberland, 1986, S. 1-31

Köhler, R. (1991), Produktinnovationsmanagement als Erfolgsfaktor, in: D. Müller-Böling, D. Seibt, U. Wienand (Hrsg.), Innovations- und Technologiemanagement, Stuttgart 1991, S. 153-175

König, H. (1995), Innovation und Beschäftigung, in: H.-J. Vosgerau (Hrsg.), Zentrum und Peripherie: Zur Entwicklung der Arbeitsteilung in Europa, Berlin 1995, S. 149176

König, H./Licht, G. (1995), Patents, R\&D and Innovation: Evidence from the Mannheim Innovation Panel, in: ifo-Studien, 41. Jg., 4/1995, S. 521-542 
Koschatzky, K. (1997), Regionale Innovationsindikatorik: Dargestellt am Beispiel der Raumordnungsregionen Neckar-Alb und Schwarzwald-Baar-Heuberg, in: RuR, Nr. 1, 1997, S. 48-58

Kostka, S. (1997), Umweltorientierte Organisationsgestaltung, in: G. Winter (Hrsg.), Ökologische Unternehmensentwicklung, Berlin u.a. 1997, S. 131-182

Kotler, P./Bliemel, F. (1992), Marketing-Management: Analyse, Planung, Umsetzung und Steuerung, 7. Aufl., Stuttgart 1992

Kottmann, H./Franke, W. (1994), Umweltorientierte Unternehmensführung: Erfahrungen aus Pilotprojekten in Baden-Württemberg, in: J. Clausen, H. Gallert (Hrsg.), Umweltmanagement und Umwelt-Audit in kleinen Unternehmen, Schriftenreihe des IÖW, Nr. 80, Berlin 1994, S. 43-55

Kreikebaum, H. (1992a), Innovationsmanagement bei aktivem Umweltschutz, in: H. Kreikebaum (Hrsg.), Integrierter Umweltschutz, 2. Aufl., Wiesbaden 1992

Kreikebaum, H. (1992b), Umweltgerechte Produktion: Integrierter Umweltschutz als Aufgabe der Unternehmensführung im Industriebetrieb, Wiesbaden 1992

Kreikebaum, H. (1994), Ökologieverträglichkeit der Produktion und deren Erfolgswirkungen, in: H. Kreikebaum, E. Seidel, H.-U. Zabel, Unternehmenserfolg durch Umweltschutz: Rahmenbedingungen, Instrumente, Praxisbeispiele, Wiesbaden 1994, S. 103-119

Kreikebaum, H. (1995), Die Notwendigkeit ökologischer Informationen, in: UmweltWirtschaftsForum, 3. Jg., 1995, S. 6-9

Kreikebaum, H. (1996), Grundlagen der Unternehmensethik, Stuttgart 1996

Kreikebaum, H. (1997), Strategische Unternehmensplanung, 6. Aufl., Stuttgart 1997

Kreilkamp, E. (1987), Strategisches Management und Marketing, Berlin, New York 1987

Kreitmeier, R. (1996), Unternehmens-Checkup: Topfit durch Benchmarking, in: ASU/BJU NEWS, 12. Jg., Nr. 3, 1996, S. $70 f$.

Kremmel, D. (1996), Das Verhältnis zwischen Unternehmensstrategie und Unternehmenskultur unter besonderer Berücksichtigung des organisationalen Lernens, Hallstadt 1996

Kroeber-Riel, W./Weinberg, P. (1996), Konsumentenverhalten, 6. Aufl., München 1996

Kromphardt, J. (1997), Direkt-Investitionen: Zerstörer oder Erhalter von Arbeitsplätzen und internationaler Wettbewerbsfähigkeit in Zeiten der Globalisierung, in: FriedrichEbert-Stiftung (Hrsg.), Globalisierung: Ende nationaler Wirtschaftspolitik?, Bonn 1997, S. 13-28

Krubasik, E.G. (1982), Technologie: Strategische Waffe, in: Wirtschaftswoche, 36. Jg., Nr. 25,1982, S. $28-33$ 
Krüger, W. (1974), Umweltwandel und Unternehmungsverhalten, in: zfo, 43. Jg., 1974, S. $62-$ 70

Krüger, W. (1988), Die Erklärung von Unternehmungserfolg: Theoretischer Ansatz und empirische Ergebnisse, in: Die Betriebswirtschaft, 48. Jg., Nr. 1, 1988, S. 27-43

Krüger, W. (1989), Hier irrten Peters und Waterman, in: HBM, 11. Jg., Nr. 1, 1989, S. 13-18

Krugman, P. (1996), Pop Internationalism, 3. Aufl., Cambridge/Mass., London 1996

Küpper, H.-U. (1997), Controlling: Konzeption, Aufgaben und Instrumente, 2. Aufl., Stuttgart 1997

Kurz, R. (1994a), Entrepreneurship, Innovation, and Growth: The Role of Innovation Policy in West Germany, in: F.M. Scherer, M. Perlman (Hrsg.), Entrepreneurship, Technological Innovation, and Economic Growth: Studies in the Schumpeterian Tradition, 2. Aufl., Ann Arbor 1994, S. 89-103

Kurz, R. (1994b), Leisten wir uns zuviel Umweltschutz?, in: Landeszentrale für politische Bildung, Stuttgart u.a. 1994, S. 154-166

Kuznets, S. (1930), Secular Movements in Production and Prices: Their Nature and their Bearing upon Cyclical Fluctuations, Boston, New York 1930

Landesanstalt für Umweltschutz (Hrsg.) (1995a), Der Weg zur Zertifizierung nach der EGÖko-Audit-Verordnung, hrsg. von der Landesanstalt für Umweltschutz BadenWürttemberg, 3. Aufl., Karlsruhe 1995

Landesanstalt für Umweltschutz (Hrsg.) (1995b), Umweltmanagement in der metallverarbeitenden Industrie: Leitfaden zur EG-Umwelt-Audit-Verordnung, hrsg. von der Landesanstalt für Umweltschutz Baden-Württemberg, Karlsruhe 1995

Landesanstalt für Umweltschutz (Hrsg.) (1995c), Umweltmanagement in Textilpflegebetrieben: Ein Praxisleitfaden zur EG-Öko-Audit-Verordnung, hrsg. von der Landesanstalt für Umweltschutz Baden-Württemberg, Karlsruhe 1995

Landesanstalt für Umweltschutz (Hrsg.) (1997), Umweltmanagement und Arbeitnehmerbeteiligung: Arbeitshilfe zur Umsetzung der EG-Öko-Audit-Verordnung, hrsg. von der Landesanstalt für Umweltschutz Baden-Württemberg, Karlsruhe 1997

Lang, H.-C. (1995), Innovation, in: J. Sattes u.a. (Hrsg.), Erfolg in kleinen und mittleren Unternehmen: Ein Leitfaden für die Führung und Organisation in KMU, Zürich 1995, S. 179-188

Langheine, R./Lehmann, J. (1986), Entstehungsbedingungen des Umweltbewußtseins, in: R. Günther, G. Winter (Hrsg.), Umweltbewußtsein und persönliches Handeln, Weinheim, Basel 1986, S. 42-54

Langner, H. (1994), Benchmarking ist mehr als der bekannte Vergleich mit der Konkurrenz, in: Marketing Journal, 27. Jg., Nr. 1, 1994, S. 36-40 
Laukamm, T. (1985), Strategisches Management von Human-Ressourcen, in: H. Raffée, K.-P. Wiedmann (Hrsg.), Strategisches Marketing, Stuttgart 1985, S. 243-282

Leder, M. (1989), Innovationsmanagement: Ein Überblick, in: H. Albach (Hrsg.) Innovationsmanagement: Theorie und Praxis im Kulturvergleich, Wiesbaden 1989, S. 1-54

Leibenstein, H. (1966), Allocative Efficiency vs. X-efficiency, in: American Economic Review, 56. Jg., 1966, S. 392-415

Leibenstein, H. (1968), Entrepreneurship and Development, in: American Economic Review, 58. Jg., 1968, S. 72-83

Leipert, C. (1989), Die heimlichen Kosten des Fortschritts: Wie Umweltzerstörung das Wirtschaftswachstum fördert, Frankfurt/M. 1989

Leipert, C. (1992), Ökologische Folgekosten des Wirtschaftens und Volkswirtschaftliche Gesamtrechnung, in: U. Steger (Hrsg.), Handbuch des Umweltmanagements: Anforderungs- und Leistungsprofile von Unternehmen und Gesellschaft, München 1992, S. 117-129

Leisinger, K.M. (1997), Unternehmensethik: Globale Verantwortung und modernes Management, München 1997

Leontief, W.W./Duchin, F. (1986), The Future of Automation on Workers, New York 1986

Levitt, T. (1960), Marketing Myopia, in: HBR, 38. Jg., Nr. 4, 1960, S. 45-56

Levitt, T. (1965), Exploit the Product Life Cycle, in: HBR, 43. Jg., Nr. 6, 1965, S. 81-94

Liessmann, K. (1987), Strategisches Controlling, in: E. Mayer (Hrsg.), Controlling-Konzepte, 2. Aufl., Wiesbaden 1987, S. 85-147

Löbbe, K. (1991), Standort Deutschland: Internationale Wettbewerbsfähigkeit und Attraktivität für Auslandskapital, in: Außenwirtschaftspolitik, hrsg. von der Landeszentrale für politische Bildung Baden-Württemberg, Stuttgart u.a. 1991, S. 53-71

Löbbe, K. (1994), Standortqualität und Wettbewerbsfähigkeit im internationalen Vergleich, in: Standort Deutschland, hrsg. von der Landeszentrale für politische Bildung Baden-Württemberg, Stuttgart u.a. 1994, S. 34-55

Löbbe, K./Wenke, M. (1995), Beschäftigung und Umweltschutz, in: M. Junkernheinrich, P. Klemmer, G.R. Wagner (Hrsg.), Handbuch zur Umweltökonomie, Berlin 1995

Long, W. (1983), The Meaning of Entrepreneurship, in: American Journal of Small Business, 8. Jg., Nr. 2, 1983, S. 47-56

Longenecker, J.G./Moore C.W. (1991), Small Business Management: An Entrepreneurial Emphasise, 8. Aufl., Cincinnati 1991

Longenecker, J.G./Schoen, J.E. (1975), The Essence of Entrepreneurship, in: Journal of Small Business Management, 13. Jg., 1975, S. 26-32 
Maas, C. (1986), Determinanten der Entwicklung und Nutzung umweltfreundlicher Neuerungen in Industriebetrieben: Theoretische Überlegungen und erste empirische Evidenz, Wirtschaftswissenschaftliche Dokumentation, Diskussionspapier Nr. 108, TU Berlin, Berlin 1986

Maas, C. (1990), Determinanten betrieblichen Innovationsverhaltens: Theorie und Empirie, Berlin 1990

Macharzina, K. (1995), Unternehmensführung: Das internationale Managementwissen, 2. Aufl., Wiesbaden 1995

Maidique, M.A./Patch, P. (1982), Corporate Strategy and Technological Policy, in: M.L. Tushman, W.L. Moore (Hrsg.), Readings in the Management of Innovation, Boston u.a. 1982 , S. $273-285$

Maier, W./Fröhlich, W. (1992), Personalmanagement für Klein- und Mittelbetriebe: Praxiswissen in Schaubildern und Checklisten, Heidelberg 1992

Malinsky, A.H. (1996), Grundzüge der betrieblichen Umweltwirtschaft, in: A.H. Malinsky (Hrsg.), Betriebliche Umweltwirtschaft: Grundzüge und Schwerpunkte, Wiesbaden 1996, S. 1-69

Malinsky, A.H./Seidel, E. (1994), Betriebswirtschaftslehre und Ökologie: Ansätze zu einer interdisziplinären Kooperation am Beispiel des betrieblichen Rechnungswesens, in: H. Kreikebaum, E. Seidel, H.-U. Zabel (Hrsg.), Unternehmenserfolg durch Umweltschutz: Rahmenbedingungen, Instrumente, Praxisbeispiele, Wiesbaden 1994, S. 31-52

Mank, P. (1991), Personalpolitik in mittelständischen Unternehmen: Eigenarten, Versäumnisse, Chancen, Frankfurt/M. 1991

Markowitz, H.M. (1959), Portfolio Selection: Efficient Diversification of Investments, New York, London 1959

Marr, R. (1993), Innovationsmanagement, in: Handwörterbuch der Betriebswirtschaft, hrsg. von W. Wittmann, 5. Aufl., Stuttgart 1993, Sp. 1796-1812

Marshall, A. (1890), Principles of Economics: An Introductory Volume, 8. Aufl., London 1938

Maslow, A.H. (1954), Motivation and Personality, New York 1954

Matraves, C. (1997), Die deutsche Industriestruktur im Vergleich, WZB-Discussion Papers, FS IV 97-10, Berlin 1997

Mauthe, K.-D./Roventa, P. (1983), Versionen der Portfolio-Analyse auf dem Prüfstand: Ein Ansatz zur Auswahl und Beurteilung strategischer Analysemethoden, in: W. Kirsch, P. Roventa (Hrsg.), Bausteine eines strategischen Managements, Berlin, New York 1983, S. 109-139 
Mayer, E. (1987), Controlling als Führungskonzept, in: E. Mayer (Hrsg.), ControllingKonzepte, 2. Aufl., Wiesbaden 1987, S. 1-42

Mayer, F. (1997), Anforderungen an das Controlling in Klein- und Mittelbetrieben: Gefragt sind Methoden- und Sozialkompetenz, in: ASU/BJU NEWS, 13. Jg., Nr. 5, 1997, S. $80 f$.

McClelland, D.C. (1961), The Achieving Society, New York 1961

McClelland, D.C. (1987), Characteristics of Successful Entrepreneurs, in: Journal of Creative Behavior, 21. Jg., Nr. 3, 1987, S. 219-233

McCombie, J.S.L./Thirlwall, A.P. (1994), Economic Growth and the Balance-of-Payments Constraint, London 1994

McGuire, J.W. (1976), The Small Enterprise in Economics and Organization Theory, in: Journal of Contemporary Business, 5. Jg., Nr. 2, 1976, S. 115-138

Meffert, H. (1983), Marketing: Eine Einfuihrung in die Absatzpolitik, 6. Aufl., Wiesbaden 1983

Meffert, H. (1988), Strategische Unternehmensführung und Marketing: Beiträge zur marktorientierten Unternehmenspolitik, Wiesbaden 1988

Meffert, H. (1990), Strategisches Marketing und Umweltschutz: Bericht aus einem Forschungsprojekt, in: G.R. Wagner (Hrsg.), Unternehmung und ökologische Umwelt, München 1990, S. 73-96

Meffert, H. (1991a), Strategisches Ökologie-Management, in: A.G. Coenenberg, E. Weise, K. Eckrich (Hrsg.), Ökologie-Management als strategischer Wettbewerbsfaktor, Stuttgart 1991, S. 7-32

Meffert, H. (1991b), Umwelt als Markt: 12 Thesen, in: Absatzwirtschaft, 34. Jg., Nr. 7, 1991, S. 93-96

Meffert, H. (1994), Marketing-Management: Analyse, Strategie, Implementierung, Wiesbaden 1994

Meffert, H./Bruhn, M. (1996), Das Umweltbewußtsein von Konsumenten, in: Die Betriebswirtschaft, 56. Jg., Nr. 5, 1996, S. 631-648

Meffert, H./Kirchgeorg, M. (1989a), Umweltschutz als Unternehmensziel, Wissenschaftliche Gesellschaft für Marketing und Unternehmensfuhrung, Arbeitspapier Nr. 50, Münster 1989

Meffert, H./Kirchgeorg, M. (1989b), Umweltschutz als Unternehmensziel, in: G. Specht, G. Silberer, W.H. Engelhardt (Hrsg.), Marketing-Schnittstellen, Stuttgart 1989, S. 179-199

Meffert, H./Kirchgeorg, M. (1993), Marktorientiertes Umweltmanagement: Grundlagen und Fallstudien, 2. Aufl., Stuttgart 1993 
Meffert, H./Kirchgeorg, M. (1994), Grundlagen des Umweltschutzes aus wettbewerbsstrategischer Perspektive, in: K.-W. Hansmann (Hrsg.), Marktorientiertes Umweltmanagement, Wiesbaden 1994, S. 21-57

Meffert, H./Kirchgeorg, M. (1995), Ökologische Zertifizierung und Marketing: Analyse der Erfolgsvoraussetzungen und marktbezogenen Wirkungen des EG-Öko-Audits, Wissenschaftliche Gesellschaft für Marketing und Unternehmensfuihrung, Arbeitspapier Nr. 95, Münster 1995

Meffert, H./Ostmeier, H. (1990), Umweltschutz und Marketing: Möglichkeiten der Verbesserung der betriebswirtschaftlichen Situation durch umweltorientierte Absatzmaßnahmen, hrsg. vom Umweltbundesamt, Berichte 8/90, Berlin 1990

Meffert, H. u.a. (1986), Meffert, H./Bruhn, M./Schubert, F./Walther, T., Marketing und Ökologie, in: Die Betriebswirtschaft, 46. Jg., Nr. 2, 1986, S. 140-159

Meffert, H. u.a. (1989), Meffert, H./Kirchgeorg, M./Ostmeier, H., Strategisches Marketing und Umweltschutz: Empirische Analyse von Einflußfaktoren und Erfolgseinschätzungen des ökologieorientierten Unternehmensverhaltens, Wissenschaftliche Gesellschaft für Marketing und Unternehmensführung, Arbeitspapier Nr. 53, Münster 1989

Meffert, H. u.a. (1990), Meffert, H./Kirchgeorg, M./Ostmeier, H., Der Einfluß von Ökologie und Marketing auf die Strategien, in: Absatzwirtschaft, 33. Jg., Sonderheft 1990, S. $42-56$

Meier, H. (1992), Personalentwicklung als Unternehmensstrategie im Mittelstand, in: REFANachrichten, Nr. 5, 1992, S. 24-28

Meißner, W. (1982), Positive volkswirtschaftliche Wirkungen der Umweltpolitik, in: A.A. Ullmann, K. Zimmermann (Hrsg.), Umweltpolitik im Wandel: Von Beschäftigungseffekten zu Innovationswirkungen des Umweltschutzes, Frankfurt/M., New York 1982, S. 55-66

Meißner, W./Hödl, E. (1978), Auswirkungen der Umweltpolitik auf den Arbeitsmarkt, Bonn 1978

Mensch, G. (1979), Beobachtungen zum Innovationsverhalten kleiner, mittlerer und mittelgroßer Unternehmen, in: ZfB, 49. Jg., 1979, S. 72-78

Meredith, G.G. u.a. (1987), Meredith, G.G./Nelson, R.E./Neck, P.A., The Practice of Entrepreneurship, 3. Aufl., Genf 1987

Merkle, E. (1989), Die Analyse technologischer Entwicklungen auf der Grundlage von Patentinformationen, in: H. Raffée, K.-P. Wiedmann (Hrsg.), Strategisches Marketing, 2. Aufl., Stuttgart 1989, S. 391-417

Miles, R.E./Snow, C.C. (1978), Organizational Strategy, Structure, and Process, New York 1978 
Mill, J.S. (1848), Principles of Political Economy with some of their Applications to Social Philosophy, Toronto 1965

Miller, A./Dess, G.G. (1996), Strategic Management, 2. Aufl., New York 1996

Milling, P./Maier, F. (1996), Invention, Innovation und Diffusion: Eine Simulationsanalyse des Managements neuer Produkte, Berlin 1996

Mintzberg, H. (1988), Generic Strategies: Toward a Comprehensive Framework, in: Advances in Strategic Management, 5. Jg., 1988, S. 1-67

Mintzberg, H. (1989), Mintzberg on Management: Inside Our Strange World of Organizations, New York, London 1989

von Moltke, H. (1925), Ausgewählte Werke, hrsg. von F. von Schmerfeld, 4 Bände, Berlin 1925

Moore, W.L./Tushman, M.L. (1982), Managing Innovation Over the Product Life Cycle, in: M.L. Tushman, W.L. Moore (Hrsg.), Readings in the Management of Innovation, Boston u.a. 1982, S. 131-150

Mugler, A. (1995), Betriebswirtschaftslehre der Klein- und Mittelbetriebe, 2. Aufl., Wien, New York 1995

Mugler, A./Schmidt, K.-H. (Hrsg.) (1995), Klein- und Mittelunternehmen in einer dynamischen Wirtschaft: Ausgewählte Schriften von H.J. Pleitner, Berlin u.a. 1995

Müller, C. (1995), Strategische Leistungen im Umweltmanagement: Ein Ansatz zur Sicherung der Lebensfähigkeit des Unternehmens, Wiesbaden 1995

Müller, K. (1990), Kooperation bei Klein- und Mittelbetrieben: Grinde, Formen, Voraussetzungen und Hemmnisse, in: H.-C. Pfohl (Hrsg.), Betriebswirtschaftslehre der Mittel- und Kleinbetriebe: Größenspezifische Probleme und Möglichkeiten zu ihrer Lösung, 2. Aufl., Berlin 1990, S. 349-374

Müller, W. (1997), SPSS-gestützte Häufigkeitsanalysen (II), in: WISU, 26. Jg., Nr. 3, S. $217-$ 222

Müller-Wenk, R. (1978), Die ökologische Buchhaltung: Ein Informations- und Steuerungsinstrument für umweltbewußte Unternehmenspolitik, Frankfurt/M., New York 1978

Nagel, K. (1993), Weiterbildung als strategischer Erfolgsfaktor: Der Weg zum unternehmerisch denkenden Mitarbeiter, Köln 1993

Neubauer, F.F. (1990), Das PIMS-Programm und Portfolio-Management, in: D. Hahn, B. Taylor (Hrsg.), Strategische Unternehmensplanung, Strategische Unternehmensführung, 5. Aufl., Heidelberg 1990, S. 283-310

Neugebauer, U. (1994), Unternehmensethik in der Betriebswirtschaftslehre: Vergleichende Analyse ethischer Ansätze in der deutschsprachigen Betriebswirtschaftslehre, Ludwigsburg, Berlin 1994 
von Neumann, J./Morgenstern, O. (1944), Theory of Games and Economic Behavior, 3. Aufl., New York u.a. 1953

Neumarkter Lammsbräu (Hrsg.) (1995), ÖKO-Controlling Bericht 1994, Neumarkt 1995

Nieschlag, R. u.a. (1991), Nieschlag, R./Dichtl, E./Hörschgen, H., Marketing, 16. Aufl., Berlin 1991

Nissen, U. (1995), Organisation des Umweltmanagements, in: R. Alijah, K. Heuvels, (Hrsg.), Praxishandbuch betriebliches Umweltmanagement: Systematische Umsetzung der EG-Öko-Audit-Verordnung, Augsburg 1995, Kapitel 5.8

Nolte, B. (1996), Engpaßfaktoren der Innovation und Innovationsinfrastruktur: Eine theoretische und empirische Analyse für ländliche Wirtschaftsräume in BadenWürttemberg, Frankfurt/M. u.a. 1996

Nolte, B. (1997), Finanzierung von Innovationen im Mittelstand, in: W. Grosskopf u.a. (Hrsg.), Innovationen im Mittelstand: Strategisches Management, Finanzierung, Kooperation, Stuttgart 1997, S. 103-112

Nonaka, I. (1991), The Knowledge-Creating Company, in: HBR, 69. Jg., Nr. 6, 1991, S. 96104

Nopper, H. (1997), Finanzierungsmanagement von Innovationen, in: W. Grosskopf u.a. (Hrsg.), Innovationen im Mittelstand: Strategisches Management, Finanzierung, Kooperation, Stuttgart 1997, S. 113-118

Nüßgens, K.H. (1974), Umweltschutz als eine Führungsaufgabe im Unternehmen, in: Fortschrittliche Betriebsfuihrung, 23. Jg., Nr. 2, 1974, S. 111-125

Nydegger, A. u.a. (1983), Nydegger, A./Oberhänsli, H./Harringer, R., Investitionen und Innovationen in kleinen Industriebetrieben, Diessenhofen 1983

Oates, W.E. (Hrsg.) (1992), The Economics of the Environment, Aldershot 1992

Oberrath, J.-D. (1997), Umweltschutz als Wettbewerbsvorteil?: Das Umwelt-Audit, in: J. Bührens (Hrsg.), Management im Mittelstand: Erfolgsorientierte Ansätze und Perspektiven, Berlin 1997, S. 255-264

Odiorne, G.S. (1989), Strategic Management of Human Resources, San Francisco, London 1989

OECD (1981), The Measurement of Scientific and Technical Activities: Proposed Standard Practice for Surveys of Research and Experimental Development, "FrascatiManual" 1980, Paris 1981

OECD (1994), The OECD Jobs Study: Evidence and Explanations, Paris 1994

OECD (1997), Main Science and Technology Indicators, Band 1, Paris 1997

Oechsler, W.A. (1997), Personal und Arbeit: Einfuihrung in die Personalwirtschaft unter Einbeziehung des Arbeitsrechts, 6. Aufl., München, Wien 1997 
Osterloh, M. (1994), Neue Ansätze im Technologiemanagement: Vom Technologieportfolio zum Portfolio der Kernkompetenzen, in: io Management Zeitschrift, 63. Jg., Nr. 5, 1994, S. 47-50

Ostmeier, H. (1990), Ökologieorientierte Produktinnovationen: Eine empirische Analyse unter besonderer Berücksichtigung ihrer Erfolgseinschätzung, Bern u.a. 1990

Ottnad, A. u.a. (1995), Ottnad, A./Wahl, S./Grünwald, R., Risse im Fundament: Die deutsche Wirtschaft bis 2005, Berlin u.a. 1995

o.V. (1995), The European Handbook of Management Consultancy: Strategic Innovation - A European Approach to Management Consultancy, European Innovation Programme (Project RA 340 Ter), Dublin 1995

Paasi, M. (1997), Technologische und ökonomische Kompetenzen der Unternehmen: Der (noch) schwache Motor im ostdeutschen Raum, in: ifo Schnelldienst, Innovation, Wachstum und Beschäftigung, 50. Jg., 17-18/1997, München 1997, S. 36-43

Pascale, R.T./Athos, A.G. (1981), The Art of Japanese Management, New York 1981

Patton, A. (1959), Top Managements Stake in a Product Life Cycle, in: Management Review, Nr. 3, 1959, S. 9-14 und S. 67-79

Pawlowsky, P./Bäumer, J. (1996), Betriebliche Weiterbildung: Management von Qualifikation und Wissen, München 1996

Peglau, R. (1995), Die Normung von Umweltmanagementsystemen und Umweltauditing im Kontext der EG-Öko-Audit-Verordnung, in: ZUR, 6. Jg., Nr. 1, 1995, S. 19-24

Perillieux, R. (1987), Der Zeitfaktor im strategischen Technologiemanagement: Früher oder spăter Einstieg bei technischen Produktinnovationen?, Berlin 1987

Perillieux, R. (1991), Strategisches Timing von F\&E und Markteintritt bei innovativen Produkten, in: Booz, Allen \& Hamilton (Hrsg.), Integriertes Technologie- und Innovationsmanagement: Konzepte zur Stärkung der Wettbewerbskraft von HighTech-Unternehmen, Berlin 1991, S. 23-48

Perillieux, R./Wittkemper, G. (1991), Ziele und Module eines integrierten Technologie- und Innovationsmanagements, in: Booz, Allen \& Hamilton (Hrsg.), Integriertes Technologie- und Innovationsmanagement: Konzepte zur Stärkung der Wettbewerbskraft von High-Tech-Unternehmen, Berlin 1991, S. 13-20

Perlitz, M./Löbler, H. (1985), Brauchen Unternehmen zum Innovieren Krisen?, in: ZfB, 55. Jg., Nr. 5, 1985, S. 424-450

Perridon, L./Steiner, M. (1997), Finanzwirtschaft der Unternehmung, 9. Aufl., München 1997

Peters, T.J. (1987), Thriving on Chaos: Handbook for a Management Revolution, London 1989 
Peters, T.J./Austin, N. (1985), A Passion for Excellence: The Leadership Difference, 3. Aufl., London 1994

Peters, T./Waterman, R. (1982), In Search of Excellence, New York 1982

Pfeifer, T./Heine, J. (1992), Qualitätssicherung in kleinen und mittleren Unternehmen, in: VDI-Gesellschaft Produktionstechnik (ADB) (Hrsg.), Qualitätssicherung für Produktionsingenieure: Qualität und Produktivität ein Widerspruch?, Düsseldorf 1992, S. $11-42$

Pfeiffer, F. (1997), Innovation, Arbeitsmarkt und Qualifikation, in: EUmagazin, Nr. 6, 1997, S. $12 \mathrm{ff}$.

Pfeiffer, W. (1980), Innovationsmanagement als Know-How-Management, in: D. Hahn (Hrsg.), Führungsprobleme industrieller Unternehmungen: Festschrift für Friedrich Thomée zum 60. Geburtstag, Berlin, New York 1980, S. 421-452

Pfeiffer, W./Staudt, E. (1975), Innovation, in: Handwörterbuch der Betriebswirtschaftslehre, hrsg. von E. Grochla, W. Wittmann, 4. Aufl., Stuttgart 1975, Sp. 1943-1953

Pfeiffer, W. u.a. (1982), Pfeiffer, W./Metze, G./Schneider, W./Amler, R., TechnologiePortfolio: Zum Management strategischer Zukunftsgeschäftsfelder, Göttingen 1982

Pfeiffer, W. u.a. (1983), Pfeiffer, W./Amler, R./Schäffner, G.J./Schneider, W., TechnologiePortfolio-Methode des strategischen Innovationsmanagements, in: zfo, 52. Jg., Nr. $5-6,1983$, S. 252-261

Pfeiffer, W. u.a. (1986), Pfeiffer, W./Schneider, W./Dögl, R., Technologie-PortfolioManagement, in: E. Staudt (Hrsg.), Das Management von Innovationen, Frankfurt/M. 1986, S. 107-124

Pfohl, H.-C./Kellerwessel, P. (1990), Abgrenzung der Klein- und Mittelbetriebe von Großbetrieben, in: H.-C. Pfohl (Hrsg.), Betriebswirtschaftslehre der Mittel- und Kleinbetriebe: Größenspezifische Probleme und Möglichkeiten zu ihrer Lösung, 2. Aufl., Berlin 1990, S. 1-23

Pfriem, R. (1986), Ökobilanzen für Unternehmen, in: R. Pfriem (Hrsg.), Ökologische Unternehmenspolitik, Frankfurt/M. 1986, S. 210-226

Pfriem, R. (1989), Ökologische Unternehmensführung, Schriftenreihe des IÖW, Nr. 13, Berlin 1989

Pfriem, R./Hallay, H. (1992), Öko-Controlling als Baustein einer innovativen Unternehmenspolitik, in: U. Steger (Hrsg.), Handbuch des Umweltmanagements: Anforderungsund Leistungsprofile von Unternehmen und Gesellschaft, München 1992, S. 295310

Pichler, J.H. u.a. (Hrsg.) (1997), Pichler, J.H./Pleitner, H.J./Schmidt, K.-H. (Hrsg.) Management in KMU: Die Führung von Klein- und Mittelunternehmen, 2. Aufl., Bern u.a. 1997 
Picot, A. (1991), Ein neuer Ansatz zur Gestaltung der Leistungstiefe, in: zfbf, 43. Jg., Nr. 4, 1991, S. 336-357

Pieske, R. (1992), Am Klassenbesten orientieren: Quelle für Wettbewerbsvorteile, in: Absatzwirtschaft, 35. Jg., Sonderheft 1992, S. 149-158

Pigou, A.C. (1923), The Economics of Welfare, London 1923

Pinter, J. (1984), Umweltpolitische Probleme und Lösungsmöglichkeiten bei Klein- und Mittelbetrieben der Industrie und des Handwerks, hrsg. vom Umweltbundesamt, Berichte $1 / 84$, Berlin 1984

Pleitner, H.J. (1984), Beobachtungen und Überlegungen zur Person des mittelständischen Unternehmers, in: H. Albach, T. Held (Hrsg.), Betriebswirtschaftslehre mittelständischer Unternehmen, Stuttgart 1984, S. 511-522

Pohl, H.-J./Rehkugler, H. (1986), Mittelständische Unternehmen: Durch qualifiziertes Management zum Erfolg, Bremen 1986

Polanyi, M. (1989), Personal Knowledge: Towards a Post-Critical Philosophy, Chicago 1989

Porter, M.E. (1980), Competitive Strategy, New York, London 1980

Porter, M.E. (1985), Competitive Advantage, New York, London 1985

Porter, M.E. (1991), Towards a Dynamic Theory of Strategy, in: Strategic Management Journal, 12. Jg., Winter Special Issue, 1991, S. 95-117

Porter, M.E. (1995), Wettbewerbsstrategie: Methoden zur Analyse von Branchen und Konkurrenten, 8. Aufl., Frankfurt/M., New York 1995

Porter, M.E. (1996), Wettbewerbsvorteile: Spitzenleistungen erreichen und behaupten, 4. Aufl., Frankfurt/M., New York 1996

Porter, M.E. (1997), Nur die Strategie sichert auf Dauer hohe Erträge: Die strategische Positionierung ist jetzt die Topaufgabe des Managements, in: HBM, 19. Jg., Nr. 3, 1997, S. $42-58$

Porter, M.E./Millar, V.E. (1986), Wettbewerbsvorteile durch Information, in: HBM, 8. Jg., Nr. 1, 1986, S. 26-35

Prahalad, C.K./Hamel, G. (1990), The Core Competence of the Corporation, in: HBR, 68. Jg., Nr. 3, 1990, S. 77-91

Prammer, H.K. (1996), Einsatzgebiete und Leistungsfähigkeit ökobilanzieller Bewertungsverfahren, in: A.H. Malinsky (Hrsg.), Betriebliche Umweltwirtschaft: Grundzüge und Schwerpunkte, Wiesbaden 1996, S. 211-243

Prätorius, G. (1992), Umweltschutz als Standortfaktor, in: U. Steger (Hrsg.), Handbuch des Umweltmanagements: Anforderungs- und Leistungsprofile von Unternehmen und Gesellschaft, München 1992, S. 145-163 
Preston, L.E. (1977), The World of Small Business: A Suggested Typology, in: American Journal of Small Business, 1. Jg., Nr. 4, 1977, S. 13-19

Probst, G.J.B./Büchel, B. (1994), Organisationales Lernen: Wettbewerbsvorteil der Zukunft, Wiesbaden 1994

Pümpin, C. (1980), Strategische Führung in der Unternehmenspraxis, Schweizerische Volksbank (Hrsg.), Die Orientierung, Nr. 76, Bern 1980

Pümpin, C. (1981), Grundlagen der strategischen Führung, in: C. Pümpin u.a. (Hrsg.), Produkt-Markt-Strategien: Neue Instrumente erfolgreicher Unternehmungsführung, Bern 1981, S. 7-32

Quévit, M. (1991), Innovative Environments and Local/International Linkages on Enterprise Strategy: A Framework for Analysis, in: R. Camagni (Hrsg.), Innovation Networks, London, New York 1991, S. 55-70

Raffée, H./Fritz, W. (1990), Unternehmensführung und Unternehmenserfolg: Grundlagen und Ergebnisse einer empirischen Untersuchung, Arbeitspapier Nr. 85 des Instituts für Marketing der Universität Mannheim, Mannheim 1990

Raffée, H./Fritz, W. (1992), Dimensionen und Konsistenz der Führungskonzeptionen von Industrieunternehmen, in: zfbf, 44. Jg., Nr. 4, 1992, S. 303-322

Raffée, H. u.a. (1988), Raffée, H./Förster, F./Krupp, W., Marketing und Ökologieorientierung: Eine empirische Studie unter besonderer Berücksichtigung der Lärmminderung, Arbeitspapier Nr. 63 des Instituts für Marketing der Universität Mannheim, Mannheim 1988

Raffée, H. u.a. (1992), Raffée, H./Förster, R./Fritz, W., Umweltschutz im Zielsystem von Unternehmen, in: U. Steger (Hrsg.), Handbuch des Umweltmanagements: Anforderungs- und Leistungsprofile von Unternehmen und Gesellschaft, München 1992, S. 241-256

Raia, A.D. (1965), Goal-Setting and Self-Control, in: Journal of Management Studies, 2. Jg., Nr. 2, 1965, S. 34-53

Rappaport, A. (1981), Selecting Strategies that create Shareholder Value, in: HBR, 59. Jg., Nr. 3, 1981, S. 139-149

Rappaport, A. (1986), Creating Shareholder Value: The new Standard for Business Performance, New York 1986

Rappaport, A. (1994), Shareholder Value: Wertsteigerung als Maßstab für die Unternehmensfuihrung, Stuttgart 1994

Rasche, C. (1994), Wettbewerbsvorteile durch Kernkompetenzen: Ein ressourcenorientierter Ansatz, Wiesbaden 1994

Rastogi, P.N. (1995), Management of Technology and Innovation: Competing Through Technological Excellence, New Delhi 1995 
Rau, H. (1996), Benchmarking: Die Fehler der Praxis, in: HBM, 18. Jg., Nr. 4, 1996, S. 21-25

Regionalverband Neckar-Alb (1995), Die Wirtschaftskrise in der Region Neckar-Alb: Studie zur regionalen Wirtschaftsstruktur, Mössingen 1995

Reichhardt, I. (1995), Strategien zur Sicherung des Erfolgspotentials: Wettbewerbsvorteile durch internationalen Standortverbund, in: H. Corsten, T. Will (Hrsg.), Unternehmensfuihrung im Wandel: Strategien zur Sicherung des Erfolgspotentials, Stuttgart 1995, S. $197-217$

Rickards, T. (1985), Stimulating Innovation: A Systems Approach, London 1985

RKW (Hrsg.) (1976), Rationalisierungs-Kuratorium der Deutschen Wirtschaft (RKW) e.V., RKW-Handbuch Forschung, Entwicklung, Konstruktion (F+E), Band 1, Berlin 1976

Roberts, E.B. (1987), Managing Technological Innovation: A Search for Generalizations, in: E.B. Roberts (Hrsg.), Generating Technological Innovation, New York, Oxford 1987, S. 3-21

Rogers, E.M (1983), Diffusion of Innovations, 3. Aufl., New York, London 1983

Rönz, B./Strohe, H.G. (Hrsg.) (1994), Lexikon Statistik, Wiesbaden 1994

Rothwell, R. (1989), Small Firms, Innovation and Industrial Change, in: Small Business Economics, 1. Jg., Nr. 1, 1989, S. 51-64

Rottmann, H. (1995), Das Innovationsverhalten von Unternehmen: Eine ökonometrische Untersuchung für die Bundesrepublik Deutschland, Frankfurt/M. u.a. 1995

Rottmann, H./Ruschinski, M. (1997), Sind Innovationen beschäftigungswirksam?: Empirische Ergebnisse für Unternehmen des verarbeitenden Gewerbes in Westdeutschland, in: ifo Schnelldienst, Innovation, Wachstum und Beschäftigung, 50. Jg., 1718/1997, München 1997, S. 21-26

Roventa, P. (1981), Portfolio-Analyse und Strategisches Management: Ein Konzept zur strategischen Chancen- und Risikobehandlung, 2. Aufl., München 1981

Sachs, L. (1992), Angewandte Statistik, 7. Aufl., Berlin, Heidelberg 1992

Sächsisches Staatsministerium (Hrsg.) (1994), Sächsisches Staatsministerium für Umwelt und Landesentwicklung (Hrsg.), Umweltmanagement in der Textilindustrie: Ein Leitfaden zur Einführung eines Umweltmanagementsystems für kleine und mittlere Betriebe, Dresden 1994

Sachverständigenrat (1988), Sachverständigenrat zur Begutachtung der gesamtwirtschaftlichen Entwicklung, Arbeitsplätze im Wettbewerb: Jahresgutachten 1988/89, Stuttgart 1988 
Sachverständigenrat (1995), Sachverständigenrat zur Begutachtung der gesamtwirtschaftlichen Entwicklung, Im Standortwettbewerb: Jahresgutachten 1995/96, Stuttgart 1995

Sattelberger, T. (Hrsg.) (1996), Die Lernende Organisation: Konzepte für eine neue Qualität der Unternehmensentwicklung, 3. Aufl., Wiesbaden 1996

Say, J.B. (1880), A Treatise on Political Economy: Or, the Production, Distribution and Consumption of Wealth, Nachdruck, New York 1971

Schäfer, E. (1953), Grundlagen der Marktforschung, 3. Aufl., Köln 1953

Schafhausen, F. (1988), Chancen der Betriebe durch ein offensives Umweltmarketing, in: E. Pieroth, L. Wicke (Hrsg.), Chancen der Betriebe durch Umweltschutz: Plädoyer für ein offensives, gewinnorientiertes Umweltmanagement, Freiburg i. Br. 1988, S. 269-305

Schaltegger, S./Kempke, S. (1996), Öko-Controlling: Überblick über bisherige Ansătze, in: Betriebliches Umweltmanagement 1996, ZfB-Ergänzungsheft 2/96, Wiesbaden 1996, S. 149-163

Schaltegger, S./Sturm, A. (1992), Öko-Controlling als Management- und Führungsinstrument, in: io Management Zeitschrift, 61. Jg., Nr. 6, 1992, S. 71-75

Schaltegger, S./Sturm, A. (1995), Öko-Effizienz durch Öko-Controlling: Zur praktischen Umsetzung von EMAS und ISO 14001, Stuttgart 1995

Schanz, G. (Hrsg.) (1991), Handbuch Anreizsysteme in Wirtschaft und Verwaltung, Stuttgart 1991

Scharff, R. (1993), Regionalpolitik und regionale Entwicklungspotentiale, Frankfurt/M. u.a. 1993

Schendel, D.E./Hofer, C.W. (Hrsg.) (1979), Strategic Management: A New View of Business Policy and Planning, Boston 1979

Scherer, F.M. (1965), Firm Size, Market Structure, Opportunity and the Output of Patented Innovations, in: American Economic Review, 55. Jg., 1965, S. 1097-1125

Schlick, G.H. (1995), Innovationen von A-Z, Renningen-Malmsheim 1995

Schmalholz, H./Penzkofer, H. (1997), Innovationsschub für mehr Wachstum erforderlich, in: ifo Schnelldienst, Innovation, Wachstum und Beschäftigung, 50. Jg., 17-18/1997, München 1997, S. 27-35

Schmid, U. (1989), Umweltschutz: Eine strategische Herausforderung für das Management, Frankfurt/M. u.a. 1989

Schmidheiny, S. (1992), Kurswechsel: Globale unternehmerische Perspektiven für die Entwicklung und Umwelt, in Zusammenarbeit mit dem Business Council for Sustainable Development, 4. Aufl., München 1992 
Schmidt, A. (1995), Der mögliche Beitrag der Kooperation zum Innovationserfolg für kleine und mittelgroße Unternehmen (KMU), in: Effizienzsteigerung im Innovationsprozeß, ZfB-Ergänzungsheft 1/95, Wiesbaden 1995, S. 103-131

Schmidt, K.-D. (1996), Small and Medium Sized Enterprises (SMEs) in International Business: A Survey of Recent Literature, Institut für Weltwirtschaft, Kieler Arbeitspapiere Nr. 721, Kiel 1996

Schmidt, R.-B. (1991), Unternehmungsphilosophie und Umweltschutz, in: E. Seidel, H. Strebel (Hrsg.), Umwelt und Ökonomie, Wiesbaden 1991, S. 181-193

Schmidt, R./Müller, H. (1995), Einführung in das Umweltrecht, 4. Aufl., München 1995

Schmookler, J. (1966), Invention and Economic Growth, Cambridge/Mass. 1966

Schneider, H. (1994), Was ist Qualifikation?, in: io Management Zeitschrift, 63. Jg., Nr. 3, 1994, S. 69ff.

Schoeffler, S. (1983), The PIMS-Program, in: K.J. Albert (Hrsg.), The Strategic Management Handbook, New York u.a. 1983, S. 23.1-23.10

Schoeffler, S. u.a. (1974), Schoeffler, S./Buzzell, R.D./Heany, D.F., Impact of Strategic Planning on Profit Performance, in: HBR, 52. Jg., Nr. 2, 1974, S. 137-145

Schoenfeld, H.M. (1993), Humanvermögen, in: Handwörterbuch des Rechnungswesens, hrsg. von K. Chmielewicz, M. Schweitzer, 3. Aufl., Stuttgart 1993, Sp. 889-896

Schröder, H.-H. (1996), Konzepte und Instrumente eines Innovations-Controllings, in: Die Betriebswirtschaft, 56. Jg., Nr. 4, 1996, S. 489-507

Schuke, A. (1977), Theorie des Unternehmens: Eine Untersuchung des approximativen Erklärungswertes des traditionellen ökonomischen Modells, Frankfurt/M. 1977

Schuler, H./Barthelme, D. (1995), Soziale Kompetenz als berufliche Anforderung, in: B. Seyfried (Hrsg.), "Stolperstein" Sozialkompetenz: Was macht es so schwierig, sie zu erfassen, zu fördern und zu beurteilen?, Bielefeld 1995, S. 77-116

Schumpeter, J.A. (1912), Theorie der wirtschaftlichen Entwicklung, Leipzig 1912

Schumpeter, J.A. (1928), Unternehmer, in: Handwörterbuch der Staatswissenschaften, Band 8, 4. Aufl., Jena 1928, S. 476-487

Schumpeter, J.A. (1934a), The Theory of Economic Development: An Inquiry into Profits, Capital, Credit, Interest, and the Business Cycle, (Nachdr. d. 1934 ersch. Aufl.) Cambridge/Mass. 1951

Schumpeter, J.A. (1934b), Theorie der wirtschaftlichen Entwicklung: Eine Untersuchung über Unternehmergewinn, Kapital, Kredit, Zins und den Konjunkturzyklus, (Nachdr. d. 1934 ersch. 4. Aufl.) 8. Aufl., Berlin 1993

Schumpeter, J.A. (1950), Kapitalismus, Sozialismus und Demokratie, 6. Aufl., Tübingen 1987 
Schumpeter, J.A. (1961), Konjunkturzyklen: Eine theoretische, historische und statistische Analyse des kapitalistischen Prozesses, Band 1, Göttingen 1961

Seghezzi, H.D. (1995), Total Quality Management: Markt- und potentialkonforme Unternehmensprofile, in: Schmalenbach-Gesellschaft-Deutsche Gesellschaft für Betriebswirtschaft e.V. (Hrsg.), Reengineering: Konzepte und Umsetzung innovativer Strategien und Strukturen, Stuttgart 1995, S. 143-158

Seghezzi, H.D. (1996), Qualitätsmanagement: Eine gesamtunternehmerische Aufgabe, in: R.M. Hammer u.a. (Hrsg.), Technologie- und Innovationsmanagement: Tools und Strategien für Führungskräfte, Wien 1996, S. 91-113

Seidel, E. (1990), Implementierung des betrieblichen Umweltschutzes: Die Organisation als Schlüsselfrage, in: J. Freimann (Hrsg.), Ökologische Herausforderung der Betriebswirtschaftslehre, Wiesbaden 1990, S. 215-230

Seiter, S. (1997), Der Beitrag Nicholas Kaldors zur Neuen Wachstumstheorie: Eine vergleichende Studie vor dem Hintergrund der Debatte über den VerdoornZusammenhang, Frankfurt/M. u.a. 1997

Senge, P.M. (1990), The Fifth Discipline: The Art and Practice of the Learning Organization, 7. Aufl., New York 1990

Senge, P.M./Scharmer, C.O. (1996), Infrastrukturen des Lernens: Über den Aufbau eines Konsortiums lemender Unternehmen am MTT, in: zfo, 65. Jg., Nr.1, 1996, S. 3236

Senge, P.M. u.a. (1994), The Fifth Discipline Fieldbook: Strategies and Tools for Building a Learning Organization, New York 1994

Senn, J.F. (1986), Ökologieorientierte Unternehmensführung: Theoretische Grundlagen, empirische Fallanalysen und mögliche Basisstrategien, Frankfurt/M. u.a. 1986

Servatius, H.-G. (1985), Methodik des strategischen Technologie-Managements. Grundlage für erfolgreiche Innovationen, Berlin 1985

Servatius, H.-G. (1988), New Venture Management: Erfolgreiche Lösungen von Innovationsproblemen für Technologie-Unternehmen, Wiesbaden 1988

Servatius, H.-G. (1992), Umsetzung umweltbewußter Führung als Prozeß eines kulturellen Wandels, in: E. Zahn, H. Gassert (Hrsg.), Umweltschutzorientiertes Management: Die unternehmerische Herausforderung von morgen, Stuttgart 1992, S. 95-117

Siegwart, H./Senti, R. (1995), Product Life Cycle Management: Die Gestaltung eines integrierten Produktlebenszyklus, Stuttgart 1995

Solow, R.M. (1957), Technical Change and the Aggregate Production Function, in: Review of Economics and Statistics, 39. Jg., 1957, S. 312-320

Solow, R.M. (1994), Perspectives on Growth Theory, in: Journal of Economic Perspectives, 8. Jg., Nr. 1, 1994, S. 45-54 
van Someren, T. (1994), Die Anwendung der EG-Umwelt-Audit-Verordnung in kleinen und mittelständischen Unternehmen, in: J. Clausen, H. Gallert (Hrsg.), Umweltmanagement und Umwelt-Audit in kleinen Unternehmen, Schriftenreihe des IÖW, Nr. 80, Berlin 1994, S. 19-30

Sommerlatte, T. (1990), Organisatorisches Lernen als Unternehmensstrategie, in: E. Zahn (Hrsg.), Europa nach 1992: Wettbewerbsstrategien auf dem Prüfstand, Stuttgart 1990, S. 201-223

Sommerlatte, T./Deschamps, J.-P. (1986), Der strategische Einsatz von Technologien, in: Arthur D. Little (Hrsg.), Management im Zeitalter der strategischen Führung, 2. Aufl., Wiesbaden 1986, S. 37-76

Sondermann, W.D. (1992), Umweltgesetze und Umwelthaftung in der Praxis, in: M. Sietz (Hrsg.), Umweltbewußtes Management, Taunusstein 1992, S. 27-59

Sonntag, K. (1996), Lernen im Unternehmen: Effiziente Organisation durch Lernkultur, München 1996

Specht, G. (1989), Qualitätsmanagement im Innovationsprozeß unter besonderer Berücksichtigung der Schnittstellen zwischen FuE und Vertrieb, in: G. Specht, G. Silberer, W.H. Engelhardt (Hrsg.), Marketing-Schnittstellen: Herausforderung für das Management, Stuttgart 1989, S. 141-163

Specht, G./Beckmann, C. (1996), F\&E-Management, Stuttgart 1996

Specht, G./Zörgiebel, W.W. (1985), Technologieorientierte Wettbewerbsstrategien, in: H. Raffée, K.-P. Wiedmann (Hrsg.), Strategisches Marketing, Stuttgart 1995, S. 491517

Sprenger, R.-U. (1982), Umweltpolitik als Wachstumsbremse?, in: A.A. Ullmann, K. Zimmermann (Hrsg.), Umweltpolitik im Wandel: Von Beschäftigungseffekten zu Innovationswirkungen des Umweltschutzes, Frankfurt/M., New York 1982, S. 6776

Sprenger, R.-U. (1989), Beschäftigungswirkungen der Umweltpolitik: Eine nachfrageorientierte Untersuchung, hrsg. vom Umweltbundesamt, Berichte 4/89, Berlin 1989

Sprenger, R.-U. (1992), Umweltschutz als Standortfaktor, hrsg. vom Forschungsinstitut der Friedrich-Ebert-Stiftung, Reihe "Wirtschaftspolitische Diskurse", Nr. 36, Bonn 1992

SRU (1988), Der Rat von Sachverständigen für Umweltfragen, Umweltgutachten 1987, Stuttgart, Mainz 1988

SRU (1994), Der Rat von Sachverständigen für Umweltfragen, Umweltgutachten 1994, Stuttgart 1994

SRU (1996), Der Rat von Sachverständigen für Umweltfragen, Umweltgutachten 1996, Stuttgart 1996 
Staehle, W.H. (1994), Management: Eine verhaltenswissenschaftliche Perspektive, 7. Aufl., München 1994

Staehle, W.H./Grabatin, G. (1979), Effizienz von Organisationen, in: Die Betriebswirtschaft, 39. Jg., Nr 1b, 1979, S. 89-102

Stahlmann, V. (1988), Umweltorientierte Materialwirtschaft: Das Optimierungskonzept für Ressourcen, Recycling, Rendite, Wiesbaden 1988

Stahlmann, V. (1994), Umweltverantwortliche Unternehmensführung, München 1994

Stalk, G. u.a. (1992), Stalk, G./Evans, P./Suhlman, L.E., Competing on Capabilities: The New Rules of Corporate Strategy, in: HBR, 70. Jg., Nr. 2, 1992, S. 57-69

Statistisches Bundesamt (Hrsg.) (1996), Statistisches Jahrbuch 1996 für die Bundesrepublik Deutschland, Stuttgart 1996

Statistisches Landesamt Baden-Württemberg (1995), Bevölkerung und Erwerbstätigkeit (A I 1-vj2/95), Stuttgart 1995

Statistisches Landesamt Baden-Württemberg (1996a), Statistische Berichte BadenWürttemberg, Produzierendes Gewerbe, EI 1-j/95, Stuttgart 1996

Statistisches Landesamt Baden-Württemberg (1996b), Statistische Berichte BadenWurttemberg, Sonderbericht Produzierendes Gewerbe, EI 1/S-j95, Stuttgart 1996

Statistisches Landesamt Baden-Württemberg (1997a), Statistische Berichte BadenWürttemberg, Sonderbericht Produzierendes Gewerbe, mehrere Jahrgänge, EI 1/Sj90-96, Stuttgart 1990-1997

Statistisches Landesamt Baden-Württemberg (1997b), Statistische Berichte BadenWürttemberg, Volkswirtschaftliche Gesamtrechnung, PI 1-hj1/96, Stuttgart 1997

Staudt, E. u.a. (1992), Staudt, E./Bock, J./Mühlemeyer, P., Informationsverhalten in innovationsaktiven kleinen und mittleren Unternehmen, in: ZfB, 62. Jg., Nr. 9, 1992, S. 989-1008

Steger, U. (1988), Umweltmanagement: Erfahrungen und Instrumente einer umweltorientierten Unternehmensstrategie, Wiesbaden 1988

Steger, U. (1992), Integrierter Umweltschutz als Gegenstand eines Umweltmanagements, in: H. Kreikebaum (Hrsg.), Integrierter Umweltschutz: Eine Herausforderung an das Innovationsmanagement, 2. Aufl., Wiesbaden 1992, S. 33-43

Steger, U. (1993), Umweltmanagement: Erfahrungen und Instrumente einer umweltorientierten Unternehmensstrategie, 2. Aufl., Wiesbaden 1993

Steinbach, R.F. (1997), Integratives Qualitäts-, Zeit- und Kostenmanagement: Entwicklung und Implementierung eines ganzheitlichen Management-Konzepts, Frankfurt/M. u.a. 1997 
Steinhilper, R./Friedel, A. (1996), Umweltmanagement, in: H.-J. Bullinger, H.J. Warnecke (Hrsg.), Neue Organisationsformen im Unternehmen: Ein Handbuch für das moderne Management, Berlin u.a. 1996, S. 394-413

Steinhoff, D./Burgess, J.F. (1993), Small Business Management Fundamentals, 6. Aufl., New York 1993

Steinle, C. u.a. (1994), Steinle, C./Lawa, D./Schollenberg, A., Ökologieorientierte Unternehmungsführung: Ansätze, Integrationskonzept und Entwicklungsperspektiven, in: ZfU, 17. Jg., Nr. 4, 1994, S. 409-444

Steven, M. (1991), Umwelt als Produktionsfaktor?, in: ZfB, 61. Jg., Nr. 4, 1991, S. 509-523

Stiefel, R.T. (1991), Innovationsfördernde Personalentwicklung in Klein- und Mittelbetrieben: Lernen vom Großbetrieb oder eigene Wege gehen?, Neuwied, Berlin 1991

Stitzel, M./Wank, L. (1990), Was kann die Lehre vom Strategischen Management zur Entwicklung einer ökologischen Unternehmensführung beitragen?, in: J. Freimann (Hrsg.), Ökologische Herausforderung der Betriebswirtschaftslehre, Wiesbaden 1990 , S. $105-131$

Stölting, P./Rubik, F. (1992), Übersicht über ökologische Produktbilanzen, Heidelberg 1992

Strebel, H. (1968), Die Bedeutung von Forschung und Entwicklung für das Wachstum industrieller Unternehmungen, Berlin 1968

Strebel, H. (1980), Umwelt und Betriebswirtschaft: Die natürliche Umwelt als Gegenstand der Unternehmenspolitik, Berlin 1980

Strebel, H. u.a. (1979), Strebel, H./Frenzel, H.-J./Silber, H./Steinhoff, D., Innovation und ihre Organisation in der mittelständischen Industrie: Ergebnisse einer empirischen Untersuchung, Berlin 1979

Strebel, P. (1996), Why Do Employees Resist Change?, in: HBR, 74. Jg., Nr. 3, 1996, S. 8692

Stützle-Leinmüller, S. (1997), Kapital und Arbeit im Innovationsprozeß kleiner und mittlerer Unternehmen: eine transaktionskostentheoretische Analyse, Dissertation Universität Hohenheim, Stuttgart 1997

Tebbe, K. (1990), Die Organisation von Produktinnovationsprozessen, Stuttgart 1990

Teufel, P. (1996), Der Prozeß der ständigen Verbesserung (KAIZEN) und dessen Einführung, in: H.-J. Bullinger, H.J. Warnecke (Hrsg.), Neue Organisationsformen im Unternehmen: Ein Handbuch für das moderne Management, Berlin u.a. 1996, S. 526548

The Boston Consulting Group (Hrsg.) (1988), Vision und Strategie: Kommentare, München 1988 
Thom, N. (1980), Grundlagen des betrieblichen Innovationsmanagements, 2. Aufl., Königstein/Ts. 1980

Thom, N. (1983), Innovations-Management: Herausforderung für den Organisator, in: zfo, 52. Jg., Nr. 1, 1983, S. 4-11

Thom, N. (1992), Innovationsmanagement, Schweizerische Volksbank (Hrsg.), Die Orientierung, Nr. 100, Bern 1992

Thomas, H. (1989), Die Finanzierung von Innovationen und die Bedeutung der Beteiligungsgesellschaften, in: H. Corsten (Hrsg.), Die Gestaltung von Innovationsprozessen, Berlin 1989, S. 82-102

Thomasberger, C. (1997), Internationale Wettbewerbsfähigkeit: Sinn und Unsinn einer wirtschaftspolitischen Konzeption, Paper vorgestellt auf der Herbsttagung des Arbeitskreises für Politische Ökonomie in Maastricht, 17.-19. Oktober 1997

Thompson, A.A./Strickland, A.J. (1996), Strategic Management: Concepts and Cases, 9. Aufl., Chicago 1996

Thompson, J.L. (1993), Strategic Management: Awareness and Change, 2. Aufl., London 1993

Tiebler, P. (1992), Umwelttrends im Konsumentenverhalten, in: U. Steger (Hrsg.), Handbuch des Umweltmanagements: Anforderungs- und Leistungsprofile von Unternehmen und Gesellschaft, München 1992, S. 183-206

Tikart, J. (1997), Unternehmenserfolg durch Wandel, in: W. Grosskopf u.a. (Hrsg.), Innovationen im Mittelstand: Strategisches Management, Finanzierung, Kooperation, Stuttgart 1997, S. $45-49$

Timmermann, A. (1985), Strategisches Denken: Lebenslanges Lernen auch für Unternehmen, in: H. Raffée, K.-Wiedmann (Hrsg.), Strategisches Marketing, Stuttgart 1985, S. 197-227

Timmons, J.A. (1994), New Venture Creation: A Guide to Entrepreneurship, 4. Aufl., Chicago u.a. 1994

Tinbergen, J. (1952), Einfuihrung in die Ökonometrie, Wien, Stuttgart 1952

Tischler, K. (1996), Ökologische Betriebswirtschaftslehre, München, Wien 1996

Tominaga, M. (1996), Erfolgsstrategien für deutsche Unternehmen: Erhöhen Sie die Produktivität durch den Einsatz japanischer und deutscher Managementtechniken, 3. Aufl., Düsseldorf 1996

Tominaga, M. (1997), Auf der Suche nach deutschen Spitzenleistungen, Düsseldorf 1997

Töpfer, A. (1985), Umwelt- und Benutzerfreundlichkeit von Produkten als strategische Unternehmungsziele, in: Marketing ZFP, 7. Jg., Nr. 4, 1985, S. 241-251 
Töpfer, A. (1986), Innovationsmanagement, in: N. Wieselhuber, A. Töpfer (Hrsg.), Strategisches Marketing, 2. Aufl., Landsberg/L. 1986, S. 391-407

Töpfer, A. (Hrsg.) (1997), Benchmarking: Der Weg zu Best Practice, Berlin 1997

Töpfer, A. (1997), Benchmarking, in: WiSt, 26. Jg., Nr. 4, 1997, S. 202-205

Troge, A. (1988), Möglichkeiten zur Verbesserung der Gewinnsituation der Betriebe durch integrierten Umweltschutz, in: E. Pieroth, L. Wicke (Hrsg.), Chancen der Betriebe durch Umweltschutz: Plädoyer für ein offensives, gewinnorientiertes Umweltmanagement, Freiburg i. Br. 1988, S. 95-120

Trommsdorff, V./Schneider, P. (1990), Grundzüge des betrieblichen Innovationsmanagement, in: V. Trommsdorff (Hrsg.), Innovationsmanagement in kleinen und mittleren Unternehmen, München 1990, S. 1-25

Türck, R. (1991), Das ökologische Produkt, 2. Aufl., Frankfurt/M. 1991

Türck, R. (1992), Das ökologische Produkt: Ansatzpunkte seiner Beschreibung und Erfassung, in: H. Kreikebaum (Hrsg.), Integrierter Umweltschutz: Eine Herausforderung an das Innovationsmanagement, 2. Aufl., Wiesbaden 1992, S. 57-72

Uhlmann, L. (1970), Innovation und Strukturwandel, in: Innovation in der Wirtschaft, hrsg. vom Ifo-Institut, München 1970, S. 49-72

Uhlman, L. (1978), Der Innovationsprozeß in westeuropäischen Industrieländern. Band 2: Der Ablauf industrieller Innovationsprozesse, Berlin, München 1978

Ullmann, A. (1976), Unternehmungspolitik in der Umweltkrise, Bern u.a. 1976

Ullmann, A.A. (1982), Industrie und Umweltschutz: Implementation von Umweltschutzgesetzen in deutschen Unternehmen, Frankfurt/M., New York 1982

Ullmann, A.A./Zimmermann, K. (1982), Struktur und volkswirtschaftliche Bedeutung der Umweltschutzindustrie in der Bundesrepublik Deutschland, in: A.A. Ullmann, K. Zimmermann (Hrsg.), Umweltpolitik im Wandel: Von Beschäftigungseffekten zu Innovationswirkungen des Umweltschutzes, Frankfurt/M., New York 1982, S. 2954

Ulrich, H. (1970), Die Unternehmung als produktives soziales System: Grundlagen der allgemeinen Unternehmungslehre, 2. Aufl., Bern 1970

Ulrich, H. (1978), Der systemorientierte Ansatz in der Betriebswirtschaftslehre, in: M. Schweitzer (Hrsg.), Auffassungen und Wissenschaftsziele in der Betriebswirtschaftslehre, Darmstadt 1978, S. 270-291

Ulrich, H. (1990), Unternehmungspolitik, 3. Aufl., Stuttgart 1990

Ulrich, H./Krieg, W. (1974), Das St. Galler Management-Modell, 3. Aufl., Bern 1974

Ulrich, H./Probst, G.J.B. (1995), Anleitung zum ganzheitlichen Denken und Handeln: Ein Brevier für Führungskräfte, 4. Aufl., Bern, Stuttgart 1995 
Ulrich, P./Fluri, E. (1995), Management: Eine konzentrierte Einführung, 7. Aufl., Bern, Stuttgart 1995

Umweltbundesamt (Hrsg.) (1992), Ökobilanzen für Produkte: Bedeutung, Sachstand, Perspektiven, hrsg. vom Umweltbundesamt, Texte 38/92, Berlin 1992

Unternehmerinstitut e.V. (1997), Öko-Audit in der mittelständischen Praxis: Evaluierung und Ansätze für eine Effizienzsteigerung von Umweltmanagementsystemen in der Praxis, Bonn 1997

U.S. Small Business Administration (1983), The State of Small Business: A Report of the President, Washington 1983

U.S. Small Business Administration (1985), The State of Small Business: A Report of the President, Washington 1985

U.S. Small Business Administration (1989), The State of Small Business: A Report of the President, Washington 1989

U.S. Small Business Administration (1990), The State of Small Business: A Report of the President, Washington 1990

U.S. Small Business Administration (1995), The State of Small Business: A Report of the President, Washington 1995

Utterback, J.M. (1971), The Process of Technological Innovation within the Firm, in: Academy of Management Journal, 14. Jg., Nr. 1, 1971, S. 75-88

Utterback, J.M. (1979), Environmental Analysis and Forecasting, in: D.E. Schendel, C.W. Hofer (Hrsg.), Strategic Management: A View of Business Policy and Planning, Boston, Toronto 1979 , S. 134-144

Utterback, J.M./Abernathy, W.J. (1975), A Dynamic Modes of Process and Product Innovation, in: OMEGA, International Journal of Management Science, 3. Jg., Nr. 6, 1975, S. $639-656$

Vaessen, P./Keeble, D. (1995), Growth-oriented SMEs in Unfavourable Regional Environments, in: Regional Studies, 29. Jg., Nr. 6, 1995, S. 489-505

Vedin, B.-A. (1980), Large Company Organization and Radical Product Innovation, Lund u.a. 1980

Verdoorn, P.J. (1949), Fattori che regolano lo sviluppo della produttività del lavoro, in: L'Industria, 1949, S. 45-53

Verdoorn, P.J. (1980), Verdoorn's Law in Retrospect: A Comment, in: Economic Journal, Band 90, S. 382-385

Vernon, R. (1966), International Investment and International Trade in the Product Cycle, in: Quarterly Journal of Economics, 80. Jg., 1966, S. 190-207 
Vieregge, R. (1992), Integrierter Umweltschutz aus der Sicht der Umweltpolitik, in: H. Kreikebaum (Hrsg.), Integrierter Umweltschutz: Eine Herausforderung an das Innovationsmanagement, Wiesbaden 1992, S. 87-103

Wächter, H. (1992), Vom Personalwesen zum Strategic Human Resource Management: Ein Zustandsbericht anhand neuerer Literatur, in: W.H. Staehle, P. Conrad (Hrsg.), Managementforschung 2, Berlin, New York 1992, S. 313-340

Walter, H. (1969), Der technische Fortschritt in der neueren ökonomischen Theorie: Versuch einer Systematik, Berlin 1969

Walter, H. (1970), Zusammenhang zwischen Forschung und Entwicklung, Innovation und technischem Fortschritt, in: Innovation in der Wirtschaft, hrsg. vom Ifo-Institut, München 1970, S. 30-48

Warnecke, H.-J. (1996), Die Fraktale Fabrik: Revolution der Unternehmenskultur, Reinbek 1996

Waskow, S. (1997), Betriebliches Umweltmanagement: Anforderungen nach der AuditVerordnung der EG und dem Umweltauditgesetz, 2. Aufl., Heidelberg 1997

Waterman, R.H. (1988), Leistung durch Innovation: Strategien zur unternehmerischen $\mathrm{Zu}-$ kunftssicherung, Hamburg 1988

Weidler, A. (1997), Entwicklung integrierter Innovationsstrategien, Frankfurt/M. u.a. 1997

Weger, H.-J. (1995), Einführung von selbstorganisierenden Teamstrukturen zur Steigerung der Unternehmensflexibilität, in: CIM Management, 11. Jg., Nr. 6, 1995, S. 36-39

Weiß, R. u.a. (1997), Nutzung von Qualifikationspotentialen: Perspektiven für einen multidisziplinären Forschungssansatz, QUEM-report, Schriften zur beruflichen Weiterbildung, Nr. 46, Berlin 1997

West, A. (1992), Innovation Strategy, New York u.a. 1992

Wicher, H. (1995), Das Promotorenkonzept: Eine Problemanalyse, in: WISU, 24. Jg., Nr. 10, 1995, S. 820-832

Wicke, L. (1986), Die ökologischen Milliarden: Das kostet die zerstörte Umwelt - so können wir sie retten, München 1986

Wicke, L. (1987), Offensiver betrieblicher Umweltschutz, in: HBM, 9. Jg., Nr. 3, 1987, S. 7482

Wicke, L. (1988), Plädoyer für ein offensives Umweltmanagement, in: E. Pieroth, L. Wicke (Hrsg.), Chancen der Betriebe durch Umweltschutz: Plädoyer für ein offensives, gewinnorientiertes Umweltmanagement, Freiburg i. Br. 1988, S. 11-33

Wicke, L. (1993), Umweltökonomie: Eine praxisorientierte Einfuhrung, 4. Aufl., München 1993 
Wicke, L. u.a. (1992), Wicke, L./Haasis, H.-D./Schafhausen, F./Schulz, W., Betriebliche Umweltökonomie, München 1992

Wiedmann, K.-P./Kreutzer, R. (1985), Strategische Marketingplanung: Ein Überblick, in: H. Raffée, K.-P. Wiedmann (Hrsg.), Strategisches Marketing, Stuttgart 1985, S. 61141

Wieselhuber, N. (1996), Formulierung strategischer Unternehmensziele, in: H.-J. Bullinger, H.J. Warnecke (Hrsg.), Neue Organisationsformen im Unternehmen: Ein Handbuch für das moderne Management, Berlin u.a. 1996, S. 333-345

WIFO (1996), Region Neckar-Alb: Fortschritt durch Tradition, in: WIRTSCHAFTsFoRUMSÜDWEST, 3. Jg., Nr. 3, 1996

Wildemann, H. (1995), Ein Ansatz zur Steigerung der Reorganisationsgeschwindigkeit von Unternehmen: Die Lernende Organisation, in: Lernende Unternehmen, ZfBErgänzungsheft 3/95, Wiesbaden 1995, S. 1-23

Wildemann, H. (1996a), Erfolgsfaktoren für schnell lernende Unternehmen, in: H.-J. Bullinger (Hrsg.), Lernende Organisationen: Konzepte, Methoden und Erfahrungsberichte, Stuttgart 1996, S. 75-103

Wildemann, H. (1996b), Wettbewerbsvorteile durch schnell lernende Unternehmen, in: H. Wildemann (Hrsg.), Schnell lernende Unternehmen: Quantensprünge im Wettbewerb, Frankfurt/M. 1996, S. 17-31

Wildemann, H. (1996c), Lösungsansätze zur Steigerung der Lerngeschwindigkeit, in Unternehmen, in: H. Wildemann (Hrsg.), Schnell lernende Unternehmen: Quantensprünge im Wettbewerb, Frankfurt/M. 1996, S. 32-44

Wildemann H. (Hrsg.) (1996), Schnell lemende Unternehmen: Quantensprünge im Wettbewerb, Frankfurt/M. 1996

Wilsdorf, D. (1991), Schlüsselqualifikationen: Die Entwicklung selbständigen Lernens und Handelns in der industriellen gewerblichen Berufsausbildung, München 1991

Williamson, O.E. (1975), Markets and Hierarchies: Antitrust Analysis and Implications, New York 1975

Wilson, J.Q. (1966), Innovation and Organizations: Notes Toward a Theory, in: J.D. Thompson (Hrsg.), Approaches to Organizational Design, Pittsburgh 1966, S. 193-218

Winter, G. (1988), Das umweltbewußte Unternehmen: Ein Handbuch der Betriebsökologie mit 22 Checklisten für die Praxis, 2. Aufl., München 1988

Witt, J. (1996), Existenz- und Wachstumssicherung durch Innovations-Management, in: J. Witt (Hrsg.), Produktinnovation: Entwicklung und Vermarktung neuer Produkte, München 1996, S. 169-183

Witte, E. (1973a), Innovationsfähige Organisation, in: Zeitschrift für Organisation, hrsg. von der Gesellschaft für Organisation e.V., 42. Jg., Wiesbaden 1973, S. 17-24 
Witte, E. (1973b), Organisation für Innovationsentscheidungen: Das Promotoren-Modell, Göttingen 1973

Witte, E. (1992), Entscheidungsprozesse, in: Handwörterbuch der Organisation, hrsg. von E. Frese, 3. Aufl., Stuttgart 1992

Wöhe, G. (1960), Einführung in die Allgemeine Betriebswirtschaftslehre, Berlin, Frankfurt/M. 1960

Wöhe, G. (1996), Einführung in die Allgemeine Betriebswirtschaftslehre, 19. Aufl., München 1996

Wolfrum, B. (1994a), Schnittstellenprobleme zwischen F\&E und Marketing im Innovationsmanagement, in: WISU, 23. Jg., Nr. 12, S. 1016-1022

Wolfrum, B. (1994b), Strategisches Technologiemanagement, 2. Aufl., Wiesbaden 1994

Zabel, H.-U. (1994), Wirtschaft und Umwelt: Systembetrachtungen unter Erfolgsgesichtspunkten, in: H. Kreikebaum, E. Seidel, H.-U. Zabel (Hrsg.), Unternehmenserfolg durch Umweltschutz: Rahmenbedingungen, Instrumente, Praxisbeispiele, Wiesbaden 1994, S. 1-29

Zahn, E. (1986), Innovations- und Technologiemanagement: Eine strategische Schlüsselaufgabe der Unternehmen, in: Technologie- und Innovationsmanagement, Berlin 1986, S. 9-48

Zahn, E. (1996), Strategische Emeuerung durch organisationales Lernen, in: H.-J. Bullinger (Hrsg.), Lernende Organisationen: Konzepte, Methoden und Erfahrungsberichte, Stuttgart 1996, S. 41-74

Zahn, E./Schmid, U. (1992), Wettbewerbsvorteile durch umweltorientiertes Management, in: E. Zahn, H. Gassert (Hrsg.), Umweltschutzorientiertes Management, Stuttgart 1992, S. 39-93

Zaltman, G. u.a. (1973), Zaltman, G./Duncan, R./Holbeck, J., Innovations and Organizations, New York u.a. 1973

Zeitel, G. (1990), Volkswirtschaftliche Bedeutung von Klein- und Mittelbetrieben, in: H.-C. Pfohl (Hrsg.), Betriebswirtschaftslehre der Mittel- und Kleinbetriebe: Größenspezifische Probleme und Möglichkeiten zu ihrer Lösung, 2. Aufl., Berlin 1990, S. 24-43

Zieger, S. (1997), Verfahrensevaluation im Rahmen der Förderung innovativer Entwicklungsvorhaben kleiner und mittlerer Unternehmen, Berlin 1997

Zimmermann, K. (1982), Der stabilisierungspolitische Beitrag des Umweltschutzes und der Umweltschutzindustrie, in: A.A. Ullmann, K. Zimmermann (Hrsg.), Umweltpolitik im Wandel: Von Beschäftigungseffekten zu Innovationswirkungen des Umweltschutzes, Frankfurt/M., New York 1982, S. 13-28 
Zink, K.J. (1995), TQM als integratives Managementkonzept: Das Europäische Qualitätsmodell und seine Umsetzung, München, Wien 1995

Zink, K.J./Hauer R. (1995), Total Quality Management als Wettbewerbsfaktor: Erfolgspotentiale integrativer Managementkonzepte, in: H. Corsten, T. Will (Hrsg.), Unternehmensführung im Wandel: Strategien zur Sicherung des Erfolgspotentials, Stuttgart 1995, S. 103-123

Zörgiebel, W.W. (1983), Technologie in der Wettbewerbsstrategie, Berlin 1983 



\section{HOHENHEIMER VOLKSWIRTSCHAFTLICHE SCHRIFTEN}

Band 1 Walter Deffaa: Anonymisierte Befragungen mit zufallsverschlüsselten Antworten. Die Randomized-Response-Technik (RRT). Methodische Grundlagen, Modelle und Anwendungen. 1982.

Band 2 Thomas Michael Baum: Staatsverschuldung und Stabilisierungspolitik in der Demokratie. Zur neoinstitutionalistischen Kritik der keynesianischen Fiskalpolitik. 1982.

Band 3 Klaus Schröter: Die wettbewerbspolitische Behandlung der leitungsgebundenen Energiewirtschaft. Dargestellt am Beispiel der Fernwärmewirtschaft der Bundesrepublik Deutschland. 1986.

Band 4 Hugo Mann: Theorie und Politik der Steuerreform in der Demokratie. 1987.

Band 5 Max Christoph Wewel: Intervallarithmetische Dependenzanalyse in der Ökonometrie. Ein konjekturaler Ansatz. 1987.

Band 6 Heinrich Pascher: Die U.S.-amerikanische Deregulation Policy im Luftverkehrs- und Bankenbereich. 1987.

Band 7 Harald Lob: Die Entwicklung der französischen Wettbewerbspolitik bis zur Verordnung Nr. 86-1243 vom 01. Dezember 1986. Eine exemplarische Untersuchung der Erfassung der Behinderungsstrategie auf der Grundlage des Konzepts eines wirksamen Wettbewerbs. 1988.

Band 8 Ulrich Kirschner: Die Erfassung der Nachfragemacht von Handelsunternehmen. Eine Analyse der ökonomischen Beurteilungskriterien und der wettbewerbsrechtlichen Instrumente im Bereich der Verhaltenskontrolle.1988.

Band 9 Friedhelm Herb: Marktwirtschaftliche Innovationspolitik. 1988.

Band 10 Claus Schnabel: Zur ökonomischen Analyse der Gewerkschaften in der Bundesrepublik Deutschland. Theoretische und empirische Untersuchungen von Mitgliederentwicklung, Verhalten und Einfluß auf wirtschaftliche Größen. 1989.

Band 11 Jan B. Rittaler: Industrial Concentration and the Chicago School of Antitrust Analysis. A Critical Evaluation on the Basis of Effective Competition. 1989.

Band 12 Thomas Märtz: Interessengruppen und Gruppeninteressen in der Demokratie. Zur Theorie des Rent-Seeking. 1990.

Band 13 Andreas Maurer: Statistische Verfahren zur Ermittlung von oligopolistischen Strukturen. 1990.

Band 14 Peter Mendler: Zur ökonomischen und politisch-institutionellen Analyse öffentlicher Kredithilfen. 1992.

Band 15 Heinrich J. Engelke: Die Interpretation der Rundfunkfreiheit des Grundgesetzes: Eine Analyse aus ökonomischer Sicht. 1992.

Band 16 Thomas Fischer: Staat, Recht und Verfassung im Denken von Walter Eucken. Zu den staats- und rechtstheoretischen Grundlagen einer wirtschaftsordnungspolitischen Konzeption. 1993.

Band 17 Stefan Elßer: Innovationswettbewerb. Determinanten und Unternehmensverhalten. 1993.

Band 18 Reinhard Scharff: Regionalpolitik und regionale Entwicklungspotentiale. Eine kritische Analyse. 1993.

Band 19 Karin Beckmann: Probleme der Regionalpolitik im Zuge der Vollendung des Europäischen Binnenmarktes. Eine ökonomische Analyse. 1995. 
Band 20 Bernd Nolte: Engpaßfaktoren der Innovation und Innovationsinfrastruktur. Eine theoretische und empirische Analyse für ländliche Wirtschaftsräume in Baden-Württemberg. 1996.

Band 21 Klaus-Rainer Brintzinger: Die Nationalökonomie an den Universitäten Freiburg, Heidelberg und Tübingen 1918 - 1945. Eine institutionenhistorische, vergleichende Studie der wirtschaftswissenschaftlichen Fakultäten und Abteilungen südwestdeutscher Universitäten. 1996.

Band 22 Steffen Binder: Die Idee der Konsumentensouveränität in der Wettbewerbstheorie. Teleokratische vs. nomokratische Auffassung. 1996.

Band 23 Alexander Burger: Deregulierungspotentiale in der Gesetzlichen Rentenversicherung. Reformnotwendigkeiten versus Reformmöglichkeiten. 1996.

Band 24 Burkhard Scherer: Regionale Entwicklungspolitik. Konzeption einer dezentralisierten und integrierten Regionalpolitik. 1997.

Band 25 Frauke Wolf: Lorenzkurvendisparität. Neuere Entwicklungen, Erweiterungen und Anwendungen. 1997.

Band 26 Hans Pitlik: Politische Ökonomie des Föderalismus. Föderative Kompetenzverteilung im Lichte der konstitutionellen Ökonomik. 1997.

Band 27 Stephan Seiter: Der Beitrag Nicholas Kaldors zur Neuen Wachstumstheorie. Eine vergleichende Studie vor dem Hintergrund der Debatte über den Verdoorn-Zusammenhang. 1997.

Band 28 André Schmidt: Ordnungspolitische Perspektiven der europäischen Integration im Spannungsfeld von Wettbewerbs- und Industriepolitik. 1998.

Band 29 Bernd Blessin: Innovations- und Umweltmanagement in kleinen und mittleren Unternehmen. Eine theoretische und empirische Analyse. 1998. 